\title{
Trace Element Proxies and Mineral Indicators of Hydrothermal Fluid Composition and Seafloor Massive Sulfide Deposit Formation Processes
}

\author{
by \\ Guy Nathaniel Evans \\ B.S., B.A., College of William and Mary, 2010 \\ Submitted in partial fulfillment of the requirements for the degree of \\ Doctor of Philosophy \\ at the \\ MASSACHUSETTS INSTITUTE OF TECHNOLOGY \\ and the \\ WOODS HOLE OCEANOGRAPHIC INSTITUTION
}

June 2017

(C) 2017 Guy Nathaniel Evans, All rights reserved.

The author hereby grants to MIT and to WHOI permission to reproduce and to distribute publicly paper and electronic copies of this thesis document in whole or in part in any medium known or hereafter created.

Author

Department of Earth, Atmospheric, and Planetary Sciences, MIT \&

Department of Geology and Geophysics, WHOI

May 25, 2017

Certified by

Margaret K. Tivey

Thesis Supervisor

Accepted by

Mark Behn

Chair, Joint Committee for Marine Geology and Geophysics 


\section{Trace Element Proxies and Mineral Indicators of Hydrothermal Fluid Composition and Seafloor Massive Sulfide Deposit Formation Processes}

By

Guy Nathaniel Evans

THESIS ABSTRACT

This thesis analyzes compositions of seafloor massive sulfide (SMS) deposits and related hydrothermal vent fluids to identify proxies of reaction zone conditions (host-rock lithology, hydrothermal fluid temperature and chemistry). Chapter 2 investigates the morphology, mineralogy, and geochemistry of SMS deposits from six vent fields along the Eastern Lau Spreading Center (ELSC), demonstrating that ELSC SMS deposits record differences in hydrothermal fluid temperature, $\mathrm{pH}$, sulfur fugacity and host-rock lithology related to proximity to the nearby Tonga Subduction Zone. Chapters 3 and 4 focus on partitioning of $\mathrm{Co}, \mathrm{Ni}, \mathrm{Ga}, \mathrm{Ag}$, and In between hydrothermal vent fluids and chalcopyrite lining fluid conduits in black smoker chimneys. Chapter 3 develops secondary ion mass spectrometry (SIMS) as a technique to measure $\mathrm{Co}, \mathrm{Ni}, \mathrm{Ga}, \mathrm{Ag}$, and In in chalcopyrite and identifies a correlation between $\mathrm{Ga}$ and In in chalcopyrite and hydrothermal fluid $\mathrm{pH}$. Chapter 4 presents new data on these elements in ELSC hydrothermal fluids that, combined with SIMS analyses of chalcopyrite chimney linings and previously published data on vent fluids from the Manus Basin, provide evidence that supports partitioning of $\mathrm{Ag}$ a lattice substitution for $\mathrm{Cu}$. Together, concentrations of $\mathrm{Ga}$, In, and $\mathrm{Ag}$ in chalcopyrite provide proxies of hydrothermal fluid $\mathrm{pH}$ and metal (i.e., $\mathrm{Ag}$ and $\mathrm{Cu}$ ) contents.

Thesis Supervisor: Dr. Margaret K. Tivey

Title: Senior Scientist, Woods Hole Oceanographic Institution 


\section{ACKNOWLEDGEMENTS}

The work presented in this thesis could not have been accomplished without a network of professional and personal support. To that end, I would like to acknowledge my advisor, Dr. Margaret K. Tivey, for her mentorship and dedication, and members of my thesis committee: Dr. Jeffrey S. Seewald, Dr. Nobumichi Shimizu, Prof. Shuhei Ono, and Prof. Olivier J. Rouxel for their valuable input and advice to improve the contents of this thesis. Dr. Brian Monteleone's help in developing secondary ion mass spectrometry of trace elements in sulfide minerals and Margaret Sulanowska's help with sample preparation are also greatly acknowledged, as are Dr. Paul R. Craddock and Dr. Jill M. McDermott, my predecessors in the MIT/WHOI Joint Program, whose theses provided significant contributions to the work presented here.

I would also like to acknowledge the captains and crews of the R/V Melville, the R/V Thompson, the R/V Atlantis III, and the R/V Roger Revelle, and the team of the ROV Jason II for their expertise in recovering fluid and SMS deposit samples from active vent fields, as well as chief scientists, Dr. Chris German (AT18-16) and Prof. Anna-Louise Reysenbach (RR1507) for welcoming my participation on research cruises to the Mid-Cayman Rise and Eastern Lau Spreading Center. Work presented in Chapter 2 of this thesis was supported by the National Science Foundation through grants OCE-1038135 to GNE and MKT, OCE-1038124, OCE0241796, OCE-1233037 to JSS, and OCE-0242088 to CGW. Chapters 3 and 4 were supported by the National Science Foundation through grants OCE-1038135 and NSF Graduate Research Fellowship to GNE and funding from grant NSF OCE-1536480 to MKT. Dr. Nobumichi Shimizu is also gratefully acknowledged for his insights into secondary ion mass spectrometry and picking of mineral grains.

I would like to thank the administrative support of the MIT/WHOI Academic Programs Office including Dr. Jim Yoder, Dr. Margaret K. Tivey, Julia Westwater, Leanor Fraser, Ronni Schwarz, and Kris Kipp for their efforts to ensure the smooth operation of the MIT/WHOI Joint Program, as well as my friends and colleagues within the Joint Program for their comradery and (at times) commiseration. These include especially Dr. Anna Wargula, Dr. Sarah Rosengard, Dr. Evan Howard, Dr. Emily Moberg, Dr. Eleanor Bors, Dr. Alice Alpert, and Dr. Sophie Chu. I would also like to thank those in my community who have offered their love and support to me and my family over these past six years. These include the members and congregation of Hope Fellowship Church in Cambridge and of John Wesley United Methodist Church in Falmouth, especially the members of our fellowship group in Cambridge and Somerville and Ken and Marika Roth in West Falmouth. The same Spirit that causes us to seek knowledge in the farthest reaches and deepest depths also calls us to reach out and welcome strangers into our homes.

I would like to thank my family, including my sister, Catrin Evans, and especially my parents, Dr. Patricia Jue and David Evans, whose experience raising me was a constant reminder that raising a child and completing a Ph.D. thesis is possible. To my son Michito and others who may follow, it is possible, but also very difficult. Please take some time to think about it.

Finally, and most of all, I would like to thank my wife, Kazue, for her consistent love, patience, and support and reminding me of the important things that I might otherwise forget. 


\section{DEDICATION}

24 April, 2015

View of Ata volcano from the deck of the R/V Roger Revelle, 1920 meters above the Mariner vent field.

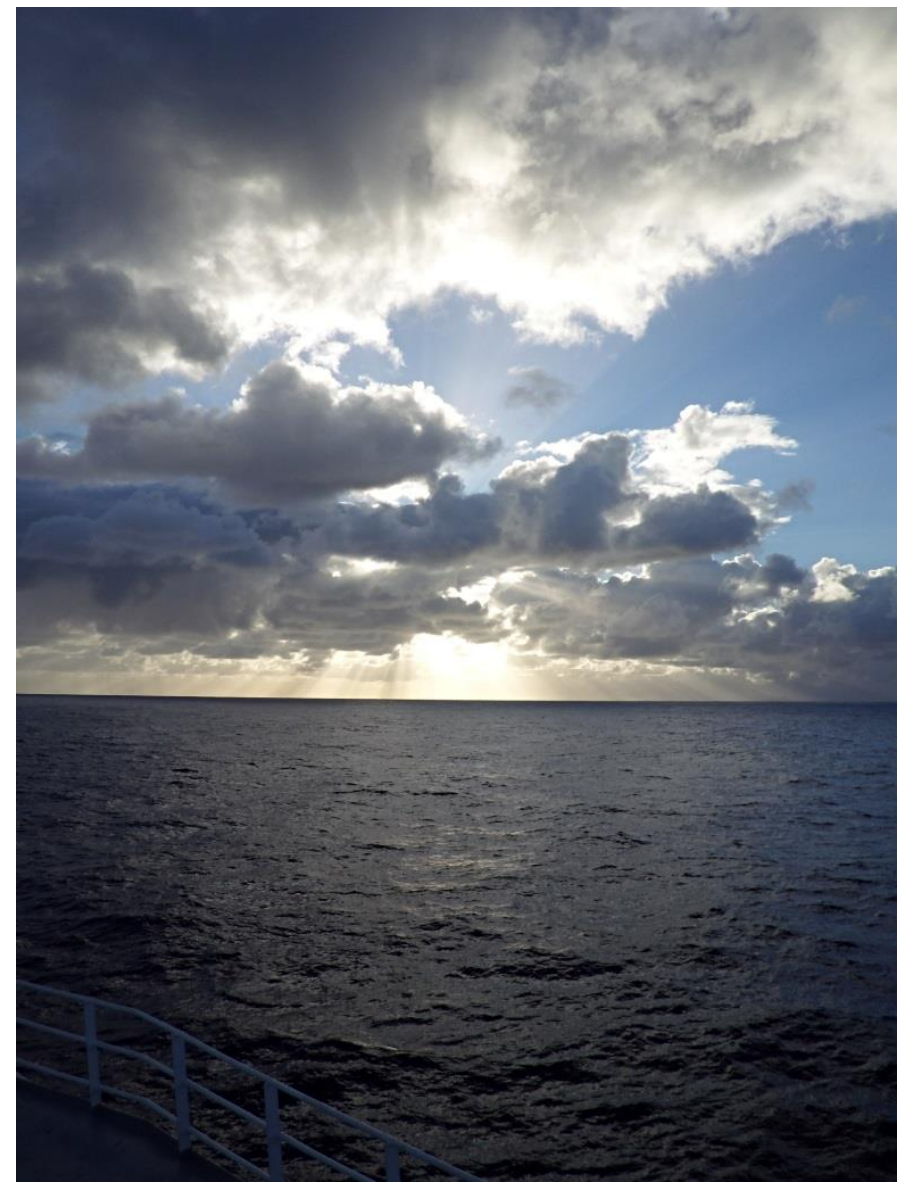

And, as if to prove its existence, I take a photograph...

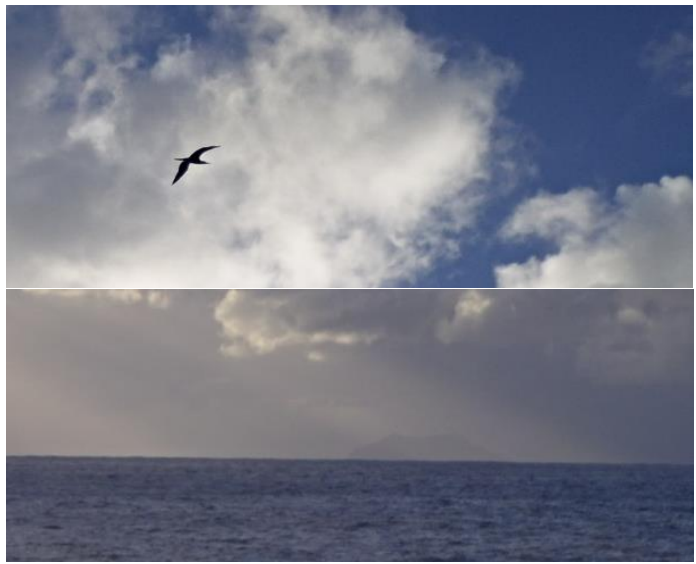

Today, dawn greets us with a splendor, a shock of daylight cut through cloud. Before it, a rainstorm curtails its trailing curtain and evaporates in steaming haze. All around, the world rests, an eternity split by sea and sky. Below, a bird - perhaps a gannet- swoops down over the water, looking for fish. And there, rising quite improbably in the east is a volcanic island, a mote of mountain made material, mirage suspended in the morning mist.

And I sit, rocking on this metal boat, a warm conglomerate of carbon, hydrogen, oxygen... congealed condensate of sky and sea. 


\section{TABLE OF CONTENTS}

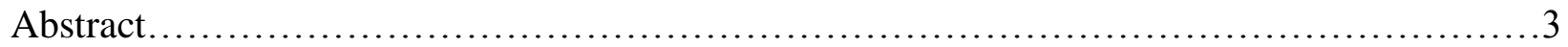

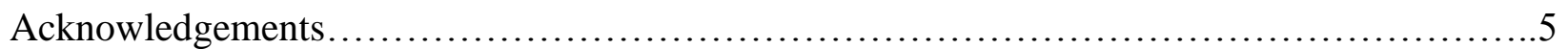

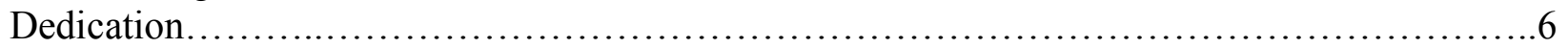

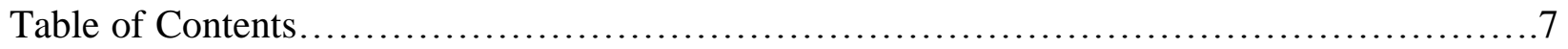

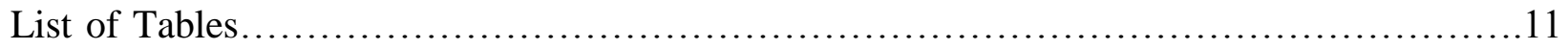

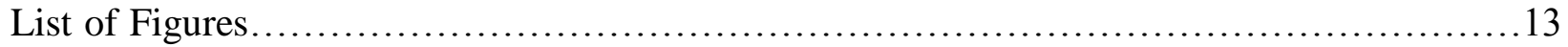

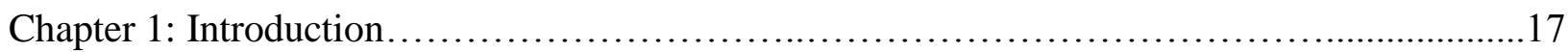

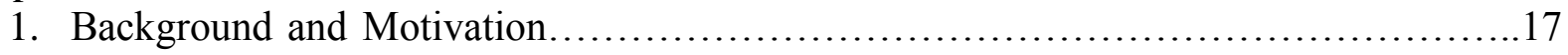

2. Formation of Seafloor Massive Sulfide Deposits................................20

3. Formation of Seafloor Hydrothermal Fluids........................................

4. Measuring Trace Metals in Hydrothermal Fluids................................... 33

5. Measuring Trace Metals in SMS Deposits..................................... 35

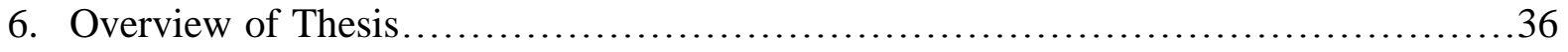

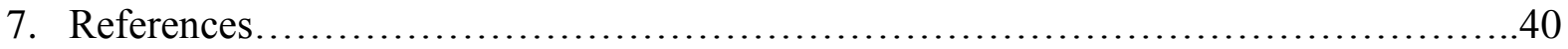

Chapter 2: Influences of the Tonga Subduction Zone on Seafloor Massive Sulfide Deposits along the Eastern Lau Spreading Center....................................................49

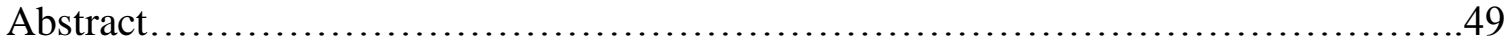

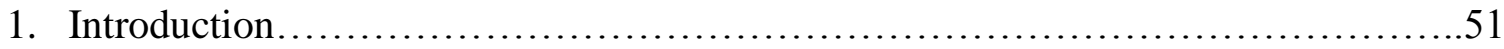

2. Geologic Setting ........................................................ 53

3. Methods.............................................................. 55

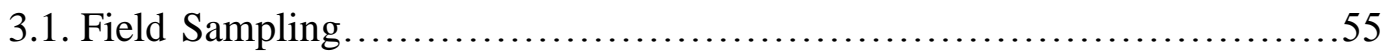

3.2. Fluid Chemistry................................................ 55

3.3. Deposit Sample Preparation......................................56

3.4. Mineralogy and Geochemistry .................................... 57

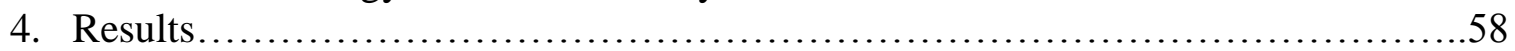

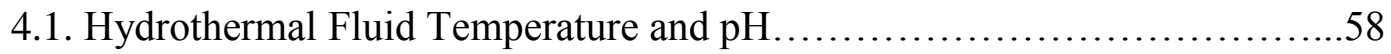

4.2. Hydrothermal Fluid Chemistry: $\mathrm{Cu}, \mathrm{Zn}, \mathrm{Ba}, \mathrm{Pb}$, and $\mathrm{H}_{2} \ldots \ldots \ldots \ldots \ldots \ldots . .58$

4.3.Morphology and Mineralogy of Seafloor Massive Sulfide Deposits.........60

4.3.1. Kilo Moana and TowCam.......................................61

4.3.2. Tahi Moana-1, ABE, Tu'i Malila................................6 63

4.3.3. Mariner..................................................66

4.4. Major, Minor, and Trace Elements in Seafloor Massive Sulfide Deposits ...68

4.4.1. Copper, Cobalt, and Selenium................................69

4.4.2. Zinc, Cadmium, and Manganese.............................70

4.4.3. Barium and Lead......................................... 71

4.4.4. Arsenic, Antimony, and Silver............................72

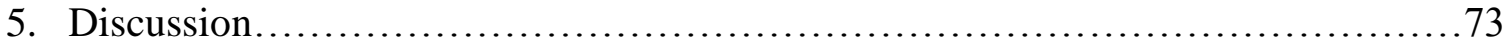

5.1. Hydrothermal Fluid Chemistry..................................... 74

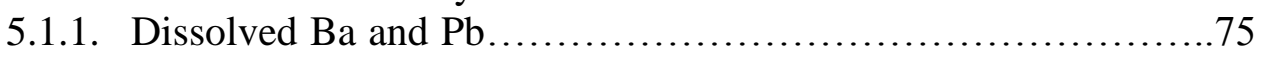

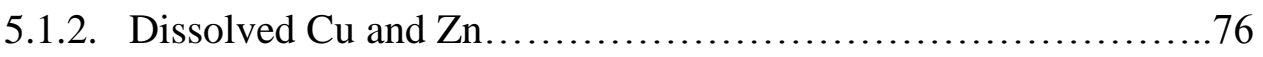

5.1.3. Dissolved Metal Ratios (Fe/Mn, $\mathrm{Cu} / \mathrm{Zn}, \mathrm{Fe} / \mathrm{Cu}) \ldots \ldots \ldots \ldots \ldots . . \ldots 77$ 
5.2. Effects of Hydrothermal Fluid Temperature and $\mathrm{pH}$ on SMS Deposits.......78

5.2.1. Thermodynamic Constraints..................................78

5.2.2. Incorporation of Trace Elements into Wurtzite/Sphalerite.........81

5.2.3. Flanges, Squat Terraces, Barite, and Amorphous Silica............84

5.3. Effects of Sulfur Fugacity $\left(\mathrm{fS}_{2}\right)$ on SMS Deposits........................85

5.4. Effects of Crustal Lithology on SMS deposits..............................89

5.5. Comparison with SMS Deposits at Other ELSC Vent Fields................91

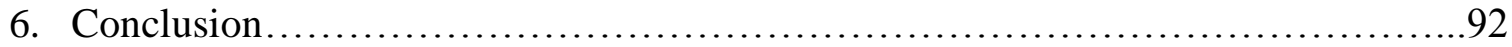

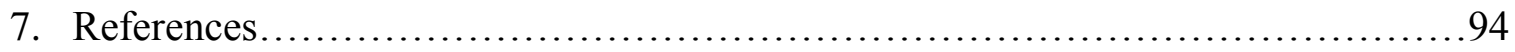

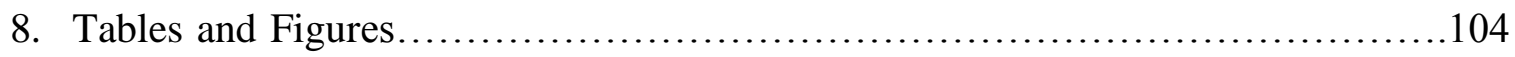

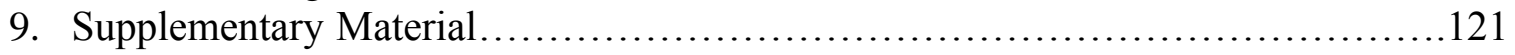

Chapter 3: Trace Element Chemistry of Black Smoker Chimney Linings Measured by Secondary

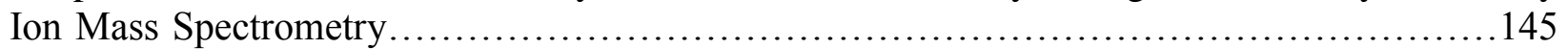

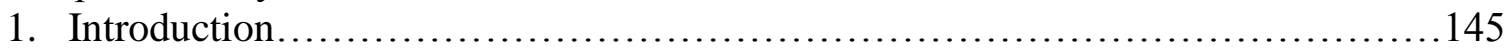

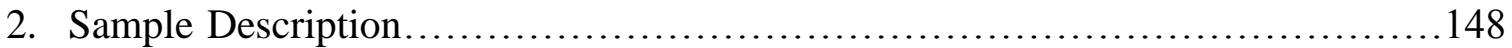

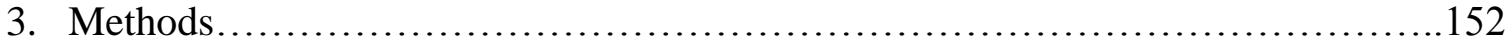

3.1. SIMS ........................................................ 153

3.2. Digestion and ICP-MS Analysis of Picked Chalcopyrite Grains............160

3.3. Principal Component Analysis.......................................161

4. Results................................................................. 161

4.1. Abundance of Trace Elements in Black Smoker Chimney Linings........162

4.2. Homogeneity of Trace Elements in Black Smoker Chimney Linings.......163

4.3. Trace Elements in Chalcopyrite Lining Picks...........................170

4.4. Trace Element Concentrations of Black Smoker Chimneys...............171

4.5. Principal Component Analyses........................................179

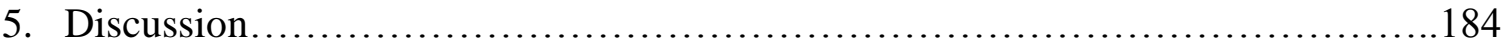

5.1. Evaluation of Calibration Curves..................................... 184

5.2. Trace Element Concentrations..................................... 186

5.3. Controls on Trace Element Concentrations..............................188

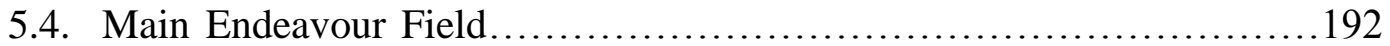

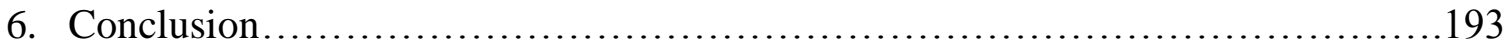

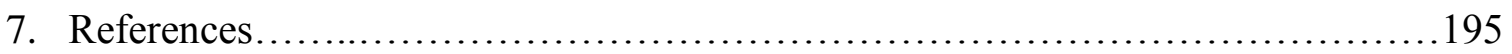

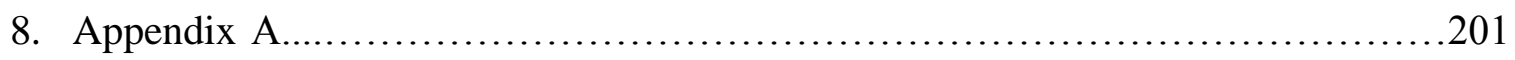

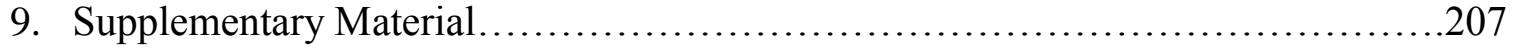

Chapter 4: Trace Element Proxies of Hydrothermal Fluid pH and Metal Content Based on Sample Pairs of Seafloor Hydrothermal Fluids and Chalcopyrite Lining Black Smoker Chimneys

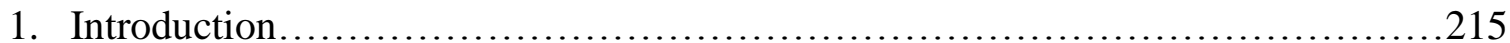

2. Geologic Settings of Fluids and Chimneys ..................................218

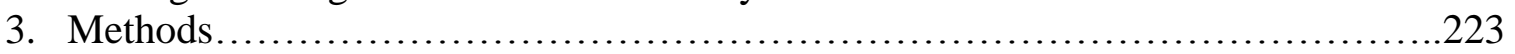

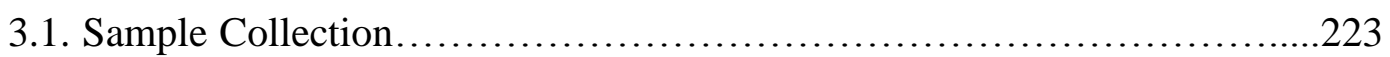

3.2. Digestion of Dregs and Filter Fractions..............................223

3.3. Major and Trace Element Analysis...............................224

3.4. Calculation of Trace Metal Concentrations in Hydrothermal Fluids......225 
3.5. Trace Element Analysis of Black Smoker Chimney Linings.............231

3.6. Fluid Chemical Modelling.......................................231

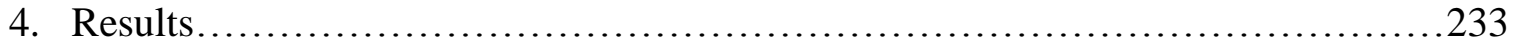

4.1. Hydrothermal fluids from the Eastern Lau Spreading Center..............233

4.1.1. Major Fluid Parameters...................................233

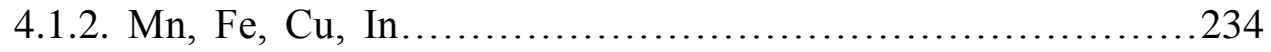

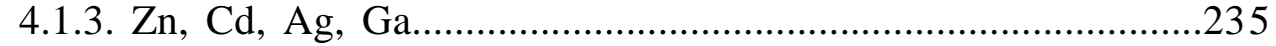

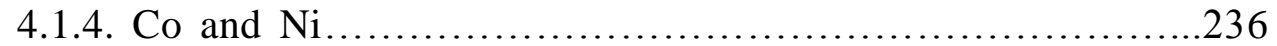

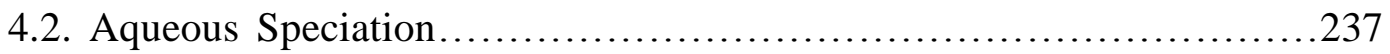

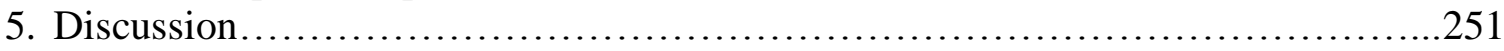

5.1. Hydrothermal Fluid Chemistry...................................251

5.2. Comparison of Fluid and Mineral Chemistry...........................256

5.2.1. Ag.................................................256

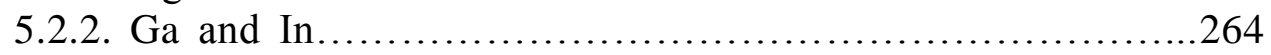

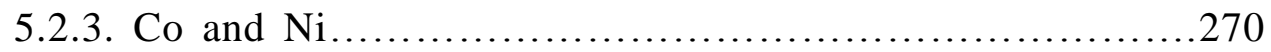

5.3. Trace element proxies of hydrothermal fluid $\mathrm{pH}$ and metal concentrations. 273

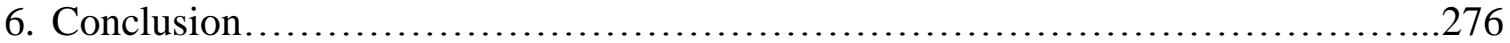

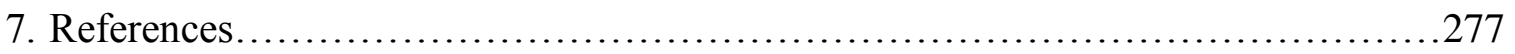

8. Appendix A (Plots of Fluid Data and zero-Mg Endmember Regressions)...........283

9. Appendix B. Calculated aqueous speciation of hydrothermal fluids...............345

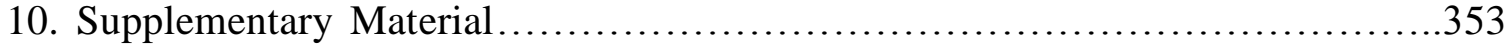

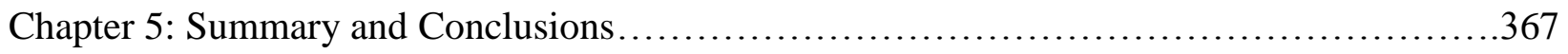

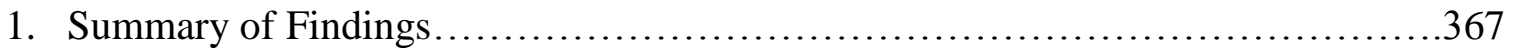

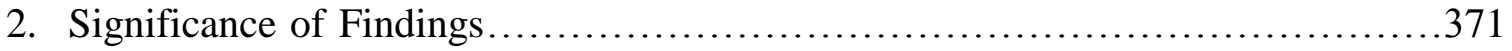

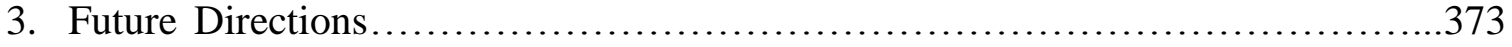

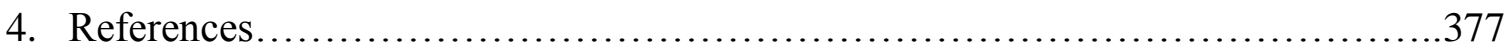




\section{LIST OF TABLES}

Chapter 1

1. Elemental Contents of Vent Fluid Precipitates from Trefry et al. (1994).................34

Chapter 2

1. Zero-Mg Endmember Concentrations of Selected Elements and Hydrogen in ELSC Hydrothermal Fluids ....................................................... 104

2. Mineral Textures of SMS Deposit Samples from ELSC Vent Fields Categorized by Sample Type........................................................ 106

3. Electron Microprobe Analyses of mol\% FeS in Wurtzite and Sphalerite................108

4. Correlation Coefficients of Elements in Bulk Samples................................ 109

5. Model Fluid Compositions Used in EQ3/6 Calculations..........................110

6. Results of EQ3/6 Fluid Modelling for Conductive Cooling of Model Vent Fluids.......111

S1. Trace Metal and Hydrogen Concentrations of ELSC Hydrothermal Fluids...............121

S2. Major Element Contents and Mineral Assemblages of Bulk Samples...........................126

S3. Minor and Trace Element Contents and Mineral Assemblages of Bulk Samples..........130

S4. Electron Microprobe Analyses of SMS Deposit Samples............................134

S4. Calculated in situ Sulfur Fugacity of Hydrothermal Fluids.......................... 143

Chapter 3

1. List of Black Smoker Chimney Samples Analyzed by Secondary Ion Mass Spectrometry....................................................... 150

2. Machine Settings for Secondary Ion Mass Spectrometry.......................... 154

3. Results of ICP-MS Analyses of Picked Chalcopyrite Grains from Selected Black Smoker Chimney Linings......................................................... 173

4. SIMS Measurements Converted to Concentration Units...........................178

5. Principal Components and Correlation Coefficients Calculated for SIMS Counts Ratios of Selected Trace Elements in Black Smoker Chimney Linings......................180.

6. Principal Components and Correlation Coefficients Calculated for SIMS Counts Ratios of Selected Trace Elements in Black Smoker Chimney Linings and Selected Hydrothermal Fluid Parameters of Hydrothermal Fluid Sample Pairs..................181

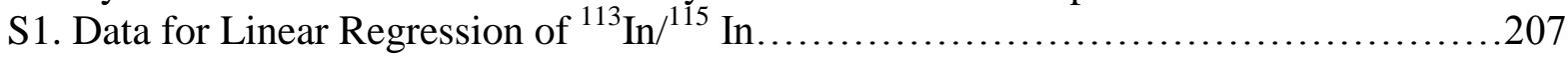

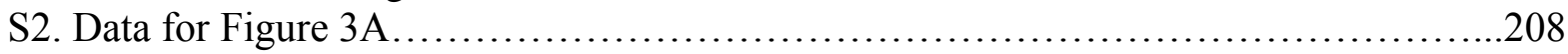

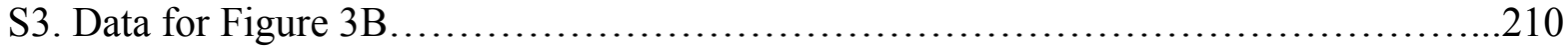

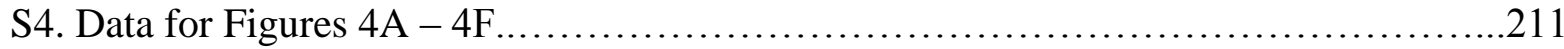

S5. Inputs and Outputs to Principal Component Analysis................................212

S6. Inputs and Outputs to Principal Component Analysis (with Fluid Data)................213

Chapter 4

1. List of Black Smoker Chimney Samples Analyzed by SIMS and Hydrothermal Fluids Analyzed by ICP-MS ....................................................216

2. Tabulated log (base 10) of the Equilibrium Reaction Coefficients Used in EQ3/6

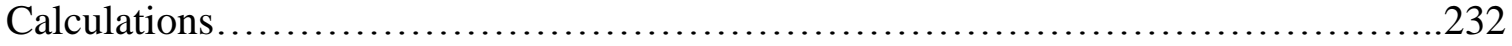


3. Measured Temperatures and Fluid Chemistry for Samples of ELSC Hydrothermal Vent

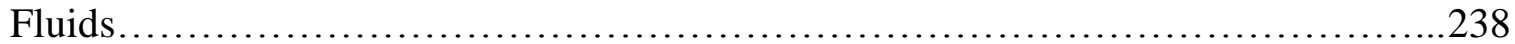

4. Zero-Mg Endmember Compositions of ELSC Hydrothermal Vent Fluids..............242

5. Temperature, $\mathrm{pH}\left(\right.$ at $25^{\circ} \mathrm{C}$ ), and Elemental Compositions of Hydrothermal Fluids Used as Inputs to EQ3/6 Thermodynamic Modeling.....................................249

6. Temperature, $\mathrm{pH}$ (at $25^{\circ} \mathrm{C}$ ), and $\mathrm{EQ} 3 / 6$ Model Outputs for in situ $\mathrm{pH}$ and $\log$ (base 10) of Oxygen and Sulfur Fugacity...................................................250

7. Results of SIMS Analyses of Black Smoker Chimney Linings Presented in Chapter 3 of This Thesis Tabulated as SIMS Counts Ratios and Concentrations...................257

S1. Elemental Concentrations in Dissolved Fractions of Hydrothermal Fluids..............353

S2. Elemental Concentrations in Filters Fractions of Hydrothermal Fluids....................355

S3. Elemental Concentrations in Dregs Fractions of Hydrothermal Fluids.....................357

S4. Selected ELSC Hydrothermal Fluid Data.......................................... 361

S5. Selected Manus Basin Hydrothermal Fluid Data..................................... 362

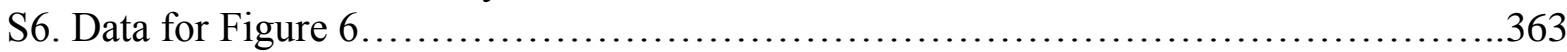

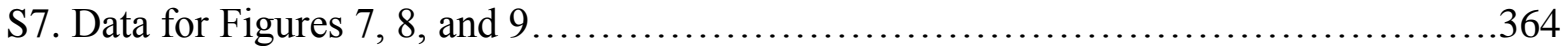




\section{LIST OF FIGURES}

Chapter 1

1. Map of the Global Distribution of Seafloor Hydrothermal Vent Fields.................19

2. Map of the Global Distribution of Volcanogenic Massive Sulfide Deposits............20

3. Schematic Diagram of Seafloor Massive Sulfide Deposits Morphology.................22

4. Schematic Diagram of Two-Stage Black Smoker Chimney Formation.................23

5. Schematic Drawing of a Cross-Section of a "White-Smoker" Spire....................24

6. Schematic Drawing of Cross-Section of Flange with Trapped Pool of Buoyant Fluid....24

7. Schematic Drawing of a Hydrothermal Edifice at the Main Endeavour Field............25

8. Schematic Drawing of a Cross-Section of the TAG Hydrothermal Mound...............26

9. Schematic Illustration of Seafloor Hydrothermal Vent Fluid Formation..................29

10. Physical Properties of Pure Water as a Function of Temperatures and Pressure..........30

11. Photograph of Hydrothermal Fluid Sampling with an Isobaric Gas-Tight (IGT) Sampler and Schematic Illustration of the Dissolved, Dregs and Filters Fractions................34

Chapter 2

1. Map of ELSC Hydrothermal Vent Fields and Regional Geologic Features

2. Plots of Temperature, $\mathrm{pH}$ (at $25^{\circ} \mathrm{C}$ ), Zero-Mg Endmember Concentrations of Selected Elements and Calculated Sulfur Fugacity of Hydrothermal Fluid Samples from the ELSC, Separated by Vent Field

3. Photographs of SMS Deposits at ELSC Vent Fields Showing Examples of SMS Deposit Morphology....

4. Photomicrographs of SMS Deposit Samples from ELSC Vent Fields Showing Selected Mineral Textures........................................................ 115

5. Plots of Selected Major, Minor, and Trace Element Concentrations in Bulk Samples of ELSC SMS Deposits Separated by Vent Field.................................116

6. Plots of Selected Trace Element Concentrations in $\mathrm{Cu}-\mathrm{Fe}$ Sulfides, Pyrite, Marcasite, Sphalerite, and Wurtzite Measured by Electron Microprobe Analysis in ELSC SMS Deposit Samples, Separated by Vent Field..................................... 117

7. Bivariate Plots of Hydrothermal Fluid Parameters vs. Temperature and $\mathrm{pH} \ldots \ldots . \ldots . . .118$

8. Plots of Correlation Coefficients Between $\mathrm{Zn}$ and Selected Trace Elements in Bulk Samples of ELSC SMS Deposits Separated by Vent Field..........................119

9. Plot of Sulfide Mineral Stability Fields as a Function of Temperature $(1 / \mathrm{K})$ and Sulfur Fugacity (log scale) Compared with ELSC Hydrothermal Fluids.... .120

Chapter 3

1. Photomicrograph and Photograph Showing Relative Spatial Scale of SIMS Measurements and Picked Grains............................................ 152

2. Mass Spectra from Secondary Ion Mass Spectrometry.......................... 155

3. Plots of Repeat Measurements of SIMS Counts Ratios Taken During Two Different Analytical Sessions...................................................... 158

4. Plots of Means and standard errors $(1 \sigma)$ of SIMS Counts Ratios for Selected Trace Elements in Black Smoker Chimney Samples. .164 
5. Bivariate Plots of SIMS Count Ratios for Co vs. Ni and In vs. Ga...................168

6. Histograms of the Relative Standard Errors $(1 \sigma)$ of SIMS Count Ratios on Multiple Spots...................................................................

7. Plots of Selected Trace Element Concentrations Measured by ICP-MS vs. SIMS Counts Ratios of the Same Elements and Derivative SIMS Calibration Curves.................174

8. Plots of vent fluid temperature vs. ${ }^{59} \mathrm{Co} /{ }^{63} \mathrm{Cu} 16 \mathrm{O}$ and ${ }^{60} \mathrm{Ni} /{ }^{63} \mathrm{Cu}^{16} \mathrm{O}$ and plots of vent fluid $\mathrm{pH}$ (at $25^{\circ} \mathrm{C}$ ) vs. ${ }^{69} \mathrm{Ga} /{ }^{63} \mathrm{Cu} 16 \mathrm{O}$ and ${ }^{115} \mathrm{In} /{ }^{63} \mathrm{Cu}^{16} \mathrm{O} \ldots \ldots \ldots \ldots \ldots \ldots . \ldots 182$

9. Plot of $\mathrm{Cu}$ and $\mathrm{Fe}$ in sample J2-613-16-R1 .................................... 190

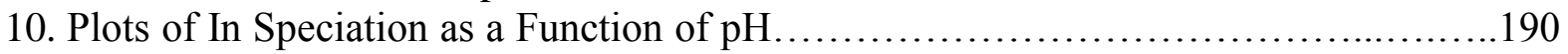

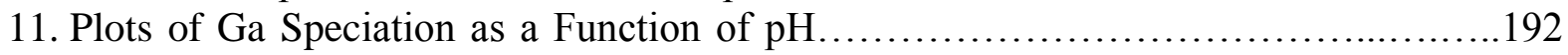

A1. Plots of the Weighed Ag Concentration in ICP-MS Standard Solutions vs. Measured Counts Normalized to Internal Spikes Sc and Y for Two Different Dillution Series of the Same Concentrated Mixed Standard Solution.................................203

A2. Plots of the Weighed Ag Concentration in ICP-MS Standard Solutions vs. the Error in Weighed Ag Concentrations and those Calculated Based on ICP-MS Measurements. 205

A2. Plots of the Weighed Ag Concentration in ICP-MS Standard Solutions vs. the Error in Weighed Ag Concentrations and those Calculated Based on ICP-MS Measurements Following Mathematical Correction of the Discrepancy between the Two Dillution Series of the Same Concentrated Mixed Standard Solution................................206

Chapter 4

1. Map of Vent Field Locations along the Eastern Lau Spreading Center.................219

2. Map of Vent Field Locations in the Manus Basin................................221

3. Plots of Measured Concentrations of $\mathrm{Mg}$ vs. (A) $\mathrm{Mn}$, (B) $\mathrm{Fe},(\mathrm{C}$ ) $\mathrm{Cu}$, and (D) $\mathrm{Ag}$ in Hydrothermal Fluid Samples from the Tu'i Malila Vent Field and Extrapolation to zeroMg Endmember Concentrations.

4. Plots of Hydrothermal Fluid Temperature, $\mathrm{pH}\left(\right.$ at $25^{\circ} \mathrm{C}$ ), and Zero-Mg Endmember Concentrations of Selected Elements for Vent Fluids from the Lau and Manus

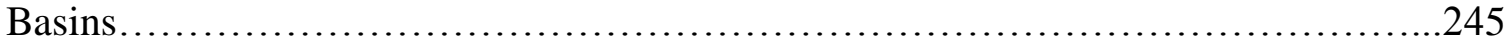

5. Plots of Hydrothermal Fluid Temperature and $\mathrm{pH}$ (at $25^{\circ} \mathrm{C}$ ) vs. Zero-Mg Endmember Concentrations of Selected Elements in Hydrothermal Fluids from the Lau and Manus Basins....................................................................254

6. Plots of the Total Concentration and Free Ion Activity Ratios of $\mathrm{Ag}$ and $\mathrm{Cu}$ in Hydrothermal Fluids vs. SIMS Counts Ratios of ${ }^{109} \mathrm{Ag} /{ }^{63} \mathrm{Cu}^{16} \mathrm{O}$ in Chalcopyrite Grains along the Innermost Linings of Paired Black Smoker Chimney Samples ........260

7. Plots of Hydrothermal Fluid $\mathrm{pH}\left(\right.$ at $25^{\circ} \mathrm{C}$ ) vs. $\mathrm{Ag}$ and $\mathrm{Cu}$ in Hydrothermal Fluids and Chalcopyrite from Black Smoker Chimney Sample Pairs...........................262

8. Plots of Hydrothermal Fluid $\mathrm{pH}$ (at $25^{\circ} \mathrm{C}$ and in situ Temperatures) vs. SIMS Counts Ratios of ${ }^{69} \mathrm{Ga} /{ }^{63} \mathrm{Cu}^{16} \mathrm{O}$ and ${ }^{115} \mathrm{In} /{ }^{63} \mathrm{Cu}^{16} \mathrm{O}$ in Chalcopyrite from Black Smoker Chimney

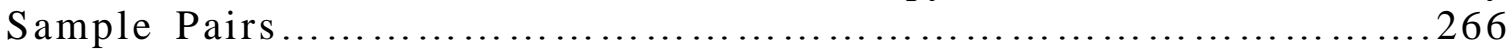

9. Plots of Total Ga Concentrations and Ratios of Free $\mathrm{Ga}^{3+}$ to Free $\mathrm{Fe}^{2+}$ in Hydrothermal Fluids vs. SIMS Counts Ratios of ${ }^{69} \mathrm{Ga} /{ }^{63} \mathrm{Cu}^{16} \mathrm{O}$ in Chalcopyrite Lining Paired Black Smoker Chimneys...........................................................268

10. Plots of $\mathrm{pH}$ vs. the $\log$ Concentration of Aqueous $\mathrm{Ga}$ and In Complexes..............269

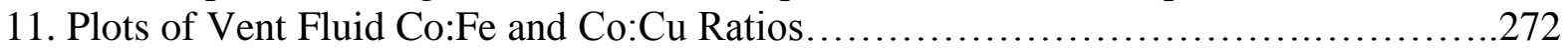


12. Plot of $\mathrm{Cu}$ and Fe Concentrations in Sample J2-613-16-R1 ......................273

13. Schematic Diagram of Partitioning between Chimney Linings and Vent Fluids........274 


\section{Chapter 1}

\section{Introduction}

\section{Background and Motivation}

Seafloor massive sulfide (SMS) deposits are accumulations of metal sulfide and other (e.g., sulfate, oxide, silicate, sulfosalt, rarely carbonate) minerals formed at or near the seafloor by the activity of venting seafloor hydrothermal fluids. Actively forming SMS deposits were first discovered in 1979 , coincident with the discovery of high-temperature $\left(380^{\circ} \mathrm{C} \pm 30^{\circ} \mathrm{C}\right)$ seafloor hydrothermal vents that followed the discovery of lower-temperature $\left(10^{\circ} \mathrm{C}\right.$ to $\left.17^{\circ} \mathrm{C}\right)$ seafloor hydrothermal vents in 1977 (Corliss et al., 1979; Spiess et al., 1980). Since this initial discovery, at least 165 active vent fields hosting SMS deposits have been found in submerged areas of high geothermal heat flux around the world, and 500 to 5,000 are estimated to exist globally (Hannington et al., 2011). Geologic settings include: ultraslow-, slow-, intermediate-, fast-, and ultrafast-spreading mid-ocean ridges, intraoceanic arcs and back-arc basins, transitional island arcs and back-arc rifts, sedimented ridges and related rifts, intracontinental rifts and back-arc rifts, off-axis and intraplate volcanoes, and volcanic rifted margins (see reviews by Hannington et al., 2010; Beaulieu, 2015; Figure 1).

In contrast to the relatively recent discovery of SMS deposits, humans have been mining copper, zinc, and other metals from volcanogenic massive sulfide (VMS) deposits - likely to be the geologically preserved remnants of ancient SMS deposits-for thousands of years. Archaeological evidence suggests that such mining began in the late-Neolithic Period (a.k.a. Chalcolithic Period) 7,000 years ago at sites in Anatolia and the Eastern Mediterranean, 
becoming more widespread with the advent of the Bronze Age, 5,000 years ago (Kassianidou and Knapp, 2005). Contemporary mining of VMS deposits occurs in ophiolite belts around the world, where pieces of oceanic crust have been uplifted onto land by geologic processes (Galley et al., 2007; Figure 2). The exact correspondence between modern SMS deposits on the seafloor and ophiolite-hosted massive sulfide deposits is not always clear as some ancient massive sulfide deposits may lack modern seafloor counterparts (Hannington et al., 2010). Nevertheless, there are clear similarities between SMS and VMS deposits with respect to deposit morphology, mineralogy, geochemistry, and (paleo-) tectonic settings (Franklin et al., 2005; Hannington et al., 2005; Hannington et al., 2010). Moreover, mineral textures interpreted to be the geologically preserved remnants of black smoker chimneys have been reported in VMS deposits in Japan (Scott, 1981), Cyprus (Oudin and Constantinou, 1984), the southern Urals (Herrington et al., 1998; Maslennikov et al., 2009), and the Eastern Pontides (Revan et al., 2014). Several of these deposits also contain fossils of hydrothermal vent fauna, including brachiopods, gastropods, mollusks, and worm tubes (see review by Little et al., 1998).

The significance of studies investigating the geochemistry of actively forming SMS deposits lies in the opportunity to directly compare SMS deposits with the hydrothermal fluids from which they form. Such studies provide insight into the formation processes of SMS deposits as well as opportunities to develop proxies of hydrothermal fluid temperature and chemistry based on the mineralogical, geochemical, or isotopic composition of SMS deposits (e.g., Hannington et al., 1995; Tivey, 1995; Tivey et al., 1995; Tivey et al., 1999; Rouxel et al., 2004; Craddock et al., 2010; McDermott et al., 2015; Kawasumi and Chiba, 2017). The overarching goal of the studies presented in this thesis is to compare samples of SMS deposit minerals with the hydrothermal fluids from which they form in order to develop mineralogical 
and trace element proxies of hydrothermal fluid temperature and chemistry and host-rock lithology. Particular focus is placed on the mineralogy and trace element contents of black smoker chimneys linings compared with the temperature and chemistry of hydrothermal fluid sample pairs and thermodynamic modelling of fluid speciation and mineral saturation at in situ temperatures and pressures.

\section{Figure 1.}

Map of seafloor hydrothermal vent locations from the InterRidge database (from Beaulieu, 2010; https://vents-data.interridge.org/)

\section{Global Distribution of Hydrothermal Vent Fields}

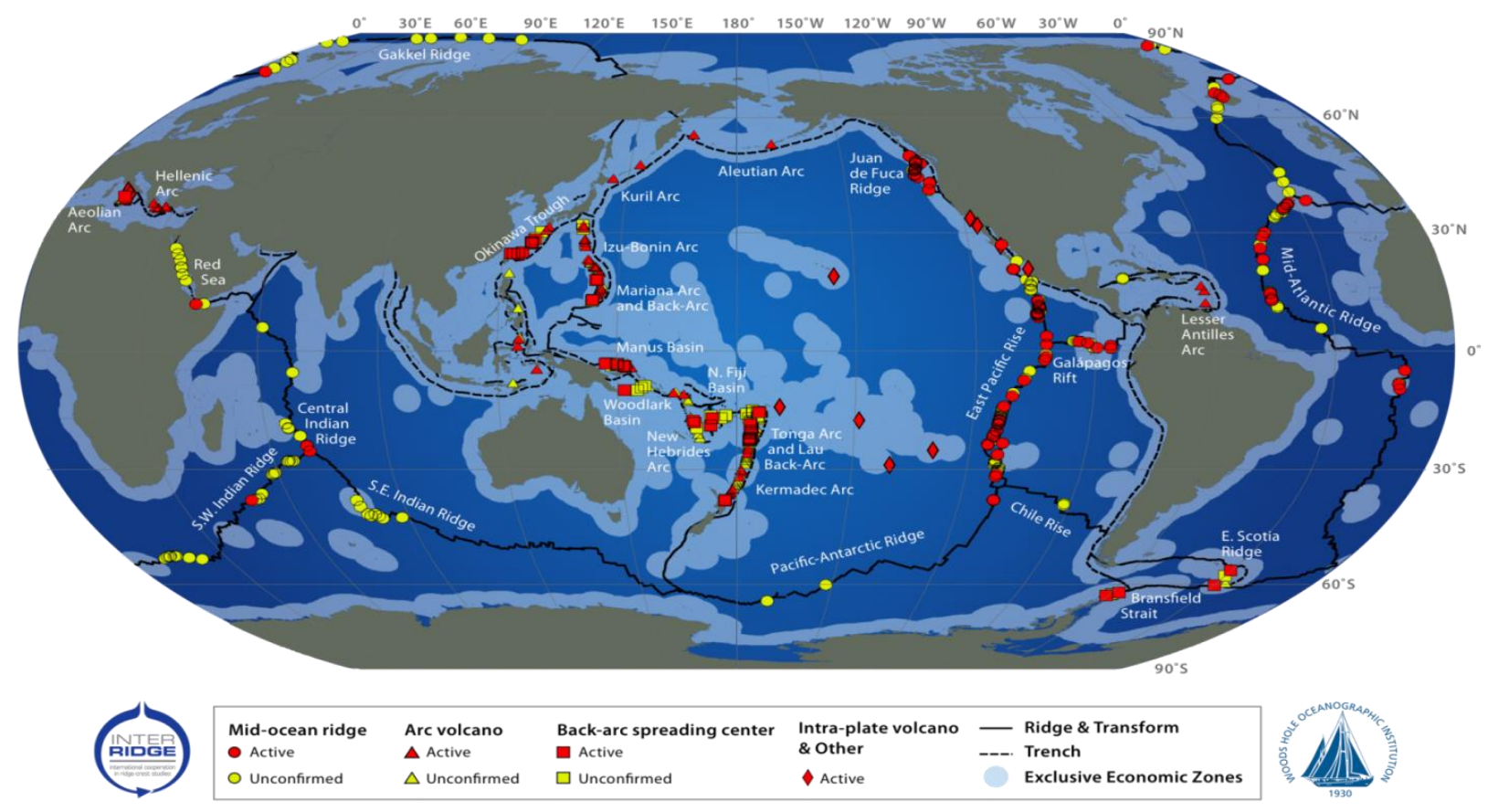




\section{Figure 2.}

Map of volcanogenic massive sulfide deposit locations (from Galley, 2007). Red symbols indicate known locations of volcanogenic massive sulfide (VMS) and seafloor massive sulfide (SMS) deposits. Black symbols indicate the locations, names, and estimated tonnages of the 45 most economically important VMS mining districts.

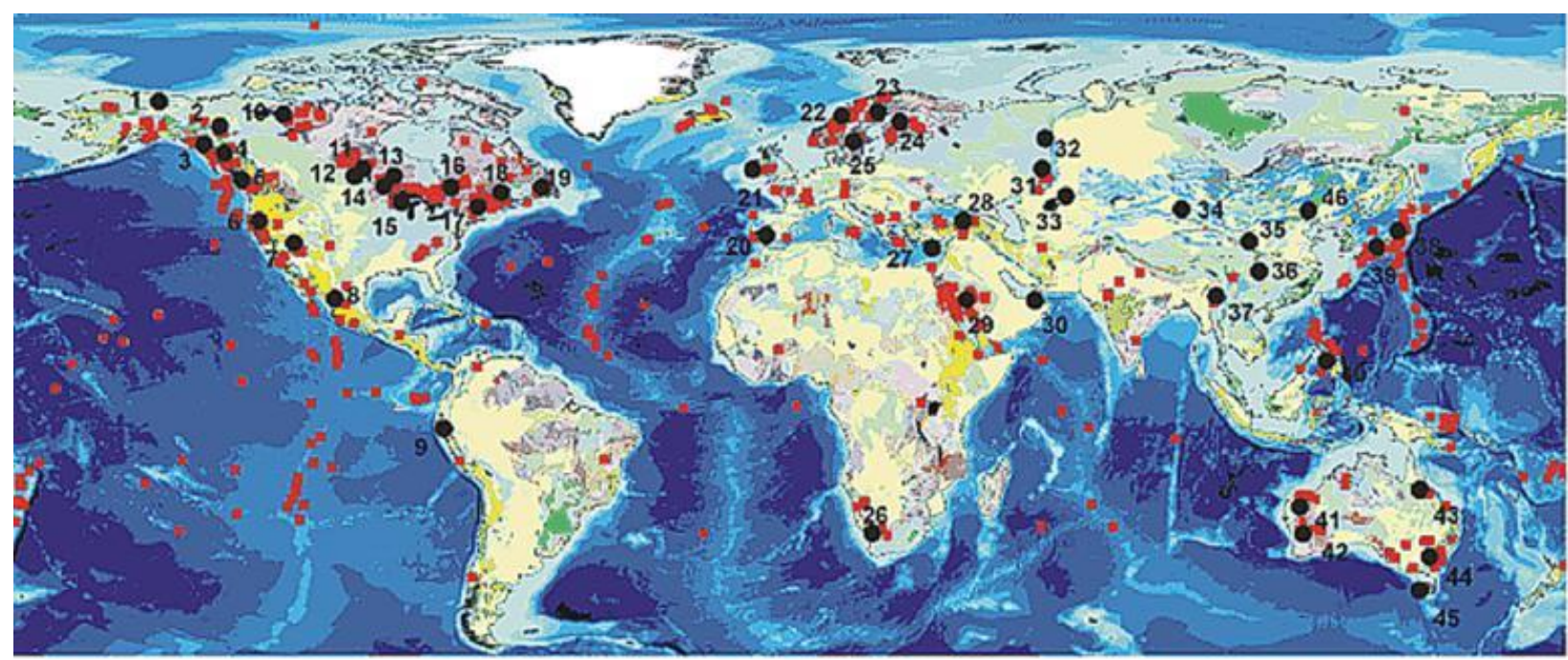

1. Alaska, Brooks Range $33 \mathrm{Mt}$

2. Finlayson, Yukon $20 \mathrm{Mt}$

3. Windy Craggy $300 \mathrm{Mt}$

4. Northern Cordillera $100 \mathrm{mt}$

5. Myra Falls $30 \mathrm{Mt}$

6. Shasta, Klammath $35 \mathrm{Mt}$

7. Jerome, Arizona $40 \mathrm{mt}$

8. Central Mexico $120 \mathrm{Mt}$

9. Tambo Grande $200 \mathrm{Mt}$

10. Slave 20-30 Mt
11. Ruttan, Manitoba $70 \mathrm{Mt}$

12. Flin Flon-Snow Lk $150 \mathrm{Mt}$

13. Geco-Manitouwadge $60 \mathrm{Mt}$

14. Sturgeon Lake $35 \mathrm{Mt}$

15. Ladysmith-Rhineland $80 \mathrm{Mt}$

16. Abitibi $600 \mathrm{Mt}$

18. Bathurst $250 \mathrm{Mt}$

19. Central Nfld. 75 Mt

20. Iberian Pyrite Belt $1000 \mathrm{Mt}$

21. Avoca $37 \mathrm{Mt}$
22. Tondheim Norway $>100 \mathrm{Mt}$

23. Skellofte Sweden $70 \mathrm{Mt}$

24. Outokumpu-Pyhsim $90 \mathrm{Mt}$

25. Bergslagen-Orijarvi $110 \mathrm{Mt}$

27. Troodos Cyprus $35 \mathrm{Mt}$

28. Turkey, Black Sea 200 Mt

29. Saudi Arabia $70 \mathrm{Mt}$

30. Semail Oman $30 \mathrm{Mt}$

31. Southern Urals $>400 \mathrm{Mt}$

32. Central Urals $>100 \mathrm{Mt}$
33. Rudny Altal $>100 \mathrm{Mt}$ 34-36. China $>500 \mathrm{Mt}$

35. Bawdwin-Laochang $>40 \mathrm{Mt}$

38. Hokuroku Japan $80 \mathrm{Mt}$

39. Besshi Japan $230 \mathrm{Mt}$

40. Philippines $65 \mathrm{Mt}$

41-42. WA >75 $\mathrm{Mt}$

43. Central Queensland

44. Lachlan Fold Beit

45. Mt. Read Tasmania $150 \mathrm{Mt}$

\section{Formation of Seafloor Massive Sulfide Deposits}

Seafloor massive sulfide deposits form as reduced and usually acidic metal- and sulfide-

rich hydrothermal fluids exit the seafloor and encounter cold, sulfate-rich, oxidized, and alkaline

seawater. As hydrothermal fluids cool during upflow and subsequent expulsion from the

seafloor, the solubility of metal sulfide minerals decreases. When metal sulfide mineral solubility

is exceeded by the concentrations of metals and sulfide in hydrothermal fluids, these minerals

become saturated and begin to precipitate. SMS deposit mineralogy is often layered based on

differences in the temperature at which different minerals become saturated. 
Mixing between hydrothermal fluids and seawater at or near the seafloor can also affect mineral precipitation and SMS deposit formation by accelerating cooling and buffering $\mathrm{pH}$, which promotes metal sulfide precipitation by decreasing solubility, or inhibits metal sulfide precipitation by diluting metal and sulfide concentrations. In addition, sulfate minerals can precipitate from the heating of seawater (anhydrite) or reactions between ions contained in hydrothermal fluid with seawater sulfate. For example, hydrothermal $\mathrm{Ba}^{2+}$ can react with seawater sulfate to form barite and hydrothermal $\mathrm{Ca}^{2+}$ can react with seawater to form additional anhydrite. Further afield, the reaction of metals contained in hydrothermal fluids with oxygenated seawater leads to the precipitation of oxide or mixed oxide and sulfide deposits, either in the vicinity of SMS deposits or as distal sediments.

Seafloor massive sulfide deposits exhibit a variety of deposit morphology related to the temperature, chemistry, and flow pathways of hydrothermal vent fluids (Figure 3; Tivey, 2007). Black smoker chimneys, which derive their name from the pipe-like shape of the deposit and the black, smoke-like appearance of buoyant hydrothermal fluid laden with sulfide mineral particulate, are formed in two stages from vigorously venting high-temperature $\left(>300^{\circ} \mathrm{C}\right)$ hydrothermal fluids (Figure 4; Haymon, 1983; Goldfarb et al., 1983). First, an anhydrite $\left(\mathrm{CaSO}_{4}\right)$ matrix containing fine-grained metal sulfide minerals is deposited as venting hydrothermal fluid heats the surrounding seawater (Figure 4). Anhydrite, which exhibits retrograde solubility, precipitates from the calcium $\left(\mathrm{Ca}^{2+}\right)$ and sulfate $\left(\mathrm{SO}_{4}{ }^{2-}\right)$ contained in seawater at $\sim 150^{\circ} \mathrm{C}$ (Bischoff and Seyfried, 1978). Additional $\mathrm{Ca}^{2+}$ may also be contributed by the hydrothermal fluid (Albarede et al., 1981). As hydrothermal fluid becomes physically and chemically insulated from interactions with the surrounding seawater, a layer of chalcopyrite $\left(\mathrm{CuFeS}_{2}\right)$ or cubanite $\left(\mathrm{CuFe}_{2} \mathrm{~S}_{3}\right) \pm$ wurtzite $((\mathrm{Zn}, \mathrm{Fe}) \mathrm{S}) \pm$ pyrite $\left(\mathrm{FeS}_{2}\right)$ or pyrrhotite $\left(\mathrm{Fe}_{1-\mathrm{x}} \mathrm{S}\right)$ is deposited along the 
inner lining of the chimney wall. Diffusive and advective interactions between hydrothermal fluids and seawater within the chimney wall lead to further precipitation of metal sulfide minerals and replacement of the previously deposited anhydrite-dominated matrix as chemical conditions become more reduced (Haymon, 1983; Goldfarb et al., 1983; Tivey, 1995).

\section{Figure 3.}

Artistic representation of seafloor massive sulfide deposits showing: (A) black smoker chimneys (B) "white smoker" spires (C) flanges (D) diffuse flows (C. (image by C. Kearney after Sarrazin et al. (1999)).

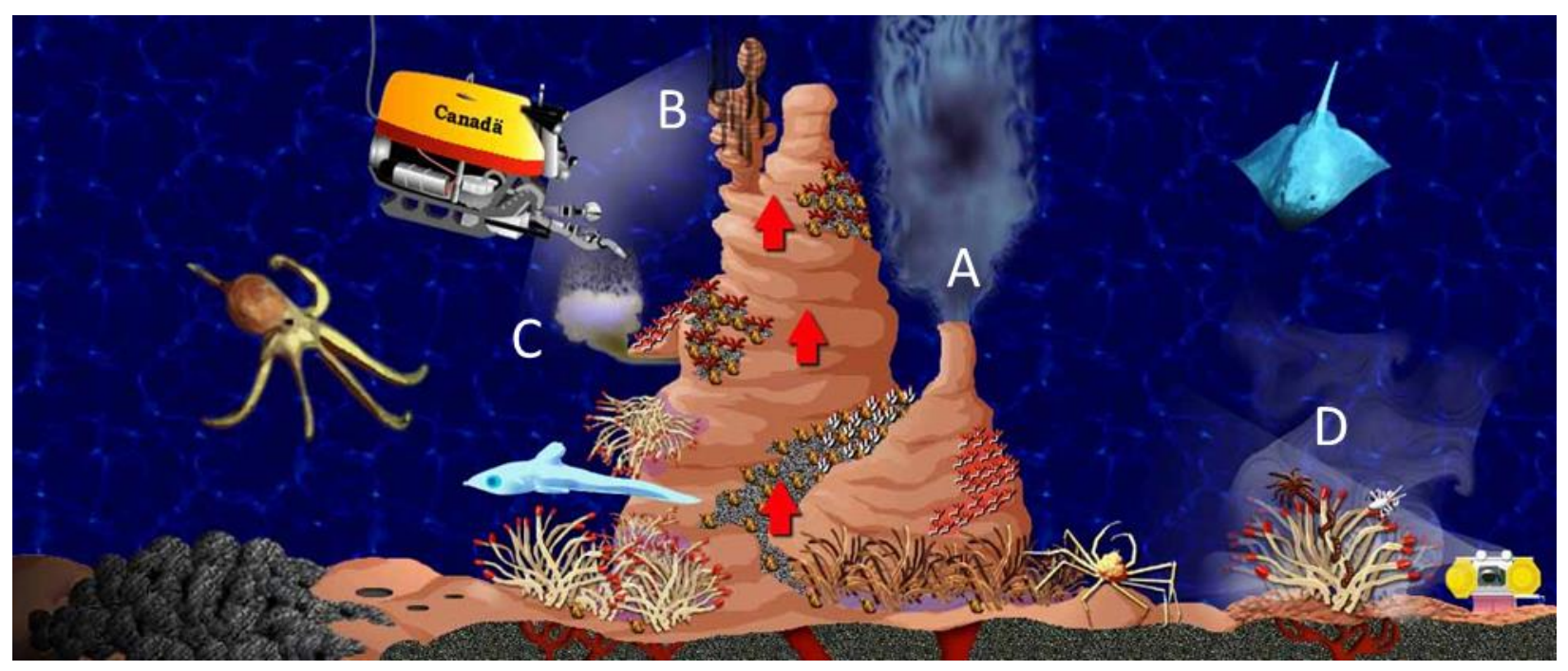

Where hydrothermal fluids vent less vigorously, and are often cooler, beehive-like SMS deposits or "white smoker" spires may also be deposited (e.g., Haymon and Kastner, 1981;

Kormas et al., 2006; Figure 5). Where deposits exhibit significant structural stability, horizontal flanges can develop as buoyant hydrothermal fluids are trapped in pools beneath mineral flanges, often spilling upward around the lip of the flange (e.g., Tivey et al., 1999; Figure 6). Lowtemperature diffuse venting occurs where hydrothermal fluids have mixed with seawater and/or substantially cooled in the subsurface prior to venting. Such fluids are often not associated with sulfide mineral deposits, but are important habitats for vent field fauna (Figure 3). SMS deposits 
can also consist of composite structures exhibiting several types of hydrothermal venting in different areas. Examples include the steep-sided edifices found at vent fields along the Endeavour Segment of the Juan de Fuca Ridge (Tivey et al., 1999; Figure 7) and the large (diameter $\approx 200 \mathrm{~m}$; height $\approx 50 \mathrm{~m}$ ) massive sulfide mound at the TAG hydrothermal field on the Mid-Atlantic Ridge (Tivey et al., 1995; Humphris and Tivey, 2000; Figure 8).

\section{Figure 4.}

Artistic representation of black smoker chimney formation processes (J. Doucette, WHOI Graphic Services, after Haymon, 1983). Stage 1 chimneys (on left) form by heating of seawater and precipitation of an anhydrite-dominated matrix. Stage 2 chimneys (on right) are characterized by precipitation of a metal sulfide inner layer that precipitates from conductively cooled hydrothermal fluids (see text for details).

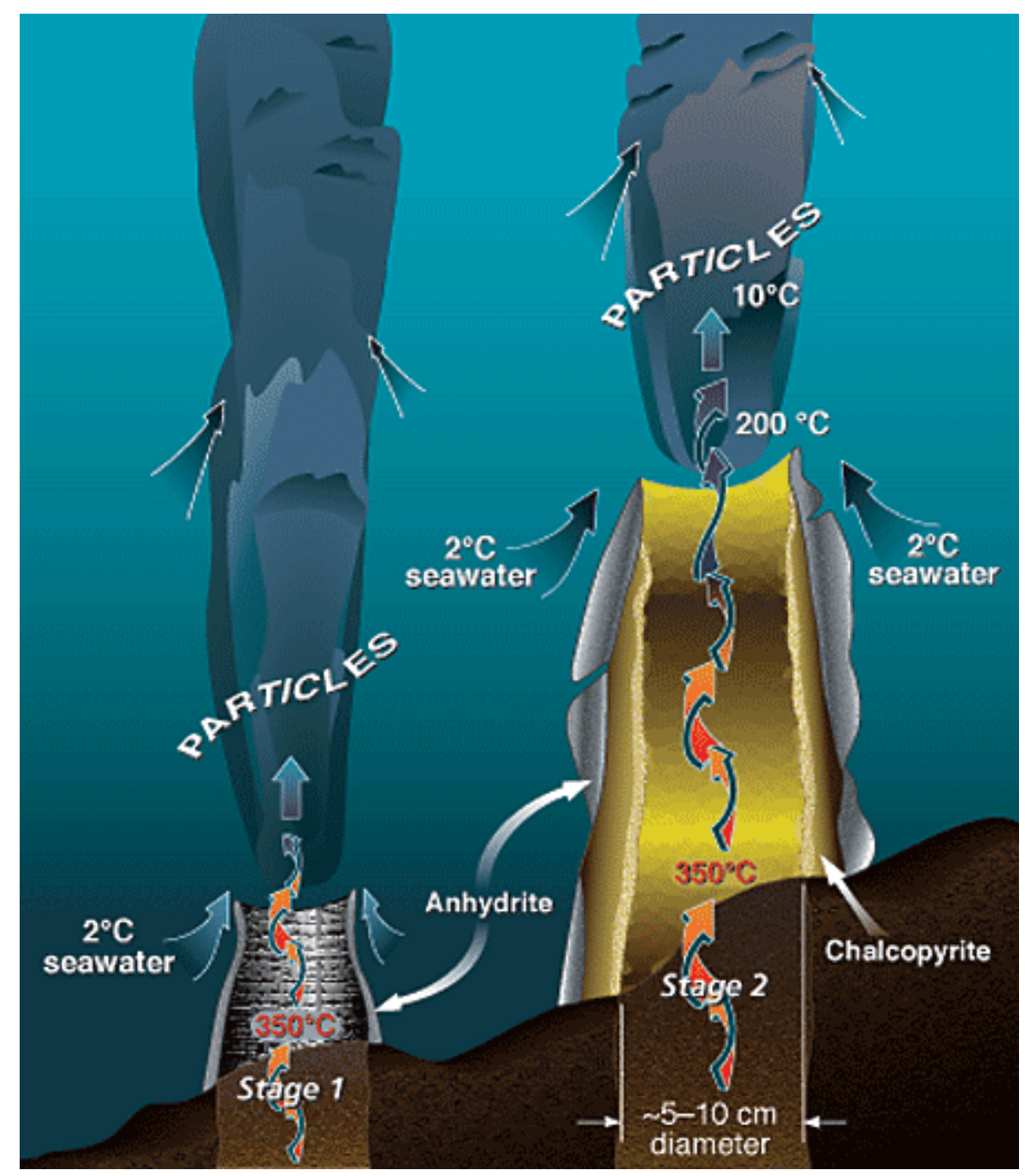




\section{Figure 5.}

Schematic drawing of a cross section of a "white-smoker" spire based on deposits collected from the East Pacific Rise (from Kormas et al., 2006).

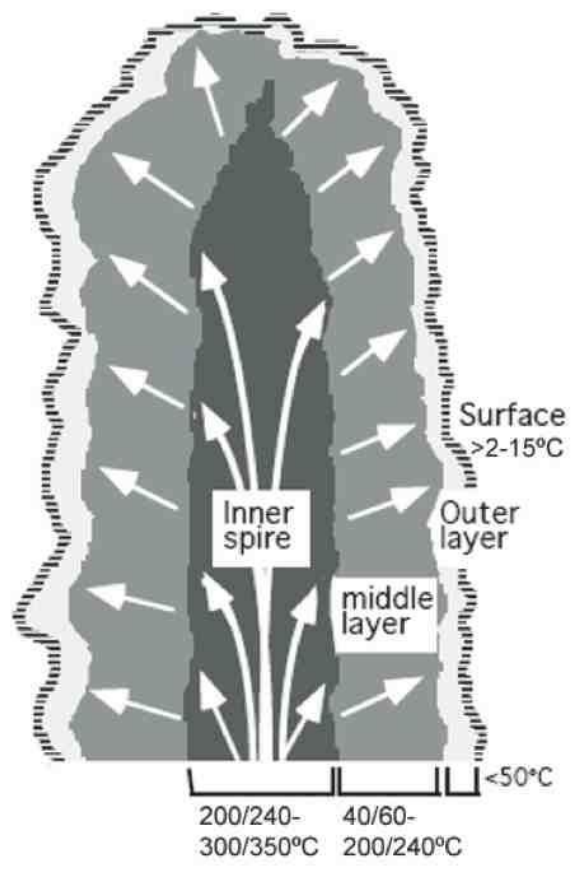

\section{Figure 6.}

Schematic drawing of cross section of flange with trapped pool of buoyant fluid (from Tivey, 2007)

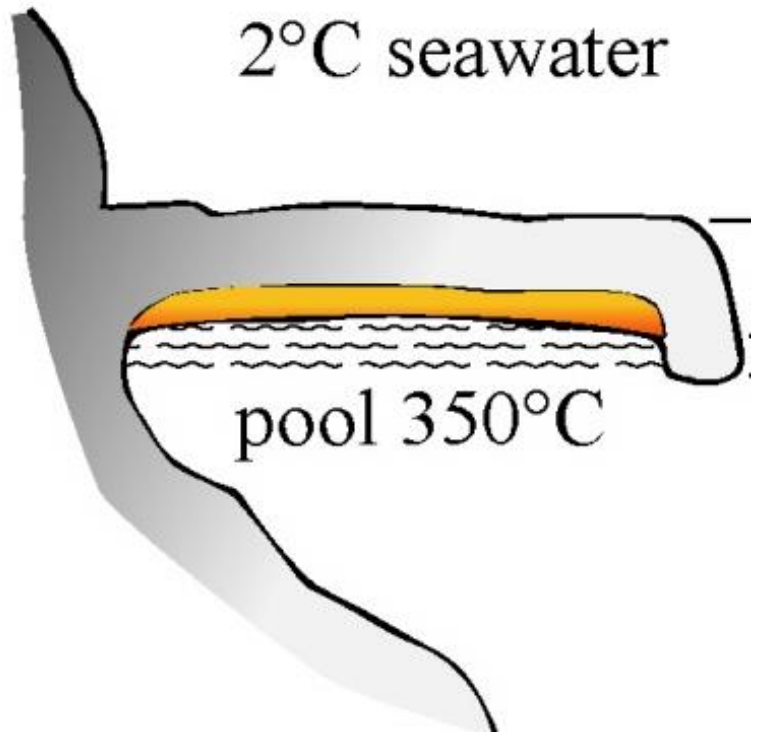




\section{Figure 7.}

Schematic drawing of a steep-sided hydrothermal edifice at the Main Endeavour Field on the Juan de Fuca Ridge and associated formation processes (from Tivey et al., 1999).

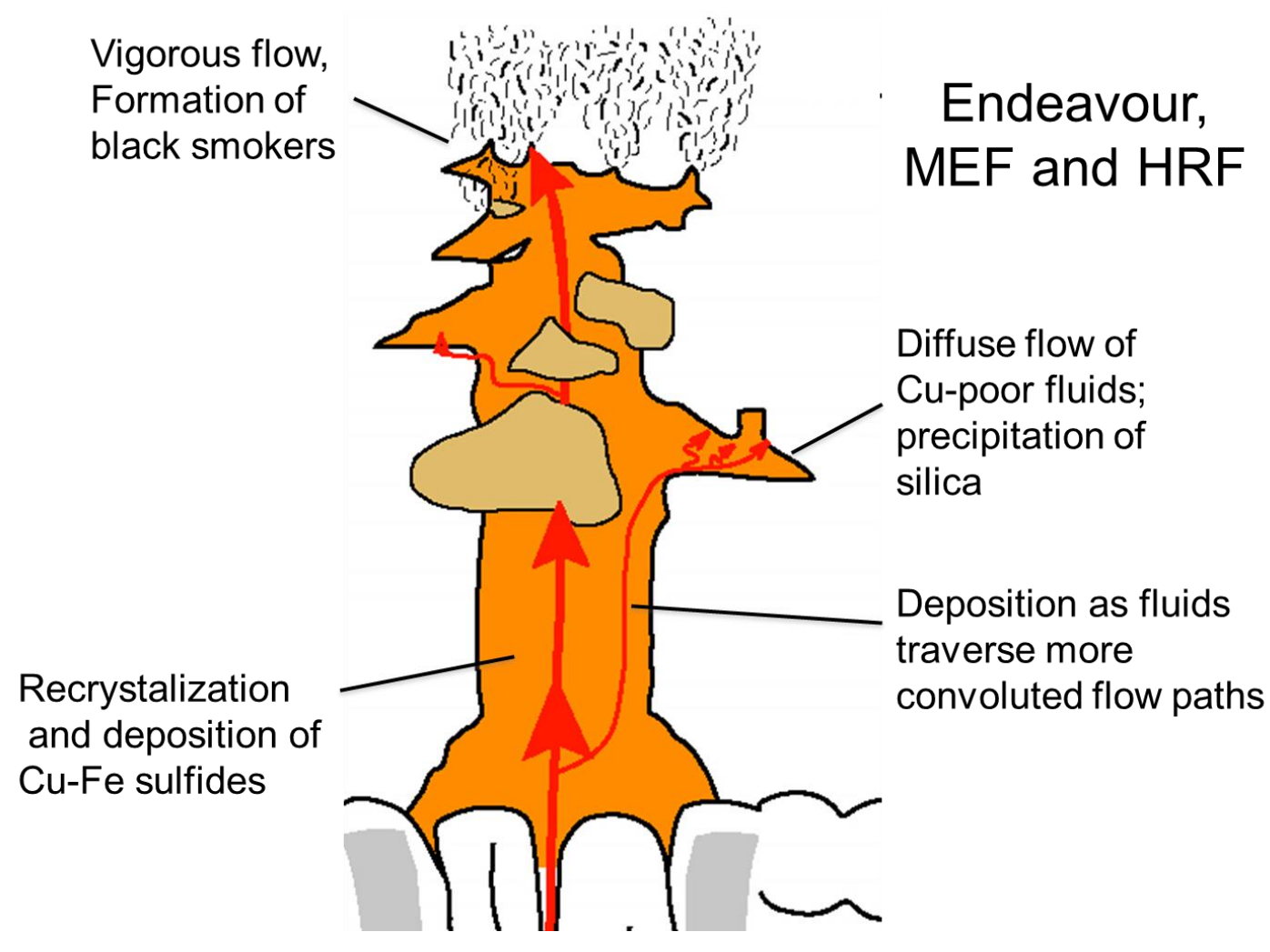




\section{Figure 8.}

Schematic drawing of a cross section of the $\sim 200 \mathrm{~m}$ diameter hydrothermal mound at the TAG hydrothermal field on the Mid-Atlantic Ridge showing formation processes including direct venting of black smoker fluids and white smoker fluids formed by mixing of black smoker fluids and seawater within the hydrothermal mound (from Humphris and Tivey, 2000).

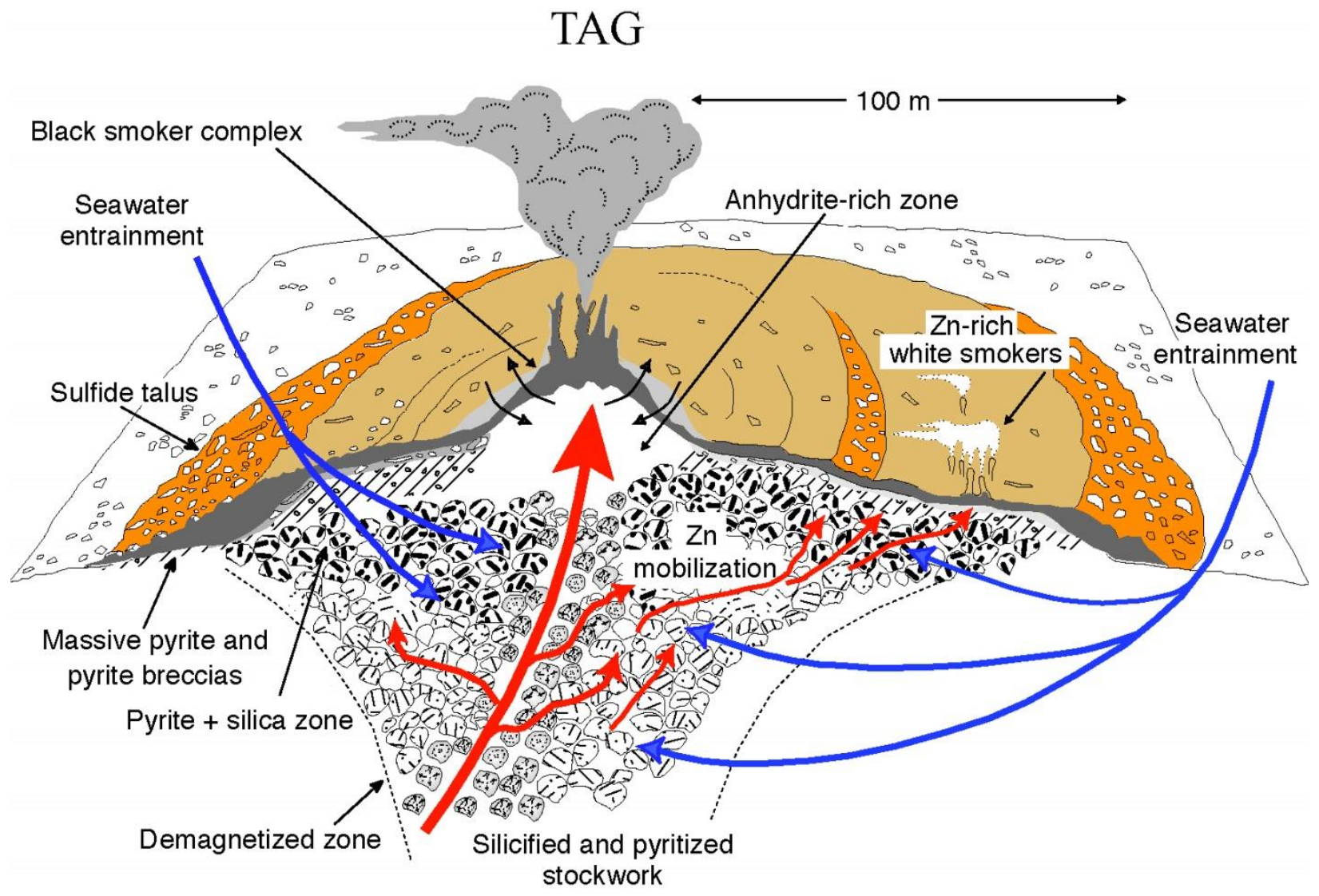




\section{Formation of Seafloor Hydrothermal Fluids}

The seafloor hydrothermal fluids that vent and form SMS deposits are a type of chemically evolved seawater produced by a series of progressively hotter chemical reactions between seawater and crustal host rock that take place as seawater percolates into the seafloor and is heated by hot rock or magma sourced from the earth's mantle (Alt, 1995). First, lowtemperature $\left(<60^{\circ} \mathrm{C}\right)$ reactions between oxidized seawater and ferrous iron $(\mathrm{Fe}(\mathrm{II}))$ contained in primary igneous minerals produce secondary alteration minerals containing ferric iron ( $\mathrm{Fe}(\mathrm{III}))$ and a reduced residual fluid (Alt, 1995; Figure 9). Above $\sim 150^{\circ} \mathrm{C}, \mathrm{Mg}^{2+}$ is removed from this fluid to form $\mathrm{Mg}$-rich smectite $\left(<200^{\circ} \mathrm{C}\right)$ and chlorite $\left(>200^{\circ} \mathrm{C}\right)$ in exchange for $\mathrm{H}^{+}, \mathrm{Ca}^{2+}$, and $\mathrm{Na}^{+}$contained in crustal host rocks (Alt, 1995; Figure 9). This process produces an acidic fluid from which Mg has been quantitatively removed (Alt, 1995; Figure 9). Also above $\sim 150^{\circ} \mathrm{C}$, precipitation of anhydrite $\left(\mathrm{CaSO}_{4}\right)$ leads to the removal of $\mathrm{Ca}$ and $\mathrm{SO}_{4}{ }^{2-}$, a process which continues as $\mathrm{Ca}^{2+}$ is leached from crustal host rocks (Alt, 1995; Figure 9). At higher temperatures, ion exchange reactions such as albitization $\left(\mathrm{CaAl}_{2} \mathrm{Si}_{2} \mathrm{O}_{8}\right.$ (anorthite) $+2 \mathrm{Na}^{+}+4 \mathrm{SiO}_{2 \text { (aq) }}$ $\rightarrow 2 \mathrm{NaAlSi}_{3} \mathrm{O}_{8}($ albite $)+\mathrm{Ca}^{2+}$ ) and reduction of seawater sulfate to sulfide additionally modify hydrothermal fluid chemistry (Alt, 1995; Figure 9). At very high temperatures $\left(\sim 425^{\circ} \mathrm{C}\right)$, these hydrothermal fluids then leach metals (e.g., $\mathrm{Cu}, \mathrm{Fe}, \mathrm{Mn}, \mathrm{Zn}$ ) and reduced sulfur from crustal rocks (e.g., Alt, 1995; Butterfield et al., 2003). Magmatic volatiles (e.g., ${ }^{3} \mathrm{He}, \mathrm{CO}_{2}, \mathrm{CH}_{4}, \mathrm{H}_{2}$, $\mathrm{H}_{2} \mathrm{O}, \mathrm{SO}_{2}$ ) can also enter hydrothermal fluids and modify fluid chemistry (e.g., Alt, 1995; Gamo et al., 1997; Reeves et al., 2011; Mottl et al., 2011).

As the temperature of hydrothermal fluids approaches the boiling curve (below the critical point) or two-phase boundary (above the critical point), the density of these fluids rapidly decreases and fluids are buoyant and rise (Norton, 1984; figure 10A). This decrease in density 
coincides with maxima in the thermal expansion coefficient and heat capacity and a minimum in kinematic viscosity of water (Norton, 1984; Figures 10B to 10D). As a result, upflow is very rapid and hydrothermal fluids generally do not fully equilibrate, chemically or thermally, with surrounding host rocks as they rise (Norton 1984; Ding and Seyfried, 1994; Von Damm, 1995). Additionally, the dielectric constant of water decreases with temperature, such that charged particles form complexes. Thus, the thermodynamic activity of free ions (including $\mathrm{H}^{+}$) is much decreased. Thermodynamic fluid modelling must thereby be implemented to calculate the thermodynamic activity of free ions and $\mathrm{pH}$ at in situ conditions. 


\section{Figure 9.}

Schematic drawing of a cross section of a hydrothermal circulation cell (Jack Cook, WHOI Graphic Services) showing important chemical reactions and associated additions and removal of components from hydrothermal fluids at increasing temperatures (see text for details).

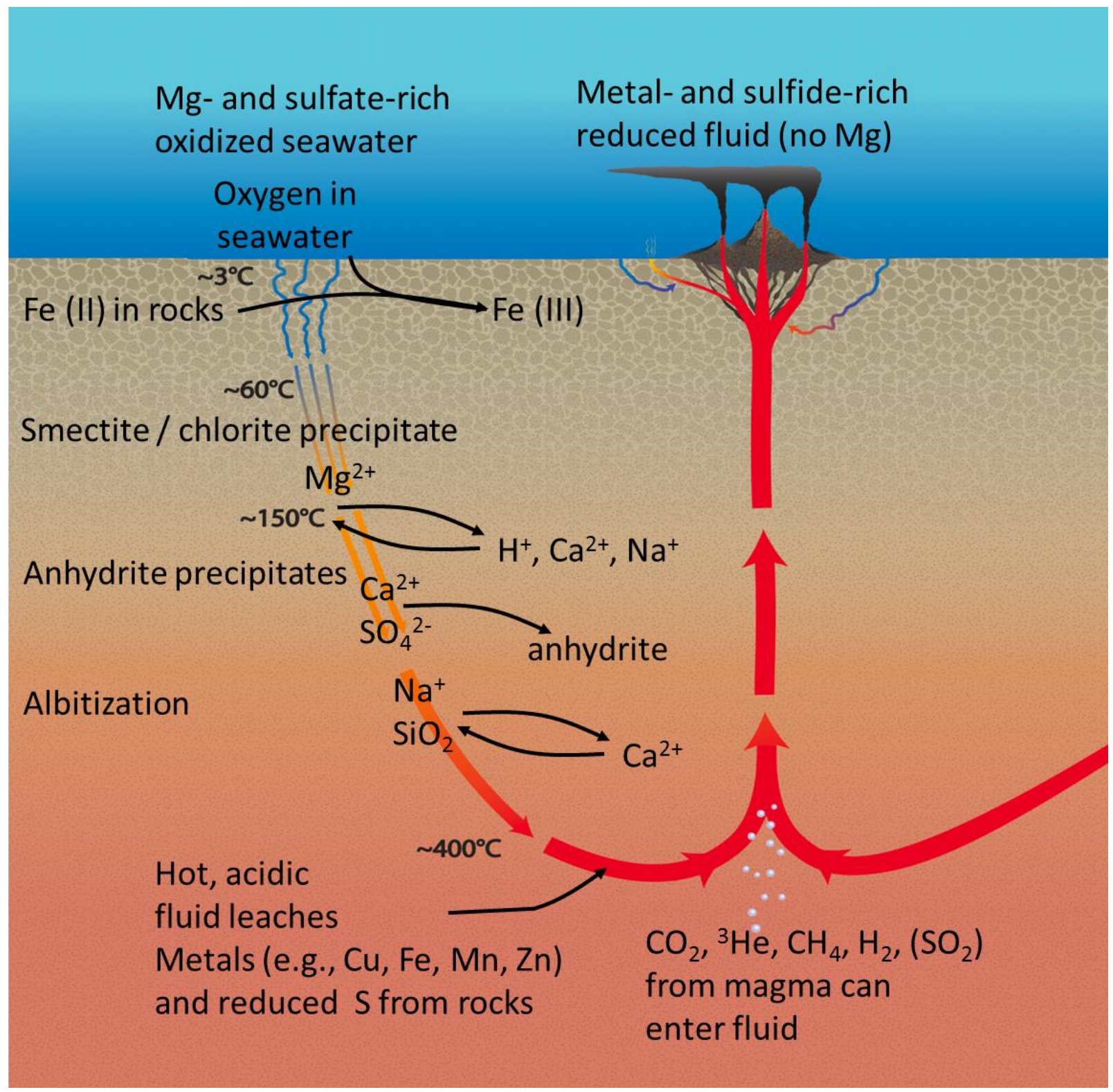




\section{Figure 10.}

Contour plots of the physical properties of pure water at temperatures from $0^{\circ} \mathrm{C}$ to $1000^{\circ} \mathrm{C}$ and pressures from 0 bar to 1000 bar including the $(A)$ density $(\rho),(B)$ thermal expansion coefficient $(\alpha),(C)$ heat capacity $\left(C_{p}\right),(D)$ kinematic viscosity $(v)$, and $(E)$ dielectric constant. Hydrothermal fluids are not pure water, but overall patterns in physical properties are thought to be comparable (from Norton, 1984).

Figure 10A. Density of Water as a Function of Temperature and Pressure

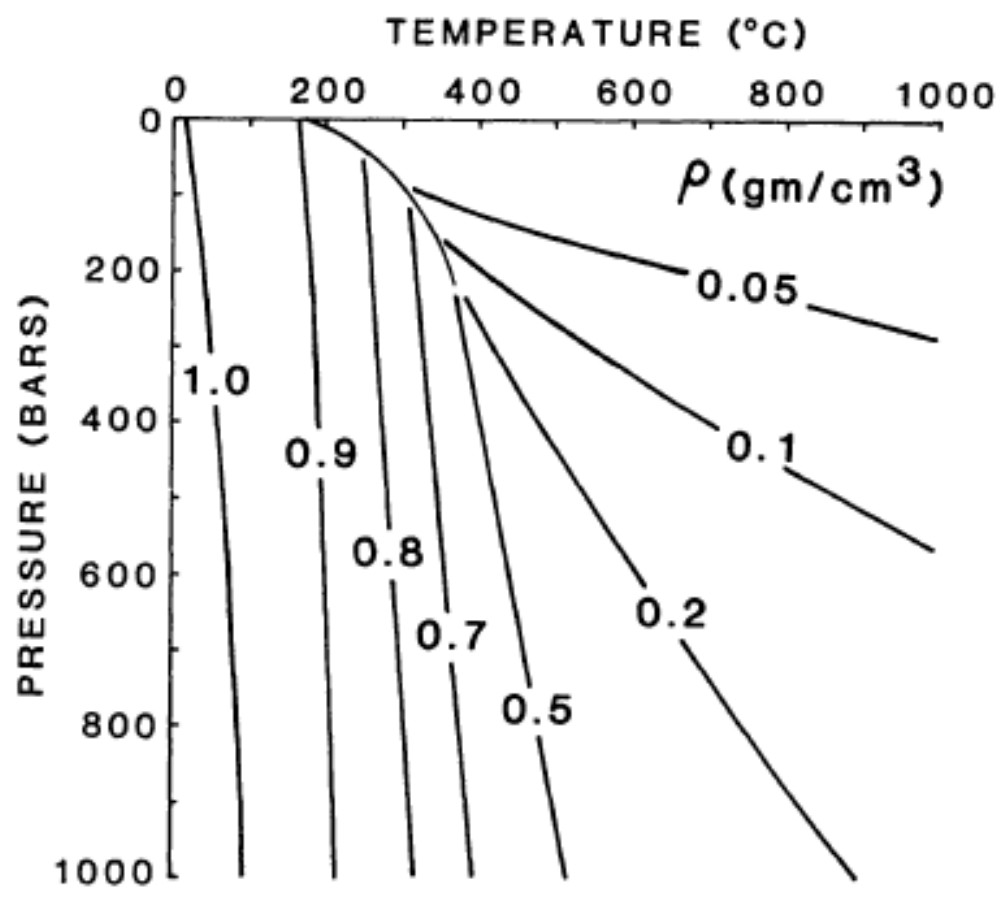


Figure 10B. Thermal Expansion Coefficient of Water as a Function of Temperature and Pressure

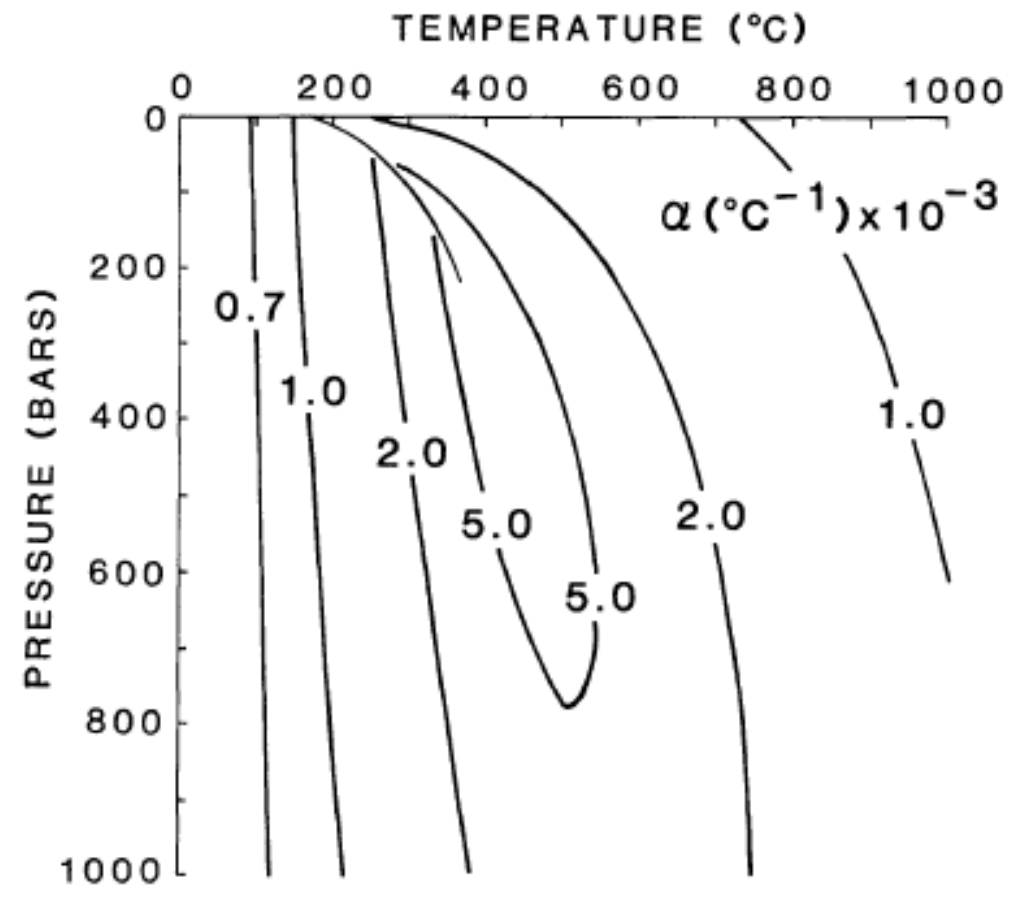

Figure 10C. Heat Capacity of Water as a Function of Temperature and Pressure

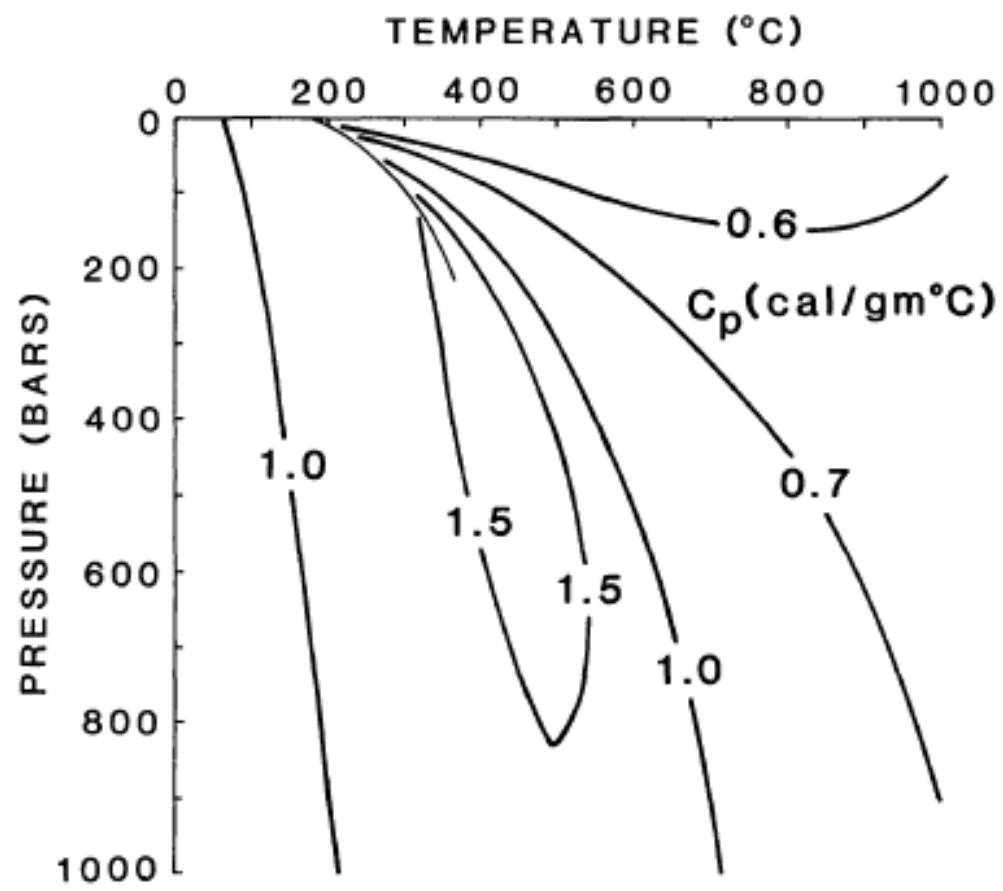


Figure 10D. Kinematic Viscosity of Water as a Function of Temperature and Pressure

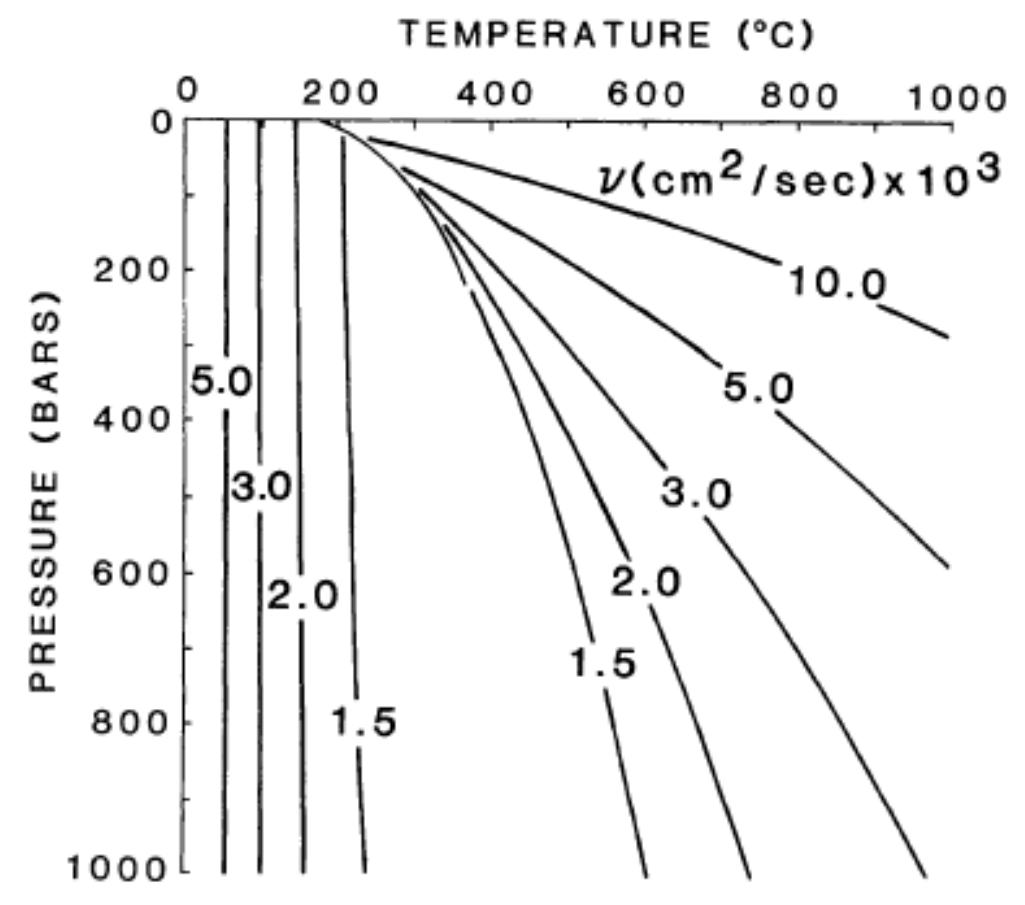

Figure 10E. Dielectric Constant of Water as a Function of Temperature and Pressure

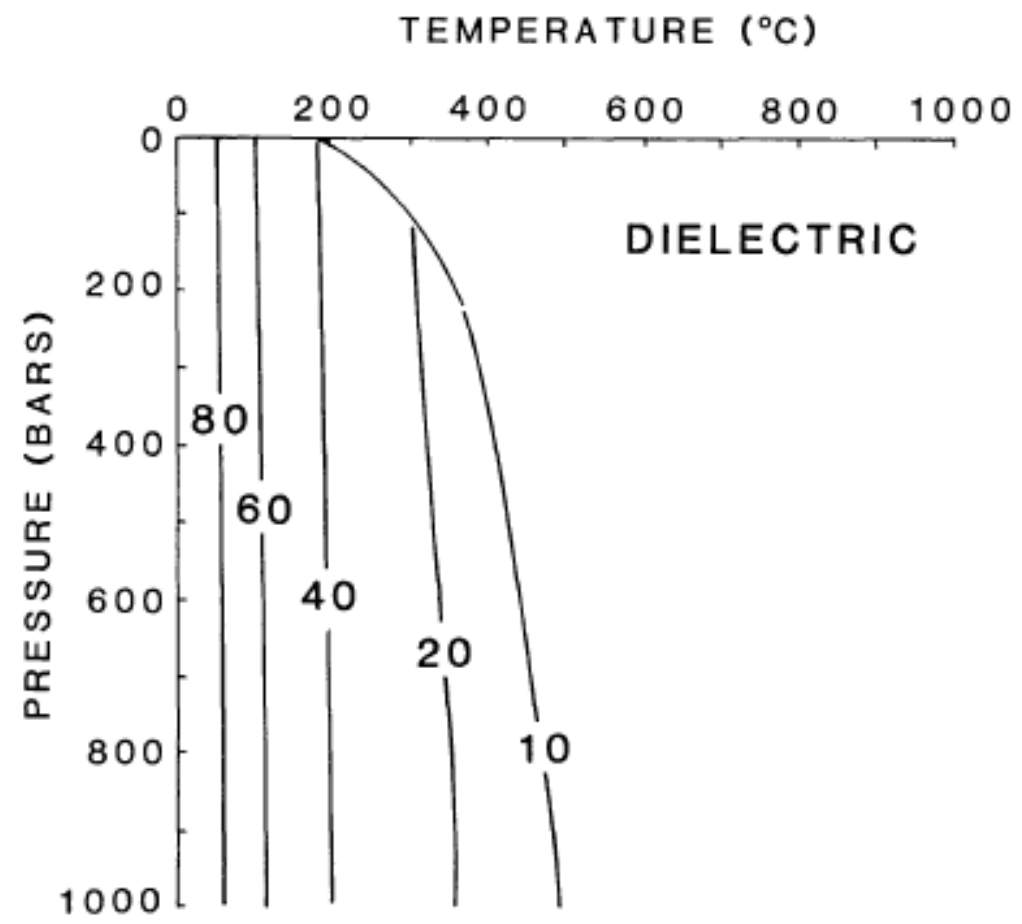




\section{Measuring Trace Metals in Hydrothermal Fluids}

Despite the potential for directly comparing SMS deposit characteristics with those of hydrothermal fluids and the importance of trace element analyses in the study of VMS and other sulfide ore deposits, relatively few data are available concerning the concentrations of sulfide mineral trace elements in hydrothermal fluids. Ironically, the paucity of data concerning these elements is partially a result of the partitioning of these elements into metal sulfide, as metal sulfide rich particulates precipitate during collection and cooling of the hydrothermal fluid sample (Figure 11). In order to obtain accurate measurements of trace metal contents of the original hydrothermal fluid, these particulate "dregs" fractions must be dissolved and analyzed (Trefry et al. 1994; Table 1). Additionally, metal-rich particulates might also precipitate from the dissolved fraction of the hydrothermal fluid sample during storage. These particulates (a.k.a. "filter" fractions) must also be filtered out, dissolved, and analyzed (Trefry et al. 1994). As with other hydrothermal fluid components, entrainment of seawater during sampling is accounted for by extrapolation to a zero-Mg endmember concentration following the assumption that endmember hydrothermal fluids contain negligible Mg (Von Damm et al., 1985).

Because dregs fractions can be contaminated with small pieces of SMS deposit materials entrained or "cored" during seafloor sampling, or incompletely recovered during shipboard sampling, accurate measurements of trace metals in hydrothermal fluid require that multiple (e.g., at least three) samples be taken from the same vent. However, such intensive sampling is time consuming and generally not performed. In cases where only one or two samples have been obtained (as is the case for all vent fluids analyzed in this thesis) the accuracy of hydrothermal fluid trace metal analyses can be posited (but not confirmed) by comparing vent fluids of similar temperature, $\mathrm{pH}$, and major element compositions from the same vent field. 


\section{Figure 11.}

Photograph of hydrothermal fluid sampling using the isobaric gas-tight (IGT) sampler described in Seewald et al. (2002) as manipulated by the Jason II remotely operated vehicle (Photograph by Chris German and the Jason Group). To the right is a schematic drawing of the IGT sampling container showing separation of a particulate "dregs" fraction (black) from the liquid "dissolved" fraction (blue). Gases, such as $\mathrm{H}_{2}$ may also be sampled, while a particulate "filters" fraction may also precipitate from the dissolved fraction (or aliquots thereof) during storage.
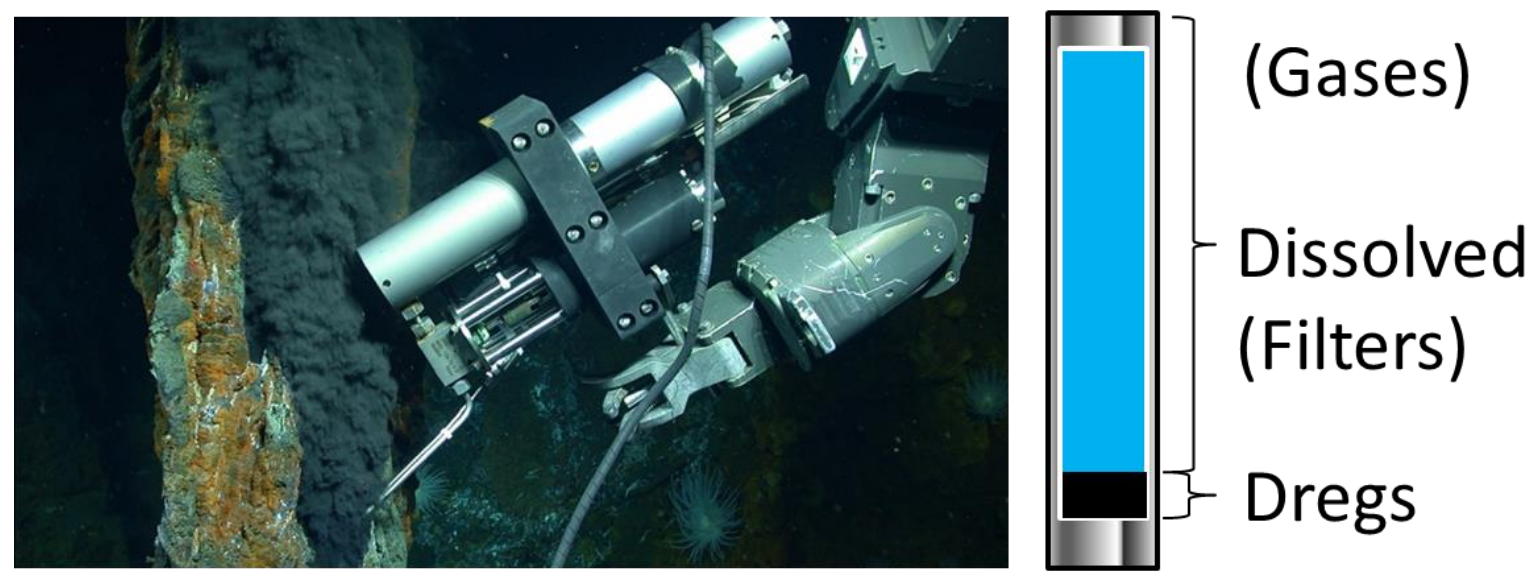

Table 1.

Reproduction of table from Trefry et al. (1994) listing the contribution of precipitates to the total concentration of various metals analyzed in hydrothermal fluids from the southern Juan de Fuca Ridge.

\begin{tabular}{lccc}
\multicolumn{4}{c}{$\begin{array}{c}\text { Contribution of Residual Precipitates to Total Concentrations of } \\
\text { Trace Metals in Vent Fluids }\end{array}$} \\
\hline Element & $\begin{array}{c}\text { Range in Amounts of } \\
\text { Metal in Precipitates, } \\
\text { nmol kg-1 Fluid }\end{array}$ & $\begin{array}{c}\text { Contributon of Precipitates } \\
\text { as Percent of Total Metal }\end{array}$ \\
\cline { 3 - 4 } & $0.6-19$ & Average & Range \\
\hline $\mathrm{Ag}$ & $1-178$ & 31 & $7-77$ \\
$\mathrm{Cd}$ & $0.4-74$ & 22 & $<1-58$ \\
$\mathrm{Co}$ & $100-2000$ & 4 & $<1-18$ \\
$\mathrm{Cu}$ & $<500-40,000$ & 24 & $<1-53$ \\
$\mathrm{Fe}$ & $<500$ & $<0.1$ & $<1$ \\
$\mathrm{Mn}$ & $<1-14$ & $<0.1$ & $<0.1$ \\
$\mathrm{Mo}$ & $2.6-288$ & 18 & $2-52$ \\
$\mathrm{~Pb}$ & $0.1-1.6$ & 16 & $0.5-38$ \\
$\mathrm{Sb}$ & $1300-159,000$ & 12 & $1-30$ \\
$\mathrm{Zn}$ & 19 & $<1-39$
\end{tabular}




\section{Measuring Trace Metals in SMS Deposits}

Measurements of trace metals in SMS deposit materials are often performed on bulk mineral samples with distributions of trace elements among various minerals either being inferred by statistical correlations or, where possible, done on individual mineral grains by electron microprobe analysis (EMPA). While use of EMPA enables accurate and non-destructive measurements of trace elements at $\sim 2 \mu \mathrm{m}$ spatial scales, the relatively high detection limits of this technique $(\sim 100 \mathrm{~s} \mu \mathrm{g} / \mathrm{g})$ severely limit analyses of many trace elements. In particular, investigations of black smoker chimneys have shown that the concentrations of many trace elements in the innermost lining of black smoker chimneys are near or below the detection limits of electron microprobe (e.g., Tivey et al., 1995; Tivey et al., 1999; Craddock, 2009). Techniques offering lower detection limits, such as laser-ablation inductively coupled plasma mass spectrometry (LA-ICPMS), proton microprobe (PIXE), and secondary ion mass spectrometry (SIMS), have also been used to investigate black smoker chimney linings (Butler and Nesbitt, 1999; Ryan, 2001; Layne et al., 2005). Generally, these techniques suffer from a lack of homogeneous matrix-matched reference materials, though some recent progress has been made using standards of synthetic glass, sulfide sinters, or pressed sulfide powder precipitates (Danyushevsky et al., 2011 and papers using these methods; Wohlgemuth-Ueberwasser et al., 2011; Maslennikov et al., 2009). A major focus of this thesis and Chapter 3 in particular is the use of SIMS to measure trace elements in chalcopyrite precipitated along the innermost linings of black smoker chimneys and the construction of SIMS calibration curves by which to quantify trace element concentrations. 


\section{Overview of Thesis}

The presence of actively forming massive sulfide deposits on the seafloor provides a unique opportunity to sample these metal-rich mineral deposits in the direct context of the high temperature $\left(250^{\circ} \mathrm{C}\right.$ to $\left.400^{\circ} \mathrm{C}\right)$ metal-bearing fluids ( \pm seawater) from which they form. Study of these deposits leads to insights into the analogous formation processes that produced hydrothermal sulfide deposits mined on land. These terrestrial deposits are important sources of $\mathrm{Ag}, \mathrm{Cu}, \mathrm{Pb}$, and $\mathrm{Zn}$, as well as several "critical" metals and metalloids used in advanced materials and electronics (e.g., $\mathrm{Co}, \mathrm{Ga}, \mathrm{Ge}, \mathrm{In}$ ). Moreover, the chemical contrast between reduced hydrothermal fluids venting at the seafloor and surrounding oxygenated seawater supplies chemical energy that supports robust deep sea ecosystems driven by chemosynthetic metabolisms. Seafloor massive sulfide deposits are important targets for biological prospecting today and may have played an essential role in the origin of life in the deep past (Corliss et al., 1981).

This thesis, entitled "Trace Element Proxies and Mineral Indicators of Hydrothermal Fluid Composition and Seafloor Massive Sulfide Deposit Formation Processes,” seeks to determine how seafloor massive sulfide (SMS) deposits record aspects of the chemistry of hydrothermal fluids that, in turn, reflect volcanic, tectonic, and geodynamic processes. The thesis is divided into two parts. The first part, Chapter 2, investigates the morphology, mineralogy, and geochemistry of SMS deposits from six hydrothermal vent fields along the Eastern Lau Spreading Center, a back-arc spreading center dynamically linked to the Tonga Subduction Zone. Additional analyses of mineral-forming elements (e.g., $\mathrm{Cu}, \mathrm{Zn}, \mathrm{Ba}$, and $\mathrm{Pb}$ ) and $\mathrm{H}_{2}$ in associated vent fluids supplement existing data and enable comparisons of SMS deposit samples with thermodynamic calculations of mineral saturation states and fluid speciation at in situ conditions. 
The second part of the thesis, Chapters 3 and 4, examines the relationship between the trace element content of black smoker chimney linings and the chemistry of the hydrothermal fluids from which they formed. Secondary ion mass spectrometry is developed as a method for measuring trace elements $(\mathrm{Co}, \mathrm{Ni}, \mathrm{Ga}, \mathrm{Ag}, \mathrm{In})$ in chalcopyrite, and analyses of trace elements in black smoker chimney linings are combined with new and published analyses of trace elements in corresponding hydrothermal fluids to more closely determine the mechanisms by which these elements are incorporated into chalcopyrite.

\section{Chapter 2: Influences of the Tonga Subduction Zone on Seafloor Massive Sulfide Deposits along the Eastern Lau Spreading Center}

Chapter 2 was submitted in August 2016 to Geochimica et Cosmochimia Acta with coauthors Dr. Margaret Tivey (Woods Hole Oceanographic Institution (WHOI)), Dr. Jeffrey Seewald (WHOI), and Dr. Geoff Wheat (University of Alaska Fairbanks) and is currently in revision. This chapter presents data on the mineralogy, bulk geochemistry, and electron microprobe analyses of mineral deposit samples collected from six hydrothermal vent fields along the Eastern Lau Spreading Center (ELSC). From north to south, the distance between each of these six vent fields and the Tonga Subduction Zone decreases from $100 \mathrm{~km}$ to $40 \mathrm{~km}$.

Seafloor massive sulfide deposits from the basalt-hosted Kilo Moana and TowCam vent fields in the north resemble those found along mid-ocean ridges of similar spreading rates and consist of steep-sided $\mathrm{Zn}$-, Fe-, and $\mathrm{Cu}$-rich edifices, some with small sulfide-rich flanges. Further to the south, SMS deposits at the Tahi Moana-1, ABE and Tu'i Malila vent fields associated with more felsic lithologies exhibit higher concentrations of mantle-incompatible elements (e.g., $\mathrm{Ba}, \mathrm{Pb}, \mathrm{As}$, and $\mathrm{Sb})$, the presence of barite $\left(\mathrm{BaSO}_{4}\right)$ and galena $(\mathrm{PbS})$, and a 
southward increasing abundance of barite-rich flanges. These differences in the elemental content, mineralogy, and morphology of SMS deposits reflect a southward increase in the abundance of intermediate and felsic igneous rocks closer to the subduction zone (Fouquet et al., 1993; Martinez and Taylor, 2002; Langmuir et al., 2006; Bézos et al., 2009; Escrig et al., 2009). Magmas along the ELSC close to the Tonga Subduction Zone are lower in temperature than their mid-ocean ridge counterparts and produce greater volumes of porous volcanic rocks (Martinez et al., 2006; Mottl et al., 2011; Sleeper and Martinez 2014). As a result, hydrothermal fluids along this length are typically lower in temperature, higher in $\mathrm{pH}$, and vent at shallower depths than those along mid-ocean ridges with similar spreading rates (Mottl et al., 2011). The moderate $\mathrm{pH}$ of hydrothermal fluids results in zinc sulfide minerals precipitating at high temperatures. Deposits are Zn-rich and Cu-poor, Zn sulfides along fluid conduits are poor in trace elements, and $\mathrm{Zn}$ concentration in bulk samples exhibit poor correlations with other elements except $\mathrm{Cd}$. An exception to this rule is found at the southernmost Mariner vent field, where $\mathrm{Cu}$-rich deposits are associated with high-temperature, low-pH $\left(<3\right.$ at $\left.25^{\circ} \mathrm{C}\right)$ fluids.

Concentrations of $\mathrm{Zn}$ in bulk samples collected at the Mariner vent field and at northern vent fields where hydrothermal fluids exhibit $\mathrm{pH}<3.5$ are significantly correlated with Ag. The exceptionally low $\mathrm{pH}$ of hydrothermal fluids at the Mariner vent field is likely caused by localized entrainment of $\mathrm{SO}_{2}$-rich magmatic volatiles sourced from oxidized magmas (Mottl et al., 2011). Because such magmas form in the regions closest to the subduction zone, even the exceptional hydrothermal fluids and deposits found at the Mariner vent field are closely related to the back-arc geologic setting. 


\section{Chapter 3: Trace Element Chemistry of Black Smoker Chimney Linings Measured by Secondary Ion Mass Spectrometry}

Chapter 3 focuses on the development of secondary ion mass spectrometry (SIMS) as a method for measuring trace elements $(\mathrm{Co}, \mathrm{Ni}, \mathrm{Ga}, \mathrm{Ag}, \mathrm{In})$ in the chalcopyrite linings of black smoker chimneys. These elements are thought to occur as substitutions for $\mathrm{Cu}$ and $\mathrm{Fe}$ in the chalcopyrite crystal lattice (e.g., Huston et al., 1995). SIMS is chosen as a preferred method because it produces smaller (and shallower) ablation pits in comparison with laser ablation inductively coupled mass spectrometry, and lower detection limits than electron microprobe analyses. Following the use of SIMS to examine the spatial homogeneity and relative abundances of selected trace elements in black smoker chimney linings, handpicked grains of chalcopyrite from selected black smoker chimney linings were digested and analyzed by inductively coupled plasma mass spectrometry and compared with serial dilutions of standard reference solutions. This allowed for the construction of calibration curves by which to derive quantitative measurements of $\mathrm{Co}, \mathrm{Ni}, \mathrm{Ga}, \mathrm{Ag}$, and $\mathrm{In}$ in chalcopyrite using SIMS. Linings of black smoker chimneys are generally homogeneous (standard error $<20 \%$ of the mean) and trace element concentrations cover a wide enough range to readily distinguish between linings from different vents and deposits. Thus, these measurements may provide useful information about differences in hydrothermal fluid chemistry. Additionally, a correlation is observed between hydrothermal fluid $\mathrm{pH}$ and the $\mathrm{Ga}$ and In contents of black smoker chimney linings measured by SIMS, providing a potential proxy of hydrothermal fluid $\mathrm{pH}$ based on the trace element contents of black smoker chimney linings. 
Chapter 4: Trace Element Proxies of Hydrothermal Fluid pH and Metal Content Based on Sample Pairs of Seafloor Hydrothermal Fluids and Chalcopyrite Lining Black Smoker Chimneys

Chapter 4 investigates the behavior of trace elements (Co, Ni, Ga, $\mathrm{Ag}, \mathrm{In})$ in "black smoker" chimneys and corresponding hydrothermal vent fluids. SIMS analyses of trace elements in black smoker chimney linings from Chapter 3 are combined with new analyses of these elements in hydrothermal fluids from the Eastern Lau Spreading Center and previously published analyses of hydrothermal fluids from vent fields in the Manus Basin (Craddock, 2009).

Thermodynamic modelling is implemented to calculate fluid speciation including the activities of free ions and $\mathrm{pH}$ at in situ temperatures and pressures. In this chapter, a linear relationship is identified between the Ag concentration of chalcopyrite lining black smoker chimneys and the free ion activity ratio of $\mathrm{Ag}+: \mathrm{Cu}+$ in hydrothermal fluids suggesting regular partitioning of $\mathrm{Ag}$ into chalcopyrite as a lattice substitution replacing $\mathrm{Cu}$. When combined with the Ga and In proxy of hydrothermal fluid $\mathrm{pH}$ identified in Chapter 3, the concentration of $\mathrm{Ag}$ in black smoker chimney linings provides a further proxy for $\mathrm{pH}$ and also for concentrations of $\mathrm{Ag}$ and $\mathrm{Cu}$ in the associated hydrothermal fluids.

\section{References}

Albarede, F., Michard, A., Minster, J. F., and Michard, G. (1981) ${ }^{87} \mathrm{Sr} /{ }^{86} \mathrm{Sr}$ ratios in hydrothermal waters and deposits from the East Pacific Rise at 21 N. Earth Planet. Sci. Lett., 55(2), 229-236.

Alt, J. C. (1995) Subseafloor Processes in Mid- Ocean Ridge Hydrothermal Systems. In Seafloor hydrothermal systems: physical, chemical, biological, and geological interactions (eds. S. E. Humphris, R. A. Zierenberg, L. S. Mullineaux, and R. E. Thomson), American Geophysical Union, Washington, D. C.. pp. 85-114. 
Beaulieu, S. E., Baker, E. T., German, C. R., and Maffei, A. (2013) An authoritative global database for active submarine hydrothermal vent fields. Geochem. Geophys. Geosys., 14(11), 4892-4905.

Beaulieu, S. E., Baker, E. T., and German, C. R. (2015) Where are the undiscovered hydrothermal vents on oceanic spreading ridges?. Deep Sea Research Part II: Topical Studies in Oceanography, 121, 202-212.

Bézos, A., Escrig, S., Langmuir, C. H., Michael, P. J., and Asimow, P. D. (2009) Origins of chemical diversity of back- arc basin basalts: A segment- scale study of the Eastern Lau Spreading Center. J. Geophys. Res.: Solid Earth, 114, B06212, doi: $10.1029 / 2008 \mathrm{JB} 005924$.

Bischoff, J. L., and Seyfried, W. E. (1978) Hydrothermal chemistry of seawater from 25 degrees to 350 degrees C. Amer. J. Sci., 278(6), 838-860.

Butler, I. B. and Nesbitt, R. W. (1999) Trace element distributions in the chalcopyrite wall of a black smoker chimney: insights from laser ablation inductively coupled plasma mass spectrometry (LA-ICP-MS) Earth Planet. Sci. Lett., 167(3), 335-345.

Butterfield, D. A., Seyfried Jr., W. E., and Lilley, M. D. (2003) Composition and evolution of hydrothermal fluids. In Energy and Mass Transfer in Marine Hydrothermal Systems (eds. P.E. Halbach, V. Tunnicliffe, J. R. Hein), Berlin, Dahlem University Press, 89, pp. 123161.

Corliss, J. B., Dymond, J., Gordon, L. I., and Edmond, J. M. (1979) Submarine Thermal Springs on the Galapagos Rift. Science, 203, 16.

Corliss, J. B., Baross, J. A., and Hoffman, S. E. (1981) An Hypothesis Concerning the Relationships Between Submarine Hot Springs and the Origin of Life on Earth. Oceanologica Acta, Special issue.

Craddock, P. R. (2009) Geochemical tracers of processes affecting the formation of seafloor hydrothermal fluids and deposits in the Manus back-arc basin. Ph.D. Thesis, MIT/WHOI Joint Program in Oceanography.

Craddock, P. R., Bach, W., Seewald, J. S., Rouxel, O. J., Reeves, E., and Tivey, M. K. (2010) Rare earth element abundances in hydrothermal fluids from the Manus Basin, Papua New Guinea: Indicators of sub-seafloor hydrothermal processes in back-arc basins. Geochim. Cosmochim Acta, 74(19), 5494-5513.

Danyushevsky, L., Robinson, P., Gilbert, S., Norman, M., Large, R., McGoldrick, P., and Shelley, M. (2011) Routine quantitative multi-element analysis of sulphide minerals by laser ablation ICP-MS: Standard development and consideration of matrix effects. Geochemistry: Exploration, Environment, Analysis, 11(1), 51-60. 
Ding, K., and W.E. Seyfried Jr. (1994) Effect of conductive cooling on chemistry of mid-ocean ridge hydrothermal fluids: Experimental and theoretical constraints. Mineralogical Magazine 58A:231-232.

Escrig, S., Bézos, A., Goldstein, S. L., Langmuir, C. H., and Michael, P. J. (2009) Mantle source variations beneath the Eastern Lau Spreading Center and the nature of subduction components in the Lau basin-Tonga arc system, Geochem. Geophys. Geosys., 10, Q04014, doi:10.1029/2008GC002281.

Fouquet, Y., von Stackelberg, U., Charlou, J. L., Erzinger, J., Herzig, P. M., Mühe, R., and Wiedicke, M. (1993) Metallogenesis in back-arc environments: the Lau Basin example. Econ. Geol., 88(8), 2154-2181.

Franklin, J. M., Gibson, H. L., Jonasson, I. R., and Galley, A. G. (2005) Volcanogenic massive sulfide deposits. Economic Geology $100^{\text {th }}$ Anniversary Volume, Society of Economic Geologists, Littleton, Colorado, USA, 523-560.

Galley, A. G., Hannington, M. D., and Jonasson, I. R. (2007) Volcanogenic massive sulphide deposits. In Mineral deposits of Canada: A synthesis of major deposit types, distinct metallogeny, and the evolution of geological provinces, and exploration methods, 5 (ed. W. Goodfellow), St. Johns, Geological Association of Canada, Mineral Deposits Division, Special Publication 5, pp. 141-162.

Gamo, T., Okamura, K., Charlou, J. L., Urabe, T., Auzende, J. M., Ishibashi, J., Shitashima, K., Chiba, H., and Shipboard Scientific Party of the ManusFlux Cruise (1997) Acidic and sulfate-rich hydrothermal fluids from the Manus back-arc basin, Papua New Guinea. Geology, 25(2), 139-142.

Goldfarb, M. S., Converse, D. R. Holland, H. D. and Edmond, J. M. (1983) The genesis of hot spring deposits on the East Pacific Rise, $21^{\circ} \mathrm{N}$, Economic Geology Monographs, 5, 184197.

Hannington, M. D., Jonasson, I. R., Herzig, P. M., and Petersen, S. (1995) Physical and chemical processes of seafloor mineralization at mid- ocean ridges. In Seafloor hydrothermal systems: physical, chemical, biological, and geological interactions (eds. S. E. Humphris, R. A. Zierenberg, L. S. Mullineaux, and R. E. Thomson), American Geophysical Union, Washington, D. C.. pp. 115-157. doi: 10.1029/GM091p0115.

Hannington, M. D., de Ronde, C. D. J., and Petersen, S. (2005) Sea-floor tectonics and submarine hydrothermal systems. Economic Geology $100^{\text {th }}$ Anniversary Volume. Society of Economic Geologists, Littleton, Colorado, USA, pp. 111-141. 
Hannington, M., Jamieson, J., Monecke, T., and Petersen, S. (2010) Modern sea-floor massive sulfides and base metal resources: Toward an estimate of global sea-floor massive sulfide potential. Society of Economic Geologists Special Publication, 15, 317-338.

Hannington, M., Jamieson, J., Monecke, T., Petersen, S., and Beaulieu, S. (2011) The abundance of seafloor massive sulfide deposits. Geology, 39(12), 1155-1158.

Haymon, R. M. (1983) Growth history of hydrothermal black smoker chimneys. Nature, 301, 695-698.

Haymon, R. M., and Kastner, M. (1981) Hot spring deposits on the East Pacific Rise at 21 N: preliminary description of mineralogy and genesis. Earth Planet. Sci. Lett., 53(3), 363381.

Humphris, S. E., and Tivey, M. K. (2000) A synthesis of geological and geochemical investigations of the TAG hydrothermal field: Insights into fluid-flow and mixing processes in a hydrothermal system. Special Papers-Geological Society of America, 213236.

Herrington, R.J., Maslennikov, V.V., Spiro, B., Zaykov, V.V., and Little, C.T.S. (1998) Ancient vent chimney structures in the Silurian massive sulphides of the Urals. In Modern Ocean Floor Processes and the Geological Records. Geol. Soc. London, Special Publications, 148 (eds. R. A. Mills, K. Harrison), pp. 241-257.

Huston, D. L., Sie, S. H., Suter, G. F., Cooke, D. R., and Both, R. A. (1995) Trace elements in sulfide minerals from eastern Australian volcanic-hosted massive sulfide deposits; Part I, Proton microprobe analyses of pyrite, chalcopyrite, and sphalerite, and Part II, Selenium levels in pyrite; comparison with delta $34 \mathrm{~S}$ values and implications for the source of sulfur in volcanogenic hydrothermal systems. Econ. Geol., 90(5), 1167-1196.

Kassianidou, V. and Knapp, A. B. (2005) Archaeometallurgy in the Mediterranean: The social context of mining, technology and trade. In The Archaeology of Mediterranean Prehistory (eds. E. Blake and A. B. Knapp), John Wiley \& Sons, pp. 215-51.

Kawasumi, S., and Chiba, H. (2017) Redox state of seafloor hydrothermal fluids and its effect on sulfide mineralization. Chem. Geol. . 451, 25-37.

Kormas, K. A., Tivey, M. K., Von Damm, K., and Teske, A. (2006) Bacterial and archaeal phylotypes associated with distinct mineralogical layers of a white smoker spire from a deep- sea hydrothermal vent site (9 N, East Pacific Rise) Environmental Microbiology, 8(5), 909-920.

Langmuir, C. H., Bézos, A., Escrig, S., and Parman, S. W. (2006) Chemical systematics and hydrous melting of the mantle in back-arc basins. In Back-Arc Spreading Systems: Geological, Biological, Chemical, and Physical Interactions (eds. D. M. Christie, C. R. 
Fisher, S.-M. Lee, and S. Givens) Geophysical Monograph Series, vol. 166, American Geophysical Union, Washington, DC. Pp. pp. 87-146.

Layne, G., Tivey, M. K., and Humphris, S. E. (2005) Trace metal concentrations in common sulfide minerals using SIMS. Fifteenth Annual V. M. Goldschmidt Conference Abstracts, A55.

Little, C. T. S., Herrington, R. J., Maslennikov, V. V., and Zaykov, V. V. (1998) The fossil record of hydrothermal vent communities. Geological Society, London, Special Publications, 148(1), 259-270.

Martinez, F. and Taylor, B. (2002) Mantle wedge control on back-arc crustal accretion. Nature. 416, 417-420.

Martinez, F., Taylor, B., Baker, E. T., Resing, J. A., and Walker, S. L. (2006) Opposing trends in crustal thickness and spreading rate along the back-arc Eastern Lau Spreading Center: Implications for controls on ridge morphology, faulting, and hydrothermal activity. Earth Planet. Sci. Lett., 245(3), 655-672.

Maslennikov, V.V., Maslennikova, S.P., Large, R.R., and Danyushevsky, L.V., (2009) Study of trace element zonation in vent chimneys from the Silurian Yaman-Kasy volcanic-hosted massive sulfide deposits (the southern Urals, Russia) using laser ablation inductively coupled plasma mass spectrometry (LA-ICP MS), Econ. Geol., 104, 1111-1141.

McDermott, J. M., Ono, S., Tivey, M. K., Seewald, J. S., Shanks, W. C., and Solow, A. R. (2015) Identification of sulfur sources and isotopic equilibria in submarine hot-springs using multiple sulfur isotopes. Geochim. Cosmochim. Acta, 160, 169-187.

Mottl, M. J., Seewald, J. S., Wheat, C. G., Tivey, M. K., Michael, P. J., Proskurowski, G., McCollom, M., Reeves, E., Sharkey, S., You, C.-F., Chan, L.-H., and Pichler, T. (2011) Chemistry of hot springs along the Eastern Lau Spreading Center. Geochim. Cosmochim. Acta, 75(4), 1013-1038.

Norton, D. L. (1984) Theory of hydrothermal systems. Annual Review of Earth and Planetary Sciences, 12(1), 155-177.

Oudin, E., Constantinou, G. (1984) Black smoker chimney fragments in Cyprus sulphide deposits. Nature, 308, 349-353.

Reeves, E. P., Seewald, J. S., Saccocia, P., Bach, W., Craddock, P. R., Shanks, W. C., Sylva. S., Walsh, E., Pichler, T., and Rosner, M. (2011) Geochemistry of hydrothermal fluids from the PACMANUS, Northeast Pual and Vienna Woods hydrothermal fields, Manus Basin, Papua New Guinea. Geochim. Cosmochim. Acta, 75(4), 1088-1123. 
Revan, M. K., Genç, Y., Maslennikov, V. V., Maslennikova, S. P., Large, R. R., and Danyushevsky, L. V. (2014) Mineralogy and trace-element geochemistry of sulfide minerals in hydrothermal chimneys from the Upper-Cretaceous VMS deposits of the eastern Pontide orogenic belt (NE Turkey) Ore Geology Reviews, 63, 129-149.

Ryan, C. G. (2001) Developments in dynamic analysis for quantitative PIXE true elemental imaging. Nuclear Instruments and Methods in Physics Research Section B: Beam Interactions with Materials and Atoms, 181(1), 170-179.

Rouxel, O., Fouquet, Y., and Ludden, J. N. (2004) Subsurface processes at the Lucky Strike hydrothermal field, Mid-Atlantic Ridge: evidence from sulfur, selenium, and iron isotopes. Geochim. Cosmochim. Acta, 68(10), 2295-2311.

Sarrazin, J., Juniper, S. K., Massoth, G., and Legendre, P. (1999) Physical and chemical factors influencing species distributions on hydrothermal sulfide edifices of the Juan de Fuca Ridge, northeast Pacific. Marine Ecology Progress Series, 89-112.

Seewald, J. S., Doherty, K. W., Hammar, T. R., and Liberatore, S. P. (2002) A new gas-tight isobaric sampler for hydrothermal fluids. Deep Sea Research Part I: Oceanographic Research Papers, 49(1), 189-196.

Scott, S.D. (1981) Small chimneys from Japanese Kuroko deposits. In Seminars on Seafloor Hydrothermal Systems (eds. R. Goldie, T. J. Botrill), Geosciences Canada. 8, pp. 103104.

Sleeper, J. D. and Martinez, F. (2014) Controls on segmentation and morphology along the back- arc Eastern Lau Spreading Center and Valu Fa Ridge. J. Geophys. Res., 119(3), 1678-1700.

Spiess, F. N., Macdonald, K. C., Atwater, T., Ballard, R., Carranza, A., Cordoba, D., Cox, C., Diaz Garcia, V. M., Francheteau, J., Guerrero, J., Hawkins, J., Haymon, R., Hessler, R., Juteau, T., Kaster, M., Larson, R., Luyendyk, B., Macdougall, J. D., Miller, S., Normark, W., Orcutt, J., Rangin, C. (1980) East Pacific Rise: Hot Springs and Geophysical Experiments. Science, 207, 1421-1433.

Tivey, M. K. (1995) The influence of hydrothermal fluid composition and advection rates on black smoker chimney mineralogy: Insights from modeling transport and reaction. Geochim. Cosmochim. Acta, 59(10), 1933-1949.

Tivey, M. K., Humphris, S. E., Thompson, G., Hannington, M. D., and Rona, P. A. (1995) Deducing patterns of fluid flow and mixing within the TAG active hydrothermal mound using mineralogical and geochemical data. J. Geophys. Res.: Solid Earth, 100(B7), $12527-12555$.

Tivey, M. K., Stakes, D. S., Cook, T. L., Hannington, M. D., and Petersen, S. (1999) A model for growth of steep- sided vent structures on the Endeavour Segment of the Juan de Fuca 
Ridge: Results of a petrologic and geochemical study. J. Geophys. Res.: Solid Earth, 104(B10), 22859-22883.

Tivey, M. K. (2007) Generation of seafloor hydrothermal vent fluids and associated mineral deposits. Oceanography 20, 1 (2007): 50-65.

Trefry, J. H., Butterfield, D. B., Metz, S., Massoth, G. J., Trocine, R. P., and Feely R. A. (1994) Trace metals in hydrothermal solutions from Cleft segment on the southern Juan de Fuca Ridge. J. Geophys. Res.: Solid Earth. 99, 4925-4935.

Von Damm, K. L. (1995) Controls on the chemistry and temporal variability of seafloor hydrothermal fluids. In Seafloor Hydrothermal Systems: Physical, Chemical, Biological, and Geological Interactions (eds. S. E. Humphris, R. A. Zierenberg, L. S. Mullineaux, and R. E. Thomson), American Geophysical Union, Washington, D. C., pp. 222-247.

Von Damm, K. L., Edmond, J. M., Grant, B., Measures, C. I., Walden, B., and Weiss, R. F. (1985) Chemistry of submarine hydrothermal solutions at $21^{\circ} \mathrm{N}$, East Pacific Rise. Geochim. Cosmochim. Acta, 49(11), 2197-2220.

Wohlgemuth-Ueberwasser, C. C., Viljoen, F., Petersen, S., and Vorster, C. (2015) Distribution and solubility limits of trace elements in hydrothermal black smoker sulfides: An in-situ LA-ICP-MS study. Geochim. Cosmochim. Acta, 159, 16-41. 


\title{
Chapter 2
}

\section{Influences of the Tonga Subduction Zone on Seafloor Massive Sulfide Deposits along the Eastern Lau Spreading Center}

(This chapter was submitted in August 2016 to Geochimica et Cosmochimia Acta and is currently under revision as a co-authored paper with Margaret K. Tivey (Woods Hole Oceanographic Institution (WHOI)), Jeffrey S. Seewald (WHOI), and C. Geoff Wheat (University of Alaska Fairbanks))

\begin{abstract}
This study investigates the morphology, mineralogy, and geochemistry of seafloor massive sulfide (SMS) deposits from six back-arc hydrothermal vent fields along the Eastern Lau Spreading Center (ELSC) in the context of endmember vent fluid chemistry and proximity to the Tonga Subduction Zone. Additional analyses of mineral-forming elements $(\mathrm{Cu}, \mathrm{Zn}, \mathrm{Ba}$, and $\mathrm{Pb}$ ) and $\mathrm{H}_{2 \text { (aq) }}$ in hydrothermal fluids supplement existing data and enable thermodynamic calculations of mineral saturation states at in situ conditions.
\end{abstract}

From north to south, a decrease in distance between the Eastern Lau Spreading Center and the Tonga Subduction Zone correlates with a change in crustal lithology from back-arc basin basalt in the north to mixed andesite, rhyolite, and dacite in the south. Results presented here document southward increases in the abundance of mantle-incompatible elements in hydrothermal fluids ( $\mathrm{Ba}$ and $\mathrm{Pb}$ ) and SMS deposits ( $\mathrm{Ba}, \mathrm{Pb}, \mathrm{As}$, and $\mathrm{Sb}$ ), which is also expressed 
in the abundance of barite $\left(\mathrm{BaSO}_{4}\right)$ and galena $(\mathrm{PbS})$ in SMS deposits. Barite influences deposit morphology, contributing to the formation of horizontal flanges and squat terraces.

From north to south, a regional-scale lowering of hydrothermal reaction zone temperatures leads to lower-temperature, higher-pH vent fluids relative to mid-ocean ridges of similar spreading rates (Mottl et al., 2011). These fluids are Zn- and Cu-poor and vent from Znrich, $\mathrm{Cu}$-poor deposits. Locally, higher-temperature and lower $\mathrm{pH}$ vent fluids at the southernmost Mariner vent field have been linked to higher reaction zone temperatures and the localized addition of acidic magmatic volatiles (Mottl et al., 2011). These fluids are $\mathrm{Zn}$ - and Cu-rich and vent from $\mathrm{Cu}$-rich, $\mathrm{Zn}$-poor and $\mathrm{Pb}$-poor SMS deposits. Thermodynamic calculations indicate that the contrasting metal contents of vent fluids and SMS deposits can be accounted for by vent fluid $\mathrm{pH}$. Wurtzite/sphalerite $((\mathrm{Zn}, \mathrm{Fe}) \mathrm{S})$ and galena $(\mathrm{PbS})$ are saturated at higher temperatures in higher-pH, $\mathrm{Zn}-, \mathrm{Cu}-$, and $\mathrm{Pb}$-poor ELSC vent fluids, but are undersaturated at similar temperatures in low-pH, $\mathrm{Zn}-, \mathrm{Cu}-$, and $\mathrm{Pb}$-rich vent fluids from the Mariner vent field.

Indicators of pH in ELSC SMS deposits include the presence of co-precipitated wurtzite and chalcopyrite along conduit linings in deposits formed from higher $\mathrm{pH}$ fluids and different correlations between concentrations of $\mathrm{Zn}$ and $\mathrm{Ag}$ in bulk geochemical analyses. Significant positive $\mathrm{Zn}$ :Ag correlations are found in deposits associated with hydrothermal fluids of $\mathrm{pH}<$ 3.6, while weak or negative correlations of $\mathrm{Zn}: \mathrm{Ag}$ are found in deposits formed from fluids of $\mathrm{pH}>3.5$ to 4 . The mineral linings of open conduit chimneys (minerals present, mol\% FeS in $(\mathrm{Zn}, \mathrm{Fe}) \mathrm{S})$, which precipitate directly from hydrothermal fluids, closely reflect the temperature and sulfur fugacity of sampled hydrothermal fluids. These mineral linings thus can be used as indicators of hydrothermal fluid temperature and composition $(\mathrm{pH}$, metal content, sulfur fugacity). 


\section{INTRODUCTION}

Seafloor massive sulfide (SMS) deposits form as acidic, metal- and sulfide-rich hydrothermal fluids discharge into cold, alkaline, oxygen- and sulfate-rich seawater. Such hydrothermal fluids are produced as a result of rock-dominated hydrothermal reactions that occur along mid-ocean- and back-arc spreading centers when seawater that has percolated into the earth's lithosphere is heated by hot rock or magma sourced from the earth's mantle. The presence of active venting provides the opportunity to directly sample hydrothermal fluids as well as the deposits that are forming either directly from these fluids (e.g., mineral linings of black smoker chimneys) or from mixtures of these fluids with seawater, providing insight into SMS formation. Specifically, SMS deposits are thought to be closely analogous to volcanicassociated massive sulfide deposits, an important class of base-metal ore deposit (Hannington et al., 1995). In this context, the study of active SMS deposits along back-arc spreading centers is especially important as more than $80 \%$ of volcanic-associated massive sulfide deposits are thought to have formed in similar geologic settings (Barrie and Hannington, 1999; Franklin et al., 2005; Hannington et al., 2005). Sampling along back-arc spreading centers has revealed a diversity of hydrothermal fluid chemistry and SMS deposit types that can be related to variations in seafloor lithology and the influences of subduction-zone geologic processes (e.g., Hannington et al., 2005 and references therein; Craddock, 2009; Reeves et al., 2011; Mottl et al., 2011).

The Eastern Lau Spreading Center (ELSC) in the Lau back-arc Basin of the southwestern Pacific Ocean (Fig.1) is an ideal setting in which to study the effects of subduction-zone geologic processes on actively forming SMS deposits. From north to south, a near-linear decrease in distance between the ELSC and the adjacent Tofua Volcanic Arc is accompanied by systematic variations in spreading center morphology, spreading rate, and seafloor lithology (Taylor and 
Martinez, 2003; Martinez et al., 2006; Ferrini et al., 2008; Bézos et al., 2009; Escrig et al., 2009;

Sleeper and Martinez, 2014). In turn, these variations have been linked to differences in hydrothermal fluid chemistry (Fouquet et al., 1993a; Ishibashi et al., 2006; Takai et al., 2008; Mottl et al., 2011), SMS deposits (Fouquet et al., 1993a; Tivey et al., 2005; Ferrini et al., 2008; Takai et al., 2008), and biological communities (Podowski et al., 2009; Beinart et al., 2012; Flores et al., 2012). Analyses by Mottl et al. (2011) of hydrothermal fluids from the vent fields investigated here document systematic regional-scale trends in vent fluid chemistry related to a southward decrease in the temperature of hydrothermal reaction zones, a transition to more felsic lithology with a subducted sediment component closer to the subduction zone, and the distinct chemistry of vent fluids from the Mariner vent field consistent with the addition of acidic magmatic volatiles.

This report provides a systematic overview of the morphology, mineralogy, and geochemistry of SMS deposits from six active hydrothermal vent fields along the ELSC. From north to south, these vent fields are: Kilo Moana, TowCam, Tahi Moana-1, ABE, Tu'i Malila, and Mariner (Fig. 1). This report also presents data on the concentrations of dissolved metals $(\mathrm{Cu}$, $\mathrm{Zn}, \mathrm{Pb}, \mathrm{Ba}$ ) and $\mathrm{H}_{2}$ in hydrothermal fluids collected from these vent fields (Table $1 \mathrm{~b}$ ). These new data are used in conjunction with previously published data from Mottl et al. (2011) to model fluid speciation and mineral saturation at in situ conditions. The results of fluid modelling are then compared with the observed mineralogy of paired mineral samples from SMS deposits. Such comparisons provide insight into the formation processes of SMS deposits along the ELSC within the regional geologic context of the Tonga Subduction Zone. 


\section{GEOLOGIC SETTING}

The ELSC is an active back-arc spreading center located in the Lau Basin between the islands of Tonga and Fiji (Fig. 1A). From a regional perspective, the triangular Lau Basin is the northern section of a 2,000 km-long southward-propagating extensional tectonic region that also includes the Kermadec Volcanic Arc and the Taupo Volcanic Zone (Fig. 1A; Parson and Wright, 1996). To the east, the near-parallel lineaments of the Tofua Volcanic Arc and the Tonga Subduction Zone form a $17^{\circ}$ angle with the strike of the ELSC and the distance between the ELSC and the Tofua Volcanic Arc decreases from $\sim 100 \mathrm{~km}$ in the north to $\sim 40 \mathrm{~km}$ in the south. Concurrent with this change in distance to the Tofua Volcanic Arc, the ELSC spans a geomorphologic transition from an axial trough in the north to an axial ridge in the south (von Stackelberg et al., 1985, 1988, 1990; Foucher et al., 1988). Between the latitudes of $20^{\circ} 50^{\prime} \mathrm{S}$ and $22^{\circ} 40^{\prime} \mathrm{S}$, the axial ridge is bathymetrically well-defined and is identified as the Valu Fa Ridge (Fig. 1B); seismic records indicate continuation of the ridge beneath sedimentary cover as far north as $20^{\circ} 20^{\prime} \mathrm{S}$ (Foucher et al., 1988; Wiedicke and Collier, 1993).

The geomorphologic transition from axial valley to axial ridge (Martinez and Taylor, 2002) is accompanied by a change in crustal lithology from tholeiitic back-arc-basin basalt in the north to mixtures of basaltic andesite, andesite, and rhyodacite in the south (Jenner et al., 1987; Frenzel et al., 1991; Vallier et al., 1991; Fouquet et al., 1993a; Fretzdorff et al., 2006; Langmuir et al., 2006; Bézos et al., 2009; Escrig et al., 2009; Sleeper and Martiner, 2014). Escrig et al. (2009) and Sleeper and Martinez (2014) identify two important sources of geochemical variation along the ELSC. First, a stepwise transition in crustal lithology and isotopic signatures at $20^{\circ} 36^{\prime} 05^{\prime \prime} \mathrm{S}$ (between the TowCam and Tahi Moana-1 vent fields) is proposed to coincide with the presence of hydrated mantle associated with the Tonga Subduction Zone (Sleeper and 
Martinez, 2014). South of this transition zone, subduction zone signatures increase with proximity to the subduction zone and crustal rocks are enriched in elements such as $\mathrm{Ba}$ and $\mathrm{Pb}$, which are fluid-mobile and preferentially partition into melts during mantle melting (Escrig et al., 2009; Sleeper and Martinez, 2014). A second-order sinusoidal variation in crustal lithology and isotopic signatures is also identified south of this transition zone and is proposed to represent the influence of hydrated melt diapirs likewise arising from the subducting slab (Escrig et al., 2009; Sleeper and Martinez, 2014). This second-order variation correlates with second-order segmentation of the ELSC and the projected locations of arc volcano clusters (Sleeper and Martinez, 2014). One of these proposed diapirs occurs at $22^{\circ} 12^{\prime} \mathrm{S}$, corresponding with a region of enhanced volcanism and the overlapping spreading center that hosts the Mariner vent field as well as the projected location of Ata volcano (Fig. 1B; Escrig et al., 2009; Sleeper and Martiner, 2014). A second proposed hydrated melt diaper occurs at $21^{\circ} 33^{\prime} \mathrm{S}$ (between the ABE and Tu'i Malila vent fields) (Escrig et al., 2009; Sleeper and Martinez, 2014).

A 460-channel towed seismic survey indicates the presence of two axial magma chambers beneath the ELSC (Harding et al., 2000; Jacobs et al., 2007). The northern magma chamber extends from $20^{\circ} 30^{\prime} \mathrm{S}$ to $21^{\circ} 30^{\prime} \mathrm{S}$ at a depth of 1.5 to $2.5 \mathrm{~km}$ (avg. $2.34 \mathrm{~km}$ ) below the seafloor, but does not directly underlie the ABE vent field (Jacobs et al., 2007). In contrast, the southern magma chamber extends from $21^{\circ} 45^{\prime} \mathrm{S}$ to at least $22^{\circ} 40^{\prime} \mathrm{S}$ (the end of the survey line), underlying both the Tu'i Malila and Mariner vent fields at a depth of 2.0 to $3.5 \mathrm{~km}$ (avg. $2.82 \mathrm{~km}$ ) below the seafloor (Jacobs et al., 2007). Earlier normal incidence four-channel wide-angle seismic reflection surveys show a rough doubling of this southern magma chamber from a crossaxis width of 0.6 to $2.3 \mathrm{~km}$ beneath the central Valu Fa Ridge (south of the Mariner vent field) to 
a width of $4 \mathrm{~km}$ beneath the overlapping spreading center that surrounds the Mariner vent field (Morton and Sleep, 1985; Collier and Sinha, 1990).

\section{METHODS}

\subsection{Field Sampling}

Samples of active and inactive SMS deposits from vent fields along the ELSC were collected during cruises TUIM05MV (2005, R/V Melville) and TN236 (2009, R/V Thompson) using the Jason II remotely operated vehicle. Many of these deposits were sampled along with the hydrothermal fluids that were flowing through them at the time of collection. Hydrothermal fluids were collected in isobaric gas-tight (IGT) samplers (Seewald et al., 2002).

\subsection{Fluid Chemistry}

Fluid samples were processed on the ship within $24 \mathrm{~h}$ of recovery. Shipboard measurements of $\mathrm{pH}\left(\right.$ at $25^{\circ} \mathrm{C}$ ) were made using a $\mathrm{Ag} / \mathrm{AgCl}$ combination reference electrode that was calibrated daily. Dissolved $\mathrm{H}_{2}$ concentration was determined shipboard following a headspace extraction using a gas chromatograph (GC) equipped with a $5 \AA$ molecular sieve packed column and a thermal conductivity detector. Total aqueous sulfide $\left(\Sigma \mathrm{H}_{2} \mathrm{~S}=\mathrm{H}_{2} \mathrm{~S}+\mathrm{HS}^{-}+\right.$ $\mathrm{S}^{2-}$ ) was sparged from a sample aliquot acidified with $25 \mathrm{wt} \%$ phosphoric acid and precipitated shipboard as $\mathrm{Ag}_{2} \mathrm{~S}$ in a $5 \mathrm{wt} \%$ solution of $\mathrm{AgNO}_{3}$ for subsequent gravimetric measurement in a shore-based laboratory.

An aliquot of each hydrothermal fluid sample that was collected in 2005 was filtered through a $0.45 \mu \mathrm{m}$ filter into high-density polyethylene bottles that were "hot" acid cleaned and acidified with ultra-pure $6 \mathrm{~N} \mathrm{HCl}$ to a $\mathrm{pH}$ of $\sim 1.8$ (Mottl et al., 2011). Another aliquot was 
diluted 1:20 with 0.1 N HCl. Solid precipitates were removed from the sampler following complete removal of the fluid by sequentially rinsing with water and acetone and collecting the particles on a $0.45 \mu \mathrm{m}$ nylon filter. Concentrations of $\mathrm{Cu}, \mathrm{Zn}, \mathrm{Pb}$, and $\mathrm{Ba}$ in filtered aliquots and digested residual particles were analyzed using inductively coupled plasma atomic emission spectrometry (ICP-AES). Total fluid metal concentrations were calculated based on the addition of dissolved-, filter-, and precipitate "dregs" fractions (Trefry et al. 1994). Analytical errors can be estimated based on repeat measurements of the sample solutions and are on the order of $10 \%$ for most measurements.

\subsection{Deposit Sample Preparation}

SMS deposit samples were photographed and air-dried following shipboard recovery and transferred to climate-controlled storage upon arrival at the Woods Hole Oceanographic Institution. Selected samples were then cut and subsampled for petrographic and geochemical study. Sample powders were produced in mild- or hard-steel barrels after which they were split into two subsamples, one for bulk geochemical analyses and a second for mineralogical analysis by x-ray diffraction. Petrographic samples were prepared as polished thin sections and examined under reflected and transmitted light with a petrographic microscope. Sphalerite and wurtzite were identified by crystal morphology and anisotropy under crossed nicols in transmitted light, while pyrite and marcasite were identified by crystal morphology and pleochroism under crossed nicols in reflected light. Following visual inspection and mineralogical description, selected thin sections were carbon-coated and analyzed by electron microprobe.

Powdered samples were selected to be representative of the whole sample and are either radial sections of concentrically layered samples or interior (i.e. unweathered) pieces of visually 
homogeneous samples. Where possible, these pieces were separated from whole samples along pre-existing fractures in order to avoid contamination from steel tools. Otherwise, they were cut using a rock saw or separated using a hammer and chisel. Petrographic thin sections are intended to match the mineralogy of sample powders and, in most cases, were cut from pieces or faces made during geochemical subsampling.

\subsection{Mineralogy and Geochemistry}

Bulk geochemical analyses were conducted by Activation Laboratories, Ltd. in Sudbury, Ontario. Concentrations of $\mathrm{As}, \mathrm{Au}, \mathrm{Ba}, \mathrm{Co}, \mathrm{Sb}, \mathrm{Se}$, and $\mathrm{Zn}$ were measured by instrumental neutron activation analysis, while concentrations of $\mathrm{Ag}, \mathrm{Ca}, \mathrm{Cd}, \mathrm{Cu}, \mathrm{Fe}, \mathrm{Mn}, \mathrm{Mo}, \mathrm{Pb}$, and $\mathrm{Sr}$ were measured by inductively coupled plasma mass spectrometry (ICP-MS) following sodium peroxide fusion. For samples collected in 2009 , analyses of total S by infrared detection on combustion and Si by ICP-OES following sodium peroxide fusion were also conducted; samples were also ground more finely in order to improve digestion of barite and anhydrite. Correlation coefficients between bulk element concentrations in samples from each vent field were calculated using the Matlab script corrcoef.

Analysis of sample powders by x-ray diffraction was conducted on a Philips Analytical PW1830 with a copper tube. Electron microprobe analyses of copper-iron-, iron-, and zinc-iron sulfides in areas free of visible inclusions were conducted at the MIT electron microprobe facility using a JEOL JXA-8200. The concentrations of Ag, As, Cd, Co, Cu, Fe, Mn, S, Sb, Se, and $\mathrm{Zn}$ were measured using 2(PbSe)AgBiS $2, \mathrm{NiAs}, \mathrm{CdS}_{40} \mathrm{ZnS}_{60}, \mathrm{Co}_{9} \mathrm{~S}_{8}, \mathrm{CuFeS}_{2}, \mathrm{MnS}, \mathrm{Sb}_{2} \mathrm{~S}_{3}$, and $\mathrm{ZnS}$ reference standards. Count times were $40 \mathrm{~s}$ for $\mathrm{Cu}, \mathrm{Fe}$, and $\mathrm{S} ; 120 \mathrm{~s}$ for $\mathrm{Ag}, \mathrm{Cd}$, and $\mathrm{Zn}$; $140 \mathrm{~s}$ for Mn; $180 \mathrm{~s}$ for Co; and $240 \mathrm{~s}$ for As, Sb, and Se. 


\section{RESULTS}

\subsection{Hydrothermal Fluid Temperature and $\mathrm{pH}$}

Vent fluid exit temperatures and $\mathrm{pH}$ presented here include and supplement those from Mottl et al., (2011). Vent fluids from the Kilo Moana vent field collected in 2005 exhibit temperatures of $300^{\circ} \mathrm{C}$ to $333^{\circ} \mathrm{C}$ and $\mathrm{pH}\left(\right.$ at $25^{\circ} \mathrm{C}$ ) of 2.9 to 4.0 (Fig. 2; Table 1). Samples collected in 2009 exhibit lower temperatures of $290^{\circ} \mathrm{C}$ to $304^{\circ} \mathrm{C}$ and higher $\mathrm{pH}$ (at $25^{\circ} \mathrm{C}$ ) of 4.0 to 4.1 (Fig. 2; Table 1). No hydrothermal activity was observed at the Kilo Moana vent field in 2015 (observation from cruise RR1507). For all other vent fields, vent fluid temperatures and pH are comparable for samples collected in 2005 and 2009. Vent fluid temperatures and pH are: $288^{\circ} \mathrm{C}$ to $320^{\circ} \mathrm{C}, \mathrm{pH}\left(\right.$ at $\left.25^{\circ} \mathrm{C}\right)=3.6$ to 4.1 at the TowCam vent field, $286^{\circ} \mathrm{C}$ to $310^{\circ} \mathrm{C}, \mathrm{pH}($ at $\left.25^{\circ} \mathrm{C}\right)=3.3$ to 3.9 at the Tahi Moana- 1 vent field, $278^{\circ} \mathrm{C}$ to $317^{\circ} \mathrm{C}, \mathrm{pH}\left(\right.$ at $\left.25^{\circ} \mathrm{C}\right)=3.9$ to 4.6 at the $\mathrm{ABE}$ vent field, $178^{\circ} \mathrm{C}$ to $317^{\circ} \mathrm{C}, \mathrm{pH}\left(\right.$ at $\left.25^{\circ} \mathrm{C}\right)=3.8$ to 5.7 at the Tu'i Malila vent field, and $240^{\circ} \mathrm{C}$ to $363^{\circ} \mathrm{C}, \mathrm{pH}\left(\right.$ at $\left.25^{\circ} \mathrm{C}\right)=2.2$ to 2.7 at the Mariner vent field (Fig. 2; Table 1).

\subsection{Hydrothermal Fluid Chemistry: $\mathrm{Cu}, \mathrm{Zn}, \mathrm{Ba}, \mathrm{Pb}$, and $\mathrm{H}_{2}$}

The concentrations of vent fluid $\mathrm{Cu}, \mathrm{Zn}, \mathrm{Ba}, \mathrm{Pb}$, and $\mathrm{H}_{2}$ reported here for all except the Tahi Moana-1 vent field are "endmember" concentrations calculated by extrapolating a least squares linear regression of an individual species plotted against $\mathrm{Mg}$ for one to three fluid samples recovered from a given vent orifice, and seawater, to zero-Mg. This method is based on the assumption that high-temperature hydrothermal fluids contain little or no $\mathrm{Mg}$, such that the measured $\mathrm{Mg}$ concentration of a hydrothermal fluid sample may be used as a tracer of seawater entrained during sampling (Von Damm et al., 1985). 
Endmember concentrations of dissolved $\mathrm{Cu}$ in high-temperature hydrothermal fluids from the ELSC are 8 to $11 \mu \mathrm{mol} / \mathrm{kg}$ at the Kilo Moana vent field, 3 to $8 \mu \mathrm{mol} / \mathrm{kg}$ at the TowCam vent field, 4 to $6 \mu \mathrm{mol} / \mathrm{kg}$ at the $\mathrm{ABE}$ vent field, and 2 to $16 \mu \mathrm{mol} / \mathrm{kg}$ at the Tu'i Malila vent field (Fig. 2; Tables 1 and S1). Compared to these vent fields, high-temperature fluids at the Mariner vent field exhibit a larger range and higher $\mathrm{Cu}$ concentrations of 4 to $171 \mu \mathrm{mol} / \mathrm{kg}$ (Fig. 2; Table 1). Endmember concentrations of dissolved $\mathrm{Zn}$ are 58 to $108 \mu \mathrm{mol} / \mathrm{kg}$ at the Kilo Moana vent field, 19 to $74 \mu \mathrm{mol} / \mathrm{kg}$ at the TowCam vent field, 33 to $44 \mu \mathrm{mol} / \mathrm{kg}$ at the $\mathrm{ABE}$ vent field, and 7 to $49 \mu \mathrm{mol} / \mathrm{kg}$ at the Tu'i Malila vent field (Fig. 2; Table 1). Endmember Zn concentrations are much higher at the Mariner vent field, covering a range of 242 to $514 \mu \mathrm{mol} / \mathrm{kg}$ (Fig. 2; Table 1). Average and maximum endmember concentrations of dissolved $\mathrm{Ba}$ and $\mathrm{Pb}$ in hightemperature hydrothermal fluids increase monotonically from the Kilo Moana to Mariner vent fields (Fig. 2; Table 1 and S1). Endmember Ba concentrations are 22 to $26 \mu \mathrm{mol} / \mathrm{kg}$ at the Kilo Moana vent field, 21 to $34 \mu \mathrm{mol} / \mathrm{kg}$ at the TowCam vent field, 7 to $63 \mu \mathrm{mol} / \mathrm{kg}$ at the $\mathrm{ABE}$ vent field, 37 to $77 \mu \mathrm{mol} / \mathrm{kg}$ at the Tu'i Malila vent field, and 44 to $131 \mu \mathrm{mol} / \mathrm{kg}$ at the Mariner vent field (Fig. 2; Table 1). Endmember concentrations of Pb likewise increase from 226 to 402 $\mathrm{nmol} / \mathrm{kg}$ at the Kilo Moana vent field, to 369 to $515 \mathrm{nmol} / \mathrm{kg}$ at the TowCam vent field, 380 to $573 \mathrm{nmol} / \mathrm{kg}$ at the $\mathrm{ABE}$ vent field, 532 to $786 \mathrm{nmol} / \mathrm{kg}$ at the Tu'i Malila vent field, and 751 to $1200 \mathrm{nmol} / \mathrm{kg}$ at the Mariner vent field (Fig. 2; Table 1). Endmember concentrations of dissolved $\mathrm{H}_{2}$ at the Kilo Moana vent field are 220 to $498 \mu \mathrm{M}$, while concentrations of dissolved $\mathrm{H}_{2}$ at all other vent fields are low by comparison with a range of 33 to $198 \mu \mathrm{M}$ (Fig. 2; Tables 1 and S1). 


\subsection{Morphology and Mineralogy of Seafloor Massive Sulfide Deposits}

ELSC SMS deposits are formed as hydrothermal edifices variously composed of open conduit chimneys, conical and bulbous spires including beehives, disk-shaped flanges, and squat columnar terraces (Fig. 3). In general, the mineralogy of these portions of SMS deposits may be divided into three layers: (1) low-porosity, sulfide-rich inner layers that were adjacent to the highest-temperature hydrothermal fluids, (2) high-porosity middle layers composed of mixtures of sulfide and sulfate minerals that were in contact with pore fluids of intermediate temperature and chemistry, and (3) low-porosity outer layers composed of marcasite, iron-oxyhydroxides, and amorphous silica that were adjacent to cold or slightly warmed seawater and/or diffuse hydrothermal flow. In the case of horizontal flanges, which trap rising hydrothermal fluids, lower-, middle-, and upper layers correspond to the inner-, middle-, and outer layers in chimneys.

Along the ELSC, morphologic variations among SMS deposits within each vent field are characterized by open conduit chimneys (black smokers) venting high-temperature fluids, active spires and diffusers (white smokers and beehives) venting intermediate- and/or high-temperature fluids, and flanges and squat terraces venting intermediate- and/or low-temperature fluids. Among high-temperature deposits, variations between vent fields are expressed in the mineralogy of sulfide-rich inner layers, which are variously composed of cubanite, chalcopyrite, cubanite/chalcopyrite intermediate solid solution (iss), pyrrhotite, pyrite, and wurtzite (Fig. 4A4H). Among low-temperature deposits, between-field variation is characterized by the presence, absence, and abundance of barite-rich flanges and horizontal deposit structures (Fig. 3, 4).

Elements that occur in deposits as major mineral-forming elements at all vent fields include $\mathrm{Ca}, \mathrm{Cu}, \mathrm{Fe}, \mathrm{S}$, and $\mathrm{Zn}$. Minor amounts of Si are also present, mostly as amorphous silica. Oxygen was not measured, but is present as a mineral-forming element in sulfate and silicate 
minerals. Joining this list at the Tahi Moana-1, ABE, Tu'i Malila, and Mariner vent fields are Ba and $\mathrm{Pb}$, both of which reach maximum concentrations in deposits from the Tu'i Malila vent field (Fig. 5). With the exception of the Mariner vent field, $\mathrm{Ba}$ and $\mathrm{Pb}$ concentrations are higher to the south, while high-temperature SMS deposits at the Mariner vent field are distinctly Cu-rich and Zn-poor compared to other vent fields (Fig. 5). Mineralogical descriptions categorized by vent field and sample type are presented in Table 2. Major and minor element data are shown in Fig. 5, with full presentation of the data in Supplementary Tables 2 and 3.

\subsubsection{Kilo Moana and TowCam}

SMS deposits at the Kilo Moana and TowCam vent fields are located along the edges of volcanic fissures at Kilo Moana or, in the case of TowCam, small extensional faults that crosscut shallow volcanic domes (Ferrini et al., 2008). SMS deposits at the Kilo Moana vent field are characterized by $\sim 5 \mathrm{~m}$-tall edifices (Fig. 3A) composed of multiple active and inactive open conduit chimneys and beehive-shaped diffusers. The bases of larger edifices are covered with short skirts of sulfide-rich talus, while shorter edifices rise directly from pillow basalts. Larger edifices also exhibit narrow, disk-shaped protrusions, which are inactive and located below or to the side of active venting on a given edifice. While described as "flanges" on the basis of sample morphology, the presence of trapped pools of buoyant fluid beneath these overhanging ledges,

which are a characteristic feature of flanges, was not confirmed during Jason dives (M. K. Tivey, pers. comm.). SMS deposits at the TowCam vent field are characterized by $<5 \mathrm{~m}$-tall edifices composed of active and relict spires. Open conduit chimneys (Fig. 3B) are rare, as are beehiveshaped diffusers. Active and relict spires are cone-shaped and exhibit steep, lumpy sides. 
Active spires at the Kilo Moana and TowCam vent fields exhibit anastomosing fluid conduits lined with low porosity layers of either euhedral bladed wurtzite or massive chalcopyrite and minor pyrite (Table 2). These fluid conduits are surrounded by a porous groundmass of intergrown dendritic structures composed of subhedral-to-euhedral sphalerite and wurtzite, euhedral pyrite \pm tabular anhydrite, and minor chalcopyrite (Table 2). Within these layers, late stage amorphous silica is also present as $<10 \mu \mathrm{m}$ coatings on sulfide and sulfate grains. Deposit exteriors are composed of marcasite dendrites coated in a thin layer $(<0.1 \mathrm{~mm})$ of iron-oxyhydroxide and amorphous silica. Relict spires are similar in texture to active spires except that wurtzite grains lining interior conduits are larger with a higher abundance of euhedral grains and alternating marcasite- and wurtzite-dominated layers are more distinct than those observed in active spires (Table 2).

High temperature $\left(\sim 330^{\circ} \mathrm{C}\right)$ open conduit chimneys at the Kilo Moana vent field are lined with massive cubanite (Fig. 4A, 4E; Table 2). Minor, interstitial grains of pyrrhotite and wurtzite are also present. In contrast, high temperature $\left(\sim 330^{\circ} \mathrm{C}\right)$ open conduit chimneys at the TowCam vent field are lined with massive chalcopyrite intergrown with wurtzite and pyrite (Table 2). At lower temperatures $\left(\sim 300^{\circ} \mathrm{C}\right)$, open conduit chimneys at both vent fields are lined with euhedral wurtzite \pm pyrite with chalcopyrite (+iss at Kilo Moana) present as inclusions and interstitial grains (Table 2). At the Kilo Moana vent field, the disk-like protrusions on the exteriors of SMS deposits share a similar mineralogy with active spires and are mainly composed of dendritic marcasite, wurtzite, and minor chalcopyrite (Table 2). 


\subsubsection{Tahi Moana-1, ABE, and Tu'i Malila}

Detailed bathymetry and mapping of the Tahi Moana-1 vent field has not been done, but analysis of dive videos and associated depth readings indicate that hydrothermal edifices are located on a low-relief bathymetric high composed of sedimented pillow basalts. A lower resolution bathymetric map presented by Martinez et al. (2006) indicates a NE-SW trend in linear bathymetric features. High-resolution bathymetric mapping and dive videos of the $\mathrm{ABE}$ and Tu'i Malila vent fields indicate that SMS deposits are associated with significant N-S and NNE-SSW striking normal faults and brecciated lava flows (Ferrini et al., 2008). At the Tu'i Malila vent field, several volcanic domes are also identified (Ferrini et al., 2008).

SMS deposits at the Tahi Moana-1 vent field are characterized by $<5 \mathrm{~m}$-tall, cone-shaped active and relict spires (Fig. 3C). Open conduit chimneys are rare and only one sample was collected. Spires at the Tahi Moana-1 vent field exhibit flat tops and narrow horizontal flanges that protrude beyond the base of the spires (Fig. 3D). The presence of white microbial mats and scale worms inhabiting these flanges suggests that they are hydrothermally active. However, these flanges have not been directly observed to be trapping pools of buoyant fluid. SMS deposits at the ABE vent field are characterized by 3-5 m-tall, cone-shaped edifices (Fig. 3E) composed of active and relict spires and open conduit chimneys. Pronounced horizontal flanges are found at the base of these edifices, elevated above a substrate of broken sulfide talus or bare a'a-type lava flows. Horizontal flanges are also present as discrete, actively venting structures with neither open conduit chimneys nor active spires (Fig. 3F). SMS deposits at the Tu'i Malila vent field are characterized by 5-10 m-tall edifices composed of horizontal flanges, relict beehives, vertical spires, and open conduit chimneys (Fig. 3G). Individual structures composed entirely of horizontal flanges that reach heights of up to $\sim 12 \mathrm{~m}$ are also present in the southern 
part of the vent field (Fig. 3H). More sulfide-rich edifices at the Tu'i Malila vent field likewise exhibit an abundance of horizontal flanges (e.g., Fig. 3G).

Hydrothermal edifices at the Tahi Moana-1, ABE, and Tu'i Malila vent fields exhibit similar mineralogy. Anastomosing fluid conduits are lined by low-porosity inner layers of massive chalcopyrite and euhedral pyrite $\left(\mathrm{T}>310^{\circ} \mathrm{C}\right)$, or euhedral wurtzite \pm chalcopyrite $(\mathrm{T}<$ $310^{\circ} \mathrm{C}$ ), surrounded by porous middle layers composed of intergrown dendrites of subhedral-toeuhedral wurtzite and/or sphalerite \pm tabular anhydrite or barite (increasing to south), with minor euhedral pyrite, marcasite, chalcopyrite and trace-to-minor galena (Table 2). Outer layers are composed of marcasite dendrites with minor acicular barite (Fig. 4I; Table 2).

Compared to SMS deposits found at the Kilo Moana and TowCam vent fields, SMS deposits at the Tahi Moana-1, ABE, and Tu'i Malila vent fields are characterized by a southward increase in the abundance of barite and horizontal flanges. Lower- and middle layers of flanges at the Tahi Moana-1 vent field are composed of dendritic sphalerite and pyrite with minor chalcopyrite; upper layers are composed of dendritic marcasite and acicular barite (Table 2). At the $\mathrm{ABE}$ vent field, flanges are larger and more abundant, trapping pools of lower-temperature buoyant fluids (e.g., Fig. 3F, $141^{\circ} \mathrm{C}$ ). These flanges are barite-rich (Table S2, max. $82 \mathrm{wt} \%$ ) and are composed of dendritic structures formed by tabular barite and interstitial fine-grained $(<5$ $\mu \mathrm{m})$ pyrite with late-stage amorphous silica filling interstices (Table 2). Barite is abundant throughout the Tu'i Malila vent field and is found in both flanges (Table S2, max. 84 wt\%), open conduit chimneys (Table S2, max. $61 \mathrm{wt} \%$ ), and as a matrix mineral in the middle and outer layers of active and relict spires (Table 2). Flanges at the Tu'i Malila vent field are likewise wide and trap pools of buoyant hydrothermal fluids (e.g., Fig. $3 \mathrm{H}, 178^{\circ} \mathrm{C}$; also Table $1 \mathrm{~A}$, fluid sample TM4). Flanges are composed of barite and minor anhydrite with interstitial pyrite, wurtzite, and 
sphalerite (Fig. 4K; Table 2). Minor interstitial chalcopyrite and marcasite are also present in upper layers, as is a late-stage coating of amorphous silica that fills interstices (Fig. 4K; Table 2). This coating is especially thick in relict samples.

High-temperature fluids at the Tahi Moana- $1\left(286^{\circ} \mathrm{C}\right.$ to $\left.310^{\circ} \mathrm{C}\right), \mathrm{ABE}\left(278^{\circ} \mathrm{C}\right.$ to $\left.317^{\circ} \mathrm{C}\right)$, and Tu'i Malila $\left(198^{\circ} \mathrm{C}\right.$ to $\left.312^{\circ} \mathrm{C}\right)$ vent fields are associated with open conduit chimneys and venting active spires. At the Tahi Moana-1 vent field, sample J2-450-3-R1, which was in contact with the $310^{\circ} \mathrm{C}$ fluid TMo5 (Table 1) at the time of collection, is lined with massive chalcopyrite with minor inclusions of $<5 \mu \mathrm{m}$ euhedral pyrite (Table 2). Minor wurtzite is also present, either as bladed grains or as oleander-leaf twinning in chalcopyrite (Table 2). At the ABE vent field, sample J2-449-6-R1, collected with $317^{\circ} \mathrm{C}$ fluid A10 (Table 1; same vent as A1), is lined with massive chalcopyrite and euhedral pyrite (Fig.4B, 4F; Table 2). The modal abundance of pyrite increases toward the outside of the sample and minor sphalerite is present near the outer edge (Table 2). Sample J2-449-5-R1, collected with $306^{\circ} \mathrm{C}$ fluid A11 (Table 1; same vent as A2), is lined with bladed grains of chalcopyrite and wurtzite (Fig. 4C, 4G; Table 2). Trace pyrite is present as inclusions in chalcopyrite and chalcopyrite is also present as oleanderleaf twinning in bladed wurtzite (Table 2). The modal abundance of wurtzite increases toward the outside of the sample (Fig. 4C). Minor anhydrite and trace bornite, digenite, covellite, and galena are present near the outer edge, as are amorphous silica, iron-oxyhydroxides, and clays (Table 2). A relict open conduit sample (J2-136-5-R1) exhibits similar mineralogy to the $306^{\circ} \mathrm{C}$ sample with a lining composed of massive chalcopyrite, bladed wurtzite, and trace euhedral pyrite. At the Tu'i Malila vent field, sample J2-442-4-R2, which was in contact with $312^{\circ} \mathrm{C}$ fluid TM11 (Table 1; same vent as TM2) is lined with massive chalcopyrite and euhedral pyrite with minor sphalerite, acicular barite, and trace galena present near the outer edge (Table 2). 
SMS deposits at the Tu'i Malila vent field contain comparatively high concentrations of $\mathrm{Pb}$, primarily present as galena (Tables 2 and $\mathrm{S} 2$ ). The most $\mathrm{Pb}$-rich sample, J2-134-9-R1, is an active spire associated with $198^{\circ} \mathrm{C}$ fluid TM7 (Table 1). This sample is lined with euhedral wurtzite intergrown with chalcopyrite and galena (Fig. 4J; Table 2). Reflected light petrography and x-ray diffraction analyses of samples collected at the Tu'i Malila vent field also indicate the presence of trace galena in both active and relict spires as well as in some open conduit chimneys and active flanges (Table S2).

\subsubsection{Mariner}

SMS deposits at the Mariner vent field occur in discrete clusters and are surrounded by volcanic domes and brecciated lava flows (Ferrini et al., 2008). Local faults or fissures, if present, are obscured by brecciated lava flows and are not evident in high resolution bathymetry or dive videos (Ferrini et al., 2008). Morphologically, SMS deposits may be divided into four types: short and slender open conduit chimneys, tall columns (Fig. 3I), bulbous edifices, and squat terraces (Fig. 3J). In comparison with other ELSC vent fields, high-temperature deposits at the Mariner vent field are $\mathrm{Cu}$-rich and $\mathrm{Zn}$-poor. Tall columns, open conduits, and bulbous spires are rich in $\mathrm{Cu}$ and $\mathrm{Ba}$, while squat terraces are rich in $\mathrm{Ba}$ and $\mathrm{Zn}$. At the Mariner vent field, SMS deposits are covered in a ubiquitous coating of orange-brown iron-oxyhydroxides and, where fluids emerge, white microbial mats likely containing abundant elemental sulfur.

High-temperature $\left(311^{\circ} \mathrm{C}\right.$ to $\left.363^{\circ} \mathrm{C}\right)$ fluids at the Mariner vent field are associated with tall columns up to $27 \mathrm{~m}$ in height (Fig. 3I; Ferrini et al., 2008) and arrays of slender open conduit chimneys $<5 \mathrm{~m}$ in height. High-temperature open conduit chimneys exhibit $0.5-2 \mathrm{~cm}$ linings of massive chalcopyrite which grade into similarly textured layers of massive bornite-covellite- 
digenite (bn-cv-dg) and outer layers of mixed tabular anhydrite and barite supporting minor interstitial sphalerite and chalcopyrite and trace tennantite (Fig. 4D, 4H; Table 2). Alternatively, some portions of outer layers are composed of dendritic pyrite and marcasite (Table 2). Chalcopyrite linings of open conduit chimneys often consist of two chalcopyrite layers of similar texture, one within the other (see Fig. 4D), likely reflecting the growth of new open conduits within the interiors of previous linings. Indeed, field observations of onlapping open conduits on the tops and sides of actively forming edifices and tall columns suggest that the formation of new open conduit chimneys and incorporation of old open conduit chimneys is an important growth mechanism of Mariner deposits. It is also worth noting that the highest temperature fluids and deposits are associated with active phase separation at the seafloor (Mottl et al., 2011).

Intermediate-temperature $\left(150^{\circ} \mathrm{C}\right.$ to $\left.250^{\circ} \mathrm{C}\right)$ fluids at the Mariner vent field are associated with bulbous edifices. These are bulky structures composed of large bulbous domes and supporting columns. The mineralogy of active spires is characterized by a porous groundmass of intergrown dendrites of chalcopyrite and bornite with less-porous outer layers of dendritic pyrite and marcasite with minor chalcopyrite, wurtzite, and acicular barite (Table 2).

Compared to the $\mathrm{ABE}$ and Tu'i Malila vent fields, overhanging structures are rare at the Mariner vent field and flanges are small, angular, and fragile. However, some bulbous edifices exhibit small protruding flanges, the upper surfaces of which are adorned with $\sim 5 \mathrm{~cm}$ antlershaped tubes of layered iron-oxyhydroxide and silica. Flanges are composed of dendrites of tabular and acicular barite with interstitial subhedral-to-euhedral sphalerite and subhedral pyrite (Table 2). Amorphous silica is absent from most portions of these structures but present as a minor phase in uppermost layers (Table 2). 
Low-temperature $\left(<150^{\circ} \mathrm{C}\right)$ fluids at the Mariner vent field are associated with squat terraces (Fig. 3J) or diffuse flows. Squat terraces are short cylindrical structures $<5 \mathrm{~m}$ in height that occur in the periphery of tall columns. These terraces lack horizontal overhangs and fluids emerge from openings beneath and between smaller disk-shaped structures on top of the cylinder. Fluids are generally low in temperature and $\mathrm{Mg}$-rich, with a maximum temperature of $109^{\circ} \mathrm{C}$ measured in 2009. Samples of squat terraces from the Mariner vent field are composed of a dendritic matrix of tabular barite with interstitial sphalerite, minor pyrite and marcasite, and trace chalcopyrite and tennantite (Fig. 4L; Table 2). The abundance of sphalerite increases toward the interior of the deposit and acicular barite is present toward the exterior (Table 2). Overall, the mineralogy of squat terraces is similar to that of active flanges from the Tu'i Malila and ABE vent fields. However, squat terraces from the Mariner vent field lack the late-stage amorphous silica coating present in active flanges at the $\mathrm{ABE}$ and Tu'i Malila vent fields.

4.4. Major, Minor, and Trace Elements in Seafloor Massive Sulfide Deposits

Elements present as major mineral-forming elements in SMS deposits include $\mathrm{Cu}, \mathrm{Fe}, \mathrm{Zn}$, $\mathrm{Pb}, \mathrm{Ca}, \mathrm{Ba}, \mathrm{S}, \mathrm{Si}$, and $\mathrm{O}$ (Fig. 5; Table S2). Minor and trace elements present at detectable levels in ELSC SMS deposits include Ag, Au, As, Cd, Co, Mn, Mo, Pb, Sb, Se, and Sr (Fig. 5; Table S3). Electron microprobe analyses for wurtzite and sphalerite in open conduit chimneys range from 3 to $14 \mathrm{~mol} \% \mathrm{FeS}$ at Kilo Moana to 1 to $6 \mathrm{~mol} \% \mathrm{FeS}$ at Mariner (Table 3). Additional results of electron microprobe analyses are presented in Fig. 6 and Table S4. 


\subsubsection{Copper, Cobalt, and Selenium}

Open conduit chimneys are $\mathrm{Cu}$-rich, as are active and relict spires from the Mariner vent field (Fig. 5; Table S2). Open conduit chimneys from the Tu'i Malila vent field are enriched in $\mathrm{Cu}$ relative to other Tu'i Malila samples, but contain lower $\mathrm{Cu}$ concentrations than open conduit chimneys at other vent fields. Concentrations of Co in bulk samples are only significant in samples from the Kilo Moana and ABE vent fields, with one additional high value in an open conduit chimney from the Tu'i Malila vent field (Fig. 5; Table S3). Concentrations of Se in bulk samples are only significant in samples from the Kilo Moana vent field (Fig. 5; Table S3). Concentrations of $\mathrm{Co}$ and $\mathrm{Se}$ in bulk samples are significantly and positively correlated with $\mathrm{Cu}$ and Fe for samples from the ABE and Tu'i Malila vent fields (at a significance level of $\mathrm{p}<0.05$, where $\mathrm{p}$ is the Pearson p-value) (Table 4). Significant and positive correlations also exist between $\mathrm{Cu}$ and $\mathrm{Se}$ in samples from the Kilo Moana vent field $(\mathrm{r}=0.90, \mathrm{n}=18)$ and between $\mathrm{Fe}$ and Se in samples from the Tahi Moana-1 vent field $(r=0.63, n=13)($ Table 4).

Electron microprobe analyses (Fig. 6; Table S4) show that high concentrations of Co occur in interior cubanite and iss in open conduit chimneys from the Kilo Moana vent field, and in chalcopyrite along inner layers of open conduit chimneys from the ABE vent field where it is intergrown with pyrite. Elevated Co concentrations also occur intermittently within exterior sphalerite and marcasite, which also host Se, As, Mn, and $\mathrm{Cd} \pm \mathrm{Sb}$ and $\mathrm{Ag}$ (Table S4).

Occurrences of Se are similar to those of Co. However, elevated concentrations of Se occur within inner-layer chalcopyrite and pyrite in open conduit chimneys from the ABE and Tu'i Malila vent fields even on spots where Co concentrations are low (Table S4). Nevertheless, Co and Se are correlated in bulk samples from these two vent fields (Table 4). For samples from the Mariner vent field, electron microprobe analyses show that Co and Se concentrations are 
elevated in interior chalcopyrite and in exterior sphalerite and marcasite as at other vent fields (Fig. 6; Table S4). However bulk concentrations of both Co and Se are low relative to other vent fields and are not significantly correlated (Fig. 5; Table 4; Table S3).

\subsubsection{Zinc, Cadmium, and Manganese}

Bulk concentrations of $\mathrm{Zn}, \mathrm{Cd}$, and $\mathrm{Mn}$ are greatest in samples from the TowCam, Tahi Moana-1 and ABE vent fields, with lower concentrations in deposits from the Kilo Moana, Tu'i Malila and Mariner vent fields (Fig. 5; Tables S2 and S3). Compared to the Zn-rich deposits from the TowCam, Tahi Moana-1 and ABE vent fields, deposits from the Kilo Moana vent field are rich in Fe, those from the Tu'i Malila vent field are rich in $\mathrm{Ba}$, and those from the Mariner vent field are rich in $\mathrm{Cu}$ and $\mathrm{Ba}$ (Fig. 5; Tables S2 and S3). All three of these elements are more abundant in active and relict spires compared to open conduit chimneys from the same vent field (Fig. 5; Tables S2 and S3).

Bulk concentrations of $\mathrm{Zn}$ are highest among active and relict spires from the Kilo Moana, TowCam, Tahi Moana-1, and ABE vent fields (Fig. 5; Table S2). In contrast, active and relict spires from the Tu'i Malila and Mariner vent fields are low in $\mathrm{Zn}$, but are instead high in Ba at the Tu'i Malila vent field and in $\mathrm{Cu}$ and Ba at the Mariner vent field (Fig. 5; Table S2).

Nevertheless, some Tu'i Malila samples do contain high concentrations of Zn, including several open conduit chimneys and a few active and relict spires (Fig. 5; Table S2). High-temperature actively venting deposits at the Mariner vent field are strikingly Zn-poor compared to those from other ELSC vent fields. In contrast, Mariner flanges and squat terraces and one sample from a Ba-rich relict spire contain high concentrations of Zn (Fig. 5; Table S2). 
Bulk concentrations of $\mathrm{Cd}$ are positively and significantly correlated with $\mathrm{Zn}$ for all vent fields (Table 4). Electron microprobe analyses show that $\mathrm{Cd}$ concentrations are invariably highest in wurtzite and sphalerite (Fig. 6). However, low $(<500 \mu \mathrm{g} / \mathrm{g})$ concentrations of Cd also occur in chalcopyrite, pyrite, and marcasite (Fig. 6). Electron microprobe analyses for Mn reveal detectable concentrations of Mn in nearly all sphalerite and wurtzite analyzed (Fig. 6; Table S4) with higher Mn concentrations in pyrite and marcasite. Mn is not significantly correlated with $\mathrm{Zn}$ in bulk samples. Manganese concentrations in all zinc- and iron sulfide minerals are higher in samples from the TowCam, Tahi Moana-1, ABE, and Tu'i Malila vent fields, compared to samples from the Kilo Moana and Mariner vent fields (Fig. 6).

\subsubsection{Barium and Lead}

Bulk concentrations of $\mathrm{Ba}$ are low in SMS deposits from the Kilo Moana, TowCam and Tahi Moana-1 vent fields and high in deposits from the Tu'i Malila and Mariner vent fields with intermediate concentrations in deposits from the ABE vent field (Fig. 5; Table S2). High concentrations of $\mathrm{Ba}$ are associated with the presence of barite, especially among barite-rich flanges from the ABE and Tu'i Malila vent fields and squat terraces from the Mariner vent field.

Bulk concentrations of $\mathrm{Pb}$ increase from the Kilo Moana vent field to the Tu'i Malila vent field, where $\mathrm{Pb}$ concentration reaches a maximum and galena is observed as an abundant minor phase (Fig. 4J, 5; Table 2, S2). However, concentrations of $\mathrm{Pb}$ in samples from the Mariner vent field are low relative to samples from the $\mathrm{ABE}$ and Tu'i Malila vent fields, being more similar to concentrations at the TowCam and Tahi Moana-1 vent fields (Fig. 5; Table S2). Concentrations of $\mathrm{Pb}$ are positively and significantly correlated with $\mathrm{As}$ and $\mathrm{Au}$ at all vent fields except Tu'i Malila and Mariner (Table 4). At the Tu'i Malila vent field, $\mathrm{Pb}$ is not significantly 
correlated with any element, while at Mariner, $\mathrm{Pb}$ is only significantly and positively correlated with $\operatorname{Sr}(r=0.90, \mathrm{n}=24)$ and $\mathrm{Se}(\mathrm{r}=0.53, \mathrm{n}=24)$ and is significantly and negatively correlated with $\mathrm{Cu}(\mathrm{r}=-0.61, \mathrm{n}=24)$ and $\mathrm{Fe}(\mathrm{r}=-0.63, \mathrm{n}=24)$ (Table 4). Electron microprobe analyses of $\mathrm{Pb}$ were attempted, but spectral interferences with $\mathrm{S}$ could not be resolved.

\subsubsection{Arsenic, Antimony, and Silver}

Bulk concentrations of As and Sb increase between the Kilo Moana and Tu'i Malila vent fields (Fig. 5; Table S3). At the Mariner vent field, Sb concentrations are less than those at the Tu'i Malila vent field, while As concentrations are greater (Fig. 5; Table S3). Concentrations of As and Sb are positively and significantly correlated for all vent fields except Kilo Moana, and are also correlated with Au for all vent fields except Mariner (Table 4). In addition, concentrations of As and Ag are positively and significantly correlated for all vent fields except TowCam (Table 4). Bulk concentrations for all of these elements are generally higher in active and relict spires than in open conduits (Fig. 5; Table S3).

Electron microprobe analyses of As and $\mathrm{Sb}$ reveal detectable concentrations of As in pyrite, marcasite, and sphalerite, and to a lesser extent in chalcopyrite and wurtzite; $\mathrm{Sb}$ concentrations are highest in sphalerite, with lesser concentrations in wurtzite and chalcopyrite (Fig. 6). Detectible concentrations of $\mathrm{Sb}$ in marcasite are only found among active flanges from the Tu'i Malila vent field and only a few samples have detectible concentrations of Sb in pyrite (Fig. 6). Concentrations of As and $\mathrm{Sb}$ in sphalerite increase from north to south as do concentrations of As in pyrite (Fig. 6). Where detectable (among open conduit chimneys and in active and relict spires from the Mariner vent field), concentrations of As and Sb in chalcopyrite also increase from north to south (Fig. 6). Concentrations of As and Sb in wurtzite are generally 
below detection limits with a few exceptions among open conduit chimneys and in active flanges from the Mariner vent field (Fig. 6). Large-grained euhedral wurtzite that lines high-temperature fluid conduits lacks detectable As and Sb.

Bulk concentrations of Ag increase between the Kilo Moana and Tahi Moana-1 vent fields and again between the $\mathrm{ABE}$ and Mariner vent fields, with lower concentrations in samples from the Kilo Moana and ABE vent fields (Fig. 5; Table S3). Maximum Ag concentrations are present in samples of barite-rich squat terraces from the Mariner vent field (249 to $639 \mu \mathrm{g} / \mathrm{g}$ ) and active flanges from the Tahi Moana-1 vent field (253 to $326 \mu \mathrm{g} / \mathrm{g}$ ) (Fig. 5). Electron microprobe analyses reveal elevated concentrations of Ag in inner-layer cubanite, chalcopyrite, and middlelayer bornite, as well as outer-layer sphalerite, wurtzite, and marcasite (Fig. 6; Table S4). On spots with detectable Ag, other trace elements are also present, especially Se and Sb in wurtzite, $\mathrm{Co}, \mathrm{Se}, \mathrm{As}$, and $\mathrm{Sb}$ in sphalerite, and $\mathrm{Mn}$ and $\mathrm{As}$ in marcasite. $\mathrm{Ag}$ is present in pyrite, sphalerite, and marcasite in active flanges from the Tu'i Malila vent field, and in sphalerite and pyrite among barite-rich squat terraces from the Mariner vent field (Fig. 6).

\section{DISCUSSION}

Analyses of SMS deposits and hydrothermal fluids from six vent fields along the ELSC reveal spatially organized differences, either in the form of north-south gradients or in distinguishing the Mariner vent field from other ELSC vent fields. These patterns mimic those identified by previous investigations of crustal lithology (e.g., Escrig et al., 2009; Sleeper and Martinez, 2014) and hydrothermal fluid chemistry (e.g., Mottl et al., 2011), which likewise point to the influence of enhanced magmatic activity near the Mariner vent field as well as more gradual trends related to the change in distance between the ELSC and the adjacent volcanic arc. 
As noted and described in Mottl et al., (2011), hydrothermal fluids from these same vent fields are consistent with a decrease in reaction zone temperature between the Kilo Moana and Tu'i Malila vent fields and a transition toward more felsic lithology closer to the subduction zone. Hydrothermal fluid chemistry at the Mariner vent field is strongly influenced by the addition of acidic magmatic volatiles, which leads to higher-temperature, lower-pH, and metal-rich hydrothermal fluids (Mottl et al., 2011). Here, we identify specific indicators of hydrothermal fluid temperature, $\mathrm{pH}$, sulfur fugacity $\left(\mathrm{fS}_{2}\right)$, and trace element content of hydrothermal fluids as expressed by the morphology, mineralogy, and geochemistry of ELSC SMS deposits, placing them within the geologic context of the ELSC and proximal Tonga Subduction Zone.

\subsection{Hydrothermal Fluid Chemistry}

Previous studies of hydrothermal fluid chemistry have identified two groups of dissolved elements, those that are rapidly and quantitatively released to solution and not controlled by mineral solubility, thus reflecting the elemental content of crustal host rocks, and those that are solubility-controlled by reversible chemical reactions between hydrothermal fluids and minerals within the seafloor (e.g., Mottl and Holland, 1978; Seyfried et al., 1984; Von Damm, 1995). Concentrations of elements in the second group are strongly affected by the temperature and $\mathrm{pH}$ of hydrothermal fluids, and concentrations of ligands (e.g., $\mathrm{Cl}^{-}$). Along most of the ELSC, i.e., north of the Mariner vent field, hydrothermal fluid temperature and $\mathrm{pH}$ co-vary with crustal lithology with no evidence of phase separation (Mottl et al., 2011). High-temperature, low-pH vent fluids at the Mariner vent field contrast with this trend, making it possible to more readily distinguish between solubility and lithology-controlled elements. Additionally, Mariner vent 
fluids exhibit $\mathrm{Cl}^{-}$of either less than or greater than seawater and variable dissolved gas contents, attributable to phase separation (Takai et al., 2008; Mottl et al., 2011).

\subsubsection{Dissolved $\mathrm{Ba}$ and $\mathrm{Pb}$}

Results of this study demonstrate that Ba concentrations in ELSC vent fluids increase gradually from north to south (Table 1b; Fig. 2). Furthermore, dissolved Ba concentrations do not correlate with vent fluid temperature or $\mathrm{pH}$ (Fig. 7). Concentrations of $\mathrm{Pb}$ in ELSC vent fluids likewise increase from north to south, weakly correlating with vent fluid $\mathrm{pH}$ only among Mariner vent fluids (Fig. 7). Concentrations of $\mathrm{Ba}$ and $\mathrm{Pb}$ in igneous rocks collected from the seafloor also increase gradually from north to south (Bézos et al., 2009; Escrig et al., 2009). These positive correlations between fluid and rock chemistry occur despite contrasting fluid temperature and $\mathrm{pH}$ (see Fig. 7), and strongly suggest that concentrations of $\mathrm{Ba}$ and $\mathrm{Pb}$ in ELSC hydrothermal fluids are primarily controlled by $\mathrm{Ba}$ and $\mathrm{Pb}$ concentrations in crustal host rocks.

The idea that crustal composition affects the concentration of $\mathrm{Ba}$ in hydrothermal fluids has been previously proposed (e.g., Hannington and Scott, 1988; Scott et al., 1990; Moore and Stakes, 1990; Fouquet et al., 1991; Bendel et al., 1993; Langmuir et al., 1997). However, high Ba concentrations $(\mathrm{Ba}>67 \mu \mathrm{mol} / \mathrm{L})$ in vent fluids from the ultramafic-hosted Rainbow vent field associated with Ba-poor sepentinized peridotites suggest that crustal lithology may not be the only factor controlling Ba concentrations (Douville, 2002; Andreani et al., 2014).

High concentrations of $\mathrm{Pb}$ in vent fluids from the Vai Lili vent field $(\mathrm{Pb}=3.8$ to 7.0 $\mu \mathrm{mol} / \mathrm{kg})$ are accompanied by high $\mathrm{Zn}$ concentrations $(\mathrm{Zn}=1.4$ to $3.0 \mathrm{mmol} / \mathrm{kg})$ and can be attributed to remobilization of subsurface mineral deposits (Fouquet et al., 1993a). Such a mechanism has also been proposed to explain elevated $\mathrm{Zn}$ and other high metal contents in the 
TAG white smoker fluids (Tivey et al., 1995) and several of the PACMANUS vent fields in the Manus Basin (Craddock, 2009).

\subsubsection{Dissolved $\mathrm{Cu}$ and $\mathrm{Zn}$}

In contrast to $\mathrm{Ba}$ and $\mathrm{Pb}$, dissolved concentrations of $\mathrm{Cu}$ and $\mathrm{Zn}$ in vent fluids positively correlate with temperature and negatively correlate with pH (Fig. 2; Fig. 7). Furthermore, dissolved concentrations of $\mathrm{Cu}$ and $\mathrm{Zn}$ exhibit similar patterns across ELSC vent fields as the solubility-controlled components $\mathrm{Mn}, \mathrm{Fe}$, and $\mathrm{H}_{2} \mathrm{~S}$ (Mottl et al., 2011; this paper, Fig. 2; Table 1). Fluid-mineral equilibrium experiments intended to mimic the formation of hydrothermal fluids suggest that lower- temperature water-rock reactions lead to elevated $\mathrm{pH}$ and lower $\mathrm{H}_{2} \mathrm{~S}, \mathrm{SiO}_{2}$, and metal contents (e.g., Seewald and Seyfried, 1990; Seyfried and Ding, 1995; Seyfried et al., 2002) compared to higher temperature conditions. As discussed in Mottl et al. (2011), hydrothermal fluid chemistry observed from the Kilo Moana to Tu'i Malila vent fields is consistent with regionally lower reaction-zone temperatures along the ELSC compared to midocean spreading centers of similar spreading rate, with a further lowering of reaction zone temperature along the Valu Fa Ridge. Low reaction-zone temperatures have been attributed to shallower seafloor depths, thicker or more porous oceanic crust, and/or lower magma temperatures, all potential results of changes in magma chemistry induced by a flux of hydrous material through the Tonga Subduction Zone (Mottl et al., 2011; Escrig et al., 2009).

The very low pH and very high metal contents of Mariner vent fluids (Fig. 2; Tables 1A, 1B) fall outside the ranges observed in high-temperature water-rock reaction experiments and are attributed to the localized addition of acidic magmatic volatiles enriched in $\mathrm{SO}_{2}, \mathrm{CO}_{2}, \mathrm{HCl}$, and HF combined with the increased solubility of metal sulfide minerals under these conditions 
(Mottl et al., 2011). Importantly, the presence of more oxidized magmas and $\mathrm{SO}_{2}$-rich magmatic volatiles is a consequence of the proximity of the subduction zone (Nilsson and Peach, 1993). Similar trends in hydrothermal fluid chemistry were also observed at the Vai Lili vent field (in 1989; Fouquet et al., 1993a) and in the Manus Basin, where crustal composition differs from basalt at the Vienna Woods vent field to more felsic compositions at the PACMANUS and SuSu Knolls vent fields and anomalously acidic hydrothermal fluids are attributed to acidic magmatic volatiles sourced from evolved felsic magmas (Reeves et al., 2011). In contrast, there is no evidence for the addition of acidic magmatic volatiles in Tu'i Malila vent fluids, despite its location above the same magma reflector (Mottl et al., 2011).

\subsubsection{Dissolved Metal Ratios (Fe/Mn, $\mathrm{Cu} / \mathrm{Zn}, \mathrm{Fe} / \mathrm{Cu}$ )}

Pester et al. (2011) present a geothermometer based on the Fe/Mn ratio of hydrothermal fluids. This thermometer is based on basalt experiments and field data from the basalt-hosted $13^{\circ} \mathrm{N}$ vent field on the East Pacific Rise and the ultramafic-hosted Rainbow vent field on the Mid-Atlantic Ridge (Pester et al., 2011). Data presented here for vent fluids from the ELSC show no clear relationship between Fe/Mn ratios and vent fluid exit temperatures (Fig. 7). In contrast, vent fluid Fe/Mn ratios negatively correlate with vent fluid pH (Fig. 7). Such a relationship has also been reported among hydrothermal fluids collected along the Mid-Atlantic Ridge (Douville et al., 2002). Interestingly, the slope of the regression between vent fluid pH (at $25^{\circ} \mathrm{C}$ ) and the $\mathrm{Fe} / \mathrm{Mn}$ ratio is less steep for most ELSC vent than the slope for the northernmost Kilo Moana vent field (Fig. 7). In turn, the slope for Kilo Moana vent fluids is less steep than the slope presented in Douville et al. (2002) for vent fluids from the Mid-Atlantic Ridge. This 
suggests an additional control on vent fluid Fe/Mn ratios, perhaps related to host-rock lithology or mineral assemblages.

Ratios of $\mathrm{Cu} / \mathrm{Zn}$ in ELSC vent fluids are positively correlated with temperature (Fig. 7). This is consistent with the experiments of Seewald and Seyfried (1990), which show that $\mathrm{Cu}$ precipitates more readily than $\mathrm{Zn}$ during cooling of hydrothermal fluids during upflow, Additionally, ratios of vent fluid Fe/Cu in ELSC hydrothermal fluids are positively correlated with vent fluid $\mathrm{H}_{2(\mathrm{aq})}$. This observation is consistent with previous work concluding that $\mathrm{Fe} / \mathrm{Cu}$ ratios are largely controlled by vent fluid redox state (Seyfried and Ding, 1993; 1995). Indeed, the calculated $\mathrm{Fe} / \mathrm{Cu}$ ratios of Kilo Moana vent fluids $(\mathrm{Fe} / \mathrm{Cu}=215$ to 405$)$ are in close agreement with values presented in Seyfried and Ding $(1993,1995)$ for fluids buffered by the pyrite-pyrrhotite-magnetite mineral assemblage while $\mathrm{Fe} / \mathrm{Cu}$ ratios for other ELSC vent fluids $(\mathrm{Fe} / \mathrm{Cu}=14$ to 146 , with the exception of one outlier $=2,456)$ are in close agreement with values for fluids buffered by the hematite-magnetite-pyrite mineral assemblage (Seyfried and Ding, $1993 ; 1995)$.

5.2. Effects of Hydrothermal Fluid Temperature and pH on SMS Deposits.

\subsubsection{Thermodynamic Constraints}

In order to compare hydrothermal fluid chemistry with the mineralogy of paired chimney linings, thermodynamic modelling of fluid speciation and mineral saturation based on the endmember fluid chemistries of fluid samples KM5, TM2, and MA3 (Table 5) at the measured in situ temperatures was conducted using the EQ3/6 software package (Wolery, 1992) and the SUPCRT92 thermodynamic database (Johnson et al., 1992) modified after Tivey (1995). Mineral precipitation was suppressed (acknowledging that fluids along the lining are rapidly replenished; 
see Tivey 1995); chalcopyrite and sphalerite were used as indicators of copper-iron sulfide and zinc sulfide saturation, respectively.

Open conduit chimneys collected from the Kilo Moana vent field in 2005 associated with the highest-temperature fluids $\left(\mathrm{T}>320^{\circ} \mathrm{C}, \mathrm{pH}\left(\right.\right.$ at $\left.25^{\circ} \mathrm{C}\right)=2.9$ to 4.0$)$ exhibit $\mathrm{Cu}$-rich inner layers (massive cubanite, iss, and chalcopyrite) (Fig. 4A, 4E; Table 2). For KM5, accounting for the effect that precipitation of bottle solids $(43.5 \mu \mathrm{mol} / \mathrm{kg} \mathrm{Fe}, 5.6 \mu \mathrm{mol} / \mathrm{kg} \mathrm{Cu}$, and $30.8 \mu \mathrm{mol} / \mathrm{kg} \mathrm{Zn}$ at zero-Mg) would have had on the measured $\mathrm{pH}$ of the fluid, the adjusted endmember $\mathrm{pH}$ at $25^{\circ} \mathrm{C}$ is 3.7 (measured $\mathrm{pH}\left(\right.$ at $\left.25^{\circ} \mathrm{C}\right)=3.5$ ), the $\mathrm{pH}$ at $329^{\circ} \mathrm{C}$ is 4.4 , and the fluid is undersaturated with respect to all sulfide minerals. However, if the $\mathrm{pH}$ at the in situ temperature is adjusted to 4.6, which corresponds to a $\mathrm{pH}$ of 3.8 at $25^{\circ} \mathrm{C}$ (considered to be within the error of the measurements for $\mathrm{pH}$ and the uncertainties associated with the thermodynamic database), then the fluid is saturated with respect to chalcopyrite (thermodynamic data for cubanite and isocubanite are not available), in agreement with the copper-iron sulfide lining of sample J2-1371-R1, the pair to fluid KM5. With conductive cooling of this fluid (Table 5), calculations indicate that pyrite is saturated at $268^{\circ} \mathrm{C}$, sphalerite is saturated at $246^{\circ} \mathrm{C}$, and galena is saturated at $189^{\circ} \mathrm{C}$ (Table 6).

At the $\mathrm{ABE}$ and Tu'i Malila vent fields, where $\mathrm{pH}\left(\right.$ at $\left.25^{\circ} \mathrm{C}\right)=3.8$ to 4.7 , open conduit chimneys are lined with chalcopyrite and pyrite in samples corresponding to fluid temperatures $>310^{\circ} \mathrm{C}$ (Fig. 4B, 4F; Table 2), and with chalcopyrite intergrown with wurtzite in samples corresponding to fluid temperatures $300^{\circ} \mathrm{C}$ to $310^{\circ} \mathrm{C}$ (Fig. $4 \mathrm{C}, 4 \mathrm{G}$; Table 2). This suggests that saturation of these fluids with respect to wurtzite occurs at high temperatures in the range $300^{\circ} \mathrm{C}$ to $310^{\circ} \mathrm{C}$. Thermodynamic calculations based on the endmember chemistry of fluid sample TM2 at the measured temperature of $312^{\circ} \mathrm{C}$ (Table 5) yield an in situ $\mathrm{pH}$ of 5.6 and 
supersaturation with respect to chalcopyrite, pyrite, and sphalerite (Table 6). However, if sulfide minerals are allowed to precipitate, reflecting the possibility of rapid precipitation of sulfide minerals along the chimney wall, $\mathrm{pH}$ is lowered; chalcopyrite and pyrite remain supersaturated at the in situ temperature of $312^{\circ} \mathrm{C}$, while sphalerite is undersaturated. With conductive cooling, sphalerite becomes saturated at $288^{\circ} \mathrm{C}$ (Table 6). These results are consistent with the observed mineralogy of the highest-temperature chimney linings. If conductive cooling models are continued, galena becomes saturated at $258^{\circ} \mathrm{C}$ if mineral precipitation is suppressed or $208^{\circ} \mathrm{C}$ if sulfide mineral precipitation is allowed (Table 6). This is roughly consistent with the observation of galena within the lining of sample J2-134-9-R1 (Fig. 4J), which was venting $198^{\circ} \mathrm{C}$ fluid TM7 (Table 1) at the time of collection.

At the Mariner vent field, where $\mathrm{pH}\left(\right.$ at $\left.25^{\circ} \mathrm{C}\right)=2.2$ to 2.7 , SMS deposits associated with high-temperature fluids are strikingly $\mathrm{Zn}$-poor and $\mathrm{Cu}$-rich relative to deposits from other ELSC vent fields (Table S2). In contrast with SMS deposits from other vent fields, wurtzite and sphalerite at Mariner are only present near the very outer edges of deposits venting hightemperature fluids, in low-temperature deposits such as squat terraces, or as late stage mineralization in the interior of relict spires, suggesting that zinc sulfide precipitation occurred at relatively low temperatures (Table 2). Accounting for metals precipitated in the bottle (61.4 $\mu \mathrm{mol} / \mathrm{kg} \mathrm{Fe}, 150.8 \mu \mathrm{mol} / \mathrm{kg} \mathrm{Cu}$, and $390.0 \mu \mathrm{mol} / \mathrm{kg} \mathrm{Zn}$ at zero-Mg) the $\mathrm{pH}$ of Mariner MA3 vent fluid would have been 3.0 at $25^{\circ} \mathrm{C}$ (vs. measured 2.7), resulting in a pH of 4.2 at $363^{\circ} \mathrm{C}$ (Table 5). Calculations predict that chalcopyrite is saturated at $363^{\circ} \mathrm{C}$, pyrite is saturated at $245^{\circ} \mathrm{C}$, sphalerite is saturated at $193^{\circ} \mathrm{C}$, and galena is saturated at $151^{\circ} \mathrm{C}$ (Table 6). The calculated saturation temperatures of sphalerite and galena for MA3 are thus much lower than those calculated for KM5 and TM2, despite the significantly higher concentrations of $\mathrm{Zn}$ and $\mathrm{Pb}$ in 
MA3 fluid. This contrast points to the importance of fluid $\mathrm{pH}$ in controlling zinc- and lead sulfide solubility.

These calculations illustrate how low-pH fluids lead to the formation of copper-iron sulfide linings at high temperatures with zinc sulfides precipitating at lower temperatures, while higher $\mathrm{pH}$ fluids result in co-precipitation of copper-iron and zinc sulfides at high temperatures. The importance of this effect of $\mathrm{pH}$ has been highlighted before, particularly for deposits on the Endeavour Segment of the Juan de Fuca Ridge (e.g., Tivey at al., 1999; Kristall et al., 2006, 2011). While not explicitly tested through the application of thermodynamic fluid modelling, differences in the mineralogy of open conduit chimney linings between samples collected at the Kilo Moana vent field in 2005 (copper-iron sulfide) and those collected in 2009 (co-precipitated copper-iron sulfide and zinc-iron sulfide) reflect changes in vent fluids to lower temperature and higher $\mathrm{pH}$ in 2009. This supports the hypothesis that chimney lining mineralogy can be a sensitive indicator of hydrothermal fluid temperature and $\mathrm{pH}$.

\subsubsection{Incorporation of Trace Elements into Wurtzite/Sphalerite}

Seafloor massive sulfide deposits along the ELSC are associated with hydrothermal fluids of both relatively high and low endmember $\mathrm{pH}$ and allows for investigation of the incorporation of trace elements into wurtzite and/or sphalerite over a range of $\mathrm{pH}$ conditions. Electron microprobe analyses of ELSC SMS samples indicate that wurtzite present along or near fluid conduit linings intergrown with chalcopyrite (indicative of high formation temperatures) contains relatively high concentrations of $\mathrm{Cd}$ and $\mathrm{Mn}$, and to a lesser extent $\mathrm{Co}$ and $\mathrm{Se}$, but low concentrations of Ag, As, and Sb (Fig. 6; Table S4). In contrast, wurtzite and sphalerite present near the exteriors of deposits (indicative of low formation temperatures) incorporate higher 
concentrations of $\mathrm{Ag}, \mathrm{As}$, and $\mathrm{Sb}$ (As and $\mathrm{Ag}$ are also incorporated into exterior marcasite and pyrite, while $\mathrm{Ag}$ and to a lesser extent $\mathrm{Sb}$ are also incorporated into copper-iron sulfides such as chalcopyrite, regardless of location; Fig. 6). The incorporation of $\mathrm{Cd}$ and $\mathrm{Mn}$ into hightemperature interior sphalerite and wurtzite and $\mathrm{Ag}, \mathrm{As}, \mathrm{Pb}$, and $\mathrm{Sb}$ into low-temperature exterior sphalerite and wurtzite has been previously noted in deposits from the Main Endeavour Field that also formed from fluids with relatively high $\mathrm{pH}\left(\mathrm{pH}\left(\right.\right.$ at $\left.25^{\circ} \mathrm{C}\right)=4.2$ to 4.5 ; Tivey et al., 1999). Thus, the presence of abundant Cd- and Mn-rich, but Ag-, As-, and Sb-poor sphalerite and wurtzite may be indicative of high zinc sulfide formation temperatures and, hence, elevated endmember fluid $\mathrm{pH}$.

Bulk geochemical analyses of deposit samples provide an alternative method for examining the relative distributions of $\mathrm{Zn}$ and $\mathrm{Ag}, \mathrm{As}, \mathrm{Pb}$, and $\mathrm{Sb}$ by a comparison of correlation coefficients between different element concentrations. Such correlations have been used in the past to investigate distributions of $\mathrm{Ag}, \mathrm{As}, \mathrm{Pb}, \mathrm{Sb}$, and $\mathrm{Au}$ with positive correlations between these elements and $\mathrm{Zn}$ attributed to the formation of Ag- and Au-bearing sulfosalts and galena in the Zn-rich lower-temperature portions of deposits (Hannington et al., 1991). A compilation of correlation coefficients for $\mathrm{Zn}$ and these elements (as well as $\mathrm{Cd}$ ) for the full range of sample types present at each of the ELSC vent fields reveals that bulk concentrations of $\mathrm{Zn}$ and $\mathrm{Ag}$ are positively correlated for samples from the Kilo Moana, Tahi Moana-1, and Mariner vent fields, where the minimum fluid $\mathrm{pH}$ is 3.3 or less. However, they are negatively or not significantly correlated for samples from the TowCam, ABE, and Tu'i Malila vent fields, where the minimum fluid $\mathrm{pH}$ is 3.6 or greater (Fig. 8). This analysis was repeated on a sulfide-normalized basis to account for the presence of barite and anhydrite with little change in the results for $\mathrm{Zn}: \mathrm{Ag}$ correlations (Fig. 8). 
Poor $\mathrm{Zn:Ag}$ correlations for deposits associated with vent fluids of relatively high $\mathrm{pH}$ have been previously reported (Tivey et al., 1999; Kristall et al. 2006, 2011). Tivey et al. (1999) observed that correlations of $\mathrm{Zn}$ with $\mathrm{Ag}$, as well as of $\mathrm{Zn}$ with $\mathrm{As}, \mathrm{Pb}$, and $\mathrm{Sb}$, were poor for deposits from the Endeavour Segment of the Juan de Fuca Ridge ( $\mathrm{pH}\left(\right.$ at $\left.25^{\circ} \mathrm{C}\right)=4.2$ to 4.5$)$, and noted that this differed significantly from correlations observed for deposits at other vent fields, such as at the Snakepit vent field ( $\mathrm{pH}\left(\right.$ at $\left.23^{\circ} \mathrm{C}\right) 3.7$ to 3.9; Edmond et al., 1995) where bulk concentrations of $\mathrm{Zn}$ were positively correlated with $\mathrm{Ag}(\mathrm{r}=0.82), \mathrm{Pb}(\mathrm{r}=0.84)$, and $\mathrm{Sb}(\mathrm{r}=$ 0.61) (Fouquet et al., 1993b). Similar poor correlations of $\mathrm{Zn}$ with $\mathrm{Ag}$, As, $\mathrm{Sb}$, and $\mathrm{Pb}$ were reported by Kristall et al. $(2006,2011)$ for SMS deposits formed from relatively high $\mathrm{pH}$ (pH (at $\left.25^{\circ} \mathrm{C}\right)=4.7$ to 4.8 ) vent fluids at the Mothra vent field, also on the Endeavour Segment. The hypothesis proposed to explain the lack of correlation for Endeavour Segment deposits was that $\mathrm{Ag}, \mathrm{As}, \mathrm{Sb}$, and $\mathrm{Pb}$ were not present in zinc sulfide minerals that precipitated at high temperatures owing to high fluid $\mathrm{pH}$ such that high-temperature portions of the deposit could be rich in $\mathrm{Zn}$ but poor in $\mathrm{Ag}, \mathrm{As}, \mathrm{Sb}$, and $\mathrm{Pb}$ (Tivey et al., 1999; Kristall et al., 2006). Bulk geochemical correlations for samples from ELSC SMS deposits support this hypothesis for correlations between $\mathrm{Zn}: \mathrm{Ag}$, $\mathrm{Zn}: \mathrm{As}$, and $\mathrm{Zn}: \mathrm{Pb}$, with poor correlations at vent fields with fluid $\mathrm{pH}$ greater than 3.6 to 4 . Furthermore, correlations of $\mathrm{Zn}: \mathrm{Ag}$ are consistently significant and positive at vent fields with lower $\mathrm{pH}$ vent fluids (at the Kilo Moana, Tahi Moana-1, and Mariner vent fields). In contrast, correlations between bulk concentrations of $\mathrm{Zn}$ and $\mathrm{Sb}$ are not consistently poor for ELSC deposits formed at vent fields that exhibit relatively high $\mathrm{pH}$, and $\mathrm{Zn}: \mathrm{Sb}, \mathrm{Zn}: \mathrm{Pb}$, and $\mathrm{Zn}: \mathrm{As}$ correlations are not consistently significant and positive at vent fields that exhibit relatively low pH (Fig. 7). Differences in these correlations may in part reflect 
precipitation of $\mathrm{Pb}, \mathrm{As}$, and $\mathrm{Sb}$ in minerals other than wurtzite and sphalerite (e.g., galena and sulfosalts), though sulfosalts are only observed at Mariner vent field and only in a few samples. Results from the ELSC suggest that correlations between bulk concentrations of $\mathrm{Zn}$ and $\mathrm{Ag}$ are an indication of the saturation temperature of zinc sulfides, which in turn reflects hydrothermal fluid $\mathrm{pH}$. A poor correlation indicates a relatively high $\mathrm{pH}$ (minimum $\mathrm{pH}>3.6$ ), while a good correlation reflects deposit formation from relatively low $\mathrm{pH}($ minimum $\mathrm{pH}<3.3$ ) vent fluids.

\subsubsection{Flanges, Squat Terraces, Barite, and Amorphous Silica}

Flanges at the ABE and Tu'i Malila vent fields and squat terraces at the Mariner vent field are composed of barite, which forms the bulk of the mineral content, with interstitial sphalerite and pyrite. Additionally, barite within flanges from the ABE and Tu'i Malila vent fields is coated with late-stage amorphous silica, while barite within squat terraces at Mariner is not (Table 2). Instead, the barite-rich flanges from the Mariner vent field are very small relative to those at the ABE and Tu'i Malila vent fields, and exhibit only minor amorphous silica associated with Fe-oxyhydroxides in exterior layers (Table 2). These observations are consistent with the hypothesis that amorphous silica precipitates at relatively high $\mathrm{pH}$ due to the absence of kinetic barriers, strengthening vent structures and enabling the formation of large flanges (Tivey et al., 1999). In contrast, kinetic barriers in low $\mathrm{pH}$ fluids inhibit the precipitation of amorphous silica (Fournier, 1985). Without the stability provided by late-stage amorphous silica, flanges at the Mariner vent field are likely to be structurally weak, breaking before they can reach the size of flanges at the ABE or Tu'i Malila vent fields. Although amorphous silica does precipitate at the Kilo Moana, TowCam, and Tahi Moana-1 vent fields, consistent with higher $\mathrm{pH}$ compared to 
the Mariner vent field, Ba concentrations in hydrothermal fluids and SMS deposits are low. This likely explains the presence of small, sulfide-rich flanges at the Kilo Moana and Tahi Moana1vent fields, but absence of large barite-rich flanges. The combined role of barite and silica in the formation of large, stable structures has been previously reported (Hannington and Scott, 1988; Tivey et al., 1999).

\subsection{Effects of Sulfur Fugacity $\left(\mathrm{fS}_{2}\right)$ on SMS Deposits}

In addition to temperature and $\mathrm{pH}$, sulfur fugacity $\left(\mathrm{fS}_{2}\right)$ is an important parameter that controls the relative stability of sulfide mineral phases. The addition of aqueous $\mathrm{H}_{2}$ concentrations to the fluid chemistry dataset presented in Mottl et al. (2011) allows for the calculation of the $\mathrm{fS}_{2}$ at in situ temperatures and pressures via the following equations:

$$
\begin{gathered}
2 \mathrm{H}_{2, \mathrm{aq}}+\mathrm{S}_{2, \mathrm{~g}}=2 \mathrm{H}_{2} \mathrm{~S}_{\mathrm{aq}} \\
f S_{2, g}=K_{e q} \frac{\left\{H_{2} S_{a q}\right\}^{2}}{\left\{H_{2, a q}\right\}^{2}}
\end{gathered}
$$

where $\left\{\mathrm{H}_{2} \mathrm{~S}_{\mathrm{aq}}\right\}$ and $\left\{\mathrm{H}_{2, a q}\right\}$ are the aqueous activity of $\mathrm{H}_{2} \mathrm{~S}$ and $\mathrm{H}_{2}$, respectively, and $K_{\mathrm{eq}}$ is the equilibrium constant. For the purpose of these calculations, activity coefficients for $\mathrm{H}_{2} \mathrm{~S}$ and $\mathrm{H}_{2}$ were assumed to be unity. The equilibrium constant at in situ temperatures and pressures was calculated using thermodynamic data in the SUPCRT92 database (Johnson et al., 1992). Acid dissociation of $\mathrm{H}_{2} \mathrm{~S}$ in the in situ $\mathrm{pH}$ range for ELSC vent fluids is calculated to be $<3 \%$ for the highest $\mathrm{pH}$ samples (Table S5) allowing the activity of $\mathrm{H}_{2} \mathrm{~S}$ to be determined directly from the measured total dissolved $\mathrm{H}_{2} \mathrm{~S}$ concentrations. 
Examination of sulfide mineral phase relations in terms of temperature and $\mathrm{fS}_{2}$ reveals some important trends (Fig. 9). In particular, there is a general increase in the sulfidation state (a function of temperature and $\mathrm{fS}_{2}$, e.g., Einaudi et al., 2003; Sillitoe and Hedenquist, 2003) of fluids from the Kilo Moana vent field in the north to the Mariner vent field in the south (Fig. 9). Between the Kilo Moana and Tu'i Malila vent fields, this increase is primarily driven by the decrease in $\mathrm{H}_{2}$ contents of hydrothermal fluids from north to south (Fig. 2; Table 1, S5). Elevated concentrations of $\mathrm{H}_{2} \mathrm{~S}$ in Mariner vent fluids and low $\mathrm{H}_{2}$ concentrations (Fig. 2) result in high sulfidation state (Fig. 9). Elevated concentrations of $\mathrm{H}_{2} \mathrm{~S}$ and low concentrations of $\mathrm{H}_{2}$ in Mariner vent fluids may reflect the addition of oxidized, sulfur-rich (i.e., $\mathrm{SO}_{2}$-rich) magmatic volatiles, as has been previously proposed (Mottl et al., 2011). According to the classification proposed by Sillitoe and Hedenquist (2003), SMS deposits along the ELSC range from lowintermediate sulfidation state to intermediate sulfidation state deposits, with an increase in sulfidation state corresponding to increasing proximity to the volcanic arc. Similar patterns are reported in the Manus Basin, where higher sulfidation state deposits are likewise located closer to the volcanic arc (Craddock, 2009).

The mineralogy of open conduit chimney linings from ELSC vent fields closely reflects the temperature and sulfur fugacity of sampled hydrothermal fluids. At Kilo Moana, fluids plot along the pyrite/pyrrhotite boundary and below the chalcopyrite/cubanite boundary on the $\log \left(\mathrm{fS}_{2}\right)$ vs. 1000/T(K) phase diagram (Fig.9). As observed in polished section, the linings of high-temperature open conduit chimneys collected in 2005 are composed of massive cubanite with minor-to-trace pyrrhotite (Fig. 4E; Table 2).

While the sulfidation state of fluids collected in 2009 cannot be directly calculated because $\mathrm{H}_{2}$ has not been measured, it is possible to estimate the sulfidation state based on the $\mathrm{H}_{2}$ 
concentrations of similar-temperature fluids collected in 2005. In using the measured $\mathrm{H}_{2}$ concentration of $306^{\circ} \mathrm{C}$ fluid $\mathrm{KM} 6$ to estimate the $\mathrm{fS}_{2}$ of $304^{\circ} \mathrm{C}$ fluid $\mathrm{KM} 9$ and in using the measured $\mathrm{H}_{2}$ concentration of $300^{\circ} \mathrm{C}$ fluid $\mathrm{KM} 4$ to estimate the $\mathrm{fS}_{2}$ of $290^{\circ} \mathrm{C}$ fluid $\mathrm{KM} 10$, it is shown that the sulfidation state of Kilo Moana vent fluids remains roughly the same, despite a decrease in temperature and $\mathrm{fS}_{2}$. The lining of sample J2-434-2-R1G, which was collected with fluid KM9, also contains cubanite suggesting that the estimation is appropriate and that sulfidation state is a persistent characteristic of Kilo Moana vent fluids despite changes in temperature, $\mathrm{pH}$, and composition.

Fluids from the TowCam and $\mathrm{ABE}$ vent fields show a range of calculated $\mathrm{fS}_{2}$ that is similar to the range observed at Kilo Moana (Fig. 2). However, fluid temperatures are lower and fluids plot within the pyrite stability field, outside the stability field of pyrrhotite and spanning the boundary between cubanite and chalcopyrite (Fig. 9). In polished section, high-temperature open conduit chimney samples from the TowCam, ABE, and Tu'i Malila vent fields are lined with chalcopyrite and pyrite or chalcopyrite and wurtzite (Fig. 4F); cubanite and pyrrhotite are absent. This is consistent with the higher calculated sulfidation state of these fluids at these lower temperatures.

At the Mariner vent field, high $\mathrm{H}_{2} \mathrm{~S}$ and low $\mathrm{H}_{2}$ result in higher $\mathrm{fS}_{2}$ among hightemperature fluids (Fig. 9). This corresponds to a higher sulfidation state, albeit within the chalcopyrite and pyrite stability fields (Fig. 9). High temperature open conduits at Mariner vent field are lined with chalcopyrite (Fig. 4H). However, the higher sulfidation assemblage of bornite and pyrite is present in mid-layers at slightly lower temperatures, possibly reflecting transformations of these fluids as they cool. Alternatively, bornite may be a secondary mineral formed by alteration of primary chalcopyrite in the presence of seawater. The observations that 
massive bornite exhibits similar textures to massive chalcopyrite and occurs primarily near the exteriors of open conduit chimney linings in association with tabular barite and anhydrite (Fig. 4D, 4H; Table 2) support the latter explanation.

The high $\mathrm{fS}_{2}$ and sulfidation state of hydrothermal fluids at Mariner relative to other ELSC vent fields is likely a reflection of the addition of $\mathrm{SO}_{2}$-rich magmatic volatiles into the hydrothermal system. Such volatiles are both oxidizing and sulfur-rich, each acting to increase the sulfur content $\left(\mathrm{H}_{2} \mathrm{~S}\right)$ of hydrothermal fluids without increasing $\mathrm{H}_{2}$. This contrasts with the effect of higher reaction zone temperatures, which increase both $\mathrm{H}_{2} \mathrm{~S}$ and $\mathrm{H}_{2}$ concentrations (Seyfried and Ding, 1995; Seyfried et al., 2002).

Sulfidation state also affects the composition of sphalerite and wurtzite. Qualitatively (based on color in transmitted light) and quantitatively (based on electron microprobe analyses), the mol\% FeS of wurtzite and sphalerite $((\mathrm{Zn}, \mathrm{Fe}) \mathrm{S})$ contained in open conduit chimneys is highest at the Kilo Moana vent field (3 to 14 mol\% FeS) and lowest at the Mariner vent field (1 to $6 \mathrm{~mol} \% \mathrm{FeS}$ ). Wurtzite and sphalerite in open conduit chimneys from the TowCam (4 to $6 \mathrm{~mol} \%$ FeS), Tahi Moana-1 (5 to 6 mol\% FeS), ABE (2 to 4 mol\% FeS), and Tu'i Malila (4 to 9 mol\% $\mathrm{FeS}$ ) vent fields exhibit intermediate concentrations of mol\% FeS in ( $\mathrm{Zn}, \mathrm{Fe}) \mathrm{S}$ (Table 3). These values match expectations for equilibrium concentrations of $\mathrm{Fe}$ in $(\mathrm{Zn}, \mathrm{Fe}) \mathrm{S}$ as a function of $\mathrm{fS}_{2}$ and temperature based on measured fluid chemistries, suggesting that the FeS content of ( $\mathrm{Zn}$, $\mathrm{Fe}) \mathrm{S}$ lining open conduit chimneys is also a reasonable indicator of hydrothermal fluid temperature and $\mathrm{fS}_{2}$ and a more sensitive indicator than copper-iron sulfide mineralogy (Fig. 9). Wurtzite and sphalerite in active spires from the Tu'i Malila vent field (10 to 14 mol\% FeS), exhibit higher mol\% FeS, which is consistent with formation at more reducing conditions within active spires (Table 6). The correspondence of fluid $\mathrm{fS}_{2}$ and temperature with SMS mineral 
assemblages and mol\% $\mathrm{FeS}$ in $(\mathrm{Zn}, \mathrm{Fe}) \mathrm{S}$ has been previously reported (e.g., Hannington et al., 1995; Kawasumi and Chiba, 2017).

\subsection{Effects of Crustal Lithology on SMS Deposits}

Concentrations of $\mathrm{Ba}$ and $\mathrm{Pb}$ in ELSC SMS deposits increase from north to south with the exception of the Mariner vent field, where bulk concentrations of $\mathrm{Ba}$ and $\mathrm{Pb}$ decrease relative to the Tu'i Malila vent field despite higher concentrations in Mariner vent fluids (Fig. 5; Table $\mathrm{S} 2$ ). These lower concentrations of $\mathrm{Ba}$ and $\mathrm{Pb}$ in Mariner deposits relative to high concentrations in Mariner fluids are the results of two mechanisms: 1) the lack of amorphous silica that would add structural support to barite-rich flanges and 2) the $\mathrm{pH}$ dependence of galena solubility. The presence of galena in samples from the more southerly Vai Lili vent field despite low fluid $\mathrm{pH}$ $\left(\mathrm{pH}\left(25^{\circ} \mathrm{C}\right)=2\right)$ is likely the result of much higher $\mathrm{Pb}$ concentrations in Vai Lili fluids (3.8 to 7 $\mu \mathrm{mol} / \mathrm{kg}$ at Vai Lili vs. 0.8 to $1.2 \mu \mathrm{mol} / \mathrm{kg}$ at Mariner), possibly as a result of near-surface remobilization of previously precipitated $\mathrm{Zn}$ - and $\mathrm{Pb}$-rich sulfide deposits (Fouquet et al., 1993a).

Analyses of ELSC SMS deposits are also consistent with the hypothesis proposed by Langmuir et al. (1997) that barite is a common vent deposit mineral when the corresponding volcanic substrate contains $>50 \mu \mathrm{g} / \mathrm{g}$ Ba, but that no barite or only minor barite is present when the substrate contains $<20 \mu \mathrm{g} / \mathrm{g}$ Ba. Chemical analyses of igneous rock dredged from the ELSC show that rocks containing $<20 \mu \mathrm{g} / \mathrm{g}$ Ba are only found north of $20^{\circ} 29^{\prime} \mathrm{S}$, while rocks containing $>50 \mu \mathrm{g} / \mathrm{g} \mathrm{Ba}$ are only found south of $20^{\circ} 37^{\prime} \mathrm{S}$ (Escrig et al., 2009). This places the transition between the zones somewhere in the vicinity, or to the north, of the Tahi Moana-1vent field, consistent with the presence of barite as a trace component in SMS deposits at the 
TowCam vent field, as a minor component at the Tahi Moana-1vent field, and as a major component at the ABE, Tu'i Malila, and Mariner vent fields.

Bulk concentrations of As and Sb in SMS deposits also increase from north to south (Fig. 5). However, bulk concentrations of Sb are lower in Mariner SMS deposits than at Tu'i Malia (Fig. 5). This likely reflects the incorporation of $\mathrm{Sb}$ into zinc sulfides and the lower abundance of zinc sulfide minerals at Mariner (a result of higher temperature, lower $\mathrm{pH}$ fluids). Nevertheless, at the individual mineral level, electron microprobe data show increasing concentrations of As in sphalerite and pyrite and increasing concentrations of $\mathrm{Sb}$ in sphalerite from north to south, suggesting that the effects of crustal lithology on As and Sb are partially transmitted to SMS deposits (Fig. 6). As and Sb were only measured in the dissolved portions of fluids, not in the dregs or filters. Concentrations of these elements in the vent deposits suggest however, that concentrations in endmember vent fluids increase from north to south, reflecting regional differences in crustal lithology as described by Escrig et al., 2009 and Sleeper and Martinez (2014).

Concentrations of Co in SMS deposits are higher at Kilo Moana than at other ELSC vent fields, reflecting more mafic lithology (Fig. 5). Electron microprobe analyses show that elevated concentrations of Co are primarily found in the linings and middle layers of open conduit chimneys, but are also present in the middle layers and exteriors of spires and flanges associated with marcasite, pyrite, and sphalerite (Fig. 6; Table S4).

The effects of crustal lithology on ELSC SMS deposits with respect to the proximity of the Tonga Subduction Zone are seen most clearly as a north-to-south increase in mantleincompatible elements such as $\mathrm{Ba}, \mathrm{Pb}, \mathrm{As}$, and $\mathrm{Sb}$ accompanied by a decrease in mantlecompatible elements such as Co in deposits and, where measured, also in fluids (Fig. 2, 5). In 
addition to crustal lithology, the incorporation of these elements into SMS deposits is controlled by deposit-forming processes at the seafloor. This includes the precipitation of $\mathrm{Ba}$ and $\mathrm{Pb}$ as barite and galena and the incorporation of $\mathrm{As}, \mathrm{Sb}$, and $\mathrm{Co}$ as trace elements in sulfide minerals.

\subsection{Comparison with SMS Deposits at Other ELSC Vent Fields}

Of the additional confirmed active vent fields along the ELSC (the Tahi Moana-2, White Church, TELVE, Vai Lili, S’i S’i, Misitelli, and Hine Hina vent fields), detailed mineralogical and geochemical descriptions are only available for SMS deposits from the White Church, Vai Lili and Hine Hina vent fields. Similar to the SMS deposits at the Tu'i Malila vent field, deposits at the White Church vent field are $\mathrm{Zn}$ - and Ba-rich and associated with normal faulting (Fouquet et al., 1993a). Chimney morphology is characterized by horizontal layers and deposit mineralogy is dominated by barite and sphalerite with abundant galena and late stage silica (Fouquet et al., 1993a). High-temperature hydrothermal activity was not observed at the White Church vent field in 1989 (Fouquet et al., 1993a). However, numerous hydrothermal plumes located in the same area in 2004 suggest active venting at or near this site (Baker et al., 2006).

High temperature $\left(280^{\circ} \mathrm{C}\right.$ to $\left.334^{\circ} \mathrm{C}\right)$, low $\mathrm{pH}\left(\mathrm{pH}\left(\right.\right.$ at $\left.\left.25^{\circ} \mathrm{C}\right)=2\right)$ hydrothermal fluids collected in 1989 from the Vai Lili vent field were associated with large, Cu-rich deposits (Fouquet et al., 1993a). These characteristics resemble those of the Mariner vent field. However, no evidence of magmatic volatile addition was found at the Vai Lili vent field and the low fluid $\mathrm{pH}$ of Vai Lili vent fluids can be attributed to subsurface deposition of $\mathrm{Cu}-\mathrm{Fe}$ sulfides and remobilization of $\mathrm{Zn}$-, $\mathrm{Cd}$-, $\mathrm{Pb}$-, and As-rich low-temperature mineral assemblages (Fouquet et al., 1993a). The maximum fluid temperature measured at the Vai Lili vent field in 2005 was $121^{\circ} \mathrm{C}$ (Tivey et al., 2012), suggesting that this vent field may have been in a waning stage in 
1989. Sulfide mineralization at the Hine Hina vent field is associated with advanced argillic alteration (alunite- pyrophyllite-silica) and exhibit negative $\delta^{34} \mathrm{~S}$ isotopic signatures (Herzig et al., 1998). Hina Hina deposits are thus substantially different from the vent fields studied here, more closely resembling those of the SuSu Knolls vent fields in the Eastern Manus Basin (Yeats et al., 2014; McDermott et al., 2015).

\section{CONCLUSION}

The influence of the Tonga Subduction Zone on ELSC SMS deposits can be divided into regional and local effects. Regional effects are associated with the decrease, from north to south, in the distance between the ELSC and the Tofua Volcanic Arc and include crustal lithology that is increasingly enriched in mantle-incompatible elements in addition to lower reaction zone temperatures that result from shallower seafloor depths, thicker or more porous crust, and/or lower magma temperatures (Mottl et al., 2011; Escrig et al., 2009).

Lower reaction zone temperatures lead to the formation of higher $\mathrm{pH}$ hydrothermal fluids with lower Mn, Fe, and $\mathrm{H}_{2} \mathrm{~S}$ concentrations (Mottl et al., 2011) and lower $\mathrm{Cu}, \mathrm{Zn}$ and $\mathrm{H}_{2}$ concentrations. The elevated fluid $\mathrm{pH}$ results in zinc sulfide mineral saturation at higher temperatures, leading to formation of $\mathrm{Zn}$-rich deposits despite low concentrations of $\mathrm{Zn}$ in vent fluids. The lower $\mathrm{H}_{2}$ results in higher sulfidation states, affecting mineral stability in deposits.

The regional gradient in crustal lithology corresponds to a general increase in mantleincompatible elements in fluids (e.g., $\mathrm{Ba}, \mathrm{Pb}$ ), and in SMS deposits (e.g., $\mathrm{Ba}, \mathrm{Pb}, \mathrm{Sb}$, As), from north to south. However concentrations of some of these elements in SMS deposits are additionally modified by localized processes of deposit formation, including the stabilization of flanges $(\mathrm{Ba})$ and effects of low $\mathrm{pH}$ on zinc- and lead-sulfide mineral saturation and precipitation 
$(\mathrm{Pb}$ and $\mathrm{Sb})$. Nevertheless, overall results reported here suggest that concentrations of $\mathrm{Ba}$ and $\mathrm{Pb}$ in hydrothermal fluids, and concentrations of these elements and Sb and As in SMS deposits, do reflect crustal lithology.

Local effects of the Tonga Subduction Zone influence the morphology, mineralogy, and geochemistry of SMS deposits at the Mariner vent field. The large active magma chamber beneath the Mariner vent field along with the associated higher-temperature reaction zone and addition of $\mathrm{SO}_{2}$-rich magmatic volatiles lead to high vent fluid concentrations of $\mathrm{Mn}, \mathrm{Fe}$, and significantly lower $\mathrm{pH}$ (Mottl et al., 2011), and high concentrations of $\mathrm{Cu}$ and $\mathrm{Zn}$, as well as an increase in the sulfidation state. The low $\mathrm{pH}$ prevents saturation of zinc- and lead- sulfide minerals at high temperatures such that high-temperature portions of Mariner SMS deposits are Cu-rich and Zn-poor relative to other ELSC deposits despite high concentrations of zinc in the vent fluids; low temperature portions of Mariner SMS deposits (e.g., small flanges and squat terraces) are $\mathrm{Zn}-, \mathrm{Pb}-$, and Ba-rich, and $\mathrm{Si}$-poor.

The SMS deposits along the ELSC also record fluid sulfidation state. Mineral content of open conduit chimney linings shifts from massive cubanite \pm pyrrhotite \pm wurtzite at the Kilo Moana vent field to massive chalcopyrite \pm pyrite \pm wurtzite at other ELSC vent fields. The FeS content of zinc sulfides among open conduit chimneys within each vent field also reflects fluid temperature and $\mathrm{fS}_{2}$, accurately recording an increase in the sulfidation state of hydrothermal fluids and SMS deposits with proximity to the Tonga Subduction zone.

The textural observations and geochemical data for ELSC deposit samples reported here, coupled with fluid analyses presented here for $\mathrm{Cu}, \mathrm{Zn}, \mathrm{Pb}, \mathrm{Ba}$, and $\mathrm{H}_{2}$, allow more quantitative assessment of the roles that crustal lithology, reaction zone temperature, and local addition of magmatic volatiles play in determining SMS deposit and composition. The mineralogy of 
chimney linings and the incorporation of $\mathrm{Fe}$ and trace elements into zinc sulfide minerals provide indications of hydrothermal fluid temperature, $\mathrm{fS}_{2}$, and $\mathrm{pH}$. In addition, the correlation between bulk geochemical concentration of $\mathrm{Zn}$ and $\mathrm{Ag}$ within a vent field is a useful indicator of hydrothermal fluid $\mathrm{pH}$ that holds for all ELSC vent fields, with positive and significant correlation between $\mathrm{Zn}$ and $\mathrm{Ag}$ reflecting deposition from low $\mathrm{pH}($ minimum $\mathrm{pH}<3.3$ ) vent fluids at the Kilo Moana, Tahi Moana-1, and Mariner vent fields, and poor correlation between $\mathrm{Zn}$ and $\mathrm{Ag}$ reflecting deposition from high $\mathrm{pH}$ (minimum $\mathrm{pH}$ > 3.6) vent fluids at the TowCam, $\mathrm{ABE}$, and Tu'i Malila vent fields. Analyses reported here demonstrate that the mineralogy and geochemistry of SMS deposits along the ELSC are accurate recorders of hydrothermal fluid chemistry, which can in turn be related to regional and local geologic processes influenced by proximity to the Tonga Subduction Zone.

\section{ACKNOWLEDGEMENTS}

We thank the captains and crews of the R/V Melville and the R/V Thompson and the team of the ROV Jason II for their expertise in recovering fluid and SMS deposit samples from active vent fields. Margaret Sulanowska's help with sample preparation is greatly acknowledged. This work was supported by the National Science Foundation [grant numbers OCE-1038135 to GNE and MKT, OCE-1038124, OCE-0241796, OCE-1233037 to JSS, and OCE-0242088 to CGW].

\section{REFERENCES}

Andreani, M., Escartin, J., Delacour, A., Ildefonse, B., Godard, M., Dyment, J., Fallick, A. E., and Fouquet, Y. (2014) Tectonic structure, lithology, and hydrothermal signature of the Rainbow massif (Mid- Atlantic Ridge $36^{\circ} 14^{\prime}$ N). Geochem. Geophys. Geosys., 15(9), 3543-3571. 
Baker, E. T., Resing, J. A., Walker, S. L., Martinez, F., Taylor, B., and Nakamura, K. I. (2006) Abundant hydrothermal venting along melt- rich and melt- free ridge segments in the Lau back- arc basin. Geophys. Res. Lett., 33(7), L07308.

Barrie, C. T. and Hannington, M. D. (1999) Classification of volcanic-associated massive sulfide deposits based on host-rock composition. Rev. Econ. Geol., 8, 1-11.

Beaulieu, S. E., Baker, E. T., and German, C. R. (2015) Where are the undiscovered hydrothermal vents on oceanic spreading ridges?. Deep Sea Research Part II: Topical Studies in Oceanography, 121, 202-212.

Beinart, R. A., Sanders, J. G., Faure, B., Sylva, S. P., Lee, R. W., Becker, E. L., Gartman, A., Luther, G. W., Seewald, J. S., Fisher, C. R., and Girguis, P. R. (2012) Evidence for the role of endosymbionts in regional-scale habitat partitioning by hydrothermal vent symbioses. PNAS, 109(47), E3241-E3250.

Bendel, V., Fouquet, Y., Auzende, J. M., Lagabrielle, Y., Grimaud, D., and Urabe, T. (1993) The White Lady hydrothermal field, North Fiji back-arc basin, southwest Pacific. Econ. Geol., 88(8), 2237-2245.

Bézos, A., Escrig, S., Langmuir, C. H., Michael, P. J., and Asimow, P. D. (2009) Origins of chemical diversity of back-arc basin basalts: A segment-scale study of the Eastern Lau Spreading Center. J. Geophys. Res.: Solid Earth, 114, B06212, doi:10.1029/2008JB005924.

Collier, J. S. and Sinha, M. C. (1990) Seismic images of a magma chamber beneath the Lau Basin back-arc spreading centre. Nature, 346, 646 to 648; doi:10.1038/346646a0.

Craddock, P. R. (2009) Geochemical tracers of processes affecting the formation of seafloor hydrothermal fluids and deposits in the Manus back-arc basin. Ph.D. Thesis, MIT/WHOI Joint Program in Oceanography.

Douville, E., Charlou, J. L., Oelkers, E. H., Bienvenu, P., Colon, C. J., Donval, J. P., Fouquet, Y., Prieur, D., and Appriou, P. (2002) The rainbow vent fluids (36 14' N, MAR): the influence of ultramafic rocks and phase separation on trace metal content in Mid-Atlantic Ridge hydrothermal fluids. Chem. Geol., 184(1), 37-48.

Edmond, J. M., Campbell, A. C., Palmer, M. R., Klinkhammer, G. P., German, C. R., Edmonds, H. N., Elderfield, H., Thompson, G., and Rona, P. (1995) Time series studies of vent fluids from the TAG and MARK sites $(1986,1990)$ Mid-Atlantic Ridge: a new solution chemistry model and a mechanism for $\mathrm{Cu} / \mathrm{Zn}$ zonation in massive sulphide orebodies. Geological Society, London, Special Publications, 87(1), 77-86.

Einaudi, M. T., Hedenquist, J. W., and Inan, E. E. (2003) Sulfidation state of fluids in active and extinct hydrothermal systems: transitions from porphyry to epithermal environments. In 
Special Publication-Society of Economic Geologists, 10 (eds. S.F. Simmons, I. Graham). Society of Economic Geologists, pp. 285-314.

Escrig, S., Bézos, A., Goldstein, S. L., Langmuir, C. H., and Michael, P. J. (2009) Mantle source variations beneath the Eastern Lau Spreading Center and the nature of subduction components in the Lau basin-Tonga arc system, Geochem. Geophys. Geosys., 10, Q04014, doi:10.1029/2008GC002281.

Ferrini, V. L., Tivey, M. K., Carbotte, S. M., Martinez, F. , and Roman, C. (2008) Variable morphologic expression of volcanic, tectonic, and hydrothermal processes at six hydrothermal vent fields in the Lau back-arc basin, Geochem. Geophys. Geosys., 9, Q07022, doi:10.1029/2008GC002047.

Flores, G. E., Shakya, M., Meneghin, J., Yang, Z. K., Seewald, J. S., Wheat, C. G., Podar, M., and Reysenbach, A.-L. (2012) Inter-field variability in the microbial communities of hydrothermal vent deposits from a back-arc basin. Geobio., 10: 333-346.

doi: $10.1111 / \mathrm{j} .1472-4669.2012 .00325 . \mathrm{x}$

Foucher, J. P. and Shipboard Scientific Party (1988) La ride de Valu Fa dans le basin de Lau meridionnal (sud-ouest Pacifique). Academie des Sciences Comptes Rendues, 307.2, 609616.

Fouquet, Y., von Stackelberg, U., Charlou, J. L., Donval, J. P., Erzinger, J., Foucher, J. P., Herzig, P., Mühe, R., Soakai, S., Wiedicke, M., and Whitechurch, H. (1991) Hydrothermal activity and metallogenesis in the Lau back-arc basin. Nature, 349(6312), 778-781.

Fouquet, Y., von Stackelberg, U., Charlou, J. L., Erzinger, J., Herzig, P. M., Mühe, R., and Wiedicke, M. (1993a) Metallogenesis in back-arc environments: the Lau Basin example. Econ. Geol., 88(8), 2154-2181.

Fouquet, Y., Wafi, A., Cambon, P., Mevel, C., Meyer, G., and Cente, P. (1993b) Tectonic Setting, mineralogical and geochemical zonation in the Snake Pit sulfide deposit (MidAtlantic Ridge at $23^{\circ}$ N). Econ. Geol., 88(8), 2018-2036.

Fournier, R. O. (1985) The behavior of silica in hydrothermal solutions. Rev. Econ. Geol., 2, 4561.

Franklin, J. M., Gibson, H. L., Jonasson, I. R., and Galley, A. G. (2005) Volcanogenic massive sulfide deposits. Economic Geology $100^{\text {th }}$ Anniversary Volume, Society of Economic Geologists, Littleton, Colorado, USA, 523-560.

Frenzel, J. M., Mühe, R., and Stoffers, P. (1990) Petrology of the volcanic rocks from the Lau basin, southwest Pacific. Geol. Jahrb. 92, 395-479. 
Fretzdorff, S., U. Schwarz-Schampera, H. L. Gibson, C.-D. Garbe-Schönberg, F. Hauff, and P. Stoffers (2006) Hydrothermal activity and magma genesis along a propagating backarc basin: Valu Fa Ridge (southern Lau basin), J. Geophys. Res., 111, sB08205, doi:10.1029/2005JB003967.

Hannington, M. D. and Scott, S. D. (1988) Mineralogy and geochemistry of a hydrothermal silica-sulfide-sulfate spire in the caldera of Axial Seamount, Juan de Fuca Ridge. Can. Mineral., 26(3), 603-625.

Hannington, M., Herzig, P., Scott, S., Thompson, G., and Rona, P. (1991) Comparative mineralogy and geochemistry of gold-bearing sulfide deposits on the mid-ocean ridges. Marine Geol., 101(1), 217-248.

Hannington, M. D., Jonasson, I. R., Herzig, P. M., and Petersen, S. (1995) Physical and chemical processes of seafloor mineralization at mid-ocean ridges. In Seafloor hydrothermal systems: physical, chemical, biological, and geological interactions (eds. S. E. Humphris, R. A. Zierenberg, L. S. Mullineaux, and R. E. Thomson), American Geophysical Union, Washington, D. C.. pp. 115-157. doi: 10.1029/GM091p0115.

Hannington, M. D., de Ronde, C. D. J., and Petersen, S. (2005) Sea-floor tectonics and submarine hydrothermal systems. Economic Geology 100 ${ }^{\text {th }}$ Anniversary Volume. Society of Economic Geologists, Littleton, Colorado, USA, 111-141.

Harding, A. J., Kent, G. M., and Collins, J. A. (2000) Initial results from a multichannel seismic survey of the Lau backarc basin, Eos Trans. AGU, 81,abstract T61C-16.

Herzig, P. M., Hannington, M. D., and Arribas Jr, A. (1998) Sulfur isotopic composition of hydrothermal precipitates from the Lau back-arc: implications for magmatic contributions to seafloor hydrothermal systems. Mineral. Dep., 33(3), 226-237.

Ishibashi, J. -I., Lupton, J. E., Yamaguchi, T., Querellou, J., Nunoura, T., and Takai, K. (2006) Expedition reveals changes in Lau Basin hydrothermal system. Eos Trans. AGU, 87(2), 13-17.

Jacobs, A. M., Harding, A. J., and Kent, G. M. (2007) Axial crustal structure of the Lau back-arc basin from velocity modeling of multichannel seismic data. Earth Planet. Sci. Lett., 259(3), 239-255.

Jenner, G. A., Cawood, P.A., Rautenschlein, M., and White, W. M. (1987) Composition of backarc basin volcanics, Valu Fa Ridge, Lau basin: Evidence for a slab-derived component in their mantle source, J. Volcanol. Geotherm. Res., 32, 209-222.

Johnson, J. W., Oelkers, E. H., and Helgeson, H. C. (1992) SUPCRT92: A software package for calculating the standard molal thermodynamic properties of minerals, gases, aqueous species, and reactions from 1 to 5000 bar and 0 to 1000 C. Computers Geosci., 18(7), 899-947. 
Kawasumi, S., and Chiba, H. (2017) Redox state of seafloor hydrothermal fluids and its effect on sulfide mineralization. Chem. Geol., 451, 25-37.

Kristall, B., Kelley, D. S., Hannington, M. D., and Delaney, J. R. (2006) Growth history of a diffusely venting sulfide structure from the Juan de Fuca Ridge: A petrological and geochemical study. Geochem. Geophys. Geosys., 7(7), doi:10.1029/2005GC001166

Kristall, B., Nielsen, D., Hannington, M. D., Kelley, D. S., and Delaney, J. R. (2011) Chemical microenvironments within sulfide structures from the Mothra Hydrothermal Field: Evidence from high-resolution zoning of trace elements. Chem. Geol., 290(1), 12-30.

Langmuir, C., Humphris, S., Fornari, D., Van Dover, C., Von Damm, K., Tivey, M. K., Colodner, D., Charlou, J.-L., Desonie, D., Wilson, C., Fouquet, Y., Klinkhammer, G., Bougault, H., (1997) Hydrothermal vents near a mantle hot spot: the Lucky Strike vent field at $37^{\circ} \mathrm{N}$ on the Mid-Atlantic Ridge. Earth Planet. Sci. Lett., 148(1), 69-91.

Langmuir, C. H., Bézos, A., Escrig, S., and Parman, S. W. (2006) Chemical systematics and hydrous melting of the mantle in back-arc basins. In Back-Arc Spreading Systems: Geological, Biological, Chemical, and Physical Interactions (eds. D. M. Christie, C. R. Fisher, S.-M. Lee, and S. Givens) Geophysical Monograph Series, vol. 166, American Geophysical Union, Washington, DC. 87-146.

Martinez, F. and Taylor, B. (2002) Mantle wedge control on back-arc crustal accretion. Nature, 416, 417-420.

Martinez, F., Taylor, B., Baker, E. T., Resing, J. A., and Walker, S. L. (2006) Opposing trends in crustal thickness and spreading rate along the back-arc Eastern Lau Spreading Center: Implications for controls on ridge morphology, faulting, and hydrothermal activity. Earth Planet. Sci. Lett., 245(3), 655-672.

McDermott, J. M., Ono, S., Tivey, M. K., Seewald, J. S., Shanks, W. C., and Solow, A. R. (2015) Identification of sulfur sources and isotopic equilibria in submarine hot-springs using multiple sulfur isotopes. Geochim. Cosmochim. Acta, 160, 169-187.

Moore, W. S. and Stakes, D. (1990) Ages of barite-sulfide chimneys from the Mariana Trough. Earth Planet. Sci. Let., 100(1), 265-274.

Morton, J. L. and Sleep, N. H. (1985) Seismic reflections from a Lau Basin magma chamber. In Geology and Offshore Resources of Pacific Island Arcs-Tonga Region (eds. D. W. Scholl and T. L. Vallier). Circum-Pacific Council for Energy and Mineral Resources, Houston, pp. 441-453.

Mottl, M. J. and Holland, H. D. (1978) Chemical exchange during hydrothermal alteration of basalt by seawater. I. Experimental results for major and minor components of seawater. Geochim. Cosmochim. Acta, 42, 1103-1115. 
Mottl, M. J., Seewald, J. S., Wheat, C. G., Tivey, M. K., Michael, P. J., Proskurowski, G., McCollom, M., Reeves, E., Sharkey, S., You, C.-F., Chan, L.-H., and Pichler, T. (2011) Chemistry of hot springs along the Eastern Lau Spreading Center. Geochim Cosmochim. Acta, 75(4), 1013-1038.

Nilsson, K. and Peach, C. L. (1993) Sulfur speciation, oxidation state, and sulfur concentration in backarc magmas. Geochim. Cosmochim. Acta , 57(15), 3807-3813.

Parson, L. M. and Wright, I. C. (1996) The Lau-Havre-Taupo back-arc basin: A southwardpropagating, multi-stage evolution from rifting to spreading. Tectonophysics, 263(1), 122.

Pester, N. J., Rough, M., Ding, K., and Seyfried, W. E. (2011) A new Fe/Mn geothermometer for hydrothermal systems: Implications for high-salinity fluids at $13 \mathrm{~N}$ on the East Pacific Rise. Geochim. Cosmochim. Acta, 75(24), 7881-7892.

Podowski, E. L., Moore, T. S., Zelnio, K. A., Luther, G. W., and Fisher, C. R. (2009) Distribution of diffuse flow megafauna in two sites on the Eastern Lau Spreading Center, Tonga. Deep Sea Research Part I: Oceano. Res. Papers, 56(11), 2041-2056.

Reeves, E. P., Seewald, J. S., Saccocia, P., Bach, W., Craddock, P. R., Shanks, W. C., Sylva. S., Walsh, E., Pichler, T., and Rosner, M. (2011) Geochemistry of hydrothermal fluids from the PACMANUS, Northeast Pual and Vienna Woods hydrothermal fields, Manus Basin, Papua New Guinea. Geochim. Cosmochim. Acta, 75(4), 1088-1123.

Ryan, W. B. F., Carbotte, S. M., Coplan, J. O., O'Hara, S., Melkonian, A., Arko, R., Weissel, R. A., Ferrini, V., Goodwillie, A., Nitsche, F., Bonczkowski, J., and Zemsky, R. (2009) Global Multi-Resolution Topography synthesis, Geochem. Geophys. Geosys., 10, Q03014, doi:10.1029/2008GC002332.

Sack, R. O., and Ebel, D. S. (2006) Thermochemistry of sulfide mineral solutions. In Reviews in mineralogy and geochemistry, 61(1) (ed. D.J. Vaughan). Geochemical Society and Mineralogical Society of America. 265-364.

Scott, S. D., Chase, R. L., Hannington, M. D., Michael, P. J., McConachy, T. F. and Shea, G.T. (1990) Sulfide deposits, tectonics, and petrogenesis of Explorer Ridge, Northeast pacific Ocean. In Ophiolites, Oceanic Crustal Analogues (eds. J. Malpas et al.), Cyprus Geol. Surv. Dep., Nicosia, pp. 719-733.

Seewald, J. S. and Seyfried, W. E. (1990) The effect of temperature on metal mobility in subseafloor hydrothermal systems: constraints from basalt alteration experiments. Earth Planet. Sci. Lett., 101(2), 388-403. 
Seewald, J. S., Doherty, K. W., Hammar, T. R., and Liberatore, S. P. (2002) A new gas-tight isobaric sampler for hydrothermal fluids. Deep Sea Research Part I: Oceanographic Research Papers, 49(1), 189-196.

Seyfried, W. E. and Ding, K. (1993) The effect of redox on the relative solubilities of copper and iron in Cl-bearing aqueous fluids at elevated temperatures and pressures: an experimental study with application to subseafloor hydrothermal systems. Geochim. Cosmochim. Acta, 57(9), 1905-1917.

Seyfried, W. E. and Ding, K. (1995) Phase equilibria in subseafloor hydrothermal systems: A review of the role of redox, temperature, $\mathrm{pH}$ and dissolved $\mathrm{Cl}$ on the chemistry of hot spring fluids at mid-ocean ridges. In Seafloor Hydrothermal Systems: Physical, Chemical, Biological, and Geological Interactions (eds. S. E. Humphris, R. A. Zierenberg, L. S. Mullineaux, and R. E. Thomson), American Geophysical Union, Washington, D. C., 248272.

Seyfried W. E. Jr., Janecky, D. R., and Mottl M. J. (1984) Alteration of the oceanic crust: implications for geochemical cycles of lithium and boron. Geochim. Cosmochim. Acta, 48, 557-569.

Seyfried, W. E., Ding, K., and Rao, B. (2002) Experimental calibration of metastable plagioclase-epidote-fluid equilibria at elevated temperatures and pressures: applications to the chemistry of hydrothermal fluids at mid-ocean ridges. In Water-rock Interactions, Ore Deposits, and Environmental Geochemistry: A Tribute to David A. Crerar. (eds. R. Hellman and S.A. Wood). The Geochemical Society, pp. 257-278.

Sillitoe, R. H. and Hedenquist, J. W. (2003) Linkages between volcanotectonic settings, ore-fluid compositions, and epithermal precious metal deposits. In Special Publication-Society of Economic Geologists, 10 (eds. S.F. Simmons, I. Graham). Society of Economic Geologists. Pp. 315-343.

Smith, W. H. and Sandwell, D. T. (1997) Global sea floor topography from satellite altimetry and ship depth soundings. Science, 277(5334), 1956-1962.

Sleeper, J. D. and Martinez, F. (2014) Controls on segmentation and morphology along the back- arc Eastern Lau Spreading Center and Valu Fa Ridge.. Res., 119(3), 1678-1700.

Stoffers, P., Worthington, T. J., Schwarz-Schampera, U., Hannington, M. D., Massoth, G. J., Hekinian, R., Schmidt, M., Lundsten, L. J., Evans, L. J., Vaiomo'unga, R., and Kerby, T. (2006) Submarine volcanoes and high-temperature hydrothermal venting on the Tonga arc, southwest Pacific. Geology, 34(6), 453-456.

Takai, K., Nunoura, T., Ishibashi, J.-I., Lupton, J., Suzuki, R., Hamasaki, H., Ueno, Y., Kawagucci, S., Gamo, T., Suzuki, Y., Hirayama, H., and Horikoshi, K. (2008) Variability in the microbial communities and hydrothermal fluid chemistry at the newly discovered 
Mariner hydrothermal field, southern Lau Basin. J. Geophys. Res., 113, G02031, doi:10.1029/2007JG000636.

Taylor, B. and Martinez, F. (2003) Back-arc basin basalt systematics. Earth Planet. Sci. Lett., 210(3), 481-497.

Tivey, M. K. (1995) The influence of hydrothermal fluid composition and advection rates on black smoker chimney mineralogy: Insights from modeling transport and reaction. Geochim. Cosmochim. Acta, 59(10), 1933-1949.

Tivey, M. K., Humphris, S. E., Thompson, G., Hannington, M. D., and Rona, P. A. (1995). Deducing patterns of fluid flow and mixing within the TAG active hydrothermal mound using mineralogical and geochemical data. J. Geophys. Res., 100(B7), 12527-12555.

Tivey, M. K., Stakes, D. S., Cook, T. L., Hannington, M. D., and Petersen, S. (1999) A model for growth of steep-sided vent structures on the Endeavour Segment of the Juan de Fuca Ridge: Results of a petrologic and geochemical study. J. Geophys. Res: Solid Earth, 104(B10), 22859-22883.

Tivey, M. K., Craddock, P. R., Seewald, J. S., Ferrini, V.L., Kim, S., Mottl, M., Sterling, N.A., Reysenbach, A., and Wheat, C. G. (2005, December) Characterization of six vent fields within the Lau Basin. In AGU Fall Meeting Abstracts (Vol. 1, p. 0477).

Tivey, M. K., Becker, E., Beinart, R., Fisher, C. R., Girguis, P. R., Langmuir, C. H., Michael, P. J., and Reysenbach, A. L. (2012). Links from mantle to microbe at the Lau Integrated Study Site: Insights from a back-arc spreading center. Oceanography, 25, 62-77.

Trefry, J. H., Butterfield, D. B., Metz, S., Massoth, G. J., Trocine, R. P., and Feely R. A. (1994) Trace metals in hydrothermal solutions from Cleft segment on the southern Juan de Fuca Ridge. J. Geophys. Res.99, 4925-4935.

Vallier, T. L., Jenner, G. A., Frey, F. A., Gill, J. B., Davis, A. S., Volpe, A. M., Hawkins, J. W., Morris, J. D., Cawood, P. A., Morton, J. L., Scholl, D. W., Rautenschlein, M., White, W. M., Williams, R. W., Stevenson, A. J., and White, L., D. (1991) Subalkaline andesite from Valu Fa Ridge, a back-arc spreading center in southern Lau Basin: petrogenesis, comparative chemistry, and tectonic implications. Chem. Geol., 91(3), 227-256.

Von Damm, K. L. (1995) Controls on the chemistry and temporal variability of seafloor hydrothermal fluids. In Seafloor Hydrothermal Systems: Physical, Chemical, Biological, and Geological Interactions (eds. S. E. Humphris, R. A. Zierenberg, L. S. Mullineaux, and R. E. Thomson), American Geophysical Union, Washington, D. C., 222-247.

Von Damm, K. L., Edmond, J. M., Grant, B., Measures, C. I., Walden, B., and Weiss, R. F. (1985) Chemistry of submarine hydrothermal solutions at $21^{\circ} \mathrm{N}$, East Pacific Rise. Geochim. Cosmochim. Acta, 49(11), 2197-2220. 
von Stackelberg, U. and Shipboard Scientific Party (1985) Hydrothermal sulfide deposits in back-arc spreading centers in the southwest Pacific, Bundesanstalt für Geowissenschaften und Rohstoffe, Circular 2, 3-14.

von Stackelberg, U. and Shipboard Scientific Party (1988) Active hydrothermalism in the Lau Back-arc Basin (SW Pacific): First results from the SONNE 48 cruise (1987). Mar. Min., 7, 431-442.

von Stackelberg, U., Marchig, V., Müller, P., and Weiser, T. (1990) Hydrothermal mineralization in the Lau and North Fiji Basins. Geol. Jahrb., Reihe D, 92, 547-613.

Wiedicke, M. and Collier, J. (1993) Morphology of the Valu Fa spreading ridge in the southern Lau Basin. J. Geophys. Res: Solid Earth, 98(B7), 11769-11782.

Wolery, T. J. (1992) EQ3/6: A software package for geochemical modeling of aqueous systems: package overview and installation guide (version 7.0). Livermore, CA: Lawrence Livermore National Laboratory.

Yeats, C. J., Parr, J. M., Binns, R. A., Gemmell, J. B., and Scott, S. D. (2014) The SuSu Knolls Hydrothermal Field, Eastern Manus Basin, Papua New Guinea: An Active Submarine High-Sulfidation Copper-Gold System. Econ, Geol., 109(8), 2207-2226. 
TABLES and FIGURES

Table 1. Endmember concentrations of mineral-forming elements and major vent fluid parameters of ELSC hydrothermal fluids.

\begin{tabular}{|c|c|c|c|c|c|c|c|c|c|c|c|c|c|}
\hline Fluid & Year & ${ }^{\mathrm{a}, \mathrm{b}} \mathrm{T}$ & ${ }^{a, c} \mathrm{pH}$ & ${ }^{\mathrm{a}} \mathrm{Cl}$ & ${ }^{a} \mathrm{H}_{2} \mathrm{~S}$ & ${ }^{\mathrm{a}} \mathrm{Mn}$ & ${ }^{\mathrm{a}} \mathrm{Fe}$ & ${ }^{d} \mathrm{Fe}$ & ${ }^{d} \mathrm{Cu}$ & ${ }^{d} Z n$ & ${ }^{d} \mathrm{~Pb}$ & ${ }^{\mathrm{d}} \mathrm{Ba}$ & $\mathrm{H} 2$ \\
\hline & & ${ }^{\circ} \mathrm{C}$ & $25^{\circ} \mathrm{C}$ & $\mathrm{mm}$ & $\mathrm{mm}$ & $\mu \mathrm{m}$ & $\mu \mathrm{m}$ & $\mu \mathrm{m}$ & $\mu \mathrm{m}$ & $\mu \mathrm{m}$ & $\mathrm{nm}$ & $\mu \mathrm{m}$ & $\mu \mathrm{M}$ \\
\hline KM1 & 2005 & 333 & 3.6 & 580 & 5.7 & 510 & 2480 & 2480 & 8 & 58 & 270 & 24 & 310 \\
\hline KM2 & 2005 & 332 & 3.6 & 570 & 5.5 & 690 & 3140 & 3200 & NM & NM & 310 & 24 & 220 \\
\hline KM3 & 2005 & 321 & 2.9 & 580 & 6.6 & 730 & 3810 & 3840 & 9 & 74 & 310 & 26 & 360 \\
\hline KM4 & 2005 & 300 & 3.2 & 570 & 5.5 & 520 & 2280 & 2470 & 11 & NM & 230 & 25 & 480 \\
\hline KM5 & 2005 & 329 & 3.5 & 580 & 6.4 & 720 & 2890 & 2900 & 11 & 108 & NM & NM & 360 \\
\hline KM6 & 2005 & 306 & 3.6 & 590 & 5.6 & 680 & 2960 & 3120 & 10 & 60 & 400 & 22 & 440 \\
\hline KM8 & 2005 & 333 & 4.0 & 580 & 5.6 & 550 & 2520 & 2560 & NM & 64 & 390 & NM & 500 \\
\hline KM9 & 2009 & 304 & 4.1 & 570 & 3.5 & 210 & 530 & NM & NM & NM & NM & NM & NM \\
\hline KM10 & 2009 & 290 & 3.9 & 570 & 3.9 & 190 & 590 & NM & NM & NM & NM & NM & NM \\
\hline TC1 & 2005 & 328 & 4.1 & 530 & 4.9 & 390 & 260 & 310 & 4 & 19 & 370 & 34 & 130 \\
\hline TC3 & 2005 & 320 & 4.0 & 530 & 4.7 & 400 & 260 & 270 & 3 & 49 & 430 & 34 & 180 \\
\hline TC4 & 2005 & 316 & 4.1 & 530 & 5.0 & 410 & 280 & 280 & 5 & 61 & 500 & 21 & 150 \\
\hline TC5 & 2005 & 302 & 3.7 & 550 & 4.6 & 330 & 320 & 340 & 7 & 53 & NM & 25 & 110 \\
\hline TC6 & 2005 & 288 & 3.9 & 550 & 3.8 & 390 & 340 & 370 & 4 & 50 & 430 & 28 & NM \\
\hline TC7 & 2005 & 288 & 4.0 & 530 & 5.3 & 370 & 290 & 310 & 8 & 74 & 520 & 29 & 200 \\
\hline TC9 & 2009 & 320 & 3.6 & 560 & 4.8 & 330 & 210 & NM & NM & NM & NM & NM & NM \\
\hline TMo1 & 2009 & 306 & 3.3 & 580 & 3.1 & 590 & 330 & NM & NM & NM & NM & NM & NM \\
\hline TMo2 & 2009 & 298 & 3.9 & 580 & 4.1 & 300 & 230 & NM & NM & NM & NM & NM & NM \\
\hline TMo3 & 2009 & 286 & 3.7 & 560 & 3.2 & 730 & 280 & NM & NM & NM & NM & NM & NM \\
\hline TMo5 & 2009 & 310 & 3.7 & 560 & 3.3 & 350 & 250 & NM & NM & NM & NM & NM & NM \\
\hline $\mathrm{A} 1$ & 2005 & 309 & 4.3 & 530 & 3.6 & 460 & 260 & 270 & 6 & 36 & 390 & 37 & 60 \\
\hline $\mathrm{A} 2$ & 2005 & 309 & 4.1 & 540 & 3.1 & 480 & 270 & 260 & 5 & 44 & 380 & 7 & NM \\
\hline A4 & 2005 & 278 & 4.4 & 590 & 2.9 & 270 & 160 & NM & NM & NM & NM & NM & 50 \\
\hline A5 & 2005 & 290 & 4.5 & 550 & 3.2 & 290 & 160 & 170 & 4 & 33 & 380 & 63 & 100 \\
\hline A8 & 2005 & 308 & 4.5 & 550 & 3.0 & 300 & 160 & NM & NM & NM & NM & NM & 80 \\
\hline A9 & 2005 & 295 & 4.6 & 590 & 2.7 & 290 & 130 & 160 & NM & 37 & 570 & 26 & 100 \\
\hline A10 & 2009 & 317 & 3.9 & 540 & 3.9 & 410 & 150 & NM & NM & NM & NM & NM & NM \\
\hline A11 & 2009 & 306 & 4.0 & 550 & 2.7 & 280 & 80 & NM & NM & NM & NM & NM & NM \\
\hline A12 & 2009 & 297 & 4.0 & 590 & 3.0 & 350 & 140 & NM & NM & NM & NM & NM & NM \\
\hline TM1 & 2005 & 279 & 4.5 & 650 & 2.4 & 430 & 200 & 220 & 16 & 48 & 530 & 51 & 50 \\
\hline TM2 & 2005 & 312 & 4.4 & 650 & 2.4 & 410 & 210 & 220 & 7 & 28 & 570 & 39 & 50 \\
\hline TM4 & 2005 & 178 & 5.7 & 630 & 1.2 & 330 & 140 & NM & NM & NM & NM & NM & 120 \\
\hline TM5 & 2005 & 265 & 4.6 & 650 & 2.4 & 440 & 200 & NM & NM & NM & NM & NM & 40 \\
\hline TM6 & 2005 & 265 & 4.4 & 650 & 2.4 & 400 & 220 & 230 & 2 & 18 & 560 & 37 & 100 \\
\hline TM7 & 2005 & 198 & 5.0 & 640 & 2.2 & 410 & 200 & NM & NM & NM & NM & NM & NM \\
\hline TM8 & 2005 & 229 & 4.4 & 640 & 2.2 & 380 & 140 & NM & 11 & 7 & 790 & 77 & 110 \\
\hline TM10 & 2005 & 274 & 4.1 & 640 & 2.1 & 380 & 230 & 270 & 4 & 49 & NM & NM & 70 \\
\hline TM11 & 2009 & 315 & 3.8 & 650 & 2.8 & 370 & 150 & NM & NM & NM & NM & NM & NM \\
\hline TM12 & 2009 & 284 & 4.2 & 640 & 2.8 & 310 & 180 & NM & NM & NM & NM & NM & NM \\
\hline MA1 & 2005 & 334 & 2.5 & 620 & 6.1 & 5940 & 11230 & 11420 & 171 & 467 & 860 & 77 & 50 \\
\hline MA2 & 2005 & 311 & 2.6 & 620 & 4.3 & 6280 & 11210 & 11270 & 105 & 514 & 750 & 44 & 30 \\
\hline MA3 & 2005 & 363 & 2.7 & 610 & 9.6 & 5730 & 12960 & 13120 & 156 & 336 & 1130 & 75 & 130 \\
\hline MA5 & 2005 & 249 & 2.6 & 530 & 4.6 & 5440 & 10450 & 10550 & 96 & 321 & 860 & 97 & 60 \\
\hline MA6 & 2005 & 240 & 2.7 & 530 & 6.5 & 4870 & 10670 & 10680 & 4 & 242 & 1200 & 131 & 180 \\
\hline MA8 & 2009 & 359 & 2.4 & 470 & 17.8 & 3860 & 9420 & NM & NM & NM & NM & NM & NM \\
\hline MA9 & 2009 & 338 & 2.3 & 540 & 8.9 & 5200 & 12550 & NM & NM & NM & NM & NM & NM \\
\hline MA11 & 2009 & 356 & 2.2 & NM & 11.8 & 4390 & 11570 & NM & NM & NM & NM & NM & NM \\
\hline MA12 & 2009 & 350 & 2.3 & 560 & 10.8 & 4630 & 13080 & NM & NM & NM & NM & NM & NM \\
\hline
\end{tabular}


for Table 1:

Endmember compositions are based on fluid samples listed in Supplementary Table S1. Analytical errors for metal analyses of individual fluid samples are estimated at $\pm 10 \%$ and $\pm 10 \mu \mathrm{mol} / \mathrm{kg}$ for measurements of $\mathrm{Mn}$ and Fe. Uncertainties resulting from differential sampling of hydrothermal fluids cannot be quantified.

a 2005 values from Mottl et al. (2011)

${ }^{\mathrm{b}} \mathrm{T}$ is maximum temperature measured at the seafloor during sampling.

${ }^{\mathrm{C}} \mathrm{pH}$ is reported as measured at $25^{\circ} \mathrm{C}$

$\mathrm{d}^{\mathrm{p}}$ includes redigested bottle solids

$\mathrm{mm}=\mathrm{mmol} / \mathrm{kg}$ fluid, $\mu \mathrm{m}=\mu \mathrm{mol} / \mathrm{kg}$ fluid, $\mu \mathrm{M}=\mu \mathrm{mol} / \mathrm{L}$ fluid, $\mathrm{NM}=$ not measured

$\mathrm{KM}=$ Kilo Moana, $\mathrm{TC}=$ TowCam, TMo = Tahi Moana-1, A = ABE, TM = Tu'i Malila, MA = Mariner 
Table 2. Mineral textures of SMS deposit samples from the Kilo Moana (KM), TowCam (TC), Tahi Moana1 (TMo), ABE (A), Tu'i Malila (TM), and Mariner (MA) vent fields categorized by sample type.

Three layers: (1) Linings $\left(\sim 330^{\circ} \mathrm{C}\right)$ : massive $\mathrm{cb}$ with minor po, grades outward to iss and $\mathrm{cp}$. Euhedral KM OC py near boundary with middle layer. Linings $\left(\sim 300^{\circ} \mathrm{C}\right)$ : euhedral wz with $\mathrm{cp}$ or iss as inclusions or interstitial grains. (2) Middle layers: matrix of $\sim 1 \mathrm{~cm}$ tabular anh with interstitial wz, sp, py, $\mathrm{cp}$ (variable grain size and texture). (3) Outer layers: dendritic mc, outer coating of $\mathrm{FeOOH}$ and amsi Porous middle layers surround anastomosing fluid conduits. Inner layers: euhedral wz or massive cp KM AS and minor py. Middle layers: dendritic wz, py, and mc with minor $\mathrm{cp}$. Late-stage amsi $(<10 \mu \mathrm{m}$ coating). From interior to exterior, the abundance of wz decreases and the abundance of $\mathrm{mc}$ increases.

\begin{tabular}{|c|c|c|}
\hline $\mathrm{KM}$ & $\mathrm{RS}$ & $\begin{array}{l}\text { Porous layers surround anastomosing fluid conduits. Inner layers: euhedral wz, minor cp and mc. } \\
\text { Middle layers: euhedral-subhedral wz, euhedral-subhedral mc. Outer layers: mc dendrites. }\end{array}$ \\
\hline $\mathrm{KM}$ & $A F$ & $\begin{array}{l}\text { Lower and middle layers: alternating layers of dendritic mc intergrown with wz (size: } 20-30 \mu \mathrm{m}) \text {, minor } \\
\text { interstitial } \mathrm{cp} \text {. Upper layer: } \mathrm{mc} \text { dendrites }(<4 \mathrm{~mm}) \text {. }\end{array}$ \\
\hline $\mathrm{KM}$ & $\mathrm{RF}$ & $\begin{array}{l}\text { Lower layer: } 1-2 \mathrm{~mm} \text { euhedral wz, minor } \mathrm{cp} \text {. Middle layer: euhedral wz (50 to } 200 \mu \mathrm{m}) \text { intergrown with } \\
\text { euhedral py, dendritic wz, and minor interstitial cp. Upper layer: mc dendrites }(<4 \mathrm{~mm}) \text {. Late-stage } \\
\text { amsi. }\end{array}$ \\
\hline
\end{tabular}

TC OC euhedral wz intergrown with $\mathrm{cp}$. Middle layers of both: euhedral-subhedral wz and py, minor anh and cp. Outer layers: mc dendrites.

Porous middle layers surround anastomosing fluid conduits. Linings: $50 \mu \mathrm{m}-400 \mu \mathrm{m}$ subhedral-

\begin{tabular}{|c|c|c|}
\hline TC & AS & $\begin{array}{l}\text { Porous middle layers surround anastomosing fluid conduits. Linings: } 50 \mu \mathrm{m}-400 \mu \mathrm{m} \text { subhedral- } \\
\text { euhedral wz and } 5-30 \mu \mathrm{m} \mathrm{cp} \text { and py. Alternatively, } \sim 1 \mathrm{~mm} \text {-long, inward-facing dendrites of }<100 \\
\mu \mathrm{m} \text { wz and } \mathrm{cp} \text {. Middle layers: dendritic matrix of wz and py, minor } \mathrm{cp} \text {. Also, interstitial anh far from } \\
\text { fluid conduits and late-stage amsi }(<10 \mu \mathrm{m} \text { coating). Outer layers: }<1 \mathrm{~mm} \text { layer of py and } \mathrm{mc} \\
\text { dendrites. Late-stage amsi }(<10 \mu \mathrm{m} \text { coating) }\end{array}$ \\
\hline TC & RS & $\begin{array}{l}\text { Porous middle layers surround anastomosing fluid conduits. Dendritic matrix of euhedral-to-subhedral } \\
\text { wz, sp, py, minor } \mathrm{cp} \text {. Outer layers: }(\sim 1 \mathrm{~mm}) \mathrm{mc} \text { dendrites, minor ba. }\end{array}$ \\
\hline TMo & $\mathrm{OC}$ & $\begin{array}{l}\text { Three layers: (1) Lining }\left(310^{\circ} \mathrm{C}\right) \text { : massive } \mathrm{cp} \text { with }<5 \mu \mathrm{m} \text { inclusions of euhedral py, minor bladed wz, } \\
\text { oleander-leaf twinning. (2) Middle layer: } \mathrm{cp}, \mathrm{wz} \text {, py (grain size variable up to } 200 \mu \mathrm{m}) \text {, interstitial } \\
\text { tabular anh. (3) Outer layer: anh up to } 500 \mu \mathrm{m} \text {; fine-grained } \mathrm{w}, \mathrm{py}, \mathrm{cp} \text {; py and mc dendrites }(<500 \\
\mu \mathrm{m}) \text {. }\end{array}$ \\
\hline TMo & AS & $\begin{array}{l}\text { Porous middle layers surround anastomosing fluid conduits. Dendritic matrix of subhedral sp, minor } \\
\text { py, } \mathrm{cp} \text {, trace ga. Outer layers: }(\sim 1 \mathrm{~mm}) \mathrm{mc} \text { dendrites, minor acicular ba. }\end{array}$ \\
\hline TMo & $\mathrm{RS}$ & no polished section. \\
\hline TMo & AF & Dendritic matrix of subhedral sp, py, and minor cp. Upper layer: acicular ba, mc dendrites. \\
\hline A & $\mathrm{OC}$ & $\begin{array}{l}\text { Two layers: (1) Lining }\left(317^{\circ} \mathrm{C}\right) \text { : massive } \mathrm{cp} \text { with } 100-500 \mu \mathrm{m} \text { inclusions of euhedral py. Lining } \\
\left(306^{\circ} \mathrm{C}\right) \text { : intergrown blades of } \mathrm{cp} \text { and wz; oleander-leaf twinning of } \mathrm{cp} \text { in wz; trace py in } \mathrm{cp} \text {. (2) Outer } \\
\text { layers: } \mathrm{sp} \text {, minor anh, trace bn, dg, cv, ga. }\end{array}$ \\
\hline A & AS & $\begin{array}{l}\text { Porous middle layers surround anastomosing fluid conduits. Linings: euhedral wz and/or cp. Middle } \\
\text { layers dendritic matrix of wz, sp, minor mc and euhedral py, trace-to-minor ba, and trace ga. Outer } \\
\text { layers: mc dendrites, minor acicular ba. }\end{array}$ \\
\hline A & $\mathrm{RS}$ & $\begin{array}{l}\text { Porous middle layers surround anastomosing fluid conduits. Linings: inward-facing dendritic } \\
\text { sphalerite. Middle layers: wz, py, } \mathrm{cp}(<50 \mu \mathrm{m}) \text {, and minor ba. Lathe-shaped voids suggest dissolution } \\
\text { of ba. Outer layers: mc dendrites. }\end{array}$ \\
\hline A & $\mathrm{AF}$ & $\begin{array}{l}\text { Dendritic matrix of tabular ba }(<100 \mu \mathrm{m}) \text { with interstitial, fine-grained }(<5 \mu \mathrm{m}) \text { sulfides. Only py } \\
\text { positively identified, using secondary electron microscope. Late-stage interstitial amsi }\end{array}$ \\
\hline TM & $O C$ & $\begin{array}{l}\text { Lining }\left(312^{\circ} \mathrm{C}\right) \text { : massive } \mathrm{cp} \text { and euhedral py }(100-200 \mu \mathrm{m}) \text {. Lining: }\left(279^{\circ} \mathrm{C}\right) \text { bladed } \mathrm{wz} \text {, intergrown } \\
\text { with lesser interstitial } \mathrm{cp} \text { and py. Outer layers: tabular anh and minor interstitial sp, acicular ba, and } \\
\text { trace ga. }\end{array}$ \\
\hline TM & AS & $\begin{array}{l}\text { Porous middle layers surround anastomosing fluid conduits. Linings: thin rims of massive sp, trace-to- } \\
\text { minor } \mathrm{cp} \text {. Middle layers: tabular ba with interstitial py, } \mathrm{sp}, \mathrm{wz} \text {, trace-to-minor ga. Outer layers: } \\
\text { dendritic mc and acicular ba. Lining of } \mathrm{J} 2-134-9-\mathrm{R} 1\left(\mathrm{~T}=198^{\circ} \mathrm{C}\right) \text { is euhedral wz, minor interstitial } \mathrm{cp} \\
\text { and ga. }\end{array}$ \\
\hline TM & $\mathrm{RS}$ & $\begin{array}{l}\text { Porous middle layers surround anastomosing fluid conduits filled with tabular ba }(<1 \mathrm{~mm}) \text {. Linings: } \\
\text { thin rims of massive wz/sp, trace-to-minor } \mathrm{cp} \text {, py, ga. Middle layers: ba lathes and interstitial py, sp, } \\
\text { wz, trace-to-minor } \mathrm{cp} \text {, ga. Outer layers: dendritic } \mathrm{mc} \text {, acicular ba, FeOOH. }\end{array}$ \\
\hline TM & AF & $\begin{array}{l}\text { Lower layer: dendritic matrix of tabular ba and interstitial sp. Middle layer: dendritic matrix of tabular } \\
\text { ba, minor anh, and interstitial py and sp. Upper layer: subhedral sp with thin mc rims, minor } \mathrm{cp} \text {. Late- } \\
\text { stage interstitial amsi }\end{array}$ \\
\hline
\end{tabular}



TM RF Dendritic matrix of tabular ba (2 to $3 \mathrm{~mm})$, interstitial euhedral-subhedral sp and minor py. Late-stage
amsi (13 wt\%).

Three layers: (1) Linings: massive cp, often doubled. (2) Middle layers: massive bn-cv-dg (0-14\% bn).

MA OC Alternatively, dendritic $\mathrm{cp}$ and bn. (3) Outer layers: tabular anh, ba, and fine-grained interstitial $\mathrm{sp}$, $\mathrm{cp}$. trace tn. Alternatively, dendritic py and mc.

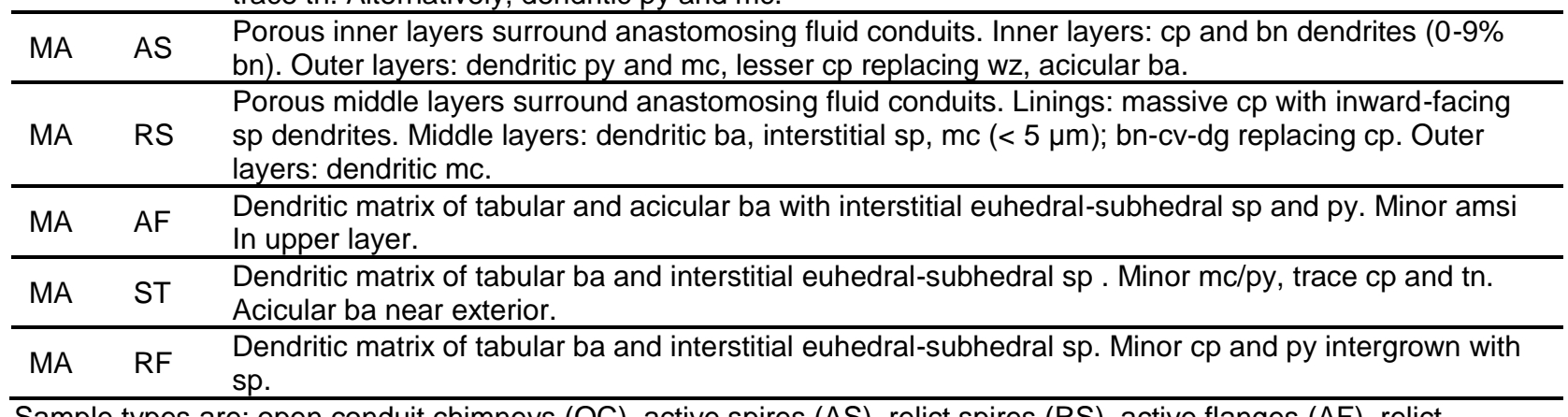

Sample types are: open conduit chimneys (OC), active spires (AS), relict spires (RS), active flanges (AF), relict flanges (RF), and squat terraces (ST).

Mineral types are: amorphous silica (amsi), anhydrite (anh), barite (ba), bornite (bn), cubanite (cb), chalcopyrite (cp), chalcopyrite-cubanite intermediate solid solution (iss), covellite (cv), digenite (dg), iron- oxyhydroxides (FeOOH), galena (ga), marcasite (mc), pyrite (py), pyrrhotite (po), sphalerite (sp), tennantite (tn), and wurtzite (wz). 
Table 3: Summary of electron microprobe analyses of mol\% FeS in wurtzite and sphalerite.

$\mathrm{KM}=$ Kilo Moana, $\mathrm{TC}=$ TowCam, $\mathrm{TMo}=$ Tahi Moana $-1, \mathrm{~A}=\mathrm{ABE}, \mathrm{TM}=$ Tu'i Malila, MA = Mariner

$\mathrm{OC}=$ open conduit chimneys, $\mathrm{AS}=$ active spires, $\mathrm{RS}=$ relict spires $. \mathrm{AF}=$ active flanges, $\mathrm{n}=$ number of spots measured

\begin{tabular}{|c|c|c|c|c|c|}
\hline & & $\mathrm{n}=$ & $\min$. & $\max$ & mean \\
\hline \multirow{3}{*}{ KM } & $\mathrm{OC}$ & 9 & 3 & 14 & 8 \\
\hline & AS & 6 & 5 & 11 & 9 \\
\hline & $\mathrm{RS}$ & 3 & 7 & 8 & 7 \\
\hline \multirow{3}{*}{ TC } & OC & 3 & 4 & 6 & 5 \\
\hline & AS & 15 & 5 & 10 & 6 \\
\hline & $\mathrm{RS}$ & 6 & 4 & 7 & 6 \\
\hline \multirow{3}{*}{ TMo } & $\mathrm{OC}$ & 9 & 5 & 6 & 5 \\
\hline & AS & 6 & 1 & 3 & 2 \\
\hline & RS & 5 & 2 & 8 & 4 \\
\hline \multirow{3}{*}{ A } & OC & 10 & 2 & 4 & 3 \\
\hline & AS & 6 & 3 & 6 & 5 \\
\hline & RS & 3 & 1 & 4 & 2 \\
\hline \multirow{4}{*}{ TM } & $O C$ & 11 & 4 & 9 & 6 \\
\hline & AS & 6 & 10 & 14 & 12 \\
\hline & AF & 7 & 1 & 7 & 3 \\
\hline & $\mathrm{RS}$ & 6 & 1 & 2 & 1 \\
\hline \multirow{4}{*}{ MA } & OC & 4 & 1 & 6 & 3 \\
\hline & AS & 4 & 1 & 7 & 4 \\
\hline & $\mathrm{AF}$ & 7 & 0 & 0 & 0 \\
\hline & RS & 5 & 0 & 2 & 1 \\
\hline
\end{tabular}


Table 4. Tables of Pearson Correlation coefficients calculated based on bulk geochemical analysis of all SMS deposits samples at each vent field. Borders indicate significance at Pearson $p$-value, $p<0.05$.

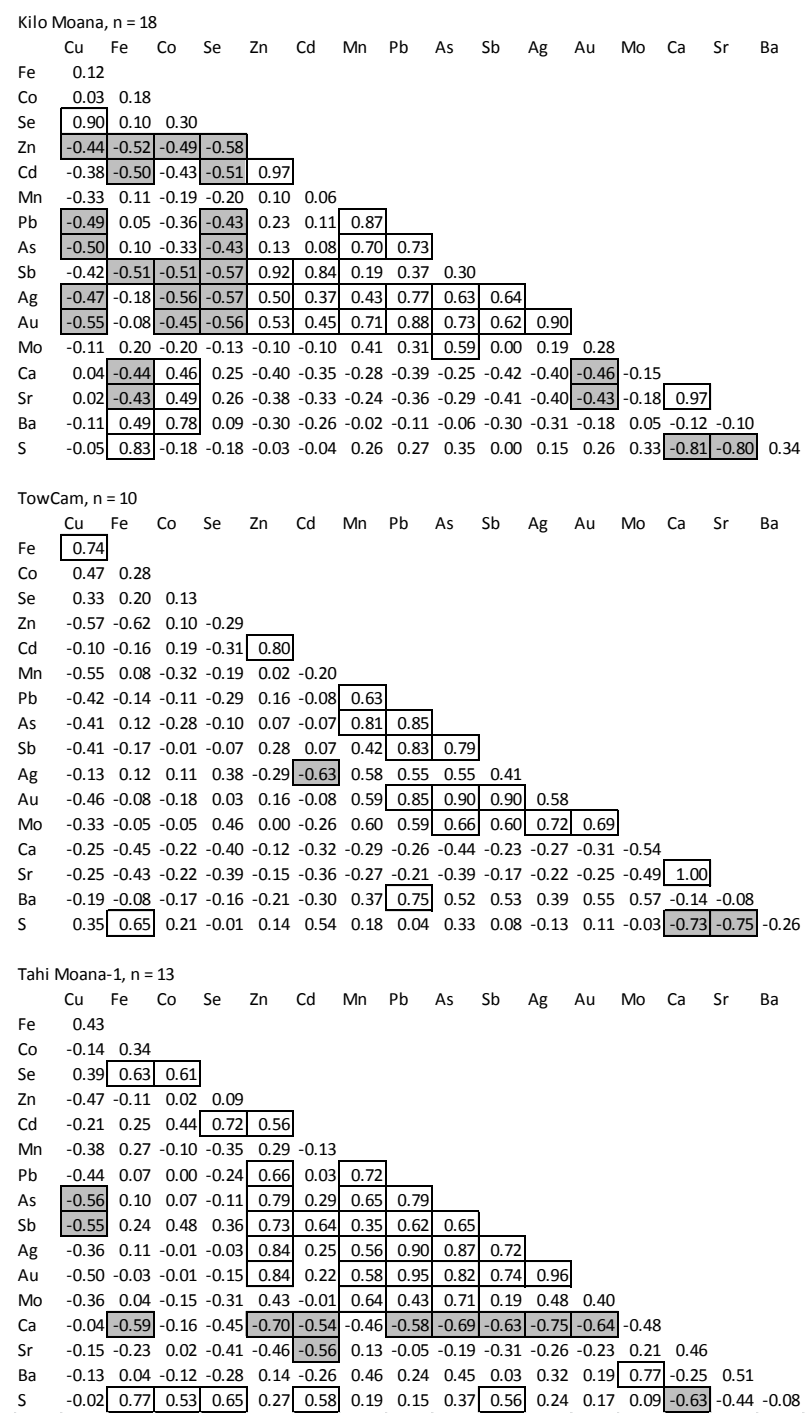

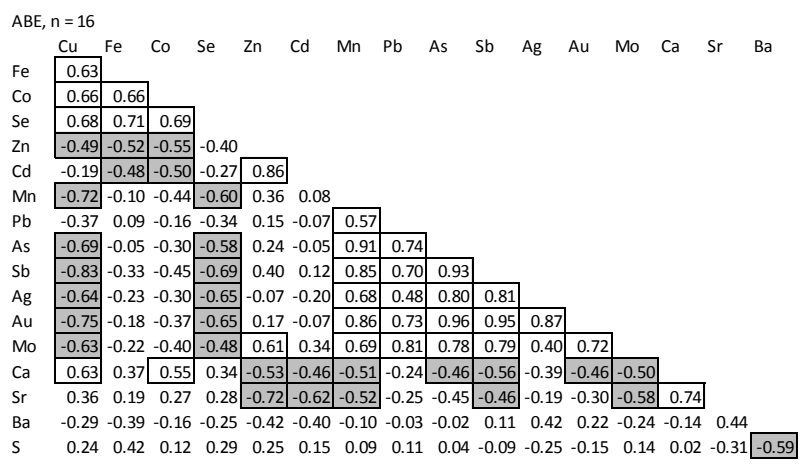

Tu'i Malila, $n=24$

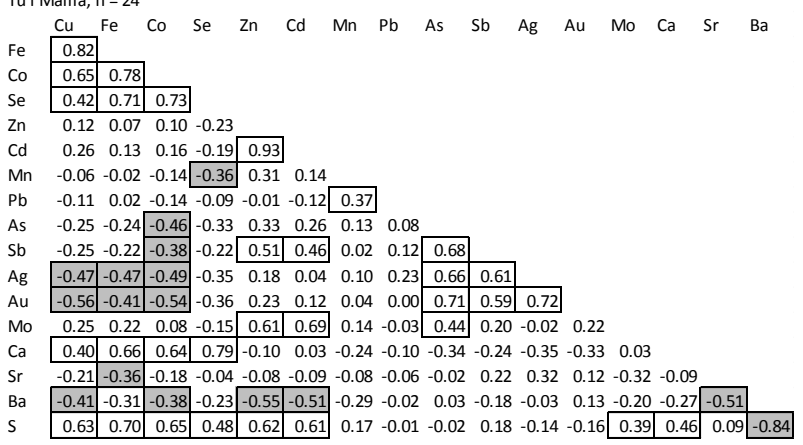

Mariner, $n=24$

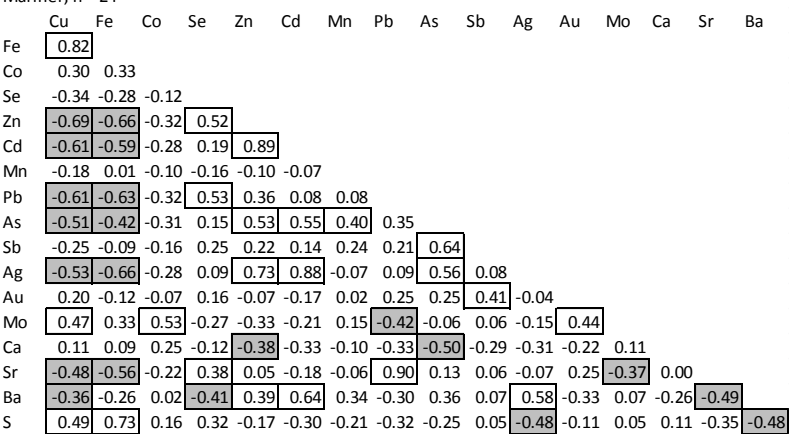




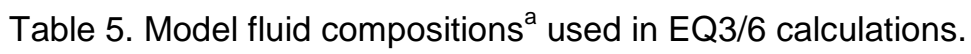

\begin{tabular}{llrrr} 
Property & Units & $\mathrm{KM} 5$ & $\mathrm{TM} 2$ & $\mathrm{MA} 3$ \\
\hline${ }^{\mathrm{D}} \mathrm{T}$ & ${ }^{\circ} \mathrm{C}$ & 329 & 312 & 363 \\
${ }^{\mathrm{c}} \mathrm{pH}$ & $\left(25^{\circ} \mathrm{C}\right)$ & 3.8 & 4.35 & 2.95 \\
$\mathrm{Cl}^{-}$ & $\mathrm{mmol} / \mathrm{kg}$ & 584 & 653 & 605 \\
${ }^{\mathrm{d}} \mathrm{Na}^{+}$ & $\mathrm{mmol} / \mathrm{kg}$ & 492 & 513 & 439 \\
$\mathrm{Ca}^{2+}$ & $\mathrm{mmol} / \mathrm{kg}$ & 34.0 & 47.5 & 43.8 \\
$\mathrm{~K}^{+}$ & $\mathrm{mmol} / \mathrm{kg}$ & 16.3 & 43.6 & 36.9 \\
$\mathrm{SiO}_{2}, \mathrm{aq}$ & $\mathrm{mmol} / \mathrm{L}$ & 21.7 & 14.6 & 15.1 \\
${ }^{\mathrm{e}} \mathrm{CO}_{2}, \mathrm{aq}$ & $\mathrm{mmol} / \mathrm{L}$ & 7.46 & 13.0 & 39.8 \\
$\mathrm{HS}^{-}$ & $\mathrm{mmol} / \mathrm{L}$ & 6.3 & 2.5 & 9.3 \\
$\mathrm{Mn}^{2+}$ & $\mu \mathrm{mol} / \mathrm{kg}$ & 718 & 406 & 5723 \\
$\mathrm{Fe}^{2+}$ & $\mu \mathrm{mol} / \mathrm{kg}$ & 2894 & 210 & 12991 \\
$\mathrm{Cu}^{+}$ & $\mu \mathrm{mol} / \mathrm{kg}$ & 10.9 & 7 & 156 \\
$\mathrm{Zn}^{2+}$ & $\mu \mathrm{mol} / \mathrm{kg}$ & 108 & 28 & 334 \\
${ }^{\mathrm{t}} \mathrm{Pb}^{2+}$ & $\mathrm{nmol} / \mathrm{kg}$ & 329 & 571 & 1135 \\
${ }^{ } \mathrm{Ba}^{2+}$ & $\mu \mathrm{mol} / \mathrm{kg}$ & 23 & 39 & 74.9 \\
$\mathrm{H}_{2}, \mathrm{aq}$ & $\mu \mathrm{mol} / \mathrm{kg}$ & 359 & 46.1 & 131 \\
$\mathrm{Mg}^{2+}$ & $\mathrm{mmol} / \mathrm{kg}$ & 0 & 0 & 0 \\
$\mathrm{HSO}_{4}^{-}$ & $\mathrm{mmol} / \mathrm{kg}$ & 0 & 0 & 0 \\
$\mathrm{O}_{2}, \mathrm{aq}$ & $\mathrm{mmol} / \mathrm{L}$ & 0 & 0 & 0
\end{tabular}

${ }^{\text {a }}$ Models represent zero-Mg endmember concentrations reported in Mottl et al. (2011) with the addition of new data for $\mathrm{Fe}, \mathrm{Cu}, \mathrm{Zn}, \mathrm{Pb}, \mathrm{Ba}$, and $\mathrm{H}_{2}$ (this paper).

${ }^{\mathrm{b}}$ Maximum measured temperature at the seafloor.

${ }^{\mathrm{C}} \mathrm{pH}$ at $25^{\circ} \mathrm{C}$. Differences in $\mathrm{pH}$ from measured values (Table 1a) reflect adjustment to what $\mathrm{pH}$ would be prior to precipitation of bottle solids. However, the $\mathrm{pH}$ of fluid KM5 was increased by 0.1 to achieve saturation with respect to chalcopyrite at $329^{\circ} \mathrm{C}$ (see text).

${ }^{d} \mathrm{Na}^{+}$has been modified to achieve charge balance.

${ }^{\mathrm{e}} \mathrm{CO}_{2}$, aq was not measured directly for fluid sample $\mathrm{KM} 5$. Model value is from fluid sample $\mathrm{KM} 3$, chosen on the basis of similar temperature, $\mathrm{Cl}^{-}$, and $\mathrm{Na}^{+}$.

${ }^{\mathrm{f}} \mathrm{Ba}^{2+}$ and $\mathrm{Pb}^{2+}$ were not measured directly for fluid sample $\mathrm{KM} 5([\mathrm{Cl}]=584 \mathrm{mM})$. Model values are the mean concentrations of fluid samples KM1, KM2, and KM6 (mean [Cl] $=583 \mathrm{mM})$. 
Table 6. Results of EQ3/6 fluid modelling for conductive cooling of model vent fluids showing saturation temperature of chalcopyrite (CP), pyrite (PY), sphalerite (SP), and galena (GA).

KM5, mineral precipitation suppressed $^{a}$

\begin{tabular}{rrrr}
\hline $\mathrm{T}\left({ }^{\circ} \mathrm{C}\right)$ & $\mathrm{pH}$ & $\left(\mathrm{fO}_{2}\right)$ & $\left(\mathrm{fS}_{2}\right)$ \\
\hline & & & \\
329 & 4.6 & -31.0 & -9.8 \\
329 & & $(\mathrm{CP})$ & \\
300 & 4.3 & -33.7 & -10.7 \\
268 & & $(\mathrm{PY})$ & \\
250 & 4.0 & -39.0 & -12.5 \\
246 & & $(\mathrm{SP})$ & \\
200 & 3.9 & -45.3 & -14.6 \\
189 & & $(\mathrm{GA})$ & \\
150 & 3.8 & -53.0 & -17.2 \\
100 & 3.8 & -62.6 & -20.5 \\
50 & 3.8 & -74.9 & -24.8 \\
25 & 3.8 & -82.6 & -27.4 \\
& & & \\
\hline
\end{tabular}

TM2, mineral precipitation suppressed $^{a}$

\begin{tabular}{rrrr}
\hline $\mathrm{T}\left({ }^{\circ} \mathrm{C}\right)$ & $\mathrm{pH}$ & $\left(\mathrm{fO}_{2}\right)$ & $\left(\mathrm{fS}_{2}\right)$ \\
\hline 312 & 5.6 & -30.7 & -9.4 \\
312 & & $(\mathrm{CP})$ & \\
312 & & $(\mathrm{PY})$ & \\
312 & & $(\mathrm{SP})$ & \\
300 & 5.5 & -31.5 & -10.0 \\
258 & & $(\mathrm{GA})$ & \\
250 & 5.0 & -36.7 & -11.6 \\
200 & 4.7 & -42.8 & -13.7 \\
150 & 4.5 & -50.4 & -16.3 \\
100 & 4.3 & -59.7 & -19.5 \\
50 & 4.3 & -71.8 & -23.8 \\
25 & 4.3 & -79.2 & -26.5
\end{tabular}

MA3, mineral precipitation

\begin{tabular}{rccc}
\multicolumn{4}{c}{ suppressed } \\
\hline $\mathrm{T}\left({ }^{\circ} \mathrm{C}\right)$ & $\mathrm{pH}$ & $\left(\mathrm{fO}_{2}\right)$ & $\left(\mathrm{fS}_{2}\right)$ \\
\hline 363 & 4.2 & -27.1 & -7.6 \\
$363^{\mathrm{c}}$ & & $(\mathrm{CP})$ & \\
350 & 4.0 & -28.2 & -8.0 \\
300 & 3.4 & -32.8 & -9.6 \\
250 & 3.1 & -38.1 & -11.3 \\
245 & & $(\mathrm{PY})$ & \\
200 & 3.0 & -44.4 & -13.4 \\
193 & & $(\mathrm{SP})$ & \\
151 & & $(\mathrm{GA})$ & \\
150 & 3.0 & -52.1 & -16.0 \\
100 & 3.0 & -61.7 & -19.3 \\
50 & 2.9 & -74.1 & -23.6 \\
25 & 3.0 & -81.8 & -26.2
\end{tabular}

TM2, mineral precipitation allowed $^{b}$

\begin{tabular}{rccc}
\hline $\mathrm{T}\left({ }^{\circ} \mathrm{C}\right)$ & $\mathrm{pH}$ & $\left(\mathrm{fO}_{2}\right)$ & $\left(\mathrm{fS}_{2}\right)$ \\
\hline 312 & 5.4 & -31.3 & -9.9 \\
312 & \multicolumn{3}{c}{$(\mathrm{CP})$} \\
312 & & $(\mathrm{PY})$ & \\
300 & 5.3 & -32.4 & -10.3 \\
288 & & $(\mathrm{SP})$ & \\
250 & 4.7 & -37.9 & -12.3 \\
208 & & $(\mathrm{GA})$ & \\
200 & 4.3 & -44.5 & -14.7 \\
150 & 4.0 & -52.3 & -17.4 \\
100 & 3.9 & -61.9 & -20.8 \\
50 & 3.8 & -74.4 & -25.2 \\
25 & 3.8 & -82.1 & -27.9
\end{tabular}

${ }^{a}$ Closed system equilibrium model in which sulfide mineral precipitation is suppressed.

${ }^{b}$ Closed system equilibrium model in which sulfide mineral precipitation is allowed.

${ }^{C}$ Chalcopyrite is slightly undersaturated in the range $355^{\circ} \mathrm{C}-294^{\circ} \mathrm{C}$ 
Figure 1. (A) Regional geology of the Eastern Lau Spreading Center (ELSC) (from Stoffer et al. (2006)). NLSC = Northern Lau Spreading Center; CLSC = Central Lau Spreading Center; ELSC = Eastern Lau Spreading Center; VFR = Valu Fa Ridge; TVZ = Taupo Volcanic Zone.) (B) Locations of confirmed and inferred active vent fields along the ELSC. Confirmed active vent fields are: (1) Kilo Moana (2003'09'S, 17608'02'W, 2620 meters below sea level (mbsl)), (2) TowCam (2019’00”S, 17608'12”W, 2700 mbsl)), (3) Tahi Moana-1 (2041'59”S, 176 $\left.10^{\prime} 58^{\prime \prime} \mathrm{W}, 2260 \mathrm{mbsl}\right)$, (4) ABE (2045'48”S, 176¹1'30”W, $\left.2220 \mathrm{mbsl}\right)$, (5) Tahi Moana-2 (1870 mbsl), (6) White Church (1960 mbsl), (7) Tu'i Malila (2159'21's, 176³4'04'W, 1870 mbsl), (8) TELVE (1760 mbsl), (9) Mariner (22 10'49’'S, 176³6’05'W, $1910 \mathrm{mbsl})$ ) and Vai Lili (1764 mbsl) vent fields, (10) Si'i Si'i (1950 mbsl), (11) Misiteli (2050 mbsl), (12) Hine Hina (1900 mbsl). Vent locations from Beaulieu et al., (2010) and references therein. Base map bathymetry from Smith and Sandwell (1997) and Martinez et al. (2006) accessed via GeoMapApp (Ryan et al., 2009).

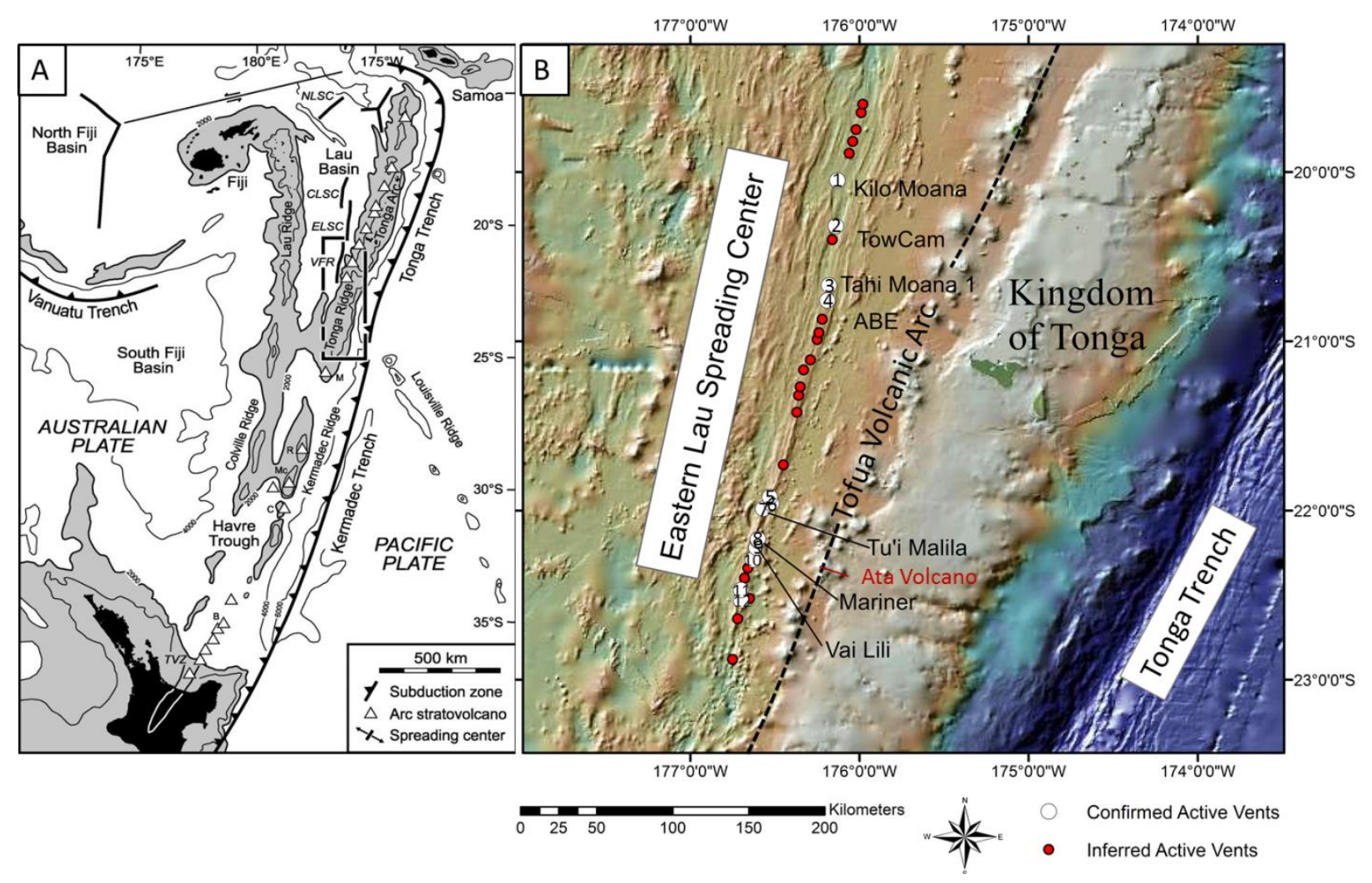


Figure 2. Temperature and endmember fluid chemistry of ELSC hydrothermal fluids.

Concentrations of $\mathrm{Fe}, \mathrm{Cu}, \mathrm{Zn}, \mathrm{Pb}$, and $\mathrm{Ba}$ include redigested bottle solids (see text). Maximum measured temperature, $\mathrm{pH}$ at $25^{\circ} \mathrm{C}$, zero- $\mathrm{Mg}$ chlorinity and $\mathrm{H}_{2} \mathrm{~S}$ (by gravimetric analysis, = grav) are from Mottl et al. (2011). $\log \left(\mathrm{fS}_{2}\right)$ at in situ temperatures and pressures was calculated using the SUPCRT92 database. $(\mathrm{mm}=\mathrm{mmol} / \mathrm{kg}$ fluid; $\mu \mathrm{m}=\mu \mathrm{mol} / \mathrm{L}$ fluid; $\mathrm{nm}=\mathrm{nmol} / \mathrm{kg}$ fluid $) . \mathrm{KM}=$ Kilo Moana, $\mathrm{TC}=$ TowCam, TMo = Tahi Moana-1, A = ABE, TM = Tu'i Malila, MA = Mariner
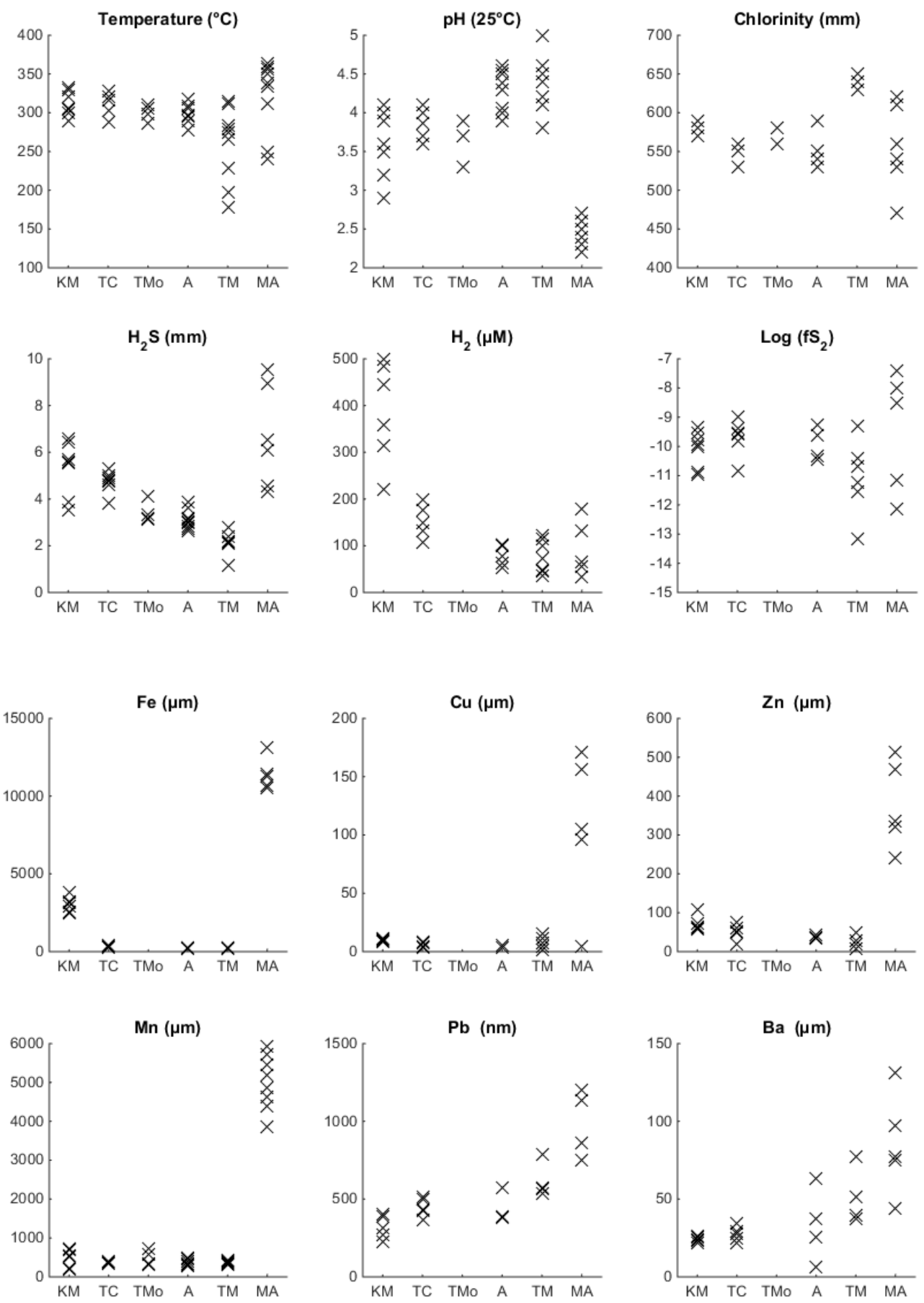
Figure 3. Photographs of ELSC SMS deposits taken by Jason II ROV. Morphologies include: (A) $>5 \mathrm{~m}$ edifice at Kilo Moana, (B) $<5 \mathrm{~m}$ edifice at TowCam with three open conduit chimneys, (C) $<5 \mathrm{~m}$ edifice and (D) close up of narrow sulfide-rich flange near base at Tahi Moana-1, (E) $\sim 5 \mathrm{~m}$ edifice and $(\mathrm{F})$ nearby barite-rich flange, $\mathrm{T}=141^{\circ} \mathrm{C}$, at $\mathrm{ABE}(\mathrm{G}) 5-10 \mathrm{~m}$ edifice at Tu'i Malila with spires offset by barite-rich flanges, $(\mathrm{H})$ low-lying barite-rich flanges at Tu'i Malila, $\mathrm{T}=178^{\circ} \mathrm{C},(\mathrm{I}) \sim 20 \mathrm{~m}$ copper-rich columns at Mariner and $(\mathrm{J})$ barite-rich squat terraces at Mariner.

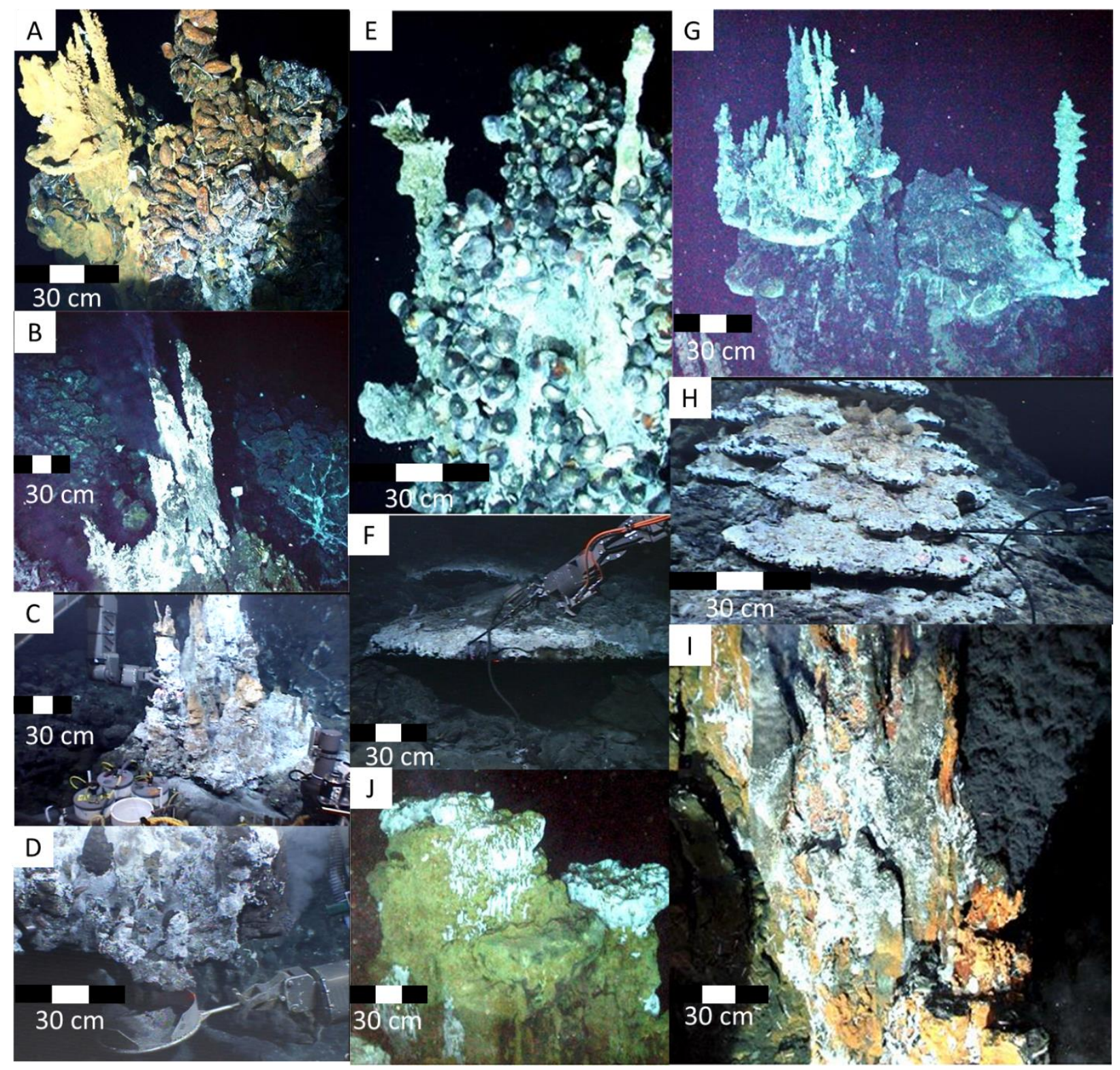


Figure 4. Images of polished sections. (A-D) Open conduit chimneys (VF = vent fluid; $\mathrm{SW}=$ seawater): (A) J2-137-1-R1; pair with Kilo Mana fluid KM5, T=329 ${ }^{\circ} \mathrm{C}$ (B) J2-449-6-R1; pair with ABE fluid A10, $\mathrm{T}=317^{\circ} \mathrm{C}$ (C) $\mathrm{J} 2-449-5-\mathrm{R} 1$; pair with $\mathrm{ABE}$ fluid A11, $\mathrm{T}=306^{\circ} \mathrm{C}$ (D) $\mathrm{J} 2-437-$ 3-R2; pair with Mariner fluid MA9, $\mathrm{T}=338^{\circ} \mathrm{C}$. (E-H) Close ups of open conduit chimney linings in (A-D). Labels indicate paired fluid samples. Lining mineralogy: (E) massive cubanite (cb) with minor pyrrhotite (po), (F) massive chalcopyrite (cp) with minor pyrite (py), $(\mathrm{G})$ intergrown $\mathrm{cp}$ and wurtzite (wz), (H) massive cp with minor bornite (bn) toward exterior. (I) J2-128-5-R1, exterior of active spire from ABE composed of marcasite dendrites, minor sphalerite (sp) toward interior and minor barite (ba) and amorphous silica (amsi) toward exterior. (J) J2-134-9-R1, interior of active spire from Tu'i Malila lined with euhedral wurtzite with cp inclusions (wz(cp)) and interstitial galena (ga) and cp. (K) J2-442-12-R2, active flange from Tu'i Malila composed of ba with interstitial wz(cp) and py, plus late-stage amorphous silica coating. (L) J2-135-5-R1, squat terrace from Mariner composed of dendrites of ba and interstitial sp. Light gray material in vent field area of images $\mathrm{E}, \mathrm{G}$, and $\mathrm{K}$ is residual carbon coat from electron microprobe analyses

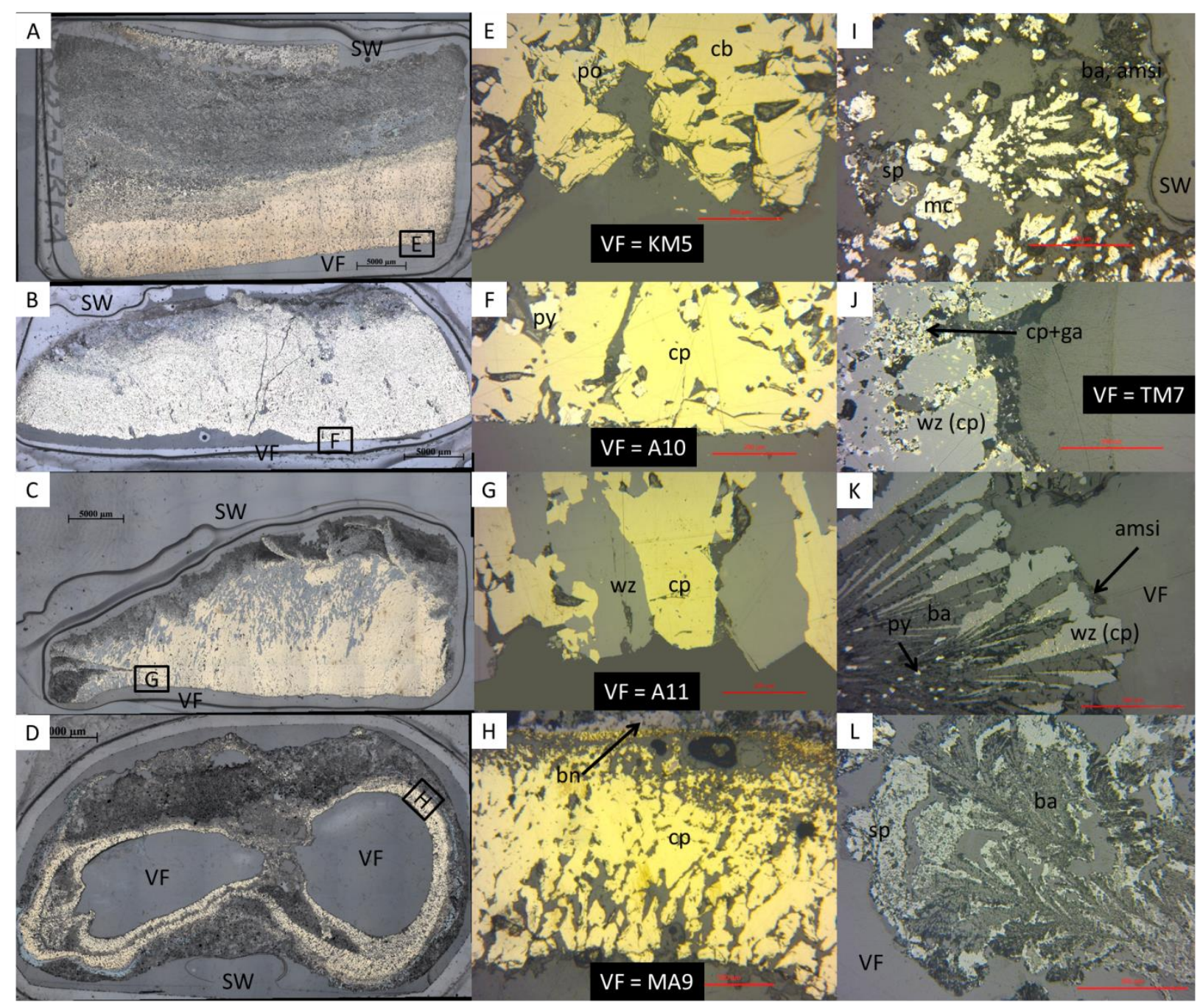


Figure 5. Elemental contents of bulk sample powders. $\mathrm{KM}=$ Kilo Moana, $\mathrm{TC}=$ TowCam, TMo $=$ Tahi Moana $-1, \mathrm{~A}=\mathrm{ABE}, \mathrm{TM}=\mathrm{Tu}$ 'i Malila, $\mathrm{MA}=$ Mariner.

Symbology and Number of Samples for Bulk Geochemical Analysis

\begin{tabular}{llcccccc} 
& KM & TC & TMo & A & TM & MA \\
\cline { 2 - 8 } & open conduit chimneys & 7 & 1 & 1 & 4 & 5 & 7 \\
$\Delta$ & active spires & 5 & 7 & 6 & 6 & 5 & 3 \\
$\nabla$ & relict spires & 4 & 2 & 2 & 4 & 11 & 8 \\
+ & 1 & 0 & 4 & 2 & 2 & 5 \\
$\times$ & active flange and squat terraces & 1 & 0 & 0 & 0 & 1 & 1 \\
$\diamond$ & relict flanges & 18 & 10 & 13 & 16 & 24 & 24
\end{tabular}
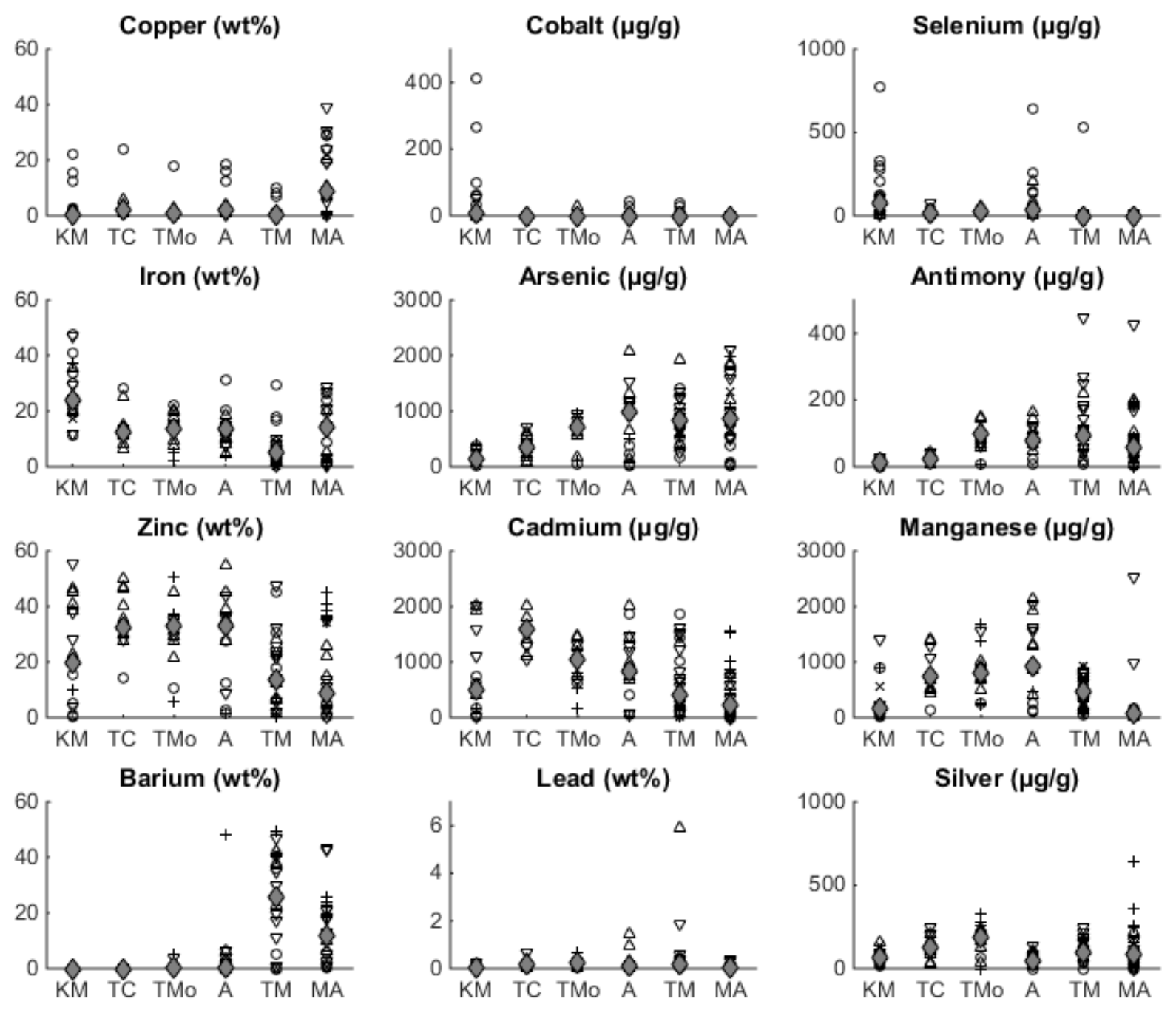
Figure 6. Trace element concentrations $(\mu \mathrm{g} / \mathrm{g})$ measured by electron microprobe: open conduit chimneys $(\circ)$, active spires $(\Delta)$, relict spires $(\nabla)$, active flanges and squat terraces $(+)$, and relict flanges $(\times)$. Values below detection limit not shown. $\mathrm{KM}=$ Kilo Moana, $\mathrm{TC}=\mathrm{TowCam}, \mathrm{TMo}=$ Tahi Moana-1, A = ABE, TM = Tu'i Malila, MA = Mariner

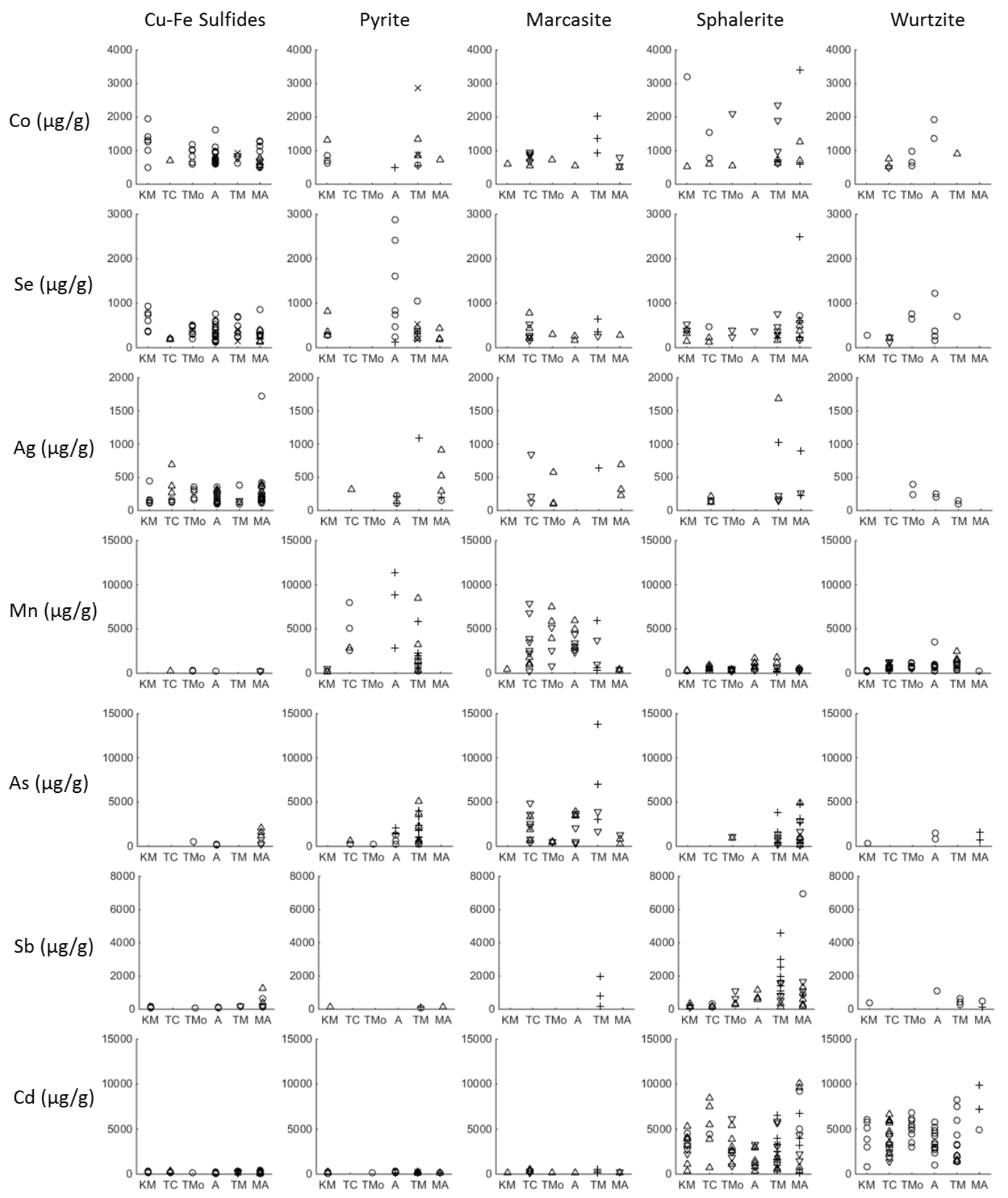


Figure 7. Bivariate plots of vent fluid temperature, $\mathrm{pH}\left(\right.$ at $\left.25^{\circ} \mathrm{C}\right)$, and metal contents. $\mathrm{KM}$ ' $05=$ Kilo Moana (collected in 2005), KM '09 = Kilo Moana (collected in 2009), TC = TowCam, TMo $=$ Tahi Moana $-1, \mathrm{~A}=\mathrm{ABE}, \mathrm{TM}=$ Tu'i Malila, $\mathrm{MA}=$ Mariner.
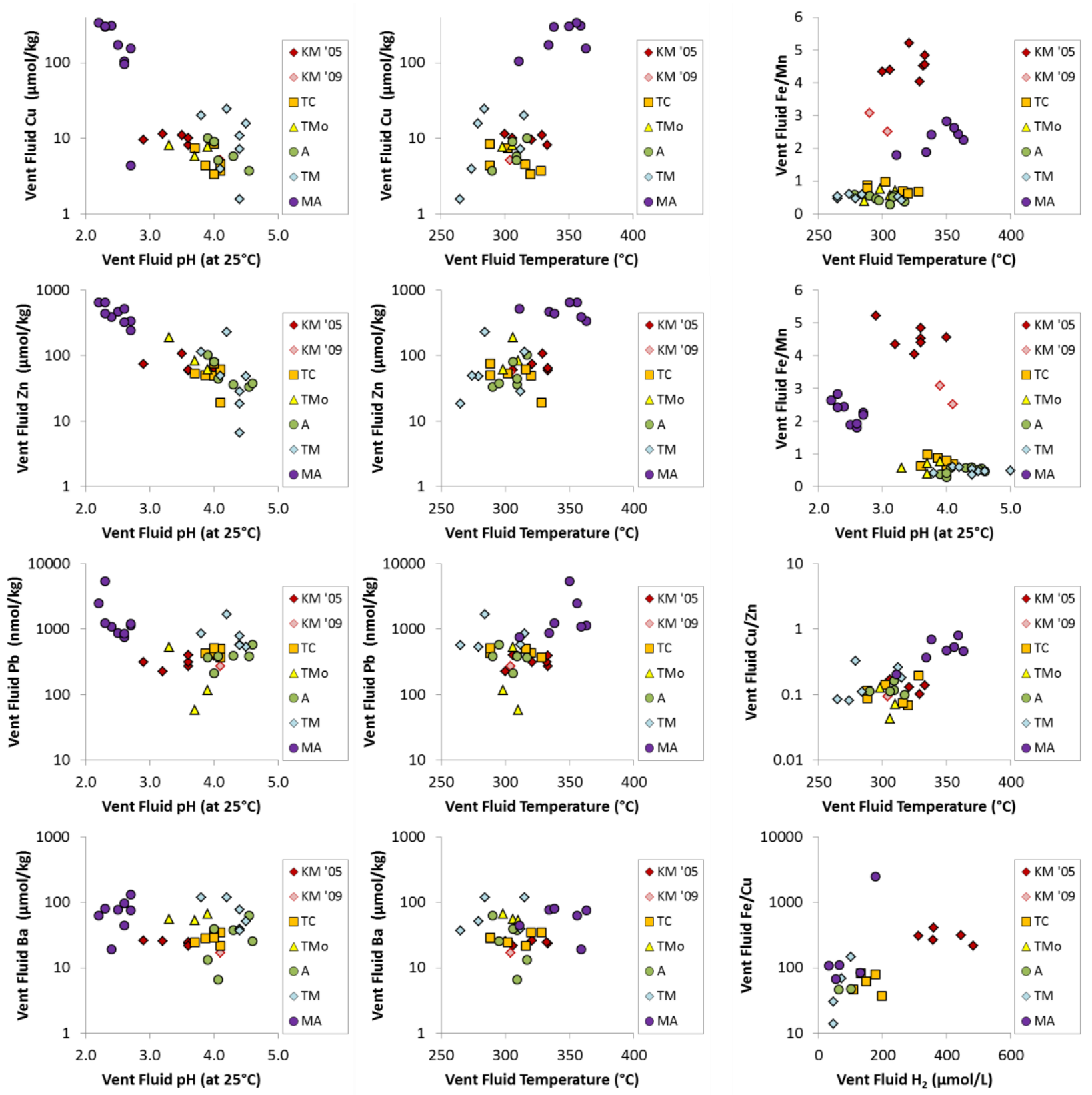
Figure 8. Correlation coefficients between concentrations of $\mathrm{Zn}$ and $\mathrm{Ag}, \mathrm{Cd}, \mathrm{Pb}, \mathrm{As}$, and $\mathrm{Sb}$ in bulk samples (bulk) and on a sulfide normalized basis (sulfide). Black bars are considered statistically significant $(\mathrm{p}<0.1)$. $\left(\mathrm{n}=\right.$ number of samples; $\mathrm{pH}\left(25^{\circ} \mathrm{C}\right)$ is the minimum $\mathrm{pH}$ of hightemperature fluids as measured at $25^{\circ} \mathrm{C}$.

Kilo Moana, Bulk

$\mathrm{Zn}: \mathrm{Ag}, \mathrm{Zn}: \mathrm{Cd}, \mathrm{Zn}: \mathrm{Pb}, \mathrm{Zn}: \mathrm{As}, \mathrm{Zn}: \mathrm{Sb}$, $n=18 \quad n=14 \quad n=18 \quad n=18 \quad n=13$

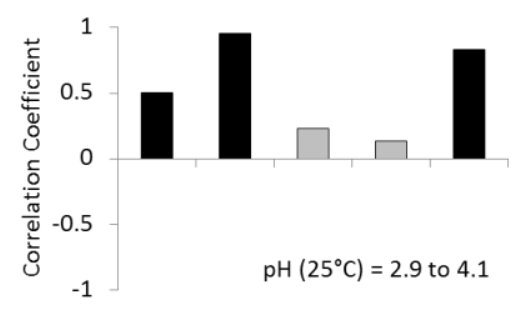

Kilo Moana, Sulfide

$\mathrm{Zn}: \mathrm{Ag}, \mathrm{Zn}: \mathrm{Cd}, \mathrm{Zn}: \mathrm{Pb}, \mathrm{Zn}: \mathrm{As}, \mathrm{Zn}: \mathrm{Sb}$, $n=18 \quad n=14 \quad n=18 \quad n=18 \quad n=13$

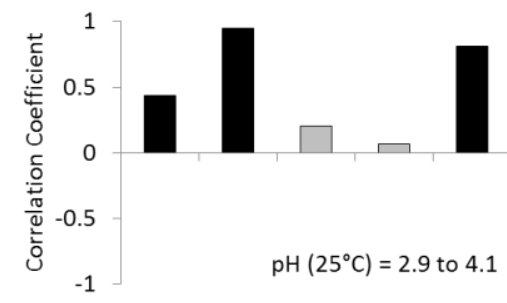

TowCam, Bulk

$\mathrm{Zn}: \mathrm{Ag}, \mathrm{Zn}: \mathrm{Cd}, \mathrm{Zn}: \mathrm{Pb}, \mathrm{Zn}: \mathrm{As}, \mathrm{Zn}: \mathrm{Sb}$, $n=10 \quad n=6 \quad n=10 \quad n=10 \quad n=10$

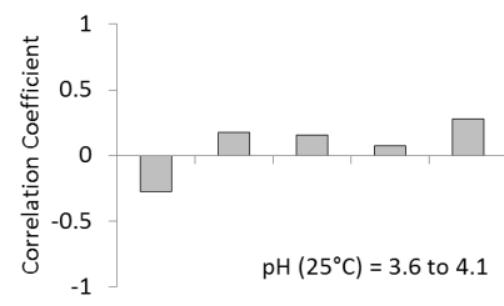

TowCam, Sulfide

$\mathrm{Zn}: \mathrm{Ag}, \mathrm{Zn}: \mathrm{Cd}, \mathrm{Zn}: \mathrm{Pb}, \mathrm{Zn}: \mathrm{As}, \mathrm{Zn}: \mathrm{Sb}$, $n=10 \quad n=6 \quad n=10 \quad n=10 \quad n=10$

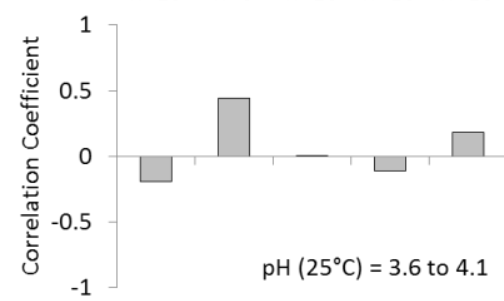

Tahi Moana-1, Bulk

$\mathrm{Zn}: \mathrm{Ag}, \mathrm{Zn}: \mathrm{Cd}, \mathrm{Zn}: \mathrm{Pb}, \mathrm{Zn}: \mathrm{As}, \mathrm{Zn}: \mathrm{Sb}$, $n=12 \quad n=13 \quad n=13 \quad n=13 \quad n=13$

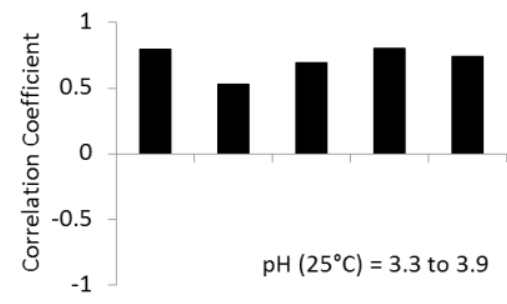

Tahi Moana-1, Sulfide

$\mathrm{Zn}: \mathrm{Ag}, \mathrm{Zn}: \mathrm{Cd}, \mathrm{Zn}: \mathrm{Pb}, \mathrm{Zn}: \mathrm{As}, \mathrm{Zn}: \mathrm{Sb}$, $n=12 \quad n=13 \quad n=13 \quad n=13 \quad n=13$

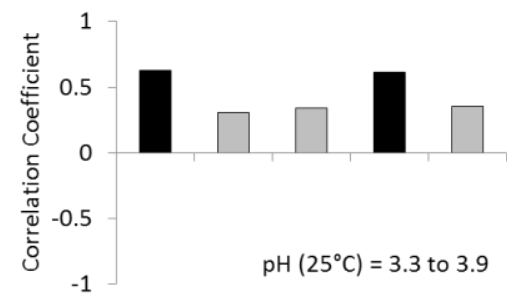

ABE, Bulk

$\mathrm{Zn}: \mathrm{Ag}, \mathrm{Zn}: \mathrm{Cd}, \mathrm{Zn}: \mathrm{Pb}, \mathrm{Zn}: \mathrm{As}, \mathrm{Zn}: \mathrm{Sb}$, $n=13 \quad n=14 \quad n=15 \quad n=15 \quad n=15$

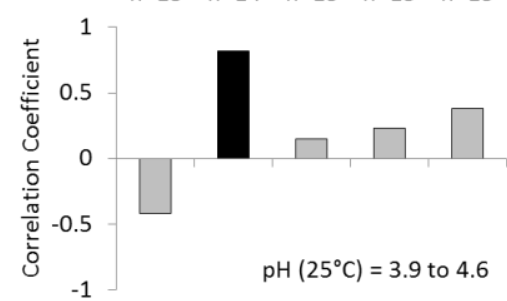

ABE, Sulfide

$\mathrm{Zn}: \mathrm{Ag}, \mathrm{Zn}: \mathrm{Cd}, \mathrm{Zn}: \mathrm{Pb}, \mathrm{Zn}: \mathrm{As}, \mathrm{Zn}: \mathrm{Sb}$, $n=13 \quad n=14 \quad n=15 \quad n=15 \quad n=15$

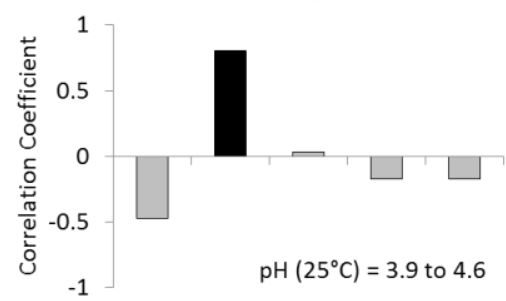

\section{Mariner, Bulk}

$\mathrm{Zn}: \mathrm{Ag}, \mathrm{Zn}: \mathrm{Cd}, \mathrm{Zn}: \mathrm{Pb}, \mathrm{Zn}: \mathrm{As}, \mathrm{Zn}: \mathrm{Sb}$, $n=20 \quad n=22 \quad n=24 \quad n=24 \quad n=22$

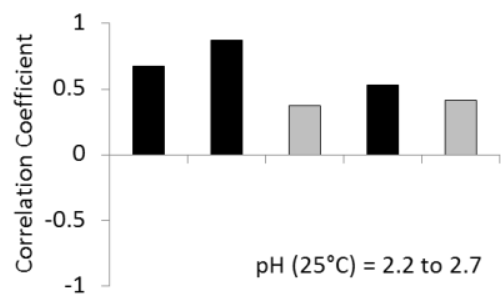

Mariner, Sulfide

$\mathrm{Zn}: \mathrm{Ag}, \mathrm{Zn}: \mathrm{Cd}, \mathrm{Zn}: \mathrm{Pb}, \mathrm{Zn}: \mathrm{As}, \mathrm{Zn}: \mathrm{Sb}$, $n=20 \quad n=22 \quad n=24 \quad n=24 \quad n=22$

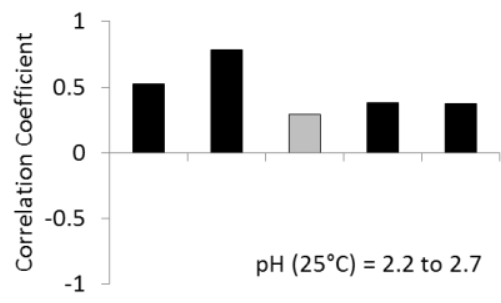

Tu'i Malila, Bulk

$\mathrm{Zn}: \mathrm{Ag}, \mathrm{Zn}: \mathrm{Cd}, \mathrm{Zn}: \mathrm{Pb}, \mathrm{Zn}: \mathrm{As}, \mathrm{Zn}: \mathrm{Sb}$, $n=23 \quad n=24 \quad n=24 \quad n=24 \quad n=24$

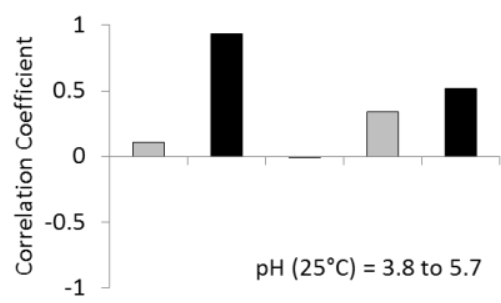

Tu'i Malila, Sulfide

$\mathrm{Zn}: \mathrm{Ag}, \mathrm{Zn}: \mathrm{Cd}, \mathrm{Zn}: \mathrm{Pb}, \mathrm{Zn}: \mathrm{As}, \mathrm{Zn}: \mathrm{Sb}$, $n=23 \quad n=24 \quad n=24 \quad n=24 \quad n=24$

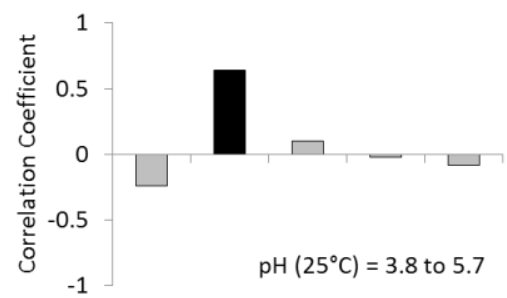


Figure 9. High-temperature ELSC hydrothermal fluids on $\log \left(\mathrm{fS}_{2}\right)$ vs. $1000 / \mathrm{T}(\mathrm{K})$ diagram: KM $=$ Kilo Moana, $\mathrm{TC}=$ TowCam $, \mathrm{A}=\mathrm{ABE}, \mathrm{TM}=\mathrm{Tu}$ 'i Malila, $\mathrm{MA}=$ Mariner. Positions of Kilo Moana fluids collected in 2009 ( $\mathrm{KM}$ '09) is estimated based on the $\mathrm{H}_{2, \text { aq }}$ concentrations of similar-temperature fluids collected in 2005. Sulfidation states as defined in Sillitoe and Hedenquist (2003) are delineated by equilibrium sulfidation reactions between minerals. Background mineral phase diagram (solid lines; pressure $=1$ bar) and isochores of mole $\% \mathrm{FeS}$ of sphalerite in equilibrium with pyrite and/or pyrrhotite (stippled lines) are reproduced from figures in Sack and Ebel (2006).

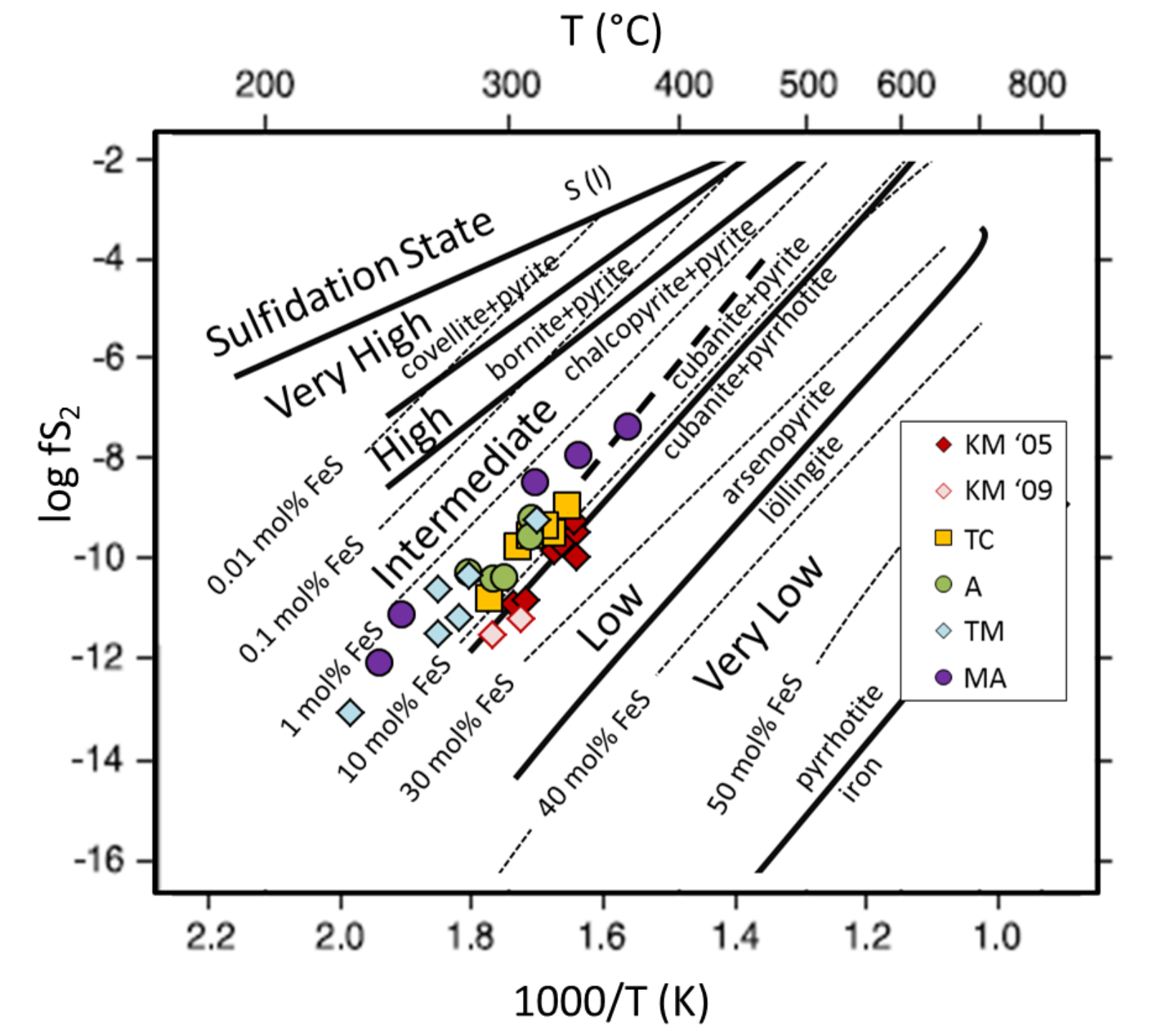


SUPPLEMENTARY MATERIAL

Table S1a. Trace metal and hydrogen concentrations of Kilo Moana hydrothermal fluids ICPAES

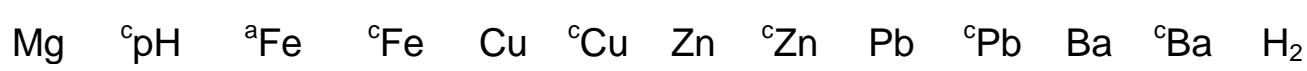
$\mathrm{mm} \quad 25^{\circ} \mathrm{C} \quad \mu \mathrm{m} \quad \mu \mathrm{m} \quad \mu \mathrm{m} \quad \mu \mathrm{m} \quad \mu \mathrm{m} \quad \mu \mathrm{m} \quad \mathrm{nm} \quad \mathrm{nm} \quad \mu \mathrm{m} \quad \mu \mathrm{m} \quad \mu \mathrm{M}$

KM1

J2-124-MR

$3.8 \quad 3.6 \quad 2200$

9

$\begin{array}{cccccccc} & 66 & & 270 & & 24 & & \\ 9 & 66 & 68 & 260 & 270 & 19 & 19 & \\ 7 & 14 & 51 & 60 & 270 & 25 & 25 & 320 \\ 7 & 11 & 51 & 50 & 240 & 25 & 25 & 280 \\ 8 & & 58 & & 270 & & 24 & 310 \\ 1 & & 4 & & 10 & & 2 & \end{array}$

J2-124-MG

2.13 .5

J2-124-IGT3

$1.7 \quad 3$

J2-124-IGT4

$1.6 \quad 3.6$

25002500

9

23002300

Endmember

25002500

25002500

$100 \quad 100$

KM4

J2-125-IGT2

J2-125-IGT5

2.23

3.1
3.2

2200

2400

$\begin{array}{lll}0.4 & 11 & 21\end{array}$

$10 \quad 220 \quad 24$

130

23002500

11

73

Endmember

$\begin{array}{lll}3.7 & 3.2 & 2100\end{array}$

1

230

\section{KM6}

J2-137-IGT3

J2-137-IGT5

$\begin{array}{lll}3.0 & 3.7 & 2800\end{array}$

0.1

1

$2.9 \quad 3.6 \quad 2800 \quad 3000$

30003100

9
10

49

56

$\begin{array}{lllll} & & 11 & & 420 \\ 230 & 380 & 18 & 20 & 430 \\ 400 & & 22 & 450\end{array}$

$\mathrm{KM} 2$

J2-125-IGT7

Endmember

$\begin{array}{lllll}2.8 & 3.6 & 3000 & 3000 & 5\end{array}$

20
$\begin{array}{lllll}90 & 300 & 23 & 23 & 210\end{array}$
$310 \quad 24 \quad 220$

$\mathrm{KM} 3$

J2-125-IGT1

Endmember

2.42

31003200

520

-

KM5

J2-137-IGT

J2-137-IGT2

$\begin{array}{lll}1.5 & 3.5 & 2800\end{array}$

3600370

38003800

3

9
9

73
74

$100 \quad 300$
310

$\begin{array}{lll}25 & 25 & 340\end{array}$

26360

Endmember

$\begin{array}{lllll}2.0 & 3.5 & 2700 & 2800 & 5\end{array}$

29002900

$\begin{array}{ccccc}2 & & 12 & & 60 \\ 5 & 11 & 73 & 104 & 710 \\ & 11 & & 108 & \end{array}$

23

350

13

350

360

KM8

J2-137-IGT8

1.8

$\begin{array}{llll}4.0 & 2400 & 2500 & 9 \\ & 2500 & 2600\end{array}$

$\begin{array}{rrrr}59 & 62 & 310 & 380 \\ & 64 & & 390\end{array}$

480

500 
Table S1b. Trace metal and hydrogen concentrations of TowCam hydrothermal fluids ICPAES GC

$\begin{array}{ccccccccccccc}\mathrm{Mg} & { }^{\mathrm{c}} \mathrm{pH} & { }^{\mathrm{a}} \mathrm{Fe} & { }^{\mathrm{c}} \mathrm{Fe} & \mathrm{Cu} & { }^{\mathrm{C}} \mathrm{Cu} & \mathrm{Zn} & { }^{\mathrm{C}} \mathrm{Zn} & \mathrm{Pb} & { }^{\mathrm{c}} \mathrm{Pb} & \mathrm{Ba} & { }^{\mathrm{c} B a} & \mathrm{H}_{2} \\ \mathrm{~mm} & 25^{\circ} \mathrm{C} & \mu \mathrm{m} & \mu \mathrm{m} & \mu \mathrm{m} & \mu \mathrm{m} & \mu \mathrm{m} & \mu \mathrm{m} & \mathrm{nm} & \mathrm{nm} & \mu \mathrm{m} & \mu \mathrm{m} & \mu \mathrm{M}\end{array}$

TC1

J2-126-IGT2

$\begin{array}{lllll}2.0 & 4.1 & 260 & 330 & 5\end{array}$

J2-126-IGT3

1.5

$4.1 \quad 250 \quad 260 \quad 1$

$\begin{array}{cccccccc} & 40 & & 290 & 430 & 28 & 28 & 130 \\ 4 & 8 & 18 & 60 & 290 & 38 & 38 & 130 \\ 4 & & 19 & & 370 & & 34 & 130\end{array}$

Endmember

260310

TC3

J2-126-IGT7

$\begin{array}{lllll}5.2 & 4.5 & 230 & 260 & 1\end{array}$

$\begin{array}{cccccccc} & 9 & & 80 & 320 & 21 & & 160 \\ 3 & 49 & 49 & 480 & 480 & 30 & 30 & \\ 3 & 46 & 46 & 410 & 420 & 37 & 37 & \\ 3 & & 49 & & 430 & & 34 & 180\end{array}$

J2-127MR

$\begin{array}{lllll}1.5 & 4.1 & 230 & 230 & 3\end{array}$

J2-127MG

0.7

$\begin{array}{llll}4.0 & 270 & 270 & 3\end{array}$

$260 \quad 270$

$10 \quad 10$

standard error

TC4

J2-126-IGT6

$\begin{array}{lllll}2.3 & 4.1 & 270 & 270 & 4\end{array}$

$280 \quad 280$

$4 \quad 58$

$58 \quad 59$

59

460

$\begin{array}{llll}480 & 21 & 21 & 140\end{array}$

Endmember

TC5

J2-127-IGT1

$\begin{array}{lllll}3.3 & 3.6 & 310 & 330 & 1\end{array}$

$\begin{array}{llll}7 & 74 & & 140 \\ 7 & 19 & 50 & 100\end{array}$

$\begin{array}{lll}18 & 20 & 110\end{array}$

J2-127-IGT2

$\begin{array}{lllll}3.5 & 3.7 & 300 & 320 & 1\end{array}$

7

53

$\begin{array}{lll}26 & 26 & 100\end{array}$

Endmember

$320 \quad 340$

$\begin{array}{llllll}2.2 & 4.0 & 330 & 380 & 1 & 4\end{array}$

$\begin{array}{lllllll}4 & 22 & 59 & 240 & 380 & 31 & 31 \\ 4 & 31 & 36 & 330 & 440 & 22 & 22 \\ 4 & & 50 & & 430 & & 28\end{array}$

TC6

J2-127-IGT5

J2-127-IGT6

2.6

4.0

$340 \quad 370$

4

$25 \quad 110$

TC7

J2-139-IGT5

1.5

$\begin{array}{llll}4.1 & 290 & 310 & 5\end{array}$

$\begin{array}{lllll}2.2 & 4.2 & 270 & 290 & 6\end{array}$

J2-139-IGT6

$290 \quad 310$

$\begin{array}{llll}9 & 71 & 75 & 520\end{array}$

$\begin{array}{llll}8 & 65 & 69 & 440\end{array}$

8 $\begin{array}{lll}28 & 31 & 190\end{array}$

$\begin{array}{lll}22 & 24 & 190\end{array}$

29200 
Table S1c. Trace metal and hydrogen concentrations of $A B E$ hydrothermal fluids

ICPAES

GC

$\begin{array}{ccccccccccccc}\mathrm{Mg} & { }^{\mathrm{c}} \mathrm{pH} & { }^{\mathrm{a}} \mathrm{Fe} & { }^{\mathrm{c}} \mathrm{Fe} & \mathrm{Cu} & { }^{\mathrm{c}} \mathrm{Cu} & \mathrm{Zn} & { }^{\mathrm{c}} \mathrm{Zn} & \mathrm{Pb} & { }^{\mathrm{c}} \mathrm{Pb} & \mathrm{Ba} & { }^{\mathrm{c}} \mathrm{Ba} & \mathrm{H}_{2} \\ \mathrm{~mm} & 25^{\circ} \mathrm{C} & \mu \mathrm{m} & \mu \mathrm{m} & \mu \mathrm{m} & \mu \mathrm{m} & \mu \mathrm{m} & \mu \mathrm{m} & \mathrm{nm} & \mathrm{nm} & \mu \mathrm{m} & \mu \mathrm{m} & \mu \mathrm{M}\end{array}$

A1

J2-128-IGT7

$\begin{array}{llll}4.0 & 4.5 & 240 & 250\end{array}$

3

$\begin{array}{llllllll}6 & 26 & 34 & 240 & 370 & 35 & 36 & 65 \\ 6 & & 36 & & 390 & & 37 & 63\end{array}$

Endmember

$\begin{array}{llll}2.3 & 4.4 & 250 & 260\end{array}$

260270

$\begin{array}{lll}44.6 & 6.4 & 40\end{array}$

$2.9 \quad 4.3 \quad 250$

$2.4 \quad 4.3 \quad 260$

$270 \quad 260$

$\begin{array}{lll}2 & & 11 \\ 5 & 5 & 41 \\ 5 & & 37\end{array}$

$\begin{array}{cccccc}1 & & 80 & & 1 & \\ 1 & 42 & 360 & 360 & 6 & 6 \\ 7 & & 340 & & 7 & \\ & 44 & & 380 & & 7\end{array}$

A4

J2-129-IGT3

$2.5 \quad 4.4$

52

J2-129-IGT4

$9.7 \quad 5.1$

43

Endmember

54

A5

J2-129-IGT5

J2-129-IGT6

Endmember

$1.7 \quad 4.5$

$\begin{array}{lll}4.5 & 160 & 190\end{array}$

$\begin{array}{lll}4 & 10 & 32\end{array}$

190

$\begin{array}{llll}370 & 55 & 61 & 94\end{array}$

$\begin{array}{lllllll}4.1 & 4.9 & 130 & 140 & 1 & 3 & 6\end{array}$

33

120

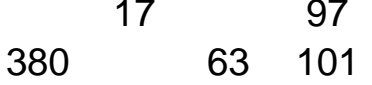

A8

J2-136-IGT5

$1.9 \quad 4.5$

76

Endmember

78

A9

J2-136-IGT6

$\begin{array}{lllll}2.8 & 4.6 & 130 & 170 & 3\end{array}$

30

$\begin{array}{cccccc}35 & 390 & 540 & 6 & 24 & 89 \\ & & & & & 95 \\ 37 & & 570 & & 26 & 101\end{array}$


Table S1d. Trace metal and hydrogen concentrations of Tu'i Malila hydrothermal fluids ICPAES GC

TM1

$\begin{array}{lcccccccccccc}\mathrm{Mg} & { }^{\mathrm{c}} \mathrm{pH} & { }^{\mathrm{a}} \mathrm{Fe} & { }^{\mathrm{c}} \mathrm{Fe} & \mathrm{Cu} & { }^{\mathrm{c}} \mathrm{Cu} & \mathrm{Zn} & { }^{\mathrm{c}} \mathrm{Zn} & \mathrm{Pb} & { }^{\mathrm{c}} \mathrm{Pb} & \mathrm{Ba} & { }^{\mathrm{C} B a} & \mathrm{H}_{2} \\ \mathrm{~mm} & 25^{\circ} \mathrm{C} & \mu \mathrm{m} & \mu \mathrm{m} & \mu \mathrm{m} & \mu \mathrm{m} & \mu \mathrm{m} & \mu \mathrm{m} & \mathrm{nm} & \mathrm{nm} & \mu \mathrm{m} & \mu \mathrm{m} & \mu \mathrm{M}\end{array}$

J2-132-IGT1

$5.5 \quad 4.5$

Endmember

$\begin{array}{llllll}4.5 & 180 & 200 & 1 & 14 & 7\end{array}$

200220

16

$\begin{array}{llll}43 & 110 & 480 & 7 \\ 48 & & 530\end{array}$

$\begin{array}{ll}46 & 43\end{array}$

TM2

J2-132-IGT3

$\begin{array}{llll}2.2 & 4.4 & 220 & 220\end{array}$

3

J2-134-MR

$1.9 \quad 4.3$

J2-134-MG

2.5

$\begin{array}{lll}4.3 & 190 & 200\end{array}$

4

4

Endmember

$210 \quad 220$

$\begin{array}{cccccccc}10 & 19 & 30 & 360 & 660 & 19 & 38 & 44 \\ 4 & 24 & 24 & 430 & 440 & 16 & & \\ & 22 & & 440 & & 13 & & \\ 7 & & 28 & & 570 & & 39 & 46\end{array}$

TM4

J2-132-IGT5 $\quad 26.0 \quad 5.7$

62

Endmember

122

TM5

J2-132-IGT6

$11.7 \quad 4.6$

27

Endmember

35

TM6

$\begin{array}{llllllllllllll}\text { J2-134-IGT3 } & 2.5 & 4.4 & 210 & 220 & 0.3 & 1 & 14 & 18 & 440 & 540 & 17 & 35 & 94 \\ \text { J2-134-IGT6 } & 2.6 & 4.4 & 200 & & 3 & & 3 & & 110 & & 14 & & 98 \\ \text { Endmember } & & & 220 & 230 & & 2 & & 18 & & 560 & & 37 & 101\end{array}$

TM8

J2-138-IGT2

J2-138-IGT4

$\begin{array}{lllll}3.3 & 4.5 & 130 & 160\end{array}$

$2.6 \quad 4.4 \quad 130$

bdl 10

140170

0.1

Endmember

11

$\begin{array}{lllllll}3 & 6 & 420 & 740 & 57 & 73 & 109 \\ 3 & & 160 & & 35 & & 108 \\ & 7 & & 790 & & 77 & 115\end{array}$

TM10

J2-138-IGT7

3.

$\begin{array}{llll}4.4 & 210 & 250 & 1\end{array}$

J2-138-IGT8

2.24.

4.2

$230 \quad 270$

1

$\begin{array}{llll}4 & 32 & 46 & 800 \\ & 11 & & 290 \\ 4 & & 49 & \end{array}$

85

68

Endmember

4

49

65

70

73 
Table S1e. Trace metal and hydrogen concentrations of Mariner hydrothermal fluids

ICPAES GC

$\begin{array}{lllllllllllll}\mathrm{Mg} & { }^{\mathrm{c}} \mathrm{pH} & { }^{\mathrm{a}} \mathrm{Fe} & { }^{\mathrm{c}} \mathrm{Fe} & \mathrm{Cu} & { }^{\mathrm{c}} \mathrm{Cu} & \mathrm{Zn} & { }^{\mathrm{C}} \mathrm{Zn} & \mathrm{Pb} & { }^{\mathrm{C}} \mathrm{Pb} & \mathrm{Ba} & { }^{\mathrm{B} B a} & \mathrm{H}_{2} \\ \mathrm{~mm} & 25^{\circ} \mathrm{C} & \mu \mathrm{m} & \mu \mathrm{m} & \mu \mathrm{m} & \mu \mathrm{m} & \mu \mathrm{m} & \mu \mathrm{m} & \mathrm{nm} & \mathrm{nm} & \mu \mathrm{m} & \mu \mathrm{m} & \mu \mathrm{M}\end{array}$

MA1

J2-130-
J2-13
J2-130-
J2-130-
Endm
MA2

J2-131-IGT7

$13.3 \quad 2.6$

$\begin{array}{lll}4.2 & 2.8 & 10400\end{array}$

145

418

1370

128

$\begin{array}{lll}18.3 & 2.5 & 6900\end{array}$

69

167

690

70

$\begin{array}{llll}2.7 & 2.5 & 10800 & 10900\end{array}$

10209

$\begin{array}{lll}27 & 475 & 100\end{array}$

$\begin{array}{llll}640 & 22 & 67 & 48\end{array}$

$3.5 \quad 2.5$

$10600 \quad 10600$

2

$\begin{array}{llll}113 & 10 & 404 & 30\end{array}$

$\begin{array}{llll}990 & 37 & 79 & 55\end{array}$

1120011400

467

860

$77 \quad 55$

J2-131-IGT8

$8.9 \quad 2.7$

7900

$7900 \quad 6$

$\begin{array}{ll}6 & 33\end{array}$

$33 \quad 130$

$\begin{array}{llll}680 & 9 & 38 & 24\end{array}$

1120011300

bdl

88

$428 \quad 20$

$\begin{array}{llll}520 & 7 & 32 & 29\end{array}$

Endmember

1120011300

515

750 bdl $44 \quad 33$

MA3

J2-131-IGT3

$\begin{array}{lll}2.5 & 2.7 & 12200\end{array}$

$\begin{array}{llll}1.9 & 2.7 & 12600 & 12700\end{array}$

1300013100

$\begin{array}{lllll}24 & 154 & 36 & 245 & 180\end{array}$

$870 \quad 18$

$\begin{array}{ll}58 & 130\end{array}$

J2-131-IGT4

0.1146

2399

10

$1300 \quad 37$

$\begin{array}{ll}85 & 130\end{array}$

Endmember

156

336

1130

$\begin{array}{ll}75 & 130\end{array}$

MA5

J2-135-IGT7

$\begin{array}{lllll}5.9 & 2.6 & 8800 & 8800 & 0.4\end{array}$

$\begin{array}{lll}89 & 68 & \\ 97 & 11 & 296 \\ & & 322\end{array}$

300

$\begin{array}{llll}690 & 18 & 68 & 60\end{array}$

$\begin{array}{llll}4.2 & 2.6 & 10100 & 10200\end{array}$

1040010500

50

860

22

$107 \quad 60$

Endmember

MA6

J2-135-IGT1

$\begin{array}{cccc}3.7 & 2.7 & 9900 & 9900 \\ & 10700 & 10700\end{array}$

$\begin{array}{lll}4 & 16 & 225 \\ 4 & & 242\end{array}$

$80 \quad 1120$
1200

22

122170

131180

for Supplementary Table S1:

Analytical errors for metal analyses of individual fluid samples are estimated at $\pm 10 \%$ and $\pm 10 \mu \mathrm{mol} / \mathrm{kg}$ for measurements of $\mathrm{Mn}$ and Fe.

${ }^{a}$ from Mottl et al. (2011)

${ }^{b} \mathrm{pH}$ is reported as measured at $25^{\circ} \mathrm{C}$

${ }^{c}$ includes redigested bottle solids

$\mathrm{mm}=\mathrm{mmol} / \mathrm{kg}$ fluid, $\mu \mathrm{m}=\mu \mathrm{mol} / \mathrm{kg}$ fluid, $\mu \mathrm{M}=\mu \mathrm{mol} / \mathrm{L}$ fluid, $\mathrm{bdl}=$ below detection limit

$\mathrm{KM}=$ Kilo Moana, TC = TowCam, TMo = Tahi Moana-1, A = ABE, TM = Tu'i Malila, MA = Mariner

ICPAES = inductively coupled plasma atomic emission spectroscopy, $\mathrm{GC}=$ gas chromatography 

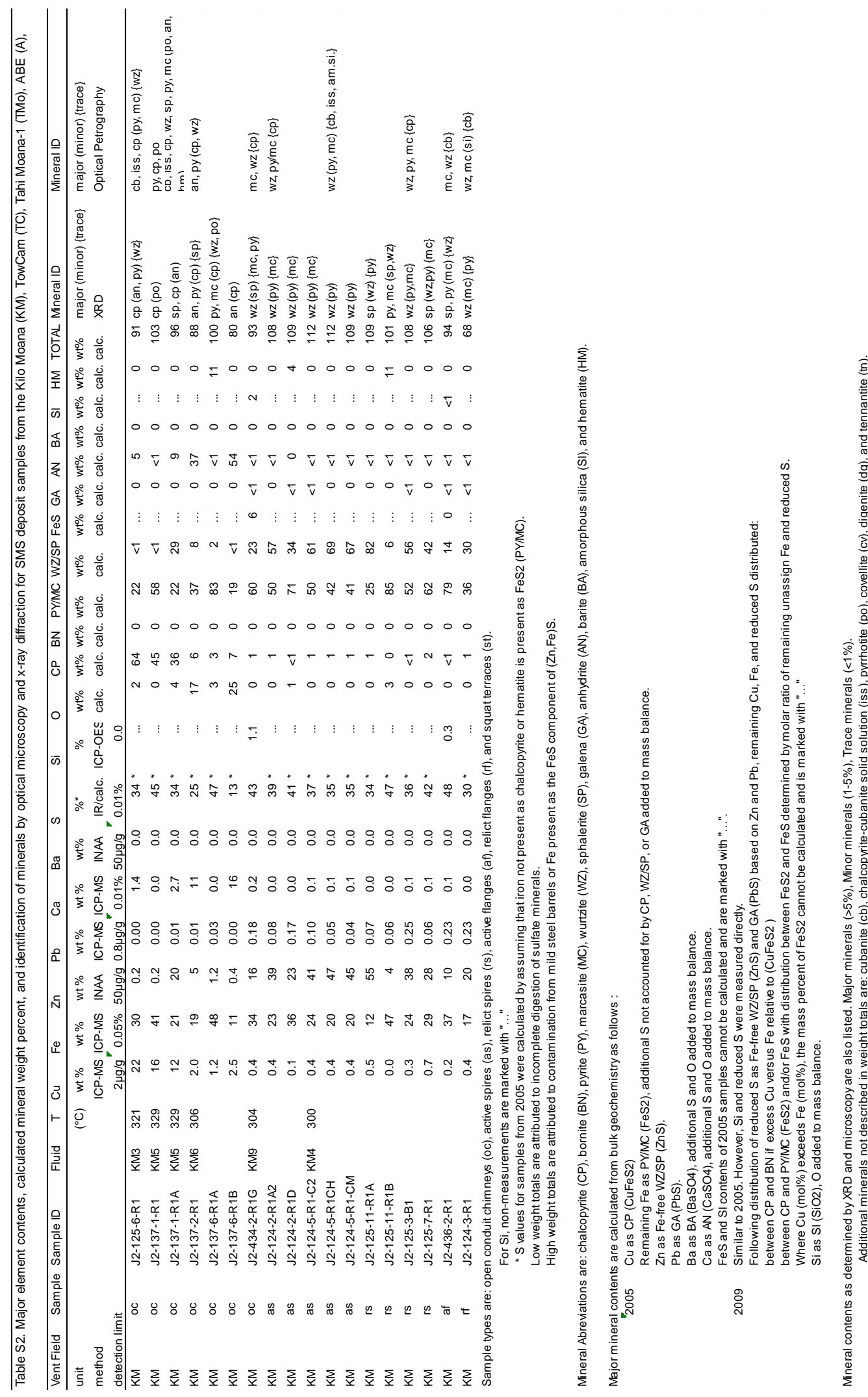


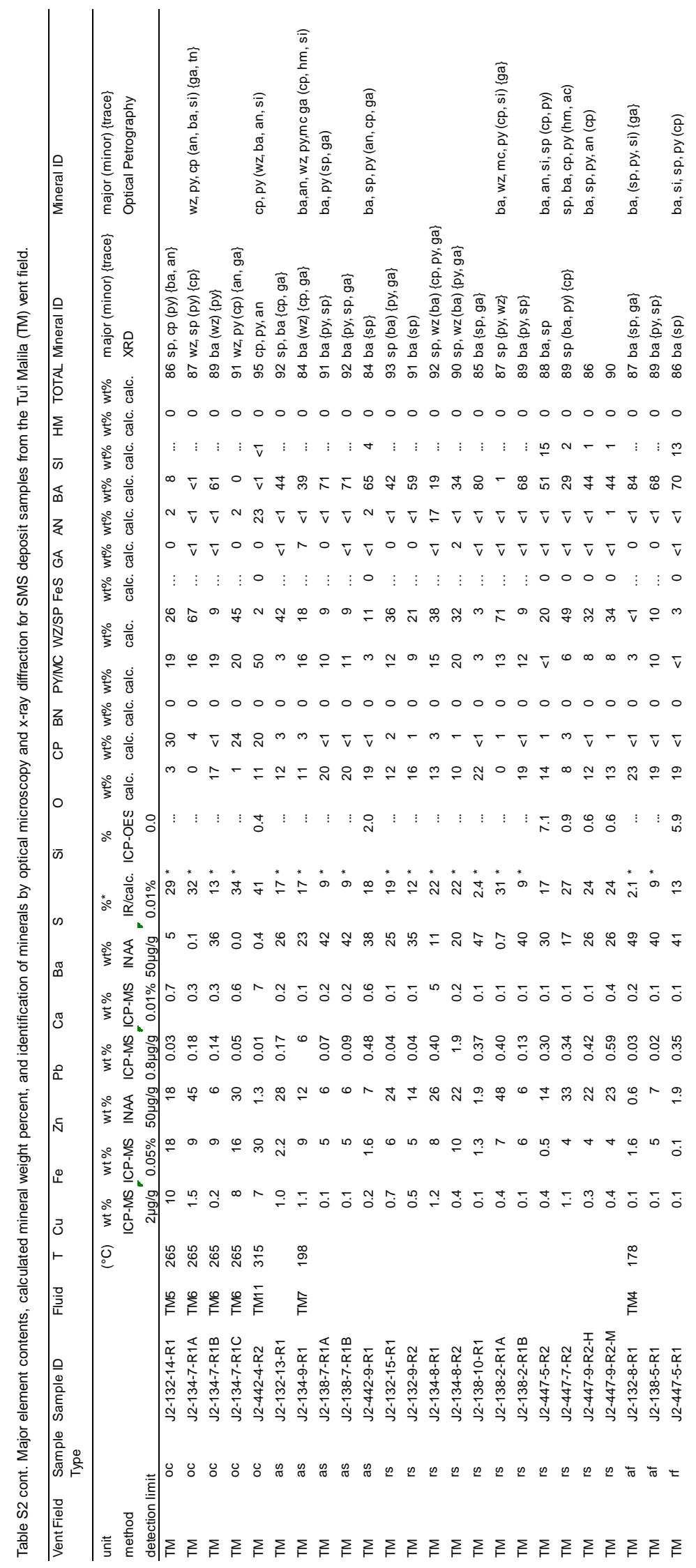




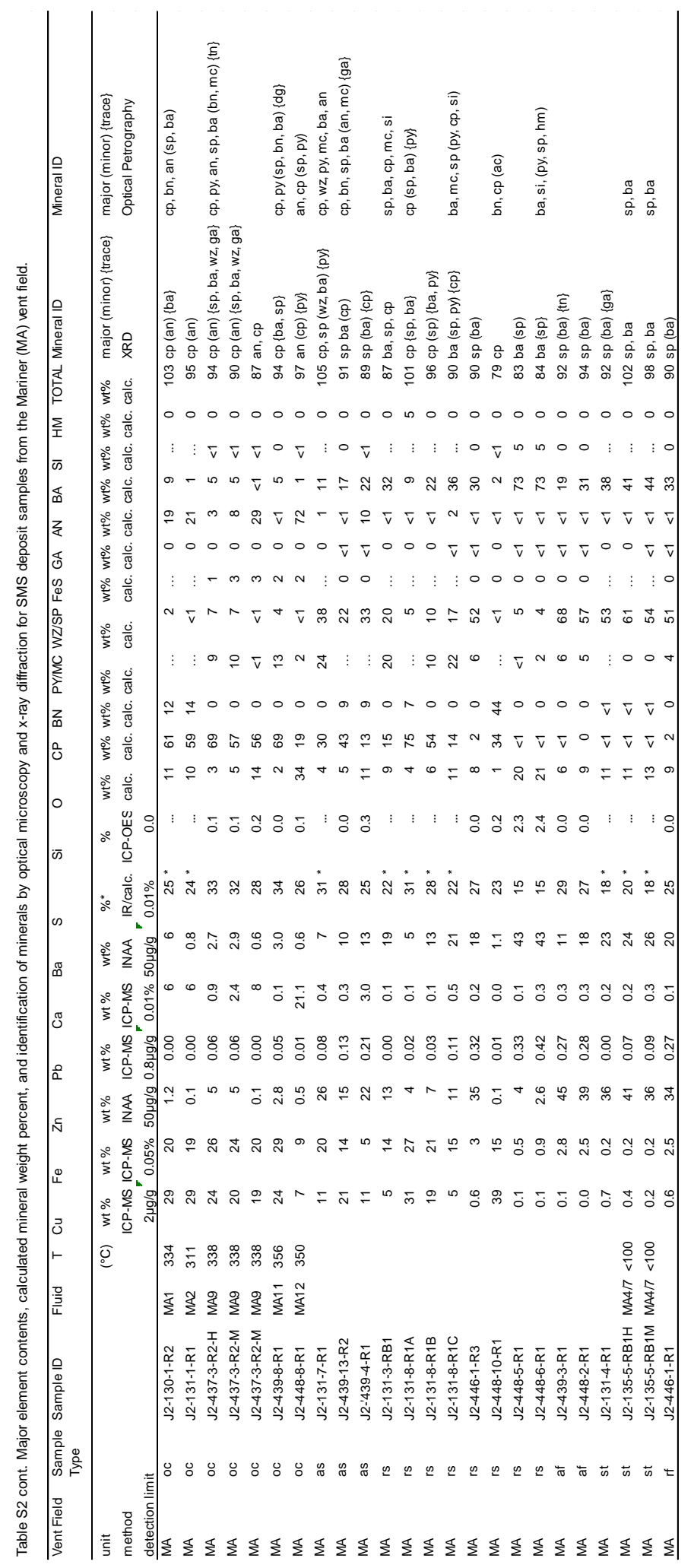


Table S3. Minor and trace element contents of SMS deposit samples from the Kilo Moana (KM), TowCam (TC), Tahi Moana-1 (TMo), ABE (A), Tu'i Malila (TM), and Mariner (MA) vent fields. Sample types are: open conduit chimneys (oc), active spires (as), relict spires (rs), active flanges (af), relict flanges (rf), and squat terraces (st). bdl $=$ below detection limits.

\begin{tabular}{|c|c|c|c|c|c|c|c|c|c|c|c|c|c|}
\hline $\begin{array}{l}\text { Vent } \\
\text { Field } \\
\end{array}$ & $\begin{array}{l}\text { Sample } \\
\text { Type }\end{array}$ & Sample ID & $\mathrm{Ag}$ & $\mathrm{Cd}$ & $\mathrm{Mn}$ & Mo & $\mathrm{Pb}$ & $\mathrm{Sr}$ & As & $\mathrm{Au}$ & Co & $\mathrm{Sb}$ & $\mathrm{Se}$ \\
\hline \multirow{3}{*}{\multicolumn{2}{|c|}{$\begin{array}{l}\text { unit } \\
\text { method } \\
\text { detection limit }\end{array}$}} & & $\mu \mathrm{g} / \mathrm{g}$ & $\mu g / g$ & $\mu g / g$ & $\mu \mathrm{g} / \mathrm{g}$ & $\mu g / g$ & $\mu \mathrm{g} / \mathrm{g}$ & $\mu \mathrm{g} / \mathrm{g}$ & $\mathrm{ng} / \mathrm{g}$ & $\mu g / g$ & $\mu \mathrm{g} / \mathrm{g}$ & $\mu \mathrm{g} / \mathrm{g}$ \\
\hline & & & ICP-MS & ICP-MS & ICP-MS & ICP-MS & ICP-MS & ICP-MS & INAA & INAA & INAA & INAA & INAA \\
\hline & & & $5 \mu \mathrm{g} / \mathrm{g}$ & $2 \mu \mathrm{g} / \mathrm{g}$ & $3 \mu \mathrm{g} / \mathrm{g}$ & $1 \mu \mathrm{g} / \mathrm{g}$ & $0.8 \mu \mathrm{g} / \mathrm{g}$ & $3 \mu \mathrm{g} / \mathrm{g}$ & $0.5 \mu \mathrm{g} / \mathrm{g}$ & $2 \mathrm{ng} / \mathrm{g}$ & $1 \mu \mathrm{g} / \mathrm{g}$ & $2 \mu \mathrm{g} / \mathrm{g}$ & $3 \mu \mathrm{g} / \mathrm{g}$ \\
\hline KM & $\mathrm{OC}$ & J2-125-6-R1 & 21 & 9 & 80 & 9 & 22 & 160 & 6 & 200 & 31 & bdl & 770 \\
\hline $\mathrm{KM}$ & oc & J2-137-1-R1 & 19 & 9 & 25 & 68 & 2 & 18 & 3 & 180 & 63 & bdl & 330 \\
\hline KM & oc & J2-137-1-R1A & 59 & 750 & 42 & 99 & 120 & 240 & 120 & 2700 & 57 & 16 & 280 \\
\hline KM & $\mathrm{OC}$ & J2-137-2-R1 & 48 & 180 & 42 & 53 & 150 & 970 & 210 & 1000 & 100 & 3 & 110 \\
\hline KM & oc & J2-137-6-R1A & 13 & 37 & 150 & 37 & 300 & 25 & 86 & 1500 & 410 & bdl & 210 \\
\hline $\mathrm{KM}$ & oc & J2-137-6-R1B & 12 & 26 & 52 & 27 & 16 & 2500 & 6 & 350 & 270 & bdl & 300 \\
\hline KM & $\mathrm{OC}$ & J2-434-2-R1G & 84 & 610 & 880 & 200 & 1800 & 23 & 370 & 7100 & bdl & 9 & 130 \\
\hline KM & as & J2-124-2-R1A2 & 110 & $>2000$ & 180 & 36 & 830 & 3 & 160 & 7000 & 4 & 15 & bdl \\
\hline $\mathrm{KM}$ & as & J2-124-2-R1D & 160 & 420 & 230 & 61 & 1700 & bdl & 190 & 9200 & 2 & 13 & bdl \\
\hline KM & as & J2-124-5-R1-C2 & 97 & 1900 & 180 & 42 & 970 & 4 & 180 & 7200 & bdl & 22 & bdl \\
\hline KM & as & J2-124-5-R1CH & 63 & $>2000$ & 130 & 48 & 510 & 10 & 91 & 4400 & bdl & 16 & bdl \\
\hline $\mathrm{KM}$ & as & J2-124-5-R1-CM & 62 & $>2000$ & 130 & 50 & 430 & 7 & 87 & 4600 & bdl & 15 & 22 \\
\hline KM & rs & J2-125-11-R1A & 74 & $>2000$ & 130 & 31 & 710 & 3 & 110 & 3800 & bdl & 28 & 15 \\
\hline $\mathrm{KM}$ & rs & J2-125-11-R1B & 24 & 27 & 230 & 42 & 640 & 8 & 97 & 1100 & bdl & bdl & bdl \\
\hline KM & rs & J2-125-3-B1 & 96 & 1600 & 1400 & 49 & 2500 & 24 & 270 & 10500 & 55 & 18 & 110 \\
\hline KM & rs & J2-125-7-R1 & 93 & 1100 & 180 & 56 & 610 & 12 & 320 & 5600 & 9 & 17 & 63 \\
\hline $\mathrm{KM}$ & af & J2-436-2-R1 & 100 & 180 & 910 & 88 & 2300 & 7 & 420 & 8700 & 8 & 9 & 79 \\
\hline KM & rf & J2-124-3-R1 & 140 & 420 & 560 & 37 & 2300 & 10 & 200 & 7400 & bdl & 15 & 30 \\
\hline TC & oc & J2-126-7-B1 & 130 & 1300 & 130 & 46 & 100 & 7 & 99 & 780 & 3 & 11 & 41 \\
\hline $\mathrm{TC}$ & as & J2-126-5-R1 & 210 & 1400 & 1400 & 140 & 4100 & 5 & 570 & 4800 & bdl & 25 & 8 \\
\hline TC & as & J2-127-1-R1C & 120 & $>2000$ & 670 & 140 & 4000 & 12 & 610 & 9800 & bdl & 44 & 26 \\
\hline $\mathrm{TC}$ & as & $\mathrm{J} 2-127-1-\mathrm{R} 2$ & 20 & $>2000$ & 450 & 130 & 490 & 6 & 220 & 1300 & bdl & 22 & 29 \\
\hline TC & as & J2-127-4-R1 & 39 & $>2000$ & 510 & 24 & 660 & 270 & 63 & 810 & bdl & 6 & bdl \\
\hline TC & as & $\mathrm{J} 2-127-5-\mathrm{R} 1$ & 100 & 1100 & 530 & 20 & 1200 & 1100 & 170 & 2700 & bdl & 23 & bdl \\
\hline TC & as & J2-139-1-R1A & 89 & 1800 & 1400 & 100 & 1900 & 16 & 570 & 5000 & bdl & 23 & bdl \\
\hline TC & as & J2-139-1-R1B & 160 & $>2000$ & 800 & 170 & 2900 & 3 & 330 & 5000 & 5 & 34 & 17 \\
\hline TC & rs & $\mathrm{J} 2-126-5-\mathrm{R} 2$ & 210 & 1300 & 1300 & 280 & 7000 & 79 & 710 & 9700 & bdl & 44 & 8 \\
\hline TC & rs & J2-127-3-R1 & 240 & 1000 & 1100 & 280 & 1200 & 18 & 400 & 5800 & bdl & 22 & 71 \\
\hline
\end{tabular}


Table S3 cont. Minor and trace element contents of SMS deposit samples from the Tahi Moana-1 (TMo) and ABE (A) vent fields. Sample types are: open conduit chimneys (oc), active spires (as), relict spires (rs), active flanges (af), relict flanges (rf), and squat terraces (st). bdl = below detection limits.

\begin{tabular}{|c|c|c|c|c|c|c|c|c|c|c|c|c|c|}
\hline $\begin{array}{l}\text { Vent } \\
\text { Field }\end{array}$ & $\begin{array}{l}\text { Sample } \\
\text { Type }\end{array}$ & Sample ID & $\mathrm{Ag}$ & $\mathrm{Cd}$ & $\mathrm{Mn}$ & Mo & $\mathrm{Pb}$ & $\mathrm{Sr}$ & As & $\mathrm{Au}$ & Co & $\mathrm{Sb}$ & $\mathrm{Se}$ \\
\hline \multirow{3}{*}{\multicolumn{2}{|c|}{$\begin{array}{l}\text { unit } \\
\text { method } \\
\text { detection limit }\end{array}$}} & & $\mu \mathrm{g} / \mathrm{g}$ & $\mu \mathrm{g} / \mathrm{g}$ & $\mu g / g$ & $\mu \mathrm{g} / \mathrm{g}$ & $\mu \mathrm{g} / \mathrm{g}$ & $\mu \mathrm{g} / \mathrm{g}$ & $\mu \mathrm{g} / \mathrm{g}$ & $\mathrm{ng} / \mathrm{g}$ & $\mu \mathrm{g} / \mathrm{g}$ & $\mu \mathrm{g} / \mathrm{g}$ & $\mu \mathrm{g} / \mathrm{g}$ \\
\hline & & & ICP-MS & ICP-MS & ICP-MS & ICP-MS & ICP-MS & ICP-MS & INAA & INAA & INAA & INAA & INAA \\
\hline & & & $5 \mu \mathrm{g} / \mathrm{g}$ & $2 \mu \mathrm{g} / \mathrm{g}$ & $3 \mu \mathrm{g} / \mathrm{g}$ & $1 \mu \mathrm{g} / \mathrm{g}$ & $0.8 \mu \mathrm{g} / \mathrm{g}$ & $3 \mu \mathrm{g} / \mathrm{g}$ & $0.5 \mu \mathrm{g} / \mathrm{g}$ & $2 \mathrm{ng} / \mathrm{g}$ & $1 \mu \mathrm{g} / \mathrm{g}$ & $2 \mu \mathrm{g} / \mathrm{g}$ & $3 \mu \mathrm{g} / \mathrm{g}$ \\
\hline TMo & oc & J2-450-3-R1 & 68 & 630 & 270 & 30 & 140 & 240 & 45 & 330 & bdl & 6 & 44 \\
\hline TMo & as & J2-444-4-R1 & 230 & 1000 & 810 & 120 & 3400 & 130 & 580 & 8800 & bdl & 114 & 20 \\
\hline TMo & as & $\mathrm{J} 2-444-10-\mathrm{R} 1$ & 130 & 740 & 1000 & 210 & 2100 & 810 & 610 & 4200 & bdl & 69 & 21 \\
\hline TMo & as & J2-444-22-R1A & 190 & 1100 & 920 & 110 & 2700 & 200 & 810 & 5800 & bdl & 99 & 29 \\
\hline TMo & as & J2-444-22-R1B & 40 & 1300 & 490 & 41 & 460 & 750 & 150 & 1800 & bdl & 56 & 34 \\
\hline TMo & as & J2-444-23-R1 & 170 & 1500 & 690 & 90 & 2600 & 540 & 710 & 5400 & 26 & 143 & 53 \\
\hline TMo & as & J2-444-23-R2 & 240 & 1400 & 720 & 67 & 2400 & 10 & 640 & 6700 & 4 & 148 & 41 \\
\hline TMo & rs & J2-444-17-R1 & 180 & 1300 & 850 & 190 & 2600 & 11 & 830 & 5700 & bdl & 63 & 23 \\
\hline TMo & rs & $\mathrm{J} 2-445-10-\mathrm{R} 1$ & 210 & 700 & 1600 & 310 & 2600 & 960 & 940 & 5200 & bdl & 73 & 14 \\
\hline TMo & af & $\mathrm{J} 2-444-13-\mathrm{R} 2$ & 280 & 1200 & 250 & 150 & 3000 & 160 & 960 & 8100 & bdl & 98 & 30 \\
\hline TMo & af & J2-445-4-R1 & 330 & 550 & 1400 & 160 & 6400 & 1100 & 890 & 11000 & bdl & 103 & 13 \\
\hline TMo & af & $\mathrm{J} 2-445-6-\mathrm{R} 2$ & 250 & 800 & 1700 & 110 & 4900 & 25 & 900 & 9000 & bdl & 100 & 17 \\
\hline TMo & af & $\mathrm{J} 2-445-7-\mathrm{R} 1$ & bdl & 170 & 230 & 14 & 180 & 930 & 93 & 580 & bdl & 7 & $<0.8$ \\
\hline$A$ & oc & J2-128-3-R1 & 37 & 48 & 120 & 18 & 1100 & 240 & 390 & 700 & 42 & 23 & 250 \\
\hline$A$ & oc & J2-136-5-B1 & 17 & 1900 & 260 & 21 & 30 & 18 & 22 & 49 & bdl & 6 & 130 \\
\hline$A$ & oc & $\mathrm{J} 2-449-5-\mathrm{R} 1$ & bdl & 410 & 250 & 9 & 140 & 480 & 33 & 130 & bdl & 6 & 150 \\
\hline$A$ & oc & J2-449-6-R1 & bdl & 32 & 140 & 10 & 190 & 220 & 240 & 170 & 27 & 7 & 640 \\
\hline$A$ & as & $\mathrm{J} 2-128-5-\mathrm{R} 1 \mathrm{~A}$ & 49 & 1400 & 1300 & 130 & 2900 & 100 & 1000 & 2600 & bdl & 108 & 58 \\
\hline$A$ & as & $\mathrm{J} 2-128-5-\mathrm{R} 1 \mathrm{~B}$ & 27 & 830 & 1900 & 94 & 2200 & 14 & 980 & 1900 & 5 & 71 & 89 \\
\hline$A$ & as & $\mathrm{J} 2-128-8-\mathrm{R} 1$ & 22 & 1000 & 860 & 96 & 1300 & 7 & 660 & 1100 & bdl & 78 & 39 \\
\hline$A$ & as & J2-129-3-R1 & 95 & 740 & 1300 & 140 & 9400 & 51 & 1300 & 3100 & 4 & 145 & bdl \\
\hline$A$ & as & $\mathrm{J} 2-136-5-\mathrm{R} 1 \mathrm{~A}$ & 13 & $>2000$ & 410 & 100 & 520 & 9 & 150 & 380 & bdl & 50 & 210 \\
\hline$A$ & as & $\mathrm{J} 2-136-5-\mathrm{R} 1 \mathrm{~B}$ & 100 & 680 & 2200 & 240 & 14600 & 58 & 2100 & 4700 & bdl & 163 & bdl \\
\hline$A$ & rs & $\mathrm{J} 2-128-1-\mathrm{R} 2$ & 130 & 80 & 2000 & 66 & 2070 & 73 & 1500 & 3300 & bdl & 117 & bdl \\
\hline$A$ & rs & J2-128-8-R2 & 89 & 1500 & 1600 & 89 & 1800 & 58 & 1200 & 2700 & 3 & 125 & bdl \\
\hline$A$ & rs & $\mathrm{J} 2-129-1-\mathrm{R} 3$ & 72 & 1200 & 930 & 120 & 1300 & 41 & 1100 & 2200 & bdl & 92 & bdl \\
\hline$A$ & rs & J2-136-6-R1 & 86 & 1300 & 1600 & 71 & 1100 & 48 & 1200 & 2700 & bdl & 120 & 30 \\
\hline$A$ & af & J2-128-2-R1 & 97 & 6 & 480 & 8 & 750 & 370 & 490 & 2300 & bdl & 77 & bdl \\
\hline
\end{tabular}


Table S3 cont. Minor and trace element contents of SMS deposit samples from the Tui' Malila (TM) vent fields. Sample types are: open conduit chimneys (oc), active spires (as), relict spires (rs), active flanges (af), relict flanges (rf), and squat terraces (st). bdl = below detection limits.

\begin{tabular}{|c|c|c|c|c|c|c|c|c|c|c|c|c|c|}
\hline $\begin{array}{l}\text { Vent } \\
\text { Field } \\
\end{array}$ & $\begin{array}{l}\text { Sample } \\
\text { Type }\end{array}$ & Sample ID & $\mathrm{Ag}$ & $\mathrm{Cd}$ & $\mathrm{Mn}$ & Mo & $\mathrm{Pb}$ & $\mathrm{Sr}$ & As & $\mathrm{Au}$ & Co & $\mathrm{Sb}$ & $\mathrm{Se}$ \\
\hline \multirow{3}{*}{\multicolumn{2}{|c|}{$\begin{array}{l}\text { unit } \\
\text { method } \\
\text { detection limit }\end{array}$}} & & $\mu \mathrm{g} / \mathrm{g}$ & $\mu \mathrm{g} / \mathrm{g}$ & $\mu g / g$ & $\mu \mathrm{g} / \mathrm{g}$ & $\mu g / g$ & $\mu \mathrm{g} / \mathrm{g}$ & $\mu g / g$ & $\mathrm{ng} / \mathrm{g}$ & $\mu \mathrm{g} / \mathrm{g}$ & $\mu \mathrm{g} / \mathrm{g}$ & $\mu g / g$ \\
\hline & & & ICP-MS & ICP-MS & ICP-MS & ICP-MS & ICP-MS & ICP-MS & INAA & INAA & INAA & INAA & INAA \\
\hline & & & $5 \mu \mathrm{g} / \mathrm{g}$ & $2 \mu \mathrm{g} / \mathrm{g}$ & $3 \mu \mathrm{g} / \mathrm{g}$ & $1 \mu \mathrm{g} / \mathrm{g}$ & $0.8 \mu \mathrm{g} / \mathrm{g}$ & $3 \mu \mathrm{g} / \mathrm{g}$ & $0.5 \mu \mathrm{g} / \mathrm{g}$ & $2 \mathrm{ng} / \mathrm{g}$ & $1 \mu \mathrm{g} / \mathrm{g}$ & $2 \mu \mathrm{g} / \mathrm{g}$ & $3 \mu \mathrm{g} / \mathrm{g}$ \\
\hline TM & OC & J2-132-14-R1 & 40 & 1000 & 560 & 97 & 280 & 62 & 880 & 1400 & bdl & 90 & bdl \\
\hline TM & oc & J2-134-7-R1A & 49 & 1900 & 800 & 140 & 1800 & 36 & 530 & 2600 & 14 & 53 & bdl \\
\hline TM & oc & J2-134-7-R1B & 110 & 76 & 710 & 49 & 1400 & 190 & 1400 & 7000 & bdl & 110 & bdl \\
\hline TM & oc & J2-134-7-R1C & 42 & 1400 & 600 & 46 & 500 & 49 & 380 & 780 & 29 & 16 & bdl \\
\hline TM & oc & J2-442-4-R2 & bdl & 59 & 35 & 15 & 130 & 530 & 160 & 110 & 36 & 6 & 530 \\
\hline TM & as & J2-132-13-R1 & 150 & 1400 & 140 & 130 & 1700 & 100 & 1900 & 7800 & bdl & 220 & bdl \\
\hline TM & as & J2-134-9-R1 & 130 & 240 & 850 & 26 & 59200 & 21 & 800 & 2700 & bdl & 120 & bdl \\
\hline TM & as & $\mathrm{J} 2-138-7-\mathrm{R} 1 \mathrm{~A}$ & 95 & 68 & 440 & 18 & 710 & 180 & 860 & 5100 & bdl & 87 & bdl \\
\hline TM & as & J2-138-7-R1B & 100 & 71 & 470 & 19 & 930 & 220 & 870 & 5600 & bdl & 96 & bdl \\
\hline TM & as & $\mathrm{J} 2-442-9-\mathrm{R} 1$ & 62 & 190 & 180 & 15 & 4800 & 5700 & 400 & 4400 & bdl & 87 & bdl \\
\hline TM & rs & $\mathrm{J} 2-132-15-\mathrm{R} 1$ & 64 & 1200 & 300 & 75 & 350 & 69 & 900 & 8500 & bdl & 140 & 4 \\
\hline TM & rs & $\mathrm{J} 2-132-9-\mathrm{R} 2$ & 98 & 720 & 340 & 34 & 400 & 140 & 720 & 7500 & bdl & 110 & bdl \\
\hline TM & rs & J2-134-8-R1 & 96 & 1500 & 610 & 80 & 4000 & 350 & 660 & 5000 & 4 & 110 & bdl \\
\hline $\mathrm{TM}$ & rs & $\mathrm{J} 2-134-8-\mathrm{R} 2$ & 190 & 560 & 840 & 89 & 18600 & 84 & 1300 & 11200 & bdl & 270 & bdl \\
\hline $\mathrm{TM}$ & rs & $\mathrm{J} 2-138-10-\mathrm{R} 1$ & 69 & 65 & 95 & 8 & 3700 & 360 & 270 & 2800 & bdl & 42 & bdl \\
\hline $\mathrm{TM}$ & rs & $\mathrm{J} 2-138-2-\mathrm{R} 1 \mathrm{~A}$ & 110 & 1500 & 810 & 24 & 4000 & 8 & 900 & 6300 & bdl & 250 & bdl \\
\hline TM & rs & J2-138-2-R1B & 92 & 99 & 670 & 15 & 1300 & 88 & 810 & 4700 & bdl & 91 & bdl \\
\hline $\mathrm{TM}$ & rs & $\mathrm{J} 2-447-5-\mathrm{R} 2$ & 160 & 260 & 730 & 6 & 3000 & 2200 & 970 & 4300 & bdl & 59 & 4 \\
\hline TM & rs & $\mathrm{J} 2-447-7-\mathrm{R} 2$ & 170 & 1600 & 320 & 28 & 3400 & 3700 & 1300 & 5100 & bdl & 450 & 19 \\
\hline $\mathrm{TM}$ & rs & $\mathrm{J} 2-447-9-\mathrm{R} 2-\mathrm{H}$ & 220 & 840 & 410 & 35 & 4200 & 4300 & 1100 & 9100 & bdl & 190 & 11 \\
\hline TM & rs & J2-447-9-R2-M & 250 & 640 & 480 & 36 & 5900 & 3400 & 1200 & 9400 & bdl & 170 & 10 \\
\hline TM & af & J2-132-8-R1 & 160 & 10 & 110 & 5 & 340 & 130 & 530 & 4100 & bdl & 79 & bdl \\
\hline $\mathrm{TM}$ & af & J2-138-5-R1 & 52 & 240 & 290 & 19 & 200 & 120 & 550 & 3700 & bdl & 48 & bdl \\
\hline TM & $r f$ & $\mathrm{~J} 2-447-5-\mathrm{R} 1$ & 57 & 14 & 940 & 1 & 3500 & 3800 & 350 & 2300 & bdl & 23 & bdl \\
\hline
\end{tabular}


Table S3 cont. Minor and trace element contents of SMS deposit samples from the Mariner (MA) vent field. Sample types are: open conduit chimneys (oc), active spires (as), relict spires (rs), active flanges (af), relict flanges (rf), and squat terraces (st). bdl = below detection limits.

\begin{tabular}{|c|c|c|c|c|c|c|c|c|c|c|c|c|c|}
\hline $\begin{array}{l}\text { Vent } \\
\text { Field } \\
\end{array}$ & $\begin{array}{l}\text { Sample } \\
\text { Type }\end{array}$ & Sample ID & $\mathrm{Ag}$ & $\mathrm{Cd}$ & $\mathrm{Mn}$ & Mo & $\mathrm{Pb}$ & $\mathrm{Sr}$ & As & $\mathrm{Au}$ & Co & $\mathrm{Sb}$ & $\mathrm{Se}$ \\
\hline \multirow{3}{*}{\multicolumn{2}{|c|}{$\begin{array}{l}\text { unit } \\
\text { method } \\
\text { detection limit }\end{array}$}} & & $\mu \mathrm{g} / \mathrm{g}$ & $\mu g / g$ & $\mu \mathrm{g} / \mathrm{g}$ & $\mu \mathrm{g} / \mathrm{g}$ & $\mu \mathrm{g} / \mathrm{g}$ & $\mu g / g$ & $\mu \mathrm{g} / \mathrm{g}$ & $\mathrm{ng} / \mathrm{g}$ & $\mu \mathrm{g} / \mathrm{g}$ & $\mu g / g$ & $\mu \mathrm{g} / \mathrm{g}$ \\
\hline & & & ICP-MS & ICP-MS & ICP-MS & ICP-MS & ICP-MS & ICP-MS & INAA & INAA & INAA & INAA & INAA \\
\hline & & & $5 \mu \mathrm{g} / \mathrm{g}$ & $2 \mu \mathrm{g} / \mathrm{g}$ & $3 \mu \mathrm{g} / \mathrm{g}$ & $1 \mu \mathrm{g} / \mathrm{g}$ & $0.8 \mu \mathrm{g} / \mathrm{g}$ & $3 \mu \mathrm{g} / \mathrm{g}$ & $0.5 \mu \mathrm{g} / \mathrm{g}$ & $2 \mathrm{ng} / \mathrm{g}$ & $1 \mu \mathrm{g} / \mathrm{g}$ & $2 \mu \mathrm{g} / \mathrm{g}$ & $3 \mu \mathrm{g} / \mathrm{g}$ \\
\hline MA & OC & J2-130-1-R2 & 24 & 47 & 140 & 130 & 1 & 250 & 380 & 4700 & 3 & 46 & bdl \\
\hline MA & oc & J2-131-1-R1 & 9 & 5 & 130 & 9 & 7 & 250 & 18 & 900 & bdl & 4 & bdl \\
\hline MA & oc & J2-437-3-R2-H & bdl & 87 & 25 & 27 & 590 & 520 & 560 & 1800 & bdl & 34 & bdl \\
\hline MA & oc & J2-437-3-R2-M & 28 & 100 & 27 & 27 & 550 & 590 & 520 & 1800 & bdl & 38 & bdl \\
\hline MA & oc & J2-437-3-R2-M & bdl & bdl & 160 & 9 & 21 & 860 & 53 & 460 & bdl & 11 & bdl \\
\hline MA & oc & J2-439-8-R1 & bdl & 44 & 13 & 31 & 500 & 470 & 530 & 690 & 1 & 23 & 11 \\
\hline MA & oc & $\mathrm{J} 2-448-8-\mathrm{R} 1$ & bdl & 12 & 38 & 22 & 53 & 1500 & 71 & 390 & 1 & 7 & 3 \\
\hline MA & as & $\mathrm{J} 2-131-7-\mathrm{R} 1$ & 71 & 760 & 99 & 30 & 770 & 58 & 1200 & 3000 & bdl & 110 & bdl \\
\hline MA & as & J2-439-13-R2 & 120 & 270 & 27 & 6 & 1300 & 1200 & 1900 & 3300 & bdl & 200 & bdl \\
\hline MA & as & J2-'439-4-R1 & 220 & 550 & 40 & 56 & 2100 & 2200 & 1800 & 9500 & bdl & 200 & 6 \\
\hline MA & rs & J2-131-3-RB1 & 170 & 590 & 980 & 43 & 41 & 41 & 1600 & 4600 & bdl & 430 & bdl \\
\hline MA & rs & J2-131-8-R1A & 19 & 110 & 22 & 15 & 240 & 66 & 530 & 1300 & bdl & 79 & bdl \\
\hline MA & rs & J2-131-8-R1B & 39 & 170 & 52 & 21 & 250 & 74 & 700 & 1800 & 3 & 87 & bdl \\
\hline MA & rs & $\mathrm{J} 2-131-8-\mathrm{R} 1 \mathrm{C}$ & 78 & 350 & 12000 & 48 & 1100 & 79 & 2100 & 2900 & bdl & 190 & bdl \\
\hline MA & rs & $\mathrm{J} 2-446-1-\mathrm{R} 3$ & 98 & 750 & 38 & 7 & 3200 & 2700 & 1700 & 3600 & bdl & 170 & 14 \\
\hline MA & rs & J2-448-10-R1 & 96 & bdl & 83 & 70 & 51 & 280 & 510 & 12100 & bdl & 39 & bdl \\
\hline MA & rs & $\mathrm{J} 2-448-5-\mathrm{R} 1$ & 41 & 14 & 91 & bdl & 3300 & 4000 & 840 & 3500 & bdl & 20 & bdl \\
\hline MA & rs & J2-448-6-R1 & 110 & 15 & 2500 & 8 & 4200 & 4400 & 980 & 4100 & bdl & 68 & bdl \\
\hline MA & af & J2-439-3-R1 & 260 & 860 & 120 & 3 & 2700 & 1600 & 1100 & 4700 & bdl & 190 & 19 \\
\hline MA & af & J2-448-2-R1 & 160 & 430 & 98 & 1 & 2800 & 2400 & 870 & 2600 & bdl & 89 & 14 \\
\hline MA & st & J2-131-4-R1 & 640 & 1500 & 40 & 17 & 30 & 42 & 2000 & bdl & bdl & 12 & bdl \\
\hline MA & st & J2-135-5-RB1H & 360 & 1600 & 26 & 15 & 710 & 60 & 950 & bdl & bdl & bdl & bdl \\
\hline MA & st & J2-135-5-RB1M & 250 & 1000 & 20 & 15 & 930 & 50 & 750 & bdl & bdl & bdl & bdl \\
\hline MA & rf & $\mathrm{J} 2-446-1-\mathrm{R} 1$ & 180 & 770 & 81 & 4 & 2700 & 2400 & 1300 & 5100 & bdl & 180 & 14 \\
\hline
\end{tabular}


Table S4. Electron microprobe data for SMS deposit samples from the Kilo Moana (KM), TowCam (TC), Tahi Moana-1 (TMo), ABE (A), Tu'i Malila (TM), and Mariner (MA) vent fields. Sample types are: open conduit chimneys (oc), relict open conduit chimneys (ro), active spires (as), relict spires (rs), active flanges (af), relict flanges (rf), breccias (br), and squat terraces (st). Minerals are: cubanite (cb), chalcopyrite (cp), pyrite (py), marcasite (mc), sphalerite (sp), wurtzite (wz), bornite (bn), and covellite (cv). "Position" represents location of electron microprobe spot relative to the presumed fluid conduits, identified by mineralogical texture. ${ }^{*} \mathrm{~Pb}$ analyses are considered unreliable because interferences with $\mathrm{S}$ could not be resolved. "..." = below detection limits.

SulfidelD Vent $\begin{array}{llllllllllllllll} & \text { Sample Mineral Position } & \mathrm{Fe} & \mathrm{Cu} & \mathrm{Zn} & \mathrm{Pb}^{*} & \mathrm{~S} & \mathrm{Co} & \mathrm{Se} & \mathrm{Ag} & \mathrm{Mn} & \mathrm{As} & \mathrm{Sb} & \mathrm{Cd} & \mathrm{TOTAL}\end{array}$ Field Type

\begin{tabular}{|c|c|c|c|c|c|c|c|c|c|c|c|c|c|c|c|c|c|}
\hline \multirow{2}{*}{$\begin{array}{l}\text { unit } \\
\text { detection limit }\end{array}$} & & & & & \multicolumn{5}{|c|}{$w t \%$} & \multicolumn{7}{|c|}{$0.1 \mathrm{mg} / \mathrm{g}$} & \multirow[t]{2}{*}{$w t \%$} \\
\hline & & & & & 0.08 & 0.055 & 0.11 & & 0.007 & 5 & 1.5 & 1 & 4 & 2 & 1 & 1 & \\
\hline J2-137-1-R1 & KM & OC & $\mathrm{cb}$ & lining & 40 & 22 & 0.2 & 0.2 & 36 & $\ldots$ & $\ldots$ & 1 & $\ldots$ & $\ldots$ & $\ldots$ & 2 & 99 \\
\hline J2-137-1-R1 & KM & oc & $\mathrm{cb}$ & lining & 39 & 23 & 0.3 & 0.1 & 36 & $\ldots$ & $\ldots$ & 1 & $\ldots$ & $\ldots$ & $\ldots$ & 2 & 99 \\
\hline J2-137-1-R1 & KM & oc & $\mathrm{cb}$ & lining & 41 & 23 & 0.1 & 0.1 & 35 & 13 & $\ldots$ & 1 & $\ldots$ & $\ldots$ & $\ldots$ & 2 & 99 \\
\hline J2-137-1-R1 & KM & $O C$ & $\mathrm{cb}$ & middle & 41 & 23 & 0.3 & 0.2 & 36 & 10 & 4 & $\ldots$ & $\ldots$ & $\ldots$ & 1 & 2 & 101 \\
\hline J2-137-1-R1 & KM & oc & $\mathrm{cb}$ & middle & 40 & 23 & $\ldots$ & 0.2 & 36 & $\ldots$ & 4 & $\ldots$ & $\ldots$ & $\ldots$ & $\ldots$ & 2 & 99 \\
\hline J2-137-1-R1 & KM & oc & $\mathrm{cb}$ & middle & 41 & 24 & $\ldots$ & 0.1 & 35 & 14 & 7 & $\ldots$ & $\ldots$ & $\ldots$ & 1 & 2 & 99 \\
\hline J2-137-1-R1 & $\mathrm{KM}$ & $O C$ & $\mathrm{cb}$ & middle & 41 & 23 & 0.1 & 0.1 & 35 & 13 & $\ldots$ & $\ldots$ & $\ldots$ & $\ldots$ & 1 & 2 & 99 \\
\hline J2-137-1-R1 & KM & oc & $\mathrm{cb}$ & middle & 42 & 22 & 0.2 & 0.1 & 35 & 20 & 9 & 2 & $\ldots$ & $\ldots$ & $\ldots$ & 2 & 100 \\
\hline J2-137-1-R1 & $\mathrm{KM}$ & oc & $\mathrm{cb} / \mathrm{cp}$ & middle & 35 & 27 & 0.1 & 0.2 & 36 & $\ldots$ & 8 & 1 & $\ldots$ & $\ldots$ & 2 & 1 & 98 \\
\hline J2-137-1-R1 & $\mathrm{KM}$ & $O C$ & $\mathrm{cp}$ & middle & 31 & 31 & 0.4 & 0.2 & 36 & $\ldots$ & 6 & 1 & $\ldots$ & $\ldots$ & $\ldots$ & 3 & 98 \\
\hline J2-137-1-R1 & KM & $\mathrm{OC}$ & $\mathrm{cp}$ & middle & 31 & 32 & 1.3 & 0.1 & 36 & $\ldots$ & $\ldots$ & 4 & $\ldots$ & $\ldots$ & $\ldots$ & 4 & 99 \\
\hline J2-137-1-R1 & $\mathrm{KM}$ & $O C$ & py & middle & 47 & $\ldots$ & $\ldots$ & 0.2 & 53 & 7 & 3 & $\ldots$ & $\ldots$ & $\ldots$ & $\ldots$ & $\ldots$ & 100 \\
\hline J2-137-1-R1 & $\mathrm{KM}$ & $O C$ & py & middle & 47 & 0.1 & $\ldots$ & 0.2 & 53 & $\ldots$ & $\ldots$ & $\ldots$ & $\ldots$ & $\ldots$ & $\ldots$ & $\ldots$ & 100 \\
\hline J2-137-1-R1 & $\mathrm{KM}$ & $O C$ & py & exterior & 46 & $\ldots$ & $\ldots$ & 0.3 & 53 & 8 & $\ldots$ & $\ldots$ & $\ldots$ & $\ldots$ & $\ldots$ & $\ldots$ & 100 \\
\hline J2-137-1-R1 & $\mathrm{KM}$ & $O C$ & py & exterior & 47 & $\ldots$ & 0.4 & 0.3 & 53 & 6 & $\ldots$ & $\ldots$ & $\ldots$ & $\ldots$ & $\ldots$ & 2 & 100 \\
\hline J2-137-1-R1 & $\mathrm{KM}$ & $O C$ & $s p$ & middle & 14 & 0.9 & 50 & 0.1 & 34 & $\ldots$ & $\ldots$ & $\ldots$ & $\ldots$ & $\ldots$ & $\ldots$ & 39 & 100 \\
\hline J2-137-1-R1 & KM & $O C$ & $s p$ & middle & 9 & 0.2 & 57 & 0.1 & 34 & 32 & $\ldots$ & $\ldots$ & $\ldots$ & $\ldots$ & $\ldots$ & 46 & 101 \\
\hline J2-137-1-R1 & $\mathrm{KM}$ & $O C$ & wz & middle & 12 & 0.7 & 52 & 0.1 & 34 & $\ldots$ & $\ldots$ & $\ldots$ & $\ldots$ & $\ldots$ & $\ldots$ & 60 & 100 \\
\hline J2-137-1-R1 & $\mathrm{KM}$ & $O C$ & wz & middle & 9 & 0.3 & 56 & 0.1 & 34 & $\ldots$ & $\ldots$ & $\ldots$ & $\ldots$ & $\ldots$ & $\ldots$ & 30 & 100 \\
\hline J2-137-1-R1 & $\mathrm{KM}$ & OC & wz & middle & 8 & 0.3 & 58 & 0.1 & 34 & $\ldots$ & 3 & $\ldots$ & $\ldots$ & $\ldots$ & $\ldots$ & 58 & 100 \\
\hline J2-137-1-R1 & KM & oc & wz & middle & 3.0 & 0.3 & 65 & 0.1 & 33 & $\ldots$ & $\ldots$ & $\ldots$ & $\ldots$ & 3 & $\ldots$ & 8 & 101 \\
\hline J2-137-1-R1 & $\mathrm{KM}$ & $O C$ & wz & middle & 7 & 0.1 & 57 & 0.1 & 34 & $\ldots$ & $\ldots$ & $\ldots$ & $\ldots$ & $\ldots$ & $\ldots$ & 51 & 99 \\
\hline J2-137-1-R1 & $\mathrm{KM}$ & $O C$ & wz & middle & 6 & 0.4 & 59 & 0.1 & 33 & $\ldots$ & $\ldots$ & $\ldots$ & $\ldots$ & $\ldots$ & 4 & 39 & 99 \\
\hline J2-124-5-R1 & $\mathrm{KM}$ & as & py & middle & 45 & 0.1 & 0.7 & 0.2 & 53 & $\ldots$ & 3 & $\ldots$ & $\ldots$ & $\ldots$ & 1 & 2 & 99 \\
\hline J2-124-5-R1 & $\mathrm{KM}$ & as & py & middle & 46 & $\ldots$ & 1.3 & 0.2 & 52 & 13 & 8 & $\ldots$ & $\ldots$ & $\ldots$ & $\ldots$ & 2 & 99 \\
\hline J2-124-5-R1 & $\mathrm{KM}$ & as & py & middle & 47 & 0.1 & 0.4 & 0.3 & 53 & $\ldots$ & 4 & $\ldots$ & $\ldots$ & $\ldots$ & $\ldots$ & 1 & 101 \\
\hline J2-124-5-R1 & $\mathrm{KM}$ & as & $\mathrm{mc}$ & exterior & 46 & 0.2 & 0.5 & 0.3 & 53 & $\ldots$ & $\ldots$ & $\ldots$ & $\ldots$ & $\ldots$ & $\ldots$ & 2 & 99 \\
\hline J2-124-5-R1 & $\mathrm{KM}$ & as & $\mathrm{mc}$ & exterior & 46 & $\ldots$ & $\ldots$ & 0.3 & 52 & 6 & $\ldots$ & $\ldots$ & $\ldots$ & $\ldots$ & $\ldots$ & $\ldots$ & 99 \\
\hline J2-124-5-R1 & $\mathrm{KM}$ & as & $\mathrm{mc}$ & exterior & 46 & $\ldots$ & 0.5 & 0.3 & 53 & $\ldots$ & $\ldots$ & $\ldots$ & 4 & $\ldots$ & $\ldots$ & 1 & 100 \\
\hline J2-124-5-R1 & KM & as & $s p$ & middle & 11 & 0.4 & 55 & 0.3 & 34 & $\ldots$ & $\ldots$ & $\ldots$ & $\ldots$ & $\ldots$ & 3 & 53 & 101 \\
\hline J2-124-5-R1 & $\mathrm{KM}$ & as & $s p$ & middle & 9 & $\ldots$ & 57 & 0.2 & 34 & $\ldots$ & $\ldots$ & $\ldots$ & $\ldots$ & $\ldots$ & 1 & 39 & 100 \\
\hline J2-124-5-R1 & $\mathrm{KM}$ & as & $s p$ & middle & 11 & 0.4 & 54 & 0.3 & 34 & $\ldots$ & $\ldots$ & $\ldots$ & $\ldots$ & $\ldots$ & $\ldots$ & 33 & 100 \\
\hline J2-124-5-R1 & $\mathrm{KM}$ & as & $s p$ & middle & 10 & $\ldots$ & 55 & 0.2 & 34 & $\ldots$ & 2 & $\ldots$ & $\ldots$ & $\ldots$ & $\ldots$ & 41 & 100 \\
\hline J2-124-5-R1 & $\mathrm{KM}$ & as & $s p$ & middle & 5 & 1.2 & 61 & 0.2 & 34 & 5 & 4 & $\ldots$ & $\ldots$ & $\ldots$ & $\ldots$ & 4 & 101 \\
\hline J2-124-5-R1 & $\mathrm{KM}$ & as & $s p$ & middle & 10 & 0.5 & 55 & 0.3 & 34 & $\ldots$ & 3 & $\ldots$ & $\ldots$ & $\ldots$ & 2 & 11 & 100 \\
\hline J2-125-3-B1 & $\mathrm{KM}$ & rs & py & middle & 46 & $\ldots$ & 2.2 & 0.4 & 53 & $\ldots$ & $\ldots$ & $\ldots$ & $\ldots$ & $\ldots$ & $\ldots$ & $\ldots$ & 102 \\
\hline J2-125-3-B1 & $\mathrm{KM}$ & rs & py & middle & 47 & $\ldots$ & $\ldots$ & 0.3 & 54 & $\ldots$ & $\ldots$ & $\ldots$ & $\ldots$ & $\ldots$ & $\ldots$ & $\ldots$ & 101 \\
\hline J2-125-3-B1 & KM & rs & py & exterior & 46 & $\ldots$ & $\ldots$ & 0.3 & 54 & $\ldots$ & $\ldots$ & $\ldots$ & 5 & $\ldots$ & $\ldots$ & $\ldots$ & 100 \\
\hline J2-125-3-B1 & $\mathrm{KM}$ & rs & $s p$ & lining & 8 & $\ldots$ & 60 & 0.2 & 34 & $\ldots$ & 5 & $\ldots$ & $\ldots$ & $\ldots$ & $\ldots$ & 28 & 102 \\
\hline J2-125-3-B1 & $\mathrm{KM}$ & rs & $\mathrm{sp}$ & middle & 7 & $\ldots$ & 61 & 0.2 & 34 & $\ldots$ & 4 & $\ldots$ & $\ldots$ & $\ldots$ & $\ldots$ & 32 & 102 \\
\hline J2-125-3-B1 & $\mathrm{KM}$ & rs & $s p$ & middle & 7 & $\ldots$ & 60 & 0.2 & 34 & $\ldots$ & $\ldots$ & $\ldots$ & $\ldots$ & $\ldots$ & 1 & 23 & 101 \\
\hline
\end{tabular}


Table S4 cont. Electron microprobe data for SMS deposit samples from the TowCam (TC) vent field

\begin{tabular}{|c|c|c|c|c|c|c|c|c|c|c|c|c|c|c|c|c|c|}
\hline \multirow{3}{*}{$\begin{array}{l}\text { SulfidelD } \\
\text { unit } \\
\text { detection limit }\end{array}$} & \multirow[t]{3}{*}{$\begin{array}{l}\text { Vent } \\
\text { Field } \\
\end{array}$} & \multirow[t]{3}{*}{$\begin{array}{l}\text { Sample } \\
\text { Type }\end{array}$} & \multicolumn{2}{|c|}{ Mineral Position } & $\mathrm{Fe}$ & \multirow[t]{2}{*}{$\mathrm{Cu}$} & \multirow{2}{*}{$\begin{array}{c}\mathrm{Zn} \\
w t \% \\
\end{array}$} & \multirow[t]{2}{*}{$\mathrm{Pb}^{*}$} & \multirow[t]{2}{*}{$\mathrm{S}$} & \multirow[t]{2}{*}{ Co } & \multirow[t]{2}{*}{ Se } & \multirow[t]{2}{*}{$\mathrm{Ag}$} & \multirow{2}{*}{\multicolumn{2}{|c|}{$\begin{array}{l}\mathrm{Mn} \\
1 \mathrm{mg} / \mathrm{g}\end{array}$}} & \multirow[t]{2}{*}{$\mathrm{Sb}$} & \multirow[t]{2}{*}{$\mathrm{Cd}$} & TOTAL \\
\hline & & & & & & & & & & & & & & & & & \\
\hline & & & & & 0.08 & 0.055 & 0.11 & & 0.007 & 5 & 1.5 & 1 & 4 & 2 & 1 & 1 & \\
\hline J2-139-2-R1 & $\mathrm{TC}$ & OC & $\mathrm{cp}$ & lining & 31 & 34 & $\ldots$ & 0.2 & 35 & $\ldots$ & $\ldots$ & 2 & $\ldots$ & $\ldots$ & $\ldots$ & 2 & 101 \\
\hline J2-139-2-R1 & TC & $\mathrm{OC}$ & $\mathrm{cp}$ & lining & 31 & 34 & $\ldots$ & 0.2 & 35 & $\ldots$ & $\ldots$ & 1 & $\ldots$ & $\ldots$ & $\ldots$ & 3 & 100 \\
\hline J2-139-2-R1 & TC & oc & $\mathrm{cp}$ & lining & 31 & 34 & 0.4 & 0.2 & 35 & $\ldots$ & 2 & 1 & $\ldots$ & $\ldots$ & $\ldots$ & 3 & 101 \\
\hline J2-139-2-R1 & TC & OC & py & lining & 47 & 0.2 & $\ldots$ & 0.3 & 54 & $\ldots$ & $\ldots$ & $\ldots$ & 51 & $\ldots$ & $\ldots$ & $\ldots$ & 102 \\
\hline J2-139-2-R1 & $\mathrm{TC}$ & $\mathrm{oc}$ & py & middle & 48 & 0.4 & 0.3 & 0.2 & 53 & $\ldots$ & $\ldots$ & $\ldots$ & $\ldots$ & $\ldots$ & $\ldots$ & $\ldots$ & 102 \\
\hline J2-139-2-R1 & TC & oc & py & middle & 45 & $\ldots$ & 1.9 & 1.7 & 52 & $\ldots$ & $\ldots$ & $\ldots$ & 26 & 2 & $\ldots$ & $\ldots$ & 101 \\
\hline J2-139-2-R1 & TC & $\mathrm{OC}$ & py & middle & 46 & $\ldots$ & $\ldots$ & 0.4 & 53 & $\ldots$ & $\ldots$ & $\ldots$ & 80 & $\ldots$ & $\ldots$ & $\ldots$ & 100 \\
\hline J2-139-2-R1 & TC & $\mathrm{OC}$ & $s p$ & middle & 4 & 0.2 & 63 & 0.2 & 33 & 15 & 5 & 1 & 6 & $\ldots$ & 3 & 45 & 102 \\
\hline J2-139-2-R1 & TC & $\mathrm{OC}$ & $\mathrm{sp}$ & middle & 5 & 0.3 & 62 & 0.2 & 34 & 8 & 5 & 2 & 9 & $\ldots$ & 1 & 45 & 102 \\
\hline J2-126-5-R1 & TC & as & $\mathrm{cp}$ & lining & 31 & 34 & $\ldots$ & 0.2 & 35 & $\ldots$ & 2 & 3 & $\ldots$ & $\ldots$ & $\ldots$ & 3 & 100 \\
\hline J2-126-5-R1 & $\mathrm{TC}$ & as & $\mathrm{cp}$ & lining & 31 & 33 & 0.4 & 0.2 & 34 & $\ldots$ & 2 & 4 & $\ldots$ & $\ldots$ & $\ldots$ & 3 & 100 \\
\hline J2-126-5-R1 & $\mathrm{TC}$ & as & py & lining & 47 & $\ldots$ & $\ldots$ & 0.3 & 53 & $\ldots$ & $\ldots$ & 3 & 28 & 6 & $\ldots$ & $\ldots$ & 101 \\
\hline J2-126-5-R1 & TC & as & $\mathrm{mc}$ & middle & 46 & 0.1 & $\ldots$ & 0.4 & 53 & $\ldots$ & 2 & $\ldots$ & 11 & 7 & $\ldots$ & 3 & 99 \\
\hline J2-126-5-R1 & TC & as & $\mathrm{mc}$ & middle & 46 & 0.1 & 0.2 & 1.0 & 52 & 8 & 8 & $\ldots$ & 18 & 33 & $\ldots$ & 5 & 100 \\
\hline J2-126-5-R1 & TC & as & $\mathrm{mc}$ & middle & 47 & $\ldots$ & 0.1 & 0.3 & 53 & 6 & 4 & $\ldots$ & 9 & 19 & $\ldots$ & 4 & 101 \\
\hline J2-126-5-R1 & TC & as & $s p$ & middle & 5 & 0.1 & 60 & 0.2 & 33 & $\ldots$ & $\ldots$ & $\ldots$ & 9 & $\ldots$ & $\ldots$ & 39 & 100 \\
\hline J2-126-5-R1 & $\mathrm{TC}$ & as & $s p$ & middle & 7 & 0.5 & 57 & 0.2 & 33 & $\ldots$ & $\ldots$ & $\ldots$ & $\ldots$ & $\ldots$ & 1 & 7 & 98 \\
\hline J2-126-5-R1 & TC & as & $s p$ & middle & 7 & 0.1 & 59 & 0.2 & 33 & 6 & $\ldots$ & $\ldots$ & 9 & $\ldots$ & $\ldots$ & 38 & 100 \\
\hline J2-126-5-R1 & TC & as & wz & lining & 7 & $\ldots$ & 60 & 0.2 & 33 & $\ldots$ & $\ldots$ & $\ldots$ & 8 & $\ldots$ & $\ldots$ & 34 & 101 \\
\hline J2-126-5-R1 & TC & as & wz & lining & 6 & $\ldots$ & 60 & 0.2 & 33 & $\ldots$ & $\ldots$ & $\ldots$ & 10 & $\ldots$ & $\ldots$ & 47 & 101 \\
\hline J2-126-5-R1 & TC & as & wz & lining & 5 & $\ldots$ & 61 & 0.2 & 34 & $\ldots$ & $\ldots$ & $\ldots$ & 5 & $\ldots$ & $\ldots$ & 24 & 100 \\
\hline J2-127-4-R1 & TC & as & $\mathrm{cp}$ & lining & 31 & 34 & 0.5 & 0.2 & 35 & $\ldots$ & $\ldots$ & $\ldots$ & $\ldots$ & $\ldots$ & $\ldots$ & $\ldots$ & 102 \\
\hline J2-127-4-R1 & TC & as & $\mathrm{cp}$ & lining & 30 & 34 & 0.9 & 0.2 & 35 & 7 & $\ldots$ & 3 & $\ldots$ & $\ldots$ & $\ldots$ & $\ldots$ & 100 \\
\hline J2-127-4-R1 & TC & as & $\mathrm{cp}$ & lining & 30 & 26 & 6 & 0.3 & 37 & $\ldots$ & $\ldots$ & 7 & $\ldots$ & $\ldots$ & $\ldots$ & 3 & 99 \\
\hline J2-127-4-R1 & TC & as & $s p$ & middle & 7 & $\ldots$ & 59 & 0.1 & 33 & $\ldots$ & $\ldots$ & $\ldots$ & 4 & $\ldots$ & $\ldots$ & 55 & 100 \\
\hline J2-127-4-R1 & TC & as & $s p$ & middle & 7 & $\ldots$ & 59 & 0.2 & 33 & $\ldots$ & 2 & 1 & 7 & $\ldots$ & 2 & 75 & 101 \\
\hline J2-127-4-R1 & TC & as & $s p$ & middle & 7 & 0.1 & 59 & 0.2 & 34 & $\ldots$ & $\ldots$ & 2 & 5 & $\ldots$ & $\ldots$ & 84 & 100 \\
\hline J2-127-4-R1 & TC & as & wz & lining & 7 & 0.1 & 60 & 0.1 & 34 & $\ldots$ & $\ldots$ & $\ldots$ & 7 & $\ldots$ & $\ldots$ & 44 & 101 \\
\hline J2-127-4-R1 & $\mathrm{TC}$ & as & wz & lining & 10 & 2.3 & 53 & 0.1 & 34 & $\ldots$ & $\ldots$ & $\ldots$ & 5 & $\ldots$ & $\ldots$ & 57 & 100 \\
\hline J2-127-4-R1 & $\mathrm{TC}$ & as & wz & lining & 7 & $\ldots$ & 59 & 0.1 & 34 & $\ldots$ & $\ldots$ & $\ldots$ & 5 & $\ldots$ & $\ldots$ & 67 & 100 \\
\hline J2-127-4-R1 & TC & as & wz & lining & 5 & $\ldots$ & 60 & 0.1 & 34 & 5 & 2 & $\ldots$ & 7 & $\ldots$ & $\ldots$ & 58 & 100 \\
\hline J2-127-4-R1 & TC & as & wz & lining & 6 & $\ldots$ & 58 & 0.1 & 33 & $\ldots$ & $\ldots$ & $\ldots$ & 7 & $\ldots$ & $\ldots$ & 60 & 99 \\
\hline J2-127-4-R1 & TC & as & wz & lining & 5 & $\ldots$ & 60 & 0.2 & 34 & 7 & $\ldots$ & $\ldots$ & 6 & $\ldots$ & $\ldots$ & 35 & 100 \\
\hline J2-126-5-R2 & TC & rs & $\mathrm{mc}$ & lining & 46 & $\ldots$ & 0.8 & 0.7 & 52 & $\ldots$ & $\ldots$ & $\ldots$ & 68 & 5 & $\ldots$ & 1 & 100 \\
\hline J2-126-5-R2 & TC & rs & $\mathrm{mc}$ & lining & 47 & 0.2 & $\ldots$ & 0.3 & 52 & 10 & 2 & $\ldots$ & $\ldots$ & 8 & $\ldots$ & $\ldots$ & 100 \\
\hline J2-126-5-R2 & TC & rs & $\mathrm{mc}$ & lining & 47 & 0.2 & $\ldots$ & 0.2 & 52 & 9 & 2 & $\ldots$ & $\ldots$ & 25 & $\ldots$ & $\ldots$ & 100 \\
\hline J2-126-5-R2 & TC & rs & $\mathrm{mc}$ & middle & 44 & $\ldots$ & 1.3 & 2.6 & 52 & $\ldots$ & 2 & 8 & 23 & 5 & $\ldots$ & 3 & 100 \\
\hline J2-126-5-R2 & TC & rs & $\mathrm{mc}$ & exterior & 46 & $\ldots$ & $\ldots$ & 0.4 & 53 & $\ldots$ & $\ldots$ & 2 & 79 & $\ldots$ & $\ldots$ & $\ldots$ & 101 \\
\hline J2-126-5-R2 & TC & rs & $\mathrm{mc}$ & exterior & 45 & $\ldots$ & 0.1 & 0.3 & 53 & $\ldots$ & $\ldots$ & $\ldots$ & 35 & 22 & $\ldots$ & 2 & 99 \\
\hline J2-126-5-R2 & TC & rs & $\mathrm{mc}$ & exterior & 45 & $\ldots$ & 0.2 & 0.3 & 52 & 9 & 5 & $\ldots$ & 25 & 49 & $\ldots$ & 1 & 98 \\
\hline J2-126-5-R2 & TC & rs & $\mathrm{mc}$ & exterior & 44 & $\ldots$ & 0.2 & 0.3 & 53 & 7 & 3 & 1 & 39 & 36 & $\ldots$ & $\ldots$ & 98 \\
\hline J2-126-5-R2 & TC & rs & wz & lining & 7 & $\ldots$ & 59 & 0.2 & 34 & $\ldots$ & $\ldots$ & $\ldots$ & 12 & $\ldots$ & $\ldots$ & 28 & 101 \\
\hline J2-126-5-R2 & TC & rs & wz & lining & 7 & 0.2 & 60 & 0.2 & 33 & $\ldots$ & $\ldots$ & $\ldots$ & 13 & $\ldots$ & $\ldots$ & 33 & 101 \\
\hline J2-126-5-R2 & TC & rs & wz & middle & 4 & $\ldots$ & 63 & 0.2 & 33 & $\ldots$ & $\ldots$ & $\ldots$ & 7 & $\ldots$ & $\ldots$ & 14 & 101 \\
\hline J2-126-5-R2 & TC & rs & wz & middle & 5 & 0.1 & 62 & 0.2 & 34 & $\ldots$ & 2 & $\ldots$ & $\ldots$ & $\ldots$ & $\ldots$ & 24 & 101 \\
\hline J2-126-5-R2 & TC & rs & wz & middle & 6 & 0.1 & 60 & 0.2 & 33 & $\ldots$ & $\ldots$ & $\ldots$ & 7 & $\ldots$ & $\ldots$ & 42 & 100 \\
\hline J2-126-5-R2 & TC & rs & wz & middle & 6 & 0.1 & 60 & 0.1 & 33 & $\ldots$ & $\ldots$ & $\ldots$ & 8 & $\ldots$ & $\ldots$ & 18 & 100 \\
\hline
\end{tabular}


Table S4 cont. Electron microprobe data for SMS deposit samples from the Tahi Moana-1 (TMo) vent field

\begin{tabular}{|c|c|c|c|c|c|c|c|c|c|c|c|c|c|c|c|c|c|}
\hline SulfideID & $\begin{array}{l}\text { Vent } \\
\text { Field }\end{array}$ & $\begin{array}{l}\text { Sample } \\
\text { Type }\end{array}$ & Miner & I Position & $\mathrm{Fe}$ & $\mathrm{Cu}$ & $\mathrm{Zn}$ & $\mathrm{Pb}^{*}$ & $S$ & Co & $\mathrm{Se}$ & $\mathrm{Ag}$ & $\mathrm{Mn}$ & As & $\mathrm{Sb}$ & $\mathrm{Cd}$ & TOTAL \\
\hline unit & & & & & & & $w t \%$ & & & & & & $1 \mathrm{mg}$ & & & & $w t \%$ \\
\hline detection limit & & & & & 0.08 & 0.055 & 0.11 & & 0.007 & 5 & 1.5 & 1 & 4 & 2 & 1 & 1 & \\
\hline J2-450-3-R1 & TMo & $O C$ & $\mathrm{cp}$ & lining & 30 & 34 & $\ldots$ & 0.2 & 35 & 10 & $\ldots$ & 2 & $\ldots$ & $\ldots$ & $\ldots$ & $\ldots$ & 100 \\
\hline J2-450-3-R1 & TMo & $\mathrm{OC}$ & $\mathrm{cp}$ & lining & 30 & 34 & $\ldots$ & 0.1 & 35 & 7 & 4 & 2 & $\ldots$ & $\ldots$ & $\ldots$ & $\ldots$ & 98 \\
\hline J2-450-3-R1 & TMo & $\mathrm{OC}$ & $\mathrm{cp}$ & middle & 30 & 34 & 0.1 & 0.2 & 35 & 10 & 5 & 4 & $\ldots$ & $\ldots$ & $\ldots$ & $\ldots$ & 100 \\
\hline J2-450-3-R1 & TMo & $\mathrm{OC}$ & $\mathrm{cp}$ & middle & 30 & 35 & $\ldots$ & 0.1 & 35 & 8 & 5 & 3 & $\ldots$ & 5 & $\ldots$ & $\ldots$ & 100 \\
\hline J2-450-3-R1 & TMo & $\mathrm{OC}$ & $\mathrm{cp}$ & middle & 30 & 35 & $\ldots$ & 0.1 & 35 & 12 & 2 & 2 & $\ldots$ & $\ldots$ & $\ldots$ & 1 & 100 \\
\hline J2-450-3-R1 & TMo & $\mathrm{OC}$ & $\mathrm{cp}$ & middle & 30 & 34 & 0.3 & 0.2 & 35 & $\ldots$ & 3 & 2 & $\ldots$ & $\ldots$ & $\ldots$ & $\ldots$ & 100 \\
\hline J2-450-3-R1 & TMo & $\mathrm{OC}$ & $\mathrm{cp}$ & middle & 30 & 34 & 0.1 & 0.2 & 35 & 10 & 3 & 2 & $\ldots$ & $\ldots$ & $\ldots$ & $\ldots$ & 100 \\
\hline J2-450-3-R1 & TMo & oc & $\mathrm{cp}$ & exterior & 29 & 35 & 0.1 & 0.1 & 35 & 6 & 5 & 3 & $\ldots$ & $\ldots$ & $\ldots$ & $\ldots$ & 100 \\
\hline J2-450-3-R1 & TMo & $\mathrm{oc}$ & py & middle & 46 & 0.2 & $\ldots$ & 0.3 & 54 & $\ldots$ & $\ldots$ & $\ldots$ & $\ldots$ & $\ldots$ & $\ldots$ & $\ldots$ & 100 \\
\hline J2-450-3-R1 & TMo & $\mathrm{OC}$ & py & middle & 45 & 0.1 & 1.0 & 0.3 & 52 & $\ldots$ & $\ldots$ & $\ldots$ & $\ldots$ & 2 & $\ldots$ & 1 & 98 \\
\hline J2-450-3-R1 & TMo & $\mathrm{OC}$ & py & middle & 47 & 0.4 & 0.4 & 0.2 & 54 & $\ldots$ & $\ldots$ & $\ldots$ & $\ldots$ & 2 & $\ldots$ & 2 & 102 \\
\hline J2-450-3-R1 & TMo & $O C$ & wz & lining & 6 & 0.2 & 61 & 0.1 & 34 & 6 & 6 & 4 & 8 & $\ldots$ & $\ldots$ & 44 & 101 \\
\hline J2-450-3-R1 & TMo & $\mathrm{oc}$ & wz & lining & 6 & 0.1 & 58 & 0.2 & 34 & $\ldots$ & $\ldots$ & $\ldots$ & 11 & $\ldots$ & $\ldots$ & 55 & 99 \\
\hline J2-450-3-R1 & TMo & $\mathrm{OC}$ & wz & middle & 5 & 0.6 & 62 & 0.2 & 34 & $\ldots$ & 8 & 2 & 5 & $\ldots$ & $\ldots$ & 30 & 101 \\
\hline J2-450-3-R1 & TMo & $\mathrm{oc}$ & wz & middle & 6 & $\ldots$ & 59 & 0.2 & 34 & $\ldots$ & $\ldots$ & $\ldots$ & 12 & $\ldots$ & $\ldots$ & 62 & 100 \\
\hline J2-450-3-R1 & TMo & $\mathrm{OC}$ & wz & middle & 6 & 0.2 & 59 & 0.1 & 34 & $\ldots$ & $\ldots$ & $\ldots$ & 7 & $\ldots$ & $\ldots$ & 52 & 99 \\
\hline J2-450-3-R1 & TMo & $\mathrm{OC}$ & wz & middle & 5 & 0.1 & 60 & 0.1 & 33 & $\ldots$ & $\ldots$ & $\ldots$ & 8 & $\ldots$ & $\ldots$ & 60 & 100 \\
\hline J2-450-3-R1 & TMo & $\mathrm{OC}$ & wz & middle & 5 & $\ldots$ & 61 & 0.1 & 34 & $\ldots$ & $\ldots$ & $\ldots$ & 6 & $\ldots$ & $\ldots$ & 34 & 100 \\
\hline J2-450-3-R1 & TMo & $\mathrm{OC}$ & wz & exterior & 5 & $\ldots$ & 59 & 0.1 & 33 & 5 & $\ldots$ & $\ldots$ & 7 & $\ldots$ & $\ldots$ & 49 & 99 \\
\hline J2-450-3-R1 & TMo & $\mathrm{OC}$ & wz & exterior & 5 & $\ldots$ & 60 & 0.2 & 33 & 10 & $\ldots$ & $\ldots$ & 8 & $\ldots$ & $\ldots$ & 68 & 99 \\
\hline J2-444-4-R1 & TMo & as & $\mathrm{mc}$ & middle & 44 & 0.2 & 1.3 & 0.3 & 53 & $\ldots$ & $\ldots$ & 6 & 75 & 5 & $\ldots$ & $\ldots$ & 100 \\
\hline J2-444-4-R1 & TMo & as & $\mathrm{mc}$ & exterior & 45 & $\ldots$ & 0.9 & 0.5 & 53 & $\ldots$ & 3 & $\ldots$ & 40 & 4 & $\ldots$ & 1 & 100 \\
\hline J2-444-4-R1 & TMo & as & $\mathrm{mc}$ & exterior & 45 & $\ldots$ & 0.6 & 0.4 & 53 & 7 & $\ldots$ & 1 & 58 & 5 & $\ldots$ & 1 & 100 \\
\hline J2-444-4-R1 & TMo & as & $s p$ & middle & 2.3 & 0.2 & 64 & 0.1 & 33 & $\ldots$ & $\ldots$ & $\ldots$ & $\ldots$ & $\ldots$ & $\ldots$ & 30 & 101 \\
\hline J2-444-4-R1 & TMo & as & $s p$ & middle & 1.4 & 0.8 & 64 & 0.6 & 33 & $\ldots$ & $\ldots$ & $\ldots$ & $\ldots$ & 9 & 3 & 11 & 100 \\
\hline J2-444-4-R1 & TMo & as & $\mathrm{sp}$ & middle & 2.3 & 0.4 & 65 & 0.2 & 33 & 6 & $\ldots$ & $\ldots$ & $\ldots$ & $\ldots$ & 3 & 38 & 101 \\
\hline J2-444-4-R1 & TMo & as & $\mathrm{sp}$ & middle & 2.0 & 0.1 & 65 & 0.2 & 33 & $\ldots$ & $\ldots$ & $\ldots$ & $\ldots$ & $\ldots$ & $\ldots$ & 27 & 101 \\
\hline J2-444-4-R1 & TMo & as & $s p$ & middle & 1.8 & 0.4 & 65 & 0.2 & 33 & $\ldots$ & $\ldots$ & $\ldots$ & 5 & $\ldots$ & 3 & 26 & 101 \\
\hline J2-444-4-R1 & TMo & as & $\mathrm{sp}$ & middle & 2.7 & 0.3 & 64 & 0.2 & 33 & $\ldots$ & $\ldots$ & $\ldots$ & $\ldots$ & $\ldots$ & $\ldots$ & 54 & 101 \\
\hline J2-444-17-R1 & TMo & rs & $\mathrm{cp}$ & middle & 31 & 33 & $\ldots$ & 0.2 & 35 & $\ldots$ & $\ldots$ & $\ldots$ & $\ldots$ & $\ldots$ & $\ldots$ & $\ldots$ & 100 \\
\hline J2-444-17-R1 & TMo & rs & $\mathrm{mc}$ & middle & 46 & $\ldots$ & $\ldots$ & 0.4 & 54 & $\ldots$ & $\ldots$ & $\ldots$ & 26 & $\ldots$ & $\ldots$ & $\ldots$ & 100 \\
\hline J2-444-17-R1 & TMo & rs & $\mathrm{mc}$ & exterior & 45 & $\ldots$ & 1.0 & 1.0 & 53 & $\ldots$ & $\ldots$ & $\ldots$ & 8 & 6 & $\ldots$ & $\ldots$ & 100 \\
\hline J2-444-17-R1 & TMo & rs & $\mathrm{mc}$ & exterior & 43 & $\ldots$ & 3 & 0.7 & 52 & $\ldots$ & $\cdots$ & $\cdots$ & 52 & $\ldots$ & $\ldots$ & $\ldots$ & 100 \\
\hline J2-444-17-R1 & TMo & rs & $s p$ & middle & 5 & 1.4 & 60 & 0.3 & 34 & $\ldots$ & $\ldots$ & $\ldots$ & 4 & $\ldots$ & 7 & 18 & 100 \\
\hline J2-444-17-R1 & TMo & rs & $\mathrm{sp}$ & middle & 3.2 & 0.1 & 61 & 0.1 & 33 & $\ldots$ & 2 & $\ldots$ & $\ldots$ & $\ldots$ & $\ldots$ & 61 & 98 \\
\hline J2-444-17-R1 & TMo & rs & $s p$ & middle & 4 & 0.2 & 60 & 0.2 & 34 & $\ldots$ & $\ldots$ & $\ldots$ & 5 & $\ldots$ & $\ldots$ & 61 & 99 \\
\hline J2-444-17-R1 & TMo & rs & $\mathrm{sp}$ & middle & 8 & 0.8 & 57 & 0.2 & 33 & 21 & $\ldots$ & $\ldots$ & $\ldots$ & $\ldots$ & $\ldots$ & 24 & 99 \\
\hline J2-444-17-R1 & TMo & rs & $\mathrm{sp}$ & exterior & 2.3 & 0.7 & 62 & 0.5 & 33 & $\ldots$ & 4 & $\ldots$ & $\ldots$ & 11 & 11 & 9 & 99 \\
\hline
\end{tabular}


Table S4 cont. Electron microprobe data for SMS deposit samples from the ABE (A) vent field

\begin{tabular}{|c|c|c|c|c|c|c|c|c|c|c|c|c|c|c|c|c|c|}
\hline SulfidelD & $\begin{array}{l}\text { Vent } \\
\text { Field } \\
\end{array}$ & $\begin{array}{l}\text { Sample } \\
\text { Type }\end{array}$ & Mineral & Position & $\mathrm{Fe}$ & $\mathrm{Cu}$ & $\mathrm{Zn}$ & $\mathrm{Pb}^{*}$ & $S$ & Co & $\mathrm{Se}$ & $\mathrm{Ag}$ & $\mathrm{Mn}$ & As & $\mathrm{Sb}$ & $\mathrm{Cd}$ & TOTAL \\
\hline \multirow{2}{*}{\multicolumn{5}{|c|}{$\begin{array}{l}\text { unit } \\
\text { detection limit }\end{array}$}} & \multicolumn{5}{|c|}{$w t \%$} & \multicolumn{7}{|c|}{$0.1 \mathrm{mg} / \mathrm{g}$} & $w t \%$ \\
\hline & & & & & 0.08 & 0.055 & 0.11 & & 0.007 & 5 & 1.5 & 1 & 4 & 2 & 1 & 1 & \\
\hline J2-449-5-R1 & $A$ & OC & $\mathrm{cp}$ & lining & 31 & 34 & $\ldots$ & 0.1 & 36 & $\ldots$ & 3 & $\ldots$ & $\ldots$ & $\ldots$ & 1 & 2 & 101 \\
\hline J2-449-5-R1 & A & oc & $\mathrm{cp}$ & lining & 30 & 34 & 0.2 & 0.2 & 35 & 9 & 3 & 1 & $\ldots$ & $\ldots$ & $\ldots$ & 2 & 101 \\
\hline J2-449-5-R1 & A & oc & $\mathrm{cp}$ & lining & 31 & 34 & $\ldots$ & 0.1 & 35 & 7 & $\ldots$ & 1 & $\ldots$ & $\ldots$ & $\ldots$ & 2 & 100 \\
\hline J2-449-5-R1 & A & oc & $\mathrm{cp}$ & lining & 30 & 33 & $\ldots$ & 0.1 & 35 & 11 & 2 & 1 & $\ldots$ & $\ldots$ & $\ldots$ & 2 & 99 \\
\hline J2-449-5-R1 & A & $\mathrm{oc}$ & $\mathrm{cp}$ & lining & 30 & 34 & 0.2 & 0.1 & 35 & 6 & 2 & $\ldots$ & $\ldots$ & $\ldots$ & $\ldots$ & 2 & 100 \\
\hline J2-449-5-R1 & A & oc & $\mathrm{cp}$ & lining & 30 & 34 & $\ldots$ & 0.1 & 35 & 9 & $\ldots$ & $\ldots$ & $\ldots$ & $\ldots$ & $\ldots$ & 2 & 99 \\
\hline J2-449-5-R1 & A & oc & $\mathrm{cp}$ & lining & 31 & 34 & 0.1 & 0.1 & 35 & 8 & 3 & $\ldots$ & $\ldots$ & $\ldots$ & $\ldots$ & 2 & 101 \\
\hline J2-449-5-R1 & A & oc & $\mathrm{cp}$ & middle & 31 & 34 & 0.1 & 0.1 & 36 & 7 & 2 & 2 & $\ldots$ & $\ldots$ & $\ldots$ & 1 & 101 \\
\hline J2-449-5-R1 & A & oc & $\mathrm{cp}$ & middle & 30 & 34 & $\ldots$ & 0.1 & 36 & 9 & 3 & $\ldots$ & $\ldots$ & $\ldots$ & $\ldots$ & 1 & 100 \\
\hline J2-449-5-R1 & A & oc & $\mathrm{cp}$ & middle & 29 & 34 & $\ldots$ & 0.1 & 35 & $\ldots$ & 8 & 2 & $\ldots$ & $\ldots$ & $\ldots$ & 1 & 99 \\
\hline J2-449-5-R1 & A & oc & $\mathrm{cp}$ & middle & 30 & 34 & $\ldots$ & 0.1 & 35 & 10 & 5 & $\ldots$ & $\ldots$ & $\ldots$ & $\ldots$ & 2 & 100 \\
\hline J2-449-5-R1 & A & oc & $\mathrm{cp}$ & middle & 30 & 34 & 0.1 & 0.1 & 35 & 6 & 3 & $\ldots$ & $\ldots$ & $\ldots$ & $\ldots$ & 1 & 99 \\
\hline J2-449-5-R1 & A & oc & $\mathrm{cp}$ & middle & 31 & 34 & $\ldots$ & 0.1 & 35 & 6 & $\ldots$ & $\ldots$ & $\ldots$ & $\ldots$ & $\ldots$ & 2 & 100 \\
\hline J2-449-5-R1 & A & oc & $\mathrm{cp}$ & middle & 30 & 34 & 0.1 & 0.1 & 36 & 10 & 5 & $\ldots$ & $\ldots$ & $\ldots$ & $\ldots$ & 1 & 99 \\
\hline J2-449-5-R1 & A & $\mathrm{oc}$ & $\mathrm{cp}$ & exterior & 30 & 34 & 0.2 & 0.1 & 35 & 10 & 4 & 1 & $\ldots$ & $\ldots$ & $\ldots$ & 2 & 100 \\
\hline J2-449-5-R1 & A & $o c$ & $\mathrm{cp}$ & exterior & 30 & 34 & $\ldots$ & 0.1 & 35 & 10 & $\ldots$ & 3 & $\ldots$ & $\ldots$ & $\ldots$ & $\ldots$ & 100 \\
\hline J2-449-5-R1 & A & oc & $\mathrm{cp}$ & exterior & 30 & 34 & 1.8 & 0.1 & 35 & 8 & 5 & 3 & $\ldots$ & 3 & $\ldots$ & 2 & 101 \\
\hline J2-449-5-R1 & A & oc & $\mathrm{cp}$ & exterior & 30 & 34 & $\ldots$ & 0.1 & 35 & 9 & 3 & 2 & $\ldots$ & $\ldots$ & $\ldots$ & 2 & 100 \\
\hline J2-449-5-R1 & A & oc & wz & lining & 3.2 & $\ldots$ & 63 & 0.1 & 34 & 19 & $\ldots$ & 2 & 35 & 15 & 11 & $\ldots$ & 101 \\
\hline J2-449-5-R1 & A & oc & wz & lining & 3.0 & $\ldots$ & 63 & 0.2 & 34 & 14 & 12 & 3 & 8 & 8 & $\ldots$ & 23 & 101 \\
\hline J2-449-5-R1 & A & oc & wz & lining & 4 & $\ldots$ & 64 & 0.1 & 34 & $\ldots$ & 2 & $\ldots$ & 10 & $\ldots$ & $\ldots$ & 35 & 102 \\
\hline J2-449-5-R1 & A & oc & wz & middle & 2.9 & $\ldots$ & 64 & 0.1 & 34 & $\ldots$ & $\ldots$ & $\ldots$ & 11 & $\ldots$ & $\ldots$ & 29 & 101 \\
\hline J2-449-5-R1 & A & oc & wz & middle & 2.9 & $\ldots$ & 64 & 0.1 & 34 & $\ldots$ & $\ldots$ & $\ldots$ & 9 & $\ldots$ & $\ldots$ & 30 & 101 \\
\hline J2-449-5-R1 & A & oc & wz & middle & 3.2 & $\ldots$ & 64 & 0.1 & 34 & $\ldots$ & 2 & $\ldots$ & 9 & $\ldots$ & $\ldots$ & 31 & 102 \\
\hline J2-449-5-R1 & A & oc & wz & middle & 2.1 & 0.1 & 64 & 0.1 & 34 & $\ldots$ & $\ldots$ & $\ldots$ & $\ldots$ & $\ldots$ & $\ldots$ & 10 & 100 \\
\hline J2-449-5-R1 & A & oc & wz & middle & 3.0 & $\ldots$ & 63 & 0.1 & 33 & $\ldots$ & $\ldots$ & $\ldots$ & 7 & $\ldots$ & $\ldots$ & 27 & 99 \\
\hline J2-449-5-R1 & A & oc & wz & exterior & 3.3 & 0.1 & 62 & 0.1 & 33 & $\ldots$ & $\ldots$ & $\ldots$ & 10 & $\ldots$ & $\ldots$ & 35 & 100 \\
\hline J2-449-5-R1 & A & oc & wz & exterior & 3.4 & $\ldots$ & 64 & 0.1 & 34 & $\ldots$ & $\ldots$ & $\ldots$ & 9 & $\ldots$ & $\ldots$ & 33 & 101 \\
\hline J2-449-5-R1 & A & oc & $\mathrm{cv}$ & exterior & 3.5 & 71 & $\ldots$ & 0.1 & 24 & $\ldots$ & 5 & 4 & $\ldots$ & 3 & $\ldots$ & 1 & 99 \\
\hline J2-449-6-R1 & A & oc & $\mathrm{cp}$ & lining & 31 & 34 & 0.1 & 0.1 & 34 & $\ldots$ & 6 & $\ldots$ & $\ldots$ & $\ldots$ & $\ldots$ & 1 & 99 \\
\hline J2-449-6-R1 & A & oc & $\mathrm{cp}$ & lining & 30 & 34 & $\ldots$ & 0.2 & 34 & $\ldots$ & 2 & $\ldots$ & $\ldots$ & $\ldots$ & $\ldots$ & $\ldots$ & 99 \\
\hline J2-449-6-R1 & A & oc & $\mathrm{cp}$ & lining & 30 & 33 & $\ldots$ & 0.2 & 34 & $\ldots$ & 4 & $\ldots$ & $\ldots$ & $\ldots$ & $\ldots$ & $\ldots$ & 98 \\
\hline J2-449-6-R1 & A & oc & $\mathrm{cp}$ & middle & 31 & 34 & $\ldots$ & 0.2 & 35 & $\ldots$ & 6 & $\ldots$ & $\ldots$ & $\ldots$ & $\ldots$ & 1 & 99 \\
\hline J2-449-6-R1 & A & oc & $\mathrm{cp}$ & middle & 31 & 34 & $\ldots$ & 0.1 & 34 & 7 & $\ldots$ & $\ldots$ & $\ldots$ & $\ldots$ & $\ldots$ & $\ldots$ & 100 \\
\hline J2-449-6-R1 & A & oc & $\mathrm{cp}$ & middle & 31 & 34 & $\ldots$ & 0.2 & 34 & $\ldots$ & 4 & $\ldots$ & $\ldots$ & $\ldots$ & $\ldots$ & $\ldots$ & 100 \\
\hline J2-449-6-R1 & A & oc & $\mathrm{cp}$ & middle & 30 & 34 & $\ldots$ & 0.1 & 35 & 16 & $\ldots$ & 2 & $\ldots$ & $\ldots$ & $\ldots$ & 2 & 100 \\
\hline J2-449-6-R1 & A & $\mathrm{OC}$ & $\mathrm{cp}$ & exterior & 30 & 34 & $\ldots$ & 0.2 & 34 & $\ldots$ & $\ldots$ & $\ldots$ & $\ldots$ & $\ldots$ & $\ldots$ & $\ldots$ & 99 \\
\hline J2-449-6-R1 & A & $\mathrm{OC}$ & $\mathrm{cp}$ & exterior & 30 & 34 & $\ldots$ & 0.2 & 35 & $\ldots$ & $\ldots$ & $\ldots$ & $\ldots$ & $\ldots$ & $\ldots$ & $\ldots$ & 99 \\
\hline J2-449-6-R1 & A & $\mathrm{OC}$ & py & lining & 46 & 0.3 & $\ldots$ & 0.2 & 53 & $\ldots$ & 8 & $\ldots$ & $\ldots$ & $\ldots$ & $\ldots$ & 2 & 100 \\
\hline J2-449-6-R1 & A & oc & py & lining & 46 & 0.4 & $\ldots$ & 0.2 & 53 & $\ldots$ & 29 & $\ldots$ & $\ldots$ & 6 & $\ldots$ & 2 & 100 \\
\hline J2-449-6-R1 & A & oc & py & lining & 47 & 0.2 & $\ldots$ & 0.2 & 54 & $\ldots$ & 2 & 2 & $\ldots$ & 3 & $\ldots$ & 2 & 101 \\
\hline J2-449-6-R1 & A & oc & py & middle & 46 & 0.1 & $\ldots$ & 0.2 & 53 & $\ldots$ & 5 & $\ldots$ & $\ldots$ & $\ldots$ & $\ldots$ & 3 & 99 \\
\hline J2-449-6-R1 & A & OC & py & middle & 46 & 0.3 & $\ldots$ & 0.3 & 53 & $\ldots$ & 7 & $\ldots$ & $\ldots$ & $\ldots$ & $\ldots$ & 2 & 100 \\
\hline J2-449-6-R1 & A & oc & py & middle & 46 & 0.5 & $\ldots$ & 0.2 & 53 & $\ldots$ & 16 & $\ldots$ & $\ldots$ & 13 & $\ldots$ & 2 & 100 \\
\hline J2-449-6-R1 & A & oc & py & middle & 46 & 0.8 & $\ldots$ & 0.2 & 53 & $\ldots$ & 24 & 2 & $\ldots$ & $\ldots$ & $\ldots$ & 2 & 100 \\
\hline J2-449-6-R1 & A & oc & py & exterior & 46 & 1.1 & $\ldots$ & 0.2 & 54 & $\ldots$ & $\ldots$ & 1 & $\ldots$ & $\ldots$ & $\ldots$ & 2 & 101 \\
\hline
\end{tabular}


Table S4 cont. Electron microprobe data for SMS deposit samples from the ABE (A) vent field

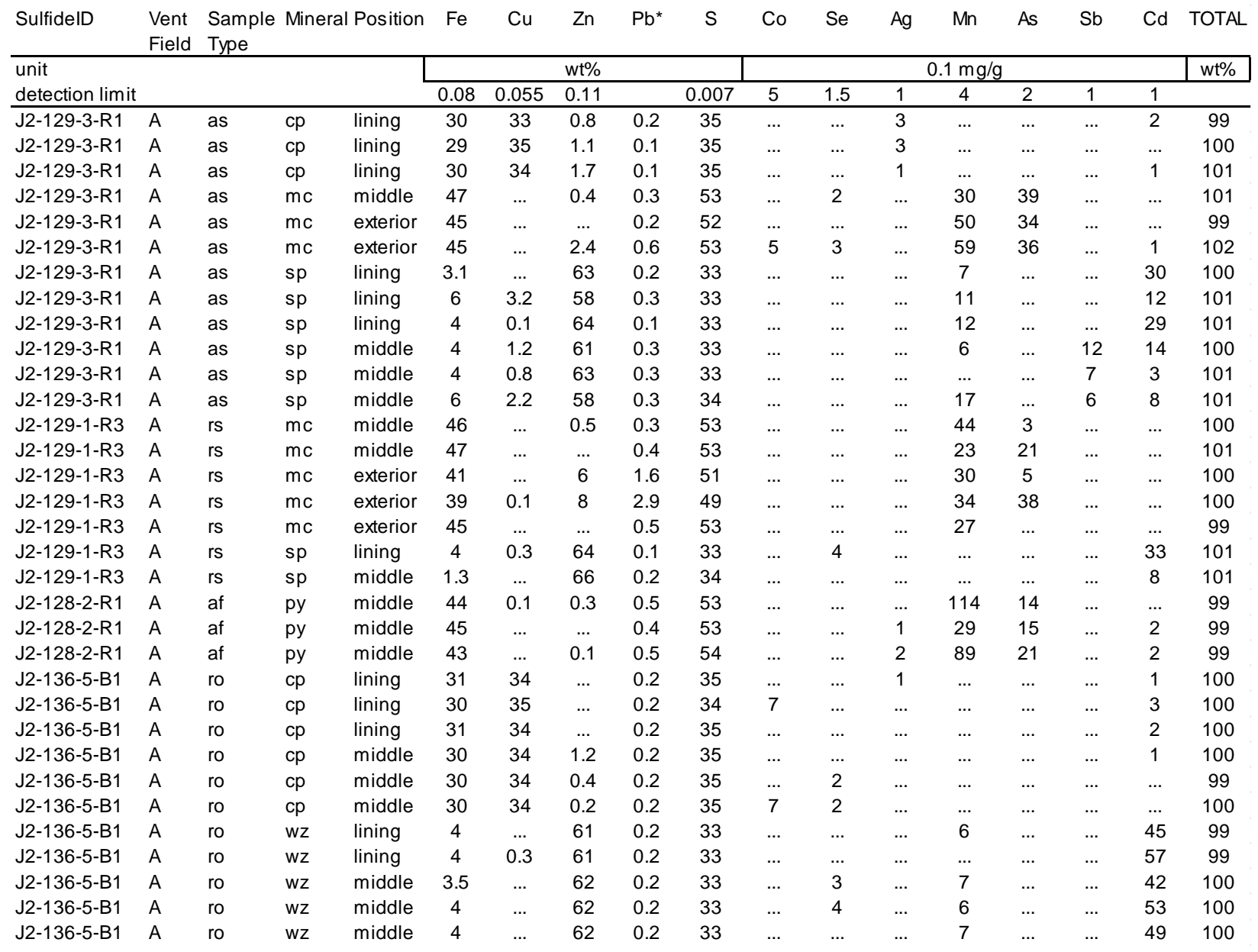


Table S4 cont. Electron microprobe data for SMS deposit samples from the Tu'i Malila (TM) vent field

\begin{tabular}{|c|c|c|c|c|c|c|c|c|c|c|c|c|c|c|c|c|c|}
\hline SulfideID & $\begin{array}{l}\text { Vent } \\
\text { Field }\end{array}$ & $\begin{array}{l}\text { Sample } \\
\text { Type }\end{array}$ & Minera & Position & $\mathrm{Fe}$ & $\mathrm{Cu}$ & $\mathrm{Zn}$ & $\mathrm{Pb}^{*}$ & S & Co & $\mathrm{Se}$ & $\mathrm{Ag}$ & $\mathrm{Mn}$ & As & $\mathrm{Sb}$ & $\mathrm{Cd}$ & TOTAL \\
\hline & & & & & & & $w t \%$ & & & & & & $1 \mathrm{mc}$ & & & & $w t \%$ \\
\hline detection limit & & & & & 0.08 & 0.055 & 0.11 & & 0.007 & 5 & 1.5 & 1 & 4 & 2 & 1 & 1 & \\
\hline J2-134-7-R1 & TM & $O C$ & $\mathrm{cp}$ & lining & 29 & 34 & 0.3 & 0.2 & 35 & $\ldots$ & $\ldots$ & 1 & $\ldots$ & $\ldots$ & $\ldots$ & 2 & 99 \\
\hline J2-134-7-R1 & TM & oc & $\mathrm{cp}$ & lining & 30 & 35 & 0.3 & 0.2 & 35 & 6 & $\ldots$ & $\ldots$ & $\ldots$ & $\ldots$ & $\ldots$ & 3 & 100 \\
\hline J2-134-7-R1 & TM & oc & $\mathrm{cp}$ & lining & 29 & 35 & 0.6 & 0.2 & 36 & $\ldots$ & $\ldots$ & 4 & $\ldots$ & $\ldots$ & $\ldots$ & 2 & 100 \\
\hline J2-134-7-R1 & TM & $\mathrm{oc}$ & $\mathrm{mc}$ & exterior & 47 & 0.1 & $\ldots$ & 0.3 & 53 & $\ldots$ & $\ldots$ & $\ldots$ & $\ldots$ & $\ldots$ & $\ldots$ & $\ldots$ & 101 \\
\hline J2-134-7-R1 & TM & oc & $\mathrm{mc}$ & exterior & 47 & 0.3 & $\ldots$ & 0.3 & 53 & $\ldots$ & $\ldots$ & $\ldots$ & $\ldots$ & $\ldots$ & $\ldots$ & $\ldots$ & 101 \\
\hline J2-134-7-R1 & TM & oc & wz & lining & 6 & $\ldots$ & 60 & 0.2 & 34 & $\ldots$ & $\ldots$ & $\ldots$ & 7 & $\ldots$ & $\ldots$ & 32 & 101 \\
\hline J2-134-7-R1 & TM & oc & wz & lining & 7 & $\ldots$ & 60 & 0.1 & 33 & $\ldots$ & $\ldots$ & $\ldots$ & 6 & $\ldots$ & $\ldots$ & 43 & 101 \\
\hline J2-134-7-R1 & TM & $O C$ & wz & lining & 6 & 0.1 & 61 & 0.1 & 34 & $\ldots$ & $\ldots$ & 2 & 4 & $\ldots$ & $\ldots$ & 44 & 101 \\
\hline J2-134-7-R1 & TM & $\mathrm{OC}$ & wz & middle & 9 & 0.1 & 58 & 0.2 & 34 & $\ldots$ & $\ldots$ & $\ldots$ & 12 & $\ldots$ & $\ldots$ & 33 & 101 \\
\hline J2-134-7-R1 & TM & $\mathrm{OC}$ & wz & middle & 7 & 0.1 & 59 & 0.2 & 33 & $\ldots$ & $\ldots$ & $\ldots$ & 8 & $\ldots$ & $\ldots$ & 21 & 100 \\
\hline J2-134-7-R1 & TM & $\mathrm{OC}$ & wz & middle & 8 & $\ldots$ & 59 & 0.2 & 34 & $\ldots$ & $\ldots$ & $\ldots$ & 10 & $\ldots$ & $\ldots$ & 14 & 100 \\
\hline J2-134-7-R1 & TM & $\mathrm{OC}$ & wz & middle & 9 & 0.6 & 57 & 0.2 & 34 & $\ldots$ & $\ldots$ & $\ldots$ & 6 & $\ldots$ & 3 & 15 & 100 \\
\hline J2-442-4-R2 & TM & $\mathrm{OC}$ & $\mathrm{cp}$ & lining & 30 & 34 & 0.2 & 0.1 & 36 & $\ldots$ & $\ldots$ & $\ldots$ & $\ldots$ & $\ldots$ & 2 & 3 & 99 \\
\hline J2-442-4-R2 & TM & oc & $\mathrm{cp}$ & lining & 29 & 34 & 0.2 & 0.1 & 35 & $\ldots$ & 7 & $\ldots$ & $\ldots$ & $\ldots$ & $\ldots$ & 3 & 100 \\
\hline J2-442-4-R2 & TM & oc & $\mathrm{cp}$ & lining & 29 & 35 & 0.1 & 0.2 & 35 & $\ldots$ & 3 & $\ldots$ & $\ldots$ & $\ldots$ & $\ldots$ & 3 & 100 \\
\hline J2-442-4-R2 & $\mathrm{TM}$ & oc & $\mathrm{cp}$ & lining & 29 & 34 & 0.2 & 0.1 & 36 & $\ldots$ & 5 & $\ldots$ & $\ldots$ & $\ldots$ & $\ldots$ & 2 & 98 \\
\hline J2-442-4-R2 & TM & oc & $\mathrm{cp}$ & middle & 29 & 34 & $\ldots$ & 0.2 & 35 & $\ldots$ & 3 & $\ldots$ & $\ldots$ & $\ldots$ & $\ldots$ & 2 & 99 \\
\hline J2-442-4-R2 & TM & oc & $\mathrm{cp}$ & middle & 29 & 35 & $\ldots$ & 0.2 & 36 & $\ldots$ & 7 & $\ldots$ & $\ldots$ & $\ldots$ & $\ldots$ & 2 & 100 \\
\hline J2-442-4-R2 & TM & oc & $\mathrm{cp}$ & exterior & 29 & 34 & $\ldots$ & 0.1 & 35 & $\ldots$ & 2 & $\ldots$ & $\ldots$ & $\ldots$ & $\ldots$ & 2 & 99 \\
\hline J2-442-4-R2 & TM & oc & py & lining & 45 & 0.1 & $\ldots$ & 0.3 & 54 & $\ldots$ & $\ldots$ & $\ldots$ & $\ldots$ & $\ldots$ & $\ldots$ & $\ldots$ & 99 \\
\hline J2-442-4-R2 & TM & oc & py & lining & 46 & 0.1 & $\ldots$ & 0.2 & 54 & 6 & 3 & $\ldots$ & $\ldots$ & $\ldots$ & 1 & $\ldots$ & 101 \\
\hline J2-442-4-R2 & TM & oc & py & lining & 46 & 0.5 & $\ldots$ & 0.2 & 53 & $\ldots$ & 4 & $\ldots$ & $\ldots$ & $\ldots$ & $\ldots$ & 2 & 100 \\
\hline J2-442-4-R2 & TM & oc & py & lining & 46 & 0.8 & $\ldots$ & 0.2 & 53 & $\ldots$ & 4 & $\ldots$ & $\ldots$ & $\ldots$ & $\ldots$ & $\ldots$ & 100 \\
\hline J2-442-4-R2 & TM & $\mathrm{oc}$ & py & middle & 45 & 0.2 & $\ldots$ & 0.3 & 54 & $\ldots$ & $\ldots$ & $\ldots$ & $\ldots$ & 2 & $\ldots$ & $\ldots$ & 99 \\
\hline J2-442-4-R2 & $\mathrm{TM}$ & oc & py & middle & 46 & 0.2 & $\ldots$ & 0.2 & 53 & $\ldots$ & $\ldots$ & $\ldots$ & $\ldots$ & $\ldots$ & $\ldots$ & 1 & 100 \\
\hline J2-442-4-R2 & $\mathrm{TM}$ & oc & py & exterior & 46 & 0.1 & $\ldots$ & 0.2 & 53 & $\ldots$ & 10 & $\ldots$ & $\ldots$ & $\ldots$ & $\ldots$ & 2 & 100 \\
\hline J2-442-4-R2 & TM & oc & wz & exterior & 4 & 0.7 & 60 & 0.1 & 33 & $\ldots$ & 7 & $\ldots$ & $\ldots$ & $\ldots$ & $\ldots$ & 83 & 99 \\
\hline J2-442-4-R2 & TM & oc & wz & exterior & 6 & 4 & 55 & 0.2 & 33 & $\ldots$ & $\ldots$ & $\ldots$ & 10 & $\ldots$ & 6 & 60 & 99 \\
\hline J2-442-4-R2 & TM & oc & wz & exterior & 4 & 0.7 & 60 & 0.1 & 33 & $\ldots$ & $\ldots$ & $\ldots$ & 4 & $\ldots$ & 4 & 75 & 99 \\
\hline J2-134-9-R1 & TM & as & py & lining & 44 & $\ldots$ & $\ldots$ & 0.5 & 53 & 13 & 2 & $\ldots$ & 85 & 5 & $\ldots$ & 2 & 98 \\
\hline J2-134-9-R1 & TM & as & py & lining & 46 & $\ldots$ & 0.9 & 0.3 & 53 & $\ldots$ & $\ldots$ & $\ldots$ & $\ldots$ & 7 & $\ldots$ & 2 & 101 \\
\hline J2-134-9-R1 & TM & as & py & middle & 46 & $\ldots$ & $\ldots$ & 0.3 & 53 & 9 & $\ldots$ & $\ldots$ & 18 & 51 & $\ldots$ & 2 & 100 \\
\hline J2-134-9-R1 & TM & as & py & exterior & 45 & $\ldots$ & $\ldots$ & 0.3 & 54 & $\ldots$ & $\ldots$ & $\ldots$ & 32 & 22 & $\ldots$ & 1 & 100 \\
\hline J2-134-9-R1 & TM & as & py & exterior & 45 & $\ldots$ & $\ldots$ & 0.4 & 53 & $\ldots$ & $\ldots$ & $\ldots$ & 14 & 38 & $\ldots$ & $\ldots$ & 99 \\
\hline J2-134-9-R1 & TM & as & $s p$ & lining & 10 & 0.7 & 55 & 0.3 & 34 & 6 & $\ldots$ & $\ldots$ & 12 & $\ldots$ & 3 & 5 & 100 \\
\hline J2-134-9-R1 & TM & as & $\mathrm{sp}$ & lining & 12 & $\ldots$ & 53 & 0.2 & 34 & 7 & $\ldots$ & $\ldots$ & 18 & $\ldots$ & $\ldots$ & 18 & 99 \\
\hline J2-134-9-R1 & TM & as & $\mathrm{sp}$ & lining & 14 & 5 & 46 & 0.4 & 34 & $\ldots$ & 2 & 17 & 13 & $\ldots$ & 1 & 6 & 99 \\
\hline J2-134-9-R1 & TM & as & wz & lining & 12 & 0.1 & 54 & 0.2 & 34 & $\ldots$ & $\ldots$ & $\ldots$ & 14 & $\ldots$ & $\ldots$ & 14 & 101 \\
\hline J2-134-9-R1 & TM & as & wz & lining & 13 & 0.1 & 52 & 0.2 & 34 & 9 & $\ldots$ & $\ldots$ & 25 & $\ldots$ & $\ldots$ & 21 & 100 \\
\hline J2-134-9-R1 & TM & as & wz & lining & 13 & $\ldots$ & 53 & 0.2 & 34 & $\ldots$ & $\ldots$ & $\ldots$ & 16 & $\ldots$ & $\ldots$ & 16 & 100 \\
\hline
\end{tabular}


Table S4 cont. Electron microprobe data for SMS deposit samples from the Tu'i Malila (TM) vent field

\begin{tabular}{|c|c|c|c|c|c|c|c|c|c|c|c|c|c|c|c|c|c|}
\hline SulfidelD & $\begin{array}{l}\text { Vent } \\
\text { Field }\end{array}$ & $\begin{array}{l}\text { Sample } \\
\text { Type }\end{array}$ & Mineral & Position & $\mathrm{Fe}$ & $\mathrm{Cu}$ & $\mathrm{Zn}$ & $\mathrm{Pb}^{*}$ & $S$ & Co & Se & $\mathrm{Ag}$ & $\mathrm{Mn}$ & As & $\mathrm{Sb}$ & $\mathrm{Cd}$ & TOTAL \\
\hline & & & & & & & $w t \%$ & & & \multicolumn{7}{|c|}{$0.1 \mathrm{mg} / \mathrm{g}$} & $w t \%$ \\
\hline detection limit & & & & & 0.08 & 0.055 & 0.11 & & 0.007 & 5 & 1.5 & 1 & 4 & 2 & 1 & 1 & \\
\hline J2-447-7-R2 & TM & rs & $\mathrm{cp}$ & lining & 31 & 35 & $\ldots$ & 0.2 & 35 & 8 & $\ldots$ & 2 & $\ldots$ & $\ldots$ & 2 & $\ldots$ & 102 \\
\hline J2-447-7-R2 & TM & rs & $\mathrm{cp}$ & lining & 31 & 35 & $\ldots$ & 0.2 & 35 & $\ldots$ & $\ldots$ & $\ldots$ & $\ldots$ & $\ldots$ & $\ldots$ & 1 & 102 \\
\hline J2-447-7-R2 & TM & rs & $\mathrm{cp}$ & lining & 31 & 35 & $\ldots$ & 0.2 & 35 & 9 & $\ldots$ & $\ldots$ & $\ldots$ & $\ldots$ & $\ldots$ & 2 & 101 \\
\hline J2-447-7-R2 & TM & rs & $\mathrm{mc}$ & middle & 44 & $\ldots$ & $\ldots$ & 0.3 & 54 & $\ldots$ & $\ldots$ & $\ldots$ & 37 & 17 & $\ldots$ & $\ldots$ & 99 \\
\hline J2-447-7-R2 & TM & rs & $\mathrm{mc}$ & exterior & 46 & 0.4 & $\ldots$ & 0.5 & 53 & $\ldots$ & $\ldots$ & $\ldots$ & 10 & 39 & $\ldots$ & $\ldots$ & 100 \\
\hline J2-447-7-R2 & TM & rs & $\mathrm{mc}$ & exterior & 46 & 0.1 & 1.1 & 0.5 & 53 & $\ldots$ & 3 & $\ldots$ & 37 & $\ldots$ & $\ldots$ & $\ldots$ & 101 \\
\hline J2-447-7-R2 & TM & rs & $s p$ & lining & 1.2 & 0.4 & 66 & 0.2 & 33 & 23 & 5 & 1 & $\ldots$ & 10 & 16 & 57 & 102 \\
\hline J2-447-7-R2 & TM & rs & $\mathrm{sp}$ & lining & 0.9 & 0.2 & 67 & 0.2 & 33 & 6 & 4 & $\ldots$ & $\ldots$ & $\ldots$ & 5 & 58 & 102 \\
\hline J2-447-7-R2 & TM & rs & $\mathrm{sp}$ & exterior & 1.4 & 0.5 & 65 & 0.4 & 33 & 10 & 3 & 2 & $\ldots$ & 14 & 15 & 11 & 101 \\
\hline J2-447-7-R2 & TM & rs & $\mathrm{sp}$ & exterior & 2.3 & 0.7 & 62 & 0.3 & 33 & 19 & 8 & 2 & 6 & 7 & 8 & 31 & 100 \\
\hline J2-132-8-R1 & TM & af & py & middle & 45 & $\ldots$ & $\ldots$ & 0.8 & 53 & $\ldots$ & $\ldots$ & 107 & 8 & $\ldots$ & $\ldots$ & $\ldots$ & 100 \\
\hline J2-132-8-R1 & TM & af & py & middle & 45 & $\ldots$ & $\ldots$ & 1.2 & 53 & $\ldots$ & $\ldots$ & $\ldots$ & 10 & 40 & $\ldots$ & $\ldots$ & 100 \\
\hline J2-132-8-R1 & TM & af & py & middle & 45 & $\ldots$ & $\ldots$ & 0.4 & 54 & $\ldots$ & $\ldots$ & 38 & 20 & 18 & $\ldots$ & 1 & 100 \\
\hline J2-132-8-R1 & TM & af & py & middle & 44 & 0.2 & $\ldots$ & 1.1 & 53 & $\ldots$ & $\ldots$ & 11 & 12 & 11 & 1 & $\ldots$ & 99 \\
\hline J2-132-8-R1 & TM & af & py & middle & 45 & 0.6 & $\ldots$ & 0.6 & 54 & $\ldots$ & $\ldots$ & 42 & 23 & 24 & $\ldots$ & 2 & 100 \\
\hline J2-132-8-R1 & TM & af & $\mathrm{mc}$ & middle & 45 & $\ldots$ & $\ldots$ & 0.3 & 53 & 9 & $\ldots$ & 6 & 59 & 30 & 2 & 2 & 101 \\
\hline J2-132-8-R1 & TM & af & $\mathrm{mc}$ & middle & 46 & $\ldots$ & $\ldots$ & 1.8 & 52 & 14 & 4 & $\ldots$ & $\ldots$ & 70 & 8 & 3 & 101 \\
\hline J2-132-8-R1 & TM & af & $\mathrm{mc}$ & exterior & 44 & 0.4 & 0.2 & 3.7 & 50 & 20 & 6 & $\ldots$ & 6 & 138 & 20 & 5 & 101 \\
\hline J2-132-8-R1 & TM & af & $s p$ & exterior & 7 & 2.0 & 55 & 0.4 & 33 & $\ldots$ & $\ldots$ & $\ldots$ & 4 & 4 & 46 & 4 & 98 \\
\hline J2-138-7-R1 & TM & af & $\mathrm{sp}$ & middle & 1.9 & 0.4 & 65 & 0.3 & 33 & $\ldots$ & $\ldots$ & 10 & $\ldots$ & $\ldots$ & 20 & 25 & 101 \\
\hline J2-138-7-R1 & TM & af & $\mathrm{sp}$ & middle & 1.8 & 0.6 & 65 & 0.2 & 33 & $\ldots$ & $\ldots$ & $\ldots$ & $\ldots$ & $\ldots$ & 14 & 16 & 101 \\
\hline J2-138-7-R1 & TM & af & $s p$ & middle & 3.3 & 2.4 & 59 & 2.2 & 33 & $\ldots$ & $\ldots$ & $\ldots$ & $\ldots$ & 38 & 25 & 10 & 100 \\
\hline $\mathrm{J} 2-442-12-\mathrm{R} 2$ & TM & af & py & middle & 44 & 0.4 & 0.3 & 0.3 & 54 & 6 & 3 & 38 & 59 & 34 & $\ldots$ & 2 & 100 \\
\hline J2-442-12-R2 & TM & af & py & middle & 47 & $\ldots$ & $\ldots$ & 0.3 & $\ldots$ & $\ldots$ & $\ldots$ & $\ldots$ & 6 & 18 & $\ldots$ & 3 & 100 \\
\hline J2-442-12-R2 & TM & af & py & middle & 45 & $\ldots$ & $\ldots$ & 1.1 & $\ldots$ & $\ldots$ & $\ldots$ & $\ldots$ & 10 & 18 & $\ldots$ & 2 & 100 \\
\hline J2-442-12-R2 & TM & af & $\mathrm{sp}$ & middle & 1.2 & 0.3 & 66 & 0.2 & $\ldots$ & $\ldots$ & $\ldots$ & $\ldots$ & $\ldots$ & $\ldots$ & 11 & 33 & 101 \\
\hline J2-442-12-R2 & TM & af & $\mathrm{sp}$ & middle & 3.1 & 0.9 & 63 & 0.2 & 33 & 7 & 2 & $\ldots$ & $\ldots$ & 4 & 10 & 65 & 101 \\
\hline J2-442-12-R2 & TM & af & $\mathrm{sp}$ & middle & 2.1 & 1.2 & 62 & 0.3 & 33 & $\ldots$ & $\ldots$ & $\ldots$ & $\ldots$ & 16 & 30 & 40 & 99 \\
\hline J2-132-10-R1 & TM & br & $\mathrm{cp}$ & middle & 30 & 34 & $\ldots$ & 0.2 & 35 & $\ldots$ & 4 & $\ldots$ & $\ldots$ & $\ldots$ & $\ldots$ & 2 & 100 \\
\hline J2-132-10-R1 & TM & br & $\mathrm{cp}$ & middle & 30 & 34 & $\ldots$ & 0.2 & 35 & 9 & 4 & $\ldots$ & $\ldots$ & $\ldots$ & $\ldots$ & 2 & 100 \\
\hline J2-132-10-R1 & TM & br & $\mathrm{cp}$ & middle & 31 & 34 & $\ldots$ & 0.2 & 35 & $\ldots$ & $\ldots$ & $\ldots$ & $\ldots$ & $\ldots$ & $\ldots$ & 3 & 100 \\
\hline J2-132-10-R1 & TM & $\mathrm{br}$ & py & middle & 47 & 0.1 & $\ldots$ & 0.3 & 53 & 9 & 2 & $\cdots$ & $\cdots$ & $\ldots$ & $\ldots$ & 3 & 101 \\
\hline J2-132-10-R1 & TM & br & py & middle & 47 & 0.1 & 0.6 & 0.3 & 52 & 29 & 4 & $\ldots$ & $\ldots$ & 9 & $\ldots$ & 2 & 100 \\
\hline J2-132-10-R1 & TM & br & py & middle & 48 & $\ldots$ & $\ldots$ & 0.3 & 53 & $\ldots$ & 5 & $\ldots$ & $\ldots$ & 2 & $\ldots$ & 1 & 101 \\
\hline J2-132-10-R1 & TM & $\mathrm{br}$ & $\mathrm{sp}$ & middle & 2.3 & 0.1 & 64 & 0.1 & 33 & $\ldots$ & $\ldots$ & $\ldots$ & 4 & $\ldots$ & $\ldots$ & 33 & 100 \\
\hline J2-132-10-R1 & TM & br & $\mathrm{sp}$ & middle & 1.4 & 0.1 & 65 & 0.2 & 33 & $\ldots$ & 3 & $\ldots$ & $\ldots$ & $\ldots$ & $\ldots$ & 23 & 100 \\
\hline J2-132-10-R1 & TM & $\mathrm{br}$ & $\mathrm{sp}$ & middle & 3.3 & $\ldots$ & 63 & 0.2 & 33 & $\ldots$ & $\ldots$ & $\ldots$ & $\ldots$ & $\ldots$ & $\ldots$ & 17 & 100 \\
\hline
\end{tabular}


Table S4 cont. Electron microprobe data for SMS deposit samples from the Mariner (MA) vent field

\begin{tabular}{|c|c|c|c|c|c|c|c|c|c|c|c|c|c|c|c|c|c|}
\hline \multirow{3}{*}{$\begin{array}{l}\text { SulfidelD } \\
\text { unit } \\
\text { detection limit }\end{array}$} & \multirow[t]{3}{*}{$\begin{array}{l}\text { Vent } \\
\text { Field }\end{array}$} & \multirow[t]{3}{*}{$\begin{array}{l}\text { Sample } \\
\text { Type }\end{array}$} & \multicolumn{2}{|c|}{ Mineral Position } & $\mathrm{Fe}$ & $\mathrm{Cu}$ & \multirow{2}{*}{$\begin{array}{c}\mathrm{Zn} \\
\mathrm{wt} \% \\
\end{array}$} & \multirow[t]{2}{*}{$\mathrm{Pb}^{*}$} & \multirow[t]{2}{*}{$S$} & \multirow[t]{2}{*}{ Co } & \multirow[t]{2}{*}{ Se } & \multirow[t]{2}{*}{$\mathrm{Ag}$} & \multirow{2}{*}{\multicolumn{2}{|c|}{$\begin{array}{l}\mathrm{Mn} \\
1 \mathrm{mg} / \mathrm{g}\end{array}$}} & \multirow[t]{2}{*}{$\mathrm{Sb}$} & \multirow[t]{2}{*}{$\mathrm{Cd}$} & \multirow{3}{*}{$\begin{array}{l}\text { TOTAL } \\
\text { wt\% } \\
\end{array}$} \\
\hline & & & & & & & & & & & & & & & & & \\
\hline & & & & & 0.08 & 0.055 & 0.11 & & 0.007 & 5 & 1.5 & 1 & 4 & 2 & 1 & 1 & \\
\hline J2-130-1-R1 & MA & $O C$ & $\mathrm{cp}$ & middle & 30 & 33 & 0.1 & 0.1 & 36 & $\ldots$ & $\ldots$ & 4 & $\ldots$ & $\ldots$ & $\ldots$ & $\ldots$ & 99 \\
\hline J2-130-1-R1 & MA & oc & $\mathrm{cp}$ & middle & 29 & 34 & $\ldots$ & 0.2 & 35 & $\ldots$ & $\ldots$ & 4 & $\ldots$ & $\ldots$ & $\ldots$ & $\ldots$ & 99 \\
\hline J2-130-1-R1 & MA & oc & $\mathrm{cp}$ & exterior & 30 & 34 & $\ldots$ & 0.1 & 35 & $\ldots$ & $\ldots$ & 2 & $\ldots$ & $\ldots$ & $\ldots$ & $\ldots$ & 100 \\
\hline J2-130-1-R1 & MA & oc & py & exterior & 45 & 0.2 & $\ldots$ & 0.7 & 54 & $\ldots$ & $\ldots$ & 2 & $\ldots$ & $\ldots$ & $\ldots$ & $\ldots$ & 99 \\
\hline J2-130-1-R1 & MA & $\mathrm{OC}$ & py & exterior & 46 & 0.1 & $\ldots$ & 0.3 & 54 & $\ldots$ & $\ldots$ & $\ldots$ & $\ldots$ & $\ldots$ & $\ldots$ & $\ldots$ & 100 \\
\hline J2-130-1-R1 & MA & oc & wz & middle & 3.4 & 0.4 & 62 & 0.2 & 34 & $\ldots$ & $\ldots$ & $\ldots$ & $\ldots$ & $\ldots$ & 5 & 50 & 100 \\
\hline J2-130-1-R1 & MA & oc & bn & middle & 12 & 59 & $\ldots$ & 0.1 & 30 & $\ldots$ & $\ldots$ & 3 & $\ldots$ & $\ldots$ & $\ldots$ & $\ldots$ & 100 \\
\hline J2-130-1-R1 & MA & $\mathrm{OC}$ & bn & middle & 9 & 63 & $\ldots$ & 0.1 & 28 & 13 & $\ldots$ & $\ldots$ & $\ldots$ & $\ldots$ & $\ldots$ & $\ldots$ & 101 \\
\hline J2-130-1-R1 & MA & $\mathrm{oc}$ & bn & exterior & 11 & 62 & $\ldots$ & 0.0 & 27 & $\ldots$ & $\ldots$ & $\ldots$ & $\ldots$ & $\ldots$ & 1 & 4 & 100 \\
\hline J2-130-1-R1 & MA & oc & $\mathrm{bn} / \mathrm{cv}$ & middle & 9 & 64 & $\ldots$ & 0.1 & 28 & $\ldots$ & $\ldots$ & $\ldots$ & $\ldots$ & $\ldots$ & $\ldots$ & $\ldots$ & 100 \\
\hline J2-130-1-R1 & MA & $\mathrm{OC}$ & $\mathrm{bn} / \mathrm{cv}$ & middle & 9 & 62 & $\ldots$ & 0.1 & 29 & $\ldots$ & $\ldots$ & 17 & $\ldots$ & $\ldots$ & $\ldots$ & $\ldots$ & 100 \\
\hline J2-130-1-R2 & MA & $\mathrm{OC}$ & $\mathrm{cp}$ & lining & 29 & 34 & $\ldots$ & 0.1 & 35 & 10 & 4 & $\ldots$ & $\ldots$ & $\ldots$ & $\ldots$ & $\ldots$ & 99 \\
\hline J2-130-1-R2 & MA & $\mathrm{OC}$ & $\mathrm{cp}$ & lining & 29 & 35 & $\ldots$ & 0.1 & 35 & 13 & 3 & $\ldots$ & $\ldots$ & $\ldots$ & $\ldots$ & 1 & 100 \\
\hline J2-130-1-R2 & MA & $\mathrm{OC}$ & $\mathrm{cV}$ & lining & 4 & 70 & 0.4 & 0.1 & 25 & 11 & 9 & $\ldots$ & $\ldots$ & 3 & 1 & 4 & 100 \\
\hline J2-130-1-R2 & MA & oc & $\mathrm{cV}$ & lining & 6 & 66 & 0.2 & 0.1 & 26 & 5 & 3 & $\ldots$ & $\ldots$ & $\ldots$ & $\ldots$ & 2 & 99 \\
\hline J2-130-1-R2 & MA & $\mathrm{OC}$ & $\mathrm{cV}$ & lining & 4 & 68 & 0.2 & 0.1 & 26 & $\ldots$ & $\ldots$ & 1 & $\ldots$ & $\ldots$ & $\ldots$ & 2 & 98 \\
\hline J2-437-3-R2 & MA & $\mathrm{OC}$ & $\mathrm{cp}$ & lining & 30 & 34 & $\ldots$ & 0.2 & 35 & $\ldots$ & $\ldots$ & 2 & $\ldots$ & $\ldots$ & $\ldots$ & 2 & 100 \\
\hline J2-437-3-R2 & MA & oc & $\mathrm{cp}$ & lining & 31 & 35 & $\ldots$ & 0.2 & 35 & $\ldots$ & $\ldots$ & $\ldots$ & $\ldots$ & $\ldots$ & $\ldots$ & 2 & 100 \\
\hline J2-437-3-R2 & MA & $\mathrm{OC}$ & $\mathrm{cp}$ & lining & 30 & 34 & $\ldots$ & 0.1 & 35 & $\ldots$ & 3 & $\ldots$ & $\ldots$ & $\ldots$ & $\ldots$ & 3 & 100 \\
\hline J2-437-3-R2 & MA & $\mathrm{OC}$ & $\mathrm{cp}$ & lining & 30 & 34 & 0.5 & 0.2 & 35 & $\ldots$ & $\ldots$ & $\ldots$ & $\ldots$ & $\ldots$ & $\ldots$ & $\ldots$ & 100 \\
\hline J2-437-3-R2 & MA & $\mathrm{OC}$ & $\mathrm{cp}$ & exterior & 30 & 34 & $\ldots$ & 0.2 & 35 & $\ldots$ & $\ldots$ & 4 & $\ldots$ & $\ldots$ & 2 & $\ldots$ & 100 \\
\hline J2-437-3-R2 & MA & $\mathrm{OC}$ & $\mathrm{cp}$ & exterior & 30 & 34 & $\ldots$ & 0.2 & 35 & 7 & $\ldots$ & 2 & $\ldots$ & $\ldots$ & $\ldots$ & $\ldots$ & 100 \\
\hline J2-437-3-R2 & MA & $\mathrm{oc}$ & $\mathrm{cp}$ & exterior & 30 & 34 & 0.3 & 0.2 & 35 & 6 & 3 & $\ldots$ & $\ldots$ & 10 & 6 & $\ldots$ & 100 \\
\hline J2-437-3-R2 & MA & $\mathrm{OC}$ & py & exterior & 48 & $\ldots$ & $\ldots$ & 0.2 & 53 & $\ldots$ & $\cdots$ & $\ldots$ & $\ldots$ & $\ldots$ & $\ldots$ & 2 & 101 \\
\hline J2-437-3-R2 & MA & $\mathrm{OC}$ & py & exterior & 48 & $\ldots$ & $\ldots$ & 0.4 & 53 & $\ldots$ & $\ldots$ & $\ldots$ & $\ldots$ & $\ldots$ & $\ldots$ & $\ldots$ & 101 \\
\hline $\mathrm{J} 2-437-3-\mathrm{R} 2$ & MA & $\mathrm{OC}$ & $s p$ & exterior & 3.4 & 1.2 & 60 & 0.2 & 33 & $\ldots$ & 7 & $\ldots$ & $\ldots$ & 9 & 70 & 92 & 99 \\
\hline J2-437-3-R2 & MA & $\mathrm{OC}$ & $\mathrm{sp}$ & exterior & 6 & 1.2 & 58 & 0.3 & 33 & $\ldots$ & $\ldots$ & $\ldots$ & 5 & 7 & 9 & 50 & 100 \\
\hline
\end{tabular}


Table S4 cont. Electron microprobe data for SMS deposit samples from the Mariner (MA) vent field

\begin{tabular}{|c|c|c|c|c|c|c|c|c|c|c|c|c|c|c|c|c|c|}
\hline SulfidelD & $\begin{array}{l}\text { Vent } \\
\text { Field }\end{array}$ & $\begin{array}{l}\text { Sample } \\
\text { Type }\end{array}$ & Mineral & Position & $\mathrm{Fe}$ & $\mathrm{Cu}$ & $\mathrm{Zn}$ & $\mathrm{Pb}^{*}$ & S & Co & $\mathrm{Se}$ & $\mathrm{Ag}$ & $\mathrm{Mn}$ & As & $\mathrm{Sb}$ & $\mathrm{Cd}$ & TOTAL \\
\hline & & & & & & & $w t \%$ & & & & & & $1 \mathrm{~m}$ & & & & $w t \%$ \\
\hline detection limit & & & & & 0.08 & 0.055 & 0.11 & & 0.007 & 5 & 1.5 & 1 & 4 & 2 & 1 & 1 & \\
\hline J2-131-7-R1 & $\mathrm{MA}$ & as & $\mathrm{cp}$ & lining & 31 & 35 & $\ldots$ & 0.2 & 35 & $\ldots$ & $\ldots$ & 2 & $\ldots$ & $\ldots$ & $\ldots$ & 2 & 102 \\
\hline J2-131-7-R1 & MA & as & $\mathrm{cp}$ & lining & 31 & 34 & $\ldots$ & 0.2 & 34 & 5 & $\ldots$ & $\ldots$ & $\ldots$ & $\ldots$ & $\ldots$ & $\ldots$ & 100 \\
\hline J2-131-7-R1 & MA & as & $\mathrm{cp}$ & middle & 31 & 34 & $\ldots$ & 0.2 & 35 & 8 & 4 & $\ldots$ & ... & $\ldots$ & $\ldots$ & 1 & 101 \\
\hline J2-131-7-R1 & MA & as & $\mathrm{cp}$ & exterior & 41 & 23 & 0.9 & 0.2 & 35 & $\ldots$ & $\ldots$ & 2 & ... & $\ldots$ & $\ldots$ & 1 & 100 \\
\hline J2-131-7-R1 & MA & as & $\mathrm{cp}$ & exterior & 39 & 25 & 0.8 & 0.2 & 35 & $\ldots$ & $\ldots$ & 1 & $\ldots$ & $\ldots$ & $\ldots$ & 1 & 101 \\
\hline J2-131-7-R1 & MA & as & $\mathrm{mc}$ & middle & 47 & 0.5 & $\ldots$ & 0.3 & 53 & $\ldots$ & 3 & 2 & $\ldots$ & 3 & $\ldots$ & 1 & 100 \\
\hline J2-131-7-R1 & MA & as & $\mathrm{mc}$ & exterior & 47 & 0.1 & 0.3 & 0.3 & 52 & 5 & $\ldots$ & 7 & $\ldots$ & 8 & $\ldots$ & 1 & 100 \\
\hline J2-131-7-R1 & MA & as & $\mathrm{mc}$ & exterior & 48 & $\ldots$ & $\ldots$ & 0.2 & 53 & $\ldots$ & $\ldots$ & 3 & 5 & $\ldots$ & $\ldots$ & $\ldots$ & 101 \\
\hline J2-131-7-R1 & MA & as & $s p$ & middle & 6 & 0.2 & 60 & 0.3 & 33 & $\ldots$ & 6 & $\ldots$ & 5 & 11 & 13 & 7 & 101 \\
\hline J2-131-7-R1 & MA & as & $\mathrm{sp}$ & exterior & 23 & 1.0 & 41 & 0.2 & 34 & 7 & 4 & $\ldots$ & 6 & $\ldots$ & 6 & 101 & 100 \\
\hline J2-131-7-R1 & MA & as & $\mathrm{sp}$ & exterior & 7 & 0.3 & 59 & 0.2 & 33 & 12 & 5 & $\ldots$ & $\ldots$ & 9 & 3 & 3 & 101 \\
\hline J2-439-13-R2 & MA & as & $\mathrm{cp}$ & middle & 31 & 35 & $\ldots$ & 0.2 & 35 & $\ldots$ & $\ldots$ & $\ldots$ & $\ldots$ & 16 & 13 & $\ldots$ & 101 \\
\hline J2-439-13-R2 & MA & as & $\mathrm{cp}$ & middle & 30 & 35 & $\ldots$ & 0.2 & 35 & $\ldots$ & $\ldots$ & 4 & $\ldots$ & 21 & 4 & $\ldots$ & 100 \\
\hline J2-439-13-R2 & MA & as & $\mathrm{cp}$ & middle & 30 & 35 & 0.1 & 0.2 & 35 & 5 & $\ldots$ & 3 & $\ldots$ & 12 & $\ldots$ & $\ldots$ & 101 \\
\hline J2-439-13-R2 & MA & as & py & exterior & 47 & 0.1 & 1.0 & 0.4 & 53 & 7 & 2 & 9 & ... & $\ldots$ & 1 & 2 & 102 \\
\hline J2-439-13-R2 & MA & as & py & exterior & 47 & $\ldots$ & $\ldots$ & 0.3 & 54 & 7 & 4 & 5 & $\ldots$ & $\ldots$ & 1 & 1 & 101 \\
\hline J2-439-13-R2 & MA & as & py & exterior & 47 & $\ldots$ & 0.7 & 0.3 & 54 & $\ldots$ & 2 & 3 & $\ldots$ & $\ldots$ & $\ldots$ & 1 & 101 \\
\hline J2-439-13-R2 & MA & as & $\mathrm{sp}$ & middle & 1.8 & 2.7 & 61 & 0.5 & 32 & $\ldots$ & $\ldots$ & $\ldots$ & $\ldots$ & 48 & 2 & 96 & 100 \\
\hline J2-439-13-R2 & MA & as & $\mathrm{sp}$ & exterior & 1.1 & 0.1 & 66 & 0.8 & 33 & $\ldots$ & 2 & $\ldots$ & $\ldots$ & $\ldots$ & $\ldots$ & $\ldots$ & 101 \\
\hline J2-439-13-R2 & MA & as & bn & middle & 11 & 62 & $\ldots$ & 0.2 & 27 & $\ldots$ & $\ldots$ & 2 & $\ldots$ & $\ldots$ & $\ldots$ & 2 & 100 \\
\hline J2-439-13-R2 & MA & as & bn & middle & 11 & 64 & 0.1 & 0.2 & 27 & $\ldots$ & 2 & 2 & $\ldots$ & $\ldots$ & $\ldots$ & $\ldots$ & 102 \\
\hline J2-439-13-R2 & MA & as & bn & middle & 12 & 62 & $\ldots$ & 0.1 & 27 & $\ldots$ & $\ldots$ & $\ldots$ & $\ldots$ & $\ldots$ & $\ldots$ & $\ldots$ & 101 \\
\hline J2-439-13-R2 & MA & as & bn & middle & 12 & 64 & $\ldots$ & 0.1 & 26 & $\ldots$ & $\ldots$ & 4 & $\ldots$ & $\ldots$ & $\ldots$ & $\ldots$ & 102 \\
\hline J2-131-3-RB1 & MA & rs & $\mathrm{cp}$ & lining & 30 & 33 & $\ldots$ & 0.2 & 35 & 5 & 3 & 1 & $\ldots$ & 3 & $\ldots$ & 1 & 98 \\
\hline J2-131-3-RB1 & MA & rs & $\mathrm{cp}$ & lining & 31 & 33 & 0.1 & 0.2 & 34 & 7 & $\ldots$ & 1 & $\ldots$ & 3 & 2 & $\cdots$ & 99 \\
\hline J2-131-3-RB1 & MA & rs & $\mathrm{cp}$ & lining & 31 & 33 & $\ldots$ & 0.2 & 35 & 5 & $\ldots$ & 2 & $\ldots$ & $\ldots$ & 2 & $\ldots$ & 99 \\
\hline J2-131-3-RB1 & MA & rs & $\mathrm{mc}$ & exterior & 46 & 0.2 & $\ldots$ & 0.3 & 53 & $\ldots$ & $\ldots$ & $\ldots$ & $\ldots$ & $\ldots$ & $\ldots$ & 3 & 99 \\
\hline J2-131-3-RB1 & MA & rs & $\mathrm{mc}$ & exterior & 46 & 0.1 & $\ldots$ & 0.3 & 53 & 5 & $\ldots$ & $\ldots$ & $\ldots$ & $\ldots$ & $\ldots$ & 2 & 99 \\
\hline J2-131-3-RB1 & MA & rs & $\mathrm{mc}$ & exterior & 46 & $\ldots$ & $\ldots$ & 0.3 & 53 & 8 & $\ldots$ & $\ldots$ & $\ldots$ & 13 & $\ldots$ & 3 & 99 \\
\hline J2-131-3-RB1 & MA & rs & $\mathrm{sp}$ & lining & 2.2 & 0.5 & 63 & 0.2 & 33 & $\ldots$ & $\ldots$ & $\ldots$ & $\ldots$ & $\ldots$ & 11 & 43 & 99 \\
\hline J2-131-3-RB1 & MA & rs & $\mathrm{sp}$ & middle & 0.6 & $\ldots$ & 66 & 0.1 & 33 & $\ldots$ & $\ldots$ & $\ldots$ & $\ldots$ & $\ldots$ & $\ldots$ & 15 & 100 \\
\hline J2-131-3-RB1 & MA & rs & $\mathrm{sp}$ & middle & 1.2 & 0.6 & 64 & 0.3 & 32 & $\ldots$ & $\ldots$ & $\ldots$ & $\ldots$ & 28 & $\ldots$ & 23 & 99 \\
\hline J2-131-3-RB1 & MA & rs & $s p$ & exterior & 1.2 & 0.6 & 63 & 0.4 & 33 & $\ldots$ & 2 & 3 & $\ldots$ & 17 & 17 & 43 & 99 \\
\hline J2-437-7-R1 & MA & af & wz & middle & $\ldots$ & 1.6 & 64 & 0.3 & 32 & $\ldots$ & $\ldots$ & $\ldots$ & $\ldots$ & 7 & 1 & 72 & 99 \\
\hline J2-437-7-R1 & MA & af & wz & middle & 0.2 & 1.7 & 63 & 0.4 & 33 & $\ldots$ & $\ldots$ & $\ldots$ & $\ldots$ & 16 & $\ldots$ & 99 & 99 \\
\hline J2-437-7-R1 & MA & st & py & middle & 46 & 0.5 & 0.7 & 0.6 & 52 & $\ldots$ & $\ldots$ & 2 & $\ldots$ & $\ldots$ & $\ldots$ & 2 & 101 \\
\hline J2-437-7-R1 & MA & st & $\mathrm{sp}$ & middle & 0.5 & 0.7 & 66 & 0.2 & 33 & 34 & 25 & 9 & $\ldots$ & 27 & 8 & 68 & 102 \\
\hline J2-437-7-R1 & MA & st & $s p$ & middle & $\ldots$ & 1.4 & 64 & 0.4 & 33 & $\ldots$ & $\ldots$ & 2 & $\ldots$ & 48 & $\ldots$ & 32 & 100 \\
\hline J2-437-7-R1 & MA & st & $\mathrm{sp}$ & middle & 0.4 & 1.3 & 64 & 0.2 & 33 & $\ldots$ & 2 & $\ldots$ & $\ldots$ & 31 & $\ldots$ & 40 & 99 \\
\hline J2-437-7-R1 & MA & st & $\mathrm{sp}$ & middle & $\ldots$ & $\ldots$ & 65 & 0.3 & 33 & 6 & 6 & $\ldots$ & $\ldots$ & 4 & $\ldots$ & 2 & 99 \\
\hline
\end{tabular}


Table S5. Log(fS2) of ELSC hydrothermal fluids as calculated at approximate in situ temperature (T_ref) and pressure (P_ref). The calculated ratio of HS- to H2S at in situ conditions is also calculated in order to justify the approximation $\mathrm{H} 2 \mathrm{~S}=$ Total $\mathrm{S}-2$, which is used to simplify calculation of $\log$ (fS2). TMo = Tahi Moana; $A=A B E$.

\begin{tabular}{|c|c|c|c|c|c|c|c|c|}
\hline unit & $\begin{array}{c}\mathrm{T} \\
\left({ }^{\circ} \mathrm{C}\right)\end{array}$ & $\begin{array}{c}\mathrm{pH} \\
\left(25^{\circ} \mathrm{C}\right)\end{array}$ & $\begin{array}{c}\text { H2S,aq } \\
(\mathrm{mM})\end{array}$ & $\begin{array}{c}\mathrm{H} 2, \mathrm{aq} \\
(\mu \mathrm{M})\end{array}$ & $\begin{array}{l}\text { Tref } \\
\left({ }^{\circ} \mathrm{C}\right)\end{array}$ & $\begin{array}{l}\text { Pref } \\
\text { (bar) }\end{array}$ & $\begin{array}{l}\text { HS- } \\
\text { H2S }\end{array}$ & $\begin{array}{l}\log \\
(f S 2)\end{array}$ \\
\hline KM1 & 333 & 3.6 & 6.0 & 313 & 330 & 260 & $0 \%$ & -9.6 \\
\hline KM2 & 332 & 3.6 & 5.4 & 220 & 330 & 260 & $0 \%$ & -9.3 \\
\hline KM3 & 321 & 2.9 & 6.4 & 359 & 320 & 260 & $0 \%$ & -9.9 \\
\hline KM4 & 300 & 3.2 & 5.4 & 483 & 300 & 260 & $0 \%$ & -11.0 \\
\hline KM5 & 325 & 3.5 & 6.3 & 359 & 325 & 260 & $0 \%$ & -9.8 \\
\hline KM6 & 306 & 3.6 & 5.4 & 445 & 300 & 260 & $0 \%$ & -10.9 \\
\hline KM8 & 333 & 4.0 & 5.5 & 498 & 330 & 260 & $0 \%$ & -10.0 \\
\hline KM9 & 304 & 4.1 & 3.5 & ${ }^{*} 445$ & 300 & 260 & $0 \%$ & -11.3 \\
\hline KM10 & 290 & 3.9 & 3.9 & **483 & 290 & 260 & $0 \%$ & -11.6 \\
\hline TC1 & 328 & 4.1 & 4.8 & 132 & 330 & 270 & $0 \%$ & -9.0 \\
\hline TC3 & 320 & 4.0 & 4.9 & 177 & 320 & 270 & $0 \%$ & -9.5 \\
\hline TC4 & 316 & 4.1 & 4.9 & 149 & 320 & 270 & $0 \%$ & -9.4 \\
\hline TC5 & 302 & 3.7 & 4.5 & 108 & 300 & 270 & $0 \%$ & -9.8 \\
\hline TC7 & 288 & 4.0 & 3.7 & 198 & 290 & 270 & $0 \%$ & -10.9 \\
\hline TC8 & 308 & 4.1 & 5.2 & 138 & 310 & 270 & $0 \%$ & -9.6 \\
\hline $\mathrm{A} 1$ & 309 & 4.3 & 3.6 & 63.1 & 310 & 210 & $3 \%$ & -9.2 \\
\hline A4 & 278 & 4.4 & 2.8 & 54 & 280 & 210 & $3 \%$ & -10.3 \\
\hline A5 & 290 & 4.5 & 3.1 & 101 & 290 & 210 & $3 \%$ & -10.5 \\
\hline A8 & 308 & 4.5 & 2.9 & 78 & 310 & 210 & $3 \%$ & -9.6 \\
\hline A9 & 295 & 4.6 & 2.6 & 101 & 295 & 210 & $3 \%$ & -10.4 \\
\hline TM1 & 279 & 4.5 & 2.3 & 48 & 280 & 190 & $3 \%$ & -10.4 \\
\hline TM2 & 312 & 4.4 & 2.5 & 46 & 310 & 190 & $3 \%$ & -9.3 \\
\hline TM4 & 178 & 5.7 & 1.2 & 122 & $\ldots$ & $\ldots$ & $\ldots$ & $\ldots$ \\
\hline TM5 & 265 & 4.6 & 2.3 & 35 & 265 & 190 & $3 \%$ & -10.7 \\
\hline TM6 & 265 & 4.4 & 2.4 & 101 & 265 & 190 & $3 \%$ & -11.6 \\
\hline TM7 & 198 & 5.0 & 2.1 & 135 & 200 & 190 & $3 \%$ & -14.6 \\
\hline TM8 & 229 & 4.4 & 2.1 & 115 & 230 & 190 & $3 \%$ & -13.2 \\
\hline TM10 & 274 & 4.2 & 2.0 & 73.2 & 270 & 190 & $3 \%$ & -11.3 \\
\hline MA1 & 334 & 2.5 & 6.2 & 55 & 330 & 190 & $0 \%$ & -8.0 \\
\hline MA2 & 311 & 2.6 & 4.2 & 33 & 310 & 190 & $0 \%$ & -8.5 \\
\hline MA3 & 363 & 2.7 & 9.3 & 131 & 360 & 190 & $0 \%$ & -7.4 \\
\hline MA5 & 249 & 2.6 & 4.5 & 65 & 250 & 190 & $0 \%$ & -11.2 \\
\hline MA6 & 240 & 2.7 & 6.4 & 179 & 240 & 190 & $0 \%$ & -12.1 \\
\hline
\end{tabular}

${ }^{*} \mathrm{H} 2$,aq of KM9 was not measured, but estimated based on the $\mathrm{H} 2$,aq content of KM6

** $\mathrm{H} 2$,aq of KM1O was not measured, but estimated based on the $\mathrm{H} 2$,aq content of KM4 


\section{Chapter 3}

Trace Element Chemistry of Black Smoker Chimney Linings Measured by Secondary Ion Mass Spectrometry

\section{INTRODUCTION}

Deep-sea hydrothermal vents are unique locations in which metal-rich seafloor massive sulfide deposits can be sampled in direct contact with deposit-forming seafloor hydrothermal fluids. Particularly relevant for the purpose of understanding the effects of hydrothermal fluid temperature and chemistry on mineral deposit composition are the mineral linings of open conduit black smoker chimneys, which precipitated directly from vigorously venting hightemperature fluids.

Black smoker chimneys are deposited in two stages (Haymon, 1983; Goldfarb et al., 1983). First, mixing between hydrothermal fluids and seawater leads to the precipitation of an initial pipe-like structure composed of an anhydrite $\left(\mathrm{CaSO}_{4}\right)$ dominated matrix that contains interstitial grains of various metal sulfide minerals. Second, a massive sulfide mineral layer is deposited on the interior of the chimney following physical and chemical separation of hydrothermal fluids and seawater by the initial chimney wall. Above $\sim 250^{\circ} \mathrm{C}$, this massive sulfide lining typically contains chalcopyrite $\left(\mathrm{CuFeS}_{2}\right)$ and/or cubanite $\left(\mathrm{CeFe}_{2} \mathrm{~S}_{3}\right)$. Because this second-stage massive sulfide layer is precipitated directly from venting hydrothermal fluids with little chemical interaction with surrounding seawater, the mineralogy and geochemistry of this innermost layer closely reflect the temperature and chemistry of venting hydrothermal fluids. 
Previous studies have noted a close correspondence between the mineralogy of this massive sulfide layer and the temperature, sulfur fugacity, and $\mathrm{pH}$ of venting hydrothermal fluids (e.g., Tivey, 1995; Tivey et al., 1999; Kawasumi and Chiba, 2017). However, these mineralogical indicators only distinguish between broad ranges of temperature and chemical composition. The trace element contents of black smoker chimney linings have the potential to provide additional information and constraints on hydrothermal fluid temperature and composition. This has been demonstrated for the Fe content of zinc sulfides such as sphalerite and wurtzite (e.g., Hannington et al., 1995; Kawasumi and Chiba, 2017). However, the homogeneity and concentrations of trace elements in these deposits at small spatial scales and the relationships between trace element concentrations and hydrothermal fluid temperature and chemistry are not well-known.

Investigations of trace elements in black smoker chimneys using electron microprobe have shown that the concentrations of many trace elements in the innermost lining of black smoker chimneys are near or below detection limits (e.g., Tivey et al., 1995; Tivey et al., 1999; Craddock, 2009). Laser-ablation inductively coupled plasma mass spectrometry (LA-ICPMS), proton microprobe (PIXE), and secondary ion mass spectrometry (SIMS), which offer significantly lower detection limits than electron microprobe, have also been used to investigate black smoker chimney linings (Butler and Nesbitt, 1999; Ryan, 2001; Layne et. al, 2005). However, these studies have been hampered by a lack of homogeneous sulfide reference materials and results are reported in relative rather than absolute quantities (Butler and Nesbitt, 1999; Layne et. al, 2005). More recently, some studies have measured trace elements in sulfide minerals using LA-ICPMS calibrated against pressed sulfide powder precipitates, sulfide sinters, 
or synthetic glass standards, (Maslennikov et al., 2009; Wohlgemuth-Ueberwasser et al., 2011; Danyushevsky et al., 2011 and papers using these methods).

This study uses SIMS to examine the homogeneity and relative abundances of trace elements in black smoker chimney linings and investigate the intriguing possibility that mineral trace element contents reflect hydrothermal fluid temperature and chemistry, thereby providing trace element proxies of deposit formation conditions. The samples investigated in this study include black smoker chimney samples collected as sample pairs with the hydrothermal fluids that were venting through them at the time of collection. In this way, the trace element concentrations of black smoker chimney linings can be directly compared with the temperature, $\mathrm{pH}, \mathrm{Cl}, \mathrm{H}_{2} \mathrm{~S}$, of the hydrothermal fluids from which they formed as well as host-rock lithology and geologic settings. While other minerals (e.g., wurtzite, pyrite) are present in the linings of some of these samples, the focus of this chapter is on the trace element contents of chalcopyrite, which is the most common lining mineral for black smoker chimneys venting high-temperature (> $250^{\circ} \mathrm{C}$ ) fluids. Some additional samples have also been included for the purpose of establishing calibration curves by which to quantify SIMS measurements. To construct SIMS calibration curves on the basis of matrix-matched standards, grains of chalcopyrite (and cubanite) were picked from a subset of the samples measured by SIMS, then digested, and analyzed by ICP-MS against serial dilutions of external standard solutions. All black smoker chimney samples used for the construction of SIMS calibration curves exhibit monomineralic massive chalcopyrite linings. 


\section{SAMPLE DESCRIPTION}

The black smoker chimney samples examined in this study were obtained from the dry storage repository of the Woods Hole Oceanographic Institution Seafloor Sample Laboratory (Table 1). Black smoker chimney samples were originally collected from active vent fields between $17^{\circ} 34^{\prime} \mathrm{S}$ and $17^{\circ} 37^{\prime} \mathrm{S}$ on the southern East Pacific Rise (AT-03, Leg 28), the Main Endeavour Field on the Juan de Fuca Ridge (AII-118, Leg 22; AT-03, Leg30), the Lucky Strike vent field on the Mid-Atlantic Ridge (DIVA1), the Beebe / Piccard vent field on the MidCayman Rise (AT18-16), the Vienna Woods, Fenway, Satanic Mills, Roman Ruins, Roger's Ruins, Suzette, and North Su vent fields in the Manus Basin (MGLN06MV), and the Tahi Moana-1, ABE, Tu'i Malila and Mariner vent fields on the Eastern Lau Spreading Center (TN236; RR1507).

The black smoker chimney samples chosen for this study formed from fluids exhibiting a range of temperature $\left(274^{\circ} \mathrm{C}\right.$ to $\left.395^{\circ} \mathrm{C}\right), \mathrm{pH}\left(\mathrm{pH}\left(\right.\right.$ at $\left.\left.25^{\circ} \mathrm{C}\right)=2.3-4.4\right)$, and metal concentrations, located within vent fields from a variety of geologic settings including back-arc basins (Lau Basin and Manus Basin), and fast-spreading (southern East Pacific Rise), intermediate-spreading (Endeavour Segment of the Juan de Fuca Ridge), slow-spreading (Lucky Strike), and ultraslow spreading (Mid-Cayman Rise) mid-ocean ridges. Hydrothermal fluid temperature, $\mathrm{pH}$, and metal content to some extent covary, with higher temperature fluids usually more acidic and metal-rich (Seyfried and Seewald, 1990; Seyfried et al., 1991; Seyfried and Ding, 1995). However, samples from several of the vent fluids from Manus Basin from the Mariner vent field in the Lau Basin are additionally affected by the influence of acidic $\mathrm{SO}_{2}$-rich magmatic volatiles, which lead to lower $\mathrm{pH}$ and higher metal contents at a given temperature (Reeves et al., 2011; Mottl et al., 2011). Conversely, vent fluids from the Main Endeavour Field on the Juan de Fuca Ridge exhibit 
higher $\mathrm{pH}$ measured at $25^{\circ} \mathrm{C}$ because of buffering by sediment-derived $\mathrm{NH}_{3}$ (Lilley et al., 1993), though the calculated $\mathrm{pH}$ at in situ temperatures $\left(\sim 350^{\circ} \mathrm{C}\right)$ is comparabile to other basalt-hosted, mid-ocean ridge vent fields (Tivey et al., 1999).

Samples used in this study include two from the Main Endeavour Field, one collected before and the other immediately after the seismic swarm and inferred event that occurred in 1999 (Johnson et al., 2000). This event led to a temporary decrease in the chlorinity and pH (at $25^{\circ} \mathrm{C}$ ) and an increase in the temperature of hydrothermal fluids venting at the Main Endeavour Field (Seyfried et al., 2003). Sample Alv3474-3-1 examined in this study was collected from the Sully deposit in 1999 on cruise AT-03, Leg 30. Compared with other vents at the Main Endeavour Field, hydrothermal fluids from the Sully deposit collected in 1999 exhibit low chlorinity (Seyfried et al., 2003). Sample Alv1931 was collected from the Main Endeavour Field in 1987 on cruise A118, Leg 22 (J. Baross, Chief Scientist). The exact location of this sample and its relationship with venting fluids is unknown. 
Table 1. (opposite)

Samples used in this study are from the southern East Pacific Rise (S. EPR), the Juan de Fuca Ridge (JdF), the Mid-Atlantic Ridge (MAR), the Mid-Cayman Rise (MCR), the Manus Spreading Center (MSC), the PACMANUS (PAC) and SuSu Knolls ( $\mathrm{SuSu}$ ) vent fields of the Eastern Manus Basin (EMB), and the Eastern Lau Spreading Center (ELSC). The innermost linings of these chimneys are composed of chalcopyrite (cp) \pm cubanite (cb), wurtzite (wz), and/or pyrite (py). Samples used in the SIMS calibration curves are marked with an " $X$ ". Those that were attempted but ultimately not used are marked with an "O". The $\mathrm{pH}$ of hydrothermal vent fluids is the shipboard measurement taken at $25^{\circ} \mathrm{C}$. Fluid $\mathrm{pH}$ at in situ temperatures is calculated with EQ3/6 software (Wolery, 1992). Concentrations of $\mathrm{Cl}$ and $\mathrm{H}_{2} \mathrm{~S}$ are both endmember concentrations extrapolated to zero-Mg. This follows the assumption that hydrothermal fluids contain negligible Mg (Von Damm et al., 1985). All sample and fluid names are as labeled in the original references and sample archive. References for fluid chemistry are as follows: S. EPR (K.L. Von Damm, unpublished data), MEF (Seyfried et al., 2003), MCR (McDermott, 2015), EMB (Reeves et al., 2011), ELSC (Mottl et al., 2011; Seewald, 2017). References from host-rock lithology are: S. EPR (Krasnov et al., 1997), Lucky Strike (Langmuir et al., 1997), MEF (Karsten et al., 1990), MCR (Elthon et al., 1995), EMB (Binns and Scott, 1993; Kamenetsky et al., 2001; Sinton et al, 2003), ELSC (Jenner et al., 1987; Frenzel et al., 1990; Vallier et al., 1991; Fouquet et al., 1993; Martinez and Taylor, 2002; Langmuir et al., 2006; Bézos et al., 2009; Escrig et al., 2009) 
Table 1.

\begin{tabular}{|c|c|c|c|c|c|c|c|c|c|c|c|}
\hline Sample ID & Vent Field & Lithology & Region & $\begin{array}{l}\text { Lining } \\
\text { Mineral }\end{array}$ & $\begin{array}{l}\text { Callibration } \\
\text { Curve }\end{array}$ & Fluid Pair & $\begin{array}{c}\mathrm{T} \\
\left({ }^{\circ} \mathrm{C}\right)\end{array}$ & $\begin{array}{c}\mathrm{pH} \\
\left.\text { (at } 25^{\circ} \mathrm{C}\right)\end{array}$ & $\begin{array}{c}\mathrm{pH} \\
\text { (in situ) }\end{array}$ & $\begin{array}{c}\mathrm{Cl} \\
(\mathrm{mmol} / \mathrm{kg})\end{array}$ & $\begin{array}{c}\mathrm{H}_{\supset} \mathrm{S} \\
(\mathrm{mmol} / \mathrm{kg})\end{array}$ \\
\hline Alv3299-6-1 & 1734 'S & basalt & S. EPR & $\mathrm{cp}$ & $\mathrm{x}$ & Hobbes & 349 & 3.2 & & 481 & 9.0 \\
\hline Alv3288-5-1a & $1737 ' S$ & basalt & S. EPR & $\mathrm{cp}$ & & Simon & 337 & 3.4 & & 751 & 3.5 \\
\hline Alv3296-2-2a & 1737 'S & basalt & S. EPR & $\mathrm{cp}$ & 0 & Maggie & & & & & \\
\hline Alv3296-3 & $1737 ' S$ & basalt & S. EPR & $\mathrm{cp}$ & $x$ & Wally & 314 & 3.4 & & 752 & 6.5 \\
\hline Alv3296-5-1a & 1737 'S & basalt & S. EPR & $c p$ & $\mathrm{O}$ & Homer & 347 & 3.3 & & 591 & 3.7 \\
\hline Alv1931 & $\begin{array}{l}\text { Main Endeavour } \\
\text { Field (pre-event) }\end{array}$ & E-MORB & $\mathrm{JdF}$ & $\mathrm{cp}$ & $x$ & & & & & & \\
\hline Alv3474-3-1 & $\begin{array}{l}\text { Main Endeavour } \\
\text { Field (post-event) }\end{array}$ & E-MORB & $\mathrm{JdF}$ & $\mathrm{cp}$ & $x$ & Sully99 & 379 & 3.6 & 4.3 & 39.0 & 20 \\
\hline Alv3480-4 & $\begin{array}{l}\text { Main Endeavour } \\
\text { Field (post-event) }\end{array}$ & E-MORB & JdF & $\mathrm{cp}$ & & & & & & & \\
\hline DV1-5B & Lucky Strike & E-MORB & MAR & $\mathrm{cp}$ & & & & & & & \\
\hline J2-613-16-R1 & Beebe / Piccard & basalt & MCR & $\mathrm{cb}$ & & BB5 & 395 & 3.3 & 5.0 & 351 & 0.0 \\
\hline J2-207-1-R1 & Vienna Woods & basalt & MSC & $\mathrm{cp} / \mathrm{wz}$ & & WW1 & 282 & 4.4 & 5.1 & 691 & 1.4 \\
\hline J2-210-7-R2 & Fenway & felsic & EMB, PAC & $\mathrm{cp}$ & & & & & & & \\
\hline J2-216-16-R1 & Fenway & felsic & EMB, PAC & $\mathrm{cp}$ & & F3 & 358 & 2.7 & 3.9 & 562 & 18.8 \\
\hline J2-214-3-R1 & Satanic Mills & felsic & EMB, PAC & $\mathrm{cp}$ & $\mathrm{O}$ & SM3 & 288 & 2.5 & 3.0 & 503 & 10.2 \\
\hline J2-208-1-R1 & Roman Ruins & felsic & $\mathrm{EMB}, \mathrm{PAC}$ & $\mathrm{cp}$ & & RMR1 & 314 & 2.3 & 2.8 & 632 & 7.5 \\
\hline J2-213-6-R1 & Roger's Ruins & felsic & EMB, PAC & $\mathrm{cp}$ & & RGR1 & 320 & 2.7 & & 648 & 3.6 \\
\hline J2-217-2-R1 & Suzette & felsic & EMB, SuSu & $\mathrm{cp}$ & $\mathrm{O}$ & SZ1 & 303 & 3.8 & 4.2 & 626 & 1.8 \\
\hline J2-217-10-R1 & Suzette & felsic & EMB, SuSu & $\mathrm{cp}$ & & SZ2 & 274 & 3.6 & 4.0 & 684 & 1.8 \\
\hline J2-219-2-R1 & Suzette & felsic & EMB, SuSu & $\mathrm{cp}$ & & & & & & & \\
\hline J2-223-1-R1 & North Su & felsic & EMB, SuSu & $\mathrm{cp}$ & & NS3 & 300 & 3.4 & 3.9 & 673 & 3.4 \\
\hline J2-227-10-R1 & North Su & felsic & EMB, SuSu & $\mathrm{cp}$ & & & & & & & \\
\hline J2-450-3-R1 & Tahi Moana 1 & felsic & ELSC & $\mathrm{cp} / \mathrm{wz}$ & & TMo5 & 310 & 3.7 & 4.6 & 555 & 3.3 \\
\hline J2-449-5-R1 & $\mathrm{ABE}$ & felsic & ELSC & $\mathrm{cp} / \mathrm{wz}$ & & $\mathrm{A} 11$ & 306 & 4.0 & 5.2 & 552 & 2.7 \\
\hline J2-449-6-R1 & $A B E$ & felsic & ELSC & $\mathrm{cp} / \mathrm{py}$ & & A10 & 317 & 3.9 & 5.1 & 543 & 3.9 \\
\hline J2-815-5-R1 & $\mathrm{ABE}$ & felsic & ELSC & $\mathrm{cp} / \mathrm{wz}$ & & A16 & 300 & 4.0 & 5.2 & 546 & 3.7 \\
\hline J2-442-4-R2 & Tu'i Malila & felsic & ELSC & cp/py & & TM11 & 315 & 3.8 & 4.5 & 653 & 2.5 \\
\hline J2-819-4-R2 & Tu'i Malila & felsic & ELSC & $\mathrm{cp} / \mathrm{wz}$ & & TM15 & 269 & 3.9 & & 598 & 2.3 \\
\hline J2-437-3-R2 & Mariner & felsic & ELSC & $\mathrm{cp}$ & $x$ & MA9 & 338 & 2.3 & 3.2 & 541 & 8.9 \\
\hline J2-817-4-R2 & Mariner & felsic & ELSC & $\mathrm{cp}$ & & MA15 & 354 & 3.0 & 3.8 & 557 & 3.1 \\
\hline
\end{tabular}




\section{METHODS}

In preparation for SIMS analysis, black smoker chimney samples were cut, mounted in epoxy, polished to $1 \mu \mathrm{m}$ grit with diamond and/or alumina abrasives, and gold coated. For the purpose of generating SIMS calibration curves, a subset of the black smoker chimneys analyzed with SIMS were also picked for chemical digestion and analysis by ICP-MS against external reference standards (Fig. 1). To ensure that samples in this subset did not contain visible inclusions of minerals other than chalcopyrite, polished sections of the same samples were examined under a reflected light petrographic microscope. Picked grains were obtained from the innermost linings of black smoker chimneys (within $<1 \mathrm{~mm}$ from the main fluid conduit) by coarse crushing with an agate motor and pestle followed by careful picking with non-metal tools. Sample grains were then individually examined under a Leica Stereo Zoom 6 Photo microscope and transferred to a separate container in order to ensure minimally tarnished samples of purest possible chalcopyrite.

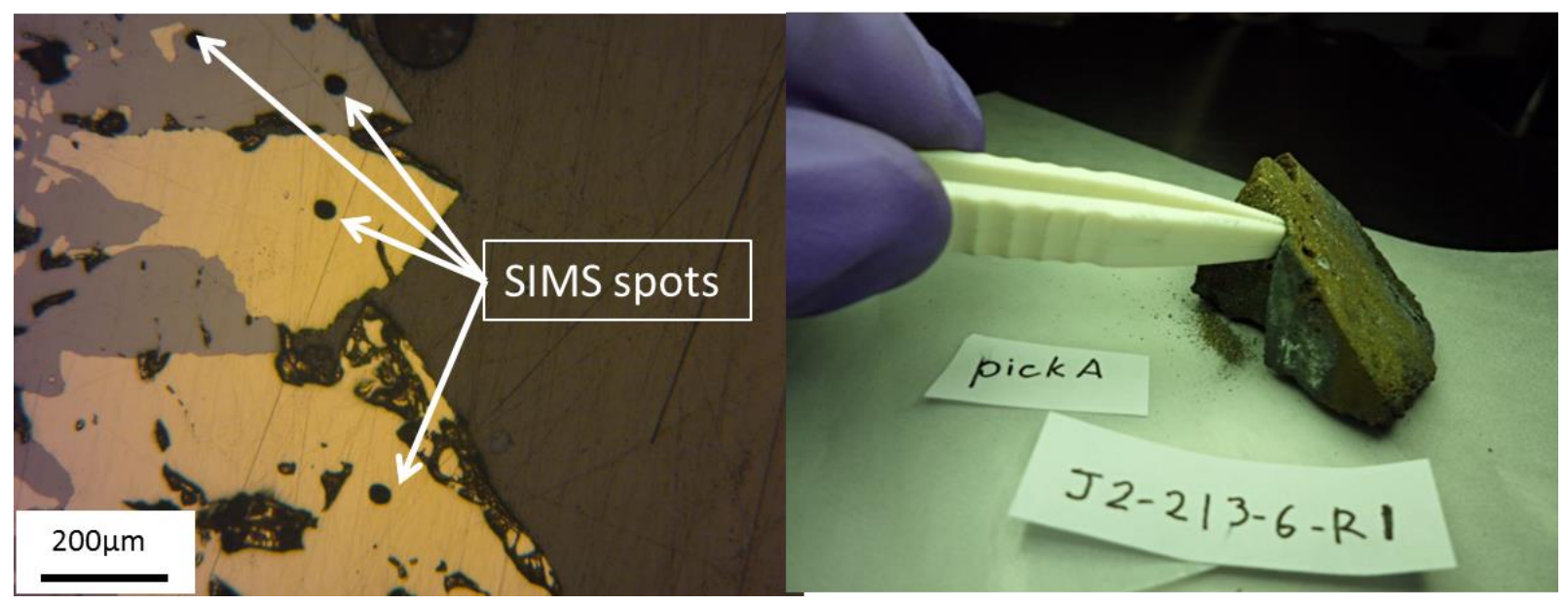

Figure 1. (On left) Photomicrograph of sample J2-207-1-R1 following SIMS measurements and removal of gold coating showing scale of SIMS spots relative to lining composed of intergrown chalcopyrite (yellow) and wurtzite (gray). The fluid conduit adjascent to chimney lining has been filled with epoxy. (On right) Non-metal tools are used to collect mineral grains from the inner lining of black smoker chimney sample J2-213-6-R1. Mineral grains were later picked to ensure purest possible chalcopyrite. 


\subsection{Secondary Ion Mass Spectrometry (SIMS)}

Trace element analyses were obtained using the Cameca IMS 1280 ion microprobe located in the Northeast National Ion Microprobe Facility at the Woods Hole Oceanographic Institution. Secondary ion intensity ratios against ${ }^{63} \mathrm{Cu}^{16} \mathrm{O}^{+}$were measured for ${ }^{59} \mathrm{Co}^{+},{ }^{60} \mathrm{Ni}^{+},{ }^{69} \mathrm{Ga}^{+}$, ${ }^{109} \mathrm{Ag}^{+},{ }^{113} \mathrm{In}^{+}$, and ${ }^{115} \mathrm{In}^{+}$. The intensity of ${ }^{54} \mathrm{Fe}^{16} \mathrm{O}^{+}$varied more than ${ }^{63} \mathrm{Cu}^{16} \mathrm{O}^{+}$and ${ }^{63} \mathrm{Cu}^{16} \mathrm{O}^{+}$was selected as a normalizing ratio. Detection limits were set at three standard deviations above the mean secondary ion intensity measured on background mass 54.7. This was evaluated to be 0.25 counts per second (cps) or $5 \times 10^{-5} \mathrm{cps} / \mathrm{cps}{ }^{63} \mathrm{Cu}^{16} \mathrm{O}^{+}$. Quantitative determination limits were set at ten standard deviations above the mean secondary ion intensity measured on the background mass 54.7. This was evaluated to be 0.6 counts per second (cps) or $1.2 \times 10^{-4} \mathrm{cps} / \mathrm{cps}{ }^{63} \mathrm{Cu}^{16} \mathrm{O}^{+}$. Machine settings, typical secondary ion intensities and associated errors for ${ }^{63} \mathrm{Cu}^{16} \mathrm{O}^{+}$, detection limits, and determination limits are listed in Table 2. Typical mass resolving power was $\sim 10,000$. Scans of the relevant masses and potential interferences at this resolution are shown in Figure 2. 
Table 2. Machine settings, typical secondary ion intensities, and associated errors for secondary ion mass spectrometry (SIMS) analyses of $\mathrm{Co}, \mathrm{Ni}, \mathrm{Ga}, \mathrm{Ag}$, and $\mathrm{In}$ in chalcopyrite. cps = counts per second.

\begin{tabular}{ll}
\hline Source & duoplasmatron $\mathrm{O}_{2^{-}}$ \\
Primary Beam Current & $10 \mathrm{nA}$ \\
Secondary Accelerating Voltage & $10 \mathrm{kV}$ \\
Energy Offset & none \\
Field Aperture & $22 \times 22 \mu \mathrm{m}$ \\
Raster Area & $20 \times 20 \mu \mathrm{m}$ \\
Spot Diameter & $40 \mu \mathrm{m}$ \\
Mass Resolving Power & $\sim 10,000$ \\
Number of Cycles & 10 \\
Pre-sputter time & $300 \mathrm{~s}$ \\
Integration Time, Trace elements and background & $10 \mathrm{~s}$ \\
Integration Time ( $\left.{ }^{63} \mathrm{Cu}{ }^{16} \mathrm{O},{ }^{54} \mathrm{Fe}{ }^{16} \mathrm{O},{ }^{64} \mathrm{Zn}{ }^{16} \mathrm{O}\right)$ & $5 \mathrm{~s}$ \\
Secondary lon Intensity on ${ }^{63} \mathrm{Cu}^{16} \mathrm{O}(1000 \mathrm{cps})$ & 5 to 10 \\
Relative Standard Deviation of lon Intensity on ${ }^{63} \mathrm{Cu}^{16} \mathrm{O}$ & $10 \%$ \\
Counting Errors on ${ }^{63} \mathrm{Cu}{ }^{16} \mathrm{O}(\%)$ & $0.5 \%$ \\
Secondary lon Intensity on background mass 54.7 (cps) & $<0.1$ \\
Detection Limit (background $+3 \times$ standard deviation) & $0.25 \mathrm{cps}\left(5 \times 10^{-5} \mathrm{cps} /{ }^{63} \mathrm{Cu}^{16} \mathrm{O} \mathrm{cps}\right)$ \\
Detection Limit (background $+10 \times$ standard deviation) & $0.6 \mathrm{cps}\left(1.2 \times 10^{-4} \mathrm{cps} /{ }^{63} \mathrm{Cu}^{16} \mathrm{O} \mathrm{cps}\right)$
\end{tabular}


Figure 2. Plots of mass vs. secondary ion intensity over the relevant mass intervals for ${ }^{59} \mathrm{Co}^{+}$, ${ }^{60} \mathrm{Ni}^{+},{ }^{69} \mathrm{Ga}^{+},{ }^{63} \mathrm{Cu}^{16} \mathrm{O}^{+},{ }^{109} \mathrm{Ag}^{+},{ }^{113} \mathrm{In}^{+}$, and ${ }^{115} \mathrm{In}^{+}$at a mass resolving power of $\sim 10,000$ as measured on chalcopyrite in black smoker chimney sample Alv3299-6-1 from the southern East Pacific Rise . Actual masses of target ion and those of potential interferences are also identified (Berglund and Wieser, 2011).
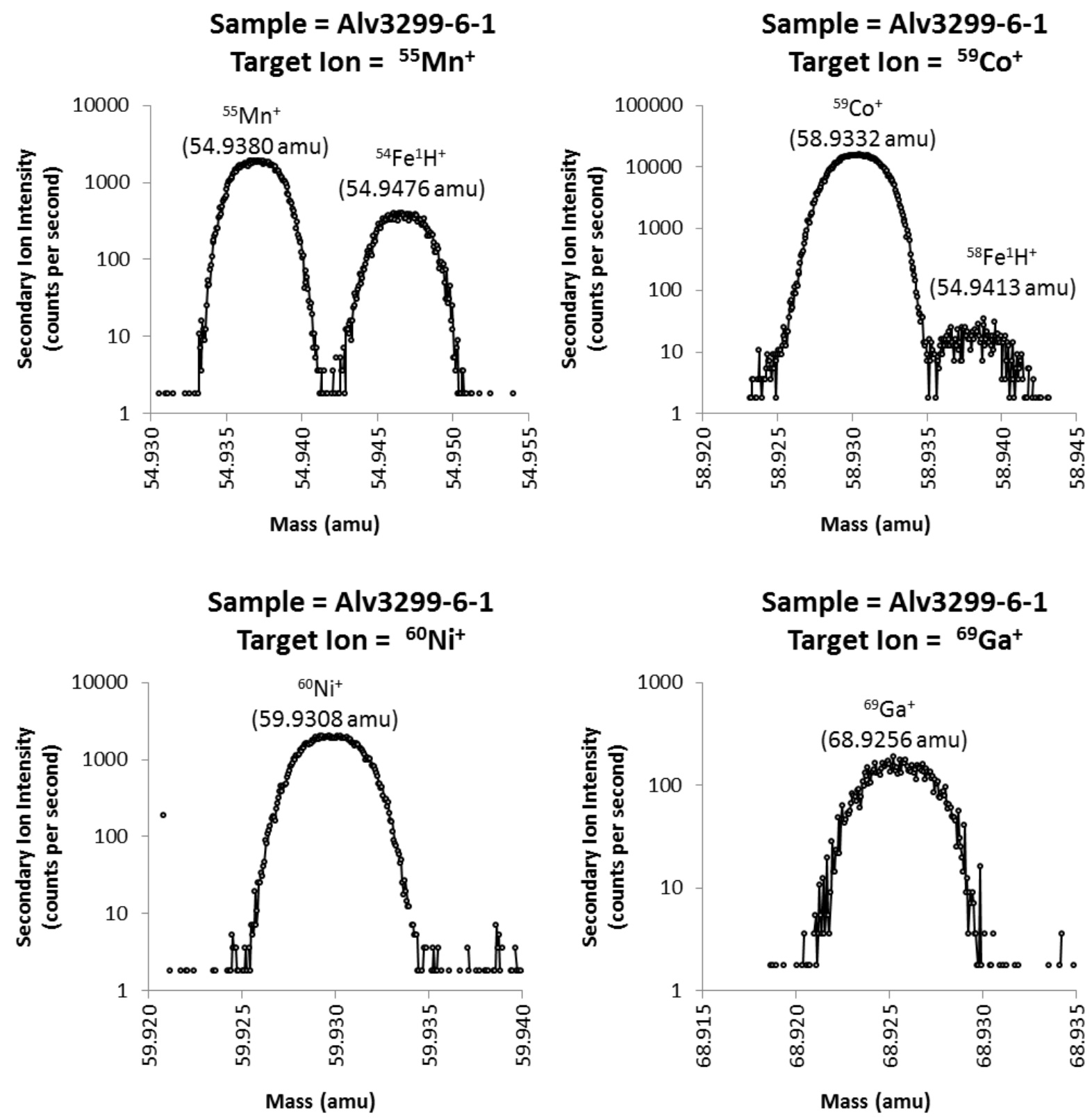
Figure 2 cont.
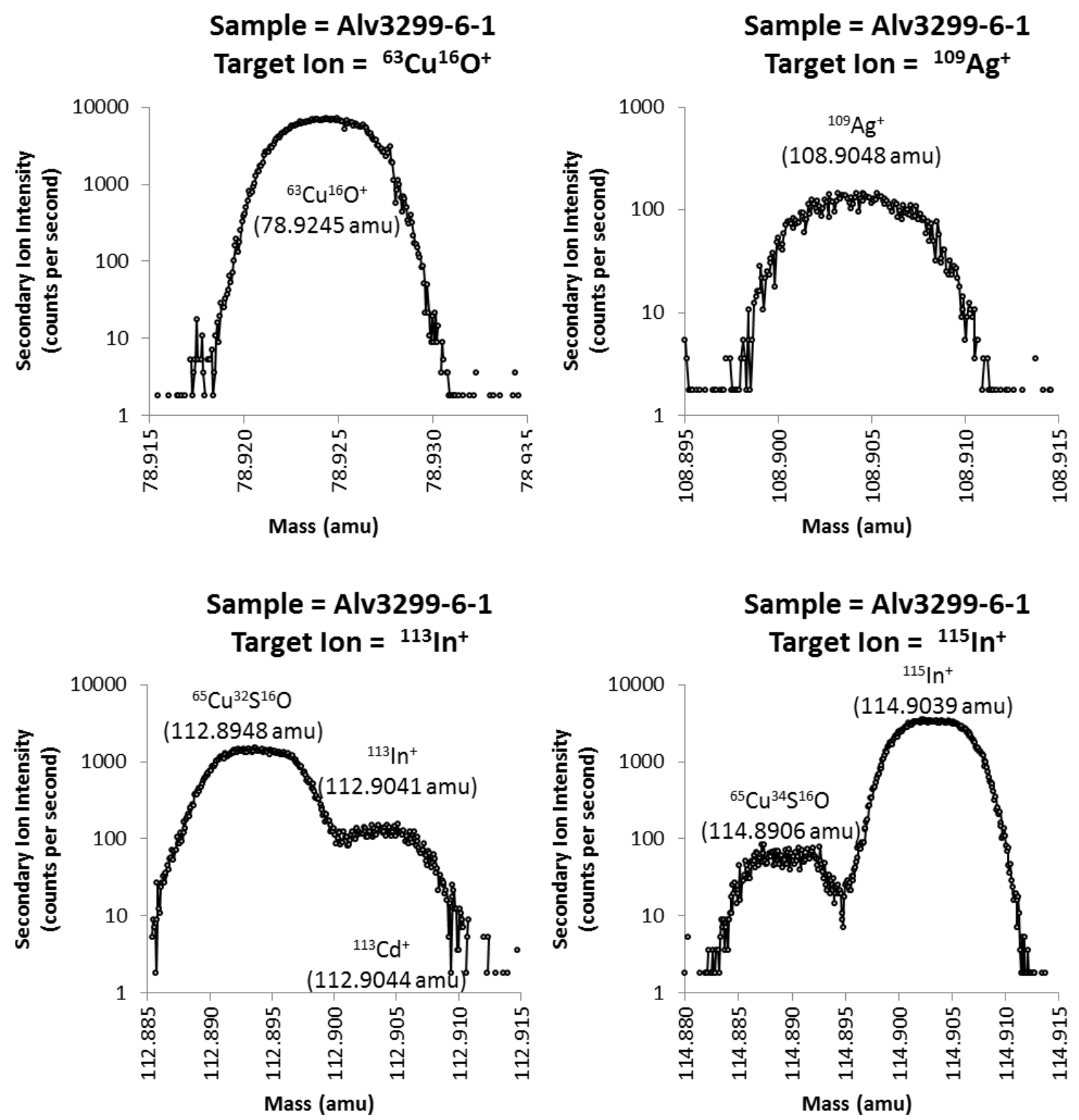
During some sessions, In was measured on mass 113 rather than mass 115 . Potential mass interferences between $\mathrm{Cd}$ and In on mass 113 could not be resolved. However, these peaks are confidently identified as ${ }^{113} \mathrm{In}^{+}$(largely free of ${ }^{113} \mathrm{Cd}^{+}$interference) because the ratio of intensities measured on these two peaks for multiple samples is identical, within error, to the natural ${ }^{113} \operatorname{In} /{ }^{115} \operatorname{In}$ isotopic abundance ratio $\left({ }^{113} \operatorname{In} /{ }^{115} \operatorname{In}=0.043406\right.$, (Berglund and Wieser, 2011); data used for regression provided in Supplementary Table S1). For the purposes of reporting results in this chapter and making comparisons between samples, measurements of In on mass 113 are reposted as estimated counts on mass 115. Measurements of ${ }^{75} \mathrm{As}^{+}$and ${ }^{74} \mathrm{Ge}^{+}$ were also conducted during some sessions. However, ${ }^{75} \mathrm{As}^{+}$was found to be heterogeneous in chalcopyrite and ion intensities for ${ }^{74} \mathrm{Ge}^{+}$were below detection limits.

Measurements of ${ }^{54} \mathrm{Fe}^{16} \mathrm{O}^{+}$and ${ }^{64} \mathrm{Zn}^{16} \mathrm{O}^{+}$were done to monitor for possible wurtzite and/or pyrite inclusions. Likely ablation of mineral inclusions was particularly notable in black smoker chimney linings composed of intergrown chalcopyrite and wurtzite and spots with anomalously high ${ }^{64} \mathrm{Zn}^{16} \mathrm{O}^{+}$intensities were removed from the dataset prior to further analysis.

For each black smoker chimney sample, sample means and standard errors were calculated over the total number of measurements on that sample in each analysis session. Reported trace element ratios obtained during different sessions were then normalized by reference to common samples analyzed during multiple sessions (Fig. 3A and 3B). During each session, a black smoker chimney sample shown to be homogeneous with respect to several of the trace elements of interest was used as a provisional standard to monitor machine stability using the sample-standard bracketing method (typically five sample spots bracketed by two standard spots). The standard error of counts ratios measured on these provisional standards during a given session was generally $<15 \%$ of the mean counts ratio. 
Figure 3. Repeat measurements of the same elements in the same samples during multiple sessions allows for cross-calibration and normalization of results between sessions. Figure 1A compares the results for $\mathrm{Co}, \mathrm{Ag}$, and In for common samples analyzed during the October, 2016 (x-axis) and December, 2015 (y-axis) sessions (Supplementary Table S2). Figure 1B compares the results for $\mathrm{Co}, \mathrm{Ni}$, and $\mathrm{Ga}$ for common samples analyzed during the September, 2016 (x-axis) and October, 2016 (y-axis) sessions (Supplementary Table S3).

Figure $3 \mathrm{~A}$
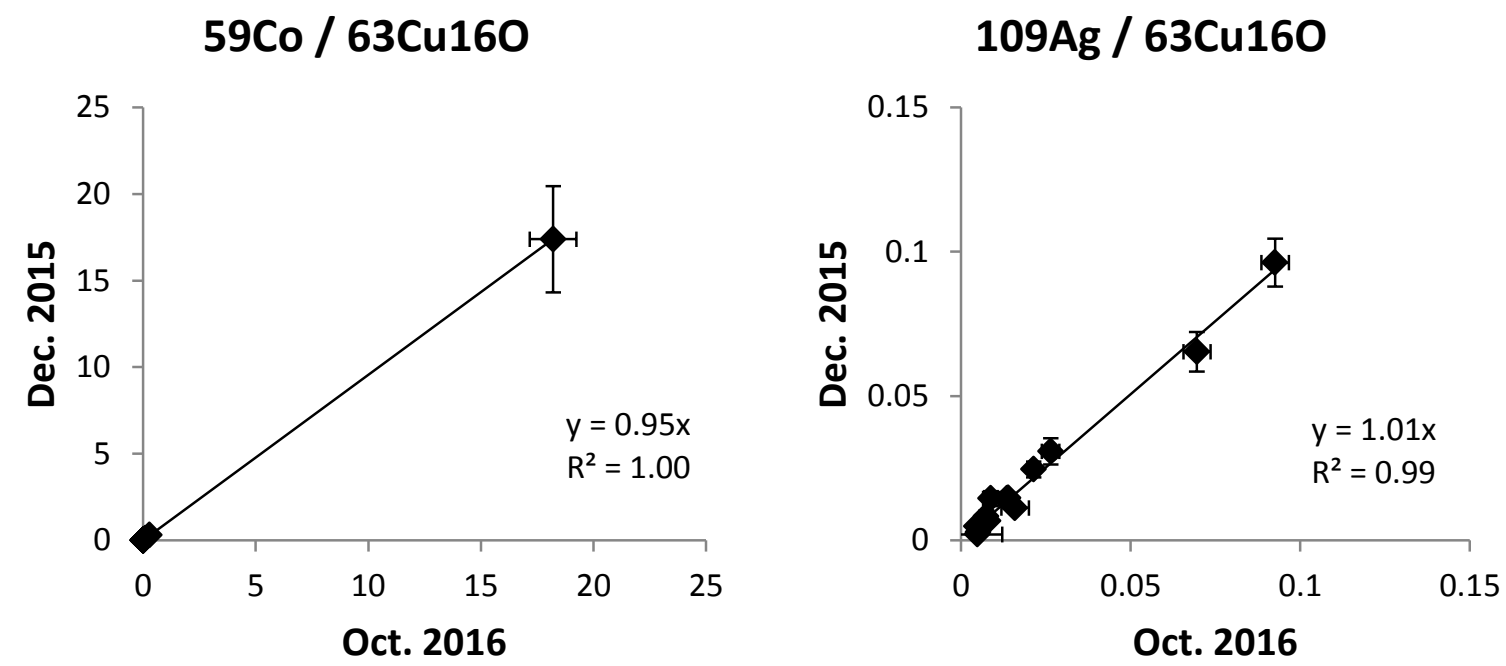

$115 \ln / 63 \mathrm{Cu} 160$

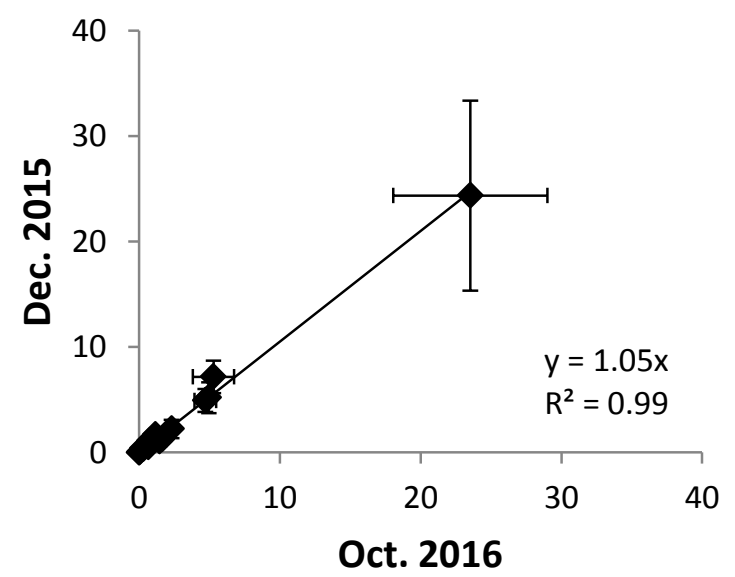


Figure 3B

59Co / 63Cu160

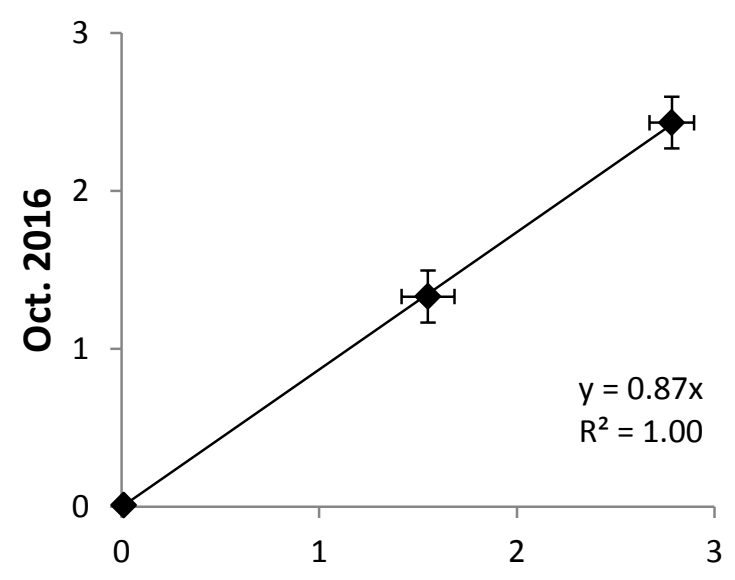

Sep. 2016

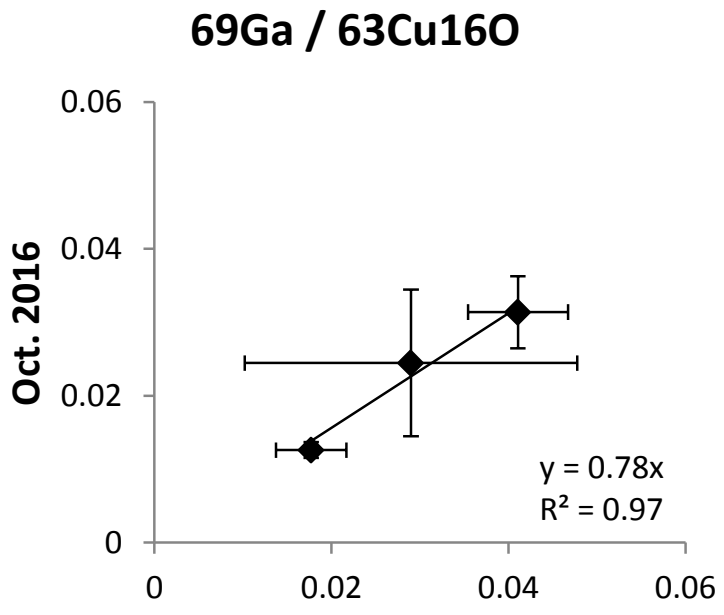

Sep. 2016
60Ni / 63Cu16O

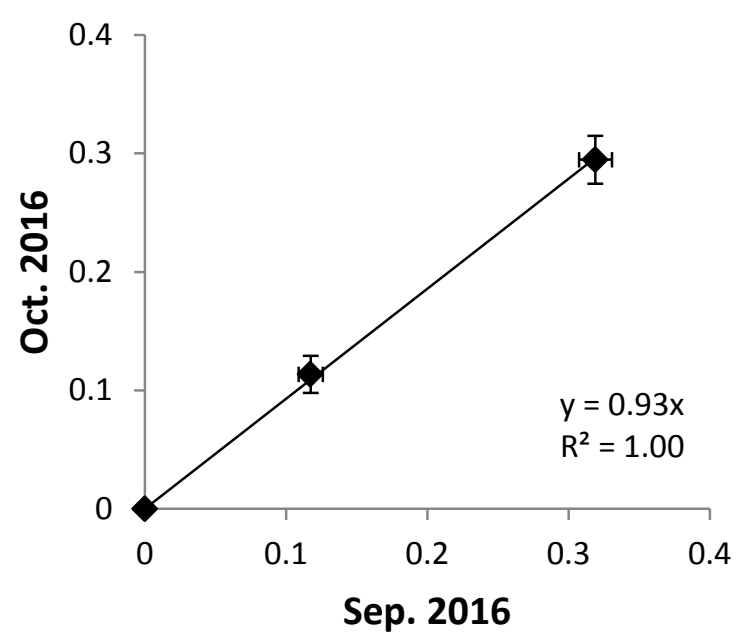




\subsection{Digestion and ICP-MS Analysis of Picked Chalcopyrite Grains}

Immediately after weighing, samples of picked chalcopyrite grains were digested in reverse aqua regia (1 part $12 \mathrm{~N} \mathrm{HCl}: 3$ parts $16 \mathrm{~N} \mathrm{HNO}_{3}$, by volume) in acid-cleaned Savillex digestion vials and diluted in $30 \mathrm{~mL}$ of $5 \mathrm{wt} . \% \mathrm{HNO}_{3}$ before being transferred to Teflon-coated bottles. All reagents are analytical-grade Optima ${ }^{\circledR}$ brand (Thermo Fisher Scientific, Waltham, USA). Milli-Q water was obtained from the Plasma Mass Spectrometry Facility at the Woods Hole Oceanographic Institution.

Major and trace element analyses of digested chalcopyrite (and cubanite) picks were obtained using the Element 2 (Thermo Fisher Scientific, Waltham, USA) in the Plasma Mass Spectrometry Facility at the Woods Hole Oceanographic Institution. Sample solutions were prepared for measurement by ICP-MS by further diluting aliquots of the $30 \mathrm{~mL}$ sample dilutions with 5 wt. \% HNO3 containing $1 \mathrm{ng} / \mathrm{g}$ Sc and Y as internal spikes to a strength of $\sim 2 \mu \mathrm{g} / \mathrm{g} \mathrm{Cu}$ for trace element analyses and a strength of $\sim 50 \mathrm{ng} / \mathrm{g} \mathrm{Cu}$ for major element analyses. Samples were measured against serial dilutions of Specpure® plasma solutions ( $\mathrm{Sb}, \mathrm{As}, \mathrm{Ba}, \mathrm{Bi}, \mathrm{Cd}, \mathrm{Ca}, \mathrm{Cr}, \mathrm{Co}$, $\mathrm{Cu}, \mathrm{Ga}, \mathrm{Ge}, \mathrm{Au}, \mathrm{Fe}, \mathrm{In}, \mathrm{Pb}, \mathrm{Mn}, \mathrm{Mo}, \mathrm{Ni}, \mathrm{Se}, \mathrm{Si}, \mathrm{Ag}, \mathrm{Sr}, \mathrm{S}, \mathrm{Te}, \mathrm{Tl}, \mathrm{Sn}, \mathrm{V}, \mathrm{Zn})$ in 5 wt\% analytical grade Optima® brand $\mathrm{HNO}_{3}$ likewise containing $1 \mathrm{ng} / \mathrm{g} \mathrm{Sc}$ and $\mathrm{Y}$ as internal spikes. All solution masses were weighed to a precision of $0.1 \mathrm{mg}$. Mass and machine settings for ICP-MS analyses

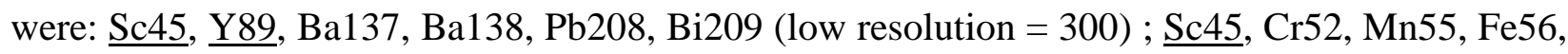
Co59, Ni60, Cu63, Cu65, Zn66, Zn68, Ga69, Y9, Mo96, Ag107, Ag109, In115, Sn118, Ba137, Ba138, Au197, Bi209 (medium resolution = 4000). Underlining indicates elements used as internal spikes. The Element 2 was fitted with Ni cones.

The creation of two standard dilution series allowed for estimation of ICP-MS analytical errors by examining the reproducibility of measurements between the two series. These errors 
are a function of element concentration in the measured sample solution and the dilution factor of the measured sample solution relative to the original sample. Analytical errors can also be estimated by comparing repeat measurements of the same sample solution. These errors are similar to those calculated by considering differences between measurements of the two standard solutions series and are on the order of $10 \%$ for most measurements.

\subsection{Principal Component Analysis}

To identify the major compositional variables that distinguish black smoker chimneys from different vent fields as well as covariances between different trace elements, principal components and correlations coefficients of the log-transformed SIMS count ratios were calculated using the MATLAB code pca. In order to investigate whether or not these compositional variations might be related to certain hydrothermal fluid parameters, principal components and correlation coefficients were also calculated for an expanded dataset that included the reciprocal absolute temperature $(1 / \mathrm{K}), \mathrm{pH}\left(\right.$ at $\left.25^{\circ} \mathrm{C}\right)$, and $\log$-transformed endmember concentrations of $\mathrm{Cl}$ and $\mathrm{H}_{2} \mathrm{~S}$ for all black smoker chimney samples collected with fluid sample pairs.

\section{RESULTS}

The small spot size and low detection limits of SIMS enable measurements of trace elements abundances in chalcopyrite present along the innermost linings of black smoker chimney linings, i.e. grains that most likely reflect the chemical and physical parameters of collected hydrothermal fluid sample pairs. By obtaining multiple spots on a single sample, it is possible to evaluate the abundance and homogeneity of trace elements in each sample. For the 
purposes of this paper, the abundance and homogeneity of trace elements in each sample is approximated by the means and standard errors $(1 \sigma)$ of SIMS analyses reported as the ratio of counts on each trace element to counts on ${ }^{63} \mathrm{Cu}^{16} \mathrm{O}$.

\subsection{Abundance of Trace Elements in Black Smoker Chimney Linings}

Analyses of Co, Ag, and In were conducted using SIMS on 29 black smoker samples of which 22 were also analyzed for $\mathrm{Ni}$ and $\mathrm{Ga}$. Trace element counts ratios are above detection limits for most samples and elements and span many orders of magnitude for each element (Fig. $4 A-4 F)$.

Count ratios of ${ }^{59} \mathrm{Co} /{ }^{63} \mathrm{Cu}^{16} \mathrm{O}$ range six orders of magnitude, from $1.2 \times 10^{-5}$ to $1.7 \times 10^{1}$, while count ratios of ${ }^{60} \mathrm{Ni} /{ }^{63} \mathrm{Cu}^{16} \mathrm{O}$ range five orders of magnitude, from $1.4 \times 10^{-5}$ to $1.3 \times 10^{0}$. Count ratios of ${ }^{59} \mathrm{Co} /{ }^{63} \mathrm{Cu}^{16} \mathrm{O}$ and ${ }^{60} \mathrm{Ni} /{ }^{63} \mathrm{Cu}^{16} \mathrm{O}$ are generally higher in black smoker chimney samples from basalt-hosted vent fields than in those from felsic-hosted back-arc vent fields in the Lau and Manus Basins with the exception of samples from SuSu Knolls, which exhibit intermediate $\mathrm{Co}$ and Ni concentrations. Additionally, the abundances of Co and Ni covary in basalt-hosted and SuSu Knolls samples, with the highest concentrations of both $\mathrm{Co}$ and $\mathrm{Ni}$ present in sample J2-613-16-R1 from the Beebe / Piccard vent field on the Mid-Cayman Rise (Fig. 4B, 4C). Count ratios of $\mathrm{Co}$ and $\mathrm{Ni}$ are low in samples from felsic-hosted systems other than SuSu Knolls and do not covary (Fig. 5A). Arranged in descending order concentrations of Co and Ni are: Mid-Cayman Rise > southern East Pacific Rise $\sim$ Main Endeavour Field (postevent) $>$ SuSu Knolls $>$ Eastern Lau Spreading Center $\sim$ Manus Spreading Center $\sim$ Eastern Manus Basin Main Endeavour Field (pre-event). 
Count ratios of ${ }^{55} \mathrm{Mn} /{ }^{63} \mathrm{Cu}^{16} \mathrm{O},{ }^{69} \mathrm{Ga} /{ }^{63} \mathrm{Cu}^{16} \mathrm{O}$ and ${ }^{115} \mathrm{In} /{ }^{63} \mathrm{Cu}^{16} \mathrm{O}$ each cover 2-3 orders of magnitude with ${ }^{55} \mathrm{Mn} /{ }^{63} \mathrm{Cu}^{16} \mathrm{O}$ ranging from $9.4 \times 10^{-4}$ to $6.3 \times 10^{-1},{ }^{69} \mathrm{Ga} /{ }^{63} \mathrm{Cu}^{16} \mathrm{O}$ ranging from $1.0 \times 10^{-2}$ to $2.6 \times 10^{0}$ and ${ }^{115} \mathrm{In} /{ }^{63} \mathrm{Cu}^{16} \mathrm{O}$ ranging from $1.3 \times 10^{-2}$ to $2.5 \times 10^{1}$. Count ratios of ${ }^{109} \mathrm{Ag}$ ${ }^{63} \mathrm{Cu}^{16} \mathrm{O}$ cover less than two orders of magnitude and range from $1.5 \times 10^{-3}$ to $9.6 \times 10^{-2}$. The abundances of Ga and In weakly covary and Ga is typically more abundant in black smoker chimney linings from felsic-hosted vent systems (Fig. 5B).Count ratios of Mn, Ag, and In exhibit no obvious association with the lithology of host rocks or geologic settings.

\subsection{Homogeneity of Trace Elements in Black Smoker Chimney Linings}

The homogeneity of trace elements in black smoker chimney linings was evaluated by calculating the standard error of the SIMS count ratios, reported as a percentage of the mean counts ratio. The extent of trace element homogeneity varies widely between samples. However, relative standard errors $(1 \sigma)$ for the majority of samples lie between $5 \%$ and $25 \%$ for $\mathrm{Mn}, \mathrm{Co}, \mathrm{Ni}$, and $\mathrm{Ag}$ and between 5\% and 50\% for Ga and In (Fig. 6). The median relative standard errors for all black smoker chimney samples examined in this study are: Mn (21\%), Co (40\%), Ni (14\%), $\mathrm{Ga}(29 \%), \mathrm{Ag}(24 \%)$, and In (35\%). For Co, relative standard errors negatively correlate with the ${ }^{59} \mathrm{Co} /{ }^{63} \mathrm{Cu}^{16} \mathrm{O}$ counts ratio. If only the 12 samples containing $>1 \mu \mathrm{g} / \mathrm{g}$ Co are considered, the median relative standard error for Co is reduced from $40 \%$ over the entire sample set to just $13 \%$ (conversion from SIMS counts ratios to concentration is described in Section 4. 3.). Relative standard errors of other trace elements do not correlate with counts ratios. 
Figure 4. Means and standard errors ( $1 \sigma)$ of SIMS measurements for each sample over the number of spots indicated (" $n=$ [number of spots]" or "NM" if not measured) reported as a ratio of counts per second (cps) measured on the target mass to counts per second measured on ${ }^{63} \mathrm{Cu}^{16} \mathrm{O}$ during the same cycle: (A) ${ }^{55} \mathrm{Mn} /{ }^{63} \mathrm{Cu}^{16} \mathrm{O}$, (B) ${ }^{59} \mathrm{Co} /{ }^{63} \mathrm{Cu}^{16} \mathrm{O}$, (C) ${ }^{60} \mathrm{Ni} /{ }^{63} \mathrm{Cu}^{16} \mathrm{O}$, (D) ${ }^{69} \mathrm{Ga} /{ }^{63} \mathrm{Cu}^{16} \mathrm{O}$, (E) ${ }^{109} \mathrm{Ag} /{ }^{63} \mathrm{Cu}^{16} \mathrm{O}$, (F) ${ }^{115} \mathrm{In} /{ }^{63} \mathrm{Cu}{ }^{16} \mathrm{O}$ (Data in Supplementary Table S4). Values are displayed on a log scale. Detection limits $\left(5 \times 10^{-5} \mathrm{cps} / \mathrm{cps}^{63} \mathrm{Cu}^{16} \mathrm{O}\right)$ and determination limits $\left(1.2 \times 10^{-4} \mathrm{cps} / \mathrm{cps}{ }^{63} \mathrm{Cu}^{16} \mathrm{O}\right)$ as determined on the background mass, 54.7 are also marked. Samples and values used for SIMS calibration curves are shaded in gray.

Figure 4A

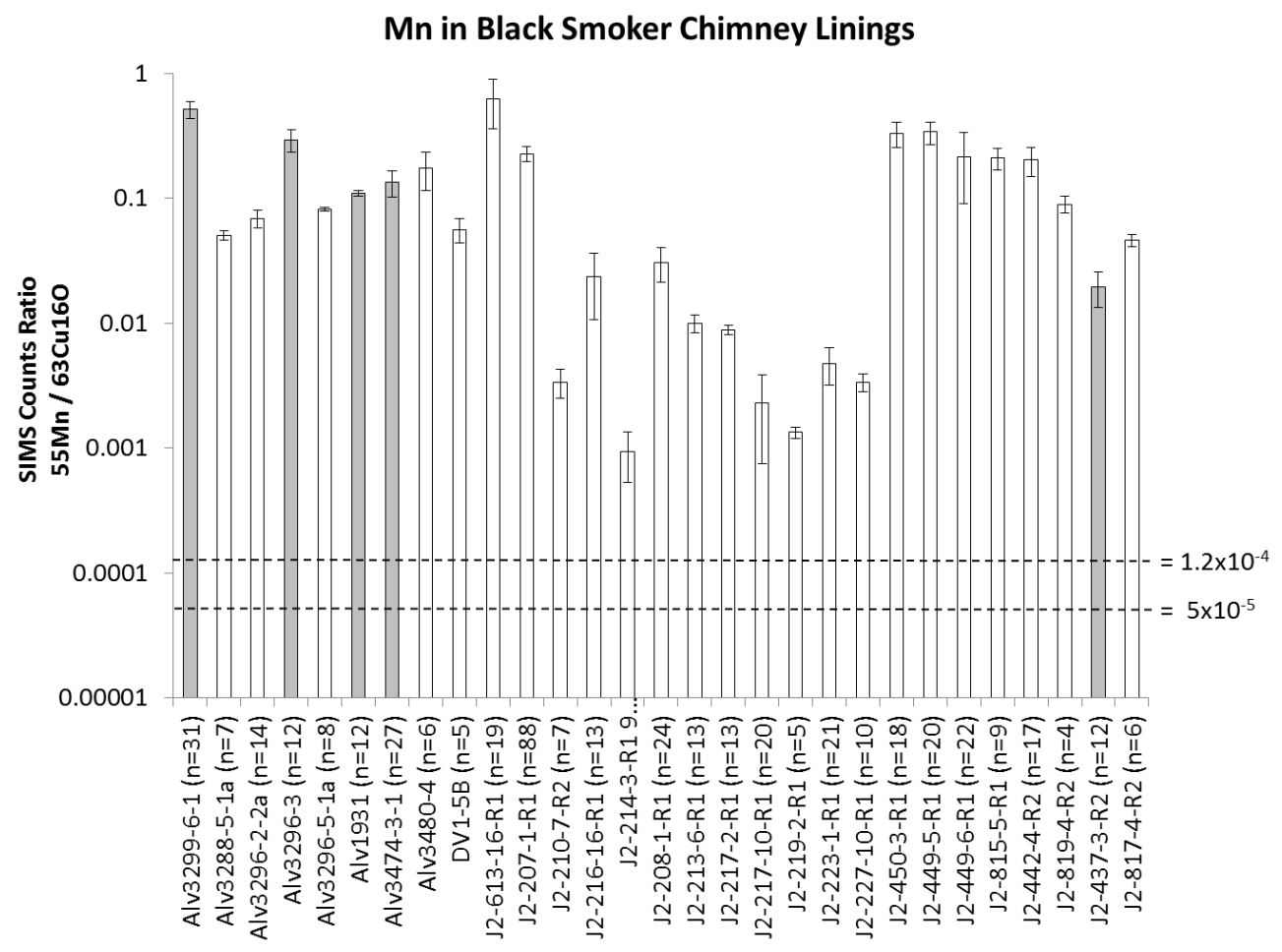


Figure 4B

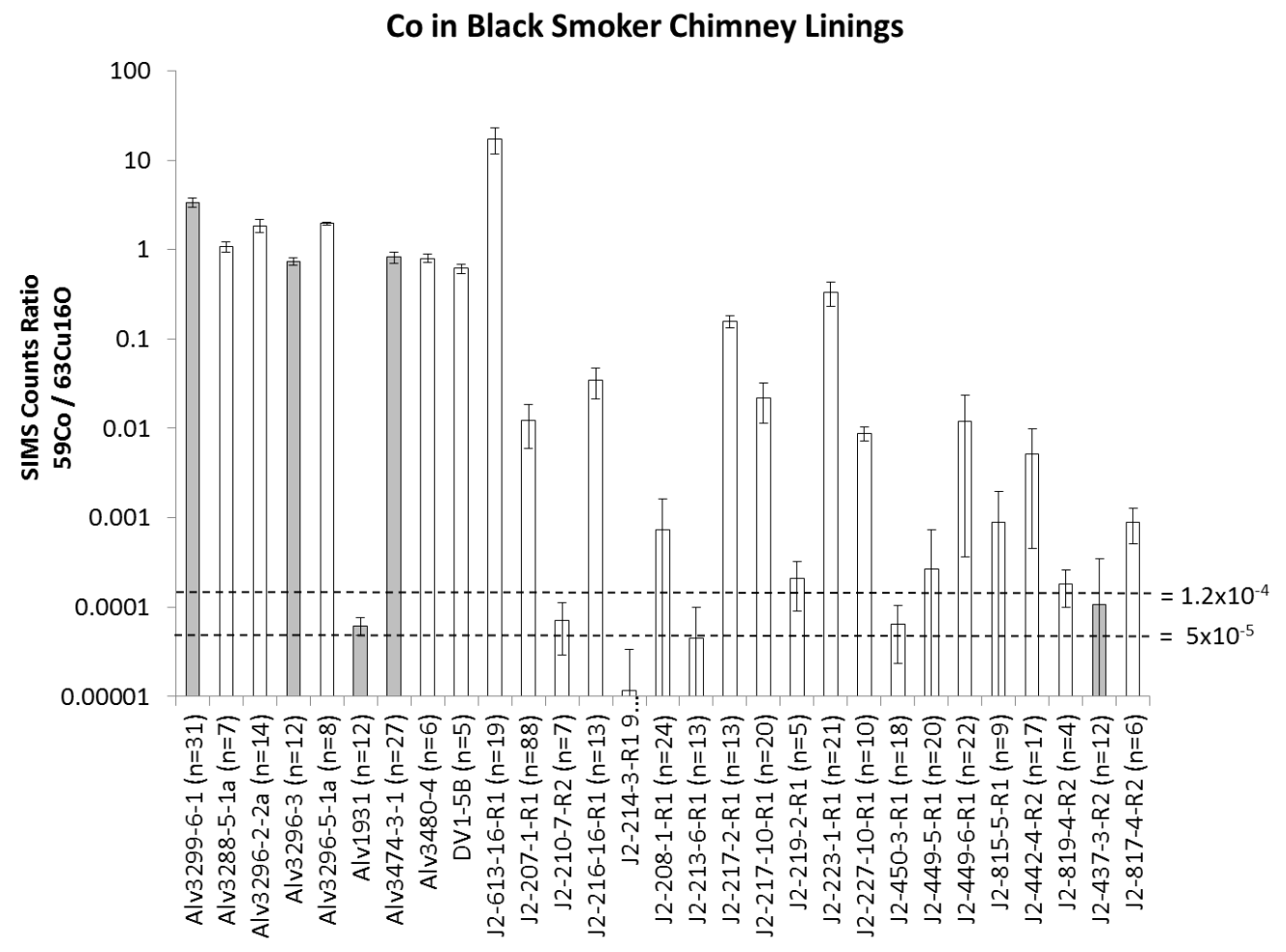

Figure 4C

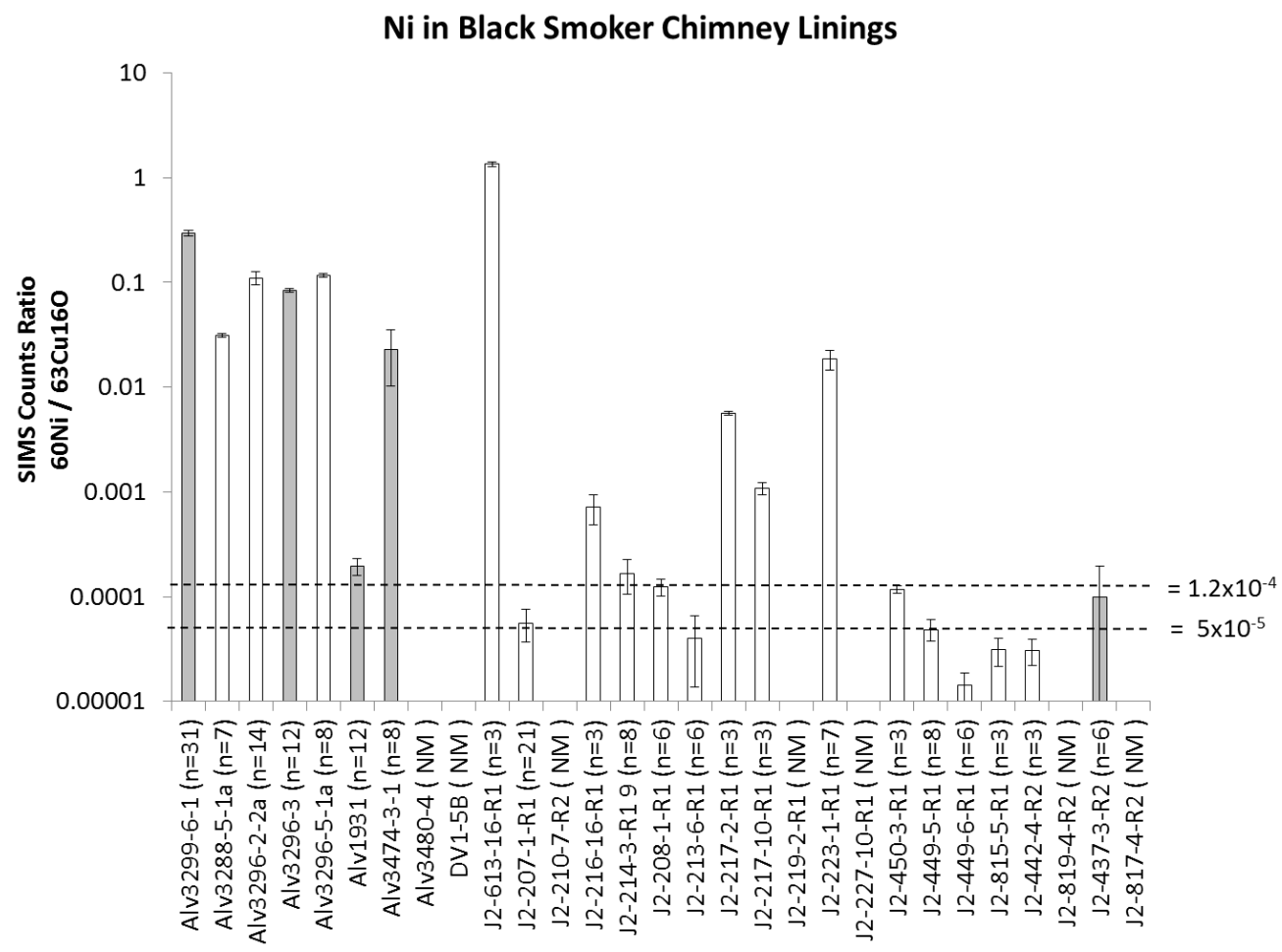


Figure 4D

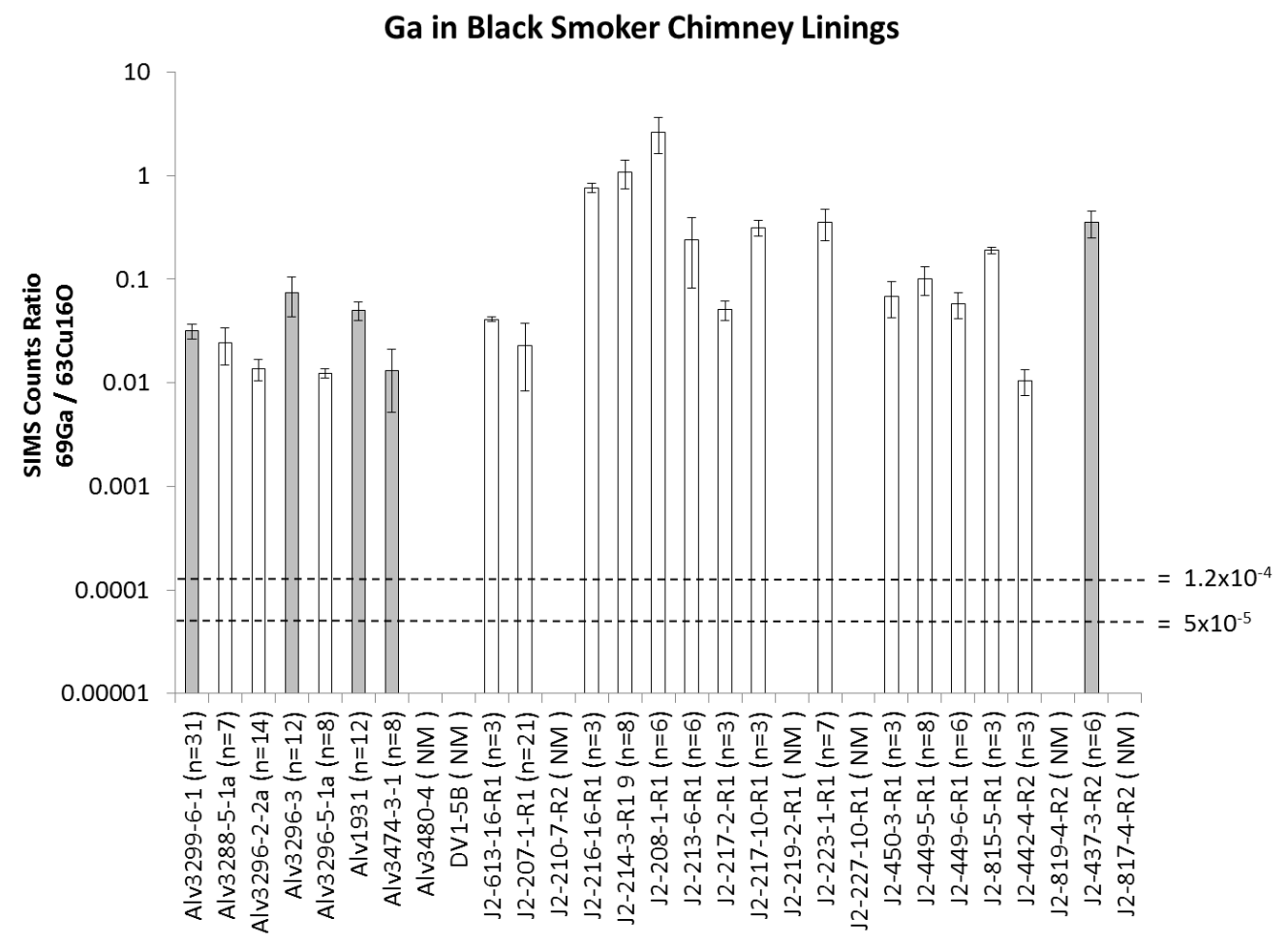

Figure 4E

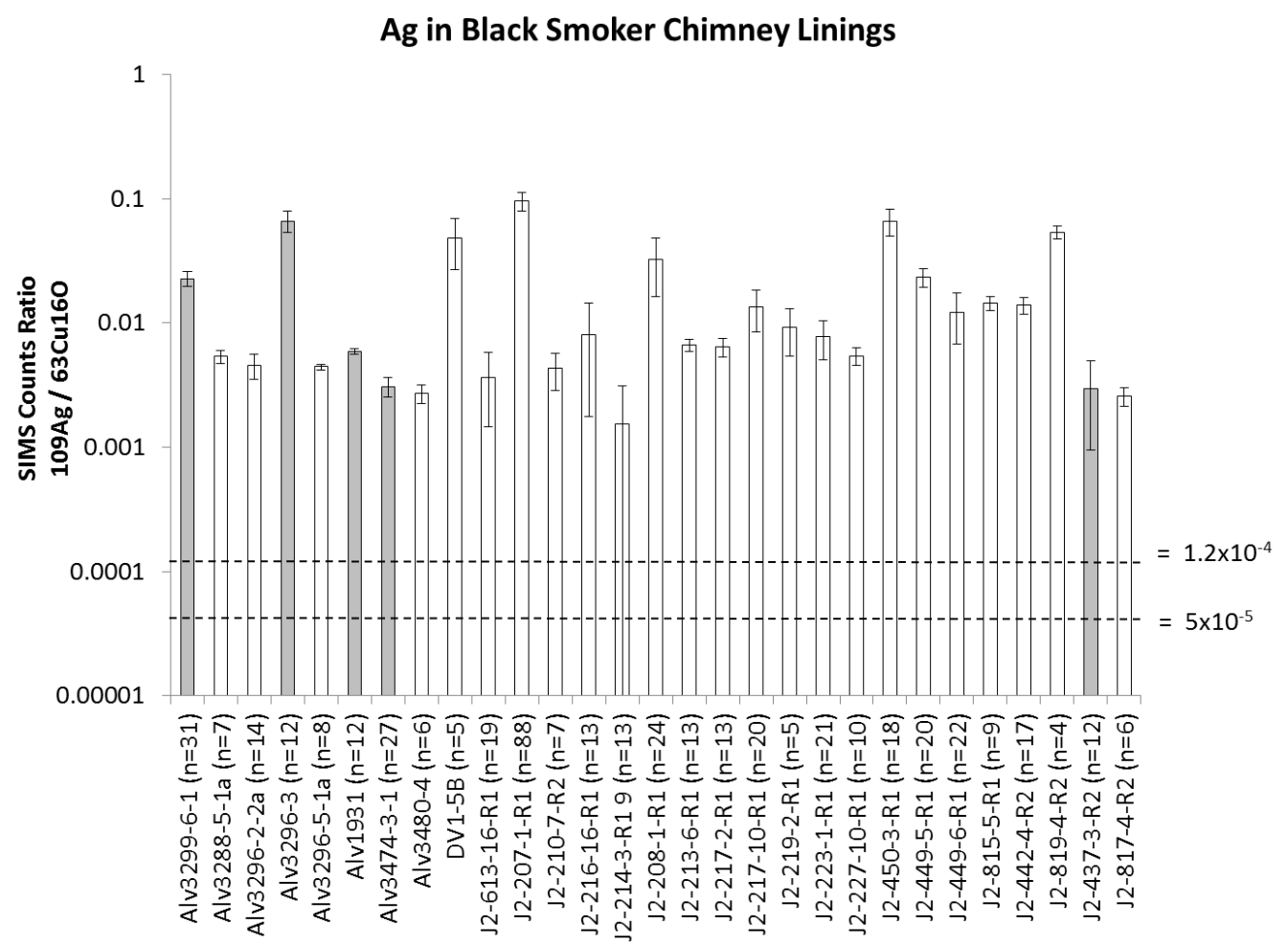


Figure 4F

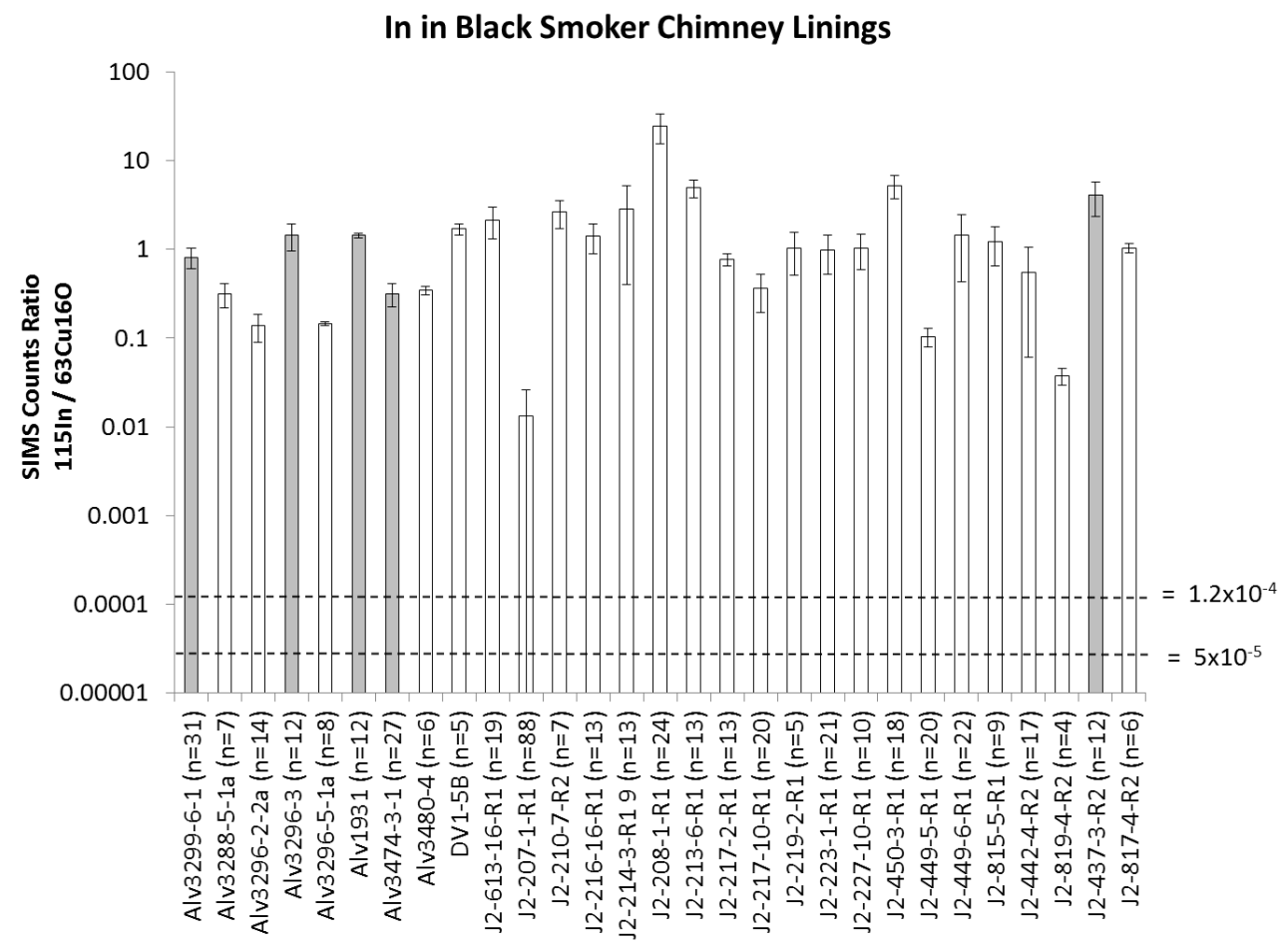


Figure 5. Bivariate plots on a log vs. log scale showing comparison of SIMS measurements for (A) ${ }^{59} \mathrm{Co} /{ }^{63} \mathrm{Cu}^{16} \mathrm{O}$ vs. ${ }^{60} \mathrm{Ni} /{ }^{63} \mathrm{Cu}{ }^{16} \mathrm{O}$ and (B) ${ }^{69} \mathrm{Ga} /{ }^{63} \mathrm{Cu}^{16} \mathrm{O}$ vs. ${ }^{115} \mathrm{In} /{ }^{63} \mathrm{Cu}^{16} \mathrm{O}$.

Figure 5A

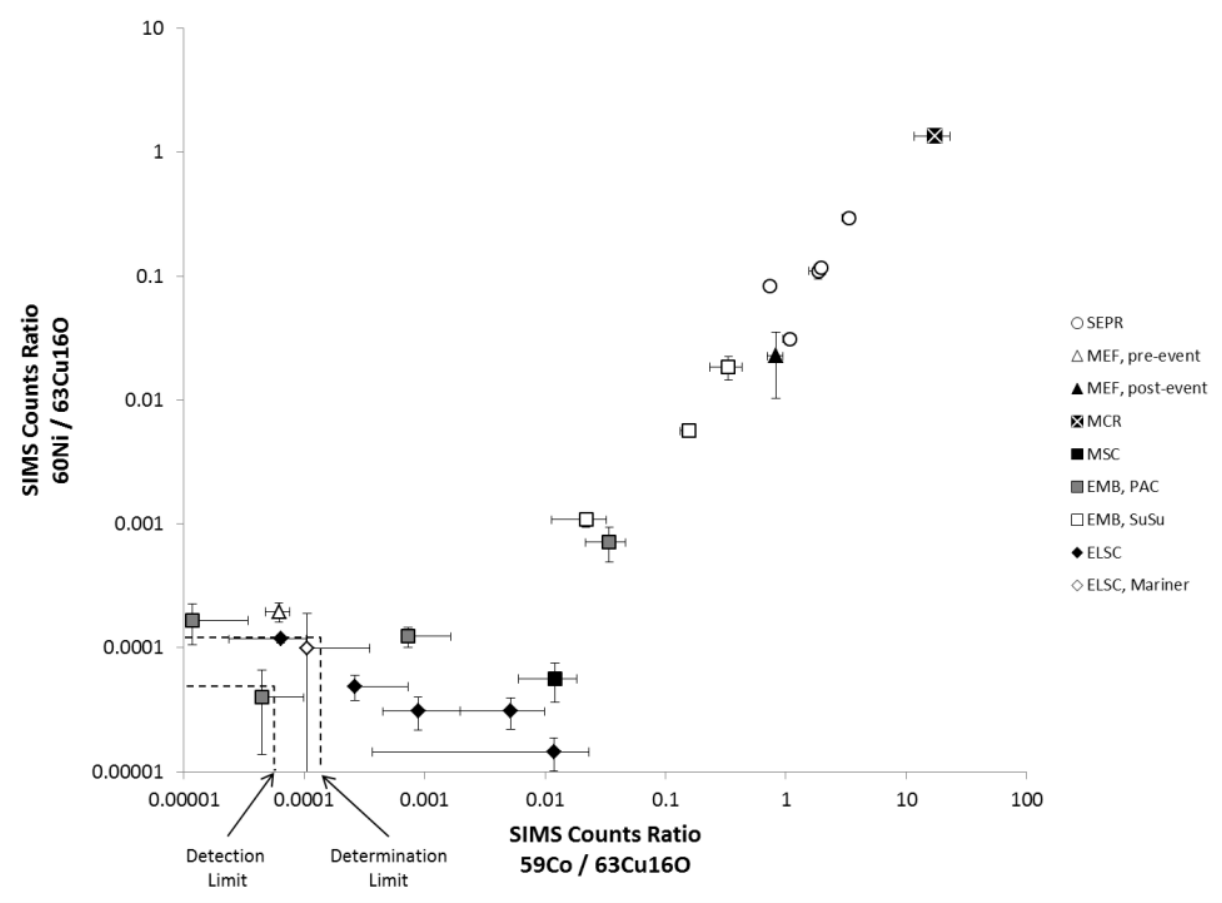

Figure 5B

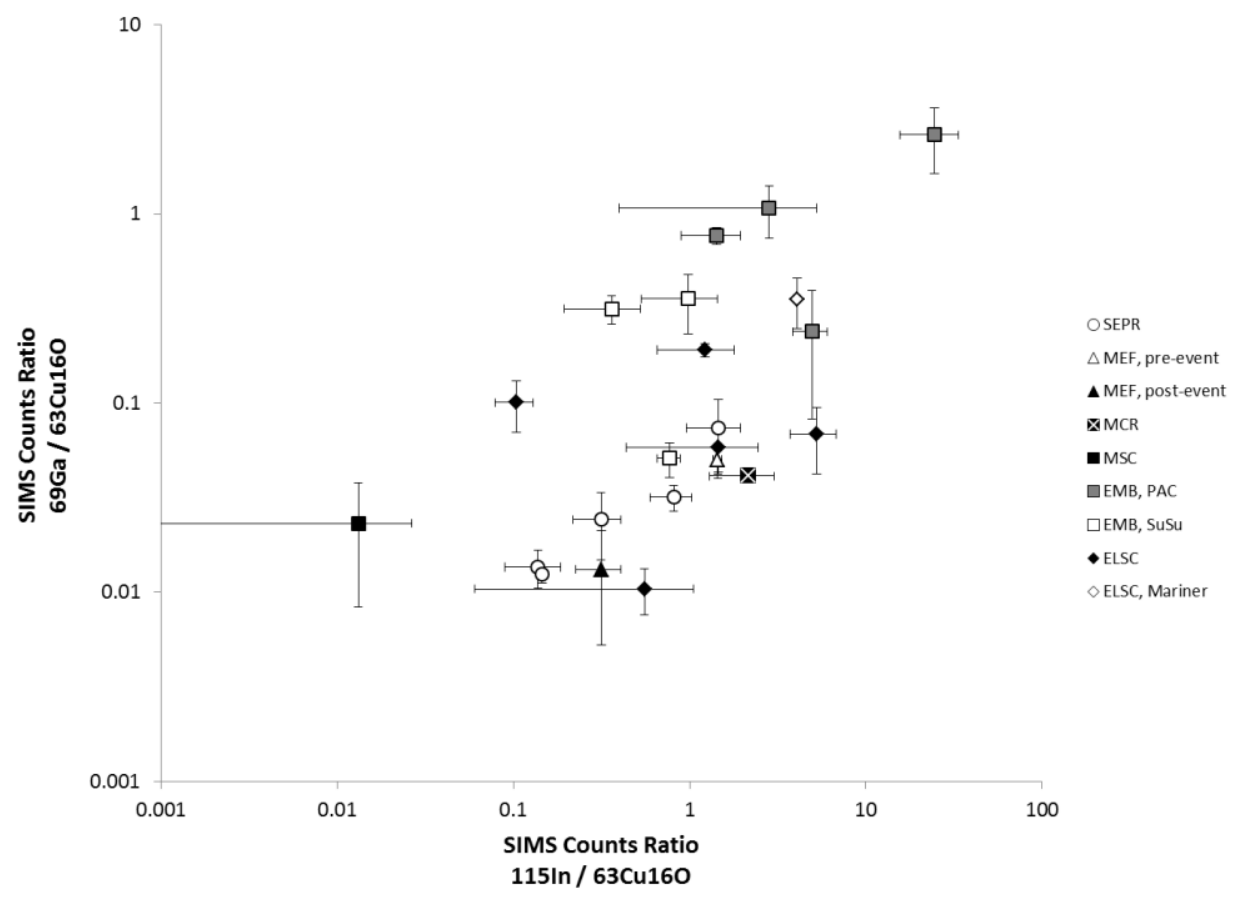




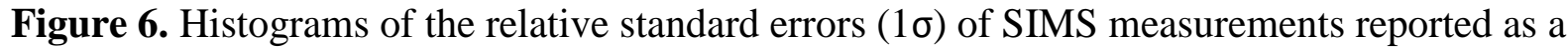
percentage of the mean. For Co, samples are separated between those containing $>1 \mu \mathrm{g} / \mathrm{g} \mathrm{Co}$ (white) and those containing < $1 \mu \mathrm{g} / \mathrm{g}$ Co (gray).

\section{Homogeneity of Mn}

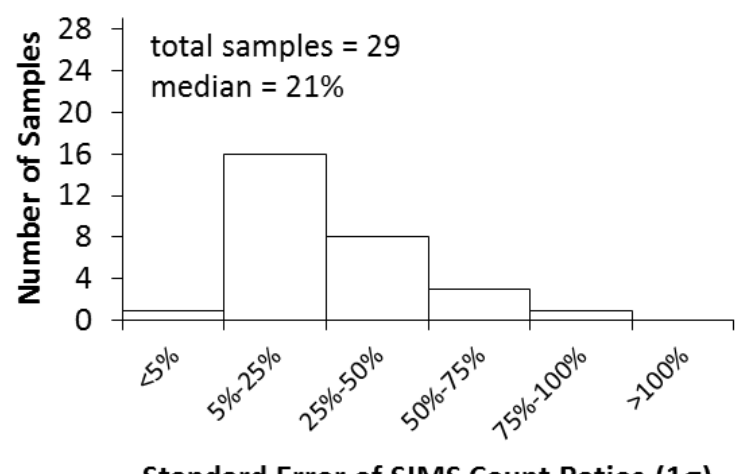

Standard Error of SIMS Count Ratios (1б)

\section{Homogeneity of Co}

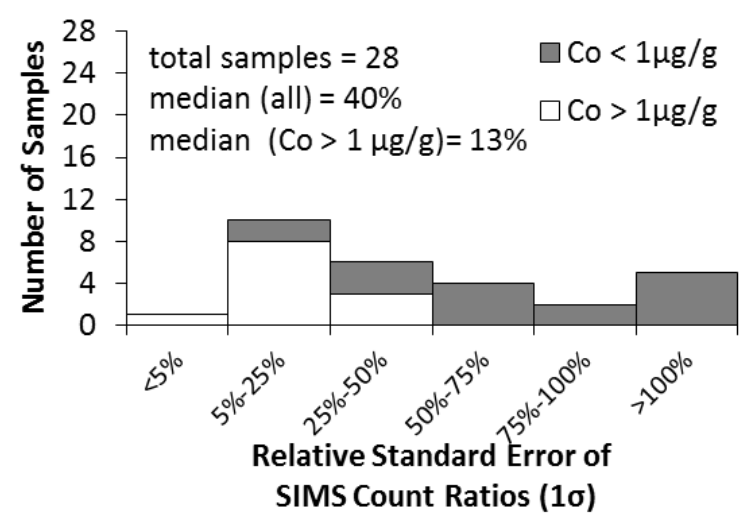

\section{Homogeneity of Ga}

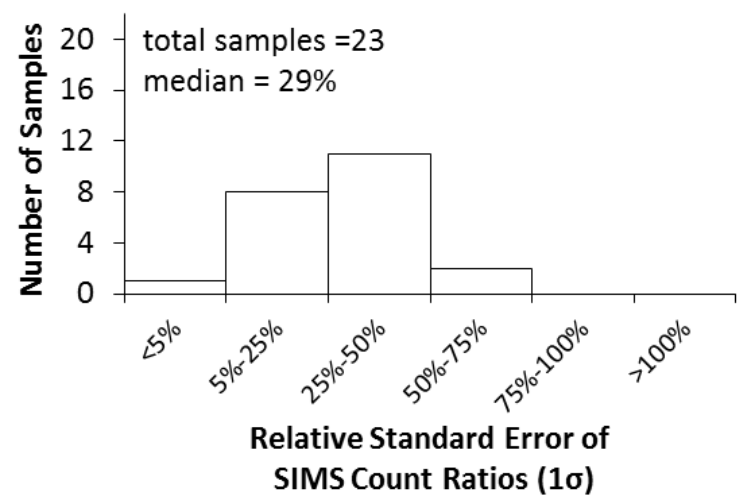

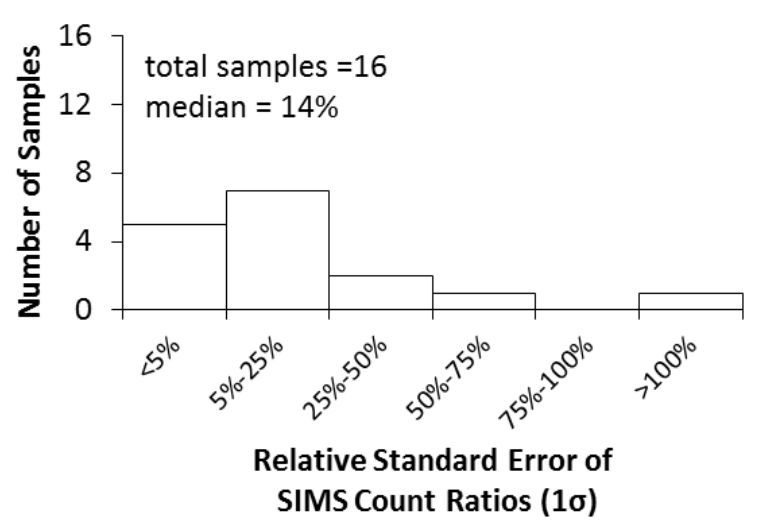

Homogeneity of Ag

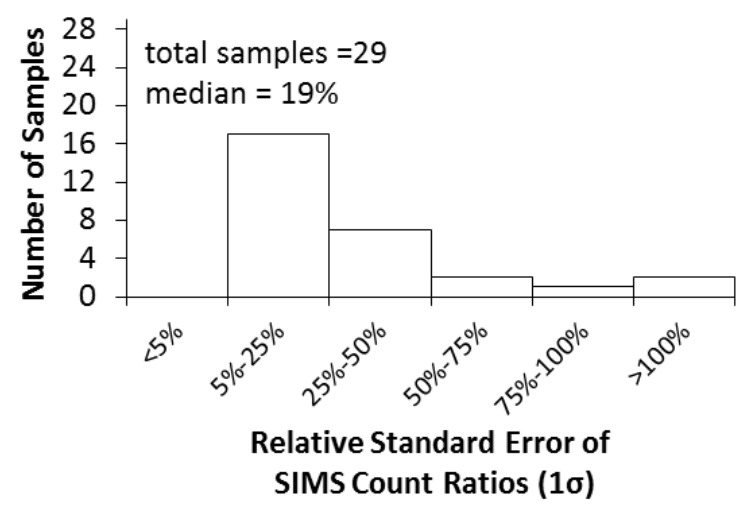

\section{Homogeneity of In}

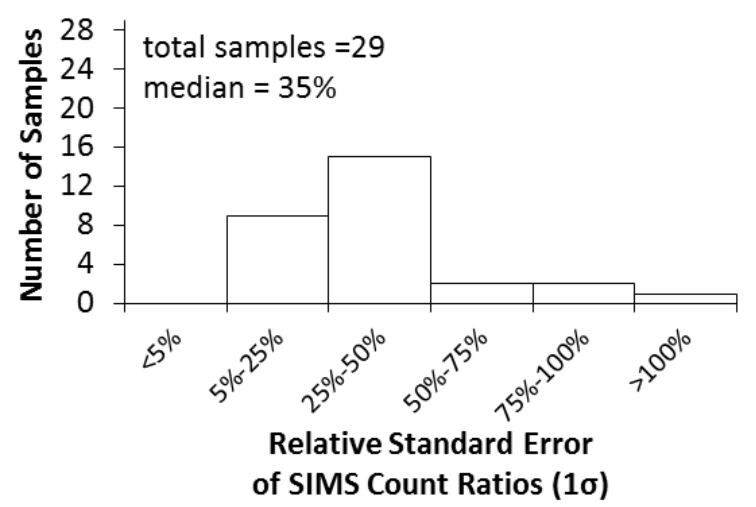




\subsection{Trace Elements in Chalcopyrite Lining Picks}

Analyses of major element concentrations in picked chalcopyrite and cubanite grains from the innermost linings of black smoker chimneys measured by ICP-MS exhibit overall reproducibility. Total recovery ranges between $86 \pm 6 \mathrm{wt} \%$ and $108 \pm 5 \mathrm{wt} \%$ with the exception of one sample with low recovery $(63 \pm 3 \mathrm{wt} \%$; see Table 2$)$. Analyses of other elements in this sample (e.g., $\mathrm{Ca}, \mathrm{Ba}, \mathrm{Si}$ ) are not anomalous. Following the assumption that differences in mass balance are primarily caused by the inefficient or unrecorded transfer of small sample grains between different laboratory containers, reported major and trace element mass fractions have been normalized to $100 \%$ recovery.

In general, concentrations are consistent between different picks of the same sample and different digestions of the same pick (Table 2). Trace element concentrations do vary widely between samples of different black smoker chimneys both within a given vent field and between

vent fields. Ranges of trace element concentrations in picked grains of chalcopyrite and cubanite analyzed by solution ICP-MS are: Mn $(6-43 \mu \mathrm{g} / \mathrm{g})$ Co $(0.3 \mu \mathrm{g} / \mathrm{g}-150 \mu \mathrm{g} / \mathrm{g}), \mathrm{Ni}(30 \mu \mathrm{g} / \mathrm{g}-$ $1120 \mu \mathrm{g} / \mathrm{g}), \mathrm{Ga}(0.3 \mu \mathrm{g} / \mathrm{g}-40.4 \mu \mathrm{g} / \mathrm{g}), \mathrm{Ag}(100 \mu \mathrm{g} / \mathrm{g}-2900 \mu \mathrm{g} / \mathrm{g})$, In $(5.9 \mu \mathrm{g} / \mathrm{g}-77 \mu \mathrm{g} / \mathrm{g})$.

Reported concentrations of Ag include a correction to account for loss of Ag in a concentration stock solution of mixed element standards during storage. Thus, absolute values should be taken with caution. Briefly, a discrepancy was observed between the Ag calibration curves generated by two different dilution series of the same concentrated stock solution of mixed element standards created several months apart. No discrepancy was observed in the calibration curves of other elements or the calibration curve of the earlier created dilution series measured during two different analysis sessions. Comparison of the two calibration curves was indicative of a loss of $\mathrm{Ag}$ in the concentrated stock solution with Ag photoreduction being the 
most likely cause. Measurements of Ag have been adjusted to correct for the discrepancy between the two calibration curves and to reflect Ag concentrations calibrated against the earlier created dilution series (i.e., the one least affected by possible Ag photoreduction). Further details are presented in Appendix A.

\subsection{Trace Element Concentrations of Black Smoker Chimneys}

By combining measurements of $\mathrm{Co}, \mathrm{Ni}, \mathrm{Ga}, \mathrm{Ag}$, and In obtained by SIMS and those obtained by ICP-MS, it is possible to develop SIMS calibration curves (Fig. 7A-F). A calibration curve for Mn was also attempted, but was not successful (Fig. 7A). Samples chosen for the construction of SIMS calibration curves are indicated in Table 1 and Figures 4A - 4F. SIMS analyses and ICP-MS analyses of multiple picks from these samples yield consistent results. An exception to this rule is sample J2-437-3-R2, which was included in order to extend the Ga and In calibration curves to higher concentrations despite the analysis of only one aliquot of picked grains.

Calibration curves for the full range of trace element concentrations are drawn for $\mathrm{Co}, \mathrm{Ni}$, and $\mathrm{Ag}$ by least squares linear regression (Figures, 7B, 7C, 7E). Calibration curves can also be drawn for Ga and In, albeit only within a limited concentration range (Figures 7D, 7F). By using these calibration curves, it is then possible to convert SIMS count ratios to concentrations of Co, $\mathrm{Ni}, \mathrm{Ga}, \mathrm{Ag}$, and In (Fig. 7B - 7F). Reported uncertainties of trace element concentrations reflect only the uncertainties derived from multiple SIMS analysis and do not reflect the additional uncertainties associated with the slopes of the calibration curves. The reasoning behind this presentation is to maintain focus on the extent of natural variability of trace element concentrations within each sample rather than propagating artifacts of the analysis. Uncertainties 
in the slopes of the calibration curves were estimated by serially removing one sample from the dataset and recalculating the regression line. As a percent of the originally calculated calibration curve, the range of slopes for the recalculated calibration curves is: $4.6 \%$ for $\mathrm{Co}, 4.4 \%$ for $\mathrm{Ni}, 4.1 \%$ for $\mathrm{Ga}, 7.9 \%$ for $\mathrm{Ag}$, and $33.5 \%$ for In. The slope of the In calibration curve is especially sensitive to sample J2-437-3-R2, which defines the high-concentration end of the calibration curve. Otherwise, the uncertainty in the slope of the In calibration curve is limited to $5.7 \%$. Using these calibration curves, the trace element contents of black smoker chimneys measured by SIMS can be converted to concentration units. The trace element contents of the black smoker chimney samples investigated here cover the following ranges: Co (below detection limit (bdl) to $760 \mu \mathrm{g} / \mathrm{g}), \mathrm{Ni}(\mathrm{bdl}-480 \mu \mathrm{g} / \mathrm{g}), \mathrm{Ga}(\mathrm{bdl}-48 \mu \mathrm{g} / \mathrm{g}), \mathrm{Ag}(60 \mu \mathrm{g} / \mathrm{g}-3800$ $\mu \mathrm{g} / \mathrm{g})$, In (bdl $-270 \mu \mathrm{g} / \mathrm{g})$. Detection limits for $\mathrm{Ni}(20 \mu \mathrm{g} / \mathrm{g})$ are high relative to other elements and are caused by uncertainties in the concentrations of Ni measured by ICP-MS for picked grains. 
Table 3. Results of ICP-MS analyses of picked chalcopyrite grains from selected black smoker chimney linings. Uncertainties in sample mass are estimated by propagation of weighing errors. Uncertainties in element concentrations estimated by comparison between two sets of standard solutions and by comparison of repeat measurements of the same sample solution. Samples chosen for inclusion in the SIMS calibration curves are marked in bold. Levels of tarnish indicates as "none" for no visible tarnish, "minor" for dark yellow or brown tarnish, and "tarnish" for blue or black tarnish.

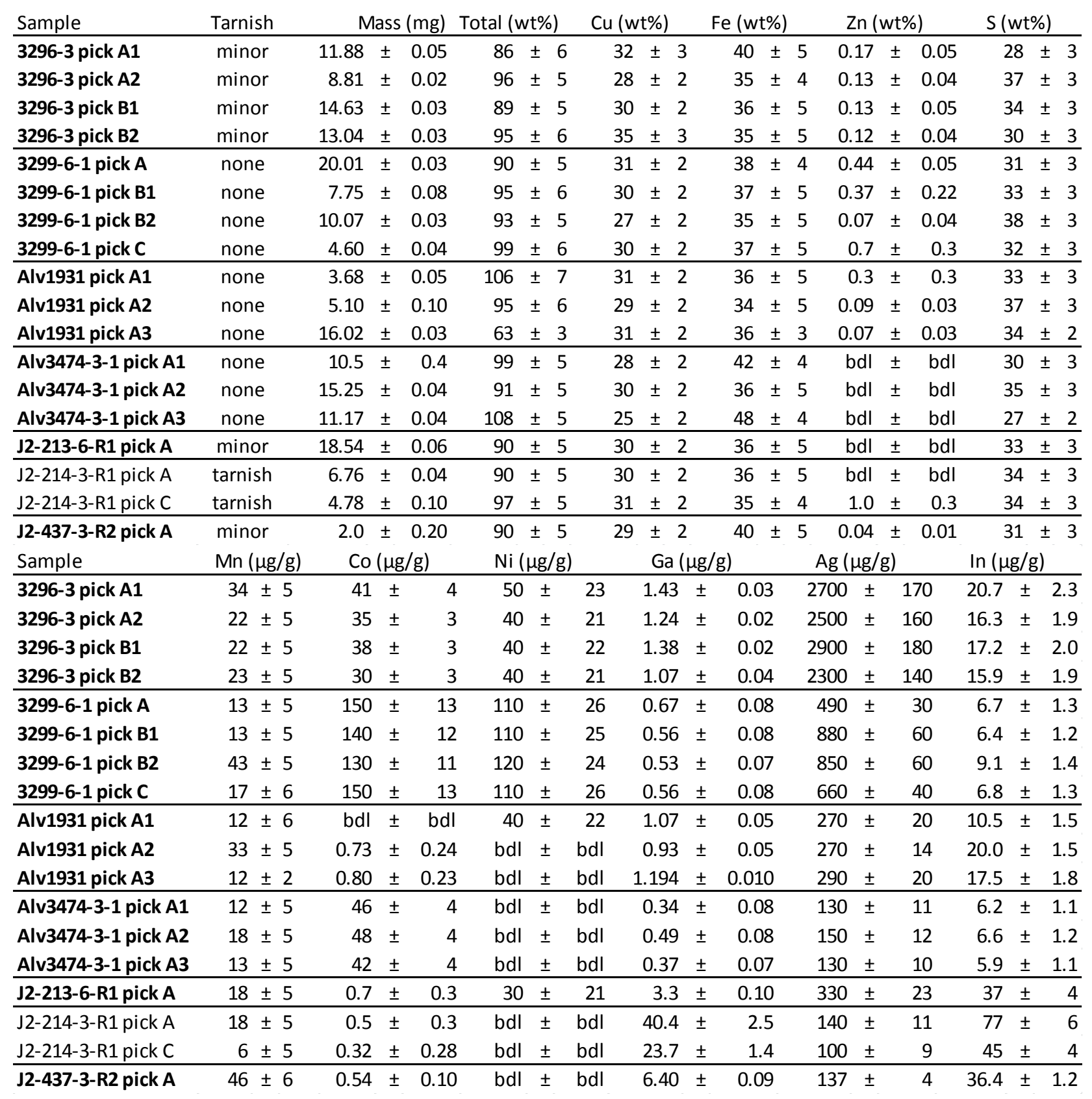


Figure 7. Calculated SIMS calibration curves for $\mathrm{Mn}, \mathrm{Co}, \mathrm{Ni}, \mathrm{Ga}, \mathrm{Ag}$, and In constructed by comparing ICP-MS measurements of these elements in aliquots of picked chalcopyrite grains ( $\mathrm{x}$ axis) and SIMS measurements of these same elements (y-axis). Separate points are plotted for each aliquot of picked grains using a single SIMS value for each black smoker chimney sample. Samples included in the regression used to calculate the calibration curve are marked in black. These correspond to the samples in bold in Table 3. Regression lines are calculated through these points without taking into account sample errors. Additional samples measured by ICP-MS and SIMS but not included in construction of the calibration curves are marked in white.

Figure 7A

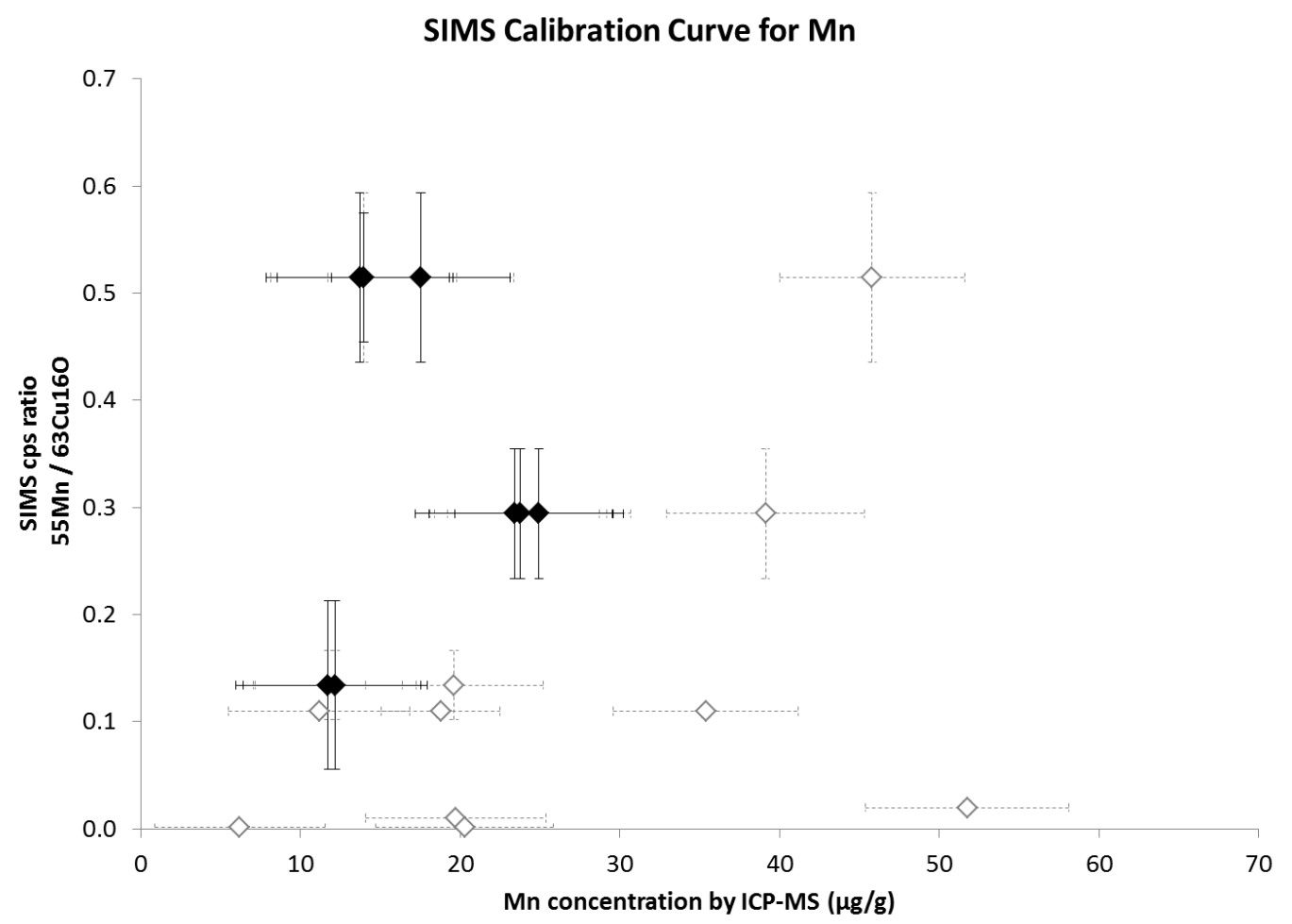


Figure 7B

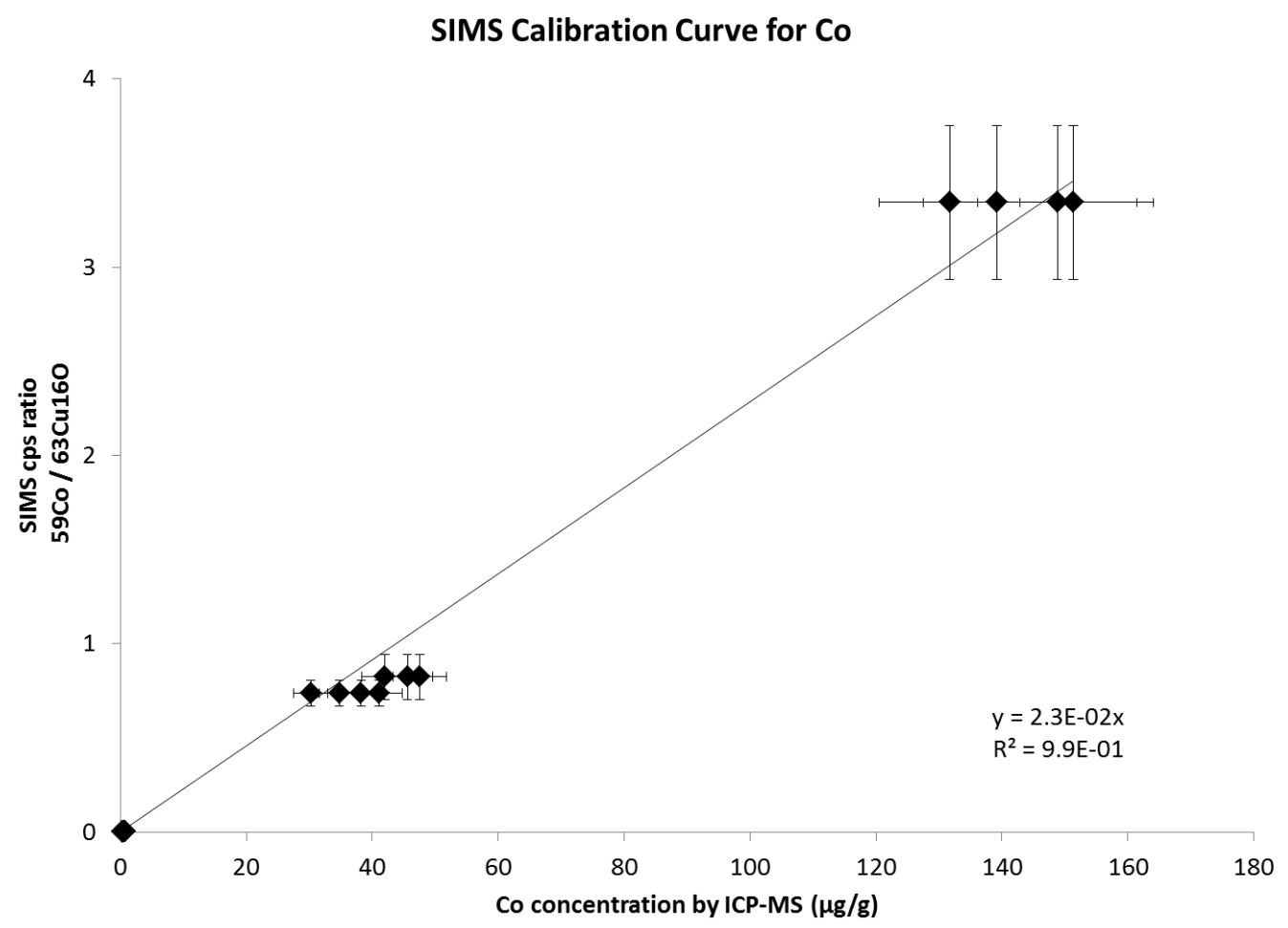

Figure 7C

SIMS Calibration Curve for $\mathbf{N i}$

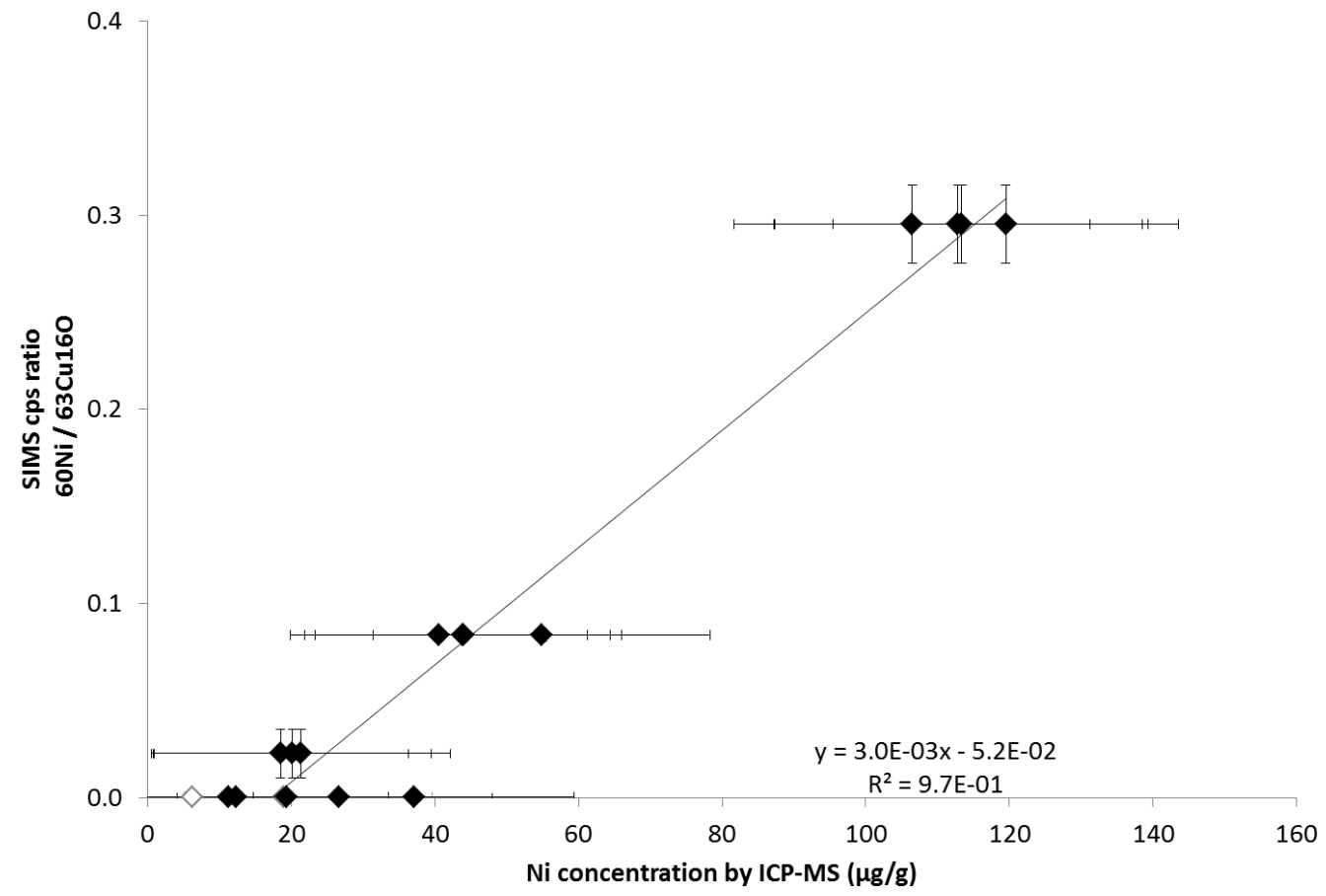


Figure 7D

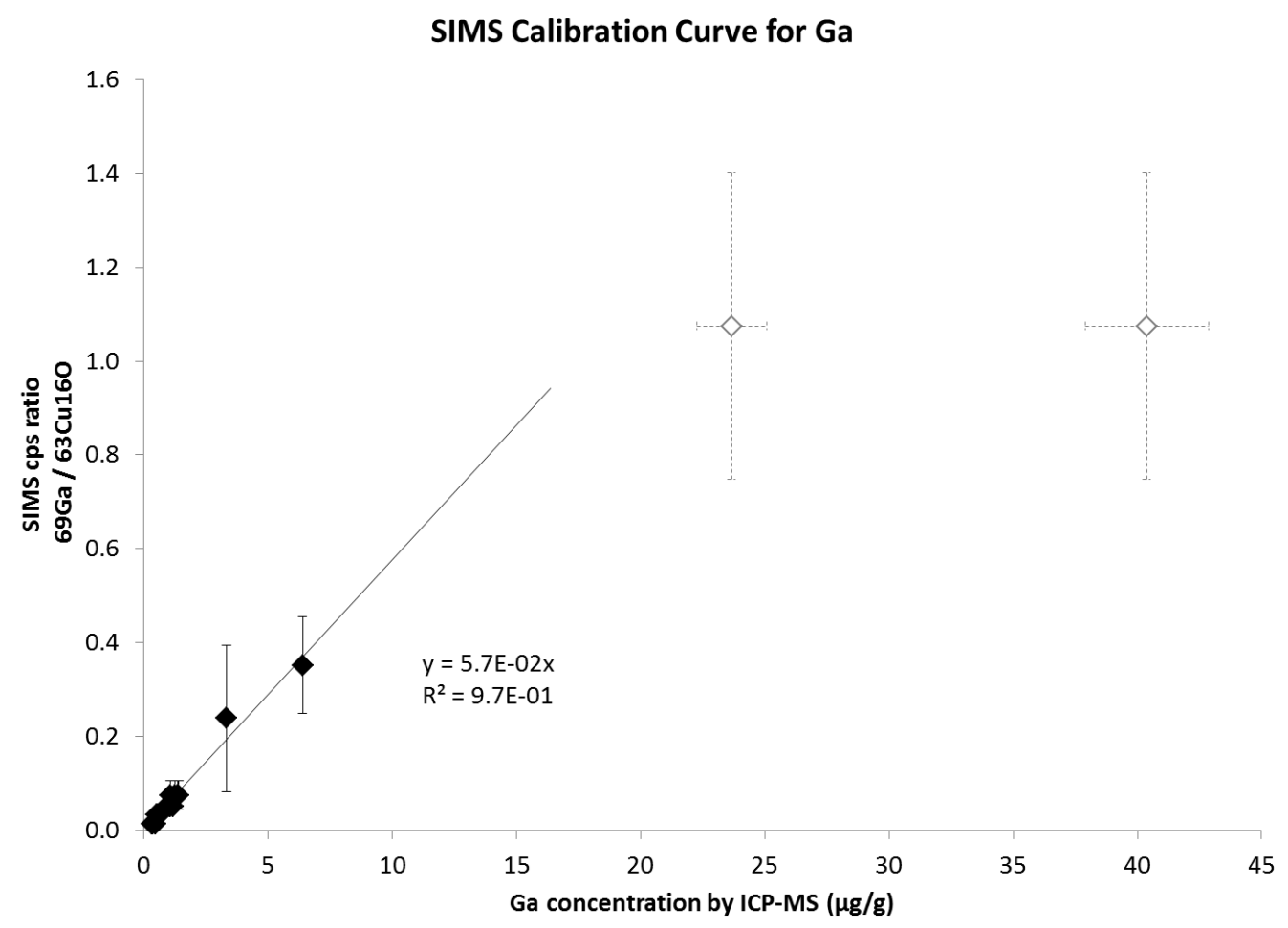

Figure 7E

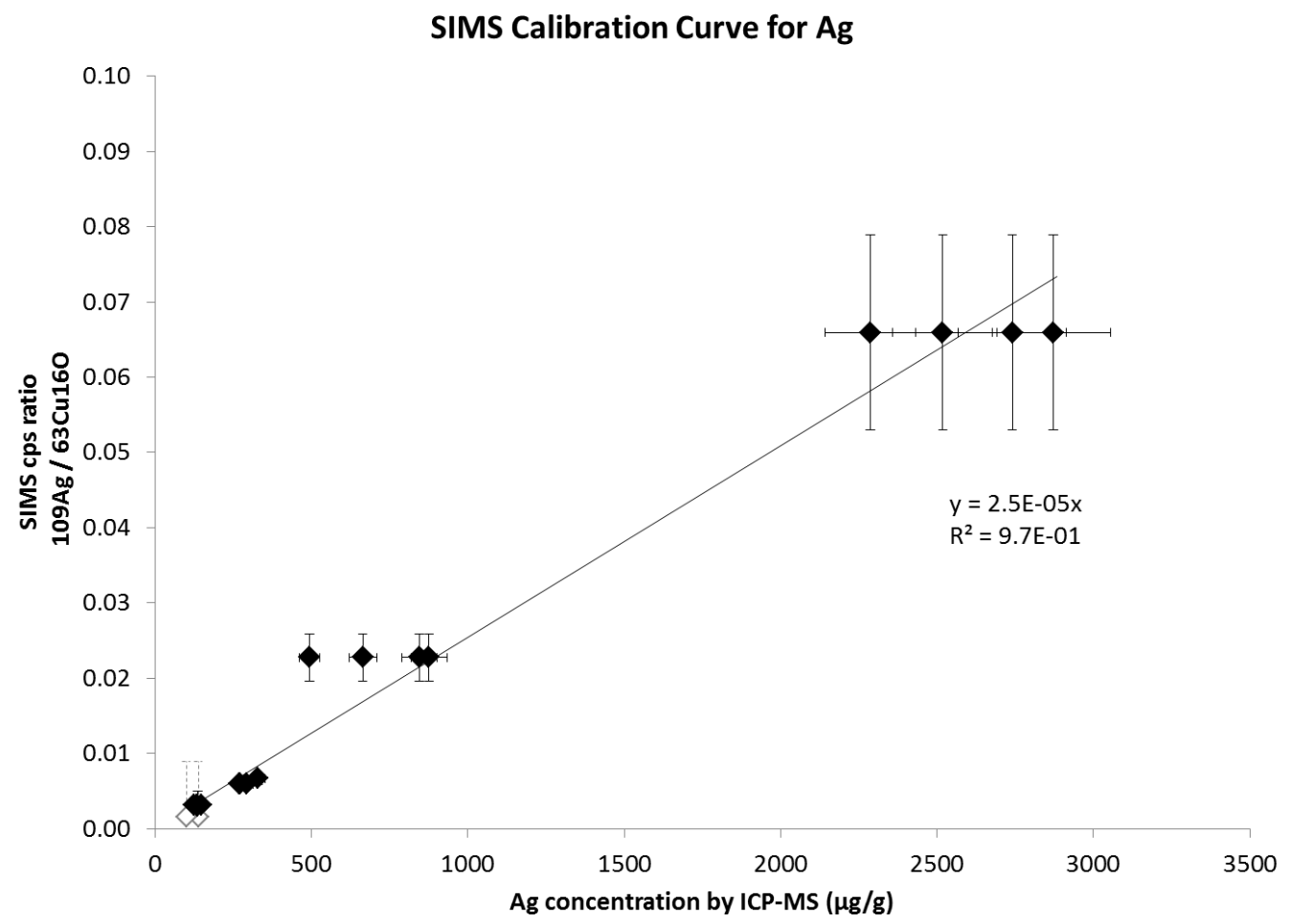


Figure 7F

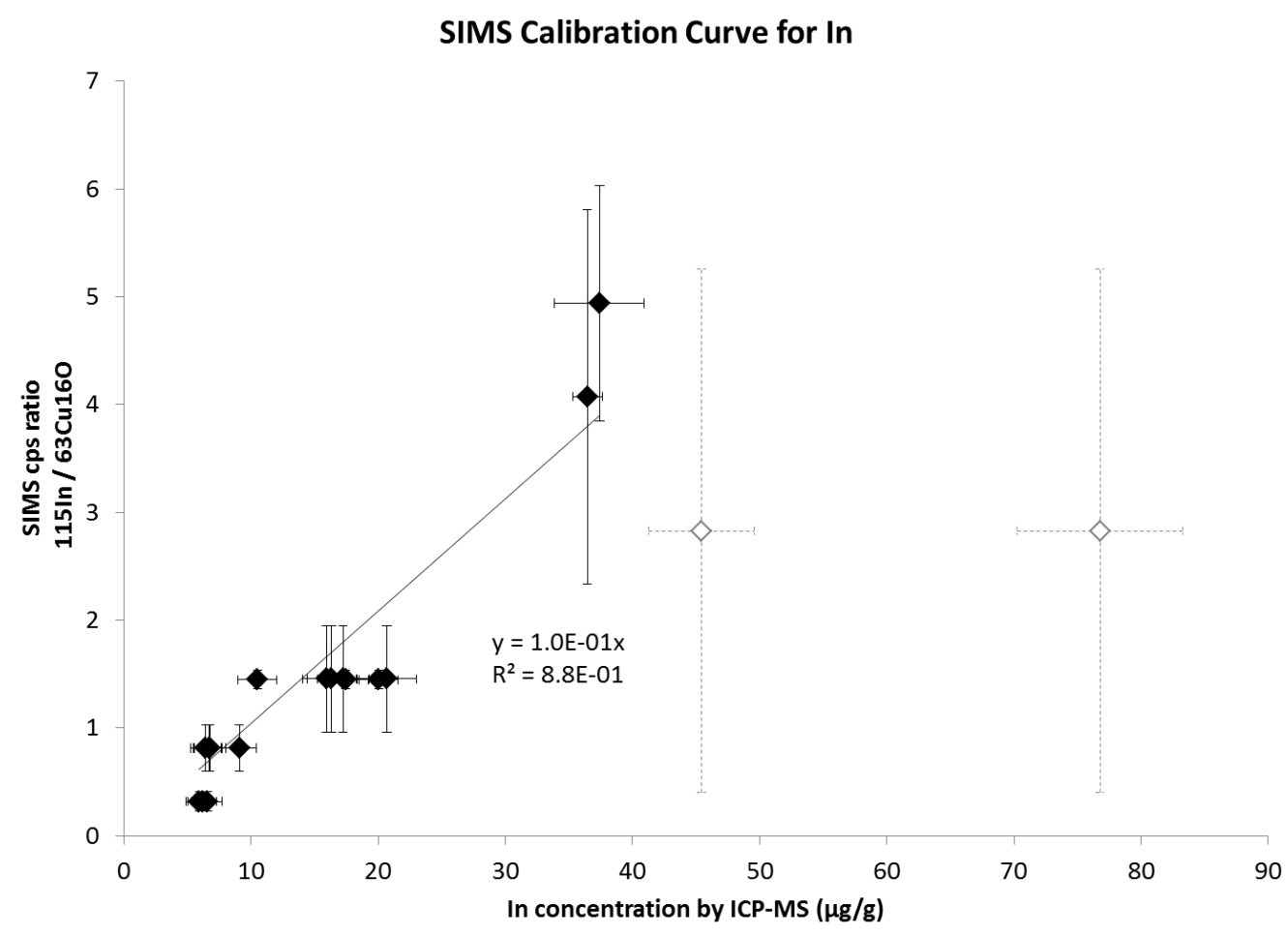


Table 4. SIMS measurements converted to concentration units by use of the calibration curves displayed in Figures 7B to 7F. Values are plotted in $\mu \mathrm{g} / \mathrm{g}$ on a linear scale. Samples used for constructing SIMS calibration curves are highlighted in bold. Also indicated are the detection limit, equivalent to $5 \times 10^{-5} \mathrm{cps} /{ }^{63} \mathrm{Cu}^{16} \mathrm{O} \mathrm{cps}$, and the determination limit, equivalent to $1.2 \times 10^{-4}$ cps $/{ }^{63} \mathrm{Cu}^{16} \mathrm{O}$ cps. Indicated sample errors are derived entirely from variation between SIMS spots and do not represent propagated errors from the calibration curves. For Ni, high detection limits $(20 \mu \mathrm{g} / \mathrm{g})$ are caused by uncertainties in ICP-MS measurements. Concentrations lower than $20 \mu \mathrm{g} / \mathrm{g}$ are measureable by SIMS, but cannot be calibrated with the current technique. bdl = below detection limit. $\mathrm{NM}=$ not measured.

\begin{tabular}{|c|c|c|c|c|c|c|}
\hline Sample ID & Vent Field & Co $(\mu \mathrm{g} / \mathrm{g})$ & $\mathrm{Ni}(\mu \mathrm{g} / \mathrm{g})$ & $\mathrm{Ga}(\mu \mathrm{g} / \mathrm{g})$ & $\mathrm{Ag}(\mu \mathrm{g} / \mathrm{g})$ & $\ln (\mu \mathrm{g} / \mathrm{g})$ \\
\hline Detection Limit & & $2 \mathrm{ng} / \mathrm{g}$ & $20 \mu \mathrm{g} / \mathrm{g}$ & $0.9 \mathrm{ng} / \mathrm{g}$ & $2 \mu \mathrm{g} / \mathrm{g}$ & $0.5 \mathrm{ng} / \mathrm{g}$ \\
\hline Determination Limit & & $5 \mathrm{ng} / \mathrm{g}$ & $120 \mu \mathrm{g} / \mathrm{g}$ & $2 \mathrm{ng} / \mathrm{g}$ & $5 \mu \mathrm{g} / \mathrm{g}$ & $1.2 \mathrm{ng} / \mathrm{g}$ \\
\hline Alv3299-6-1 & EPR, 17 34'S & $147 \pm 18$ & $116 \pm 22$ & bdl & $890 \pm 120$ & $8.8 \pm 2.3$ \\
\hline Alv3288-5-1a & EPR, 17 37'S & $47 \pm 6$ & $25 \pm 15$ & bdl & $211 \pm 25$ & $3.4 \pm 1.0$ \\
\hline Alv3296-2-2a & EPR, 1737 'S & $81 \pm 13$ & $52 \pm 20$ & bdl & $180 \pm 40$ & $1.5 \pm 0.5$ \\
\hline Alv3296-3 & EPR, 1737 'S & $32 \pm 3$ & $43 \pm 16$ & $1.4 \pm 0.6$ & $2600 \pm 500$ & $16 \pm 5$ \\
\hline Alv3296-5-1a & EPR, 1737 'S & $86 \pm 3$ & $55 \pm 16$ & bdl & $174 \pm 9$ & $1.57 \pm 0.08$ \\
\hline Alv1931 & MEF (pre-event) & $2.7 \mathrm{ng} / \mathrm{g} \pm 0.6 \mathrm{ng} / \mathrm{g}$ & bdl & $0.9 \pm 0.2$ & $232 \pm 12$ & $15.6 \pm 0.9$ \\
\hline Alv3474-3-1 & MEF (post-event) & $36 \pm 5$ & $22 \pm 19$ & bdl & $121 \pm 22$ & $3.4 \pm 1.0$ \\
\hline Alv3480-4 & MEF (post-event) & $35 \pm 4$ & NM & NM & $106 \pm 18$ & $3.7 \pm 0.4$ \\
\hline DV1-5B & Lucky Strike & $27 \pm 3$ & NM & NM & $1900 \pm 800$ & $18 \pm 3$ \\
\hline J2-613-16-R1 & Beebe & $760 \pm 250$ & $480 \pm 40$ & bdl & $140 \pm 90$ & $23 \pm 9$ \\
\hline J2-207-1-R1 & Vienna Woods & $0.53 \pm 0.27$ & bdl & bdl & $3800 \pm 700$ & bdl \\
\hline J2-210-7-R2 & Fenway & $3.1 \mathrm{ng} / \mathrm{g} \pm 3.1 \mathrm{ng} / \mathrm{g}$ & NM & NM & $170 \pm 60$ & $28 \pm 10$ \\
\hline J2-216-16-R1 & Fenway & $1.5 \pm 0.6$ & bdl & NM & $320 \pm 250$ & $15 \pm 6$ \\
\hline J2-214-3-R1 & Satanic Mills & bdl & bdl & $20 \pm 6$ & $60 \pm 60$ & $31 \pm 26$ \\
\hline J2-208-1-R1 & Roman Ruins & $32 \mathrm{ng} / \mathrm{g} \pm 40 \mathrm{ng} / \mathrm{g}$ & bdl & $48 \pm 18$ & $1300 \pm 600$ & $265 \pm 100$ \\
\hline J2-213-6-R1 & Roger's Ruins & bdl & bdl & $4.4 \pm 2.9$ & $260 \pm 30$ & $53 \pm 12$ \\
\hline J2-217-2-R1 & Suzette & $6.9 \pm 1.0$ & bdl & bdl & $250 \pm 40$ & $8.3 \pm 1.2$ \\
\hline J2-217-10-R1 & Suzette & $1.0 \pm 0.5$ & bdl & $5.8 \pm 1.0$ & $530 \pm 200$ & $3.9 \pm 1.8$ \\
\hline J2-219-2-R1 & Suzette & $9 \mathrm{ng} / \mathrm{g} \pm 5 \mathrm{ng} / \mathrm{g}$ & NM & NM & $360 \pm 150$ & $11 \pm 6$ \\
\hline J2-223-1-R1 & North Su & $15 \pm 4$ & bdl & $6.5 \pm 2.2$ & $300 \pm 100$ & $11 \pm 5$ \\
\hline J2-227-10-R1 & North Su & $0.38 \pm 0.07$ & NM & NM & $210 \pm 30$ & $11 \pm 5$ \\
\hline J2-450-3-R1 & Tahi Moana-1 & $2.8 \mathrm{ng} / \mathrm{g} \pm 1.7 \mathrm{ng} / \mathrm{g}$ & bdl & $1.3 \pm 0.5$ & $2600 \pm 600$ & $57 \pm 17$ \\
\hline J2-449-5-R1 & $\mathrm{ABE}$ & $12 \mathrm{ng} / \mathrm{g} \pm 20 \mathrm{ng} / \mathrm{g}$ & bdl & $1.8 \pm 0.6$ & $920 \pm 160$ & $1.1 \pm 0.3$ \\
\hline J2-449-6-R1 & $\mathrm{ABE}$ & $0.5 \pm 0.5$ & bdl & $1.1 \pm 0.3$ & $470 \pm 210$ & $16 \pm 11$ \\
\hline J2-815-5-R1 & $\mathrm{ABE}$ & $39 \mathrm{ng} / \mathrm{g} \pm 47 \mathrm{ng} / \mathrm{g}$ & bdl & $3.5 \pm 0.3$ & $570 \pm 70$ & $13 \pm 6$ \\
\hline J2-442-4-R2 & Tu'i Malila & $0.2 \pm 0.2$ & bdl & bdl & $540 \pm 80$ & $6 \pm 5$ \\
\hline J2-819-4-R2 & Tu'i Malila & $8 \mathrm{ng} / \mathrm{g} \pm 4 \mathrm{ng} / \mathrm{g}$ & NM & NM & $2110 \pm 250$ & bdl \\
\hline J2-437-3-R2 & Mariner & $5 \mathrm{ng} / \mathrm{g} \pm 11 \mathrm{ng} / \mathrm{g}$ & bdl & $6.4 \pm 1.9$ & $120 \pm 80$ & $44 \pm 19$ \\
\hline J2-817-4-R2 & Mariner & $39 \mathrm{ng} / \mathrm{g} \pm 17 \mathrm{ng} / \mathrm{g}$ & NM & NM & $100 \pm 20$ & $11.2 \pm 1.3$ \\
\hline
\end{tabular}




\subsection{Principal Component Analysis}

Principal component analysis conducted on the log-transformed dataset of SIMS counts ratios reveals that trace element concentrations of black smoker chimney linings are spread along two principal components that together account for $90.2 \%$ of the total variance (Table 5A). The first principal component, which contributes $79.7 \%$ of the total variance, is strongly associated with Co and Ni concentrations. The second principal component, which contributes $10.6 \%$ of the total variance, is strongly associated with concentrations of In and secondarily $\mathrm{Ga}$ and $\mathrm{Ni}$. Correlation coefficients calculated on the same dataset reveal significant positive correlations between $\mathrm{Co}$ and $\mathrm{Ni}\left(\mathrm{r}=0.86 ; \mathrm{p}=2.6 \times 10^{-7}\right.$, where $\mathrm{r}$ is the Pearson correlation coefficient and $\mathrm{p}$ is the Pearson $\mathrm{p}$-value $)$ and between $\mathrm{Ga}$ and $\mathrm{In}\left(\mathrm{r}=0.63 ; \mathrm{p}=1.6 \times 10^{-3}\right)($ Table 5B; see Fig. 5A and $5 B)$.

Principal components and correlation coefficients can also be evaluated in the context of commonly measured hydrothermal fluid parameters such as temperature, $\mathrm{pH}$, and concentrations of $\mathrm{H}_{2} \mathrm{~S}$, and $\mathrm{Cl}$. Following the addition of these hydrothermal fluid parameters and calculation of principal components and correlation coefficients over the expanded dataset, the two primary principal components identified from the SIMS dataset are maintained (Table 6A). The first principal component associated with concentrations of $\mathrm{Co}$ and $\mathrm{Ni}$ accounts for $71.2 \%$ of the total variance. The second principal component associated with In, and seondarily $\mathrm{Ga}$ and $\mathrm{Ni}$, accounts $14.6 \%$ of the total variance. It is also associated with fluid $\mathrm{pH}$. In addition to the significant positive correlation between $\mathrm{Co}$ and Ni identified previously, Co and Ni are both positively correlated with hydrothermal fluid temperature, while concentrations of Ga and In are positively correlated with each other and negatively correlated with fluid $\mathrm{pH}$ (Table 6B). Bivariate plots of $\mathrm{Co}$ and $\mathrm{Ni}$ against fluid temperature and $\mathrm{Ga}$ and $\mathrm{In}$ against fluid $\mathrm{pH}$ reveal 
broad correlating trends, particularly between concentrations of In and fluid $\mathrm{pH}$ (Figures $8 \mathrm{~A}-$

8D). Concentrations of Co covary with temperature, particularly among samples with relatively

high concentrations of Co, from the Mid-Cayman Rise, southern East Pacific Rise, and SuSu

Knolls.

Table 5. Principal components (A) and Pearson correlation coefficients (B) calculated for the log-transformed SIMS counts ratios of $59 \mathrm{Co}, 60 \mathrm{Ni}, 69 \mathrm{Ga}, 109 \mathrm{Ag}$, and $115 \mathrm{In}$ using the MATLAB code pca. Also indicated is the percent of total variance accounted for by each principal component (A). Significant correlations (Pearson's $\mathrm{p}<0.05$ ) are enclosed in boxes (B). (Inputs and outputs to principal component analysis in Supplementary Table S5)

Table 5A

\begin{tabular}{lccccc} 
& \multicolumn{5}{c}{ Principal Components } \\
& pca-1 & pca-2 & pca-3 & pca-4 & pca-5 \\
\cline { 2 - 6 } LogCo & 0.8 & -0.2 & 0.5 & -0.3 & -0.1 \\
LogNi & 0.6 & 0.5 & -0.4 & 0.4 & 0.3 \\
LogGa & -0.2 & 0.5 & 0.4 & -0.4 & 0.6 \\
LogAg & -0.1 & -0.2 & 0.6 & 0.7 & 0.3 \\
LogIn & -0.1 & 0.7 & 0.4 & 0.2 & -0.6 \\
\cline { 2 - 6 } & 79.7 & \multicolumn{6}{c}{ Percent of Total Variance } \\
& 10.6 & 4.8 & 2.7 & 2.3
\end{tabular}

Table 5B

Pearson Correlation Coefficients

\begin{tabular}{|c|c|c|c|c|}
\hline & LogCo & LogNi & LogGa & LogAg \\
\hline LogNi & 0.9 & & & \\
\hline LogGa & -0.5 & -0.4 & & \\
\hline LogAg & -0.2 & -0.3 & 0.0 & \\
\hline LogIn & -0.4 & -0.2 & 0.6 & 0.0 \\
\hline
\end{tabular}


Table 6. Principal components (A) and Pearson correlation coefficients (B) calculated for an expanded dataset including the log-transformed SIMS counts ratios of $59 \mathrm{Co}, 60 \mathrm{Ni}, 69 \mathrm{Ga}, 109 \mathrm{Ag}$, and 115In and the hydothermal fluid parameters: temperature $(1 / \mathrm{K}), \mathrm{pH}\left(\right.$ at $\left.25^{\circ} \mathrm{C}\right), \mathrm{Cl}(\log 10)$, $\mathrm{H} 2 \mathrm{~S}(\log 10)$. Also indicated is the percent of total variance accounted for by each principal component. (Inputs and outputs to principal component analysis in Supplementary Table S6)

Table 6A

\begin{tabular}{|c|c|c|c|c|c|c|c|c|c|}
\hline & \multicolumn{9}{|c|}{ Principal Components } \\
\hline & pсa-1 & pсa-2 & pca-3 & pca-4 & pca-5 & pca-6 & pca-7 & pca-8 & pсa-9 \\
\hline $1 / K$ & 0.0 & 0.0 & 0.0 & 0.0 & 0.0 & 0.0 & 0.0 & 0.0 & 1.0 \\
\hline $\mathrm{pH}$ & 0.0 & -0.5 & -0.1 & 0.0 & 0.2 & 0.1 & 0.8 & 0.0 & 0.0 \\
\hline $\log \mathrm{Cl}$ & 0.0 & 0.0 & 0.1 & 0.0 & 0.0 & 0.0 & 0.0 & 1.0 & 0.0 \\
\hline LogH2S & -0.1 & 0.1 & 0.9 & -0.1 & 0.1 & -0.2 & 0.2 & -0.1 & 0.0 \\
\hline LogCo & 0.7 & -0.2 & 0.2 & 0.4 & -0.4 & 0.0 & 0.0 & 0.0 & 0.0 \\
\hline LogNi & 0.6 & 0.4 & -0.1 & -0.4 & 0.5 & 0.1 & 0.1 & 0.0 & 0.0 \\
\hline LogGa & -0.1 & 0.4 & 0.1 & 0.1 & -0.3 & 0.8 & 0.2 & 0.0 & 0.0 \\
\hline $\operatorname{LogAg}$ & 0.0 & -0.2 & 0.2 & 0.6 & 0.7 & 0.3 & -0.3 & 0.0 & 0.0 \\
\hline \multirow[t]{3}{*}{ LogIn } & -0.1 & 0.5 & -0.2 & 0.6 & 0.1 & -0.5 & 0.4 & 0.0 & 0.0 \\
\hline & \multicolumn{9}{|c|}{ Percent of Total Variance } \\
\hline & 71.2 & 14.5 & 4.7 & 3.9 & 2.7 & 2.0 & 1.0 & 0.0 & 0.0 \\
\hline
\end{tabular}

Table 6B

\begin{tabular}{|c|c|c|c|c|c|c|c|c|}
\hline & & & & Pearson Corr & elation Coe & ficients & & \\
\hline & $1 / K$ & $\mathrm{pH}$ & LogCl & $\operatorname{LogH} 2 \mathrm{~S}$ & LogCo & LogNi & LogGa & LogAg \\
\hline $\mathrm{pH}$ & 0.4 & & & & & & & \\
\hline $\log C l$ & 0.6 & 0.2 & & & & & & \\
\hline LogH2S & 0.3 & -0.3 & 0.5 & & & & & \\
\hline LogCo & -0.5 & 0.2 & 0.0 & -0.4 & & & & \\
\hline LogNi & -0.5 & -0.1 & -0.2 & -0.4 & 0.9 & & & \\
\hline LogGa & 0.2 & -0.7 & 0.0 & 0.4 & -0.5 & -0.3 & & \\
\hline $\operatorname{LogAg}$ & 0.3 & 0.3 & 0.4 & 0.1 & -0.1 & -0.3 & -0.1 & \\
\hline LogIn & -0.2 & -0.7 & -0.3 & 0.1 & -0.3 & -0.1 & 0.6 & -0.1 \\
\hline
\end{tabular}


Figure 8. Bivariate plots of vent fluid parameters and trace elements in black smoker chimney linings including: (A) vent fluid temperature vs. ${ }^{59} \mathrm{Co} /{ }^{63} \mathrm{Cu}{ }^{16} \mathrm{O}$, (B) vent fluid temperature vs. ${ }^{60} \mathrm{Ni} /{ }^{63} \mathrm{Cu}^{16} \mathrm{O}$, (C) vent fluid $\mathrm{pH}$ vs. ${ }^{69} \mathrm{Ga} /{ }^{63} \mathrm{Cu}^{16} \mathrm{O}$, (D) vent fluid $\mathrm{pH}$ vs. ${ }^{115} \mathrm{In} /{ }^{63} \mathrm{Cu}^{16} \mathrm{O}$.

\section{Figure 8A}

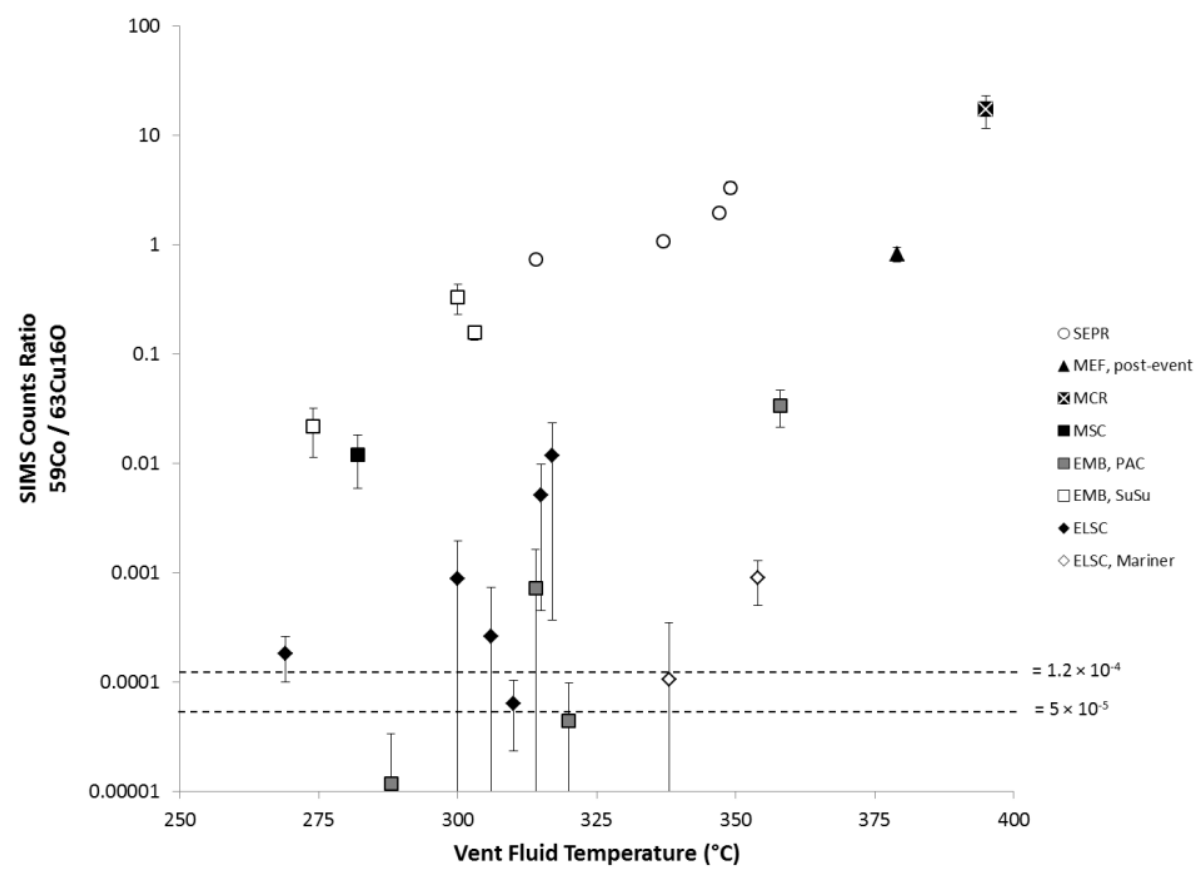

Figure $8 \mathrm{~B}$

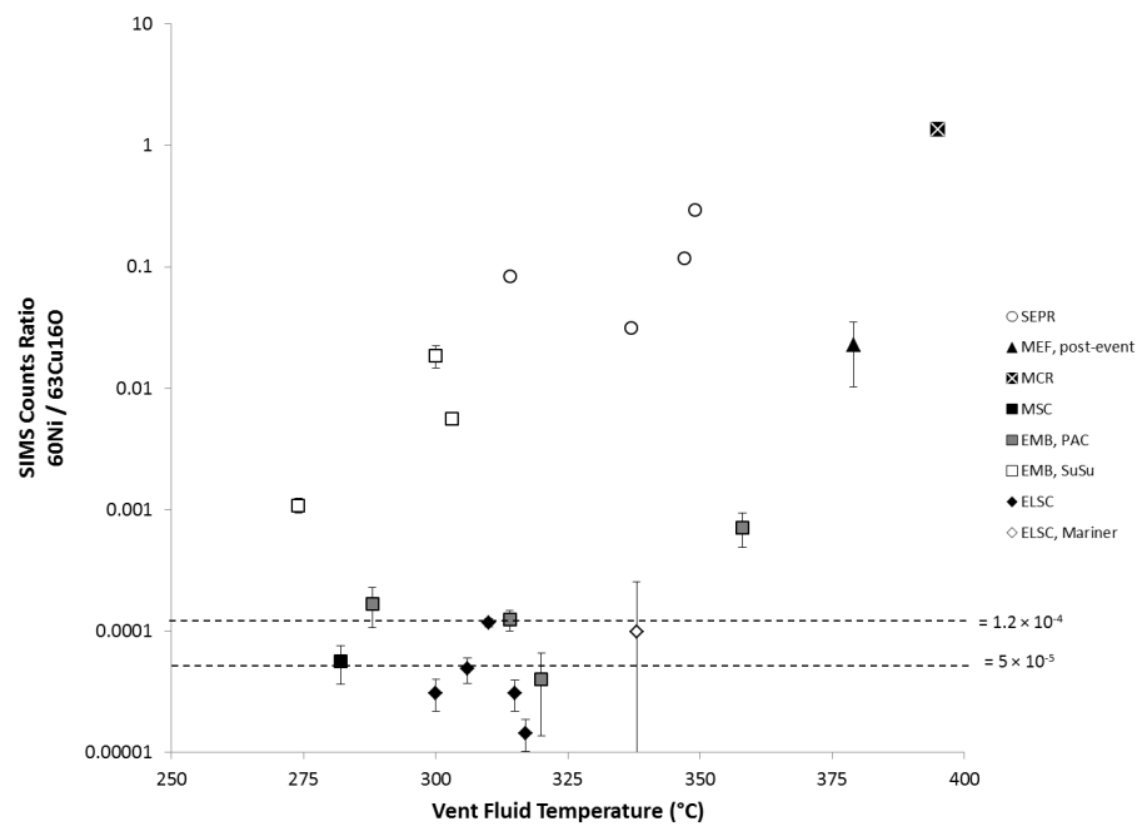


Figure 8C

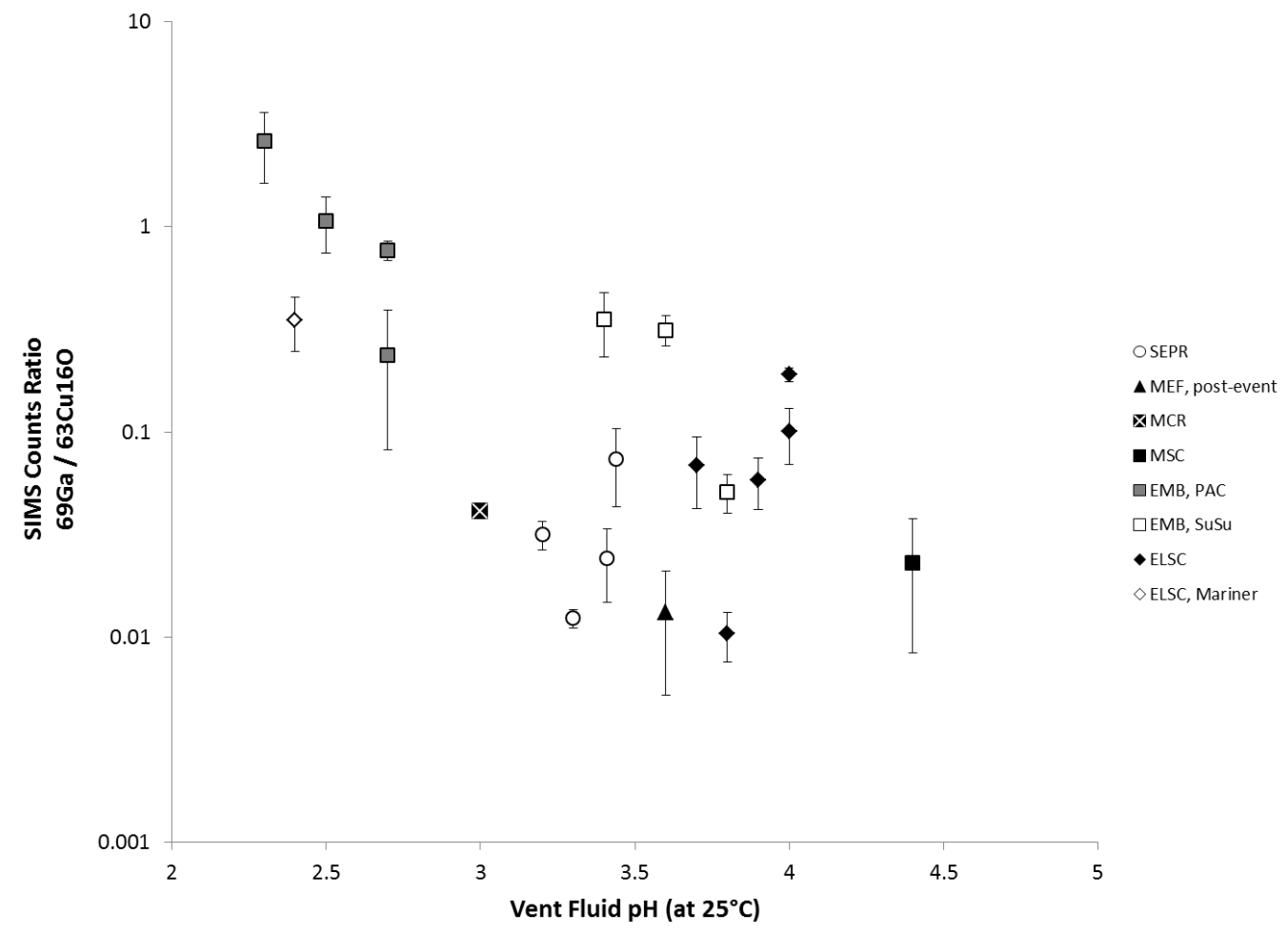

Figure 8D

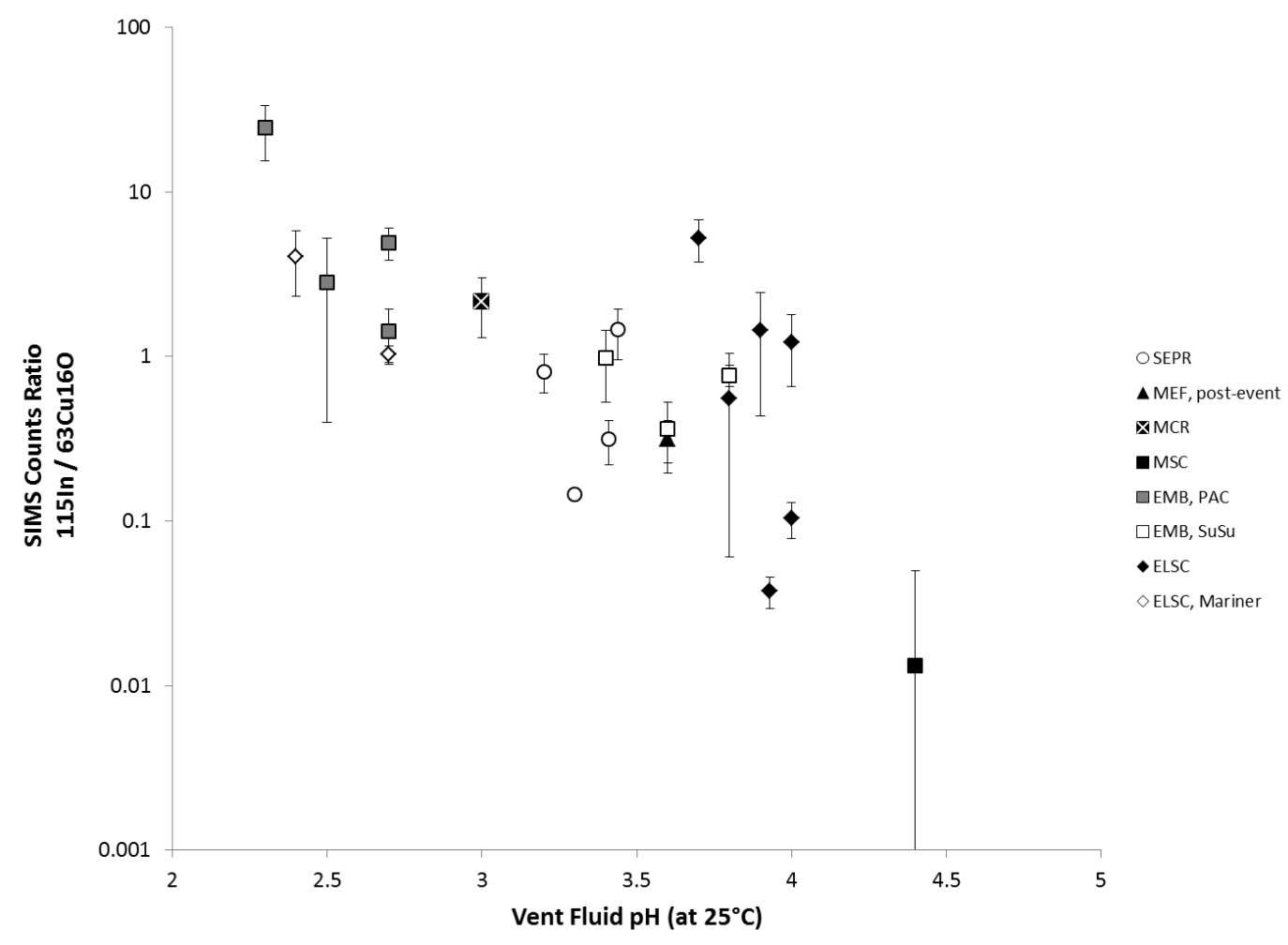




\section{DISCUSSION}

This study demonstrates the utility of secondary ion mass spectrometry (SIMS) for measuring trace element concentrations in black smoker chimney linings. The variation of trace element concentrations between samples is much larger than the heterogeneity observed within a single sample (Fig. 4A - 4F; Table 4). Therefore, it is possible that the trace element concentrations of black smoker chimney linings contain measureable and meaningful signals that may, in turn, reflect physical and chemical properties of hydrothermal fluid chemistry and/or the conditions and processes through which these mineral linings are deposited. A subset of these samples are sufficiently homogeneous with respect to $\mathrm{Co}, \mathrm{Ni}, \mathrm{Ga}, \mathrm{Ag}$, and $\mathrm{In}$ and collectively cover a wide enough range of concentrations to be used in defining SIMS calibration curves by which to quantify measurements. In addition, many of the black smoker chimney linings examined in this study were deposited by fluids of known temperature and chemical composition, allowing for further investigation of the geochemical processes that control trace element concentrations in black smoker chimney linings.

\subsection{Evaluation of Calibration Curves}

Construction of the calibration curves presented here requires quantitative comparison of SIMS analyses of the innermost $100 \mu \mathrm{m}$ of a black smoker chimney lining with solution ICP-MS analyses of chalcopyrite grains picked from the innermost $1 \mathrm{~mm}$ of a different section of the same sample, usually 1-10 cm apart (Fig. 1). Thus, samples chosen for inclusion in the calibration curves must be homogeneous with respect to the desired trace elements at $\mu \mathrm{m}-, \mathrm{mm}-$, and $\mathrm{cm}$-scales. Additionally, picked grains should be not be tarnished or contain inclusions of other sulfide minerals. While the use of SIMS allows for analyses at small spatial scales and 
removal of measurements thought to result from mineral inclusions following the analysis, the same level of control is not possible for the picked grains of chalcopyrite analyzed by solution ICP-MS. The lack of inclusions is especially important for elements which preferentially partition into sphalerite or wurtzite relative to chalcopyrite, such as such as $\mathrm{Mn}, \mathrm{Ga}$, and In (Cook and Ciobanu, 2015).

The samples ultimately used in constructing SIMS calibration curves are black smoker chimneys that exhibit monomineralic chalcopyrite linings and from which both reproducible SIMS measurements and untarnished (or mildly tarnished) chalcopyrite grains could be obtained. These samples incude: Alv3296-3 and Alv3299-6-1 from the southern East Pacific Rise, Alv1931 and Alv 3474-3-1 from the Main Endeavour Field on the Juan de Fuca Ridge, J2, 2136-R1 from the Roger' sRuins vent field in the Eastern Manus Basin, and J2-437-3-R2 from the Mariner vent field on the Eastern Lau Spreading Center. Sample J2-214-3-R1 from Satanic Mills vent field in the Manus Basin was also evaluated by SIMS and ICP-MS, but ultimately excluded from the calibration curve because only tarnished chalcopyrite grains could be picked and because SIMS measurements of Ag were heterogeneous (Fig. 4E).

Of the various trace elements investigated in this study, Ag and In are both thought to occur as lattice substitutions in chalcopyrite (Ag for $\mathrm{Cu}$, In for Fe; Huston et al., 1995). This determination is based on four criteria: (1) the crystal chemistry of the host mineral, (2) experimental studies on the solubilities of the elements of interest in the host mineral, (3) the presence or absence of minerals that contain major concentrations of the elements of interest, and (4) variations in the level of the elements of interest between and within samples (Huston et al., 1995). Extending this logic to the data presented here and considering the overall reproducability of measurements within individual black smoker chimney samples, it is likely that $\mathrm{Co}, \mathrm{Ni}$, and 
Ga also occur as lattice substitutions in chalcopyrite. A main factor that may affect the quality of developed SIMS calibration curves is the extent of homogeneity with respect to the element at $\mathrm{mm}$ - to $\mathrm{cm}$-scales. Small amounts of zinc sulfide contamination in aliquots of picked chalcopyrite grains could also explain the uncertainty of the $\mathrm{Ga}$ and In calibration curves at higher concentrations. However, arguments against this explaniation include the lack of significant correlations between $\mathrm{Zn}$ and any of these elements in ICP-MS analyses of picked grains and the absense of intergrown wurtzite or sphalerite observable under the petrographic microscope. Alternatively, Ga and In could be less homogeneously distributed in chaclopyrite chimney linings than $\mathrm{Co}, \mathrm{Ni}$, or Ag. This explanation is supported by SIMS analyses where the standard errors calculated over multiple spots are typically greater for $\mathrm{Ga}$ and In than for $\mathrm{Co}, \mathrm{Ni}$, and Ag.

The occurance of $\mathrm{Mn}$ in chalcopyrite, whether as a lattice substitution or as inclusions is not well known. The concentrations of Mn measured here are low (typically $<50 \mu \mathrm{g} / \mathrm{g}$, Table 4) and attempts to develop a SIMS calibration curve for Mn were unsuccessful (Fig. 7A). High detection limits for $\mathrm{Ni}$ are caused by uncertainties in the concentrations of Ni measured by ICPMS for picked grains measured by ICP-MS, which become increasingly important at low $\mathrm{Ni}$ concentrations. This may be an artifact of $\mathrm{Ni}$ cones used in the Element 2 which interfere with $\mathrm{Ni}$ measurements at low concentrations. Subsequent analyzes of Ni should make use of Pt cones.

\subsection{Trace Element Concentrations}

To date, few studies have provided quantitative analyses of trace element concentrations in black smoker chimney linings using microanalytical techniques with low detection limits. Wohlgemuth-Ueberwasser et al. (2015) used LA-ICPMS to analyze 27 black smoker chimney samples for a number of trace elements including $\mathrm{As}, \mathrm{Sb}, \mathrm{Se}, \mathrm{Te}$, and $\mathrm{Au}$, none of which are 
treated here. Comparable data do exist for the trace element contents of chalcopyrite from the inner wall of fossilized black smoker chimney linings from the Yaman-Kazy deposit in the Southern Urals with the results: Co $(0.1 \mu \mathrm{g} / \mathrm{g}$ to $5.97 \mu \mathrm{g} / \mathrm{g}), \mathrm{Ni}(0.2 \mu \mathrm{g} / \mathrm{g}$ to $0.9 \mu \mathrm{g} / \mathrm{g}), \mathrm{Ag}(7$ $\mu \mathrm{g} / \mathrm{g}$ to $584 \mu \mathrm{g} / \mathrm{g}$ ) (“Chp2” in Maslennikov et al., 2009). Average concentrations of the same elements in chalcopyrite from the inner linings (Zone B) of fossil chimneys from Çayeli and Kutlular volcanogenic massive sulfide (VMS) deposits in the Eastern Pontide orogenic belt are: Co $(0.24 \mu \mathrm{g} / \mathrm{g}$ to $2.19 \mu \mathrm{g} / \mathrm{g}), \mathrm{Ni}(0.12 \mu \mathrm{g} / \mathrm{g}$ to $2.04 \mu \mathrm{g} / \mathrm{g}), \mathrm{Ag}(14.4 \mu \mathrm{g} / \mathrm{g}$ to $98.19 \mu \mathrm{g} / \mathrm{g})$ (Revan et al., 2014). Analyses of trace elements in chalcopyrite from the Wocan hydrothermal field on the Carlsberg Ridge obtained by LA-ICP-MS yield average concentrations of: Co $(0.1 \mu \mathrm{g} / \mathrm{g}), \mathrm{Ni}$

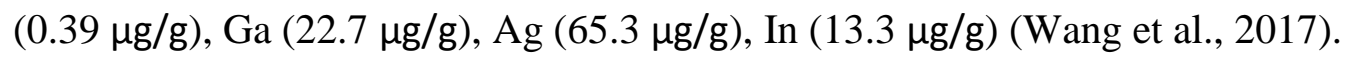

The concentrations of trace elements in the chalcopyrite linings of black smoker chimneys investigated in this study are comparable to those reported previously, but cover a wider range of trace element concentrations (Table 4). This is consistent with the examination of black smoker chimneys from a variety of geologic settings, including basalt-hosted vent fields along fast-, intermediate-, slow-, and ultraslow spreading mid-ocean ridges and basalt-hosted and felsic-hosted systems along back-arc spreading centers and volcanic zones (Table 1). Additionally, the samples investigated here are associated with a wide range of hydrothermal fluid parameters, e.g., $\mathrm{pH}\left(\right.$ at $\left.25^{\circ} \mathrm{C}\right)=2.3$ to 4.4 and temperature $=274^{\circ} \mathrm{C}$ to $395^{\circ} \mathrm{C}($ Table 1$)$.

Notably, the low Co and Ni contents of fossil chimneys from the Yaman-Kazy, Çayeli, and Kutlular deposits are comparable to black smoker chimneys from felsic-hosted vent fields in the Lau and Manus back-arc Basins. The Yaman-Kazy deposit is thought to have formed in a narrow pull-apart extensional zone in a Silurian marginal sea, while the Late Cretaceous Çayeli, and Kutlular deposits are thought to have formed in an island arc setting; all of these deposits are 
associated with rhyolite-dacite lavas (Maslennikov et al., 2009, Revan et al., 2014). The similarity in trace element content between chalcopyrite from active and fossil black smoker chimneys associated with similar lithology suggests that at least some trace element signatures may be geologically preserved. Concentrations of $\mathrm{Co}$ and $\mathrm{Ni}$ are similarly low in chalcopyrite from the presumably basalt-hosted Wocan deposit, which contrasts with the majority of basalthosted mid-ocean ridge samples investigated here, but is comparable to concentrations in chimneys from the basalt-hosted Vienna Woods vent field and the pre-event Main Endeavour Field (Table 4). Additional data from a greater number of vent fields is needed to better investigate the relationships between vent fluid chemistry, host rock lithology, and black smoker trace element content. This is an area ripe for further study.

\subsection{Controls on Trace Element Concentrations}

Principal compoenet analysis highlights two types of geochemical variability among black smoker chimney deposits (Tables 5A and 6A). The first type concerns the concentrations of Co and Ni (Fig. 4B, 4C; Fig. 5A, Table 4). Black smoker chimneys from non-sedimented, basalt-hosted vent fields such as the Mid-Cayman Rise and southern East Pacific Rise have higher concentrations of $\mathrm{Co}$ and $\mathrm{Ni}$ than black smoker chimneys from the felsic-hosted vent fields of Manus Basin and Lau Basin, while samples from the basalt-hosted Vienna Woods field exhibit intermediate $\mathrm{Co}$ and $\mathrm{Ni}$ concentrations. The chalcopyrite linings of black smoker chimneys collected from the Main Endeavour Field on the Juan de Fuca Ridge following the 1999 event and the Lucky Strike vent field on the Mid-Atlantic Ridge exhibit higher concentrations of Co than back-arc basin samples and lower Co concentrations than most of the southern East Pacific Rise samples. However, the chalcopyrite lining of sample Alv1931, 
collected from the Main Endeavour Field prior to the 1999 event exhibits low concentrations of Co and Ni, comparable to back-arc basin samples. For samples from basalt-hosted vent fields, concentrations of $\mathrm{Co}$ and $\mathrm{Ni}$ also correlate with vent fluid temperature (Table 6B, Figures 8A and 8B). The association of higher $\mathrm{Co}$ and $\mathrm{Ni}$ concentrations with more mafic lithology and higher temperatures has been previously recognized and is generally attributed to higher concentrations of these elements in mafic and ultramafic rocks and elevated Co concentrations in hightemperature fluids (Hannington et al., 1991; Hannington et al., 1995; Hannington et al., 2005). Alternatively, Co has been shown to prefferentially partition into isocubanite or Fe-rich intermediate solid solution over chalcopyrite (Rouxel et al., 2004). Data presented here suggests that Ni may partition similarly to Co. Moreover, electron microprobe data show that the composition of sample J2-613-16-R1, which has the highest Co and Ni concentrations of the black smoker chimney linings in this study is compositionally intermediate between stoichiometric chalcopyrite $\left(\mathrm{CuFeS}_{2}\right)$ and isocubanite $\left(\mathrm{CuFe}_{3} \mathrm{~S}_{4}\right)$ (Fig. 9).

The second source of geochemical variability is related to concentrations of In and secondarily Ga (Tables 5B and 6B, Fig. 5B). Concentrations of these elements broadly correlate, with concentrations of In most highly correlated with fluid pH (Table 6B, Fig. 8D). Studies of $\mathrm{In}^{3+}$ speciation under hydrothermal conditions highlight the importance of hydroxide $\left(\mathrm{OH}^{-}\right)$ complexes (Wood and Samson, 2006). Figure 10A shows the prevalence of such complexes at $20^{\circ} \mathrm{C}, 1$ bar pressure, $1 \mathrm{M} \mathrm{NaClO}_{4}$, total sulfide $=0.01 \mathrm{M}$. This provides a possible mechanism for the observed $\mathrm{pH}$ dependence of In in black smoker chimney linings. Figure 10B shows the aquous speciation of $\mathrm{In}^{3+}$ at $25^{\circ} \mathrm{C}$ and 1 bar pressure as a function of $\mathrm{pH}$ and $\mathrm{Cl}^{-}$concentration. 
Figure 9. Plot of $\mathrm{Cu}$ and $\mathrm{Fe}$ in $\mathrm{CuFe}$ sulfide lining of sample J2-613-16-R1 from the Beebe/Piccard vent field on the Mid-Cayman Rise measured by electron microprobe. Results reported as weight percent normalized to total $=\mathrm{Cu}(\mathrm{wt} \%)+\mathrm{Fe}(\mathrm{wt} \%)+\mathrm{S}(\mathrm{wt} \%)$.

\section{Electron Microprobe Analyses of Open Conduit Chimney Lining from Beebe/Piccard Vent Field}

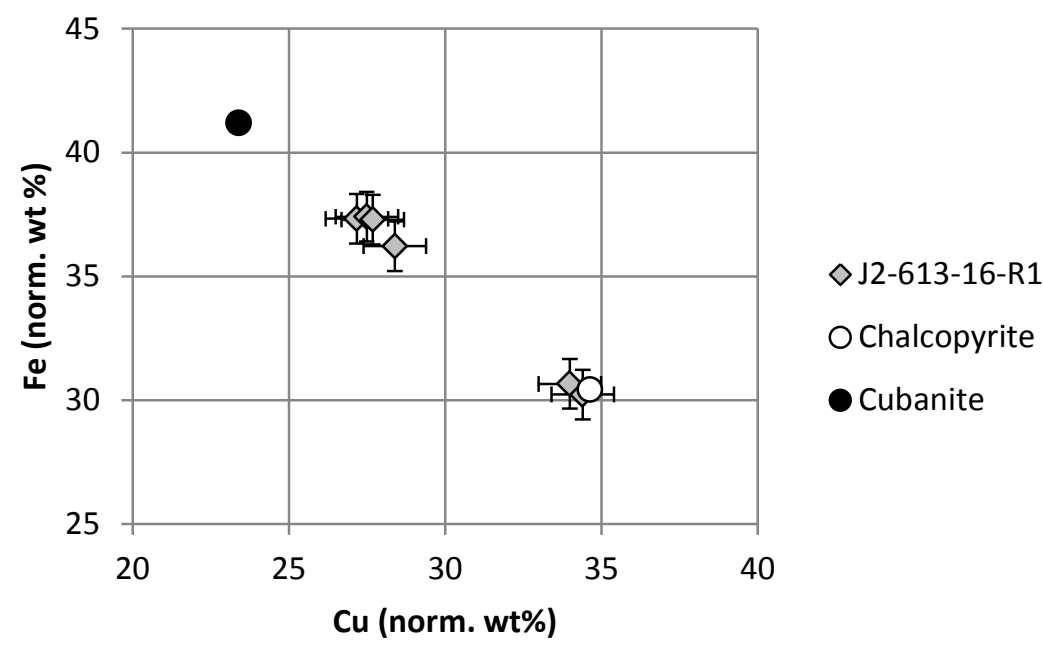

Figure 10. Plots from Wood and Samson (2006) showing (A) the abundance of aquous $\mathrm{In}^{3+}$ complexes contributing to the solubility of $\operatorname{In}_{2} \mathrm{~S}_{3}(\mathrm{~s})$ as a function of $\mathrm{pH}$ at (A) the aqueous speciation of $\mathrm{In}^{3+}$ vs. the $\log$ concentration of $\operatorname{In}^{3+}$ aqueous complexes at $20^{\circ} \mathrm{C}, 1$ bar pressure, 1 $\mathrm{M} \mathrm{NaClO}_{4}$, total sulfide $=0.01 \mathrm{M}$ and (B) the aqueous specitation of $\mathrm{In}^{3+}$ as a function of $\mathrm{pH}$ and $\log \mathrm{Cl}^{-}$concentration at $25^{\circ} \mathrm{C}$ and 1 bar pressure. Red line highlights the concentration of $\mathrm{In}^{3+}$ as a function of $\mathrm{pH}$. Dashed box outlines approximate compositional range of typical black smoker hydrothermal fluids.
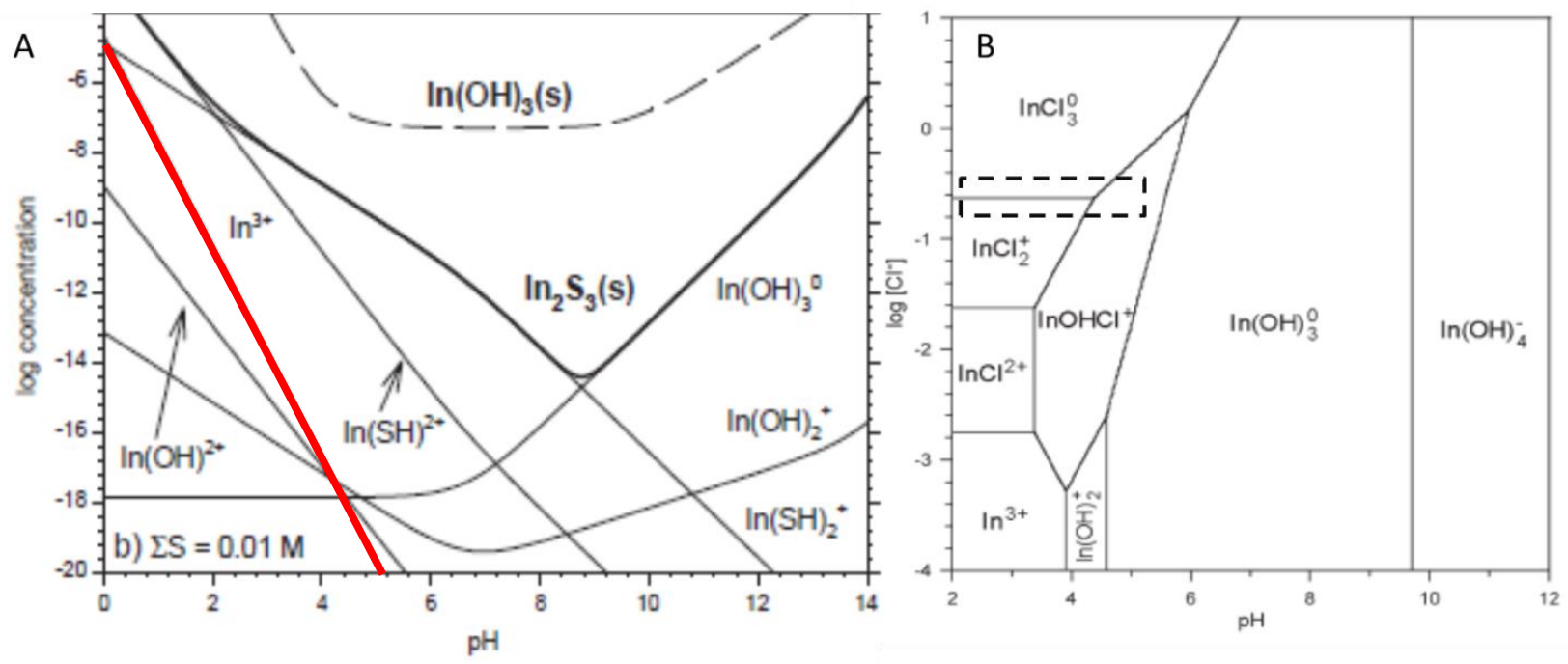
If it is assumed that In occurs in chalcopyrite by regualrly partitioning and substitution of $\mathrm{Fe}^{3+}$ in the chalcopyrite lattice, then, according to the theoretical description of trace element partitioning proposed by McIntire (1963), the following partitioning equation can be written:

$$
D_{h f, c p}=\frac{\frac{\left\{\operatorname{In}^{3+}\right\}_{h f}}{\left\{F e^{3+}\right\}_{h f}}}{\frac{\left\{\operatorname{In}^{3+}\right\}_{c p}}{\left\{F e^{3+}\right\}_{c p}}}
$$

where $\mathrm{D}_{\mathrm{hf}, \mathrm{cp}}$ is the partition coefficient between hydrothermal fluid (hf) and chalcopyrite (cp), $\left\{\mathrm{In}^{3+}\right\}_{\mathrm{hf}}$ and $\left\{\mathrm{Fe}^{3+}\right\}_{\mathrm{hf}}$ are the activities of $\mathrm{In}^{3+}$ and $\mathrm{Fe}^{3+}$ in the hydrothermal fluid, respectively, and $\left\{\mathrm{In}^{3+}\right\}_{\mathrm{cp}}$ and $\left\{\mathrm{Fe}^{3+}\right\}_{\mathrm{cp}}$ are the thermodynamic activities of $\mathrm{In}^{3+}$ and $\mathrm{Fe}^{3+}$ in chalcopyrite. The activity and thus concentration of $\mathrm{In}$ in chalcopyrite is therefore related to the activity of $\operatorname{In}^{3+}$ in the corresponding hydrothermal fluid. At higher $\mathrm{pH}$ (and higher $\mathrm{OH}^{-}$activity), In would primarily be present as hydroxide complexes and the activity of the free ion $\left\{\operatorname{In}^{3+}\right\}$ in the hydrothermal fluid would be low relative to the total In concentration (Wood and Samson, 2006; Charlotte Ashworth, personal communcation). The In concentration in chalcopyrite chimney linings would thus be low. Conversely, at lower $\mathrm{pH}$, the activity of the free ion, $\left\{\operatorname{In}^{3+}\right\}$, in hydrothermal fluids would be higher relative to the total In concentration than at higher $\mathrm{pH}$, and chalcopyrite formed from these fluids would contain greater concentrations of In. Analogous reasoning can be used to explain the correlation between hydrothermal fluid $\mathrm{pH}$ and $\mathrm{Ga}$, for which hydroxide $\left(\mathrm{OH}^{-}\right)$complexes are likewise important (Wood and Samson, 2006; Fig. 11).

Few reliable data are available for the concentrations of In in seafloor hydrothermal fluids or natural fluids more generally (Douville et al., 2002; Wood and Samson, 2006). Thus, the factors influencing total In concentration cannot by evaluated at this time. Additionally, new experimental data indicate that the activity of $\mathrm{In}^{3+}$ at low $\mathrm{pH}$ is strongly controlled by chloride 
complexes for which the appropriate thermodynamic data have not been published (Charlotte Ashworth, personal communcation). Nevertheless, the observed strong negative correlation between the In concentration in chalcopyrite chimney linings and hydrothermal fluid $\mathrm{pH}$ presents the intriguing possibility of In in chalcopyrite as a proxy of hydrothermal fluid $\mathrm{pH}$.

Figure 11. Reproduction of plots in Wood and Samson (2006) of pH vs. the log concentration of aqueous $\mathrm{Ga}$ complexes contributing to the solubility of $\mathrm{GaOOH}$ at $200^{\circ} \mathrm{C}$ and $300^{\circ} \mathrm{Cat}$ vapor saturated pressures using the thermodynamic data of Benézéth et al., (1997). Red lines highlight the concentration of $\mathrm{Ga}^{3+}$ as a function of $\mathrm{pH}$.
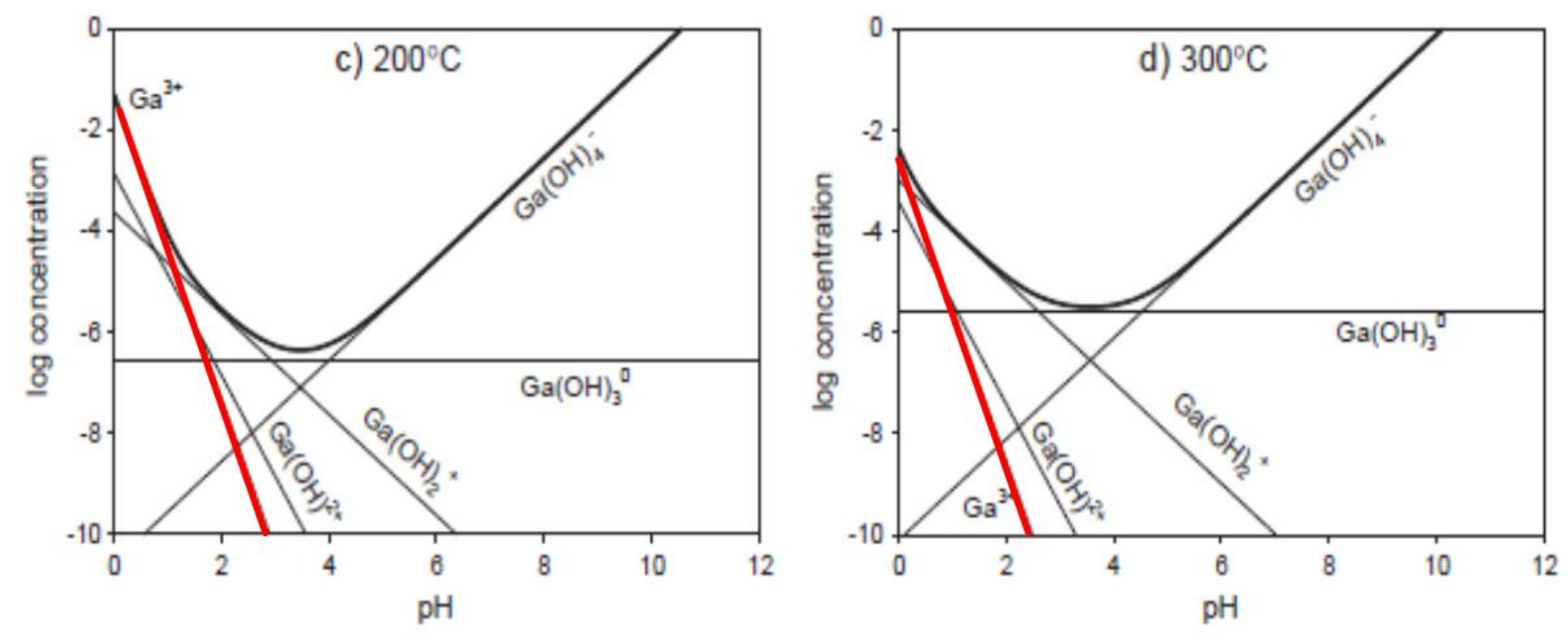

\subsection{Main Endeavour Field}

The two samples examined in this study from the Main Endeavour Field provide a particularly interesting case study by which to evaluate the potential for black smoker chimney linings to record changes in hydrothermal fluid temperature and/or chemistry. Chalcopyrite lining the conduit of sample Alv3474-3-1, which was collected shortly after the 1999 event, contains higher concentrations of $\mathrm{Co}$ and $\mathrm{Ni}$ and lower concentrations of $\mathrm{Ga}, \mathrm{Ag}$, and In than chalcopyrite lining the conduit of sample Alv1931, collected before the 1999 event. Fluids collected in 1999, when Alv3474-1-3 was collected, exhibit lower chlorininty, lower pH, higher concentrations of $\mathrm{Fe}$ and $\mathrm{Zn}$ and similar concentrations of $\mathrm{Cu}$ as those collected in 1987, when 
Alv1931 was sampled (Seyfried et al., 2003; Butterfield and Massoth, 1994). Concentrations of Co, $\mathrm{Ni}$, and Ag were not measured in fluid sampled in 1984, 1987, or 1988. However, fluids collected in 1999 from the Dante deposit in 1999 exhibit higher concentrations of Co and Ni and lower concentrations of Ag than fluids collected in 2000 from the same deposit. These changes in hydrothermal fluid chemistry are thought to represent a partial recovery toward the pre-event state (Seyfried et al., 2003). In light of this, it is intriguing to find similar patterns of trace elements (i.e. higher Co and $\mathrm{Ni}$, lower $\mathrm{Ag}$ ) in the post-1999 event chimney lining relative to the pre-event black smoker chimney lining (Table 4). Considering the number of samples recovered from the Main Endeavour Field and the relative wealth of knowledge about the distribution and history hydrothermal activity at this site, the examination of trace elements in black smoker chimney linings recovered from the Main Endeavour Field presents a particularly promising avenue for future research into the relationship between hydrothermal activity and mineral deposit geochemistry.

\section{CONCLUSION}

This study has used secondary ion mass spectrometry (SIMS) to measure concentrations of $\mathrm{Co}, \mathrm{Ag}$, and In at high spatial resolutions (spot size $=\sim 40 \mu \mathrm{m})$ and low detection limits $(2$ $\mathrm{ng} / \mathrm{g} ; 2 \mu \mathrm{g} / \mathrm{g}$, and $0.5 \mathrm{ng} / \mathrm{g}$, respectively) in chalcopyrite along the innermost ( 100s $\mu \mathrm{m})$ linings of fluid conduits in 29 black smoker samples; 22 of these samples were also analyzed for $\mathrm{Ni}$ and Ga. Chimney samples represent a variety of geologic settings (e.g., fast-, intermediate-, slow-, and ultraslow-spreading mid-ocean ridges, and back-arc spreading centers) and hydrothermal fluid conditions (e.g., $\mathrm{pH}\left(25^{\circ} \mathrm{C}\right)=2.3$ to 4.4 and temperature $=274^{\circ} \mathrm{C}$ to $395^{\circ} \mathrm{C}$ ), allowing for comparisons between the trace element content of black smoker chimney linings and 
hydrothermal fluid parameters for different geologic settings. Accomplishments of this study include the development of SIMS as a technique for measuring $\mathrm{Co}, \mathrm{Ni}, \mathrm{Ga}, \mathrm{Ag}$, and In concentrations in chalcopyrite and the identification of patterns between the concentrations of these elements and hydrothermal fluid parameters, which present possible trace element proxies of deposit formation conditions.

Homogeneous distributions of $\mathrm{Co}, \mathrm{Ni}, \mathrm{Ga}, \mathrm{Ag}$, and $\mathrm{In}$ in samples are consistent with the presence of these elements primarily as lattice substitutions. Concentrations of Co and Ni covary with high concentrations of these elements assocaited with high-temperature vent fluids from basalt-hosted mid-ocean ridge vent fields. Concentrations of In and secondarily Ga covary with hydrothermal fluid $\mathrm{pH}$, providing a possible proxy.

Calibration curves developed by comparing SIMS measurements of $\mathrm{Co}, \mathrm{Ni}, \mathrm{Ga}, \mathrm{Ag}$, and In in the monomineralic chalcopyrite linings of selected black smoker chimney linings with solution ICP-MS analyses of digested picked grains of the same samples are constrained within 5\% for $\mathrm{Co}, \mathrm{Ni}, \mathrm{Ga}$, and In and within $10 \%$ for Ag, allowing for quantification of SIMS data. Additionally, several of the natural chalcopyrite samples investigated in this study are homogeneous with respect to $\mathrm{Co}, \mathrm{Ni}, \mathrm{Ga}, \mathrm{Ag}$, and $\mathrm{In}$ and my be suitable for use as calibration standards in geochemical analysis. Further refinement of the calibration curves presented here could be achieved by cross-calibration with other microanalytical techniques such as LA-ICPMS, especially as the development of and routine use of standard reference materials for sulfide analyses improves.

Overall, this study demonstrates the potential of SIMS to quantitatively measure $\mathrm{Co}, \mathrm{Ni}$, $\mathrm{Ga}, \mathrm{Ag}$, and In (and other trace elements) in chalcopyrite. Once SIMS calibration curves have been established and calibration standards identified, this technique is viable for a range of 
applications in which analyses of chalcopyrite at similarly fine spatial scales and low detection limits are desired. Immediate applications include the analysis of trace elements along the innermost linings of other black smoker chimneys or within the small grains of chalcopyrite present in the interiors of chimney walls with the intent of testing and continuing to search for geochemical proxies of hydrothermal fluid temperature and chemistry.

\section{REFERENCES}

Benézéth, P., Diakonov, I. I., Pokrovski, G. S., Dandurand, J. L., Schott, J., and Khodakovsky, I. L. (1997) Gallium speciation in aqueous solution. Experimental study and modelling: Part 2. Solubility of $\alpha-\mathrm{GaOOH}$ in acidic solutions from 150 to $250 \mathrm{C}$ and hydrolysis constants of gallium (III) to 300 C. Geochim. Cosmochim. Acta, 61(7), 1345-1357.

Berglund, M., and Wieser, M. E. (2011) Isotopic compositions of the elements 2009 (IUPAC Technical Report) Pure and Applied chemistry, 83(2), 397-410.

Bézos, A., Escrig, S., Langmuir, C. H., Michael, P. J., and Asimow, P. D. (2009) Origins of chemical diversity of back- arc basin basalts: A segment- scale study of the Eastern Lau Spreading Center. J. Geophys. Res.: Solid Earth, 114, B06212, doi: $10.1029 / 2008 \mathrm{JB} 005924$.

Binns, R. A. and Scott, S. D. (1993) Actively forming polymetallic sulfide deposits associated with felsic volcanic rocks in the eastern Manus back-arc basin, Papua New Guinea. Econ. Geol., 88(8), 2226-2236.

Butler, I. B. and Nesbitt, R. W. (1999) Trace element distributions in the chalcopyrite wall of a black smoker chimney: insights from laser ablation inductively coupled plasma mass spectrometry (LA-ICP-MS) Earth Planet. Sci. Lett., 167(3), 335-345.

Butterfield, D. A., and Massoth, G. J. (1994) Geochemistry of north Cleft segment vent fluids: Temporal changes in chlorinity and their possible relation to recent volcanism. $J$. Geophys. Res.: Solid Earth, 99(B3), 4951-4968.

Cook, N. J., Ciobanu, C. L., Pring, A., Skinner, W., Shimizu, M., Danyushevsky, L., Melcher, F., and Melcher, F. (2009) Trace and minor elements in sphalerite: A LA-ICPMS study. Geochim. Cosmochim. Acta, 73(16), 4761-4791. 
Craddock, P. R. (2009) Geochemical tracers of processes affecting the formation of seafloor hydrothermal fluids and deposits in the Manus back-arc basin. Ph.D. Thesis, MIT/WHOI Joint Program in Oceanography.

Danyushevsky, L., Robinson, P., Gilbert, S., Norman, M., Large, R., McGoldrick, P., and Shelley, M. (2011) Routine quantitative multi-element analysis of sulphide minerals by laser ablation ICP-MS: Standard development and consideration of matrix effects. Geochemistry: Exploration, Environment, Analysis, 11(1), 51-60.

Douville, E., Charlou, J. L., Oelkers, E. H., Bienvenu, P., Colon, C. J., Donval, J. P., Fouquet, Y., Prieur, D., and Appriou, P. (2002) The rainbow vent fluids (36 14' N, MAR): the influence of ultramafic rocks and phase separation on trace metal content in Mid-Atlantic Ridge hydrothermal fluids. Chem. Geol., 184(1), 37-48.

Elthon, D., Ross, D. K., and Meen, J. K. (1995) Compositional variations of basaltic glasses from the Mid- Cayman Rise Spreading Center. J. Geophys. Res.: Solid Earth, 100(B7), 12497-12512.

Escrig, S., Bézos, A., Goldstein, S. L., Langmuir, C. H., and Michael, P. J. (2009) Mantle source variations beneath the Eastern Lau Spreading Center and the nature of subduction components in the Lau basin-Tonga arc system, Geochem. Geophys. Geosys., 10, Q04014, doi:10.1029/2008GC002281.

Fouquet, Y., von Stackelberg, U., Charlou, J. L., Erzinger, J., Herzig, P. M., Mühe, R., and Wiedicke, M. (1993) Metallogenesis in back-arc environments: the Lau Basin example. Econ. Geol., 88(8), 2154-2181.

Frenzel, J. M., Mühe, R., and Stoffers, P. (1990) Petrology of the volcanic rocks from the Lau basin, southwest Pacific. Geol. Jahrb. 92, 395-479.

Goldfarb, M. S., Converse, D. R. Holland, H. D. and Edmond, J. M. (1983) The genesis of hot spring deposits on the East Pacific Rise, 21 ${ }^{\circ}$ N, Econ. Geol. Monogr., 5, 184-197.

Hannington, M., Herzig, P., Scott, S., Thompson, G., and Rona, P. (1991) Comparative mineralogy and geochemistry of gold-bearing sulfide deposits on the mid-ocean ridges. Marine Geology, 101(1-4), 217-248.

Hannington, M. D., Jonasson, I. R., Herzig, P. M., and Petersen, S. (1995) Physical and chemical processes of seafloor mineralization at mid- ocean ridges. In Seafloor hydrothermal systems: physical, chemical, biological, and geological interactions (eds. S. E. Humphris, R. A. Zierenberg, L. S. Mullineaux, and R. E. Thomson), American Geophysical Union, Washington, D. C.. pp. 115-157. doi: 10.1029/GM091p0115. 
Hannington, M. D., de Ronde, C. D. J., and Petersen, S. (2005) Sea-floor tectonics and submarine hydrothermal systems. Economic Geology $100^{\text {th }}$ Anniversary Volume. Society of Economic Geologists, Littleton, Colorado, USA, 111-141.

Haymon, R. M. (1983) Growth history of hydrothermal black smoker chimneys. Nature, 301, 695-698.

Huston, D. L., Sie, S. H., Suter, G. F., Cooke, D. R., and Both, R. A. (1995) Trace elements in sulfide minerals from eastern Australian volcanic-hosted massive sulfide deposits; Part I, Proton microprobe analyses of pyrite, chalcopyrite, and sphalerite, and Part II, Selenium levels in pyrite; comparison with delta $34 \mathrm{~S}$ values and implications for the source of sulfur in volcanogenic hydrothermal systems. Econ. Geol., 90(5), 1167-1196.

Jenner, G. A., Cawood, P.A., Rautenschlein, M., and White, W. M. (1987) Composition of backarc basin volcanics, Valu Fa Ridge, Lau basin: Evidence for a slab-derived component in their mantle source, J. Volcanol. Geotherm. Res., 32, 209-222.

Johnson, H. P., Hutnak, M., Dziak, R. P., Fox, C. G., Urcuyo, I., Cowen, J. P., Nabelek, J., and Fisher, C. (2000) Earthquake-induced changes in a hydrothermal system on the Juan de Fuca mid-ocean ridge. Nature, 407(6801), 174-177.

Kamenetsky, V. S., Binns, R. A., Gemmell, J. B., Crawford, A. J., Mernagh, T. P., Maas, R., and Steele, D. (2001) Parental basaltic melts and fluids in eastern Manus backarc basin: Implications for hydrothermal mineralization. Earth Planet. Sci. Lett., 184(3), 685-702.

Karsten, J. L., Delaney, J. R., Rhodes, J. M., and Liias, R. A. (1990) Spatial and temporal evolution of magmatic systems beneath the Endeavour Segment, Juan de Fuca Ridge: Tectonic and petrologic constraints. J. Geophys. Res.: Solid Earth, 95(B12), 1923519256.

Kawasumi, S. and Chiba, H. (2017) Redox state of seafloor hydrothermal fluids and its effect on sulfide mineralization. Chemical Geology. 451, 25-37.

Krasnov, S., Poroshina, I., Cherkashev, G., Mikhalsky, E., and Maslov, M. (1997) Morphotectonics, volcanism and hydrothermal activity on the East Pacific Rise between 21 12' S and 22 40' S. Marine Geophysical Researches, 19(4), 287-317.

Langmuir, C., Humphris, S., Fornari, D., Van Dover, C., Von Damm, K. L., Tivey, M. K., Colodner, D., Charlou, J. - L. Desonie, D., Wilson, C., and Fouquet, Y. (1997) Hydrothermal vents near a mantle hot spot: the Lucky Strike vent field at $37 \mathrm{~N}$ on the Mid-Atlantic Ridge. Earth Planet. Sci. Lett., 148(1-2), 69-91.

Langmuir, C. H., Bézos, A., Escrig, S., and Parman, S. W. (2006) Chemical systematics and hydrous melting of the mantle in back-arc basins. In Back-Arc Spreading Systems: Geological, Biological, Chemical, and Physical Interactions (eds. D.M. Christie, C.R. 
Fisher, S.-M. Lee, and S. Givens) Geophysical Monograph Series, vol. 166, American Geophysical Union, Washington, DC. 87-146.

Layne, G., Tivey, M. K., and Humphris, S. E. (2005) Trace metal concentrations in common sulfide minerals using SIMS. Fifteenth Annual V. M. Goldschmidt Conference Abstracts, A55.

Lilley, M. D., Butterfield, D. A., Olson, E. J., Lupton, J. E., Macko, S. A., and McDuff, R. E. (1993) Anomalous $\mathrm{CH}_{4}$ and $\mathrm{NH}_{4}^{+}$concentrations at an unsedimented mid-ocean-ridge hydrothermal system. Nature, 364(6432), 45-47.

Martinez, F. and Taylor, B. (2002) Mantle wedge control on back-arc crustal accretion. Nature. 416, 417-420.

Maslennikov, V. V., Maslennikova, S. P., Large, R. R., and Danyushevsky, L. V. (2009) Study of trace element zonation in vent chimneys from the Silurian Yaman-Kasy volcanichosted massive sulfide deposit (Southern Urals, Russia) using laser ablation-inductively coupled plasma mass spectrometry (LA-ICPMS) Econ. Geol., 104(8), 1111-1141.

McDermott, J. M. (2015) Geochemistry of deep-sea hydrothermal vent fluids from the MidCayman Rise, Caribbean Sea. Ph.D. Thesis, MIT/WHOI Joint Program in Oceanography.

McIntire, W. L. (1963) Trace element partition coefficients - a review of theory and applications to geology. Geochim. Cosmochim. Acta, 27(12), 1209-1264.

Mottl, M. J., Seewald, J. S., Wheat, C. G., Tivey, M. K., Michael, P. J., Proskurowski, G., McCollom, M., Reeves, E., Sharkey, S., You, C.-F., Chan, L.-H., and Pichler, T. (2011) Chemistry of hot springs along the Eastern Lau Spreading Center. Geochim Cosmochim. Acta, 75(4), 1013-1038.

Reeves, E. P., Seewald, J. S., Saccocia, P., Bach, W., Craddock, P. R., Shanks, W. C., Sylva. S., Walsh, E., Pichler, T., and Rosner, M. (2011) Geochemistry of hydrothermal fluids from the PACMANUS, Northeast Pual and Vienna Woods hydrothermal fields, Manus Basin, Papua New Guinea. Geochim. Cosmochim. Acta, 75(4), 1088-1123.

Revan, M. K., Genç, Y., Maslennikov, V. V., Maslennikova, S. P., Large, R. R., and Danyushevsky, L. V. (2014) Mineralogy and trace-element geochemistry of sulfide minerals in hydrothermal chimneys from the Upper-Cretaceous VMS deposits of the eastern Pontide orogenic belt (NE Turkey) Ore Geology Reviews, 63, 129-149.

Rouxel, O., Fouquet, Y., and Ludden, J. N. (2004) Copper isotope systematics of the Lucky Strike, Rainbow, and Logatchev sea-floor hydrothermal fields on the Mid-Atlantic Ridge. Econ. Geol., 99(3), 585-600. 
Ryan, C. G. (2001) Developments in dynamic analysis for quantitative PIXE true elemental imaging. Nuclear Instruments and Methods in Physics Research Section B: Beam Interactions with Materials and Atoms, 181(1), 170-179.

Seewald, J. S. (2017) Chemical composition of hydrothermal fluids collected on RV/Roger Revelle RR1507 in the Eastern Lau Spreading Center and Valu Fa Ridge, April-May 2015 (Functional microbial dynamics of vent deposits project) Biological and Chemical Oceanography Data Management Office (BCO-DMO) Dataset version 2017-01-13 http://lod.bco-dmo.org/id/dataset/674750 (accessed, May 2017).

Seewald, J. S., and Seyfried, W. E. (1990) The effect of temperature on metal mobility in subseafloor hydrothermal systems: constraints from basalt alteration experiments. Earth Planet. Sci. Lett., 101(2-4), 388-403.

Seyfried, W. E. and Ding, K. (1995) Phase equilibria in subseafloor hydrothermal systems: A review of the role of redox, temperature, $\mathrm{pH}$ and dissolved $\mathrm{Cl}$ on the chemistry of hot spring fluids at mid- ocean ridges. In Seafloor Hydrothermal Systems: Physical, Chemical, Biological, and Geological Interactions (eds. S. E. Humphris, R. A. Zierenberg, L. S. Mullineaux and R. E. Thomson), American Geophysical Union, Washington, D. C., pp. 248-272.

Seyfried, W. E., Ding, K., and Berndt, M. E. (1991) Phase equilibria constraints on the chemistry of hot spring fluids at mid-ocean ridges. Geochim. Cosmochim. Acta, 55(12), 3559-3580.

Seyfried, W. E., Seewald, J. S., Berndt, M. E., Ding, K., and Foustoukos, D. I. (2003) Chemistry of hydrothermal vent fluids from the Main Endeavour Field, northern Juan de Fuca Ridge: Geochemical controls in the aftermath of June 1999 seismic events. J. Geophys. Res.: Solid Earth, 108(B9).

Sinton, J. M., Ford, L. L., Chappell, B., and McCullouch, M. T. (2003) Magma genesis and mantle heterogeneity in the Manus back-arc basin, Papua New Guinea. J. Petrol., 44(1), 159-195.

Tivey, M. K. (1995) The influence of hydrothermal fluid composition and advection rates on black smoker chimney mineralogy: Insights from modeling transport and reaction. Geochim. Cosmochim. Acta, 59(10), 1933-1949.

Tivey, M. K., Stakes, D. S., Cook, T. L., Hannington, M. D., and Petersen, S. (1999) A model for growth of steep- sided vent structures on the Endeavour Segment of the Juan de Fuca Ridge: Results of a petrologic and geochemical study. J. Geophys. Res: Solid Earth, 104(B10), 22859-22883.

Vallier, T. L., Jenner, G. A., Frey, F. A., Gill, J. B., Davis, A. S., Volpe, A. M., Hawkins, J. W., Morris, J. D., Cawood, P. A., Morton, J. L., Scholl, D. W., Rautenschlein, M., White, W. M., Williams, R. W., Stevenson, A. J., and White, L., D. (1991) Subalkaline andesite 
from Valu Fa Ridge, a back-arc spreading center in southern Lau Basin: petrogenesis, comparative chemistry, and tectonic implications. Chem. Geol., 91(3), 227-256.

Von Damm, K. L., Edmond, J. M., Grant, B., Measures, C. I., Walden, B., and Weiss, R. F. (1985) Chemistry of submarine hydrothermal solutions at $21^{\circ} \mathrm{N}$, East Pacific Rise. Geochim. Cosmochim. Acta, 49(11), 2197-2220.

Wohlgemuth-Ueberwasser, C. C., Viljoen, F., Petersen, S., and Vorster, C. (2015) Distribution and solubility limits of trace elements in hydrothermal black smoker sulfides: An in-situ LA-ICP-MS study. Geochim. Cosmochim. Acta, 159, 16-41.

Wolery, T. J. (1992) EQ3/6: A software package for geochemical modeling of aqueous systems: package overview and installation guide (version 7.0) Livermore, CA: Lawrence Livermore National Laboratory.

Wood, S. A. and Samson, I. M. (2006) The aqueous geochemistry of gallium, germanium, indium and scandium. Ore Geology Reviews, 28(1), 57-102. 
Appendix A

ICP-MS standard solutions were created by serial dilution of a major element and minor element stock solution prepared from Specpure ${ }^{\circledR}$ plasma solutions. Major element and minor element stock solutions, standard solutions prepared by serial dilution, and dilutions of digested samples have a matrix of $5 \mathrm{wt} \% \mathrm{HNO}_{3}$ that contained $\sim 1 \mathrm{ng} / \mathrm{g} \mathrm{Sc}$ and $\sim 1 \mathrm{ng} / \mathrm{g} \mathrm{Y}$ as internal spikes.

The major element stock solution contained:
$825 \mathrm{ng} / \mathrm{g} \mathrm{Cu}$
952 ng/g Zn
$952 \mathrm{ng} / \mathrm{g} \mathrm{S}$
$0.93 \mathrm{ng} / \mathrm{g} \mathrm{Sc}$
$1079 \mathrm{ng} / \mathrm{g} \mathrm{Fe}$
$0.93 \mathrm{ng} / \mathrm{g} \mathrm{Y}$

in $5 \mathrm{wt} \% \mathrm{HNO}_{3}$

The precision of these concentrations is $\sim 3 \mathrm{ng} / \mathrm{g}$ for $\mathrm{Cu}, \mathrm{Fe}, \mathrm{Zn}$, and $\mathrm{S}$ and $0.03 \mathrm{ng} / \mathrm{g}$ for $\mathrm{Sc}$ and $\mathrm{Y}$.

The minor element stock solution contained:

$\begin{array}{lll}948 \mathrm{ng} / \mathrm{g} \mathrm{Sb} & 1043 \mathrm{ng} / \mathrm{g} \mathrm{Ga} & 948 \mathrm{ng} / \mathrm{g} \mathrm{Se} \\ 901 \mathrm{ng} / \mathrm{g} \mathrm{As} & 806 \mathrm{ng} / \mathrm{g} \mathrm{Ge} & 948 \mathrm{ng} / \mathrm{g} \mathrm{Si} \\ 996 \mathrm{ng} / \mathrm{g} \mathrm{Ba} & 948 \mathrm{ng} / \mathrm{g} \mathrm{Au} & 948 \mathrm{ng} / \mathrm{g} \mathrm{Ag} \\ 901 \mathrm{ng} / \mathrm{g} \mathrm{Bi} & 948 \mathrm{ng} / \mathrm{g} \mathrm{In} & 996 \mathrm{ng} / \mathrm{g} \mathrm{Sr} \\ 948 \mathrm{ng} / \mathrm{g} \mathrm{Cd} & 948 \mathrm{ng} / \mathrm{g} \mathrm{Pb} & 901 \mathrm{ng} / \mathrm{g} \mathrm{Te} \\ 948 \mathrm{ng} / \mathrm{g} \mathrm{Ca} & 948 \mathrm{ng} / \mathrm{g} \mathrm{Mn} & 948 \mathrm{ng} / \mathrm{g} \mathrm{Tl} \\ 996 \mathrm{ng} / \mathrm{g} \mathrm{Cr} & 995 \mathrm{ng} / \mathrm{g} \mathrm{Mo} & 1043 \mathrm{ng} / \mathrm{g} \mathrm{Sn} \\ 901 \mathrm{ng} / \mathrm{g} \mathrm{Co} & 1090 \mathrm{ng} / \mathrm{g} \mathrm{Ni} & 901 \mathrm{ng} / \mathrm{g} \mathrm{V}\end{array}$

$0.92 \mathrm{ng} / \mathrm{g} \mathrm{Sc}$

$0.92 \mathrm{ng} / \mathrm{g} \mathrm{Y}$

The precision of these concentrations is $5 \mathrm{ng} / \mathrm{g}$ for minor elements and $0.03 \mathrm{ng} / \mathrm{g}$ for Sc and Y. On 14 November 2016, the following standard solutions were prepared by serial dilution.

\begin{tabular}{|l|l|l|l|l|l|}
\hline & $\begin{array}{l}\text { Target major } \\
\text { element } \\
\text { concentration }\end{array}$ & $\begin{array}{l}\text { Target minor } \\
\text { element } \\
\text { concentration }\end{array}$ & $\begin{array}{l}\text { Major element } \\
\text { dilution factor }\end{array}$ & $\begin{array}{l}\text { Minor Element } \\
\text { dilution factor }\end{array}$ & $\begin{array}{l}\text { Sc, Y Spike } \\
\text { concentration }\end{array}$ \\
\hline 2A & $100 \mathrm{ng} / \mathrm{g}$ & $10 \mathrm{ng} / \mathrm{g}$ & 9.91 & 97.6 & $0.93 \mathrm{ng} / \mathrm{g}$ \\
\hline 2B & $50 \mathrm{ng} / \mathrm{g}$ & $5 \mathrm{ng} / \mathrm{g}$ & 20.3 & 187. & $0.93 \mathrm{ng} / \mathrm{g}$ \\
\hline 2C & $10 \mathrm{ng} / \mathrm{g}$ & $1 \mathrm{ng} / \mathrm{g}$ & 99.9 & 984. & $0.93 \mathrm{ng} / \mathrm{g}$ \\
\hline 2D & $5 \mathrm{ng} / \mathrm{g}$ & $0.5 \mathrm{ng} / \mathrm{g}$ & 210. & 1930 & $0.93 \mathrm{ng} / \mathrm{g}$ \\
\hline 2E & $1 \mathrm{ng} / \mathrm{g}$ & $0.1 \mathrm{ng} / \mathrm{g}$ & 927. & 9120 & $0.93 \mathrm{ng} / \mathrm{g}$ \\
\hline 2F & $0.5 \mathrm{ng} / \mathrm{g}$ & $0.05 \mathrm{ng} / \mathrm{g}$ & 2200 & 20300 & $0.93 \mathrm{ng} / \mathrm{g}$ \\
\hline
\end{tabular}

These standard solutions were analyzed on 15, 16, 17 November 2016. 
On 13 January 2017, an additional set of standard solutions were prepared by serial dilution.

\begin{tabular}{|l|l|l|l|l|l|}
\hline & $\begin{array}{l}\text { Target major } \\
\text { element } \\
\text { concentration }\end{array}$ & $\begin{array}{l}\text { Target minor } \\
\text { element } \\
\text { concentration }\end{array}$ & $\begin{array}{l}\text { Major element } \\
\text { dilution factor }\end{array}$ & $\begin{array}{l}\text { Minor Element } \\
\text { dilution factor }\end{array}$ & $\begin{array}{l}\text { Sc, Y Spike } \\
\text { concentration }\end{array}$ \\
\hline 3A & $100 \mathrm{ng} / \mathrm{g}$ & $10 \mathrm{ng} / \mathrm{g}$ & 10.0 & 97.4 & $0.94 \mathrm{ng} / \mathrm{g}$ \\
\hline 3B & $50 \mathrm{ng} / \mathrm{g}$ & $5 \mathrm{ng} / \mathrm{g}$ & 19.3 & 193. & $0.94 \mathrm{ng} / \mathrm{g}$ \\
\hline 3C & $10 \mathrm{ng} / \mathrm{g}$ & $1 \mathrm{ng} / \mathrm{g}$ & 96.6 & 936. & $0.94 \mathrm{ng} / \mathrm{g}$ \\
\hline 3D & $5 \mathrm{ng} / \mathrm{g}$ & $0.5 \mathrm{ng} / \mathrm{g}$ & 190. & 1890 & $0.94 \mathrm{ng} / \mathrm{g}$ \\
\hline 3E & $1 \mathrm{ng} / \mathrm{g}$ & $0.1 \mathrm{ng} / \mathrm{g}$ & 959. & 9300 & $0.94 \mathrm{ng} / \mathrm{g}$ \\
\hline 3F & $0.5 \mathrm{ng} / \mathrm{g}$ & $0.05 \mathrm{ng} / \mathrm{g}$ & 1870 & 18700 & $0.94 \mathrm{ng} / \mathrm{g}$ \\
\hline
\end{tabular}

These standards were analyzed on 17 January 2017. The standard solutions prepared on 14

November 2016 were also analyzed.

During the 17 January 2017 session, a discrepancy was noted between the Ag counts per second measured in the $3 \mathrm{~A}-3 \mathrm{~F}$ standard solution series and the Ag counts per second measured in the 2A-2F standard solution series. These are shown on the following graphs. 


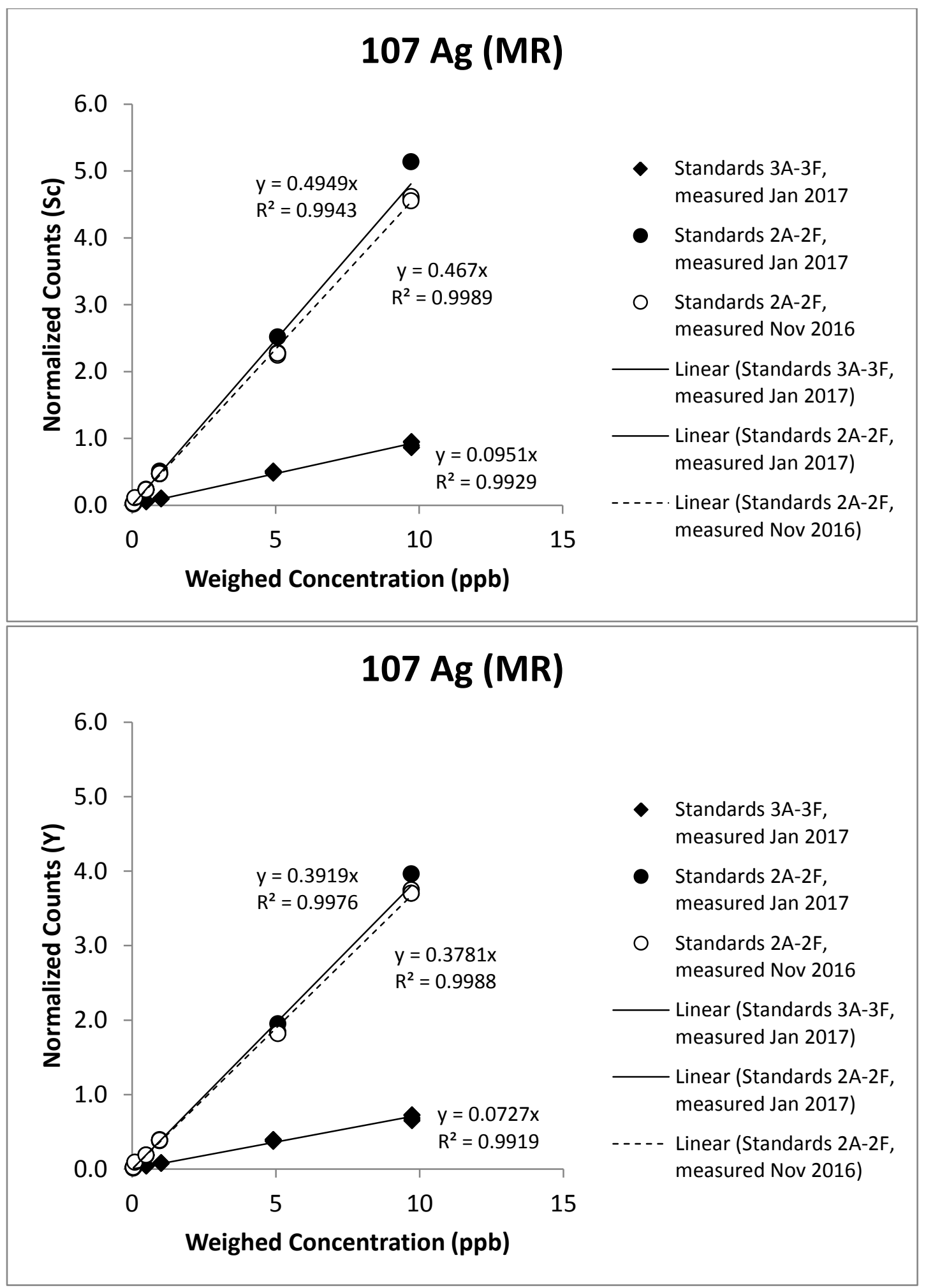


Measurements of Ag in standard solutions 2A-2F completed in January 2017 gave the same results (within error) as those completed in November 2016. Measurements of Ag in standard solutions $3 \mathrm{~A}-3 \mathrm{~F}$ were much lower than expected and all dilutions are lower by the same factor (5.2 \pm 0.2 . Because no change was observed in the $2 \mathrm{~A}-2 \mathrm{~F}$ solutions and all $3 \mathrm{~A}-3 \mathrm{~F}$ solutions were affected by the same ratio, the most likely explanation is that there was a loss in Ag from the minor element stock solution prior to serial dilution. Because no other elements were affected, this suggests a process unique to Ag. One possibility is photo-reduction of $\mathrm{Ag}$ caused by exposure of the minor element stock solution to light during storage. The $2 \mathrm{~A}-2 \mathrm{~F}$ solutions were not affected by this process, possibly because they are much more diluting than the stock solution or because they were stored in a dark cabinet.

Hypothesis: Ag in the minor element stock solution precipitated due to photo-reduction that occurred between the time at which the $2 \mathrm{~A}-2 \mathrm{~F}$ series of standard dilutions was created (November) and the time at which the 3A-3F series of standard solutions was created (January). The same process did not affect the $2 \mathrm{~A}-2 \mathrm{~F}$ standard solutions either because they were stored in the dark (unknown) or because they are more dilute. It is not known whether or not photoreduction and precipitation of $\mathrm{Ag}$ occurred in the period between creation of the minor element stock solution and creation of the $2 \mathrm{~A}-2 \mathrm{~F}$ series of standard solutions is unknown. However, this period was less than one day.

If uncorrected, calculated values of $\mathrm{Ag}$ concentrations in standard solutions $2 \mathrm{~A}-2 \mathrm{~F}$ and all other samples measured against standard solutions $3 \mathrm{~A}-3 \mathrm{~F}$ are overestimated. 

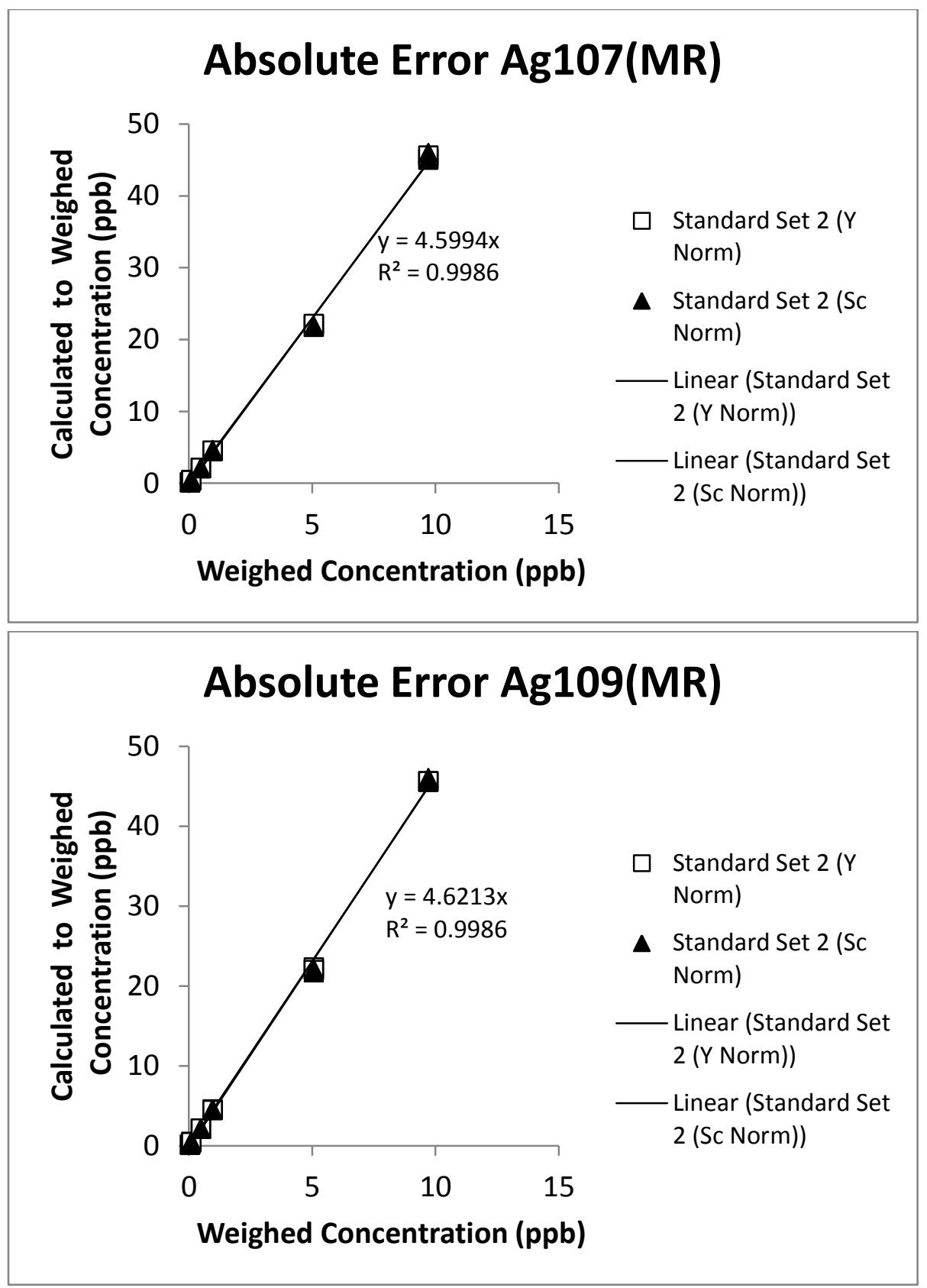

To correct, all values of Ag concentrations calculated by comparison to the $3 \mathrm{~A}-3 \mathrm{~F}$ standard solutions should be divided by a factor of $5.2 \pm 0.2$ (or the slope of the $2 \mathrm{~A}-2 \mathrm{~F}$ line divided by the 3A-3F line). This can be validated by plotting difference between the calculated concentrations of the $2 \mathrm{~A}-2 \mathrm{~F}$ standard solutions and weighed concentrations of the $2 \mathrm{~A}-2 \mathrm{~F}$ standard solution series as a function of the weighed concentration of the $2 \mathrm{~A}-2 \mathrm{~F}$ standard solutions. This should by 
symmetrical around zero and close to zero. This procedure assumes that only the $3 \mathrm{~A}-3 \mathrm{~F}$ series of standard solutions were significantly affected by photo-reduction of Ag and that the weighed concentrations of the $2 \mathrm{~A}-2 \mathrm{~F}$ standard solutions are accurate. It is not possible to definitively demonstrate that this assumption is correct, but at least makes all measurements comparable between sessions.
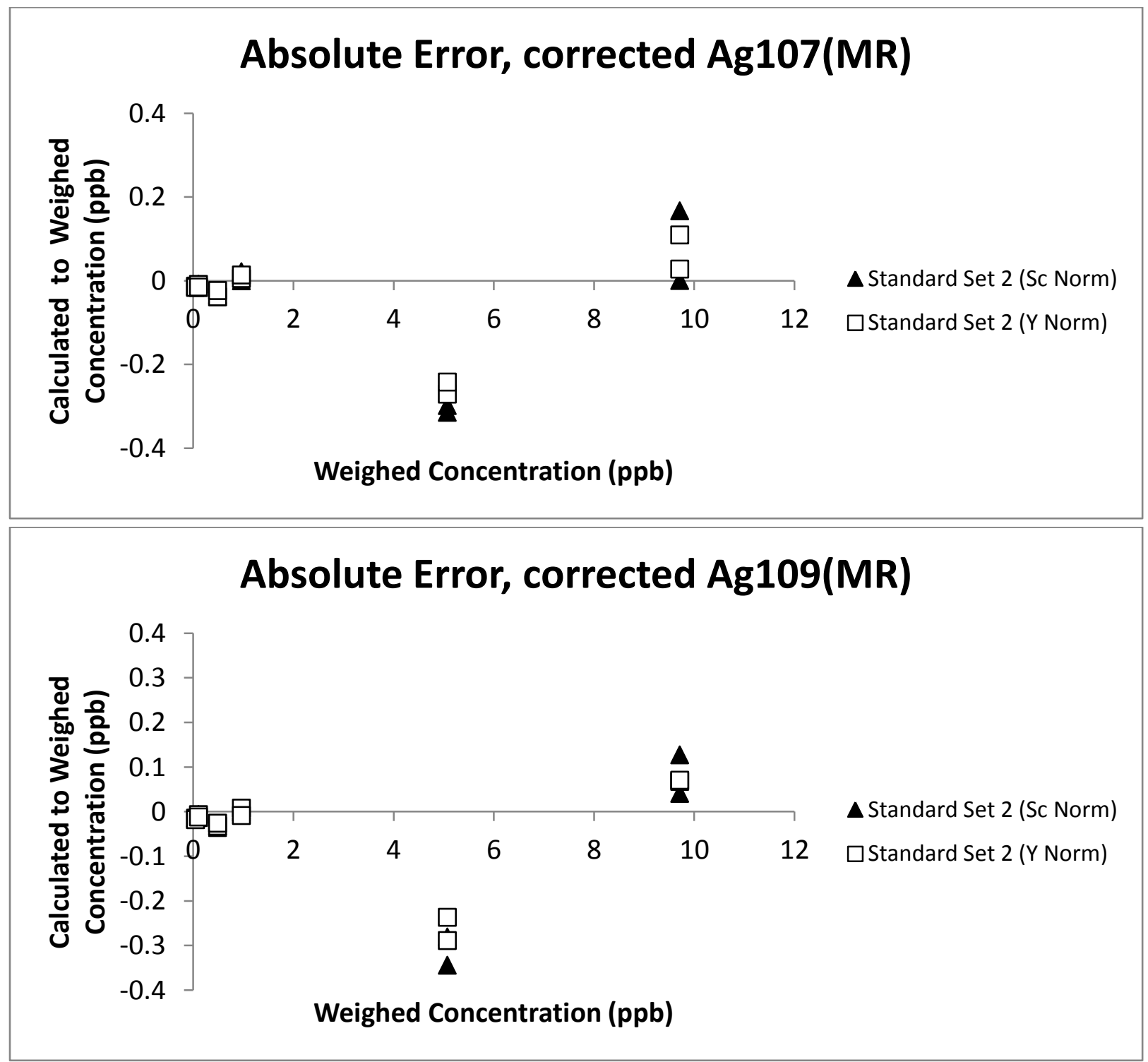


\section{SUPPLEMENTARY MATERIAL}

Supplementary Table S1: Data for Linear Regression of ${ }^{113} \mathrm{In} /{ }^{115} \mathrm{In}$

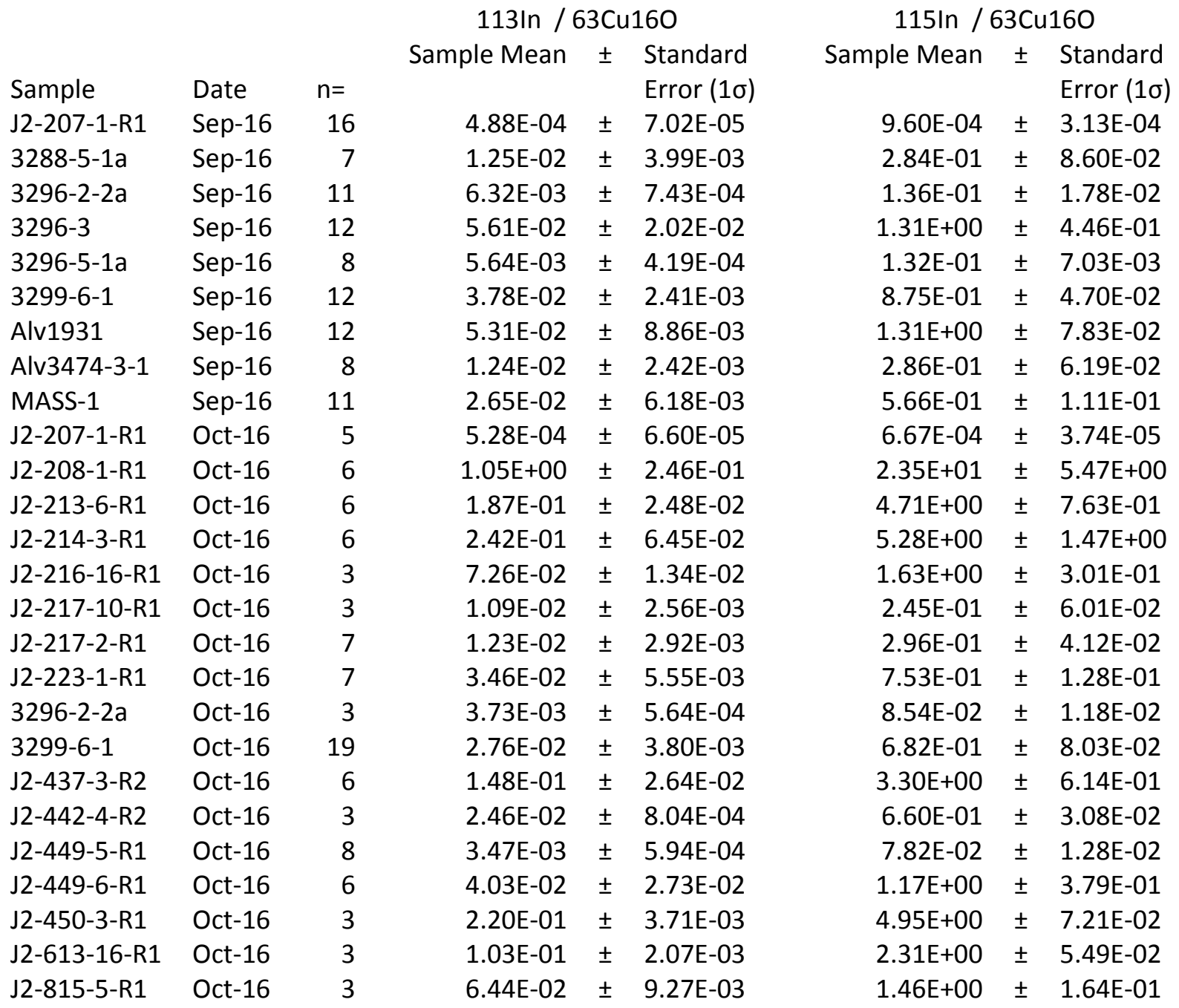


Supplementary Table S2: Data for Figure 3A

\begin{tabular}{|c|c|c|c|c|c|c|c|}
\hline \multirow[t]{2}{*}{ Sample } & \multirow[t]{2}{*}{ Date } & \multirow[t]{2}{*}{$\mathrm{n}=$} & $55 \mathrm{Mn}$ & 59Co & 109Ag & $115 \ln$ & $115 \ln$ \\
\hline & & & \multicolumn{5}{|c|}{ Sample Mean of Counts Ratio over $63 \mathrm{Cu} 160$} \\
\hline J2-207-1-R1 & Oct. 2016 & 5 & 1.97E-01 & $1.04 \mathrm{E}-02$ & $9.26 \mathrm{E}-02$ & $5.28 \mathrm{E}-04$ & 6.67E-04 \\
\hline J2-208-1-R1 & Oct. 2016 & 6 & $2.29 \mathrm{E}-02$ & 4.93E-05 & $2.64 \mathrm{E}-02$ & $1.05 \mathrm{E}+00$ & $2.35 \mathrm{E}+01$ \\
\hline J2-213-6-R1 & Oct. 2016 & 6 & $8.98 \mathrm{E}-03$ & $5.05 \mathrm{E}-05$ & $6.48 \mathrm{E}-03$ & 1.87E-01 & $4.71 \mathrm{E}+00$ \\
\hline J2-214-3-R1 & Oct. 2016 & 6 & 1.96E-03 & 2.93E-05 & 4.83E-03 & $2.42 \mathrm{E}-01$ & $5.28 \mathrm{E}+00$ \\
\hline $\mathrm{J} 2-216-16-\mathrm{R} 1$ & Oct. 2016 & 3 & $2.10 \mathrm{E}-02$ & $3.26 \mathrm{E}-02$ & 8.04E-03 & $7.26 \mathrm{E}-02$ & $1.63 E+00$ \\
\hline J2-217-10-R1 & Oct. 2016 & 3 & $1.24 \mathrm{E}-03$ & $1.36 \mathrm{E}-02$ & 1.59E-02 & $1.09 \mathrm{E}-02$ & $2.45 \mathrm{E}-01$ \\
\hline J2-217-2-R1 & Oct. 2016 & 7 & 5.96E-03 & $9.73 \mathrm{E}-02$ & 4.60E-03 & $1.23 \mathrm{E}-02$ & $2.96 \mathrm{E}-01$ \\
\hline J2-223-1-R1 & Oct. 2016 & 7 & 4.60E-03 & 2.89E-01 & $7.45 \mathrm{E}-03$ & $3.46 \mathrm{E}-02$ & 7.53E-01 \\
\hline$J 2-442-4-R 2$ & Oct. 2016 & 3 & 1.95E-01 & 3.77E-03 & 1.35E-02 & $2.46 \mathrm{E}-02$ & $6.60 \mathrm{E}-01$ \\
\hline J2-449-5-R1 & Oct. 2016 & 8 & 2.91E-01 & $3.25 \mathrm{E}-05$ & $2.14 \mathrm{E}-02$ & $3.47 \mathrm{E}-03$ & 7.82E-02 \\
\hline J2-449-6-R1 & Oct. 2016 & 6 & $1.24 \mathrm{E}-01$ & 6.71E-03 & $8.80 \mathrm{E}$ & 4.03E-02 & $1.17 E+00$ \\
\hline J2-450-3-R1 & Oct. 2016 & 3 & $E-01$ & & 6.9 & 2.2 & 4.95 \\
\hline J2-613-16-R1 & Oct. 2016 & 3 & 5.87E-01 & $1.82 \mathrm{E}$ & 5.0 & 1.03 & $2.31 E+00$ \\
\hline J2-815-5-R1 & Oct. 2016 & 3 & 1.90E-01 & & & & \\
\hline \multirow[t]{2}{*}{ Sample } & Date & $\mathrm{n}=$ & $55 \mathrm{Mn}$ & $59 \mathrm{Co}$ & $109 \mathrm{Ag}$ & $115 \ln$ & $115 \ln$ \\
\hline & & & \multicolumn{5}{|c|}{ Standard Error 1 sigma } \\
\hline J2-207-1-R1 & Oct. 2016 & 5 & $3.84 \mathrm{E}-03$ & $3.90 \mathrm{E}-04$ & $4.04 \mathrm{E}-03$ & $6.60 \mathrm{E}-05$ & $3.74 \mathrm{E}-05$ \\
\hline J2-208-1-R1 & Oct. 2016 & 6 & 1.77E-03 & $1.15 \mathrm{E}-05$ & $2.57 \mathrm{E}-$ & $2.46 \mathrm{E}-01$ & $5.47 \mathrm{E}+00$ \\
\hline$J 2-213-6-R 1$ & Oct. 2016 & 6 & $1.52 \mathrm{E}-03$ & 3.73E-05 & 4.62E-04 & $2.48 \mathrm{E}-02$ & 7.63E-01 \\
\hline J2-214-3-R1 & Oct. 2016 & 6 & $3.63 E-04$ & 7.31E-06 & 7.24E-03 & $6.45 \mathrm{E}-02$ & $1.47 \mathrm{E}+00$ \\
\hline $\mathrm{J} 2-216-16-\mathrm{R} 1$ & Oct. 2016 & 3 & 4.17E-03 & & 7.75E-04 & $1.34 \mathrm{E}-02$ & $3.01 \mathrm{E}-01$ \\
\hline $\mathrm{J} 2-217-10-\mathrm{R} 1$ & Oct. 2016 & 3 & 1.07E-04 & $6.77 \mathrm{E}-04$ & 4.07E-03 & $2.56 \mathrm{E}-03$ & $6.01 E-02$ \\
\hline J2-217-2-R1 & Oct. 2016 & 7 & 2.07E-04 & 4.34E-03 & $3.29 E-04$ & 2.92E-03 & 4.12E-02 \\
\hline J2-223-1-R1 & Oct. 2016 & 7 & 1.16E-03 & & 1.07E-03 & $5.55 \mathrm{E}-03$ & $1.28 \mathrm{E}-01$ \\
\hline$J 2-442-4-R 2$ & Oct. 2016 & 3 & 3.04E-03 & $7.35 \mathrm{E}-04$ & 1.63E-03 & 8.04E-04 & $3.08 \mathrm{E}-02$ \\
\hline J2-449-5-R1 & Oct. 2016 & 8 & 4.46E-02 & 4.92E-06 & $1.56 \mathrm{E}-03$ & 5.94E-04 & $1.28 \mathrm{E}-02$ \\
\hline J2-449-6-R1 & Oct. 2016 & 6 & 5.09E-02 & $5.96 \mathrm{E}-03$ & 2.37E-03 & 2.73E-02 & 3.79E-01 \\
\hline J2-450-3-R1 & Oct. 2016 & 3 & $9.41 \mathrm{E}-03$ & 7.97E-06 & 3.99E-03 & $3.71 E-03$ & $7.21 \mathrm{E}-02$ \\
\hline J2-613-16-R1 & Oct. 2016 & 3 & $2.42 \mathrm{E}-01$ & & $1.56 \mathrm{E}-03$ & 2.07E-03 & 5.49E-02 \\
\hline J2-815-5-R1 & Oct. 2016 & 3 & 3.87E-03 & 7.01E-06 & 6.47E-04 & $9.27 \mathrm{E}-03$ & $1.64 \mathrm{E}-01$ \\
\hline
\end{tabular}


Supplementary Table S2: Data for Figure 3A cont.

\begin{tabular}{|c|c|c|c|c|c|c|c|}
\hline \multirow[t]{2}{*}{ Sample } & \multirow[t]{2}{*}{ Date } & \multirow[t]{2}{*}{$\mathrm{n}=$} & $55 \mathrm{Mn}$ & 59Co & $109 \mathrm{Ag}$ & $115 \mathrm{In}$ & $115 \mathrm{In}$ \\
\hline & & & \multicolumn{5}{|c|}{ Sample Mean of Counts Ratio over $63 \mathrm{Cu} 16 \mathrm{O}$} \\
\hline J2-207-1-R1 & Dec. 2015 & 30 & $2.24 \mathrm{E}-01$ & $1.08 \mathrm{E}-02$ & $9.62 \mathrm{E}-02$ & $8.10 \mathrm{E}-04$ & $1.82 \mathrm{E}-02$ \\
\hline J2-208-1-R1 & Dec. 2015 & 5 & $3.34 \mathrm{E}-02$ & $4.12 \mathrm{E}-05$ & $3.08 \mathrm{E}-02$ & $1.09 \mathrm{E}+00$ & $2.44 \mathrm{E}+01$ \\
\hline J2-213-6-R1 & Dec. 2015 & 7 & $1.00 \mathrm{E}-02$ & $2.30 \mathrm{E}-05$ & $6.72 \mathrm{E}-03$ & 2.20E-01 & $4.94 \mathrm{E}+00$ \\
\hline J2-214-3-R1 & Dec. 2015 & 6 & $2.06 \mathrm{E}-03$ & $1.27 \mathrm{E}-05$ & $2.08 \mathrm{E}-03$ & $3.20 \mathrm{E}-01$ & $7.18 \mathrm{E}+00$ \\
\hline J2-216-16-R1 & Dec. 2015 & 5 & $2.38 \mathrm{E}-02$ & $2.81 \mathrm{E}-02$ & $6.67 \mathrm{E}-03$ & 5.57E-02 & $1.25 \mathrm{E}+00$ \\
\hline J2-217-10-R1 & Dec. 2015 & 6 & $2.63 \mathrm{E}-03$ & $1.98 \mathrm{E}-02$ & $1.12 \mathrm{E}-02$ & $1.84 \mathrm{E}-02$ & 4.13E-01 \\
\hline J2-217-2-R1 & Dec. 2015 & 6 & $6.72 \mathrm{E}-03$ & $1.08 \mathrm{E}-01$ & $4.85 \mathrm{E}-03$ & $1.66 \mathrm{E}-02$ & 3.73E-01 \\
\hline J2-223-1-R1 & Dec. 2015 & 10 & $4.42 \mathrm{E}-03$ & $3.02 E-01$ & $8.32 \mathrm{E}-03$ & 4.99E-02 & $1.12 \mathrm{E}+00$ \\
\hline$J 2-442-4-R 2$ & Dec. 2015 & 7 & $1.82 \mathrm{E}-01$ & $4.53 \mathrm{E}-03$ & $1.45 \mathrm{E}-02$ & $2.29 \mathrm{E}-02$ & 5.13E-01 \\
\hline J2-449-5-R1 & Dec. 2015 & 6 & 3.47E-01 & $2.68 \mathrm{E}-05$ & $2.46 \mathrm{E}-02$ & $3.88 \mathrm{E}-03$ & 8.70E-02 \\
\hline J2-449-6-R1 & Dec. 2015 & 5 & 2.61E-01 & $4.55 \mathrm{E}-03$ & $1.45 \mathrm{E}-02$ & 7.53E-02 & $1.69 \mathrm{E}+00$ \\
\hline J2-450-3-R1 & Dec. 2015 & 10 & $3.06 \mathrm{E}-01$ & $5.04 \mathrm{E}-05$ & $6.54 \mathrm{E}-02$ & $2.32 \mathrm{E}-01$ & $5.21 E+00$ \\
\hline J2-613-16-R1 & Dec. 2015 & 6 & $6.39 \mathrm{E}-01$ & $1.74 \mathrm{E}+01$ & $2.88 \mathrm{E}-03$ & $9.96 \mathrm{E}-02$ & $2.23 E+00$ \\
\hline J2-815-5-R1 & Dec. 2015 & 6 & $2.08 \mathrm{E}-01$ & $5.72 \mathrm{E}-04$ & $1.46 \mathrm{E}-02$ & $4.76 \mathrm{E}-02$ & $1.07 E+00$ \\
\hline \multirow[t]{2}{*}{ Sample } & \multirow[t]{2}{*}{ Date } & \multirow[t]{2}{*}{$n=$} & $55 \mathrm{Mn}$ & $59 \mathrm{Co}$ & $109 \mathrm{Ag}$ & $115 \ln$ & $115 \ln$ \\
\hline & & & \multicolumn{5}{|c|}{ Standard Error 1 sigma } \\
\hline J2-207-1-R1 & Dec. 2015 & 30 & $2.68 \mathrm{E}-02$ & $1.09 \mathrm{E}-03$ & $8.32 \mathrm{E}-03$ & $2.02 \mathrm{E}-04$ & 4.53E-03 \\
\hline J2-208-1-R1 & Dec. 2015 & 5 & $6.49 \mathrm{E}-03$ & $6.31 \mathrm{E}-06$ & $4.54 \mathrm{E}-03$ & $4.02 \mathrm{E}-01$ & $9.01 \mathrm{E}+00$ \\
\hline$J 2-213-6-R 1$ & Dec. 2015 & 7 & 1.47E-03 & $9.20 \mathrm{E}-06$ & $5.74 \mathrm{E}-04$ & $4.86 \mathrm{E}-02$ & $1.09 E+00$ \\
\hline J2-214-3-R1 & Dec. 2015 & 6 & $2.05 \mathrm{E}-04$ & $6.04 \mathrm{E}-06$ & $2.11 \mathrm{E}-04$ & $6.86 \mathrm{E}-02$ & $1.54 \mathrm{E}+00$ \\
\hline J2-216-16-R1 & Dec. 2015 & 5 & $1.26 \mathrm{E}-02$ & $2.54 \mathrm{E}-03$ & $6.65 \mathrm{E}-04$ & $9.10 \mathrm{E}-03$ & 2.04E-01 \\
\hline J2-217-10-R1 & Dec. 2015 & 6 & $1.55 \mathrm{E}-03$ & 3.67E-03 & $7.62 \mathrm{E}-04$ & $4.76 \mathrm{E}-03$ & 1.07E-01 \\
\hline $\mathrm{J} 2-217-2-\mathrm{R} 1$ & Dec. 2015 & 6 & 5.09E-04 & 4.17E-03 & $3.50 \mathrm{E}-04$ & $4.89 \mathrm{E}-03$ & 1.10E-01 \\
\hline J2-223-1-R1 & Dec. 2015 & 10 & 1.17E-03 & $3.14 \mathrm{E}-02$ & $2.10 \mathrm{E}-03$ & $1.85 \mathrm{E}-02$ & 4.14E-01 \\
\hline$J 2-442-4-R 2$ & Dec. 2015 & 7 & $1.03 E-02$ & $6.66 \mathrm{E}-04$ & $1.26 \mathrm{E}-03$ & $8.63 E-03$ & $1.94 \mathrm{E}-01$ \\
\hline J2-449-5-R1 & Dec. 2015 & 6 & $3.86 \mathrm{E}-02$ & $1.12 \mathrm{E}-05$ & $2.71 \mathrm{E}-03$ & $1.12 \mathrm{E}-03$ & $2.51 \mathrm{E}-02$ \\
\hline J2-449-6-R1 & Dec. 2015 & 5 & $6.33 \mathrm{E}-02$ & $4.51 \mathrm{E}-03$ & $2.58 \mathrm{E}-03$ & 5.17E-03 & $1.16 \mathrm{E}-01$ \\
\hline J2-450-3-R1 & Dec. 2015 & 10 & $3.13 \mathrm{E}-02$ & 7.17E-06 & $6.88 \mathrm{E}-03$ & $6.54 \mathrm{E}-02$ & $1.47 \mathrm{E}+00$ \\
\hline J2-613-16-R1 & Dec. 2015 & 6 & $1.59 \mathrm{E}-01$ & $3.06 \mathrm{E}+00$ & $5.16 \mathrm{E}-04$ & $3.82 \mathrm{E}-02$ & 8.56E-01 \\
\hline J2-815-5-R1 & Dec. 2015 & 6 & $4.00 \mathrm{E}-02$ & $9.18 \mathrm{E}-04$ & $1.85 \mathrm{E}-03$ & $1.85 \mathrm{E}-02$ & 4.15E-01 \\
\hline
\end{tabular}


Supplementary Table S3: Data for Figure 3B

\begin{tabular}{|c|c|c|c|c|c|c|c|c|c|}
\hline \multirow[t]{2}{*}{ Sample } & Date & $n=$ & $55 \mathrm{Mn}$ & 59 Co & $60 \mathrm{Ni}$ & 69Ga & 109Ag & $113 \ln$ & $115 \ln$ \\
\hline & & & \multicolumn{7}{|c|}{ Sample Mean of Counts Ratio over 63Cu160 } \\
\hline J2-207-1-R1 & Sep. 2016 & 16 & 2.35E-01 & 1.13E-02 & $6.08 \mathrm{E}-05$ & $2.90 \mathrm{E}-02$ & $1.05 \mathrm{E}-01$ & $4.88 \mathrm{E}-04$ & $9.60 \mathrm{E}-04$ \\
\hline $3296-2-2 a$ & Sep. 2016 & 11 & $6.96 \mathrm{E}-02$ & $1.55 \mathrm{E}+00$ & 1.17E-01 & 1.77E-02 & 5.17E-03 & $6.32 \mathrm{E}-03$ & $1.36 \mathrm{E}-01$ \\
\hline $3299-6-1$ & Sep. 2016 & 12 & 5.55E-01 & $2.78 \mathrm{E}+00$ & 3.19E-01 & 4.11E-02 & $2.54 \mathrm{E}-02$ & $3.78 \mathrm{E}-02$ & 8.75E-01 \\
\hline \multirow[t]{2}{*}{ Sample } & Date & $n=$ & $55 \mathrm{Mn}$ & 59Co & $60 \mathrm{Ni}$ & $59 \mathrm{Ga}$ & 109Ag & 113In & $115 \ln$ \\
\hline & & & \multicolumn{7}{|c|}{ Standard Error 1 sigma } \\
\hline J2-207-1-R1 & Sep. 2016 & 16 & $1.45 \mathrm{E}-02$ & 8.40E-04 & 2.10E-05 & $1.88 \mathrm{E}-02$ & 5.68E-03 & 7.02E-05 & $3.13 \mathrm{E}-04$ \\
\hline $3296-2-2 a$ & Sep. 2016 & 11 & $7.08 \mathrm{E}-03$ & 1.34E-01 & 8.64E-03 & 3.99E-03 & 5.91E-04 & 7.43E-04 & $1.78 \mathrm{E}-02$ \\
\hline $3299-6-1$ & Sep. 2016 & 12 & $3.45 \mathrm{E}-02$ & $1.12 \mathrm{E}-01$ & 1.17E-02 & $5.65 \mathrm{E}-03$ & $9.22 \mathrm{E}-04$ & 2.41E-03 & 4.70E-02 \\
\hline \multirow[t]{2}{*}{ Sample } & Date & $n=$ & $55 \mathrm{Mn}$ & $59 \mathrm{Co}$ & $60 \mathrm{Ni}$ & $59 \mathrm{Ga}$ & 109Ag & 113In & $115 \ln$ \\
\hline & & & \multicolumn{7}{|c|}{ Sample Mean of Counts Ratio over 63Cu160 } \\
\hline J2-207-1-R1 & Oct. 2016 & 5 & 1.97E-01 & 1.04E-02 & 5.46E-05 & 2.44E-02 & $9.26 \mathrm{E}-02$ & $5.28 \mathrm{E}-04$ & 6.67E-04 \\
\hline $3296-2-2 a$ & Oct. 2016 & 3 & $5.75 \mathrm{E}-02$ & $1.33 \mathrm{E}+00$ & $1.14 \mathrm{E}-01$ & $1.26 \mathrm{E}-02$ & 3.77E-03 & 3.73E-03 & 8.54E-02 \\
\hline $3299-6-1$ & Oct. 2016 & 19 & 4.40E-01 & $2.43 \mathrm{E}+00$ & 2.95E-01 & 3.14E-02 & $2.21 \mathrm{E}-02$ & $2.76 \mathrm{E}-02$ & $6.82 \mathrm{E}-01$ \\
\hline \multirow[t]{2}{*}{ Sample } & Date & $n=$ & $55 \mathrm{Mn}$ & 59Co & $60 \mathrm{Ni}$ & $9 \mathrm{Ga}$ & 109Ag & 113In & $115 \ln$ \\
\hline & & & \multicolumn{7}{|c|}{ Standard Error 1 sigma } \\
\hline J2-207-1-R1 & Oct. 2016 & 5 & $3.84 \mathrm{E}-03$ & 3.90E-04 & $9.23 \mathrm{E}-06$ & 9.99E-03 & 4.04E-03 & 6.60E-05 & $3.74 \mathrm{E}-05$ \\
\hline $3296-2-2 a$ & Oct. 2016 & 3 & 7.31E-03 & $1.66 \mathrm{E}-01$ & $1.56 \mathrm{E}-02$ & $1.08 \mathrm{E}-03$ & $4.65 \mathrm{E}-04$ & $5.64 \mathrm{E}-04$ & 1.18E-02 \\
\hline 3299-6-1 & Oct. 2016 & 19 & 4.57E-02 & 1.64E-01 & $2.02 \mathrm{E}-02$ & 4.90E-03 & $2.39 \mathrm{E}-03$ & $3.80 \mathrm{E}-03$ & 8.03E-02 \\
\hline
\end{tabular}




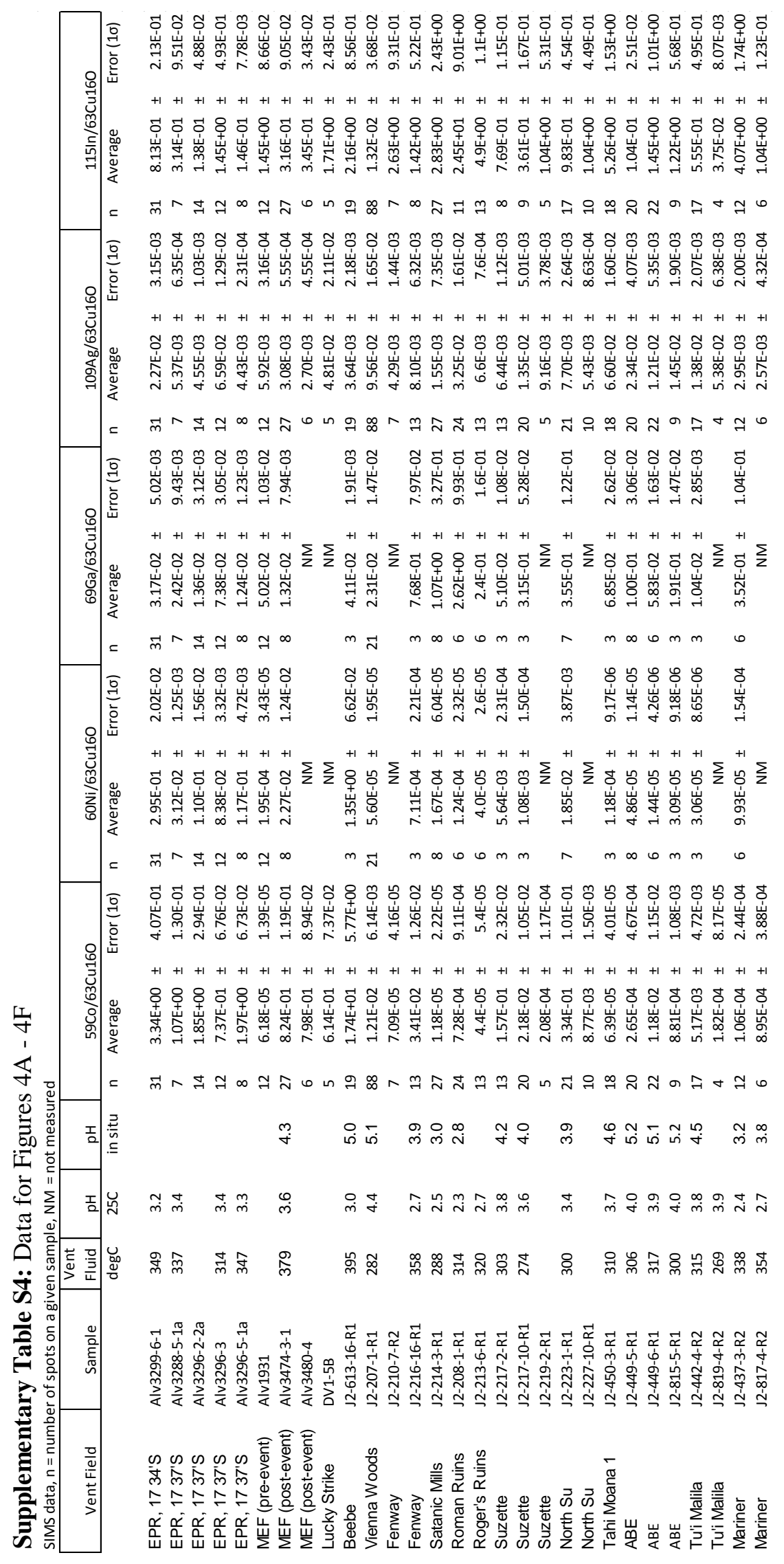




\section{Supplementary Table S5}

\begin{tabular}{|c|c|c|c|c|c|}
\hline \multicolumn{6}{|c|}{ Input to pca (SIMS data only) } \\
\hline Sample & $\begin{array}{r}\log (59 C o / \\
63 C u 160) \\
\end{array}$ & $\begin{array}{l}\log (60 \mathrm{Ni} / \\
63 \mathrm{Cu} 160) \\
\end{array}$ & $\begin{array}{l}\log (69 \mathrm{Ga} / \\
63 \mathrm{Cu} 160) \\
\end{array}$ & $\begin{array}{c}\log (109 A g / \\
63 C u 160)\end{array}$ & $\begin{array}{c}\log (115 \ln / \\
63 C u 160) \\
\end{array}$ \\
\hline Alv3299-6-1 & 0.52 & -0.53 & -1.50 & -1.64 & -0.09 \\
\hline Alv3288-5-1a & 0.03 & -1.51 & -1.62 & -2.27 & -0.50 \\
\hline Alv3296-2-2a & 0.27 & -0.96 & -1.87 & -2.34 & -0.86 \\
\hline Alv3296-3 & -0.13 & -1.08 & -1.13 & -1.18 & 0.16 \\
\hline Alv3296-5-1a & 0.29 & -0.93 & -1.91 & -2.35 & -0.84 \\
\hline Alv1931 & -4.21 & -3.71 & -1.30 & -2.23 & 0.16 \\
\hline Alv3474-3-1 & -0.08 & -1.64 & -1.88 & -2.51 & -0.50 \\
\hline J2-613-16-R1 & 1.24 & 0.13 & -1.39 & -2.44 & 0.33 \\
\hline J2-207-1-R1 & -1.92 & -4.25 & -1.64 & -1.02 & -1.88 \\
\hline J2-216-16-R1 & -1.47 & -3.15 & -0.11 & -2.09 & 0.15 \\
\hline J2-214-3-R1 & -4.93 & -3.78 & 0.03 & -2.81 & 0.45 \\
\hline J2-208-1-R1 & -3.14 & -3.91 & 0.42 & -1.49 & 1.39 \\
\hline J2-213-6-R1 & -3.21 & -4.40 & -0.62 & -1.06 & 0.69 \\
\hline J2-217-2-R1 & -0.80 & -2.25 & -1.29 & -2.19 & -0.11 \\
\hline J2-217-10-R1 & -1.66 & -2.97 & -0.50 & -1.87 & -0.44 \\
\hline J2-223-1-R1 & -0.48 & -1.73 & -0.45 & -2.11 & -0.01 \\
\hline J2-450-3-R1 & -4.19 & -3.93 & -1.16 & -1.18 & 0.72 \\
\hline J2-449-5-R1 & -3.58 & -4.31 & -1.00 & -1.63 & -0.98 \\
\hline J2-449-6-R1 & -1.93 & -4.84 & -1.23 & -1.92 & 0.16 \\
\hline J2-815-5-R1 & -3.05 & -4.51 & -0.72 & -1.84 & 0.09 \\
\hline$J 2-442-4-R 2$ & -2.29 & -4.51 & -1.98 & -1.86 & -0.26 \\
\hline$J 2-437-3-R 2$ & -3.98 & -4.00 & -0.45 & -2.53 & 0.61 \\
\hline
\end{tabular}

\begin{tabular}{|c|c|c|c|c|c|}
\hline \\
\hline \multicolumn{6}{|c|}{$\begin{array}{l}\text { Output from pca (SIMS data only) } \\
\begin{array}{ll}\text { Correlation } \log (59 \mathrm{Co} / \log (60 \mathrm{Ni} / \log (69 \mathrm{Ga} /\end{array}\end{array}$} \\
\hline Coefficients & 63Cu160) & 63Cu160) & 63Cu160) & 63Cu160) & 63Cu160) \\
\hline $\log (59 \mathrm{Co} / 63 \mathrm{Cu} 160)$ & 1.00 & 0.86 & -0.52 & -0.16 & -0.37 \\
\hline $\log (60 \mathrm{Ni} / 63 \mathrm{Cu} 16 \mathrm{O})$ & 0.86 & 1.00 & -0.38 & -0.33 & -0.18 \\
\hline $\log (69 \mathrm{Ga} / 63 \mathrm{Cu} 160)$ & -0.52 & -0.38 & 1.00 & 0.05 & 0.63 \\
\hline $\log (109 \mathrm{Ag} / \mathrm{63Cu160})$ & -0.16 & -0.33 & 0.05 & 1.00 & 0.00 \\
\hline $\log (115 \ln / 63 \mathrm{Cu} 160)$ & -0.37 & -0.18 & 0.63 & 0.00 & 1.00 \\
\hline \multicolumn{6}{|c|}{$\log (59 \mathrm{Co} / \mathrm{log}$} \\
\hline $\begin{array}{l}\text { Pearson P value } \\
\log (59 C o / 63 C u 160)\end{array}$ & $\begin{array}{c}63 \text { Cu160) } \\
1.00\end{array}$ & $\begin{array}{c}\text { 63Cu160) } \\
0.00\end{array}$ & $\begin{array}{c}\text { 63Cu160) } \\
0.01\end{array}$ & $\begin{array}{c}63 \text { Cu160) } \\
0.47\end{array}$ & $\begin{array}{c}63(0160) \\
0.09\end{array}$ \\
\hline log (60Ni / 63Cu160) & 0.00 & 1.00 & 0.08 & 0.14 & 0.43 \\
\hline $\log (69 \mathrm{Ga} / 63 \mathrm{Cu} 160)$ & 0.01 & 0.08 & 1.00 & 0.84 & 0.00 \\
\hline $\log (109 \mathrm{Ag} / 63 \mathrm{Cu} 160)$ & 0.47 & 0.14 & 0.84 & 1.00 & 1.00 \\
\hline $\log (115 \ln / 63 C u 160)$ & 0.09 & 0.43 & 0.00 & 1.00 & 1.00 \\
\hline Principle Components & pсa-1 & pсa-2 & рса-3 & pсa-4 & pca-5 \\
\hline $\log (59 \mathrm{Co} / 63 \mathrm{Cu} 160)$ & 0.76 & -0.21 & 0.51 & -0.31 & -0.14 \\
\hline $\log (60 \mathrm{Ni} /$ 63Cu160) & 0.62 & 0.48 & -0.43 & 0.37 & 0.25 \\
\hline $\log (69 \mathrm{Ga} / 63 \mathrm{Cu} 160)$ & -0.15 & 0.51 & 0.35 & -0.43 & 0.64 \\
\hline $\log$ (109Ag / 63Cu160) & -0.05 & -0.18 & 0.55 & 0.75 & 0.32 \\
\hline $\log (115 \ln / 63 \mathrm{Cu} 160)$ & -0.10 & 0.66 & 0.35 & 0.16 & -0.63 \\
\hline & pca-1 & pca-2 & pca-3 & pca-4 & pca-5 \\
\hline $\begin{array}{l}\text { Contribution to total } \\
\text { variance (\%) }\end{array}$ & 79.65 & 10.56 & 4.83 & 2.70 & 2.26 \\
\hline
\end{tabular}




\section{Supplementary Table S6}

\begin{tabular}{|c|c|c|c|c|c|c|c|c|c|}
\hline \multicolumn{3}{|c|}{ Input to pca (SIMS and fluid data) } & \multicolumn{7}{|c|}{ SIMS count ratio over 63 Cu160 (log 10) } \\
\hline Sample & $1 / \mathrm{K}$ & $\mathrm{pH}$ & $\log (\mathrm{mmol} \mathrm{Cl})$ & $\log$ (umol H2S) & $\begin{array}{r}\log (59 \mathrm{Co} / \\
63 \mathrm{Cu} 160)\end{array}$ & $\begin{array}{r}\log (60 \mathrm{Ni} / \\
63 \mathrm{Cu} 160)\end{array}$ & $\begin{array}{r}\log (69 \mathrm{Ga} / \\
63 \mathrm{Cu} 160)\end{array}$ & $\begin{array}{c}\log (109 \mathrm{Ag} / \\
63 \mathrm{Cu} 160)\end{array}$ & $\begin{array}{c}\log (115 \ln / \\
63 C u 160)\end{array}$ \\
\hline Alv3299-6-1 & $1.61 \mathrm{E}-03$ & 3.20 & 2.68 & 0.95 & 0.52 & -0.53 & -1.50 & -1.64 & -0.09 \\
\hline Alv3288-5-1a & $1.64 \mathrm{E}-03$ & 3.41 & 2.88 & 0.54 & 0.03 & -1.51 & -1.62 & -2.27 & -0.50 \\
\hline Alv3296-3 & $1.70 \mathrm{E}-03$ & 3.44 & 2.88 & 0.81 & -0.13 & -1.08 & -1.13 & -1.18 & 0.16 \\
\hline Alv3296-5-1a & $1.61 \mathrm{E}-03$ & 3.30 & 2.77 & 0.57 & 0.29 & -0.93 & -1.91 & -2.35 & -0.84 \\
\hline J2-207-1-R1 & $1.80 \mathrm{E}-03$ & 4.40 & 2.84 & 0.15 & -1.92 & -4.25 & -1.64 & -1.02 & -1.88 \\
\hline J2-208-1-R1 & $1.70 \mathrm{E}-03$ & 2.30 & 2.80 & 0.88 & -3.14 & -3.91 & 0.42 & -1.49 & 1.39 \\
\hline J2-213-6-R1 & $1.69 \mathrm{E}-03$ & 2.70 & 2.81 & 0.56 & -3.21 & -4.40 & -0.62 & -1.06 & 0.69 \\
\hline J2-214-3-R1 & $1.78 \mathrm{E}-03$ & 2.50 & 2.70 & 1.01 & -4.93 & -3.78 & 0.03 & -2.81 & 0.45 \\
\hline J2-216-16-R1 & $1.58 \mathrm{E}-03$ & 2.70 & 2.75 & 1.27 & -1.47 & -3.15 & -0.11 & -2.09 & 0.15 \\
\hline J2-217-10-R1 & $1.83 \mathrm{E}-03$ & 3.60 & 2.84 & 0.26 & -1.66 & -2.97 & -0.50 & -1.87 & -0.44 \\
\hline J2-217-2-R1 & $1.74 \mathrm{E}-03$ & 3.80 & 2.80 & 0.26 & -0.80 & -2.25 & -1.29 & -2.19 & -0.11 \\
\hline J2-223-1-R1 & $1.74 \mathrm{E}-03$ & 3.40 & 2.83 & 0.53 & -0.48 & -1.73 & -0.45 & -2.11 & -0.01 \\
\hline J2-437-3-R2 & $1.64 \mathrm{E}-03$ & 2.30 & 2.73 & 0.95 & -3.98 & -4.00 & -0.45 & -2.53 & 0.61 \\
\hline J2-442-4-R2 & $1.70 \mathrm{E}-03$ & 3.80 & 2.81 & 0.40 & -2.29 & -4.51 & -1.98 & -1.86 & -0.26 \\
\hline J2-449-5-R1 & $1.73 \mathrm{E}-03$ & 4.00 & 2.74 & 0.44 & -3.58 & -4.31 & -1.00 & -1.63 & -0.98 \\
\hline J2-449-6-R1 & $1.69 \mathrm{E}-03$ & 3.90 & 2.73 & 0.59 & -1.93 & -4.84 & -1.23 & -1.92 & 0.16 \\
\hline $\mathrm{J} 2-450-3-\mathrm{R} 1$ & $1.71 \mathrm{E}-03$ & 3.70 & 2.74 & 0.52 & -4.19 & -3.93 & -1.16 & -1.18 & 0.72 \\
\hline J2-613-16-R1 & $1.50 \mathrm{E}-03$ & 3.30 & 2.55 & -1.93 & 1.24 & 0.13 & -1.39 & -2.44 & 0.33 \\
\hline J2-815-5-R1 & $1.74 \mathrm{E}-03$ & 4.00 & 2.74 & 0.57 & -3.05 & -4.51 & -0.72 & -1.84 & 0.09 \\
\hline
\end{tabular}

\begin{tabular}{|c|c|c|c|c|c|c|c|c|c|}
\hline \multicolumn{10}{|c|}{ Output from pca (SIMS and fluid data) } \\
\hline Correlation Coefficients & $1 / \mathrm{K}$ & $\mathrm{pH}$ & $\log (\mathrm{mmol} \mathrm{Cl})$ & $\log ($ umol H2S $)$ & $\begin{array}{r}\log (59 \mathrm{Co} / \\
63 \mathrm{Cu} 160) \\
\end{array}$ & $\begin{array}{r}\log (60 \mathrm{Ni} / \\
63 \mathrm{Cu} 160) \\
\end{array}$ & $\begin{array}{r}\log (69 \mathrm{Ga} / \\
63 \mathrm{Cu} 160) \\
\end{array}$ & $\begin{array}{c}\log (109 A g / \\
63 \text { Cu160) }\end{array}$ & $\begin{array}{r}\log (115 \ln / \\
63 \text { Cu160) } \\
\end{array}$ \\
\hline $1 / \mathrm{K}$ & 1.00 & 0.35 & 0.55 & 0.31 & -0.51 & -0.54 & 0.23 & 0.30 & -0.23 \\
\hline $\mathrm{pH}$ & 0.35 & 1.00 & 0.17 & -0.32 & 0.21 & -0.08 & -0.65 & 0.33 & -0.69 \\
\hline $\log (\mathrm{mmol} \mathrm{Cl})$ & 0.55 & 0.17 & 1.00 & 0.48 & -0.03 & -0.20 & -0.03 & 0.40 & -0.26 \\
\hline $\log ($ umol H2S) & 0.31 & -0.32 & 0.48 & 1.00 & -0.41 & -0.37 & 0.37 & 0.11 & 0.14 \\
\hline $\log (59 \mathrm{Co} / 63 \mathrm{Cu} 160)$ & -0.51 & 0.21 & -0.03 & -0.41 & 1.00 & 0.86 & -0.51 & -0.12 & -0.31 \\
\hline $\log (60 N i / 63 C u 160)$ & -0.54 & -0.08 & -0.20 & -0.37 & 0.86 & 1.00 & -0.31 & -0.28 & -0.08 \\
\hline $\log (69 \mathrm{Ga} / 63 \mathrm{Cu} 160)$ & 0.23 & -0.65 & -0.03 & 0.37 & -0.51 & -0.31 & 1.00 & -0.11 & 0.60 \\
\hline $\log (109 \mathrm{Ag} / \mathrm{63Cu160})$ & 0.30 & 0.33 & 0.40 & 0.11 & -0.12 & -0.28 & -0.11 & 1.00 & -0.08 \\
\hline $\log (115 \ln / 63 C u 160)$ & -0.23 & -0.69 & -0.26 & 0.14 & -0.31 & -0.08 & 0.60 & -0.08 & 1.00 \\
\hline Pearson $\mathrm{P}$ value & $1 / \mathrm{K}$ & $\mathrm{pH}$ & $\log (\mathrm{mmol} \mathrm{Cl})$ & $\log (\mathrm{umol} \mathrm{H} 2 \mathrm{~S})$ & $\begin{array}{l}\log (59 \mathrm{Co} / \\
63 \text { Cu160) }\end{array}$ & $\begin{array}{l}\log (60 \mathrm{Ni} / \\
63 \mathrm{Cu} 160)\end{array}$ & $\begin{array}{r}\log (69 \mathrm{Ga} / \\
63 \mathrm{Cu} 160)\end{array}$ & $\begin{array}{c}\log (109 \mathrm{Ag} / \\
63 \mathrm{Cu} 160)\end{array}$ & $\begin{array}{r}\log (115 \ln / \\
63 \text { Cu160) }\end{array}$ \\
\hline $1 / K$ & 1.00 & 0.14 & 0.01 & 0.20 & 0.03 & 0.02 & 0.35 & 0.21 & 0.33 \\
\hline $\mathrm{pH}$ & 0.14 & 1.00 & 0.48 & 0.18 & 0.39 & 0.73 & 0.00 & 0.16 & 0.00 \\
\hline $\log (\mathrm{mmol} \mathrm{Cl})$ & 0.01 & 0.48 & 1.00 & 0.04 & 0.89 & 0.42 & 0.91 & 0.09 & 0.28 \\
\hline $\log (\mathrm{umol} \mathrm{H} 2 \mathrm{~S})$ & 0.20 & 0.18 & 0.04 & 1.00 & 0.08 & 0.12 & 0.12 & 0.66 & 0.56 \\
\hline $\log (59 \mathrm{Co} / 63 \mathrm{Cu} 16 \mathrm{O})$ & 0.03 & 0.39 & 0.89 & 0.08 & 1.00 & 0.00 & 0.02 & 0.62 & 0.20 \\
\hline $\log (60 \mathrm{Ni} / 63 \mathrm{Cu} 16 \mathrm{O})$ & 0.02 & 0.73 & 0.42 & 0.12 & 0.00 & 1.00 & 0.20 & 0.25 & 0.73 \\
\hline $\log (69 \mathrm{Ga} / 63 \mathrm{Cu} 160)$ & 0.35 & 0.00 & 0.91 & 0.12 & 0.02 & 0.20 & 1.00 & 0.66 & 0.01 \\
\hline $\log (109 \mathrm{Ag} / \mathrm{63Cu160)}$ & 0.21 & 0.16 & 0.09 & 0.66 & 0.62 & 0.25 & 0.66 & 1.00 & 0.73 \\
\hline $\log (115 \ln / 63 \mathrm{Cu} 160)$ & 0.33 & 0.00 & 0.28 & 0.56 & 0.20 & 0.73 & 0.01 & 0.73 & 1.00 \\
\hline Principle Components & pca-1 & pca-2 & pca-3 & pca-4 & pca-5 & рса- 6 & pca-7 & pса-8 & pca-9 \\
\hline $1 / K$ & 0.00 & 0.00 & 0.00 & 0.00 & 0.00 & 0.00 & 0.00 & 0.00 & 1.00 \\
\hline $\mathrm{pH}$ & 0.04 & -0.52 & -0.11 & 0.03 & 0.15 & 0.11 & 0.83 & 0.00 & 0.00 \\
\hline $\log (\mathrm{mmol} \mathrm{Cl})$ & 0.00 & -0.02 & 0.08 & 0.02 & 0.02 & 0.02 & 0.00 & 1.00 & 0.00 \\
\hline $\log (\mathrm{umol} \mathrm{H} 2 \mathrm{~S})$ & -0.13 & 0.13 & 0.91 & -0.15 & 0.07 & -0.22 & 0.23 & -0.06 & 0.00 \\
\hline $\log (59 \mathrm{Co} / 63 \mathrm{Cu} 160)$ & 0.74 & -0.16 & 0.24 & 0.42 & -0.43 & -0.01 & -0.04 & -0.02 & 0.00 \\
\hline $\log (60 \mathrm{Ni} / 63 \mathrm{Cu} 16 \mathrm{O})$ & 0.63 & 0.41 & -0.08 & -0.39 & 0.50 & 0.10 & 0.12 & 0.01 & 0.00 \\
\hline $\log (69 \mathrm{Ga} /$ 63Cu160) & -0.14 & 0.44 & 0.10 & 0.13 & -0.26 & 0.80 & 0.23 & -0.01 & 0.00 \\
\hline $\log (109 \mathrm{Ag} / \mathrm{63Cu} 160)$ & -0.04 & -0.18 & 0.19 & 0.56 & 0.68 & 0.28 & -0.27 & -0.05 & 0.00 \\
\hline $\log (115 \ln /$ 63Cu160) & -0.08 & 0.55 & -0.21 & 0.56 & 0.07 & -0.46 & 0.35 & 0.03 & 0.00 \\
\hline & pca-1 & pca-2 & pca-3 & pca-4 & pca-5 & pсa-6 & pca-7 & pca-8 & pca-9 \\
\hline $\begin{array}{l}\text { Contribution to total } \\
\text { variance }(\%)\end{array}$ & 71.16 & 14.55 & 4.72 & 3.86 & 2.73 & 1.98 & 0.96 & 0.04 & 0.00 \\
\hline
\end{tabular}




\section{Chapter 4}

\section{Trace Element Proxies of Hydrothermal Fluid pH and Metal Content Based on Sample Pairs of Seafloor Hydrothermal Fluids and Chalcopyrite Lining Black Smoker Chimneys}

\section{INTRODUCTION}

The metal sulfide linings of black smoker chimney deposits that form in association with focused vents of high-temperature seafloor hydrothermal fluids provide a unique opportunity to sample paired mineral and fluid samples in order to quantitatively investigate the relationships between mineral trace element chemistry and the temperature and chemistry of deposit-forming hydrothermal fluids. Especially interesting is the opportunity to sample and measure the major and trace metal contents of venting hydrothermal fluids, an aspect of hydrothermal fluid chemistry that is unavailable for inactive or fossil hydrothermal systems. This paper presents new data on the major and trace metal chemistry of hydrothermal fluids from the Kilo Moana, Tahi Moana-1, ABE, Tu'i Malila, and Mariner vent fields on the Eastern Lau Spreading Center. These new data, as well as existing data on major element and trace metal chemistry in seafloor hydrothermal fluids, are then combined with trace metal concentration data for chalcopyrite that lines related black smoker chimneys (from Chapter 3 of this thesis) to provide quantitative insights into the partitioning of trace metals from vent fluids into solids. Furthermore, this comparison allows for investigation of the extents to which these trace element signatures in black smoker chimney linings can be used as proxies for hydrothermal fluid chemistry, including $\mathrm{pH}$ and trace metal concentrations. 
Table 1. (opposite)

Black smoker chimney and hydrothermal fluid samples used in this study, from the southern East Pacific Rise (S. EPR), the Main Endeavour Field (MEF) on the Juan de Fuca Ridge (JdF), the Mid-Cayman Rise (MCR), the Manus Spreading Center (MSC), the PACMANUS (PAC) and $\mathrm{SuSu}$ Knolls ( $\mathrm{SuSu}$ ) areas of the Eastern Manus Basin (EMB) and the Eastern Lau Spreading Center (ELSC). Vent fields are hosted in basalt, enriched mid-ocean ridge basalts (E-MORB) or felsic host rocks including andesites, rhyolites, and dacites. Chimneys are lined with chalcopyrite (cp), cubanite (cb), co-deposited chalcopyrite and wurtzite (cp/wz), or co-deposited chalcopyrite and pyrite (cp/py). Samples from vent fields thought to be influenced by acidic magmatic volatiles are enclosed in boxes. All sample and fluid names are as labeled in the original references and sample archive. References for fluid chemistry are as follows: S. EPR (K.L. Von Damm, unpublished data), MEF (Seyfried et al., 2003), MCR (McDermott, 2015), EMB (Reeves et al., 2011), ELSC (Mottl et al., 2011; Seewald, 2017). References from host-rock lithology are: S. EPR ( Krasnov et al., 1997), Lucky Strike (Langmuir et al., 1997), MEF (Karsten et al., 1990), MCR (Elthon et al., 1995), EMB (Binns and Scott, 1993; Kamenetsky et al., 2001; Sinton et al, 2003), ELSC (Jenner et al., 1987; Frenzel et al., 1990; Vallier et al., 1991; Fouquet et al., 1993; Martinez and Taylor, 2002; Langmuir et al., 2006; Bézos et al., 2009; Escrig et al., 2009) 
Table 1

\begin{tabular}{|c|c|c|c|c|c|c|c|c|c|c|c|}
\hline Sample ID & $\begin{array}{l}\text { Fluid } \\
\text { Pair } \\
\end{array}$ & Year & $\begin{array}{l}\text { Vent } \\
\text { Field }\end{array}$ & Region & Lithology & $\begin{array}{l}\text { Lining } \\
\text { Mineral }\end{array}$ & $\begin{array}{c}\mathrm{T} \\
\left({ }^{\circ} \mathrm{C}\right) \\
\end{array}$ & $\begin{array}{c}\mathrm{pH} \\
\text { (at } 25^{\circ} \mathrm{C} \text { ) } \\
\end{array}$ & $\begin{array}{c}\mathrm{pH} \\
\text { (in situ) } \\
\end{array}$ & $\begin{array}{c}\mathrm{Cl} \\
(\mathrm{mmol} / \mathrm{kg})\end{array}$ & $\begin{array}{c}\mathrm{H}_{2} \mathrm{~S} \\
(\mathrm{mmol} / \mathrm{kg}) \\
\end{array}$ \\
\hline Alv3299-6-1 & Hobbes & 1998 & 1734 'S & S. EPR & basalt & $\mathrm{cp}$ & 349 & 3.2 & & 481 & 9.0 \\
\hline Alv3288-5-1a & Simon & 1998 & $1737^{\prime} \mathrm{S}$ & S. EPR & basalt & $\mathrm{cp}$ & 337 & 3.4 & & 751 & 3.5 \\
\hline Alv3296-2-2a & Maggie & 1998 & $1737^{\prime} S$ & S. EPR & basalt & $\mathrm{cp}$ & & & & & \\
\hline Alv3296-3 & Wally & 1998 & $1737^{\prime} \mathrm{S}$ & S. EPR & basalt & $\mathrm{cp}$ & 314 & 3.4 & & 752 & 6.5 \\
\hline Alv3296-5-1a & Homer & 1998 & 1737 'S & S. EPR & basalt & $c p$ & 347 & 3.3 & & 591 & 3.7 \\
\hline Alv1931 & & 1987 & MEF & $\mathrm{JdF}$ & E-MORB & $\mathrm{cp}$ & & & & & \\
\hline Alv3474-3-1 & Sully99 & 1999 & MEF & $\mathrm{JdF}$ & E-MORB & $c p$ & 379 & 3.6 & 4.3 & 39.0 & 20 \\
\hline Alv3480-4 & & 1999 & MEF & $\mathrm{JdF}$ & E-MORB & $\mathrm{cp}$ & & & & & \\
\hline J2-613-16-R1 & BB5 & 2013 & Beebe / Piccard & MCR & basalt & $\mathrm{cb}$ & 395 & 3.0 & 5.0 & 351 & 0.0 \\
\hline J2-207-1-R1 & VW1 & 2006 & Vienna Woods & MSC & basalt & $\mathrm{cp} / \mathrm{wz}$ & 282 & 4.4 & 5.1 & 691 & 1.4 \\
\hline J2-210-7-R2 & & 2006 & Fenway & EMB, PAC & felsic & $\mathrm{cp}$ & & & & & \\
\hline J2-216-16-R1 & F3 & 2006 & Fenway & EMB, PAC & felsic & $\mathrm{cp}$ & 358 & 2.7 & 3.9 & 562 & 18.8 \\
\hline J2-214-3-R1 & SM3 & 2006 & Satanic Mills & EMB, PAC & felsic & $\mathrm{cp}$ & 288 & 2.5 & 3.0 & 503 & 10.2 \\
\hline J2-208-1-R1 & RMR1 & 2006 & Roman Ruins & EMB, PAC & felsic & $\mathrm{cp}$ & 314 & 2.3 & 2.8 & 632 & 7.5 \\
\hline J2-213-6-R1 & RGR1 & 2006 & Roger's Ruins & EMB, PAC & felsic & $\mathrm{cp}$ & 320 & 2.7 & & 648 & 3.6 \\
\hline J2-217-2-R1 & SZ1 & 2006 & Suzette & EMB, SuSu & felsic & $\mathrm{cp}$ & 303 & 3.8 & 4.2 & 626 & 1.8 \\
\hline J2-217-10-R1 & SZ2 & 2006 & Suzette & EMB, SuSu & felsic & $\mathrm{cp}$ & 274 & 3.6 & 4.0 & 684 & 1.8 \\
\hline J2-219-2-R1 & & 2006 & Suzette & EMB, SuSu & felsic & $\mathrm{cp}$ & & & & & \\
\hline J2-223-1-R1 & NS3 & 2006 & North Su & EMB, SuSu & felsic & $\mathrm{cp}$ & 300 & 3.4 & 3.9 & 673 & 3.4 \\
\hline \multirow[t]{4}{*}{ J2-227-10-R1 } & & 2006 & North Su & EMB, SuSu & felsic & $\mathrm{cp}$ & & & & & \\
\hline & KM9 & 2009 & Kilo Moana & ELSC & basalt & $\mathrm{cb}$ & 304 & 4.1 & & & 3.5 \\
\hline & TMo1 & 2009 & Tahi Moana 1 & ELSC & felsic & & 306 & 3.7 & & & 3.1 \\
\hline & TMo2 & 2009 & Tahi Moana 1 & ELSC & felsic & & 298 & 3.9 & & & 4.1 \\
\hline J2-450-3-R1 & TMo5 & 2009 & Tahi Moana 1 & ELSC & felsic & $\mathrm{cp} / \mathrm{wz}$ & 310 & 3.7 & 4.6 & 555 & 3.3 \\
\hline J2-449-6-R1 & A10 & 2009 & $\mathrm{ABE}$ & ELSC & felsic & $\mathrm{cp} / \mathrm{py}$ & 317 & 3.9 & 5.1 & 543 & 3.9 \\
\hline \multirow[t]{4}{*}{ J2-449-5-R1 } & A11 & 2009 & $A B E$ & ELSC & felsic & $\mathrm{cp} / \mathrm{wz}$ & 306 & 4.0 & 5.2 & 552 & 2.7 \\
\hline & $\mathrm{A} 13$ & 2015 & $\mathrm{ABE}$ & ELSC & felsic & & 283 & 4.3 & & & 3.5 \\
\hline & A14 & 2015 & ABE & ELSC & felsic & & 300 & 4.0 & & & 3.7 \\
\hline & A15 & 2015 & ABE & ELSC & felsic & & 290 & 4.4 & & & 3.1 \\
\hline J2-815-5-R1 & A16 & 2015 & $\mathrm{ABE}$ & ELSC & felsic & $\mathrm{cp} / \mathrm{wz}$ & 300 & 4.0 & 5.2 & 546 & 3.7 \\
\hline \multirow[t]{4}{*}{$J 2-442-4-R 2$} & TM11 & 2009 & Tu'i Malila & ELSC & felsic & $\mathrm{cp} / \mathrm{py}$ & 315 & 3.8 & 4.5 & 653 & 2.8 \\
\hline & TM12 & 2009 & Tu'i Malila & ELSC & felsic & & 284 & 4.2 & & & 2.8 \\
\hline & TM13 & 2015 & Tu'i Malila & ELSC & felsic & & 262 & 3.9 & & & 2.4 \\
\hline & TM14 & 2015 & Tu'i Malila & ELSC & felsic & & 290 & 4.0 & & & 2.3 \\
\hline \multirow[t]{4}{*}{ J2-819-4-R2 } & TM15 & 2015 & Tu'i Malila & ELSC & felsic & $\mathrm{cp} / \mathrm{wz}$ & 269 & 3.9 & & 598 & 2.3 \\
\hline & TM16 & 2015 & Tu'i Malila & ELSC & felsic & & 251 & 3.9 & & & 2.0 \\
\hline & TM17 & 2015 & Tu'i Malila & ELSC & felsic & & 258 & 3.9 & & & 2.1 \\
\hline & TM19 & 2015 & Tu'i Malila & ELSC & felsic & & 232 & 4.2 & & & 2.2 \\
\hline \multirow{5}{*}{ J2-437-3-R2 } & MA8 & 2009 & Mariner & ELSC & felsic & & 359 & 2.4 & & & 17.8 \\
\hline & MA9 & 2009 & Mariner & ELSC & felsic & $\mathrm{cp}$ & 338 & 2.4 & 3.2 & 541 & 8.9 \\
\hline & MA11 & 2009 & Mariner & ELSC & felsic & & 328 & 2.2 & & & 11.8 \\
\hline & MA12 & 2009 & Mariner & ELSC & felsic & & 350 & 2.3 & & & 10.8 \\
\hline & MA14 & 2015 & Mariner & ELSC & felsic & & 319 & 2.4 & & & 3.7 \\
\hline \multirow[t]{5}{*}{ J2-817-4-R2 } & MA15 & 2015 & Mariner & ELSC & felsic & $\mathrm{cp}$ & 354 & 2.7 & 3.8 & 557 & 3.1 \\
\hline & MA17 & 2015 & Mariner & ELSC & felsic & & 362 & 2.8 & & & 17.5 \\
\hline & MA19 & 2015 & Mariner & ELSC & felsic & & 308 & 2.6 & & & 7.0 \\
\hline & MA20 & 2015 & Mariner & ELSC & felsic & & 344 & 2.7 & & & 8.8 \\
\hline & MA21 & 2015 & Mariner & ELSC & felsic & & 345 & 2.7 & & & 9.6 \\
\hline
\end{tabular}




\section{GEOLOGIC SETTINGS OF FLUIDS AND CHIMNEYS}

Vent fluids analyzed as part of this study are all from the Eastern Lau Spreading Center (ELSC, Fig. 1). Data for these vent fluids are combined with data for vent fluids from the Manus Basin, Juan de Fuca Ridge (Main Endeavour Field), and the Mid-Cayman Rise (Beebe / Piccard vent field) to encompass a range of hydrothermal system reaction zone conditions (lithology, temperature, pressure, presence/absence of magmatic volatiles; see Table 1).

Samples of hydrothermal vent fluids considered in this paper were collected from the Kilo Moana, Tahi Moana-1, ABE, Tu'i Malila, and Mariner vent fields on cruise TN236 (2009, R/V Thompson) and cruise RR1507 (2015, R/V Roger Revelle). Black smoker chimney linings were collected as sample pairs with hydrothermal fluid samples at the Tahi Moana-1, ABE, Tu'i Malila, and Mariner vent fields. These black smoker chimney linings are composed of massive chalcopyrite \pm euhedral wurtzite or pyrite. Along the length of the ELSC, there is a lithologic transition from tholeiitic back-arc-basin basalt in the north to mixtures of basaltic andesite, andesite, and rhyodacite in the south (Jenner et al., 1987; Frenzel et al., 1990; Vallier et al., 1991; Fouquet et al., 1993; Martinez and Taylor, 2002; Langmuir et al., 2006; Fretzdorff et al., 2006; Bézos et al., 2009; Escrig et al., 2009; Sleeper and Martinez, 2014). The Kilo Moana vent field is located in the north and is associated with basalt, the Tahi Moana-1 and ABE vent fields occur in a geomorphologic and lithologic transition zone, while the Tu'i Malila and Mariner vent fields occur on the Valu Fa Ridge where host rocks are more felsic in composition (Fig. 1; Mottl et al., 2011). 
Figure 1. Map of vent field locations along the Eastern Lau Spreading Center. Active vents in white have been confirmed to exist by submersible while active vents in red are inferred to exist based on water column chemistry. Vent field locations, activity, and confirmed status are as listed in the InterRidge database (Beulieu et al., 2010). Background bathymetric data are from Taylor (2006) accessed through GeoMapApp (http://www.geomapapp.org/). Data have been rendered using ArcGIS, version 10.2.2.

\section{Seafloor Hydrothermal Fields on the Eastern Lau Spreading Center}

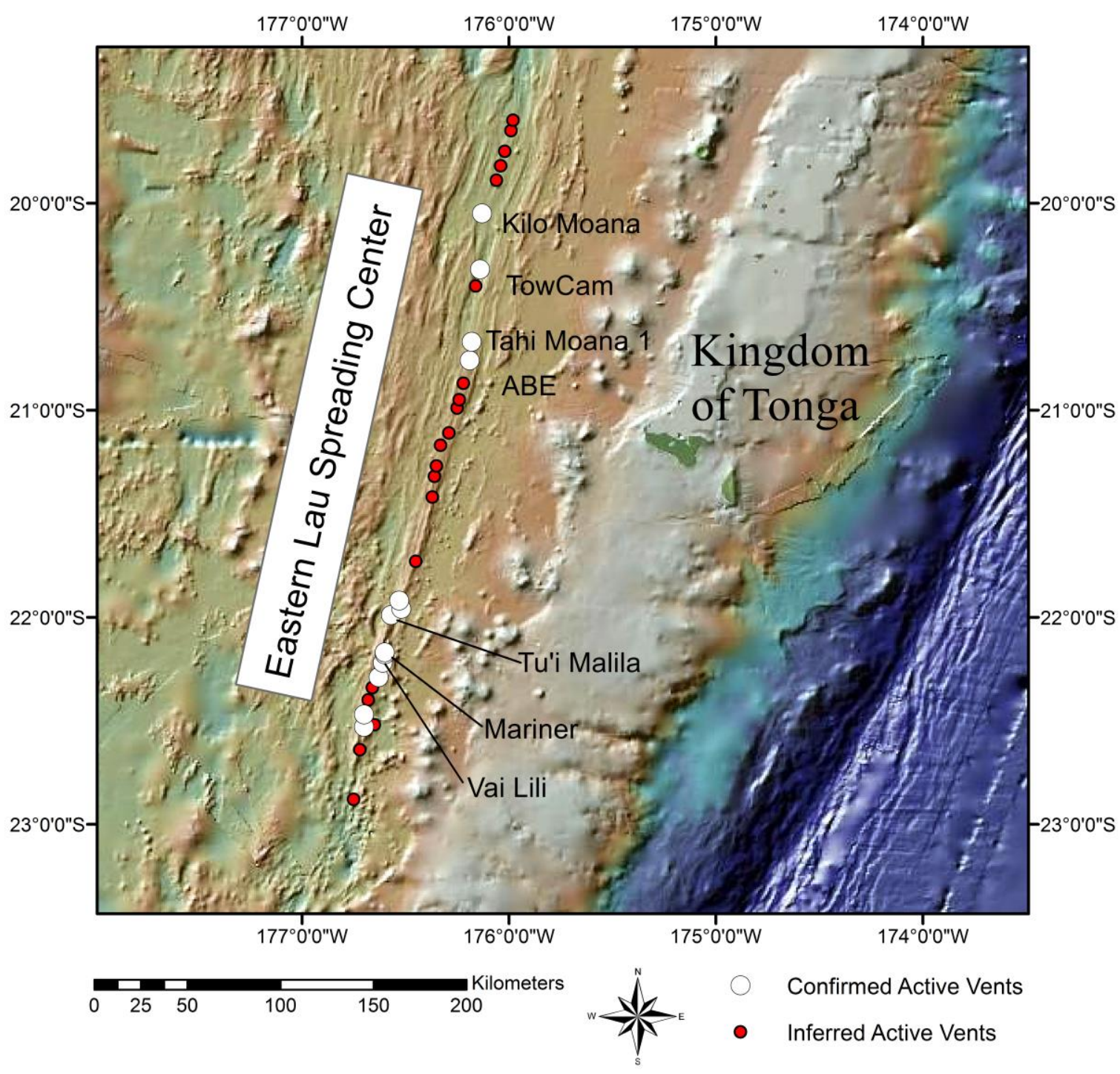


Other existing vent fluid data considered are from the Manus Basin, located in the Bismarck Sea within the territorial waters of Papua New Guinea (Fig. 2). The complex back-arc extension and spreading centers of the Manus Basin are dynamically linked to the New Britain Subduction Zone (Taylor, 1979; Davies et al., 1987; Martinez and Taylor, 1996). Near the center of the Manus Basin, dominantly basaltic lavas erupt along the Manus Spreading Center (Both et al., 1986; Sinton et al., 2003), which hosts the Vienna Woods vent field. Toward the eastern end of the Manus Basin, andesite-rhyolite lavas erupt along a series of en echelon neovolcanic ridges that accommodate rifting and extension of previously deposited crust associated with the New Ireland arc (Sinton et al., 2003; Martinez and Taylor, 2006). Hydrothermal venting occurs on the Pual Ridge in the PACMANUS area and at SuSu Knolls, where black smoker and additional acid-sulfate fluids vent from the tops and sides of three volcanic domes: Suzette, North Su, and South Su (Craddock, 2009; Reeves et al., 2011; Seewald et al., 2015). The focus of this paper is exclusively on black smoker fluids. The low pH of vent fluids at the PACMANUS and SuSu Knolls vent fields are attributed to buffering from argillic alteration assemblages and/or the addition of $\mathrm{SO}_{2}$-rich acidic magmatic volatiles (Reeves et al., 2011; Seewald et al., submitted). In addition, the variability of base metal concentrations in some of these fluids is attributed to remobilization of previously deposited metal sulfides (e.g., Roman Ruins and Roger's Ruins), which leads to locally enriched concentrations of $\mathrm{Zn}, \mathrm{Pb}, \mathrm{Cd}, \mathrm{Ag}, \mathrm{As}$, and Sb in venting hydrothermal fluids (Craddock, 2009). The black smoker chimney lining from the Vienna Woods vent field examined in this study is composed of intergrown euhedral wurtzite and chalcopyrite. Black smoker chimney linings from the PACMANUS and SuSu Knolls vent fields are all composed of massive chalcopyrite. 
Figure 2. Map of vent field locations in the Manus Basin with inset highlighting vent field locations in the Eastern Manus Basin.Active vents in white and inactive vents in black have been confirmed to exist by submersible while active vents in red are inferred to exist based on water column chemistry. Vent field locations, activity, and confirmed status are as listed in the InterRidge database (Beaulieu et al., 2010). Background bathymetric data are from Taylor (2006) accessed through GeoMapApp (http://www.geomapapp.org/). Data have been rendered using ArcGIS, version 10.2.2.

\section{Seafloor Hydrothermal Fields of the Manus Basin}

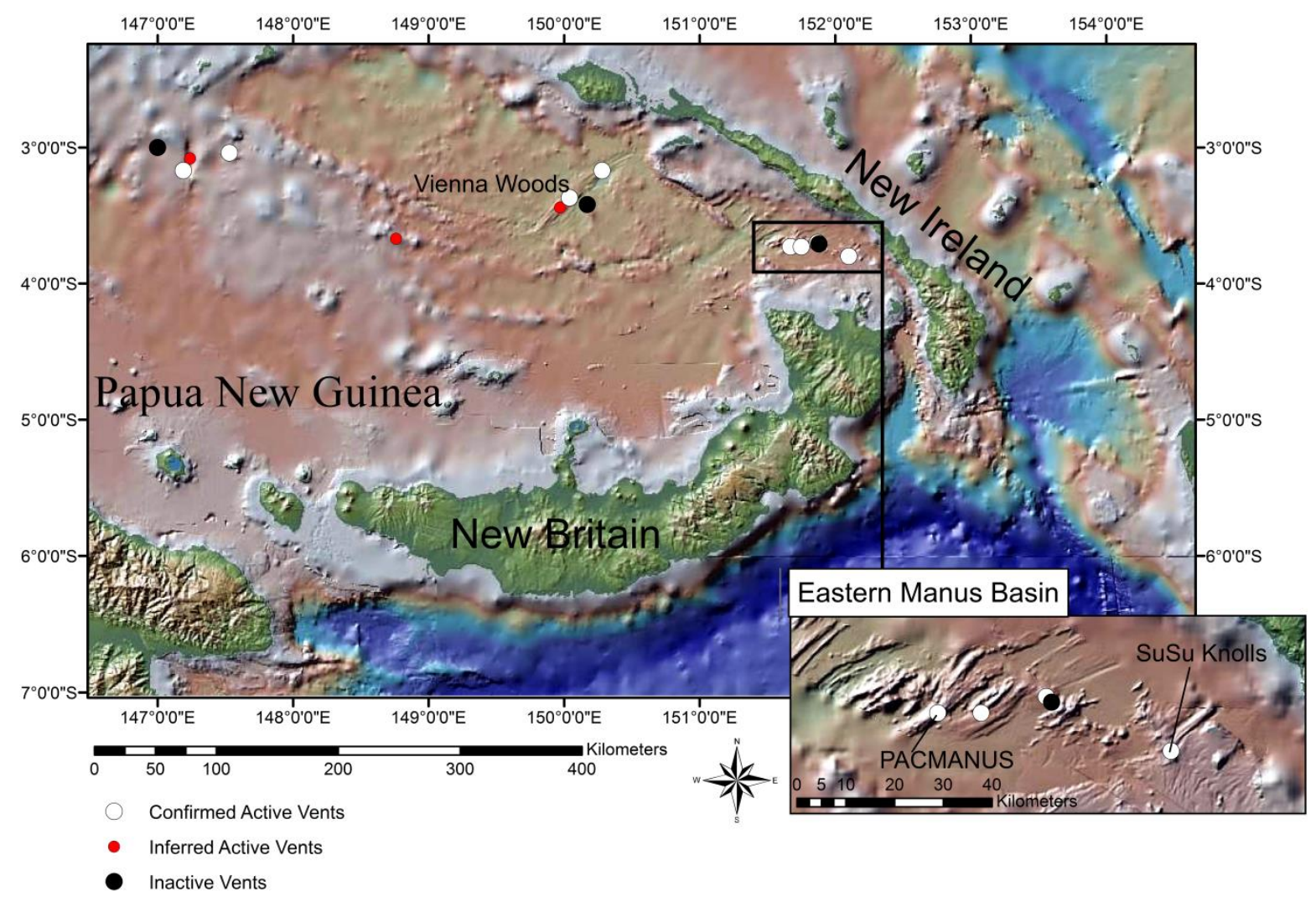


Additional black smoker chimney samples examined in this study include those collected from vent fields between $17^{\circ} 34^{\prime} \mathrm{S}$ and $17^{\circ} 37^{\prime} \mathrm{S}$ on the southern East Pacific Rise, the Main Endeavour Field on the Juan de Fuca Ridge, and the Beebe / Piccard vent field on the MidCayman Rise. Inclusion of these samples adds to the diversity of geologic settings represented in the sample suite, specifically ultrafast- (southern East Pacific Rise), intermediate- (Juan de Fuca Ridge), and ultraslow- (Mid-Cayman Rise) spreading mid-ocean ridges. Existing data for fluid pairs of samples from the southern East Pacific Rise (K.L. Von Damm, unpublished data) do not include trace element concentrations. Data for hydrothermal vent fluids from the and Main Endeavour Field from 1999 and the Beebe / Piccard vent field in 2012 are more extensive and include data for $\mathrm{Ag}, \mathrm{Co}, \mathrm{Cu}, \mathrm{Fe}$, and $\mathrm{Ni}$ for vent fluids at the Main Endeavour Field and data for $\mathrm{Co}, \mathrm{Cu}$, and Fe for fluids from the Beebe / Piccard vent field (Seyfried et al., 2003; McDermott, 2015).

The three samples from the Main Endeavour Field were collected prior to (Alv1931) and immediately following (Alv3474-3-1 and Alv3480-4) the seismic swarm and inferred event that occurred in 1999 (Johnson et al., 2000). This event led to changes in the temperature and chemistry of hydrothermal fluids venting at the Main Endeavour Field including a temporary decrease in chlorinity and $\mathrm{pH}\left(\right.$ at $25^{\circ} \mathrm{C}$ ) and an increase in temperature (Seyfried et al., 2003). 


\section{METHODS}

\subsection{Sample Collection}

Hydrothermal fluid samples were collected from active hydrothermal vents along the Eastern Lau Spreading Center in 2009 (TN236) and 2015 (RR1507) using the ROV Jason II. One to three fluid samples from each vent were collected in $150 \mathrm{~mL}$ isobaric gas-tight (IGT) samplers (Seewald et al., 2002). Temperatures were measured with a thermocouple mounted on the IGT sampler inlet snorkel. Following shipboard recovery, fluid samples were analyzed for $\mathrm{pH}$ using a $\mathrm{Ag} / \mathrm{AgCl}$ combination reference electrode that was calibrated daily. Aliquots for major element and trace metal analysis were transferred to acid-washed high-density polyethylene (HDPE) Nalgene ${ }^{\mathrm{TM}}$ bottles. Aliquots for trace metal analysis were acidified with analytical-grade Optima ${ }^{\mathrm{TM}} \mathrm{HCl}$ prior to storage. In many fluid samples, a precipitate "dregs" fraction formed upon initial collection and cooling of the sample. This was recovered from the inside of the IGT sampling bottle and collected on a $0.22 \mu \mathrm{m}$ pore-size, $44 \mathrm{~mm}$ diameter Nylon filter by rinsing with Milli-Q filtered water and high-purity acetone.

\subsection{Digestion of Dregs and Filter Fractions}

Dissolved aliquots of hydrothermal fluid samples intended for minor and trace element analysis by inductively coupled plasma mass spectrometry were filtered into HDPE Nalgene ${ }^{\mathrm{TM}}$ bottles through $0.22 \mu \mathrm{m}$ pore-size, $22 \mathrm{~mm}$ diameter Nuclepore ${ }^{\circledR}$ nylon filters. This was done to remove additional precipitates (a.k.a. "filter" fraction) that might have formed from the "dissolved" fraction still remaining in solution during the time between shipboard collection and laboratory analysis. Syringes, filters, filter units, and handling equipment were all acid-cleaned 
with $5 \mathrm{wt} \%$ analytical grade Optima ${ }^{\circledR} \mathrm{HNO}_{3}$ (Fisher Scientific) prepared by dilution in Milli-Q filtered water. Visible particles sticking to the sides of laboratory vessels were transferred with the aid of Milli-Q filtered water and high-purity ethanol.

Precipitate filter and dregs fractions were digested in reverse aqua regia (three parts $16 \mathrm{~N}$ are analytical grade Optima ${ }^{\circledR} \mathrm{HNO}_{3}$ to 1 part $12 \mathrm{~N}$ are analytical grade Optima ${ }^{\circledR} \mathrm{HCl}$ by volume) in Savillex ${ }^{\mathrm{TM}}$ digestion vials and left at $70^{\circ} \mathrm{C}$ until dry. Samples were then brought up in $5 \mathrm{~mL}$ are analytical grade Optima ${ }^{\circledR} \mathrm{HNO}_{3}$ to remove any remaining $\mathrm{HCl}$ and left to dry a second time. Finally, these samples were brought up in $30 \mathrm{~mL} 5 \mathrm{wt} \%$ are analytical grade Optima ${ }^{\circledR} \mathrm{HNO}_{3}$ and stored in HDPE Nalgene ${ }^{\circledR}$ prior to further analysis.

\subsection{Major and Trace Element Analysis}

Analyses of major elements ( $\mathrm{Na}, \mathrm{K}, \mathrm{Li}, \mathrm{Ca}, \mathrm{Mg}$ ) were conducted on diluted samples of the "dissolved" fractions of hydrothermal fluids by ion chromatography (Seewald, 2017). Dilution factors were 1000x for $\mathrm{Na}$ and $\mathrm{Cl}$ and 150x for $\mathrm{K}, \mathrm{Li}$, and $\mathrm{Mg}$. Analyses of minor elements $(\mathrm{Fe}, \mathrm{Mn})$ and trace elements $(\mathrm{Cr}, \mathrm{Co}, \mathrm{Ni}, \mathrm{Cu}, \mathrm{Zn}, \mathrm{Ga}, \mathrm{Rb}, \mathrm{Mo}, \mathrm{Ag}, \mathrm{Cd}, \mathrm{In}, \mathrm{Sn}, \mathrm{Cs}, \mathrm{Au}$, and $\mathrm{Pb}$ ) were carried out on diluted samples of "dissolved" fractions and digested "filter" and “dregs" fractions using the Element 2 inductively coupled plasma mass spectrometer (ICP-MS) in the Plasma Mass Spectrometry Facility at the Woods Hole Oceanographic Institution. For the purposes of ICP-MS analysis, samples were diluted with $5 \mathrm{wt} \% \mathrm{HNO}_{3}$ containing $1 \mathrm{ng} / \mathrm{g}$ dilutions of Specpure ® plasma standard solutions as internal spikes. For samples collected in 2009, elements used as internal spikes were Sc, In, and Bi. For samples collected in 2015, Sc and Y spikes were used, which allowed for In analysis. Dilution factors were generally 1000x for minor 
elements and 100x for trace elements. Results from ICP-MS were calibrated against a six-point calibration curve composed of serial dilutions of Specpure ${ }^{\circledR}$ plasma solutions (for dregs and filter fractions: $\mathrm{Sb}, \mathrm{As}, \mathrm{Ba}, \mathrm{Bi}, \mathrm{Cd}, \mathrm{Ca}, \mathrm{Cr}, \mathrm{Co}, \mathrm{Cu}, \mathrm{Ga}, \mathrm{Ge}, \mathrm{Au}, \mathrm{Fe}, \mathrm{In}, \mathrm{Pb}, \mathrm{Mn}, \mathrm{Mo}, \mathrm{Ni}, \mathrm{Se}, \mathrm{Si}$, Ag, Sr, S, Te, Tl, Sn, V, Zn; for dissolved fractions: Sb, Al, Cd, Cr, Cs, Co, Cu, Au, Fe, Mn, Mo, $\mathrm{Ni}, \mathrm{Pb}, \mathrm{Rb}, \mathrm{Ag}, \mathrm{Tl}, \mathrm{U}, \mathrm{Zn})$ in $5 \mathrm{wt} \%$ analytical grade Optima ${ }^{\circledR}$ brand $\mathrm{HNO}_{3}$. For trace element analyses of dissolved fractions, $4.6807 \mathrm{mmol} / \mathrm{kg} \mathrm{NaCl}$ was added to the serial dilution series to approximate a matrix of 100x-diluted seawater. For dregs and filters samples collected in 2009, mass and machine settings for ICP-MS analyses were: $\underline{\operatorname{Sc} 45}, \underline{\operatorname{In} 115}, \mathrm{Ba} 137, \mathrm{Ba} 138, \mathrm{~Pb} 208$, $\underline{\text { Bi209 }}$ (low resolution $=300$ ); $\underline{\text { Sc45 }}, \mathrm{Mn55}$, Fe56, Co59, Ni60, Cu63, Cu65, Zn66, Zn68, Rb85, Mo96, Ag107, Ag109, In115, Cs133, Au197, Bi209 (medium resolution = 4000). For dregs and filters samples collected in 2015, mass and machine settings were: $\underline{\text { Sc45 }}$, $\underline{\text { 189 }}$, Ba137, Ba138, Pb208, Bi209 (low resolution = 300) ; $\underline{\mathrm{Sc} 45}, \mathrm{Cr52}, \mathrm{Mn55,}$ Fe56, Co59, Ni60, Cu63, Cu65, Zn66, Zn68, Ga69, Y89, Mo96, Ag107, Ag109, In115, Sn118, Ba137, Ba138, Au197, Bi209 (medium resolution $=4000)$. Underlining indicates elements used as internal spikes.

\subsection{Calculation of Trace Metal Concentrations in Hydrothermal Fluids}

In order to obtain the comprehensive chemical composition of a hydrothermal fluid, the dregs-, filter-, and dissolved fractions must each be considered in the analysis (Trefry et al., 1994; Metz and Trefry, 2000). This was done by calculating the contribution of each of these fractions to the original hydrothermal fluid sample for each element and summing the total. Following mathematical reconstitution of the original fluid samples, the compositions of endmember hydrothermal fluids prior to mixing are obtained by extrapolating to zero-Mg composition by 
projecting a linear regression forced through the composition of seawater through the measured sample compositions and onto the zero-Mg axis (Fig. 3A to 3D). This method follows the assumption that hydrothermal fluids contain negligible $\mathrm{Mg}$ and that measured $\mathrm{Mg}$ concentrations are thus attributable to entrainment of seawater prior to or during collection of samples (Von Damm et al., 1985). While this method in generally effective, significant uncertainty arise as mineral deposit particles can be accidentally entrained during sampling and recovery of dregs and filter fractions can be incomplete. In cases where multiple fluid samples have been taken from the same vent, the quality of fluid sampling can be confirmed if multiple samples extrapolate to similar zero-Mg endmember concentrations. Alternatively, likely sampling artifacts can be identified if multiple samples extrapolate to extremely different endmember compositions. In cases where only one fluid sample has been taken from a given vent, it may not be possible to determine the quality of fluid sampling. However, the likely quality of fluid sampling can in some cases be inferred by comparison with vent fluid samples from the same vent field that exhibit similar temperature, $\mathrm{pH}$, chlorinity, etc. 
Figure 3. Plots of measured concentrations of $\mathrm{Mg}$ vs. (A) $\mathrm{Mn},(\mathrm{B}) \mathrm{Fe},(\mathrm{C}) \mathrm{Cu}$, and (D) $\mathrm{Ag}$ in hydrothermal fluid samples from the Tu'i Malila vent field analyzed by considering dissolved fractions only (hollow symbols) and by combining analyses of dissolved, dregs, and filters fractions (filled symbols). Samples marked in red exhibit anomalously high concentrations of $\mathrm{Cu}$, $\mathrm{Fe}$, and $\mathrm{Ag}$, and are thought to be contaminated by entrained particles of SMS deposit materials. Following removal of these samples from the analysis, endmember concentrations of hydrothermal fluids are calculated by projection of a linear regression line forced through the composition of seawater onto the y-axis (i.e. zero-Mg).

Figure 3A

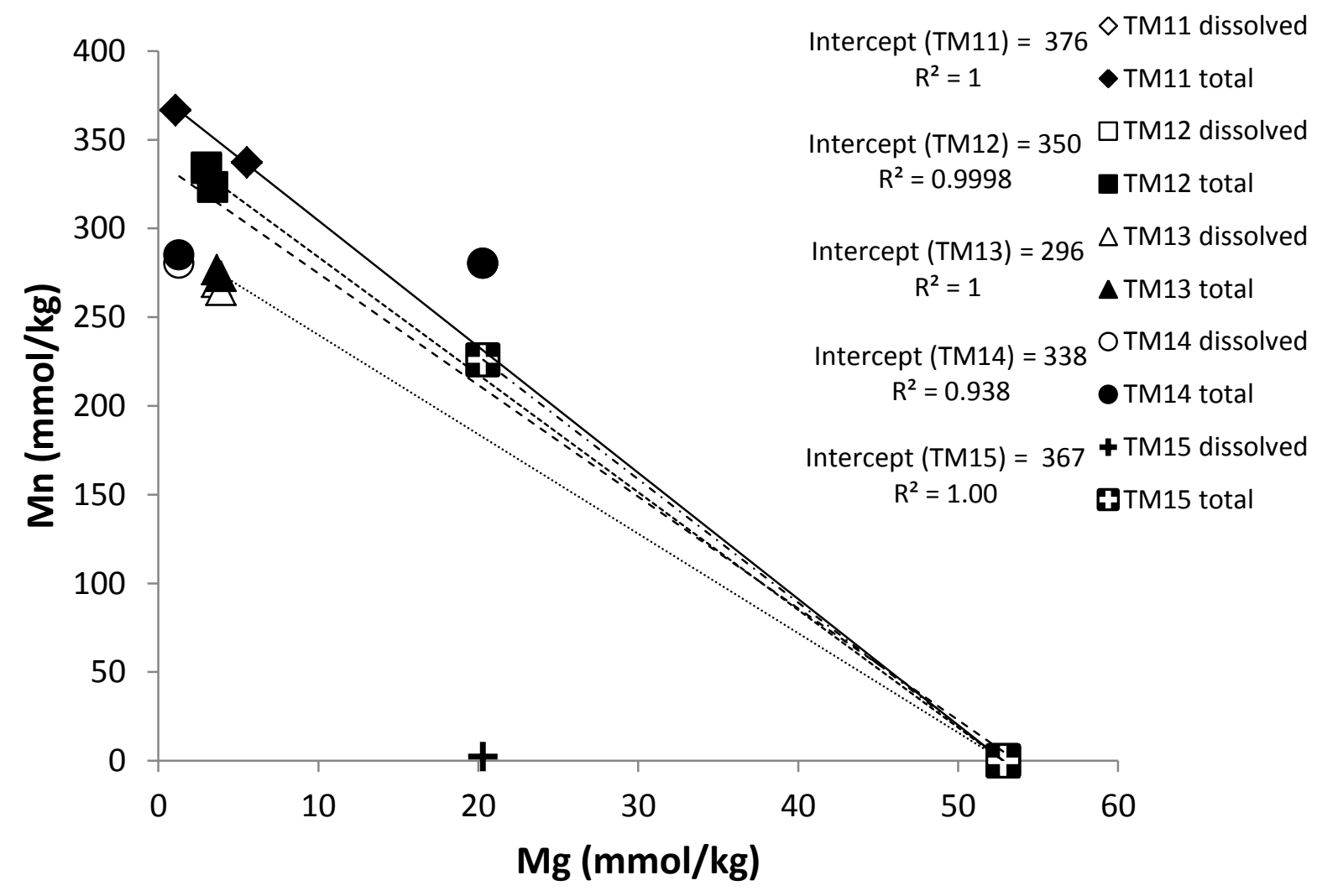




\section{Figure 3B}

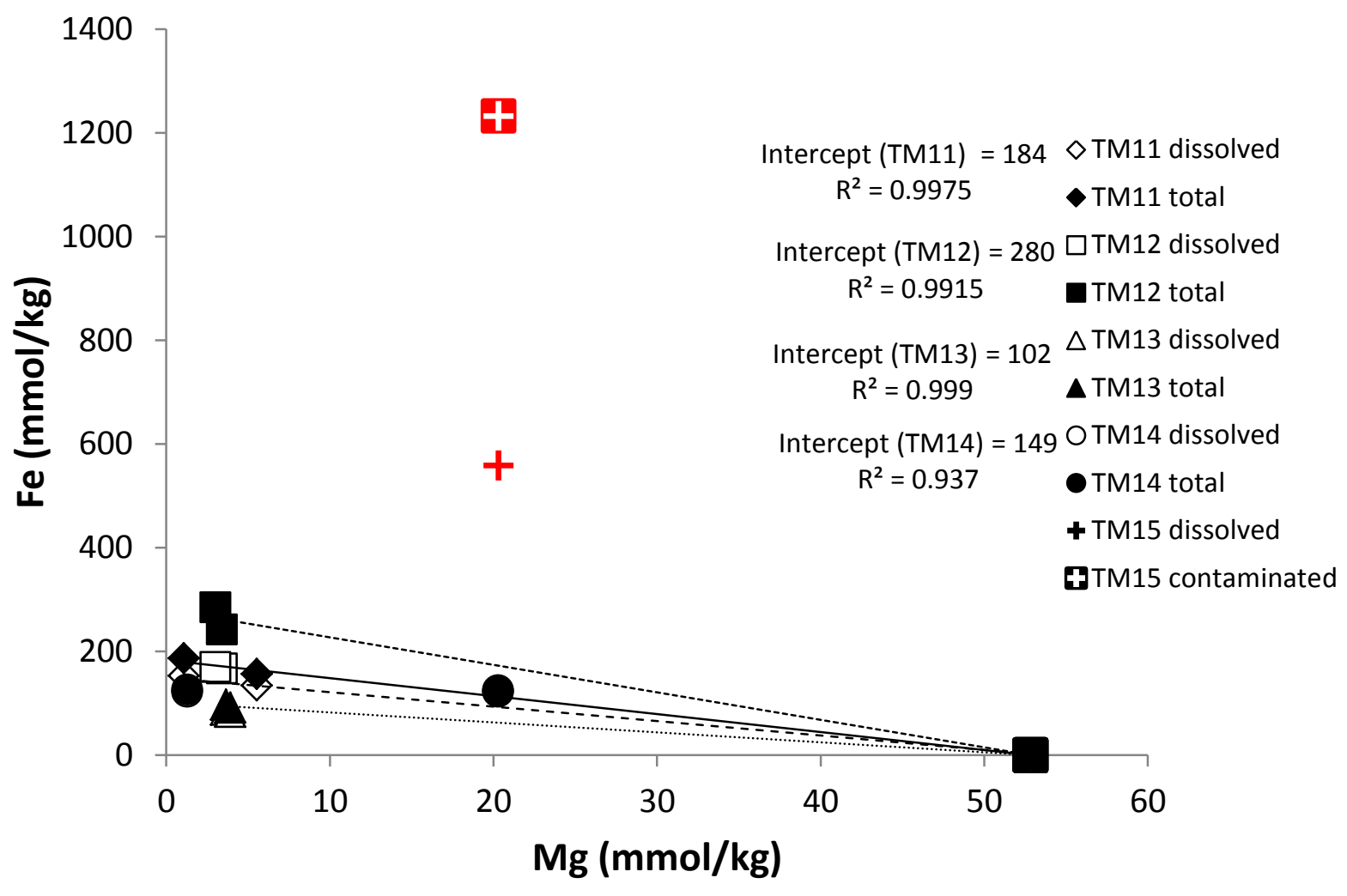




\section{Figure 3C}

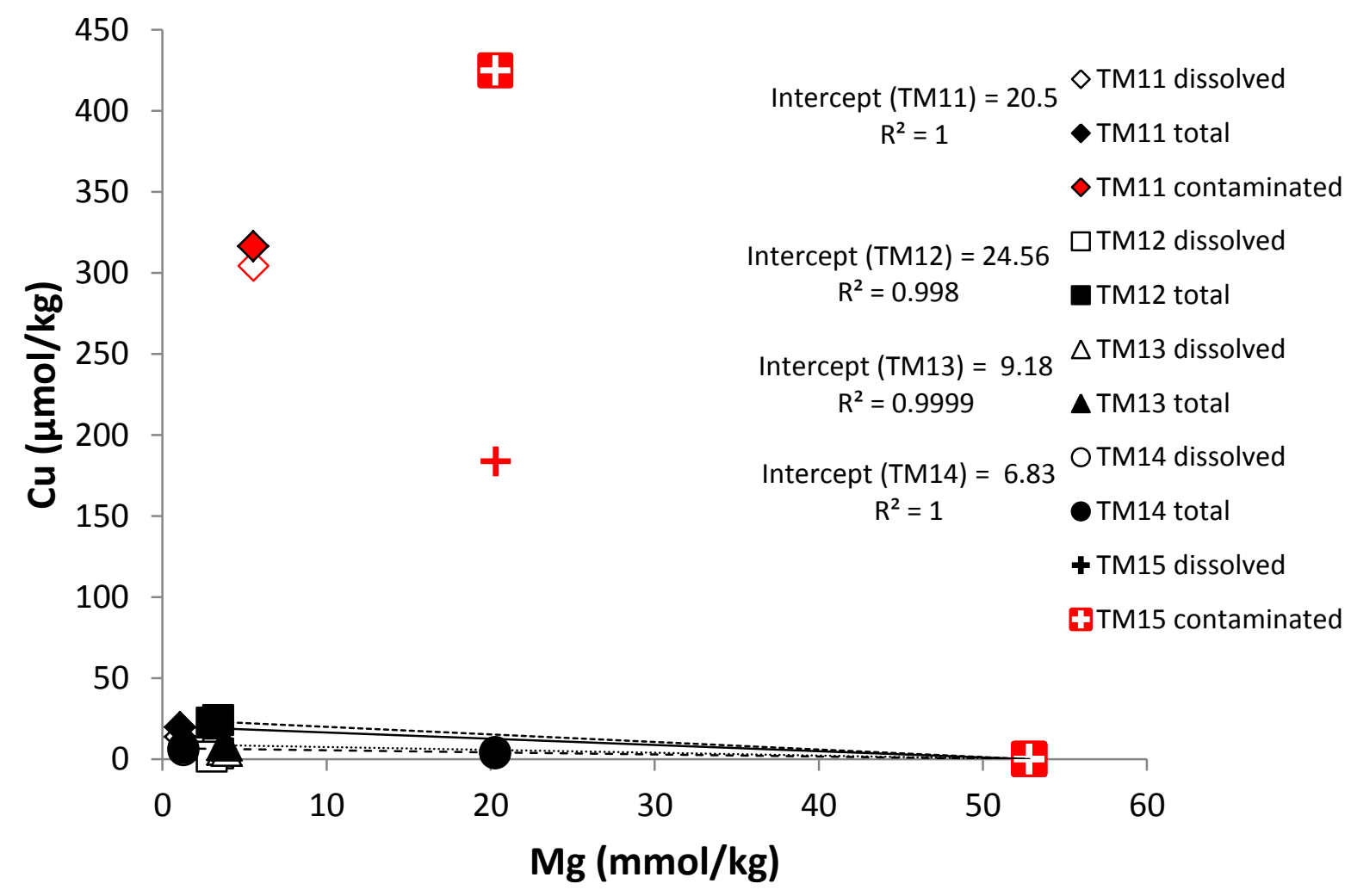




\section{Figure 3D}

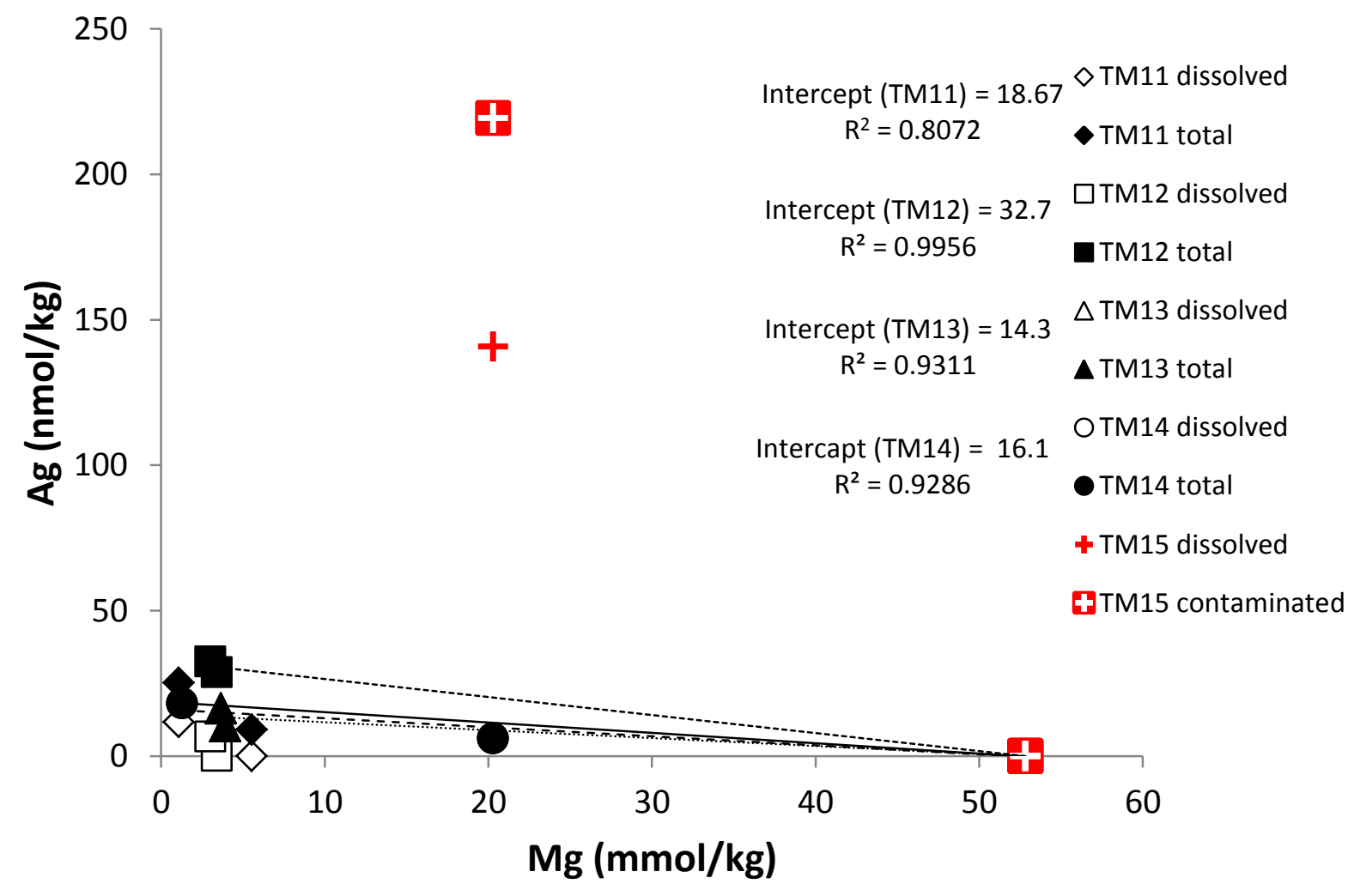




\subsection{Trace Element Analysis of Black Smoker Chimney Linings}

The $\mathrm{Co}, \mathrm{Ni}, \mathrm{Ga}, \mathrm{Ag}$, and In contents of chalcopyrite precipitated along the innermost linings of black smoker chimney linings were analyzed by secondary ion mass spectrometry (SIMS) using the Cameca 1280 Ion Microprobe in the Northeast National Ion Microprobe Facility at the Woods Hole Oceanographic Institution. Details of these analyses and calibration against picked grains of chalcopyrite analyzed by ICP-MS are found in Chapter 3 of this thesis.

\subsection{Fluid Chemical Modelling}

To compare measured trace element chemistry of black smoker chimney linings with the relevant hydrothermal fluid chemistry at in situ temperatures and pressures, the activities of aqueous complexes and free ions (including in situ $\mathrm{pH}$ ) were calculated using the EQ3/6 software package (Wolery, 1992) and thermodynamic data from SUPCRT92 (Johnson et al., 1992) modified as described by Tivey et al. (1999) and Tivey (2004). Additionally, thermodynamic data for the chloride complexes of $\mathrm{Co}, \mathrm{Ni}$, and $\mathrm{In}$, and hydroxide complexes of $\mathrm{Ga}$ and In were obtained from the SLOP07 database available at http://geopig3.la.asu.edu:8080/GEOPIG pigopt1.html (Shock et al., 1997; Sverjensky et al., 1997). The dissociation reaction constants for select complexes are listed in Table 2. 


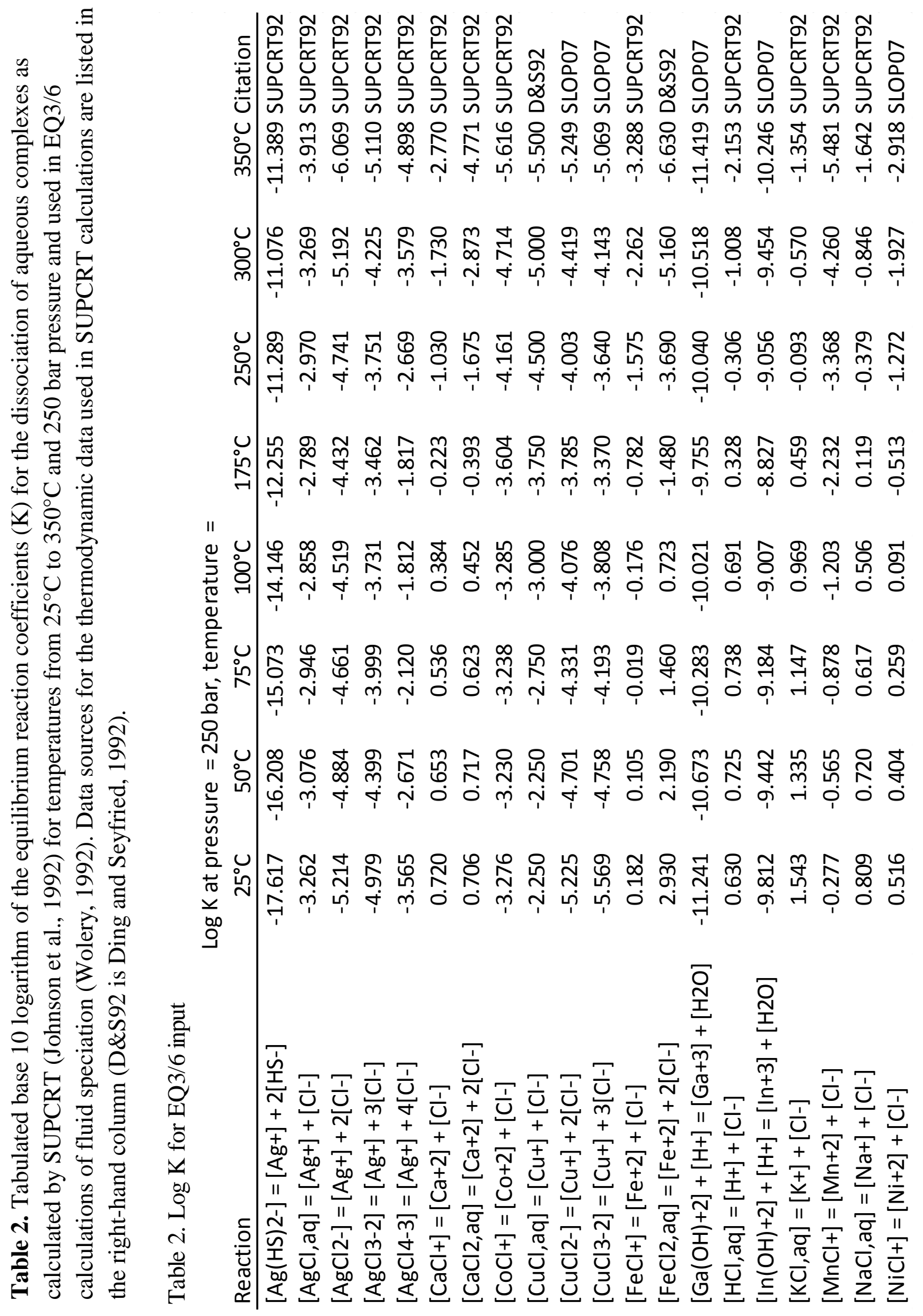




\section{RESULTS}

\subsection{Hydrothermal fluids from the Eastern Lau Spreading Center}

A total of 62 fluid samples were collected from 34 vents (13 in 2009 and 21 in 2015) at five different vent fields (five vent fields in 2009 and three vent fields in 2015) along the Eastern Lau Spreading Center (ELSC). Of these samples, 47 contained low concentrations of $\mathrm{Mg}(<10$ $\mathrm{mmol} / \mathrm{kg})$ indicative of low extents of mixing $(<20 \%)$ with seawater. The measured compositions of fluid samples analyzed for this study are presented in Tables 3A to 3D. The calculated zero-Mg endmember compositions of low-Mg vent fluids are presented in Tables 4A to 4B. Endmember concentrations of selected elements for vent fluids from the Eastern Lau Spreading Center and Manus Basin are additionally presented in Figure 4. The separate contributions of the dissolved-, filter-, and dregs fractions to each fluid sample are supplied in Supplementary Tables S1 to S3. Plots of linear regressions are supplied in Appendix A.

\subsubsection{Major Fluid Parameters}

The measured temperatures, $\mathrm{pH}$, and zero- $\mathrm{Mg}$ endmember concentrations of major ions (Na, Li, K, Ca) for vent fluids presented in this study from the Kilo Moana, Tahi Moana-1, ABE, Tu'i Malila, and Mariner vent fields overlap values previously reported by Mottl et al., (2011) and Chapter 2 of this thesis. The general characteristics of ELSC vent fluids and inferred vent fluid formation processes are discussed in Mottl et al. (2011) and are not addressed further here. 


\subsection{2. $\mathrm{Mn}, \mathrm{Fe}, \mathrm{Cu}, \mathrm{In}$}

Zero-Mg endmember concentrations of $\mathrm{Mn}, \mathrm{Fe}$, and $\mathrm{Cu}$ are significantly greater in fluids collected from the Mariner vent field than those collected from other ELSC vent fields (Table 4A; Fig. 4A). Within individual vent fluid samples, $\mathrm{Mn}$ and $\mathrm{Fe}$ are dominantly contained in the dissolved fraction in contrast to $\mathrm{Cu}$, which is variably contained in the dregs fraction. Because of the use of ${ }^{115}$ In as an internal spike during ICP-MS analysis, concentrations of In in vent fluid samples were only measured in the dregs and filter fractions of fluids collected in 2015 from the ABE, Tu'i Malila, and Mariner vent fields. As with $\mathrm{Mn}, \mathrm{Fe}$, and $\mathrm{Cu}$, endmember In concentrations are higher in vent fluids collected from the Mariner vent field compared to vent fluids from the ABE and Tu'i Malila vent fields (Table 4B, Fig. 4C).

Endmember Mn concentrations for low-Mg vent fluids from the Mariner vent field range from $3,700 \pm 120 \mu \mathrm{mol} / \mathrm{kg}$ (MA17) to $6090 \pm 50 \mu \mathrm{mol} / \mathrm{kg}$ (MA13). In comparison, endmember Mn concentrations for vent fluids from the Kilo Moana, Tahi Moana-1, ABE, and Tu'i Malila vent fields are lower, but similar to each other and range from $215 \pm 1 \mu \mathrm{mol} / \mathrm{kg}$ (KM9) to $580 \pm$ $2 \mu \mathrm{mol} / \mathrm{kg}$ (TMo1).

Endmember concentrations of Fe in Mariner vent fluids range from $6,730 \pm 70 \mu \mathrm{mol} / \mathrm{kg}$ to $14,000 \pm 300 \mu \mathrm{mol} / \mathrm{kg}$. Endmember concentrations of Fe in other ELSC vent fluids range from $\mathrm{Fe}=248 \pm 3 \mu \mathrm{mol} / \mathrm{kg}$ to $370 \pm 30 \mu \mathrm{mol} / \mathrm{kg}$ for the Tahi Moana-1 vent field, $\mathrm{Fe}=67 \pm 3 \mu \mathrm{mol} / \mathrm{kg}$ to $340 \mu \mathrm{mol} / \mathrm{kg}$ for the $\mathrm{ABE}$ vent field, and $\mathrm{Fe}=102 \pm 3 \mu \mathrm{mol} / \mathrm{kg}$ to $500 \pm 140 \mu \mathrm{mol} / \mathrm{kg}$ for the Tu'i Malila vent field. The endmember Fe concentration of fluid KM9 from the Kilo Moana vent field is somewhat higher, at $1100 \pm 110 \mu \mathrm{mol} / \mathrm{kg}$. 
Endmember $\mathrm{Cu}$ concentrations for low-Mg vent fluids from the Mariner vent field range from $109 \pm 1 \mu \mathrm{mol} / \mathrm{kg}$ to $1100 \pm 800 \mu \mathrm{mol} / \mathrm{kg}$ while endmember concentrations of $\mathrm{Cu}$ for fluids from Kilo Moana, Tahi Moana-1, and ABE vent fields range from $4 \pm \mu \mathrm{mol} / \mathrm{kg}$ (A16) to $75 \mu \mathrm{mol} / \mathrm{kg}$ (A14). Endmember $\mathrm{Cu}$ concentrations of fluids from the Tu'i Malila vent field are slightly higher and range from $6.8 \pm 0.03 \mu \mathrm{mol} / \mathrm{kg}$ to $25 \pm 1 \mu \mathrm{mol} / \mathrm{kg}$. Endmember In concentrations for low-Mg fluids from the Mariner vent field range from $84 \pm 3 \mathrm{nmol} / \mathrm{kg}$ to $240 \pm 50 \mathrm{nmol} / \mathrm{kg}$ while endmember In concentrations for ABE and Tu'i Malila vent fluids range from $30 \pm 15 \mathrm{nmol} / \mathrm{kg}$ to $57 \pm 3 \mathrm{nmol} / \mathrm{kg}$.

\subsubsection{Zn, Cd, Ag, Ga}

Endmember concentrations of $\mathrm{Zn}, \mathrm{Cd}, \mathrm{Ag}$, and Ga are generally higher in the low-pH, high-temperature fluids from the Mariner vent field than in fluids from other ELSC vent fields (Table 4A, 4B; Fig. 4B, 4C). While several fluid samples from the Tu'i Malila vent field also exhibit high concentrations of these elements, these high concentrations are not constrained by multiple fluid samples and could represent sampling artifacts. With the exception of these outliers (TM16 and TM17 for Zn, TM19 for Ag, MA14 for Ga and Ag) strong correlations are observed between endmember concentrations of $\mathrm{Zn}$ and $\mathrm{Cd}(\mathrm{r}=0.95), \mathrm{Ag}(\mathrm{r}=0.81), \mathrm{Ga}(\mathrm{r}=$ $0.87)$ and endmember $\mathrm{Zn}$ concentrations also correlate with vent fluid temperature $(\mathrm{r}=0.70)$.

Endmember Zn concentrations for fluids from the Mariner vent field range from 300 $\mu \mathrm{mol} / \mathrm{kg}$ (MA18) to $1800 \pm 100 \mu \mathrm{mol} / \mathrm{kg}$ (MA14). Endmember Cd concentrations of Mariner vent fluids range from $230 \mathrm{nmol} / \mathrm{kg}$ (MA18) to 1,560 $\pm 40 \mu \mathrm{mol} / \mathrm{kg}$ (MA14). Endmember Ag concentrations for Mariner vent fluids range from $40 \pm 28 \mathrm{nmol} / \mathrm{kg}$ to $100 \pm 14 \mathrm{nmol} / \mathrm{kg}$. 
Endmember Ga concentrations for Mariner vent fluids range from $90 \pm 13 \mathrm{nmol} / \mathrm{kg}$ to $280 \pm 20$ $\mathrm{nmol} / \mathrm{kg}$.

Endmember Zn concentrations from the Kilo Moana, Tahi Moana-1, ABE, and Tu'i Malila vent fields are highly variable and range from $37 \pm 1 \mu \mathrm{mol} / \mathrm{kg}$ (A16) to $960 \mu \mathrm{mol} / \mathrm{kg}$ (TM16). Endmember Cd concentrations range from $31 \mathrm{nmol} / \mathrm{kg}$ (A10) to 1,600 $\pm 700 \mathrm{nmol} / \mathrm{kg}$. Endmember Ag concentrations range from below detection limits (A16) to $520 \mathrm{nmol} / \mathrm{kg}$ (TM19). Endmember Ga concentrations are $<15 \mathrm{nmol} / \mathrm{kg}$ for fluids from the Kilo Moana and Tahi Moana-1 vent fields. Endmember Ga concentrations range from $6 \mathrm{nmol} / \mathrm{kg}$ to $114 \mathrm{nmol} / \mathrm{kg}$ at the ABE vent field and $6 \pm 4 \mathrm{nmol} / \mathrm{kg}$ to $91 \mathrm{nmol} / \mathrm{kg}$ at the Tu'i Malila vent field.

\subsubsection{Co and Ni}

Endmember Co concentrations are similar for vent fluids from the Tahi Moana-1 $(\mathrm{Co}=$ $110 \pm 8 \mathrm{nmol} / \mathrm{kg}$ to $160 \pm 28 \mathrm{nmol} / \mathrm{kg})$ and $\mathrm{ABE}(\mathrm{Co}=73 \pm 1 \mathrm{nmol} / \mathrm{kg}$ to $180 \pm 18 \mathrm{nmol} / \mathrm{kg})$ vent fields and are higher for vent fluids from the Tu'i Malila (Co $=100 \pm 15 \mathrm{nmol} / \mathrm{kg}$ to $240 \mathrm{nmol} / \mathrm{kg}$ ) and Mariner vent field ( $\mathrm{Co}=200 \pm 20 \mathrm{nmol} / \mathrm{kg}$ to $500 \pm 130 \mathrm{nmol} / \mathrm{kg}$ ) (Table 4A; Fig. 4B, 4C). The endmember Co concentration of fluid KM9 from Kilo Moana vent field is higher, $560 \pm 50$ $\mathrm{nmol} / \mathrm{kg}$.

Endmember Ni concentrations are highest in fluids from the Mariner vent field with a range of $120 \pm 50 \mathrm{nmol} / \mathrm{kg}$ to $1,100 \pm 600 \mathrm{nmol} / \mathrm{kg}$ (Table 4A; Fig. 4B, 4C). Endmember Ni concentrations range from $76 \pm 3 \mathrm{nmol} / \mathrm{kg}$ to $700 \pm 200 \mathrm{nmol} / \mathrm{kg}$ at the Tu'i Malila vent field, $110 \mathrm{nmol} / \mathrm{kg}$ to $570 \mathrm{nmol} / \mathrm{kg}$ at the $\mathrm{ABE}$ vent field, and $200 \pm 140 \mathrm{nmol} / \mathrm{kg}$ to $700 \pm 140 \mathrm{nmol} / \mathrm{kg}$ at the Tahi Moana-1 vent field (Table 4A; Fig. 4B, 4C). The endmember Ni concentration of fluid KM9 from Kilo Moana vent field is $100 \pm 06 \mathrm{nmol} / \mathrm{kg}$ (Table 4A; Fig. 4B, 4C). 


\subsection{Aqueous Speciation}

Thermodynamic modelling of fluid speciation using EQ3/6 indicates that ions will be more greatly complexed at in situ temperatures than at $25^{\circ} \mathrm{C}$. This leads to higher $\mathrm{pH}$ at in situ temperatures compared to the $\mathrm{pH}$ measured at $25^{\circ} \mathrm{C}$ and a decrease in the activity of free ions relative to total elemental concentrations. The $\mathrm{pH}, \log \mathrm{fO} 2$ and $\log \mathrm{fS} 2$ of modelled fluids at in situ temperatures and 250 bar are presented in Table 6 . According to the thermodynamic calculations, $\mathrm{Cu}, \mathrm{Fe}, \mathrm{Co}, \mathrm{Ag}$, and In are dominantly present as chloride complexes while $\mathrm{Ni}$ is split between free ions and chloride complexes and Ga is predominantly present as hydroxide complexes. 
Table 3. Measured temperatures and fluid chemistry for hydrothermal fluid samples from the Kilo Moana (KM), Tahi Moana-1 (TMo), ABE (A), Tu'i Malila (TM), and Mariner (MA) vent fields. One or two samples were collected in IGT samplers of each "fluid" defined by fluid emanating from a particular vent and values reflect summation of the dissolved, dregs, and filter fractions. Temperature was measured by a thermocouple mounted to the IGT sampler snorkel, $\mathrm{pH}$ was measured shipboard by a daily calibrated $\mathrm{Ag} / \mathrm{AgCl}$ combination reference electrode, $\mathrm{Mg}$, $\mathrm{Na}, \mathrm{Li}$, and $\mathrm{K}$ were measured by ion chromatography, and all other elements were measured by ICP-MS. Temperature, $\mathrm{pH}, \mathrm{Mg}$ are from Seewald (2017), Mn and Fe concentrations for KM9, TMo1, TMo2, TMo5, A10, A11, TM11, TM12, MA8, MA9, MA10, MA11, and MA12 are from C. G. Wheat, pers. comm. Components that were not measured are labelled with "NM".

Table 3A.Measured Fluid Chemistry (1 of 4)

\begin{tabular}{|c|c|c|c|c|c|c|c|c|c|c|c|c|}
\hline Fluid & Sample & $\max \mathrm{T}$ & $\mathrm{pH}$ & $\mathrm{Mg}$ & $\mathrm{Cr}$ & $\mathrm{Mn}$ & $\mathrm{Fe}$ & Co & $\mathrm{Ni}$ & $\mathrm{Cu}$ & $\mathrm{Zn}$ & $\mathrm{Ga}$ \\
\hline & & ${ }^{\circ} \mathrm{C}$ & $25^{\circ} \mathrm{C}$ & $\mathrm{mmol} / \mathrm{k}$ & $\mathrm{mol} / \mathrm{kg}$ & umol $/ \mathrm{kg}$ & umol/kg & $\mathrm{nmol} / \mathrm{kg}$ & $\mathrm{nmol} / \mathrm{kg}$ & umol/kg & umol/kg & $\mathrm{nmol} / \mathrm{kg}$ \\
\hline KM9 & J2-434-IGT1 & 301 & 4.1 & 2.5 & 1500 & 200 & 990 & 490 & 200 & 5 & 38 & 5 \\
\hline KM9 & J2-434-IGT4 & 304 & 5.0 & 3.0 & NM & 200 & 1200 & 580 & 17 & 5 & 68 & NM \\
\hline TMo1 & J2-444-IGT1 & 297 & 3.3 & 2.9 & 8500 & 550 & 380 & 140 & 760 & 15 & 230 & 11 \\
\hline TMo1 & J2-444-IGT6 & 306 & 3.7 & 2.4 & 1100 & 560 & 320 & 130 & 500 & 8 & 180 & 18 \\
\hline TMo2 & J2-444-IGT3 & 298 & 4.4 & 4.6 & 1100 & 270 & 220 & 170 & 320 & 6 & 56 & 3 \\
\hline TMo2 & J2-444-IGT4 & 297 & 3.9 & 1.0 & 1100 & 290 & 250 & 130 & 72 & 8 & 170 & 20 \\
\hline TMo5 & J2-450-IGT4 & 309 & 3.7 & 1.4 & 590 & 390 & 280 & 120 & 640 & 6 & 80 & 1 \\
\hline TMo5 & J2-450-IGT6 & 310 & 3.8 & 2.0 & 630 & 380 & 260 & 100 & 60 & 6 & 79 & 2 \\
\hline A10 & J2-449-IGT5 & 317 & 4.4 & 2.1 & 4200 & 420 & 160 & 77 & 100 & 10 & 98 & 10 \\
\hline A11 & J2-449-IGT1 & 306 & 4.0 & 2.5 & 3500 & 280 & 100 & 70 & 220 & 5 & 77 & 8 \\
\hline A11 & J2-449-IGT6 & 312 & 3.9 & 2.1 & 710 & 450 & 160 & 70 & 120 & 12 & 77 & 4 \\
\hline A13 & J2-815-IGT7 & 283 & 5.0 & 12.8 & 3300 & 320 & 150 & 94 & 2200 & 4 & 85 & 87 \\
\hline A13 & J2-815-IGT8 & 283 & 4.3 & 2.3 & 1400 & 450 & 2900 & 110 & 550 & 110 & 3000 & 140 \\
\hline A14 & J2-815-IGT1 & 288 & 5.1 & 16.8 & 1800 & 250 & 1800 & 150 & 1400 & 250 & 5500 & 94 \\
\hline A14 & J2-815-IGT3 & 300 & 4.0 & 1.9 & 1400 & 400 & 330 & 170 & 380 & 72 & 420 & 80 \\
\hline A15 & J2-815-IGT2 & 290 & 4.9 & 8.1 & 930 & 170 & 94 & 130 & 480 & 7 & 49 & 53 \\
\hline A15 & J2-815-IGT4 & 279 & 4.4 & 1.9 & 1600 & 250 & 120 & 100 & 390 & 9 & 96 & 75 \\
\hline A16 & J2-815-IGT5 & 262 & 4.6 & 1.7 & 890 & 250 & 63 & 59 & 250 & 5 & 35 & 63 \\
\hline A16 & J2-815-IGT6 & 263 & 4.5 & 1.7 & 420 & 250 & 68 & 130 & 140 & 3 & 37 & 57 \\
\hline TM11 & J2-442-IGT3 & 313 & 4.1 & 5.5 & 1400 & 340 & 160 & 100 & 420 & 320 & 86 & 9 \\
\hline TM11 & J2-442-IGT4 & 315 & 3.8 & 1.1 & 4900 & 370 & 190 & 81 & 860 & 20 & 120 & 2 \\
\hline TM12 & J2-442-IGT1 & 284 & 4.3 & 3.4 & 7700 & 320 & 240 & 110 & 220 & 24 & 110 & 14 \\
\hline TM12 & J2-442-IGT6 & 268 & 4.2 & 3.0 & 7000 & 330 & 280 & 110 & 180 & 22 & 310 & 87 \\
\hline TM13 & J2-819-IGT6 & 260 & 3.9 & 4.3 & 290 & 280 & 97 & 150 & 52 & 9 & 83 & 55 \\
\hline TM13 & J2-819-IGT8 & 262 & 3.9 & 3.6 & 280 & 270 & 92 & 160 & 140 & 8 & 75 & 67 \\
\hline TM14 & J2-819-IGT4 & 214 & 4.0 & 1.5 & 260 & 280 & 120 & 170 & 55 & 4 & 57 & 67 \\
\hline TM14 & J2-819-IGT5 & 290 & 3.9 & 1.7 & 330 & 290 & 130 & 170 & 72 & 7 & 89 & 63 \\
\hline TM15 & J2-819-IGT2 & 269 & 5.0 & 22.0 & 920 & 230 & 1200 & 210 & 550 & 420 & 3500 & 190 \\
\hline TM16 & J2-819-IGT3 & 251 & 3.9 & 5.5 & 290 & 390 & 590 & 170 & 67 & 16 & 880 & 79 \\
\hline TM16 & J2-819-IGT7 & 242 & 4.2 & 6.7 & 380 & 340 & 320 & 150 & 70 & 5 & 110 & 59 \\
\hline TM17 & J2-819-IGT4B & 258 & 3.9 & 3.1 & 680 & 270 & 530 & 180 & 220 & 22 & 770 & 98 \\
\hline TM17 & J2-819-IGT5B & 257 & 4.0 & 4.4 & 310 & 250 & 300 & 80 & 63 & 10 & 550 & 69 \\
\hline TM18 & J2-819-IGT2B & 296 & 4.6 & 10.4 & 5100 & 96 & 160 & 150 & 460 & 4 & 47 & 67 \\
\hline TM18 & J2-819-IGT7B & 232 & 5.4 & 36.9 & 540 & 250 & 160 & 150 & 110 & 13 & 370 & 74 \\
\hline TM19 & J2-819-IGT6B & 232 & 4.2 & 3.0 & 550 & 250 & 190 & 230 & 140 & 7 & 130 & 75 \\
\hline TM20 & J2-819-IGT3B & 138 & 5.3 & 33.4 & 240 & 120 & 120 & 140 & 45 & 24 & 150 & 51 \\
\hline
\end{tabular}


Table 3B. Measured Fluid Chemistry (2 of 4)

\begin{tabular}{|c|c|c|c|c|c|c|c|c|c|c|c|c|}
\hline \multirow[t]{2}{*}{ Fluid } & Sample & $\max T$ & $\mathrm{pH}$ & $\mathrm{Mg}$ & $\mathrm{Cr}$ & $\mathrm{Mn}$ & $\mathrm{Fe}$ & Co & $\mathrm{Ni}$ & $\mathrm{Cu}$ & $\mathrm{Zn}$ & $\mathrm{Ga}$ \\
\hline & & ${ }^{\circ} \mathrm{C}$ & $25^{\circ} \mathrm{C}$ & $\mathrm{mmol} / \mathrm{k}$ & $\mathrm{nmol} / \mathrm{kg}$ & umol/kg & umol/kg & $\mathrm{nmol} / \mathrm{kg}$ & $\mathrm{nmol} / \mathrm{kg}$ & umol/kg & umol/kg & $\mathrm{nmol} / \mathrm{kg}$ \\
\hline MA8 & J2-437-IGT1 & 359 & 2.6 & 5.6 & NM & 3600 & 9100 & 340 & 65 & 290 & 350 & NM \\
\hline MA8 & J2-437-IGT3 & 359 & 2.4 & 3.8 & NM & 3500 & 10800 & 640 & 170 & 1800 & 380 & NM \\
\hline MA9 & J2-437-IGT5 & 338 & 2.4 & 6.7 & 2000 & 3800 & 9500 & 200 & 370 & 250 & 460 & 100 \\
\hline MA9 & J2-437-IGT6 & 336 & 2.3 & 3.2 & NM & 5000 & 15900 & 170 & 360 & 300 & 340 & NM \\
\hline MA10 & J2-439-IGT1 & 109 & 5.2 & 48.1 & NM & 7 & 3600 & 83 & 160 & 260 & 17600 & NM \\
\hline MA11 & J2-439-IGT6 & 328 & 2.2 & 3.7 & 2900 & 4100 & 11100 & 270 & 190 & 320 & 600 & 205 \\
\hline MA12 & J2-446-IGT3 & 350 & 2.3 & 2.9 & 600 & 49 & 150 & 14 & 76 & 59 & 140 & 41 \\
\hline MA12 & J2-446-IGT6 & 350 & 2.3 & 3.5 & 2700 & 4200 & 11500 & 290 & 580 & 280 & 600 & 160 \\
\hline MA13 & J2-816-IGT5 & 140 & 2.6 & 20.4 & 210 & 4100 & 1500 & 120 & 270 & 19 & 2300 & 49 \\
\hline MA13 & J2-816-IGT6 & 78 & 2.6 & 18.1 & 590 & 4300 & 1700 & 150 & 970 & 5 & 1100 & 70 \\
\hline MA14 & J2-817-IGT5 & 318 & 2.4 & 2.6 & 640 & 5300 & 6400 & 210 & 250 & 100 & 1600 & 280 \\
\hline MA14 & J2-817-IGT6 & 319 & 2.3 & 2.8 & 1100 & 5200 & 6300 & 190 & 770 & 100 & 1800 & 240 \\
\hline MA15 & J2-817-IGT2 & 354 & 3.0 & 12.7 & 940 & 3400 & 9400 & 260 & 270 & 200 & 330 & 150 \\
\hline MA15 & J2-817-IGT4 & 345 & 2.7 & 1.4 & 1800 & 4300 & 12500 & 210 & 290 & 220 & 350 & 160 \\
\hline MA16 & J2-817-IGT1 & 363 & 5.8 & 6.8 & 2800 & 4200 & 12400 & 220 & 1600 & 180 & 530 & 110 \\
\hline MA16 & J2-817-IGT8 & 364 & 2.7 & 2.1 & 2100 & 4400 & 13700 & 260 & 550 & 210 & 330 & 140 \\
\hline MA17 & J2-817-IGT5B & 360 & 2.9 & 8.0 & 690 & 3100 & 13900 & 590 & 510 & 3700 & 740 & 170 \\
\hline MA17 & J2-817-IGT6B & 362 & 2.8 & 8.1 & 1700 & 3300 & 9700 & 360 & 470 & 440 & 550 & 190 \\
\hline MA18 & J2-818-IGT4 & 300 & 2.7 & 12.8 & 970 & 3700 & 9000 & 210 & 510 & 110 & 170 & 90 \\
\hline MA18 & J2-818-IGT5 & 300 & 4.3 & 35.5 & 1500 & 1500 & 3900 & 170 & 700 & 99 & 290 & 91 \\
\hline MA19 & J2-818-IGT2 & 308 & 2.9 & 15.6 & 1100 & 3400 & 8400 & 290 & 1000 & 630 & 400 & 140 \\
\hline MA19 & J2-818-IGT3 & 297 & 2.6 & 9.4 & 1500 & 3900 & 9400 & 230 & 720 & 430 & 460 & 190 \\
\hline MA20 & J2-818-IGT6 & 344 & 2.6 & NM & 1100 & 4900 & 11500 & 180 & 380 & 190 & 520 & 160 \\
\hline MA20 & J2-818-IGT8 & 342 & 2.7 & 2.7 & 1200 & 4800 & 10900 & 200 & 470 & 120 & 310 & 130 \\
\hline MA21 & J2-818-IGT7 & 345 & 2.7 & 2.8 & 1200 & 4200 & 11600 & 240 & 330 & 270 & 460 & 170 \\
\hline MA21 & J2-818-M1 & & 3.4 & 22.8 & 350 & 2600 & 7200 & 160 & 200 & 110 & 180 & 55 \\
\hline
\end{tabular}


Table 3C. Measured Fluid Chemistry (3 of 4)

\begin{tabular}{|c|c|c|c|c|c|c|c|c|c|c|c|}
\hline Sample & $\max T$ & $\mathrm{pH}$ & Mg & Mo & $\mathrm{Ag}$ & $\mathrm{Cd}$ & In & Sn & $\mathrm{Sb}$ & $\mathrm{Au}$ & $\mathrm{Pb}$ \\
\hline & ${ }^{\circ} \mathrm{C}$ & $25^{\circ} \mathrm{C}$ & $\mathrm{mmol} / \mathrm{kg}$ & $\mathrm{nmol} / \mathrm{kg} \mathrm{n}$ & $\mathrm{mol} / \mathrm{kg}$ & $\mathrm{nmol} / \mathrm{kg}$ & $\mathrm{nmol} / \mathrm{kg}$ & $\mathrm{nmol} / \mathrm{kg}$ & $\mathrm{nmol} / \mathrm{kg}$ & $\mathrm{nmol} / \mathrm{kg} \mathrm{n}$ & $\mathrm{mol} / \mathrm{kg}$ \\
\hline J2-434-IGT1 & 301 & 4.1 & 2.5 & 170 & 47 & 29 & NM & NM & 1676 & 0 & 160 \\
\hline J2-434-IGT4 & 304 & 5.0 & 3.0 & 150 & 51 & 83 & NM & NM & 1700 & NM & 350 \\
\hline J2-444-IGT1 & 297 & 3.3 & 2.9 & 130 & 52 & 210 & NM & NM & 21 & 0 & 1000 \\
\hline J2-444-IGT6 & 306 & 3.7 & 2.4 & 65 & 30 & 180 & NM & 6 & 49 & 1 & 510 \\
\hline J2-444-IGT3 & 298 & 4.4 & 4.6 & 110 & 45 & 47 & NM & 6 & 28 & 0 & 110 \\
\hline J2-444-IGT4 & 297 & 3.9 & 1.0 & 72 & 41 & 170 & NM & 5 & 51 & 0 & 510 \\
\hline J2-450-IGT4 & 309 & 3.7 & 1.4 & 50 & 26 & 92 & NM & 2 & 33 & 0 & 57 \\
\hline J2-450-IGT6 & 310 & 3.8 & 2.0 & 39 & 25 & 94 & NM & 1 & 21 & 0 & 55 \\
\hline J2-449-IGT5 & 317 & 4.4 & 2.1 & 43 & 13 & 30 & NM & 3 & 49 & 0 & 350 \\
\hline J2-449-IGT1 & 306 & 4.0 & 2.5 & 73 & 8 & 30 & NM & 2 & 14 & 0 & 300 \\
\hline J2-449-IGT6 & 312 & 3.9 & 2.1 & 66 & 2 & 44 & NM & 2 & 23 & 0 & 110 \\
\hline J2-815-IGT7 & 283 & 5.0 & 12.8 & 1300 & 19 & 130 & 53 & 72 & 45 & 840 & 370 \\
\hline J2-815-IGT8 & 283 & 4.3 & 2.3 & 1300 & 63 & 3200 & 42 & 23 & 430 & 1800 & 7800 \\
\hline J2-815-IGT1 & 288 & 5.1 & 16.8 & 1800 & 62 & 7000 & 42 & 52 & 2200 & 3000 & 8500 \\
\hline J2-815-IGT3 & 300 & 4.0 & 1.9 & 1300 & 9 & 590 & 53 & 97 & 170 & 800 & 530 \\
\hline J2-815-IGT2 & 290 & 4.9 & 8.1 & 770 & 0 & 68 & 41 & 56 & 1600 & 4400 & 470 \\
\hline J2-815-IGT4 & 279 & 4.4 & 1.9 & 99 & 49 & 120 & 20 & 42 & 98 & 230 & 1100 \\
\hline J2-815-IGT5 & 262 & 4.6 & 1.7 & 980 & 0 & 57 & 43 & 130 & 49 & 300 & 690 \\
\hline J2-815-IGT6 & 263 & 4.5 & 1.7 & 810 & 0 & 48 & 35 & 40 & 38 & 1000 & 430 \\
\hline J2-442-IGT3 & 313 & 4.1 & 5.5 & 310 & 9 & 61 & NM & 3 & 39 & 0 & 350 \\
\hline J2-442-IGT4 & 315 & 3.8 & 1.1 & 100 & 25 & 81 & NM & 86 & 29 & NM & 1200 \\
\hline J2-442-IGT1 & 284 & 4.3 & 3.4 & 120 & 29 & 53 & NM & NM & 25 & 1 & 2400 \\
\hline J2-442-IGT6 & 268 & 4.2 & 3.0 & 110 & 33 & 470 & NM & NM & 50 & NM & 730 \\
\hline J2-819-IGT6 & 260 & 3.9 & 4.3 & 860 & 16 & 180 & NM & 34 & 44 & 2200 & 680 \\
\hline J2-819-IGT8 & 262 & 3.9 & 3.6 & 1200 & 10 & 130 & 41 & 41 & 46 & 1800 & 51 \\
\hline J2-819-IGT4 & 214 & 4.0 & 1.5 & 1000 & 6 & 110 & 44 & 39 & 52 & 0 & 770 \\
\hline J2-819-IGT5 & 290 & 3.9 & 1.7 & 1100 & 18 & 150 & 42 & 68 & 50 & 2900 & 820 \\
\hline J2-819-IGT2 & 269 & 5.0 & 22.0 & 1400 & 220 & 6900 & 53 & 86 & 1700 & 5200 & 5000 \\
\hline J2-819-IGT3 & 251 & 3.9 & 5.5 & 1300 & 110 & 1500 & 43 & 40 & 150 & 2800 & 2900 \\
\hline J2-819-IGT7 & 242 & 4.2 & 6.7 & 1000 & 0 & 230 & 39 & 67 & 51 & 1700 & 390 \\
\hline J2-819-IGT4B & 258 & 3.9 & 3.1 & 1200 & 130 & 1300 & 45 & 44 & 67 & 2800 & 3300 \\
\hline J2-819-IGT5B & 257 & 4.0 & 4.4 & 1100 & 65 & 1000 & 37 & 33 & 160 & 2200 & 3000 \\
\hline J2-819-IGT2B & 296 & 4.6 & 10.4 & 1300 & 0 & 120 & 39 & 40 & 54 & 1200 & 300 \\
\hline J2-819-IGT7B & 232 & 5.4 & 36.9 & 1100 & 2 & 1300 & 45 & 45 & 55 & 4400 & 1100 \\
\hline J2-819-IGT6B & 232 & 4.2 & 3.0 & 1100 & 500 & 120 & 48 & 46 & 440 & 8300 & 11000 \\
\hline J2-819-IGT3B & 138 & 5.3 & 33.4 & 910 & 8 & 320 & 34 & 40 & 52 & 3000 & 880 \\
\hline
\end{tabular}


Table 3D. Measured Fluid Chemistry (4 of 4)

\begin{tabular}{|c|c|c|c|c|c|c|c|c|c|c|c|}
\hline \multirow[t]{2}{*}{ Sample } & $\max \mathrm{T}$ & $\mathrm{pH}$ & $\mathrm{Mg}$ & Mo & $\mathrm{Ag}$ & $\mathrm{Cd}$ & In & $\mathrm{Sn}$ & $\mathrm{Sb}$ & $\mathrm{Au}$ & $\mathrm{Pb}$ \\
\hline & ${ }^{\circ} \mathrm{C}$ & $25^{\circ} \mathrm{C}$ & $\mathrm{mmol} / \mathrm{kg}$ & $\mathrm{nol} / \mathrm{kg}$ & $\mathrm{nol} / \mathrm{kg}$ & $\mathrm{mol} / \mathrm{kg}$ & $\mathrm{ol} / \mathrm{kg}$ & ol/kg & $101 / \mathrm{kg}$ & $\mathrm{mol} / \mathrm{kg}$ & $\mathrm{nmol} / \mathrm{kg}$ \\
\hline J2-437-IGT1 & 359 & 2.6 & 5.6 & 170 & 33 & 270 & NM & NM & 1654 & NM & 710 \\
\hline J2-437-IGT3 & 359 & 2.4 & 3.8 & 320 & 67 & 270 & NM & NM & 1680 & 1 & 1300 \\
\hline J2-437-IGT5 & 338 & 2.4 & 6.7 & 210 & 58 & 390 & NM & NM & 1664 & 1 & 1100 \\
\hline J2-437-IGT6 & 336 & 2.3 & 3.2 & 2000 & 1600 & 10300 & NM & NM & 25 & 1 & 338400 \\
\hline J2-439-IGT1 & 109 & 5.2 & 48.1 & 2000 & 1500 & 10300 & NM & NM & 26 & 3 & 342000 \\
\hline J2-439-IGT6 & 328 & 2.2 & 3.7 & 210 & 55 & 290 & NM & NM & 1714 & 1 & 2300 \\
\hline J2-446-IGT3 & 350 & 2.3 & 2.9 & 35 & 10 & 72 & NM & 6 & 50 & 1 & 710 \\
\hline J2-446-IGT6 & 350 & 2.3 & 3.5 & 160 & 90 & 460 & NM & NM & 92 & 2 & 5100 \\
\hline J2-816-IGT5 & 140 & 2.6 & 20.4 & 790 & 950 & 2500 & 36 & 42 & 100 & 880 & 5400 \\
\hline J2-816-IGT6 & 78 & 2.6 & 18.1 & 1300 & 36 & 130 & 48 & 350 & 46 & 1600 & 11900 \\
\hline J2-817-IGT5 & 318 & 2.4 & 2.6 & 350 & 14 & 1500 & 140 & 110 & 120 & 1800 & 1200 \\
\hline J2-817-IGT6 & 319 & 2.3 & 2.8 & 1000 & 67 & 1400 & 170 & 57 & 150 & 3500 & 3200 \\
\hline J2-817-IGT2 & 354 & 3.0 & 12.7 & 1200 & 29 & 300 & 82 & 64 & 110 & 2300 & 1300 \\
\hline J2-817-IGT4 & 345 & 2.7 & 1.4 & 1400 & 66 & 330 & 85 & 75 & 91 & 960 & 1300 \\
\hline J2-817-IGT1 & 363 & 5.8 & 6.8 & 540 & 78 & 550 & 74 & 61 & 160 & 2000 & 1500 \\
\hline J2-817-IGT8 & 364 & 2.7 & 2.1 & 1100 & 26 & 280 & 84 & 130 & 870 & 2500 & 2600 \\
\hline J2-817-IGT5B & 360 & 2.9 & 8.0 & 840 & 76 & 260 & 150 & 43 & 180 & 23000 & 470 \\
\hline J2-817-IGT6B & 362 & 2.8 & 8.1 & 1500 & 100 & 430 & 100 & 110 & 56 & 26700 & 6200 \\
\hline J2-818-IGT4 & 300 & 2.7 & 12.8 & 1000 & 81 & 180 & 77 & 48 & 110 & 1200 & 490 \\
\hline J2-818-IGT5 & 300 & 4.3 & 35.5 & 1100 & 74 & 290 & 67 & 44 & 210 & 2700 & 460 \\
\hline J2-818-IGT2 & 308 & 2.9 & 15.6 & 2000 & 78 & 350 & 230 & 78 & 260 & 6600 & 3900 \\
\hline J2-818-IGT3 & 297 & 2.6 & 9.4 & 1200 & 70 & 440 & 170 & 92 & 310 & 1900 & 1000 \\
\hline J2-818-IGT6 & 344 & 2.6 & NM & 1200 & 110 & 440 & 100 & 56 & 91 & 2600 & 1900 \\
\hline J2-818-IGT8 & 342 & 2.7 & 2.7 & 1100 & 33 & 290 & 75 & 48 & 160 & 1400 & 970 \\
\hline J2-818-IGT7 & 345 & 2.7 & 2.8 & 1100 & 55 & 460 & 110 & 100 & 180 & 1400 & 760 \\
\hline J2-818-M1 & & 3.4 & 22.8 & 1000 & 17 & 170 & 39 & 35 & 60 & 150 & 660 \\
\hline
\end{tabular}


Table 4. (opposite)

Endmember fluid compositions calculated by extrapolation of the fluid data presented in Table 3 to zero-Mg concentration. Where multiple samples are available, uncertainties are estimated by the range of endmember fluid concentrations calculated for each sample. Components that were not measured are labelled "NM". Those affected by contamination of the sample by entrained particles are labelled "cont". Samples for which recovery of the element is thought to be incomplete are labeled with "inc". 


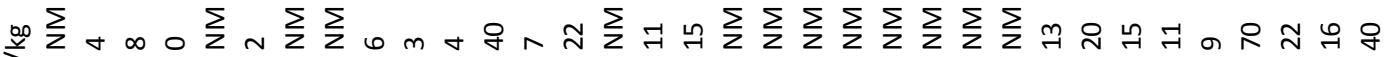
$2+1+1+1+1+1+1+1+1+1+1+1+1+1+1+1+1+1+1+1+1+1+1+1+1+1+1+1+1+1+1+1+1+1$

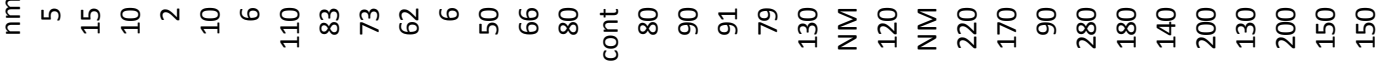

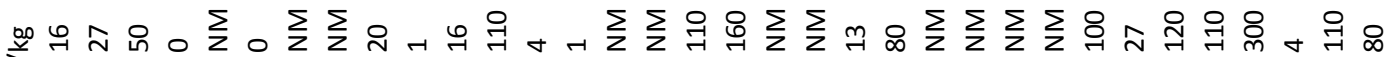
$\mathrm{N} \quad \overline{0}+1+1+1+1+1+1+1+1+1+1+1+1+1+1+1+1+1+1+1+1+1+1+1+1+1+1+1+1+1+1+1+1+1+1$

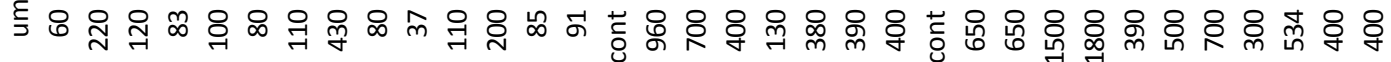

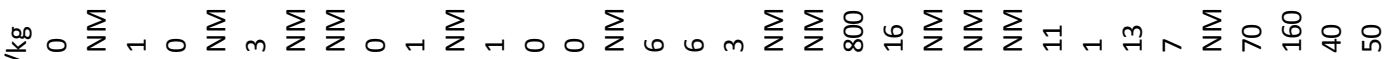
$2+1+1+1+1+1+1+1+1+1+1+1+1+1+1+1+1+1+1+1+1+1+1+1+1+1+1+1+1+1+1+1+1+1$

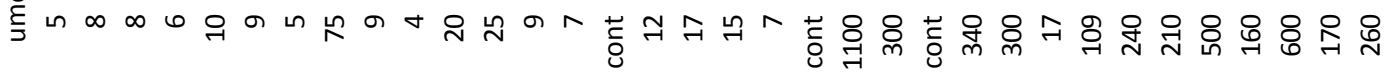

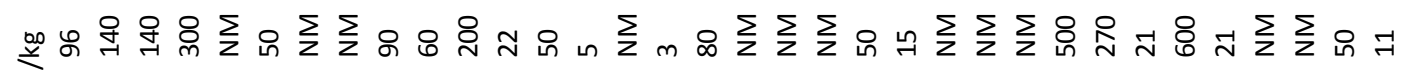

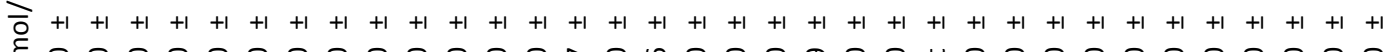

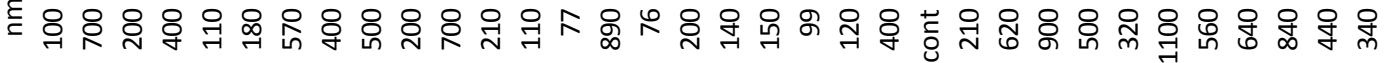

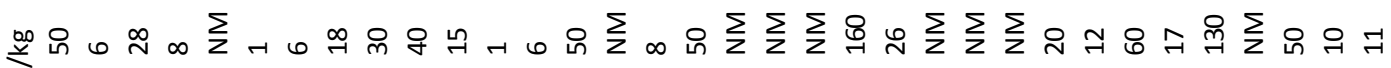
0
$0+1+1+1+1+1+1+1+1+1+1+1+1+1+1+1+1+1+1+1+1+1+1+1+1+1+1+1+1+1+1+1+1$

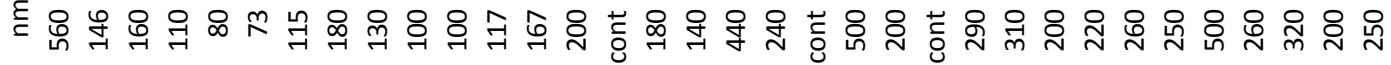

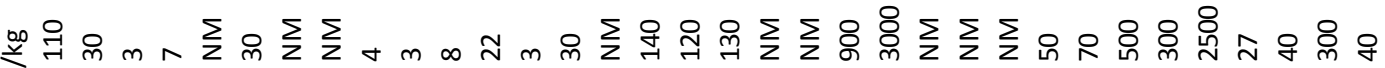
20

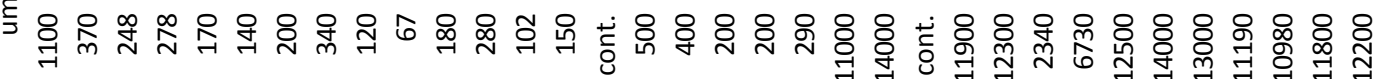

政 N

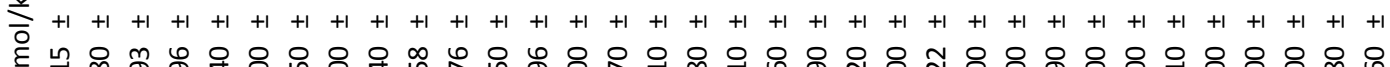

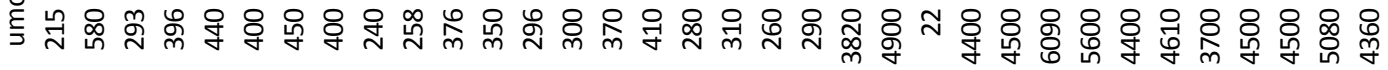

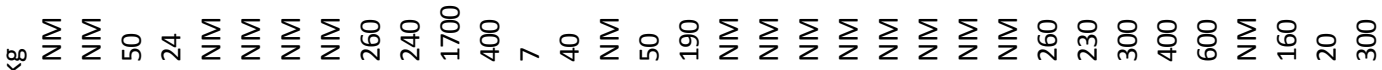

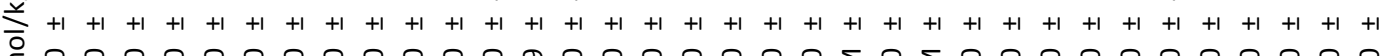

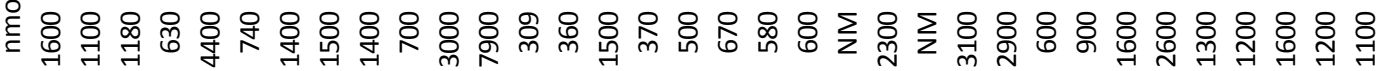

吕平

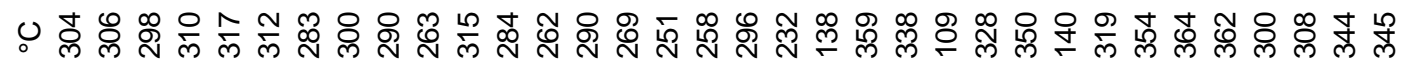

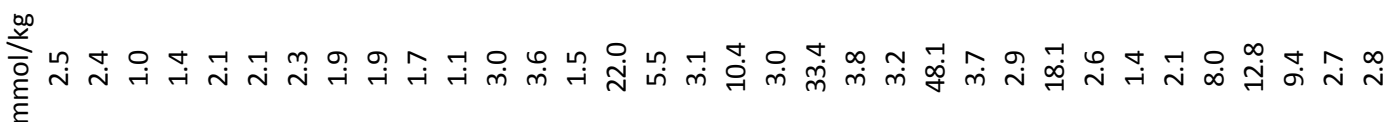

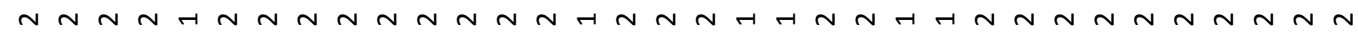

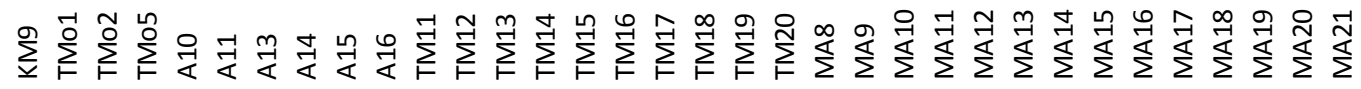




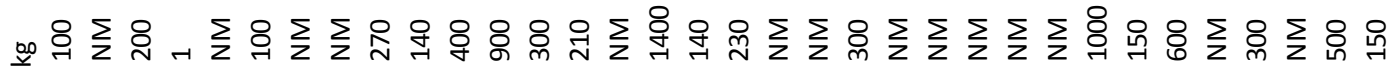

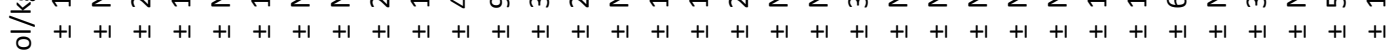
छ \&

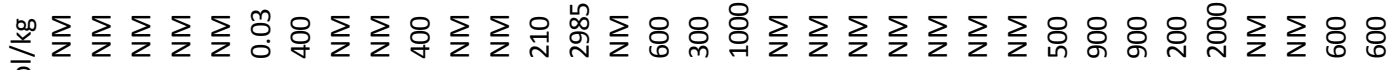
$\begin{aligned} & 0 \\ & 0\end{aligned}+1+1+1+1+1+1+1+1+1+1+1+1+1+1+1+1+1+1+1+1+1+1+1+1+1+1+1+1+1+1+1+1+1$

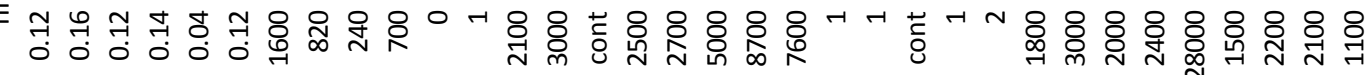

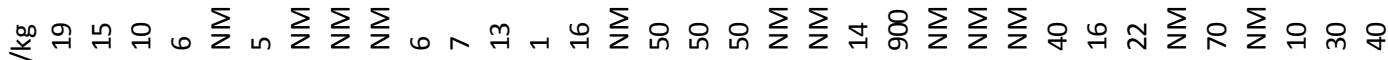

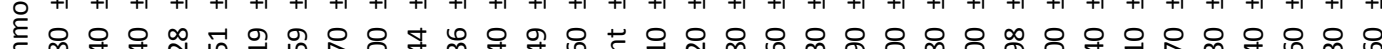
品 웜

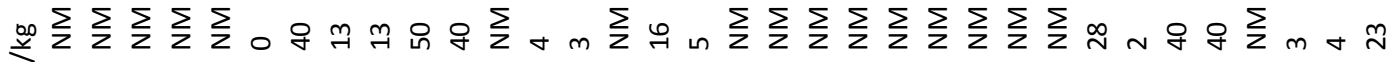

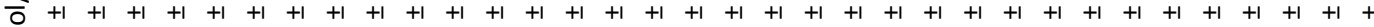

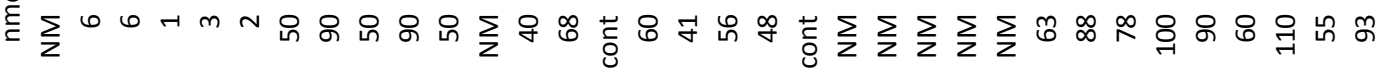

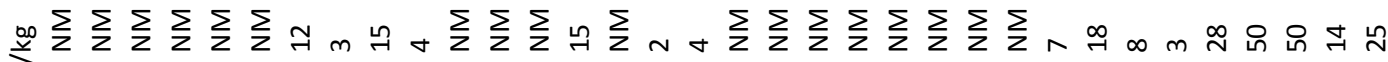

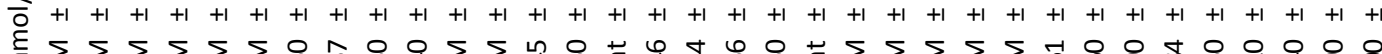

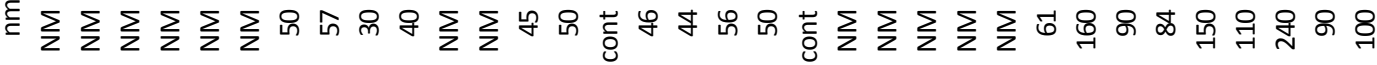

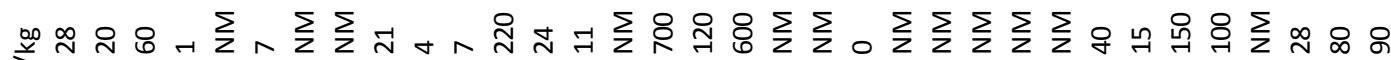
$00+1+1+1+1+1+1+1+1+1+1+1+1+1+1+1+1+1+1+1+1+1+1+1+1+1+1+1+1+1+1+1+1+1+1$ ह 웡 궝

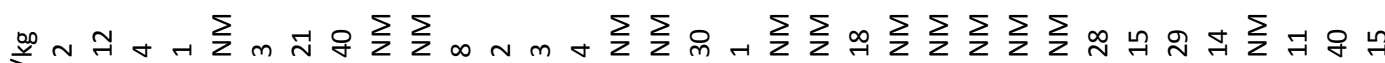
$\overline{0}+1+1+1+1+1+1+1+1+1+1+1+1+1+1+1+1+1+1+1+1+1+1+1+1+1+1+1+1+1+1+1+1+1+1$ 约

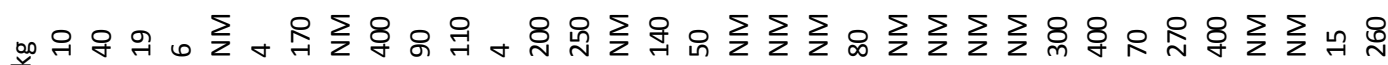
00
$0+1+1+1+1+1+1+1+1+1+1+1+1+1+1+1+1+1+1+1+1+1+1+1+1+1+1+1+1+1+1+1+1+1+1$ 宅 육 \&

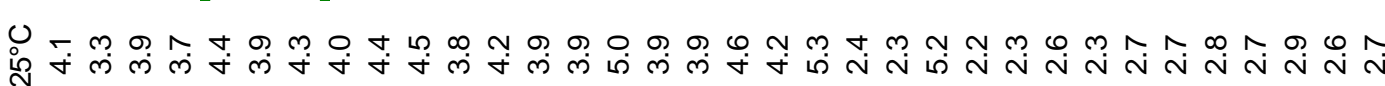

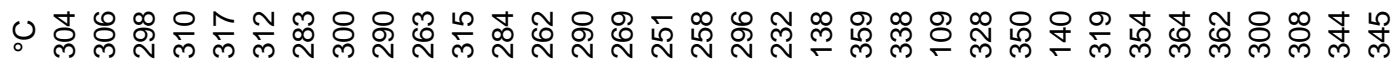

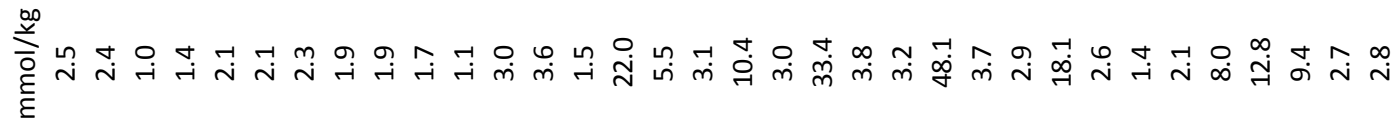

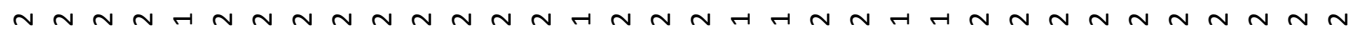

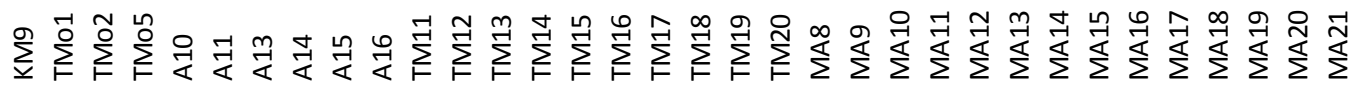


Figures 4A to 4D. (A, B, and C) Results from this paper (gray diamonds) for maximum temperatures, $\mathrm{pH}\left(\right.$ at $25^{\circ} \mathrm{C}$ ), and zero- $\mathrm{Mg}$ endmember concentrations of $\mathrm{Mn}, \mathrm{Fe}, \mathrm{Cu}, \mathrm{Zn}, \mathrm{Ag}, \mathrm{Co}$, and Cd for hydrothermal vent fluids from the Kilo Moana (KM), TowCam (TC), Tahi Moana-1 (TMo), ABE (A), Tu'i Malila (TM), and Mariner (MA) vent fields in the Lau Basin are compared with those of Mottl et al. (2011) (white squares) for the same vent fields and those of Craddock (2009) (white circles) for hydrothermal vent fluids from the Vienna Woods (VW), PACMANUS (PAC), and SuSu Knolls (SuSu) vent fields in the Manus Basin. Vent fields in the PACMANUS area are separated into three groups based on differences in vent fluid temperature and pH: the Roger's and Roman Ruins vent fields (PAC-R), the Satanic Mills vent field (PAC-S), and the Fenway vent field (PAC-F). (D) Results from this paper (gray diamonds) for zero-Mg endmember concentrations of $\mathrm{Cu}, \mathrm{Fe}, \mathrm{Zn}, \mathrm{Co}, \mathrm{Ni}, \mathrm{Ga}, \mathrm{In}$, and $\mathrm{Pb}$ for hydrothermal vent fluids from the Kilo Moana, Tahi Moana-1, ABE, Tu'i Malila, and Mariner vent fields in the Lau Basin are compared with those of Chapter 2 of this thesis for $\mathrm{Cu}, \mathrm{Fe}, \mathrm{Zn}, \mathrm{Pb}$ in hydrothermal vent fluids from the Kilo Moana, TowCam, ABE, Tu'i Malila, and Mariner same vent fields (white squares). Uncertainties around results from this paper reflect those reported in Table 4A and 4B.

Figure 4A

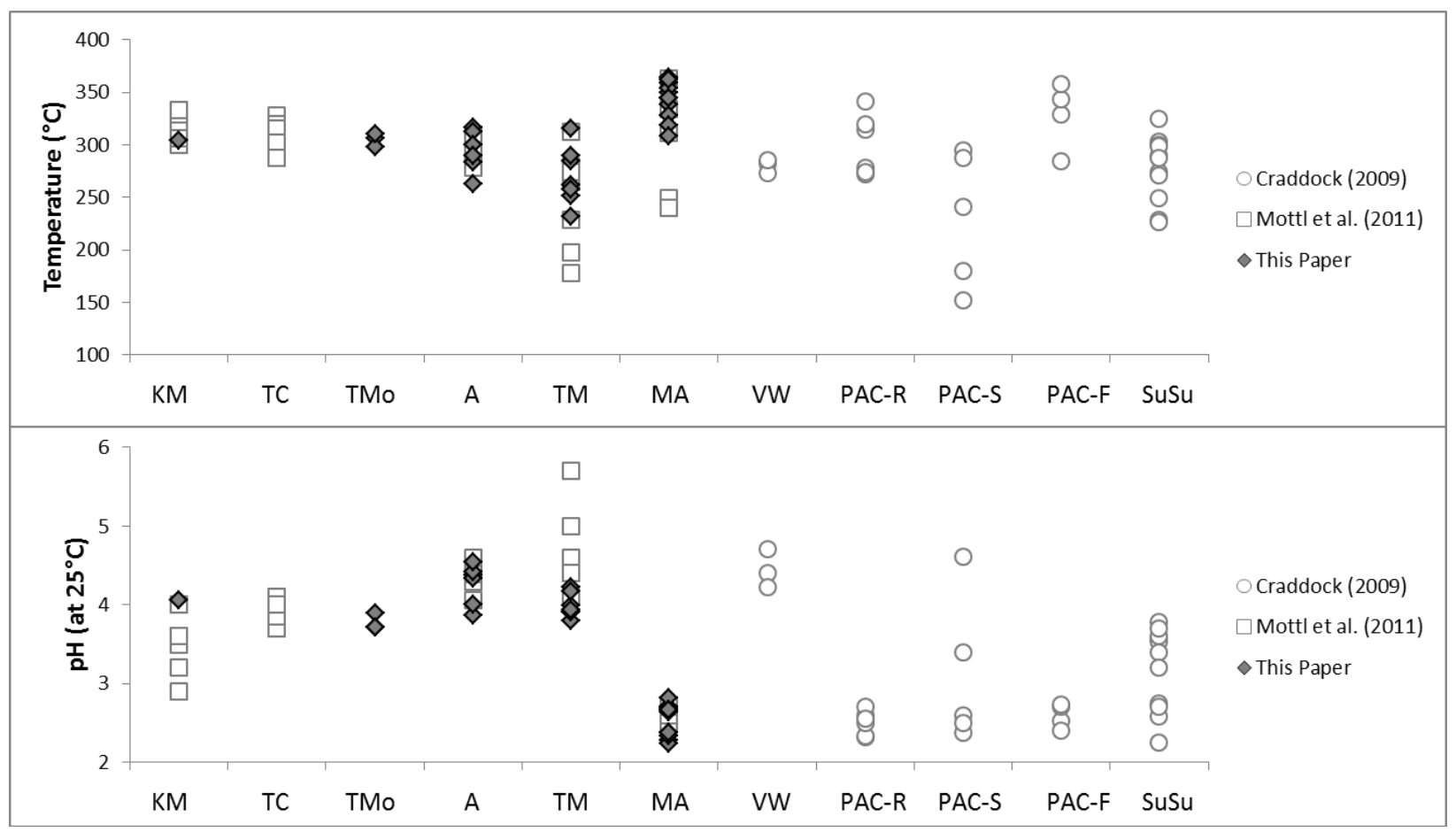


Figure 4B

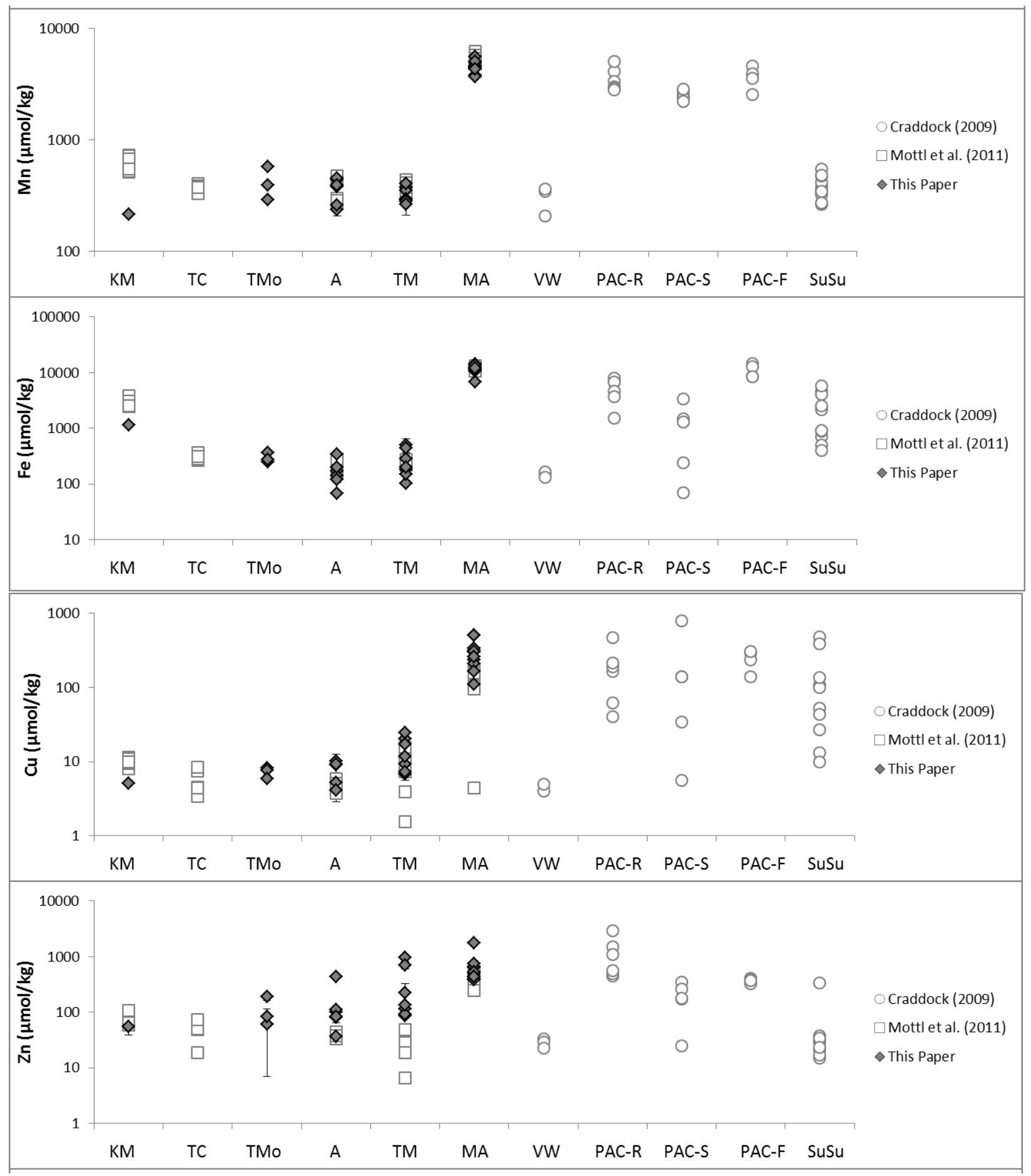


Figure 4C

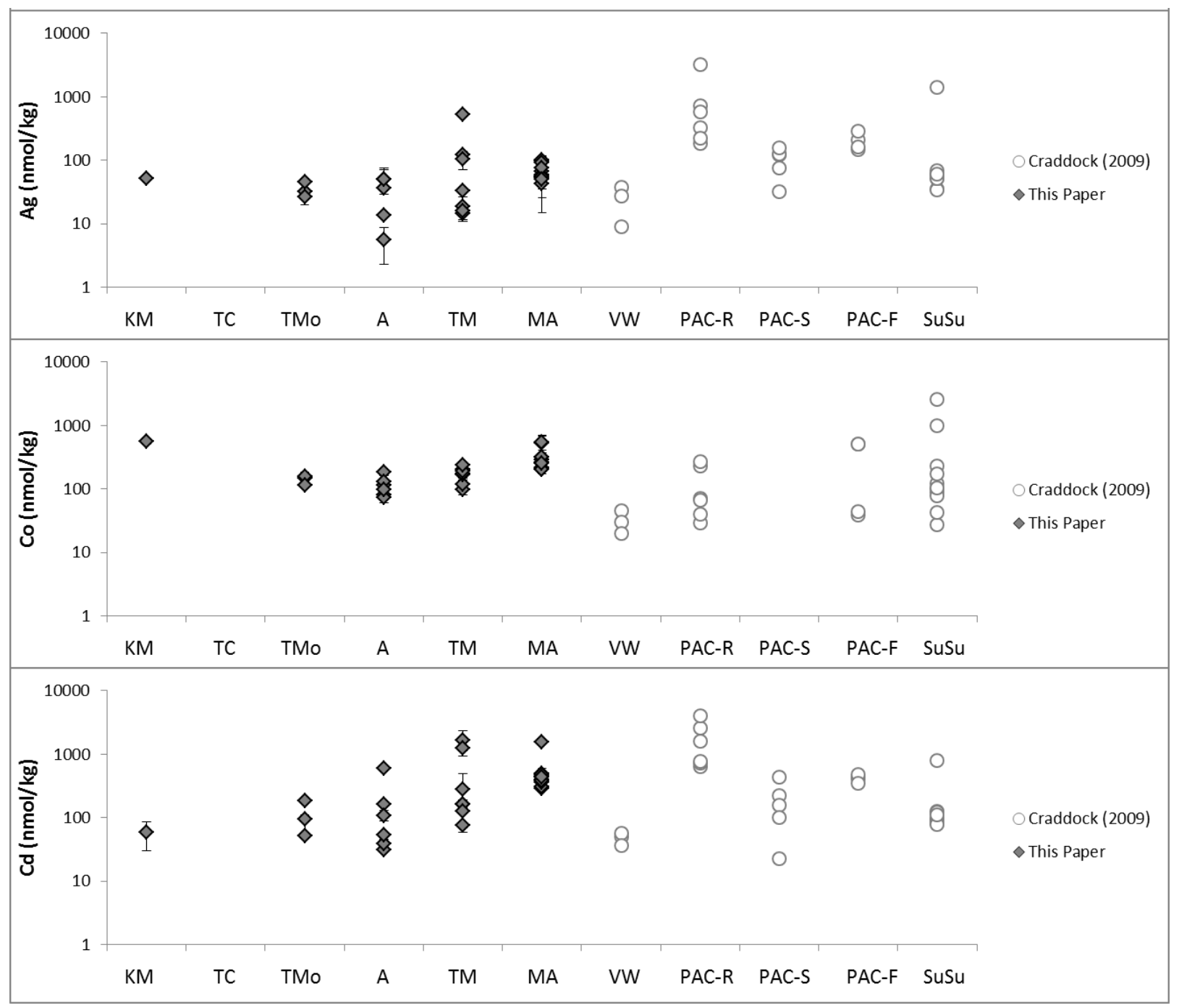



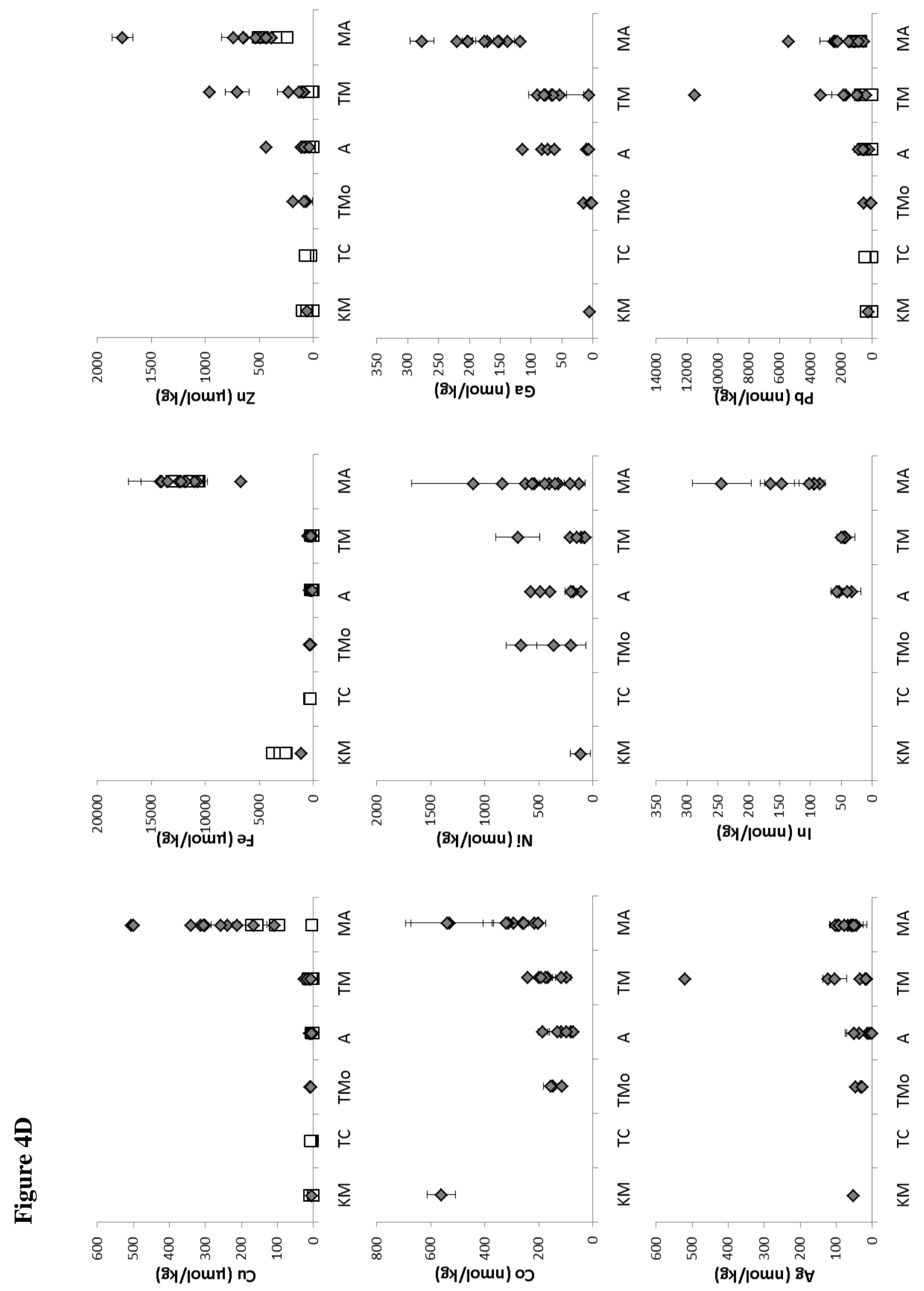
Table 5. Temperature, $\mathrm{pH}\left(\right.$ at $\left.25^{\circ} \mathrm{C}\right)$, and elemental compositions of hydrothermal fluids used as inputs to the EQ3/6 model. These compositions represent fluids for which SIMS analyses of the chalcopyrite lining of a paired black smoker chimney are also available. Data for vent fluids from the Eastern Lau Spreading Center are from this paper and Chapter 2 of this thesis, data for vent fluids in the Manus Basin are from Craddock (2009), data for fluid Sully99 from the Main Endeavour Field are from Seyfried et al. (2003) and data for fluid BB5 from the Beebe / Piccard vent field are from McDermott (2015). Values listed in red for $\mathrm{Ni}, \mathrm{Ga}$, and In are estimated based on observed patterns between these elements and fluid $\mathrm{pH} . \mu \mathrm{M}=\mu \mathrm{mol} / \mathrm{L}$ vent fluid; $\mathrm{mm}=$ $\mathrm{mmol} / \mathrm{kg}$ vent fluid; $\mu \mathrm{m}=\mu \mathrm{mol} / \mathrm{kg}$ vent fluid; $\mathrm{nm}=\mathrm{nmol} / \mathrm{kg}$ vent fluid

\begin{tabular}{|c|c|c|c|c|c|c|c|c|c|c|c|c|c|c|c|c|}
\hline Fluid ID & Temp. & $\mathrm{pH}$ & $\mathrm{H}_{2}$ & $\mathrm{H}_{2} \mathrm{~S}$ & $\mathrm{Cl}$ & $\mathrm{Na}$ & $\mathrm{Ca}$ & K & $\mathrm{Mn}$ & $\mathrm{Fe}$ & $\mathrm{Cu}$ & Co & $\mathrm{Ni}$ & $\mathrm{Ag}$ & Ga & In \\
\hline & $\left({ }^{\circ} \mathrm{C}\right)$ & (at $25^{\circ} \mathrm{C}$ ) & $\mu \mathrm{M}$ & $\mathrm{mm}$ & $\mathrm{mm}$ & $\mathrm{mm}$ & $\mathrm{mm}$ & $\mathrm{mm}$ & $\mu \mathrm{m}$ & $\mu \mathrm{m}$ & $\mu \mathrm{m}$ & $\mathrm{nm}$ & $\mathrm{nm}$ & $\mathrm{nm}$ & $\mathrm{nm}$ & $\mathrm{nm}$ \\
\hline \multicolumn{17}{|c|}{ Eastern Lau Spreading Center } \\
\hline TMo5 & 310 & 3.7 & 114 & 3.3 & 555 & 405 & 64.4 & 19.2 & 400 & 280 & 6 & 120 & 360 & 26 & 2 & 50 \\
\hline A10 & 317 & 3.9 & 63 & 3.9 & 543 & 437 & 40.3 & 24.6 & 440 & 170 & 10 & 80 & 80 & 14 & 10 & 50 \\
\hline A11 & 306 & 4.0 & 114 & 2.7 & 552 & 446 & 40.2 & 24.9 & 380 & 140 & 9 & 73 & 180 & 6 & 6 & 50 \\
\hline A16 & 300 & 4.0 & 114 & 3.0 & 552 & 449 & 38.4 & 25.6 & 260 & 67 & 4 & 98 & 200 & 6 & 62 & 40 \\
\hline TM11 & 315 & 3.8 & 418 & 2.8 & 652 & 510 & 48.7 & 43.0 & 380 & 180 & 20 & 96 & 690 & 19 & 6 & 50 \\
\hline MA9 & 338 & 2.4 & 414 & 8.9 & 470 & 313 & 43.4 & 28.3 & 5200 & 12500 & 300 & 20 & 400 & 230 & 120 & 150 \\
\hline MA15 & 354 & 2.7 & 78 & 10.0 & 521 & 370 & 41.7 & 30.1 & 4400 & 12500 & 240 & 260 & 320 & 56 & 180 & 94 \\
\hline \multicolumn{17}{|c|}{ Manus Basin } \\
\hline VW1 & 282 & 4.4 & 43 & 1.4 & 691 & 509 & 80.1 & 21.2 & 350 & 150 & 5 & 45 & 250 & 38 & 50 & 50 \\
\hline RGR1 & 320 & 2.7 & 20 & 3.6 & 648 & 489 & 27.1 & 81.1 & 3000 & 6900 & 200 & 35 & 250 & 200 & 150 & 150 \\
\hline RMR1 & 314 & 2.3 & 76 & 7.5 & 632 & 482 & 19.8 & 81.7 & 4000 & 5600 & 160 & 230 & 250 & 780 & 150 & 150 \\
\hline SM3 & 288 & 2.7 & 8 & 10.2 & 503 & 398 & 13.7 & 68.0 & 2300 & 1200 & 140 & 32 & 250 & 73 & 150 & 150 \\
\hline F3 & 358 & 2.7 & 407 & 18.8 & 562 & 407 & 22.3 & 76.1 & 3800 & 11800 & 140 & 520 & 250 & 600 & 150 & 150 \\
\hline NS3 & 300 & 3.4 & 82 & 3.4 & 673 & 541 & 30.6 & 65.0 & 430 & 2300 & 110 & 1000 & 250 & 44 & 50 & 50 \\
\hline SZ1 & 303 & 3.8 & 12 & 1.8 & 626 & 508 & 33.8 & 48.0 & 270 & 750 & 53 & 230 & 250 & 36 & 50 & 50 \\
\hline SZ2 & 274 & 3.6 & 7 & 1.8 & 684 & 533 & 49.4 & 49.2 & 370 & 780 & 27 & 100 & 250 & 53 & 50 & 50 \\
\hline \multicolumn{17}{|l|}{ Others } \\
\hline Sully99 & 379 & 3.6 & 960 & 20.0 & 39 & 32 & 1.9 & 2.0 & 90 & 400 & 12 & 100 & 250 & 4 & 50 & 50 \\
\hline BB5 & 395 & 3.0 & 19200 & 12.3 & 352 & 313 & 6.1 & 11.5 & 560 & 6500 & 170 & 1000 & 250 & 50 & 50 & 50 \\
\hline
\end{tabular}


Table 6. Temperature, $\mathrm{pH}$ (at $25^{\circ} \mathrm{C}$ ), and EQ3/6 model outputs for in situ $\mathrm{pH}$ and $\log$ (base 10) of oxygen and sulfur fugacity at in situ conditions (temperature listed in second column, 250 bar pressure, closed system, mineral precipitation suppressed).

\begin{tabular}{|c|c|c|c|c|c|}
\hline Fluid ID & Temp. & $\mathrm{pH}$ & $\mathrm{pH}$ & $\log \mathrm{fO} 2$ & $\log \mathrm{fS} 2$ \\
\hline & $\left({ }^{\circ} \mathrm{C}\right)$ & (at $\left.25^{\circ} \mathrm{C}\right)$ & & in situ & \\
\hline \multicolumn{6}{|c|}{ Eastern Lau Spreading Center } \\
\hline TMo5 & 310 & 3.7 & 4.6 & -31.7 & -10.0 \\
\hline A10 & 317 & 3.9 & 4.6 & -31.6 & -9.5 \\
\hline A11 & 306 & 4.0 & 5.2 & -32.1 & -10.3 \\
\hline A16 & 300 & 4.0 & 5.2 & -32.7 & -10.4 \\
\hline TM11 & 315 & 3.8 & 4.5 & -32.4 & -11.1 \\
\hline MA9 & 338 & 2.4 & 3.2 & -30.2 & -9.3 \\
\hline MA15 & 354 & 2.7 & 3.8 & -27.4 & -7.3 \\
\hline \multicolumn{6}{|c|}{ Manus Basin } \\
\hline VW1 & 282 & 4.4 & 5.1 & -33.7 & -10.9 \\
\hline RGR1 & 320 & 2.7 & 4.0 & -30.5 & -9.4 \\
\hline RMR1 & 314 & 2.3 & 2.8 & -29.9 & -8.3 \\
\hline SM3 & 288 & 2.5 & 3.0 & -31.7 & -7.5 \\
\hline F3 & 358 & 2.7 & 3.9 & -28.5 & -8.1 \\
\hline NS3 & 300 & 3.4 & 3.9 & -32.5 & -10.0 \\
\hline SZ1 & 303 & 3.8 & 4.1 & -35.7 & -10.6 \\
\hline SZ2 & 274 & 3.6 & 4.0 & -33.0 & -9.4 \\
\hline \multicolumn{6}{|l|}{ Others } \\
\hline Sully99 & 379 & 3.6 & 4.3 & -28.0 & -8.7 \\
\hline BB5 & 395 & 3.0 & 5.0 & -28.7 & -10.7 \\
\hline
\end{tabular}




\section{DISCUSSION}

By examining paired samples of black smoker chimney linings and the hydrothermal fluids flowing through them at the time of collection, it is possible to directly investigate the effects of hydrothermal fluid chemistry on mineral chemistry and search for proxies of hydrothermal fluid chemistry based on mineral trace element contents. Additionally, analyses of the same elements in hydrothermal fluids and the chalcopyrite linings of black smoker chimneys allows for investigation of trace element partitioning between hydrothermal fluids and chalcopyrite.

\subsection{Hydrothermal Fluid Chemistry}

Similarities between the measured temperatures, $\mathrm{pH}$, and zero-Mg endmember concentrations of major ions $(\mathrm{Na}, \mathrm{Li}, \mathrm{K}, \mathrm{Ca})$ and transition metals ( $\mathrm{Mn}, \mathrm{Fe}, \mathrm{Cu}, \mathrm{Zn}$ ) of vent fluids collected from the ABE, Tu'i Malila and Mariner vent fields in 2005, 2009, and 2015 suggest that vent fluid temperature and chemistry have been relatively stable over this time period. Between 2005 and 2009, vent fluids from the Kilo Moana vent field exhibited a systematic decrease in temperature and transition metal concentrations and an increase in vent fluid $\mathrm{pH}$ (Chapter 2 of this thesis). No hydrothermal activity was observed at the Kilo Moana vent field in 2015 (J. Seewald, A-L. Reysenbach, pers. comm. 2015). Vent fluids at the Mariner vent field exhibit a bimodal range of chlorinity and $\mathrm{H}_{2} \mathrm{~S}$ contents associated with phase separation at the seafloor and in the shallow subsurface (Takai et al, 2008; Mottl et al., 2011). However, there is no indication of systematic changes in high chloride or low chloride Mariner vent fluids between 2005 and 2015. Black smoker chimneys from the Mariner vent field were collected as sample 
pairs with the fluids flowing through them at the time of collection, allowing for comparison of the chemistry of black smoker chimney linings and hydrothermal fluids.

New analyses of $\mathrm{Mn}, \mathrm{Fe}, \mathrm{Cu}$, and $\mathrm{Zn}$ for hydrothermal vent fluids collected from the ELSC in 2015 agree with concentrations measured in fluids collected in 2005 reported in Mottl et al. (2011) and fluids collected in 2009 reported in Chapter 2 of this thesis. Data are consistent with the conclusions of previous studies, that concentrations of $\mathrm{Mn}, \mathrm{Fe}, \mathrm{Cu}$, and $\mathrm{Zn}$ in hydrothermal fluids are primarily controlled by the temperature- and $\mathrm{pH}$-sensitive solubility of minerals in the subsurface (e.g., Mottl and Holland, 1978; Seyfried et al., 1984; Von Damm, 1995). Similarities in variabilities of concentrations with temperature and $\mathrm{pH}$, as shown in plots of $\mathrm{Ga}$, and In vs. hydrothermal fluid temperature and $\mathrm{pH}$, suggest that these elements are likewise solubility controlled (Fig. 5A and 5B). Additionally, higher concentrations of Ga (and to a lesser extent, In) in the felsic-hosted ABE and Tu'i Malila vent fluids compared with similar temperature and $\mathrm{pH}$ vent fluids from the basalt-hosted Kilo Moana vent field and the Tahi Moana-1 vent field hosted in transitional lithology suggest some degree of lithologic control on Ga (and In) concentrations (Fig. 4C). In contrast to Ga and In, Co and Ni show significantly less difference in concentration as functions of temperature and $\mathrm{pH}$ than $\mathrm{Mn}, \mathrm{Fe}, \mathrm{Cu}, \mathrm{Zn}$, In, or $\mathrm{Ga}$ (Fig. 5A, 5B), while Ag concentrations do not correlate with temperature (Fig. 5B), and show some trend with $\mathrm{pH}$ (Fig. 5A), though some of that trend is due to local metal remobilization (e.g., RMR2, SZ5, RGR2) as opposed to reaction zone conditions (Craddock, 2009). For Co, higher concentrations in the Kilo Moana vent fluid KM9 compared with the higher temperature, lower $\mathrm{pH}$ vent fluids from Mariner vent field suggests that higher Co concentrations may be associated with basaltic as opposed to felsic lithology (Fig. 4C). Thus the shallower trends of Co 
and $\mathrm{Ni}$ vs temperature and $\mathrm{pH}$ are hypothesized to reflect limited $\mathrm{Co}$ and $\mathrm{Ni}$ along the fluid-rock reaction path for back-arc basin fluids.

Previous studies of hydrothermal vent fluids from the Vai Lili vent field on the ELSC (Fouquet et al., 1993), the TAG hydrothermal mound on the Mid-Atlantic Ridge (Tivey et al., 1995) and the PACMANUS vent fields in the Manus Basin (Craddock, 2009) have demonstrated the sensitivity of $\mathrm{Zn}$ and $\mathrm{Ag}$ concentrations to near-surface remobilization of previously deposited Zn- and Ag-rich sulfide. Typical evidence for significant subsurface remobilization includes highly elevated concentrations of $\mathrm{Zn}, \mathrm{Cd}, \mathrm{Ag}$, and $\mathrm{Pb}$ and low $\mathrm{pH}$ relative to hightemperature vent fluids from the same vent field (Fouquet et al., 1993; Tivey et al., 1995; Craddock, 2009). Such evidence is absent from the ELSC vent fluids analyzed here (but not for some of the Manus Basin vent fluids) and it is concluded that subsurface remobilization does not play a significant role in determining the metal concentrations of vent fluids from the Kilo Moana, Tahi Moana-1, ABE, Tu'i Malila or Mariner vent fields. 


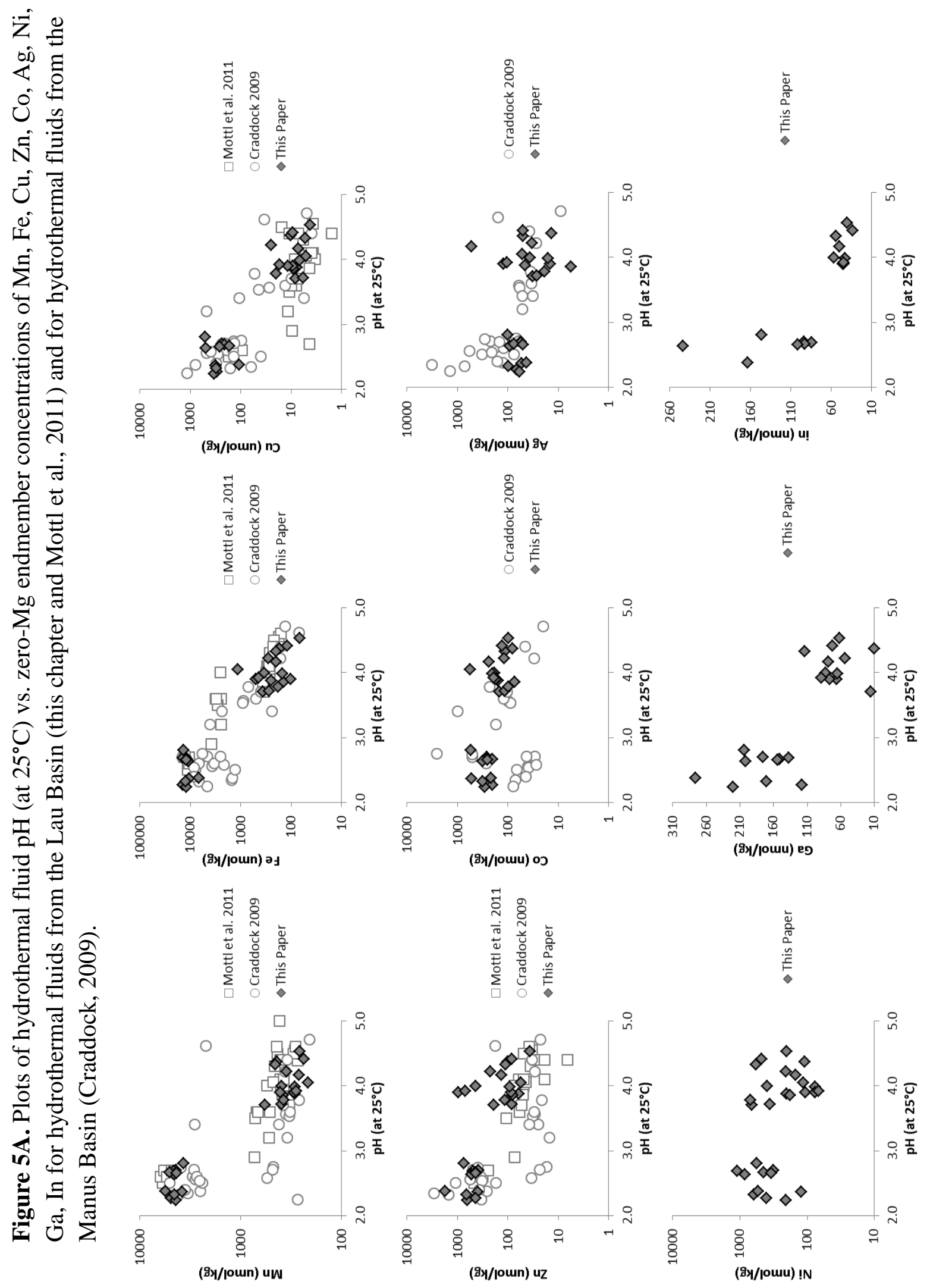




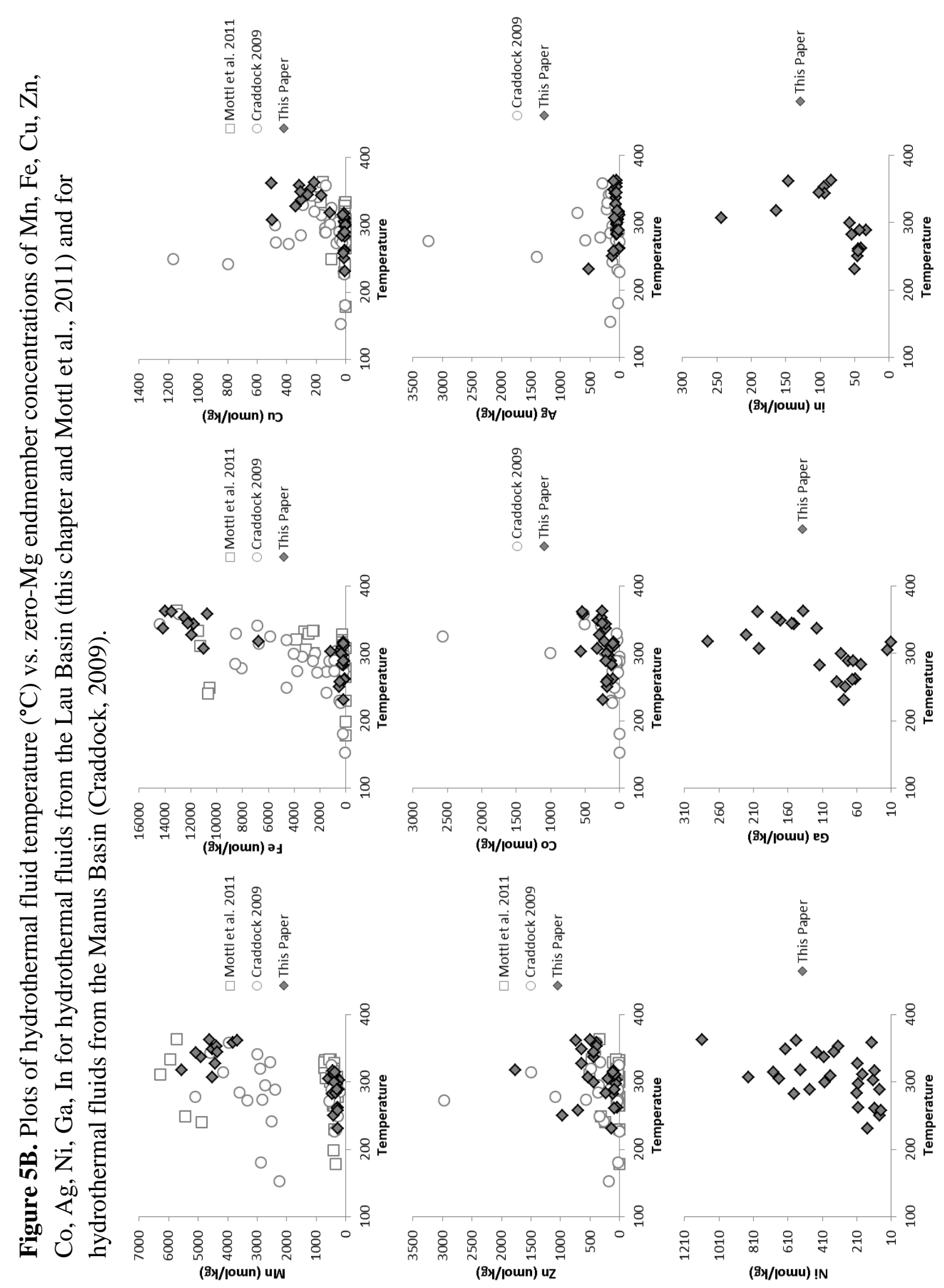




\subsection{Comparison of Fluid and Mineral Chemistry}

The analyses of $\mathrm{Cu}, \mathrm{Fe}, \mathrm{Co}, \mathrm{Ni}, \mathrm{Ag}, \mathrm{Ga}$, and In concentrations in ELSC hydrothermal vent fluids presented here can be compared with SIMS measurements of $\mathrm{Co}, \mathrm{Ni}, \mathrm{Ag}$, Ga, and In concentrations in the chalcopyrite linings of black smoker chimney samples that were in contact with these fluids at the time of collection (Chapter 3 of this thesis). Additional SIMS analyses of black smoker chimney linings from the Manus Basin, Main Endeavour Field on the Juan de Fuca Ridge, and Mid-Cayman Rise (also in Chapter 3 of this thesis) may likewise be compared with published trace element analyses of hydrothermal fluid pairs from these vent fields. Because of uncertainties in the SIMS calibration curves, especially at low concentrations, SIMS count ratios are used for the comparison. The compositions of the relevant fluids are presented in Tables 4A and 4B. Selected results of SIMS analyses presented in Chapter 3 of this thesis are presented in Table 7A with conversions to concentration units provided in Table 7B.

\subsubsection{Ag}

Comparing the trace element contents of paired black smoker chimneys and fluids, the $\mathrm{Ag}$ content of chalcopyrite black smoker chimney linings correlates with the ratio of $\mathrm{Ag}$ to $\mathrm{Cu}$ in the corresponding fluid (Fig. 6A). This correlation is improved if the Ag contents of black smoker chimney linings are compared with the ratios of the activities of the free ions, $\mathrm{Ag}^{+}$and $\mathrm{Cu}^{+}$obtained through thermodynamic fluid modelling (Fig. 6B; see Appendix B). 

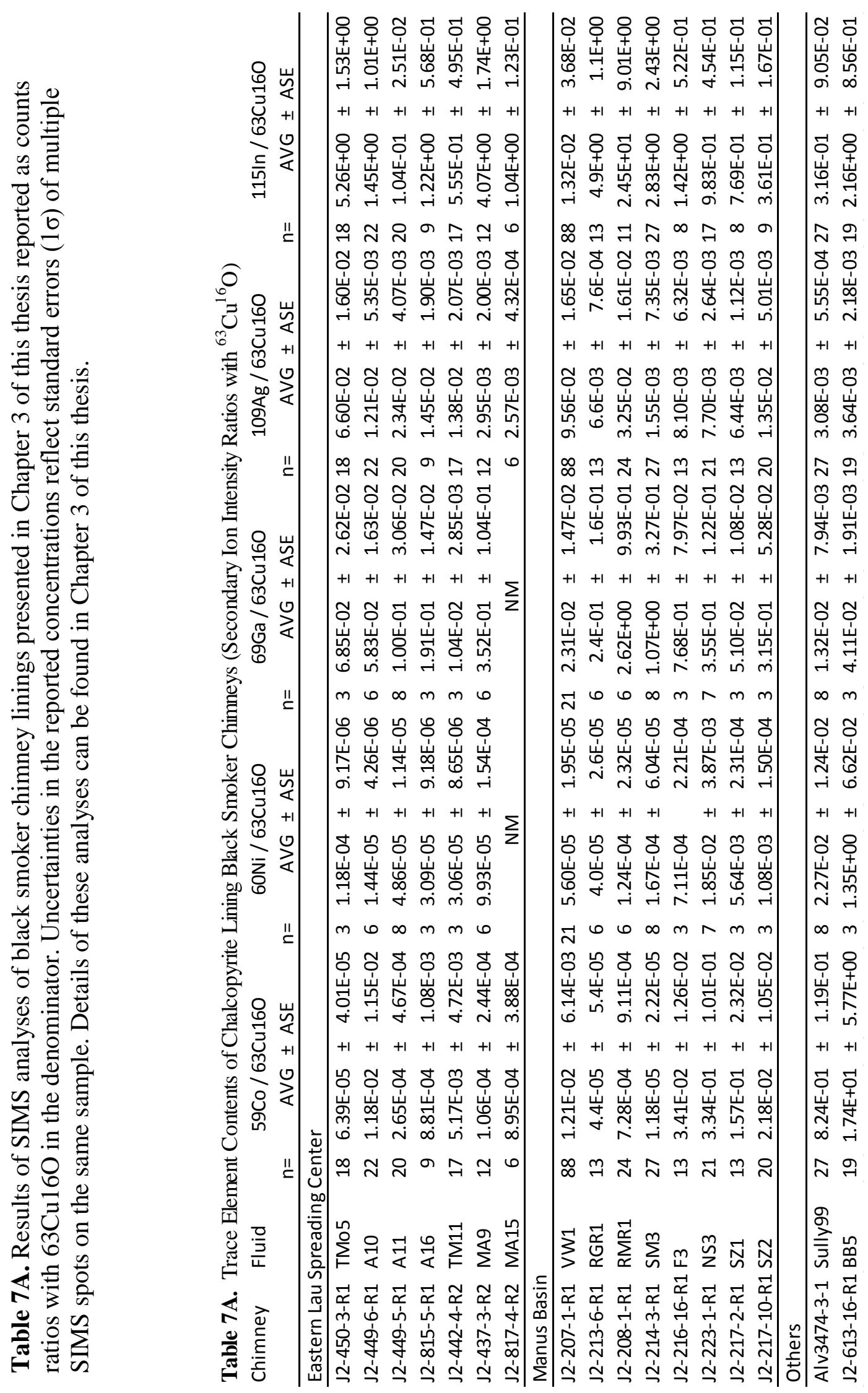
Table 7B. Trace Element in Chalcopyrite Lining Black Smoker Chimneys $(\mu \mathrm{g} / \mathrm{g})$

Concentrations in $\mu \mathrm{g} / \mathrm{g}$ were derived based on the SIMS calibration curves presented in Chapter 3 of this thesis. Uncertainties in the reported concentrations reflect standard errors $(1 \sigma)$ of multiple SIMS spots on the same sample. Details of these analyses can be found in Chapter 3 of this thesis.

\begin{tabular}{|c|c|c|c|c|c|c|}
\hline Chimney & Fluid & Co & $\mathrm{Ni}$ & $\mathrm{Ga}$ & $\mathrm{Ag}$ & In \\
\hline & & nean $\pm 1 \sigma$ & nean $\pm 1 \sigma$ & lean $\pm 1 \sigma$ & mean $\pm 1 \sigma$ & nean $\pm 1 \sigma$ \\
\hline \multicolumn{7}{|c|}{ Eastern Lau Spreading Center } \\
\hline J2-450-3-R1 & TMo5 & $\mathrm{bdl} \pm \mathrm{bdl}$ & $\mathrm{bdl} \pm \mathrm{bdl}$ & $1.3 \pm 0.5$ & $2600 \pm 600$ & $60 \pm 17$ \\
\hline$J 2-449-6-R 1$ & A10 & $0.5 \pm 0.2$ & $\mathrm{bdl} \pm \mathrm{bdl}$ & $1.1 \pm 0.3$ & $500 \pm 210$ & $20 \pm 11$ \\
\hline J2-449-5-R1 & A11 & $\mathrm{bdl} \pm \mathrm{bdl}$ & $\mathrm{bdl} \pm \mathrm{bdl}$ & $1.8 \pm 0.6$ & $900 \pm 160$ & $1.1 \pm 0.3$ \\
\hline$J 2-815-5-R 1$ & A16 & $\mathrm{bdl} \pm \mathrm{bdl}$ & $\mathrm{bdl} \pm \mathrm{bdl}$ & $3.5 \pm 0.3$ & $570 \pm 70$ & $13 \pm 6$ \\
\hline$J 2-442-4-R 2$ & TM11 & $0.2 \pm 0.2$ & $\mathrm{bdl} \pm \mathrm{bdl}$ & $0.19 \pm 0.05$ & $540 \pm 80$ & $6 \pm 5$ \\
\hline$J 2-43$ & MA9 & $\mathrm{bdl} \pm \mathrm{bdl}$ & $\mathrm{bdl} \pm \mathrm{bdl}$ & $6.4 \pm 1.9$ & $120 \pm 80$ & $40 \pm 19$ \\
\hline $\mathrm{J} 2-817-4-\mathrm{R} 2$ & MA15 & $\mathrm{bdl} \pm \mathrm{bdl}$ & NM & NM & $100 \pm 17$ & $11 \pm 1.3$ \\
\hline \multicolumn{7}{|c|}{ Manus Basin } \\
\hline J2-207-1-R1 & VW1 & $0.5 \pm 0.3$ & $\mathrm{bdl} \pm \mathrm{bdl}$ & $0.4 \pm 0.3$ & $3800 \pm 600$ & $0.1 \pm 0.4$ \\
\hline$J 2-213-6-R 1$ & RGR1 & $b d l \pm b d l$ & $\mathrm{bdl} \pm \mathrm{bdl}$ & $4.4 \pm 2.9$ & $260 \pm 30$ & $50 \pm 12$ \\
\hline R1 & RMR1 & $\mathrm{bdl} \pm \mathrm{bdl}$ & $\mathrm{bdl} \pm \mathrm{bdl}$ & $48 \pm 18$ & $1300 \pm 600$ & $50 \pm 12$ \\
\hline J2-214-3-R1 & SM3 & $\mathrm{bdl} \pm \mathrm{bdl}$ & $\mathrm{bdl} \pm \mathrm{bdl}$ & $20 \pm 6$ & $100 \pm 290$ & $31 \pm 26$ \\
\hline J2-216-16-R1 & F3 & $1.5 \pm 0.6$ & $15 \pm 15$ & $14.1 \pm 1.5$ & $300 \pm 250$ & $15 \pm 6$ \\
\hline J2-223-1-R1 & NS3 & $15 \pm 4$ & $21 \pm 16$ & $6.5 \pm 2.2$ & $300 \pm 100$ & $11 \pm 5$ \\
\hline J2-217-2-R1 & SZ1 & $6.9 \pm 1.0$ & $16 \pm 15$ & $0.93 \pm 0.20^{\top}$ & $250 \pm 40$ & $8.3 \pm 1.2$ \\
\hline $\mathrm{J} 2-217-10-\mathrm{R} 1$ & $\mathrm{SZ2}$ & $1.0 \pm 0.5$ & $15 \pm 15$ & $5.8 \pm 1.0$ & $500 \pm 200$ & $3.9 \pm 1.8$ \\
\hline \multicolumn{7}{|l|}{ Others } \\
\hline Alv3474-3-1 & Sully99 & $36 \pm 5$ & $20 \pm 19$ & $0.2 \pm 0.1$ & $120 \pm 22$ & $3.4 \pm 1.0$ \\
\hline J2-613-16-R1 & BB5 & $760 \pm 250$ & $480 \pm 40$ & $0.75 \pm 0.04$ & $140 \pm 85$ & $23 \pm 9$ \\
\hline
\end{tabular}


Previous studies have posited that $\mathrm{Ag}^{+}$substitutes for $\mathrm{Cu}^{+}$in the chalcopyrite lattice $\left(\left(\mathrm{Cu}^{+}\right.\right.$, $\left.\mathrm{Ag}^{+}\right) \mathrm{Fe}^{3+} \mathrm{S}_{2}$; e.g., Huston et al., 1995). Assuming that Ag regularly partitions into chalcopyrite according to the definition provided by McIntire (1963), the following equation may be applied:

$$
D_{h f, c p}=\frac{\frac{\left\{\mathrm{Ag}^{+}\right\}_{h f}}{\left\{C u^{+}\right\}_{h f}}}{\frac{(A g)_{c p}}{(C u)_{c p}}}
$$

where $\mathrm{D}_{\mathrm{hf}, \mathrm{cp}}$ is the partitioning coefficient between hydrothermal fluid (hf) and chalcopyrite (cp), the top term on the right hand side of the equation is the thermodynamic activity ratio of free (i.e. uncomplexed) $\mathrm{Ag}^{+}$to free $\mathrm{Cu}^{+}$in the hydrothermal fluid and the bottom term is the molar ratio of $\mathrm{Ag}$ to $\mathrm{Cu}$ in the corresponding chalcopyrite. By comparing the black smoker chimney linings and fluids investigated here, the partitioning coefficient is $\mathrm{D}_{\mathrm{hf}, \mathrm{cp}}=1.37 \pm 0.04$.

With the exception of a few samples from the PACMANUS vent fields of the Manus Basin, the concentration of $\mathrm{Ag}$ in black smoker chimney linings positively correlates with hydrothermal fluid $\mathrm{pH}$ (Fig. 7A). This correlation can be explained by regular partitioning of $\mathrm{Ag}$ into chalcopyrite combined with the relatively greater sensitivity of $\mathrm{Cu}$ concentrations in hydrothermal fluids to hydrothermal fluid $\mathrm{pH}$. That is, vent fluid $\mathrm{Cu}$ concentrations are greatest when reaction zones are high temperature and low $\mathrm{pH}$. While both $\mathrm{Cu}$ and $\mathrm{Ag}$ concentrations in hydrothermal fluids are greater at low $\mathrm{pH}$, the $\mathrm{Ag}$ : $\mathrm{Cu}$ ratio is low at low $\mathrm{pH}$ and high at high $\mathrm{pH}$, except in cases where there has been metal remobilization, for example at the Roman Ruin's vent field (Fig. 7B to 7D). The occurence of Ag-rich black smoker chimney lining associated with low $\mathrm{pH}$ hydrothermal fluids at the PACMANUS vent fields can be explained by elevated concentrations of $\mathrm{Ag}$ in these vent fields attributed to sub-surface dissolution and remobilization 
of previously precipitated $\mathrm{Zn}$ - and Ag-rich massive sulfides that significantly enrich fluids in $\mathrm{Zn}$, Cd, Ag, Pb, but not Cu (Craddock, 2009).

\section{Figure 6A}

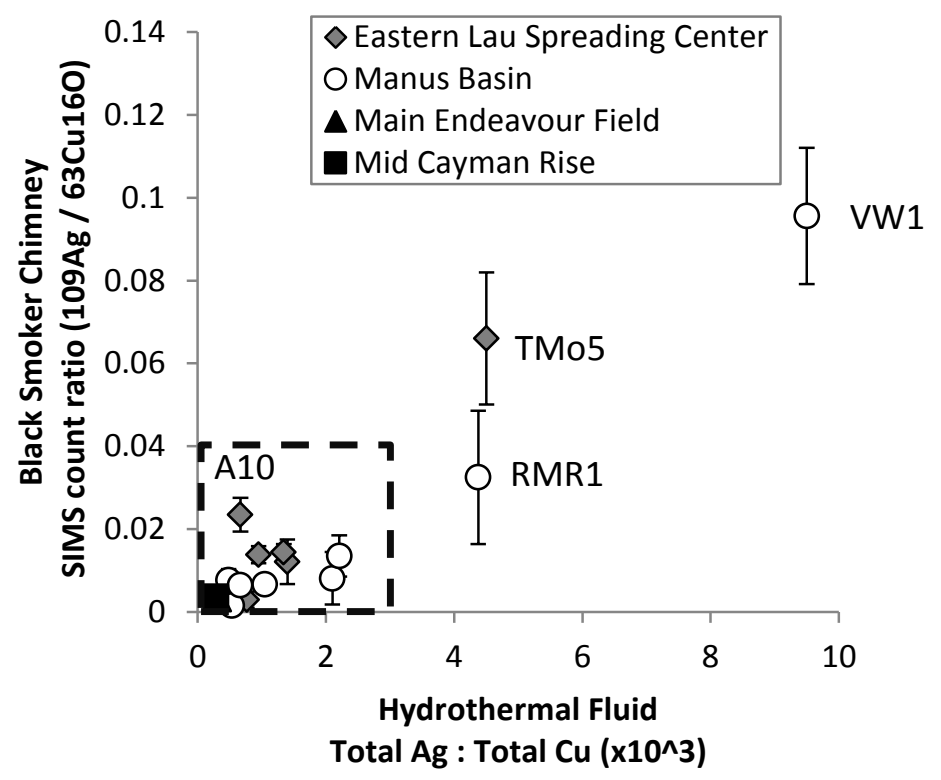

Figure 6B

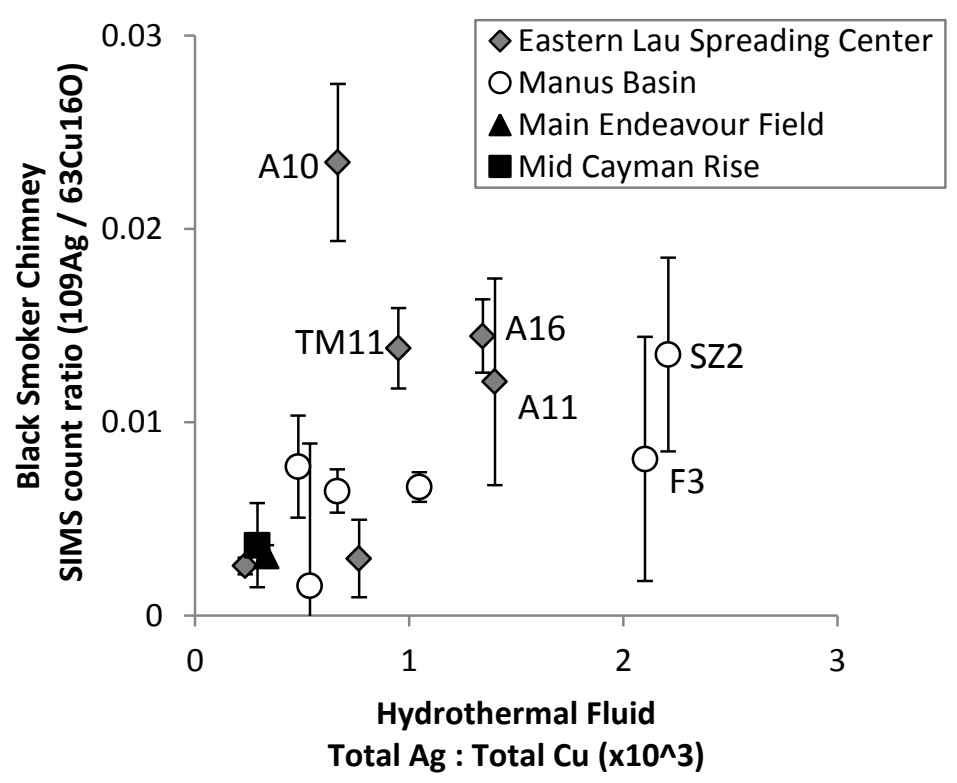

\section{Figures 6A to 6D.}

Plots of (A and $\mathrm{B})$ the ratios of $\mathrm{Ag}: \mathrm{Cu}$ total concentrations measured in hydrothermal fluids and $(\mathrm{C}$ and $\mathrm{D})$ the ratios of $\mathrm{Ag}^{+}: \mathrm{Cu}^{+}$free ion activities as calculated by EQ3/6 modelling vs. the SIMS counts ratios of ${ }^{109} \mathrm{Ag} /{ }^{63} \mathrm{Cu}^{16} \mathrm{O}$ for chalcopyrite grains along the innermost linings of paired black smoker chimney samples. Dashed boxes in Fig. 6A and 6C are the extent of close-up views of the same plots in Fig. 6B and 6D. All SIMS data are from Chapter 3 of this thesis (Table 7A). Data for vent fluids from the Eastern Lau Spreading Center are from this paper, data for vent fluids in the Manus Basin are from Craddock (2009), data for fluid Sully99 from the Main Endeavour Field are from Seyfried et al. (2003) and data for fluid BB5 from the Beebe / Piccard vent field are from McDermott (2015) (Supplementary Table S6). Uncertainties in SIMS count ratios reflect standard errors $(1 \sigma)$ of multiple SIMS spots on the same sample. Details of these analyses can be found in Chapter 3 of this thesis. 
Figure 6C

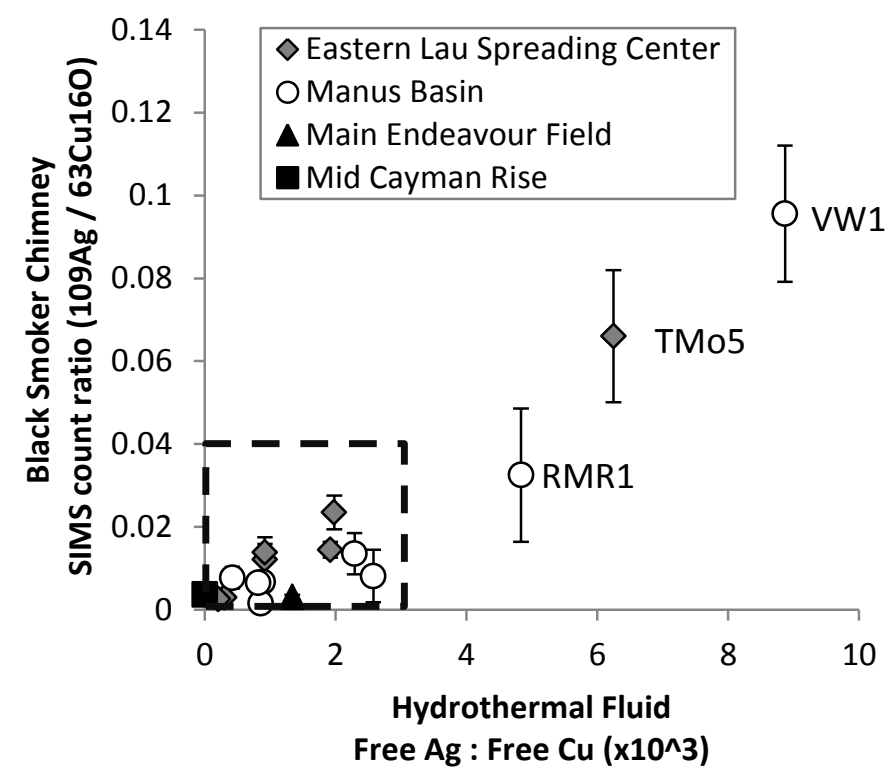

Figure 6D

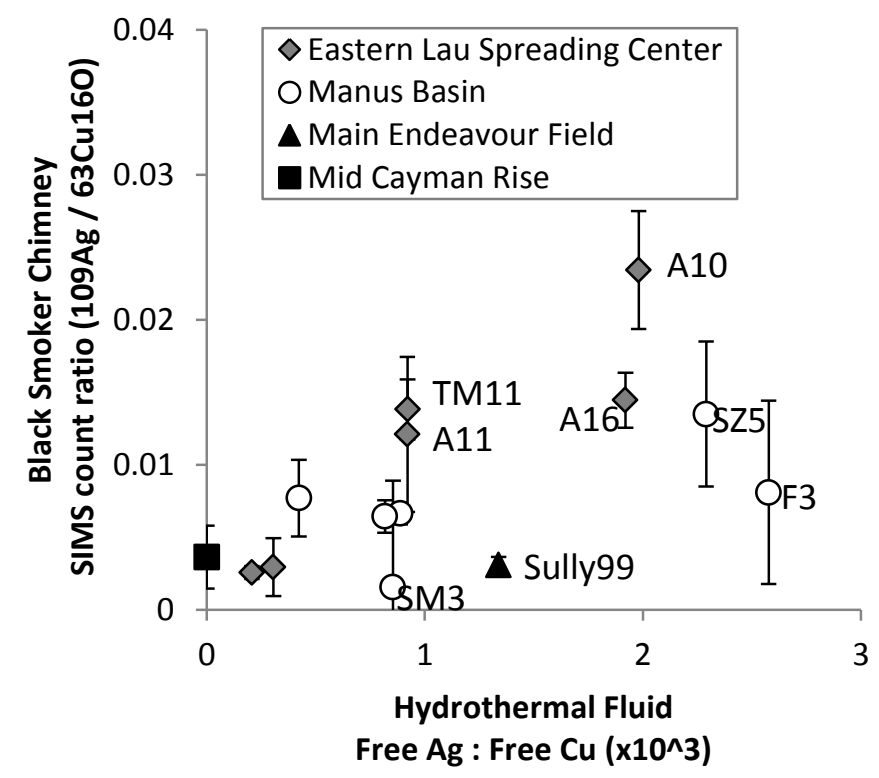


Figure 7A

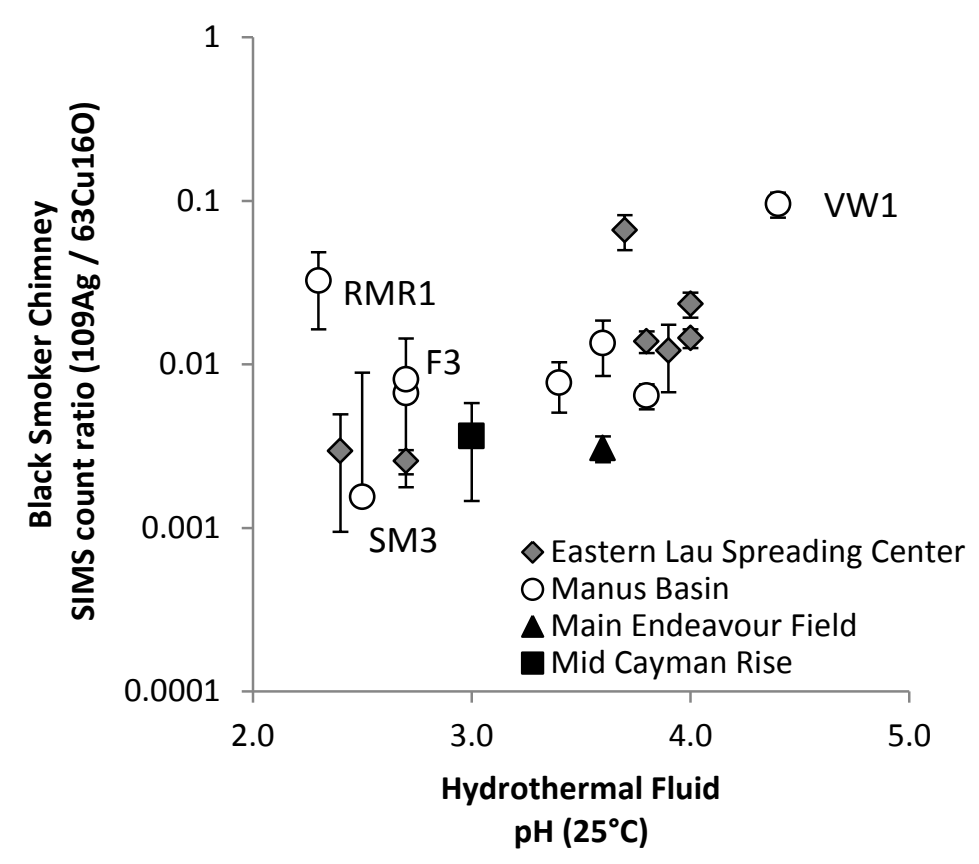

Figure 7B

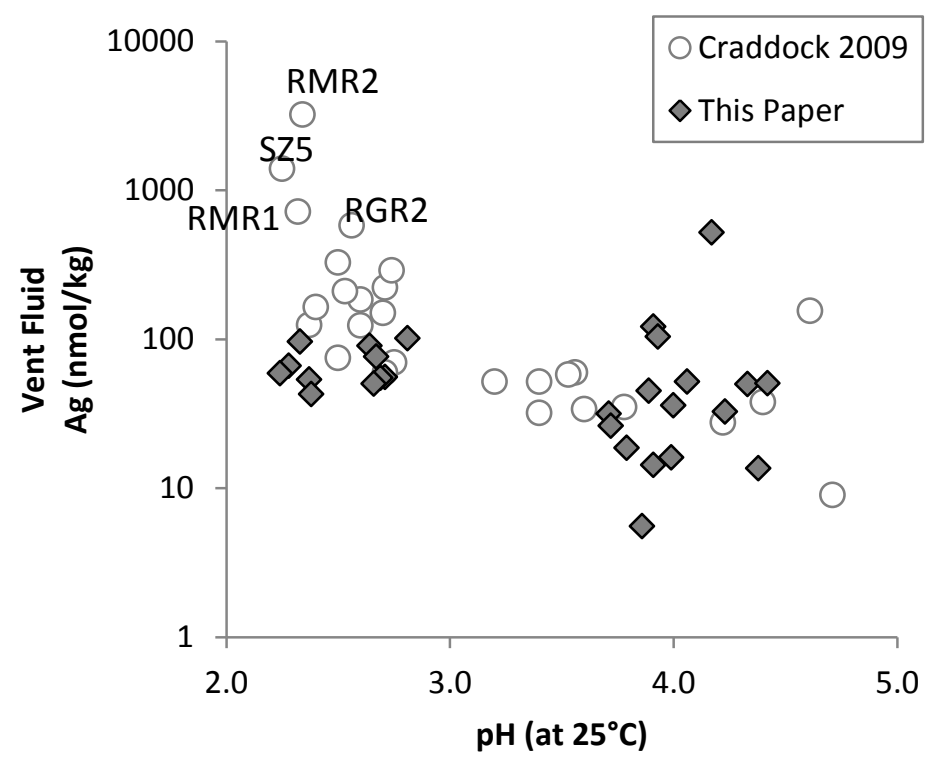

Figures 7A to 7D.

Plots of hydrothermal fluid $\mathrm{pH}$ (at $25^{\circ} \mathrm{C}$ ) vs. (A) SIMS counts ratios of ${ }^{109} \mathrm{Ag} /$ ${ }^{63} \mathrm{Cu}^{16} \mathrm{O}$ for chalcopyrite grains along the innermost linings of paired black smoker chimney samples, (B) the zero-Mg endmember Ag concentration of the fluid, (C) the zero-Mg endmember $\mathrm{Cu}$ concentration of the fluid, and (D) the total concentration ratio of Ag: $\mathrm{Cu}$ in the fluid. Data for vent fluids from the Eastern Lau Spreading Center are from this paper, data for vent fluids in the Manus Basin are from Craddock (2009) (Supplementary Table S7). SIMS data are from Chapter 3 of this thesis (Table7A). Uncertainties in SIMS count ratios reflect standard errors $(1 \sigma)$ of multiple SIMS spots on the same sample. Details of these analyses can be found in Chapter 3 of this thesis. 
Figure 7C

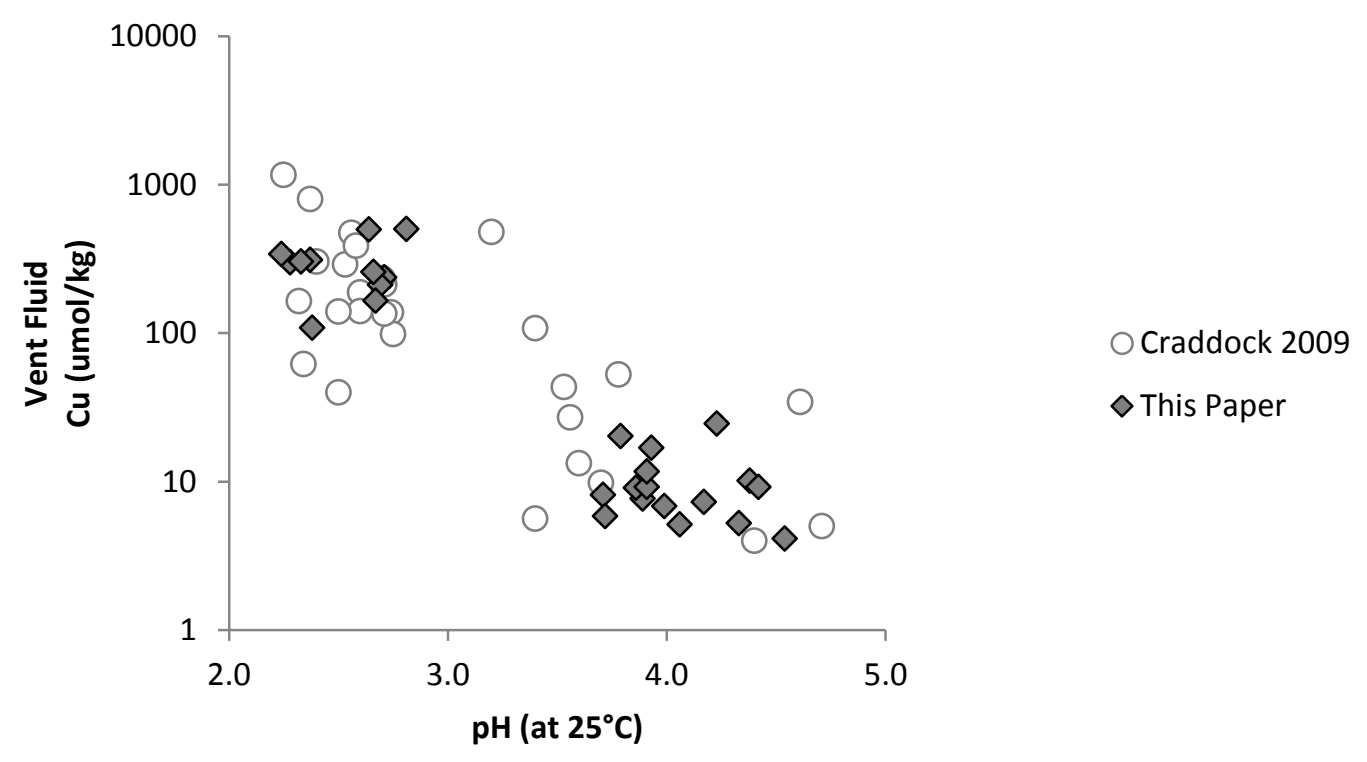

Figure 7D

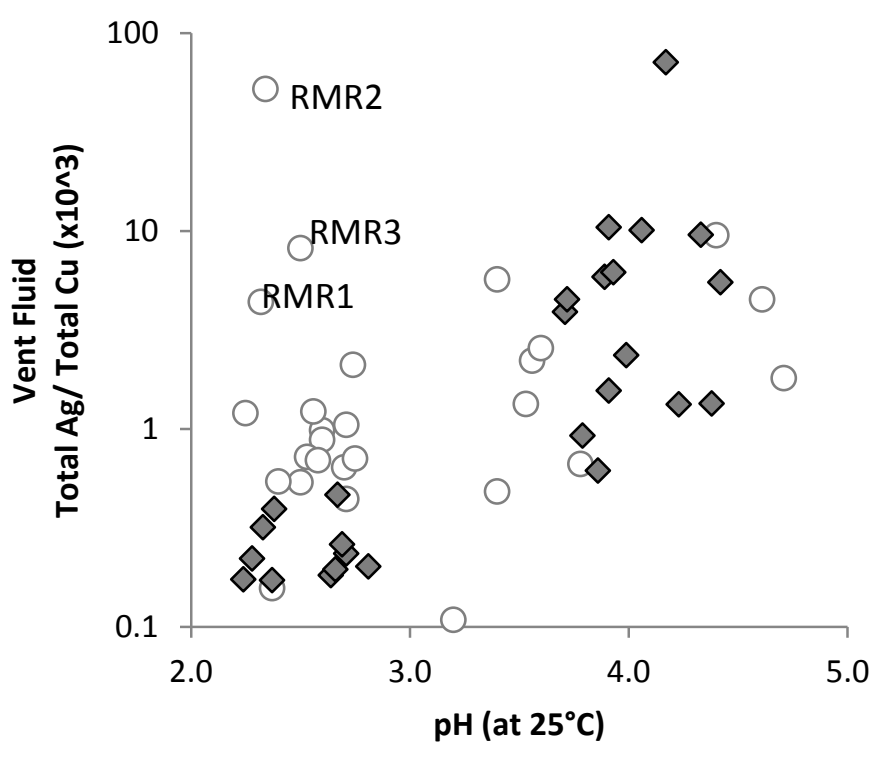

O Craddock 2009

$\diamond$ This Paper 


\subsubsection{Ga and In}

As discussed in Chapter 3 of this thesis, the Ga and In contents of chalcopyrite lining black smoker chimneys correlate with the $\mathrm{pH}$ of paired vent fluids (Fig. 8A and 8B), likely owing to the effect of hydroxide complexing (more prevalent at higher $\mathrm{pH}$ ) on free $\mathrm{Ga}^{3+}$ and $\mathrm{In}^{3+}$ concentrations. Thermodynamic fluid modelling allows for a comparison of $\mathrm{Ga}$ and In contents of black smoker chimney linings with in situ fluid $\mathrm{pH}$, which is likewise correlated (Fig. 8C and 8D). Compared with the lower-temperature, higher-pH vent fluids collected at the ABE and Tu'i Malila vent fields, total concentrations of Ga and In in the high-temperature, low-pH Mariner vent fluids are higher by a factor of 3 and 2, respectively. Data for Ga concentrations in paired hydrothermal fluids and black smoker chimney linings are only available for six samples from the Eastern Lau Spreading Center. The Ga concentrations of black smoker chimney linings for these samples correlate with free $\mathrm{Ga}^{3+}$ to free $\mathrm{Fe}^{2+}$ ratios calculated for paired hydrothermal fluids, but not the ratio of total Ga to total Fe (Fig. 9A, 9B). For In there are not enough data (data are only available for two fluid-chimney pairs) to examine trends.

Presumably, similar to $\mathrm{Ag}^{+}$substituting for $\mathrm{Cu}^{+}, \mathrm{Ga}^{3+}$ and $\mathrm{In}^{3+}$ are present in chalcopyrite as lattice substitutions for $\mathrm{Fe}^{3+}$. If this is the case, then a possible explanation for the observed negative correlation between hydrothermal fluid $\mathrm{pH}$ and the Ga and In contents of paired black smoker chimney linings is complexing of $\mathrm{Ga}$ and $\mathrm{In}$ by $\mathrm{OH}^{-}$, as discussed by Wood and Samson (2006). At higher $\mathrm{pH}$, the activity of $\mathrm{OH}^{-}$is high, $\mathrm{Ga}$ and In are predominantly complexed, and the activity of the free ions is low relative to the total concentrations of these elements. Hence, the $\mathrm{Ga}$ and In contents of paired black smoker chimney linings will be low at high $\mathrm{pH}$ and conversely higher at low $\mathrm{pH}$. Thermodynamic fluid modelling performed here confirms that $\mathrm{Ga}$ is predominantly complexed as $\mathrm{Ga}(\mathrm{OH})^{+2}$ while $\mathrm{In}$ is primarily complexed as $\mathrm{InCl}^{+2}$ and 
secondarily as $\operatorname{In}(\mathrm{OH})^{+2}$ (see Appendix B). However, thermodynamic data for $\mathrm{Ga}$ and In complexes at the conditions of interest are highly uncertain (Woods and Samson, 2006). Figure $10 \mathrm{~A}$ shows complexes of $\mathrm{Ga}$ at $200^{\circ} \mathrm{C}$ and $300^{\circ} \mathrm{C}$ at vapor saturated pressure as a function of $\mathrm{pH}$ (Wood and Samson, 2006). Figure 10B shows complexes of In as a functions of $\mathrm{pH}$ at $200^{\circ} \mathrm{C}$ and vapor saturated pressure (Charlotte Ashworth, pers. comm.). There are data for $\mathrm{InCl}$ complexes in a paper that is currently in review (Charlotte Ashworth, pers. comm.). In future there is a need to make more measurements of In and Ga on paired vent fluids and chalcopyrite linings, and to then model the free concentrations using additional updated thermodynamic data. 
Figure 8A

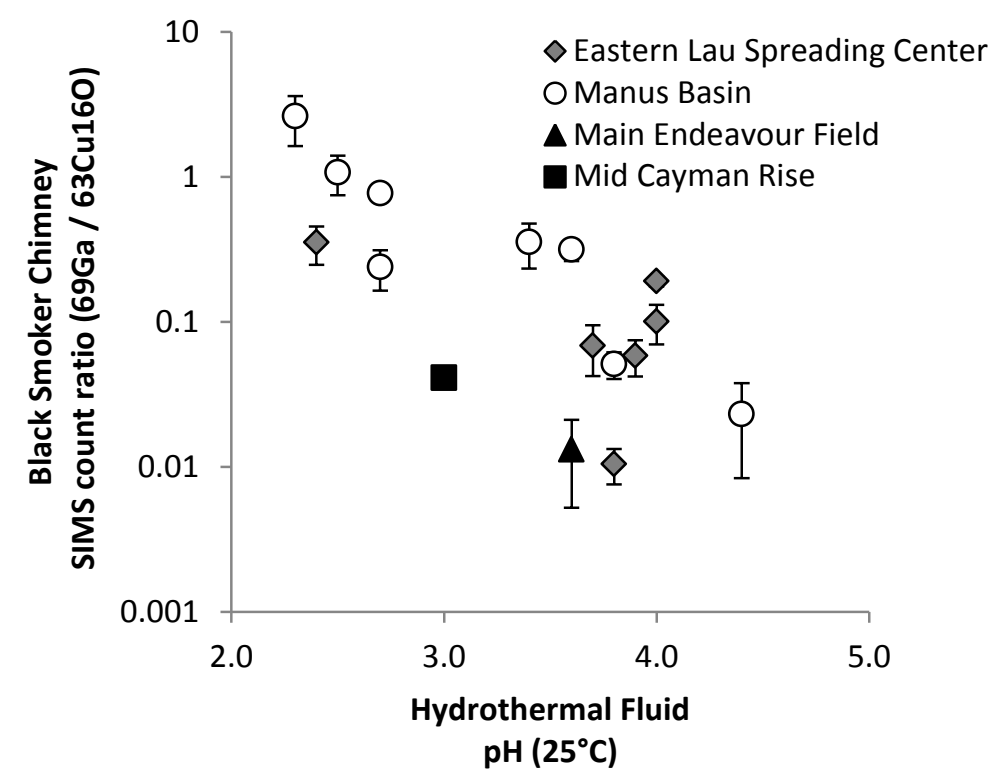

Figure 8B

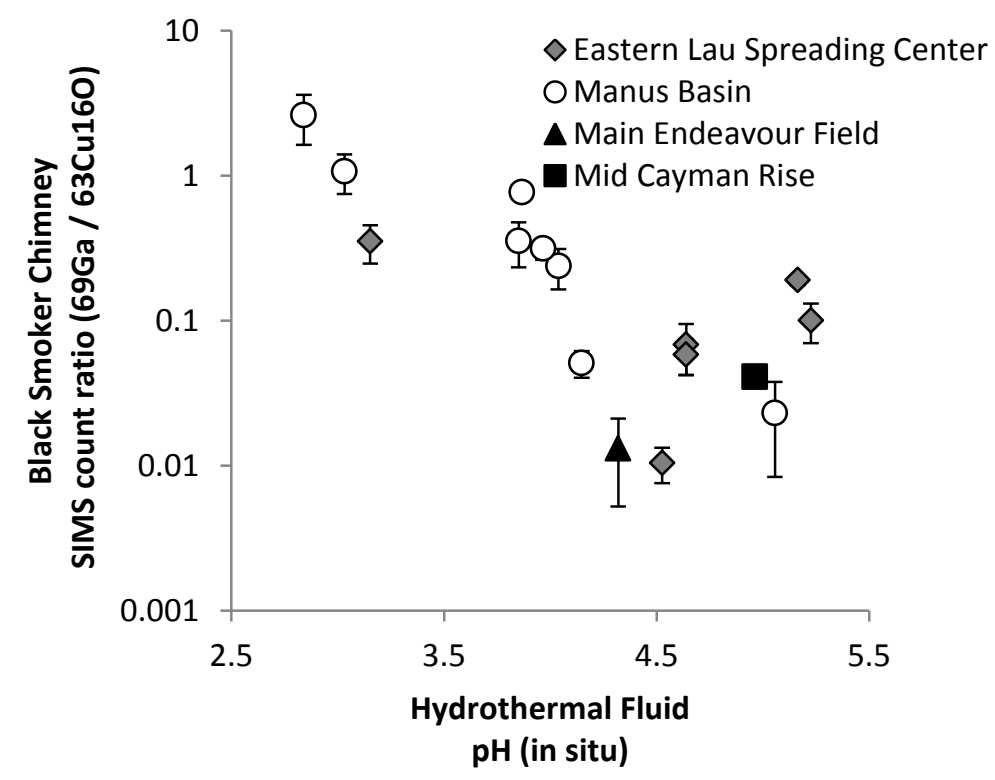

\section{Figures 8A to 8D}

Plots of (A) hydrothermal fluid $\mathrm{pH}$ (at $25^{\circ} \mathrm{C}$ ) vs. SIMS counts ratios of ${ }^{69} \mathrm{Ga} /{ }^{63} \mathrm{Cu}^{16} \mathrm{O}(\mathrm{B})$ hydrothermal fluid $\mathrm{pH}$ (in situ) vs. SIMS counts ratios of ${ }^{69} \mathrm{Ga}$ $/{ }^{63} \mathrm{Cu}^{16} \mathrm{O}$, (C) hydrothermal fluid $\mathrm{pH}$ (at $25^{\circ} \mathrm{C}$ ) vs. SIMS counts ratios of ${ }^{115} \mathrm{In} /{ }^{63} \mathrm{Cu}^{16} \mathrm{O}$, and (D) hydrothermal fluid $\mathrm{pH}$ (in situ) vs. SIMS counts ratios of ${ }^{115} \mathrm{In} /{ }^{63} \mathrm{Cu}^{16} \mathrm{O}$ for sample pairs of black smoker fluids and chimney linings. All SIMS data are from Chapter 3 of this thesis (Table 7A). Data for vent fluids from the Eastern Lau Spreading Center are from this paper, data for vent fluids in the Manus Basin are from Craddock (2009), data for fluid Sully99 from the Main Endeavour Field are from Seyfried et al.(2003) and data for fluid BB5 from the Beebe / Piccard vent field are from McDermott (2015) (Supplementary Table S7). Uncertainties in SIMS count ratios reflect standard errors $(1 \sigma)$ of multiple SIMS spots on the same sample. Details of these analyses can be found in Chapter 3 of this thesis. 
Figure 8C

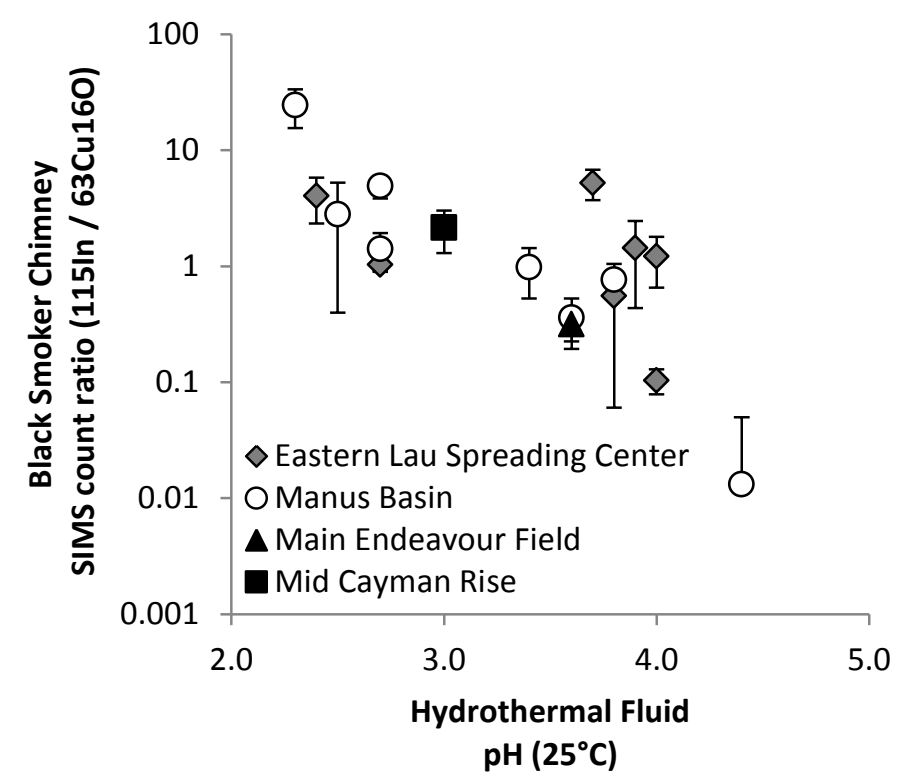

Figure 8D

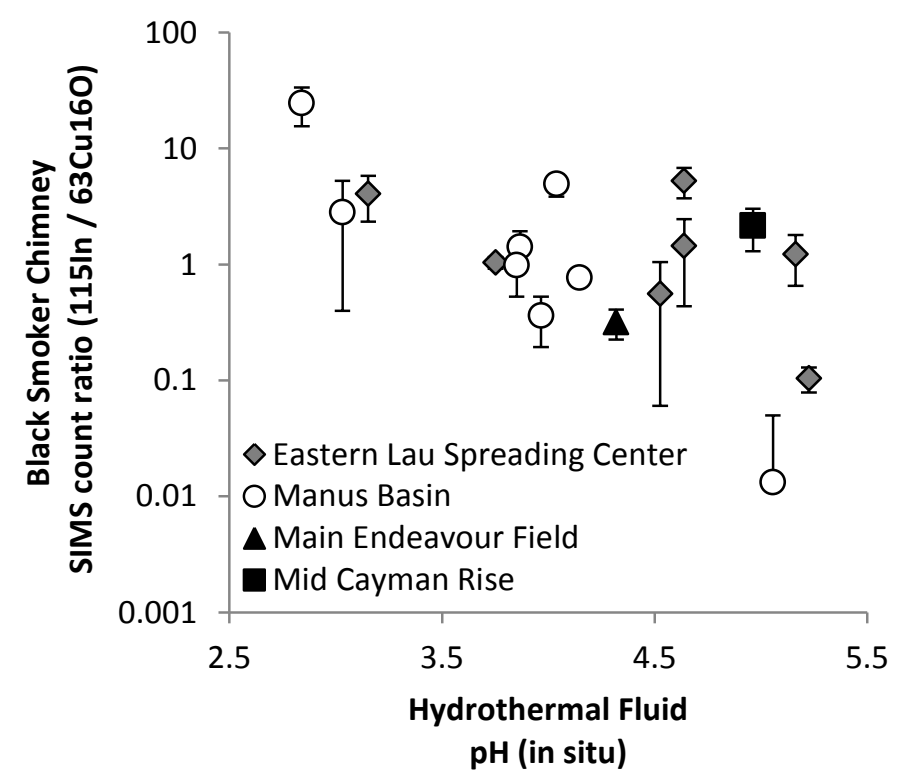


Figure 9. Plots of (A) the total Ga concentrations of hydrothermal fluids (Supplementary Table S7) and (B) the ratio of free $\mathrm{Ga}^{3+}$ to free $\mathrm{Fe}^{2+}$ calculated by EQ3/6 (Supplementary Table S7) vs. SIMS counts ratios of ${ }^{69} \mathrm{Ga} /{ }^{63} \mathrm{Cu}^{16} \mathrm{O}$ in chalcopyrite lining paired black smoker chimneys. SIMS data are from Chapter 3 of this thesis (Table 7A). Uncertainties in SIMS count ratios reflect standard errors $(1 \sigma)$ of multiple SIMS spots on the same sample. Details of these analyses can be found in Chapter 3 of this thesis.

Figure 9A

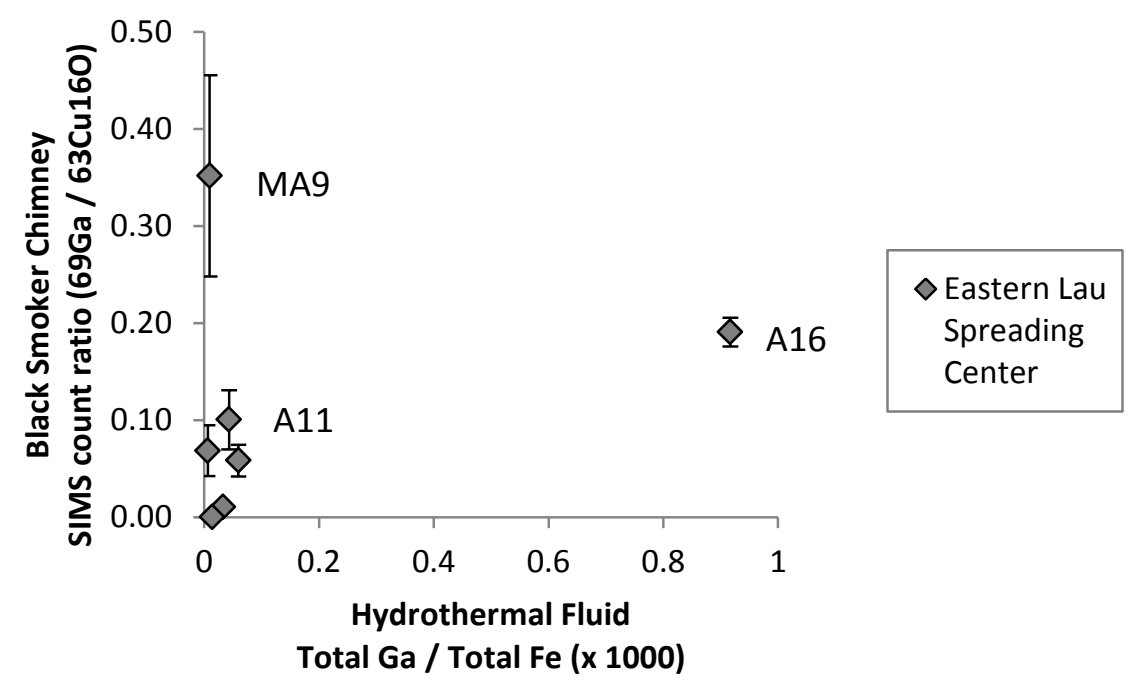

Figure 9B

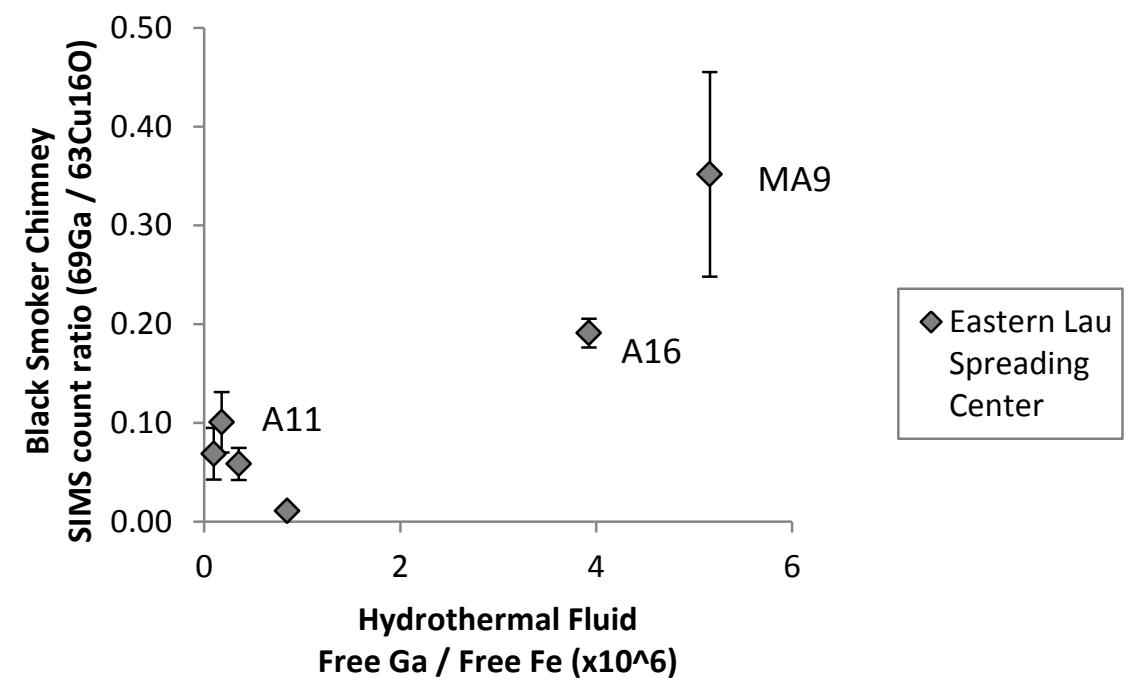


Figure 10. (A) Plots from Wood and Samson (2006) of $\mathrm{pH}$ vs. the log concentration of aqueous Ga complexes contributing to the solubility of $\mathrm{GaOOH}$ at $200^{\circ} \mathrm{C}$ and $300^{\circ} \mathrm{C}$ at vapor saturated pressures using the thermodynamic data of Benézéth et al. (1997) and (B) pH vs. the log concentration of aqueous In complexes contributing to the solubility of $\operatorname{In}_{2} \mathrm{~S}_{3}$ at $20^{\circ} \mathrm{C}$ and $1 \mathrm{M}$ $\mathrm{NaClO}_{4}$, total $\mathrm{S}=0.01 \mathrm{M}$ using thermodynamic data from Tunaboylu and Schwarzenbach (1970). Red lines highlight the concentrations of free ions, $\mathrm{Ga}^{3+}$ and $\mathrm{In}^{3+}$, as a function of $\mathrm{pH}$. (C) Plot of $\mathrm{pH}$ vs. $\log$ concentration of In complexes at $200^{\circ} \mathrm{C}$ (Charlotte Ashworth, pers. comm.)

Figure 10A
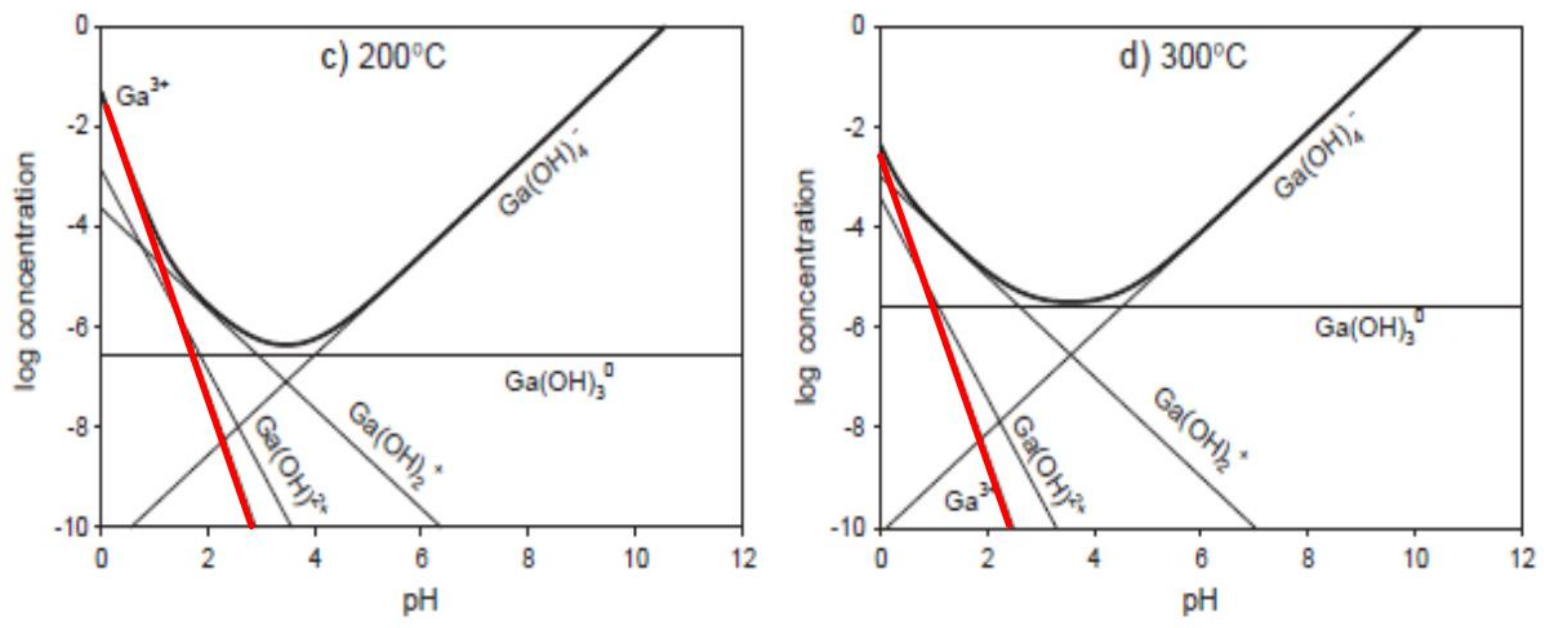

Figure 10B

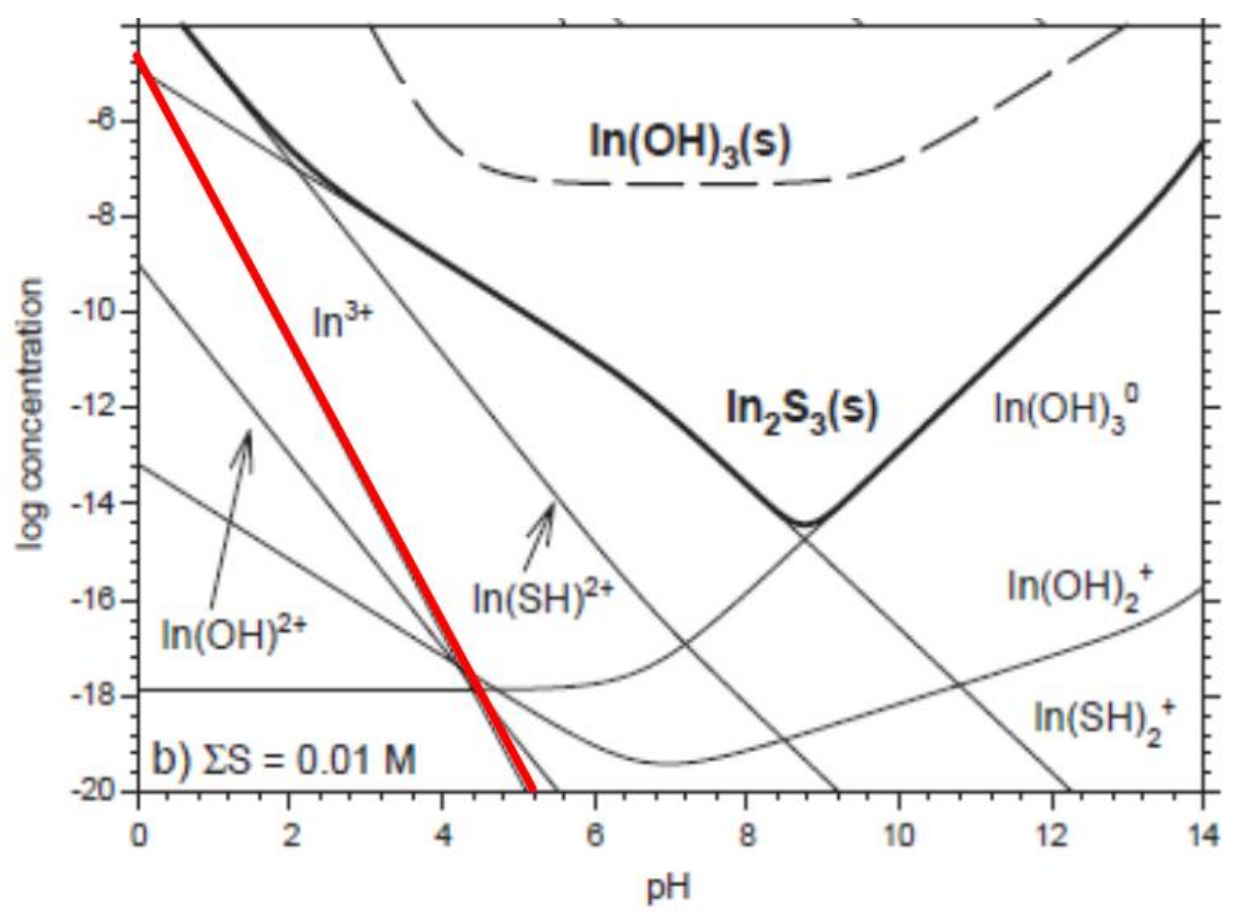


Figure 10C

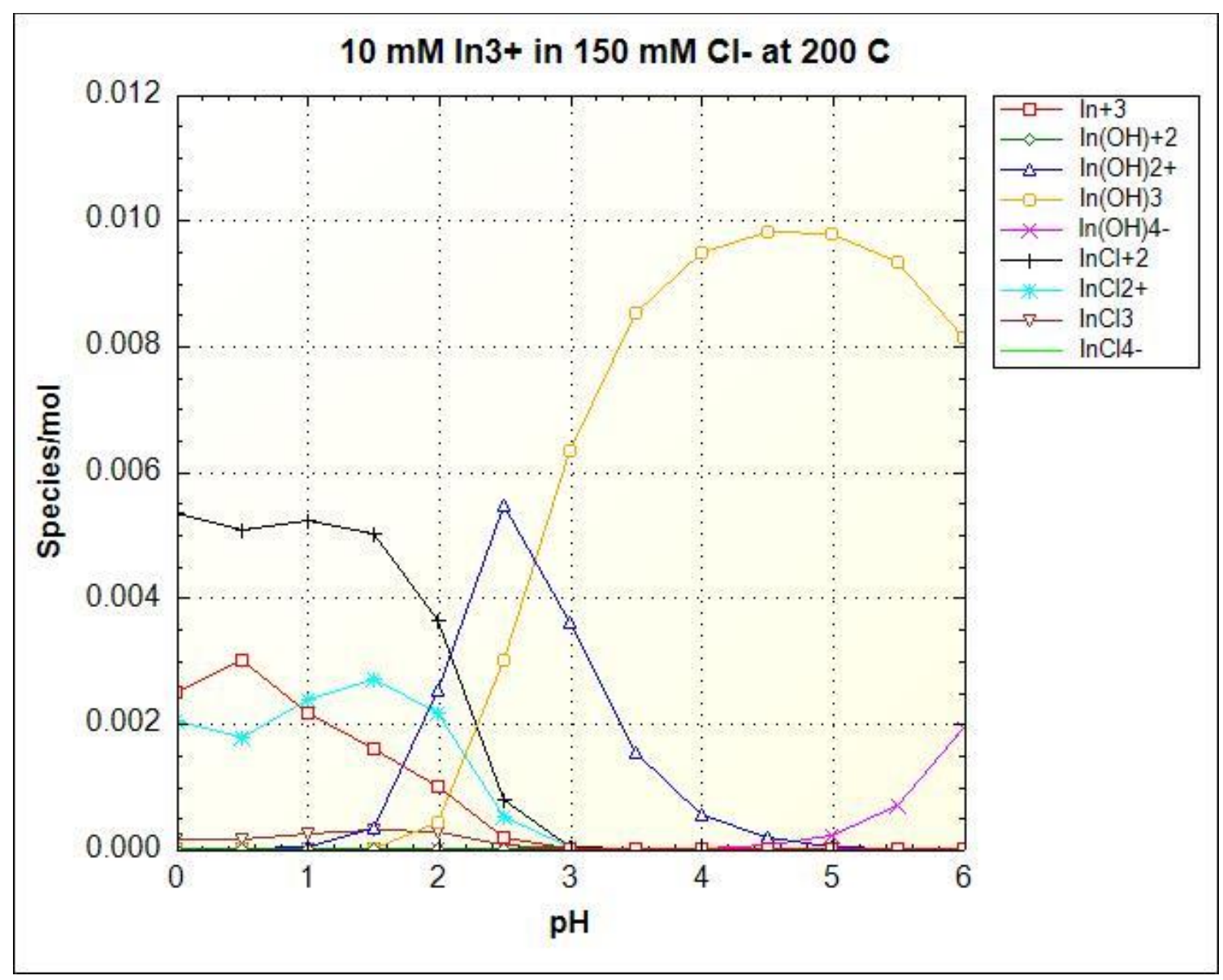

\subsubsection{Co and Ni}

No clear patterns or correlations were observed between the $\mathrm{Co}$ and $\mathrm{Ni}$ contents of black smoker chimney linings and the temperature, $\mathrm{pH}, \mathrm{fO}_{2}, \mathrm{fS}_{2}$, free or total Co or $\mathrm{Ni}$ concentrations or ratios of these elements to $\mathrm{Cu}$ or $\mathrm{Fe}$ (Fig. 11). As discussed in Chapter 3 of this thesis, the Co and $\mathrm{Ni}$ contents of black smoker chimney linings correlate with each other except in more felsic hosted systems where concentrations of both Co and Ni are very low (Fig. 4A of Chapter 3). Additionally, data from basalt-hosted hydrothermal systems (discussed in Chapter 3) show correlations between hydrothermal fluid temperature and the Co and Ni contents of black smoker chimney linings, especially among samples from the southern East Pacific Rise. These black 
smoker chimney samples are not considered in this chapter, because no Co and Ni data are available for the associated hydrothermal fluids. However, the lack of correlation between the Co content of black smoker chimney linings and the ratio of $\mathrm{Co}$ to $\mathrm{Fe}$ or $\mathrm{Cu}$ for fluids sampled from the Manus Basin, Mid-Cayman Rise, and Main Endeavour Field on the Juan de Fuca Ridge, which share the correlation between $\mathrm{Co}$ and $\mathrm{Ni}$, suggest that $\mathrm{Co}$ (and likely $\mathrm{Ni}$ ) concentrations in chimney linings are not primarily controlled by the Co content of hydrothermal fluids or the ratio of free $\mathrm{Co}^{2+}$ to free $\mathrm{Cu}^{+}$or free $\mathrm{Fe}^{2+}$.

Alternatively, crystal chemistry may play an important role in determining the Co content of black smoker chimney linings. The idea that more Fe-rich intermediate solid solutions (e.g., $\mathrm{CuFe}_{2} \mathrm{~S}_{3}, \mathrm{CuFe}_{3} \mathrm{~S}_{4}$ ) will host higher Co concentrations than chalcopyrite has been previously proposed (e.g., Rouxel et al., 2004). Such Fe-rich compositions are associated with lower sulfidation states which are in turn associated with more mafic lithologies (Kojima and Sugaki, 1985; Sack and Ebel, 2006; Einaudi, 2006). This hypothesis is supported by studies of metal valence in cubanite $\left(\mathrm{CuFe}_{2} \mathrm{~S}_{3}\right)$ that propose a valence structure of $\mathrm{Cu}^{+} \mathrm{Fe}^{2+} \mathrm{Fe}^{3+} \mathrm{S}_{3}$ (Greenwood and Whitfield, 1968; Goh et al., 2010). The presence of $\mathrm{Fe}^{2+}$ in the cubanite crystal lattice provides a substitution site for divalent $\mathrm{Co}^{2+}$ and $\mathrm{Ni}^{2+}$, in contrast to the chalcopyrite valence structure, where $\mathrm{Fe}$ is trivalent (i.e., $\mathrm{Cu}^{+} \mathrm{Fe}^{3+} \mathrm{S}_{2}$, Pearce et al., 2006). Electron microprobe analyses of samples J2-613-16-R1 from the Beebe/Piccard vent field on the Mid-Cayman Rise document intermediate composition between chalcopyrite $\left(\mathrm{CuFeS}_{2}\right)$ and isocubanite $\left(\mathrm{CuFe}_{2} \mathrm{~S}_{3}\right)$ (Fig. 12). Further testing of the effect of crystal chemistry on Co and Ni concentrations in black smoker chimney linings can be achieved by coordinating SIMS and electron microprobe studies of these samples. 

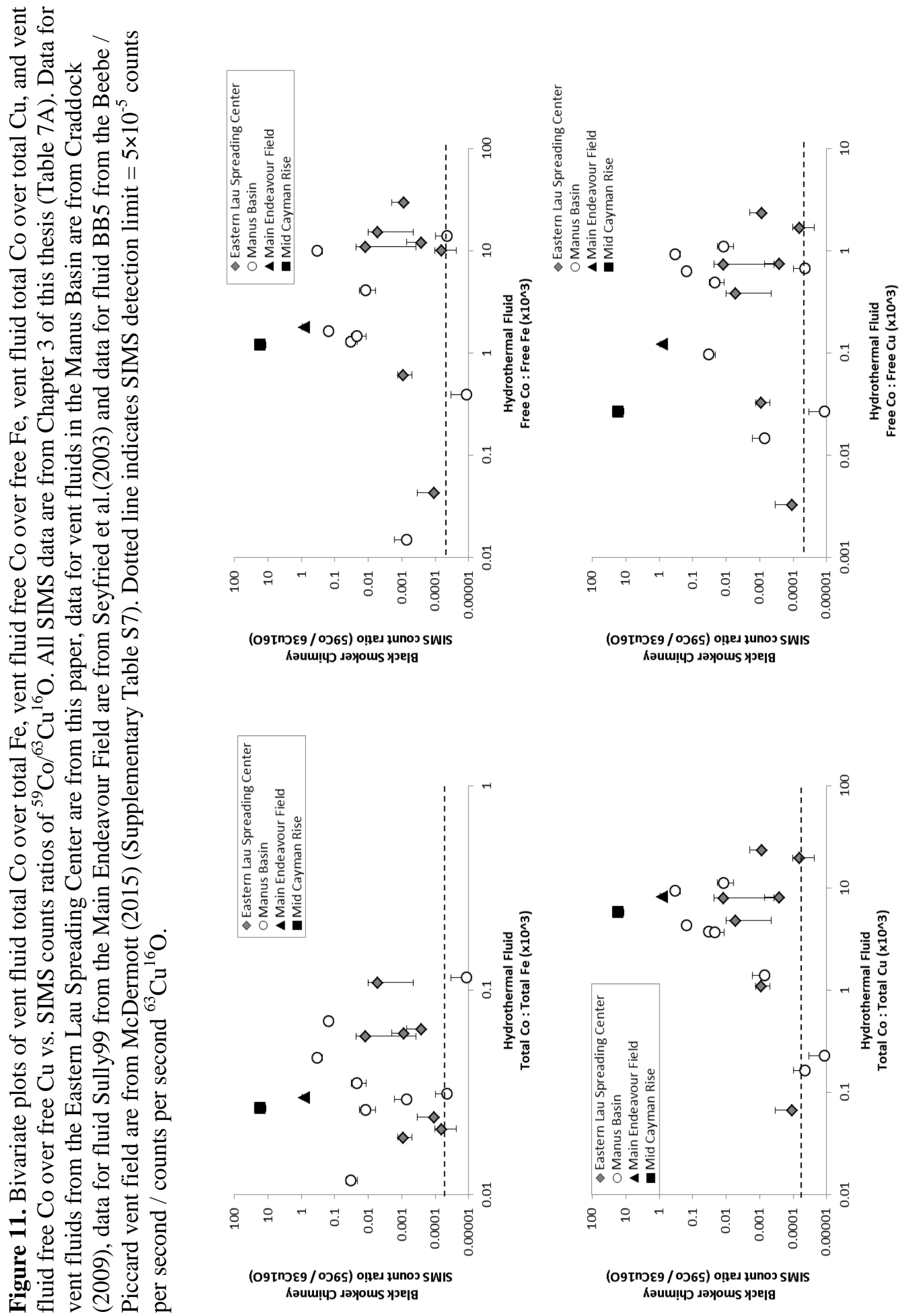

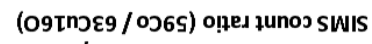

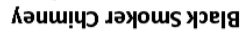

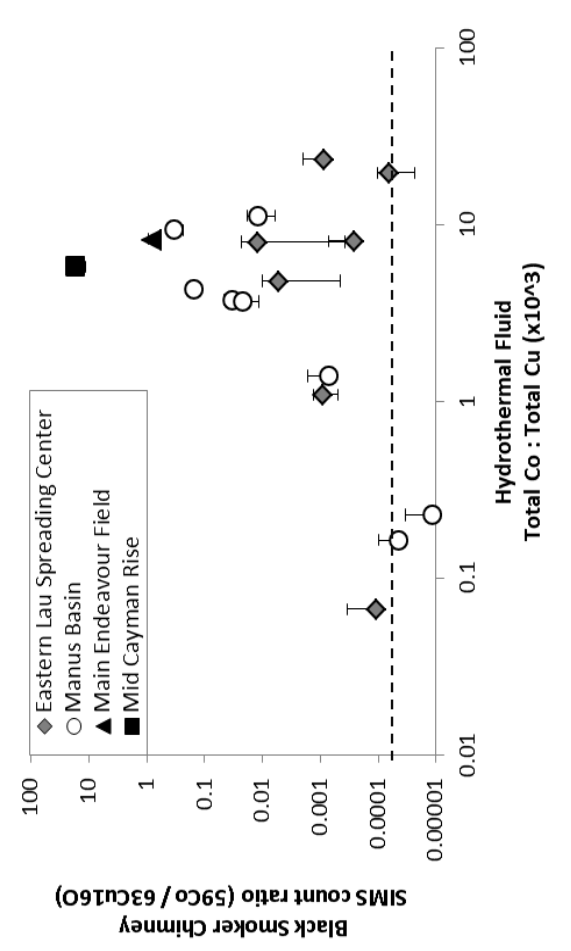


Figure 12. Plot of $\mathrm{Cu}$ and $\mathrm{Fe}$ in $\mathrm{CuFe}$ sulfide lining of sample J2-613-16-R1 from the Beebe/Piccard vent field on the Mid-Cayman Rise measured by electron microprobe. Also shown are compositions of chalcopyrite and cubanite chimney linings from vent fields in the Manus Basin (Craddock, 2009) and Eastern Lau Spreading Center (Chapter 2 of this thesis), likewise measured by electron microprobe. Results reported as weight percent normalized to total $=\mathrm{Cu}(\mathrm{wt} \%)+\mathrm{Fe}(\mathrm{wt} \%)+\mathrm{S}(\mathrm{wt} \%)$.

\section{Electron Microprobe Analyses of Open Conduit Chimney Lining from the Beebe/Piccard Vent Field}

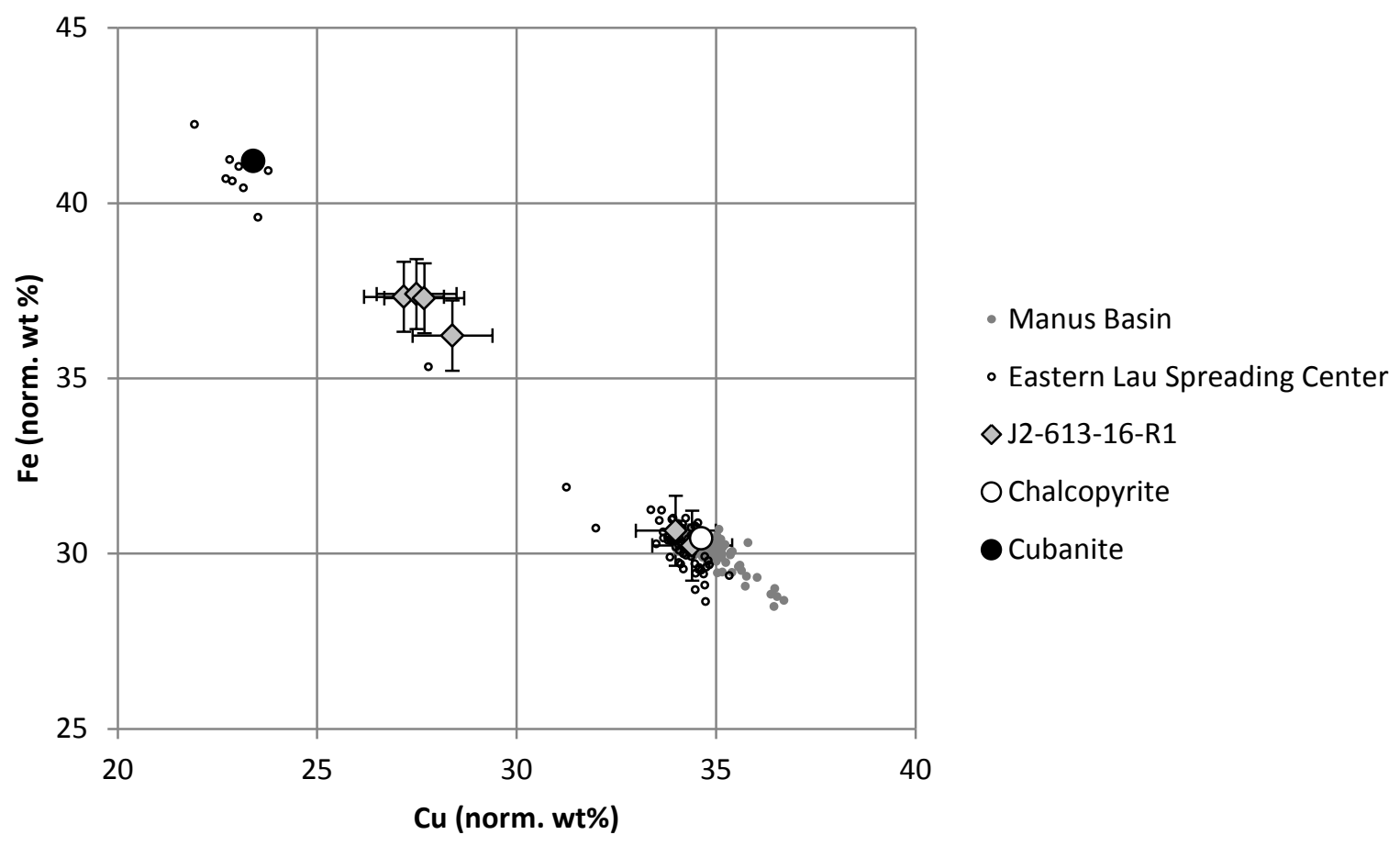

5.3. Trace element proxies of hydrothermal fluid $\mathrm{pH}$ and metal concentrations

The trace element content of black smoker chimney linings is controlled by the partitioning of trace elements between lining minerals and hydrothermal fluids (Fig. 13, marker A). For a given mineral, this partitioning is controlled by the free ion activity ratio of the trace element to the major (or "carrier") element it replaces in the crystal lattice (e.g., $\mathrm{Ag}^{+}$for $\mathrm{Cu}^{+}$, $\mathrm{Ga}^{3+}$ and $\mathrm{In}^{3+}$ for $\mathrm{Fe}^{3+}$ ). 
Figure 13. Schematic diagram of (A) partitioning between minerals in black smoker chimney linings and aqueous species in hydrothermal vent fluids and processes: (B) reaction zone conditions and $(\mathrm{C})$ remobilization of previously deposited minerals that can affect element ratios in hydrothermal vent fluids.

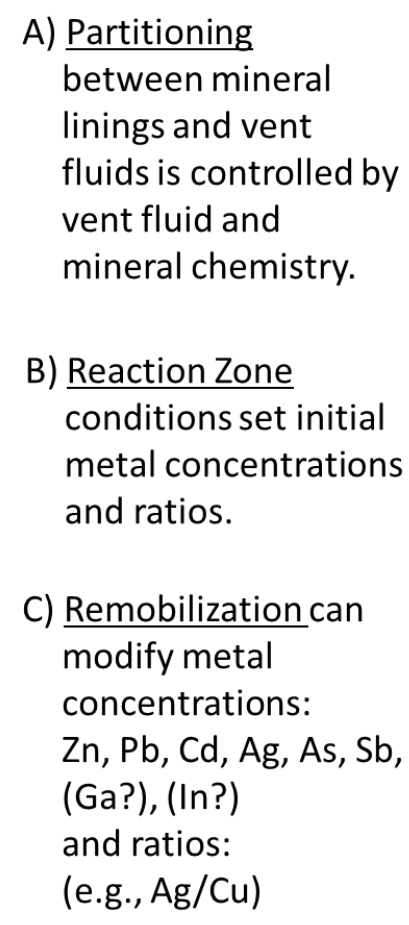

A) Partitioning between mineral linings and vent fluids is controlled by vent fluid and mineral chemistry.

B) Reaction Zone conditions set initial metal concentrations and ratios.
C) Remobilization can modify metal concentrations: $\mathrm{Zn}, \mathrm{Pb}, \mathrm{Cd}, \mathrm{Ag}, \mathrm{As}, \mathrm{Sb}$, (Ga?), (In?) and ratios: (e.g., $\mathrm{Ag} / \mathrm{Cu}$ )

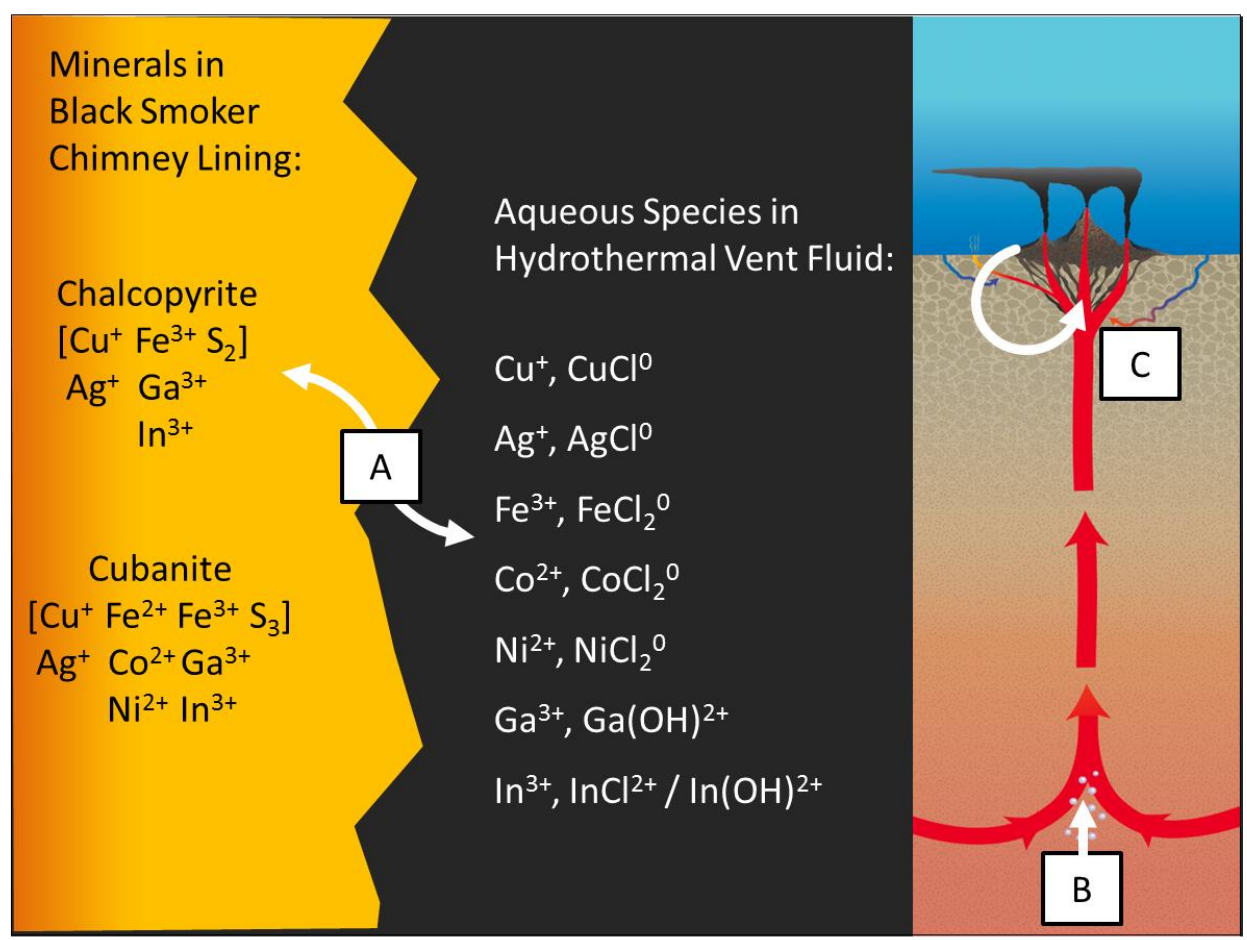

In the case of $\mathrm{Ag}$ replacing $\mathrm{Cu}$, where both elements are similarly complexed by $\mathrm{Cl}-$ in high temperature vent fluids (e.g., Reed and Palandri, 2006), the free ion activity ratio of $\mathrm{Ag}^{+} / \mathrm{Cu}^{+}$is primarily a reflection of the total $\mathrm{Ag}$ : total $\mathrm{Cu}$ concentration ratio (Fig. 6A to 6D). This ratio is initially set in the hydrothermal reaction zone (Fig. 13, marker B). Lower pH vent fluids, which can be caused by higher reaction zone temperatures or the influence of acidic magmatic volatiles, contain higher concentrations of $\mathrm{Cu}$ than higher $\mathrm{pH}$ vent fluids (Fig. 5A). Because the effect of $\mathrm{pH}$ on vent fluid $\mathrm{Ag}$ concentrations is less severe than the effect for $\mathrm{Cu}$, lower $\mathrm{pH}$ vent fluids will tend to have a lower $\mathrm{Ag} / \mathrm{Cu}$ ratio than higher $\mathrm{pH}$ vent fluids (Fig. 7D). Likewise, chalcopyrite formed from lower $\mathrm{pH}$ vent fluids will tend to contain lower 
concentrations of $\mathrm{Ag}$ than chalcopyrite formed from high $\mathrm{pH}$ vent fluids (Fig. 7A). However, ratios of $\mathrm{Ag}$ to $\mathrm{Cu}$ in hydrothermal fluids can be additionally modified by remobilization of previously deposited metal sulfides in the subsurface (Fig. 13, marker C). Elevated concentrations of $\mathrm{Ag}$ in these fluids can lead to high $\mathrm{Ag} / \mathrm{Cu}$ ratios despite low fluid $\mathrm{pH}$ (e.g., Fig. 7D, fluids RMR1, RMR2, and RMR3). Chalcopyrite formed from these fluids has correspondingly high concentrations of Ag (e.g., Fig. 6A, 6C, sample RMR1). Thus, high concentrations of $\mathrm{Ag}$ in the chalcopyrite linings of black smoker chimneys indicate either: 1) formation from higher-pH, Cu-poor vent fluids or 2) formation from Ag-rich vent fluids affected by remobilization of previously deposited Ag-rich metal sulfides in the subsurface.

In the case of $\mathrm{Ga}$ or In replacing $\mathrm{Fe}$, the trace elements $\mathrm{Ga}$ and In are strongly complexed by $\mathrm{OH}^{-}$in high-temperature hydrothermal fluids, while $\mathrm{Fe}$ is predominantly present as $\mathrm{Cl}^{-}$ complexes (Fig. 13, marker A). As a result, the dominant control on the free ion activity ratios of $\mathrm{Ga} / \mathrm{Fe}$ and $\mathrm{In} / \mathrm{Fe}$ is not the total concentration ratio of the trace and carrier elements, $\mathrm{Ga} / \mathrm{Fe}$ and $\mathrm{In} / \mathrm{Fe}$, but rather the relative concentrations of the complexing ligands, $\mathrm{Cl}^{-}$and $\mathrm{OH}^{-}$. Among seafloor hydrothermal fluids associated with black smoker chimneys, the variation in $\mathrm{Cl}^{-}$ concentrations (here, 39 to $753 \mathrm{mmol} / \mathrm{kg}$ ) is less than the variation in $\mathrm{OH}^{-}$concentrations associated with $\mathrm{pH}$ (here, $\mathrm{pH}$ (in situ) $=3.2$ to 5.2). Hence, the dominant control on the free ion activity ratios of $\mathrm{Ga} / \mathrm{Fe}$ and $\mathrm{In} / \mathrm{Fe}$ is $\mathrm{pH}$ and the $\mathrm{Ga}$ and In content of chalcopyrite lining black smoker chimney linings provides a proxy of vent fluid $\mathrm{pH}$ (Fig. 8A to 8D). When combined with $\mathrm{Ag}$, the addition of $\mathrm{Ga}$ and $\mathrm{In}$ as indicators of hydrothermal fluid $\mathrm{pH}$ allows for a distinction to be made between Ag-rich chalcopyrite formed from higher-pH, Cu-poor vent fluids and similarly Ag-rich chalcopyrite lower-pH Ag-rich vent fluids. Specifically, high Ag concentrations, but low $\mathrm{Ga}$ and In concentrations in chalcopyrite are indicative of precipitation 
from higher-pH, $\mathrm{Cu}$-poor hydrothermal fluids while high $\mathrm{Ag}, \mathrm{Ga}$, and In concentrations in chalcopyrite are indicative of precipitation from low-pH, $\mathrm{Ag}$ - and $\mathrm{Cu}$-rich hydrothermal fluids likely related to remobilization of $\mathrm{Ag}$.

\section{CONCLUSION}

By analyzing the concentrations of trace elements, especially $\mathrm{Co}, \mathrm{Ni}, \mathrm{Ga}, \mathrm{Ag}$, and In, contained in the dregs, dissolved, and filter fractions of hydrothermal fluids from vent field along the Eastern Lau Spreading Center, this study expands previously published data on the chemistry of hydrothermal fluids from these vent fields. This study then makes use of these new data, in combination with previously published data on the trace element chemistry of hydrothermal fluids from the Manus Basin from Craddock (2009) and secondary ion mass spectrometry measurements of trace element $(\mathrm{Co}, \mathrm{Ni}, \mathrm{Ga}, \mathrm{Ag}, \mathrm{In})$ concentrations in chalcopyrite from paired black smoker chimney linings presented in Chapter 3 of this thesis, to directly compare fluid and mineral trace element chemistry and thus identify potential proxies of hydrothermal fluid chemistry based on mineral trace element chemistry.

A significant result of this study is a linear correlation between the Ag content of black smoker chimney linings with the free ion activity ratio of $\mathrm{Ag}: \mathrm{Cu}$ in the corresponding hydrothermal fluids, which supports regular partitioning of Ag into chalcopyrite as a lattice substitution for $\mathrm{Cu}$, once aqueous complexing is considered. A partition coefficient of $\mathrm{D}_{\mathrm{hf}, \mathrm{cp}}=$ 1.37 is calculated. When combined with the correlation between the Ga and In of black smoker chimney linings and hydrothermal fluid $\mathrm{pH}$ presented in Chapter 3 of this thesis, concentrations of $\mathrm{Ag}$ in chalcopyrite provide a proxy of $\mathrm{Ag}$ and $\mathrm{Cu}$ concentrations in hydrothermal fluids. 
Specifically, chalcopyrite linings containing high concentrations of Ag, but low concentrations of $\mathrm{Ga}$ and In are indicative of formation from higher-pH, Cu-poor fluids; chalcopyrite linings containing low concentrations of Ag, but high concentrations of Ga and In are indicative of formation from low-pH fluids; and chalcopyrite linings containing high concentrations of $\mathrm{Ag}$, $\mathrm{Ga}$, and In are indicative of formation from low-pH fluids in which Ag is highly enriched, likely as a result of subsurface remobilization of previously deposited sulfide minerals. Also highlighted in this study is the need for additional data on the concentrations of trace elements such as Ga and In in hydrothermal fluids and the need to refine understandings of the thermodynamic properties of aqueous $\mathrm{Ga}$ and In complexes at elevated temperatures and pressures.

\section{REFERENCES}

Benézéth, P., Diakonov, I. I., Pokrovski, G. S., Dandurand, J. L., Schott, J., and Khodakovsky, I. L. (1997) Gallium speciation in aqueous solution. Experimental study and modelling: Part 2. Solubility of $\alpha-\mathrm{GaOOH}$ in acidic solutions from 150 to $250 \mathrm{C}$ and hydrolysis constants of gallium (III) to 300 C. Geochim. Cosmochim. Acta, 61(7), 1345-1357.

Bézos, A., Escrig, S., Langmuir, C. H., Michael, P. J., and Asimow, P. D. (2009) Origins of chemical diversity of back- arc basin basalts: A segment- scale study of the Eastern Lau Spreading Center. J. Geophys. Res.: Solid Earth, 114, B06212, doi:10.1029/2008JB005924

Binns, R. A. and Scott, S. D. (1993) Actively forming polymetallic sulfide deposits associated with felsic volcanic rocks in the eastern Manus back-arc basin, Papua New Guinea. Econ. Geol., 88(8), 2226-2236.

Both, R., Crook, K., Taylor, B., Brogan, S., Chappell, B., Frankel, E., Liu, L., Sinton, J., and Tiffin, D. (1986) Hydrothermal chimneys and associated fauna in the Manus Back- Arc Basin, Papua New Guinea. Eos, Transactions American Geophysical Union, 67(21), 489490. 
Craddock, P. R. (2009) Geochemical tracers of processes affecting the formation of seafloor hydrothermal fluids and deposits in the Manus back-arc basin. Ph.D. Thesis, MIT/WHOI Joint Program in Oceanography.

Davies, H. L., Honza, E., Tiffin, D. L., Lock, J., Okuda, Y., Keene, J. B., Murakami, F., and Kisimoto, K. (1987) Regional setting and structure of the western Solomon Sea. GeoMarine Letters, 7(3), 153-160.

Einaudi, M. T., Hedenquist, J. W., and Inan, E. E. (2003) Sulfidation state of fluids in active and extinct hydrothermal systems: transitions from porphyry to epithermal environments. In Special Publication-Society of Economic Geologists, 10 (eds. S.F. Simmons, I. Graham). Society of Economic Geologists, 285-314.

Elthon, D., Ross, D.K., Meen, J.K. (1995) Compositional variations of basaltic glasses from the Mid-Cayman Rise spreading center. J. Geophys. Res.: Solid Earth, 100, 12497-12512.

Escrig, S., Bézos, A., Goldstein, S. L., Langmuir, C. H., and Michael, P. J. (2009) Mantle source variations beneath the Eastern Lau Spreading Center and the nature of subduction components in the Lau basin-Tonga arc system, Geochem. Geophys. Geosys., 10, Q04014, doi:10.1029/2008GC002281.

Fouquet, Y., von Stackelberg, U., Charlou, J. L., Erzinger, J., Herzig, P. M., Mühe, R., and Wiedicke, M. (1993) Metallogenesis in back-arc environments: the Lau Basin example. Econ. Geol., 88(8), 2154-2181.

Frenzel, G., Mühe, R., and Stoffers, P. (1990) Petrology of the volcanic rocks from the Lau Basin, southwest Pacific. Geologisches Jahrbuch, 92, 395-479.

Fretzdorff, S., Schwarz- Schampera, U., Gibson, H. L., Garbe- Schönberg, C. D., Hauff, F., and Stoffers, P. (2006) Hydrothermal activity and magma genesis along a propagating backarc basin: Valu Fa Ridge (southern Lau Basin). J. Geophys. Res.: Solid Earth, 111(B8).

Huston, D. L., Sie, S. H., Suter, G. F., Cooke, D. R., and Both, R. A. (1995) Trace elements in sulfide minerals from eastern Australian volcanic-hosted massive sulfide deposits; Part I, Proton microprobe analyses of pyrite, chalcopyrite, and sphalerite, and Part II, Selenium levels in pyrite; comparison with delta $34 \mathrm{~S}$ values and implications for the source of sulfur in volcanogenic hydrothermal systems. Econ. Geol., 90(5), 1167-1196.

Jenner, G. A., Cawood, P. A., Rautenschlein, M., and White, W. M. (1987) Composition of back-arc basin volcanics, Valu Fa Ridge, Lau Basin: evidence for a slab-derived component in their mantle source. J. Volcanol. Geotherm. Res., 32(1-3), 209-222.

Johnson, J. W., Oelkers, E. H., and Helgeson, H. C. (1992) SUPCRT92: A software package for calculating the standard molal thermodynamic properties of minerals, gases, aqueous species, and reactions from 1 to 5000 bar and 0 to 1000 C. Computers Geosci., 18(7), 899-947. 
Johnson, H. P., Hutnak, M., Dziak, R. P., Fox, C. G., Urcuyo, I., Cowen, J. P., Nabelek, J., and Fisher, C. (2000) Earthquake-induced changes in a hydrothermal system on the Juan de Fuca mid-ocean ridge. Nature, 407(6801), 174-177.

Kamenetsky, V. S., Binns, R. A., Gemmell, J. B., Crawford, A. J., Mernagh, T. P., Maas, R., and Steele, D. (2001) Parental basaltic melts and fluids in eastern Manus backarc basin: Implications for hydrothermal mineralization. Earth Planet. Sci. Lett., 184(3), 685-702.

Karsten, J. L., Delaney, J. R., Rhodes, J. M., and Liias, R. A. (1990) Spatial and temporal evolution of magmatic systems beneath the Endeavour Segment, Juan de Fuca Ridge: Tectonic and petrologic constraints. J. Geophys. Res.: Solid Earth, 95(B12), 1923519256.

Krasnov, S., Poroshina, I., Cherkashev, G., Mikhalsky, E., and Maslov, M. (1997) Morphotectonics, volcanism and hydrothermal activity on the East Pacific Rise between 21 12' S and 22 40' S. Marine Geophysical Researches, 19(4), 287-317.

Kojima, S., and Sugaki, A. (1985) Phase relations in the Cu-Fe-Zn-S system between 500 degrees and 300 degrees $C$ under hydrothermal conditions. Econ. Geol., 80(1), 158-171.

Langmuir, C., Humphris, S., Fornari, D., Van Dover, C., Von Damm, K. L., Tivey, M. K., Colodner, D., Charlou, J. -L. Desonie, D., Wilson, C., and Fouquet, Y. (1997) Hydrothermal vents near a mantle hot spot: the Lucky Strike vent field at $37 \mathrm{~N}$ on the Mid-Atlantic Ridge. Earth Planet. Sci. Lett., 148(1-2), 69-91.

Langmuir, C. H., Bézos, A., Escrig, S., and Parman, S. W. (2006) Chemical systematics and hydrous melting of the mantle in back-arc basins. In Back-Arc Spreading Systems: Geological, Biological, Chemical, and Physical Interactions (eds. D. M. Christie, C. R. Fisher, S.-M. Lee, and S. Givens) Geophysical Monograph Series, vol. 166, American Geophysical Union, Washington, DC. pp. 87-146.

Martinez, F., and Taylor, B. (1996) Backarc spreading, rifting, and microplate rotation, between transform faults in the Manus Basin. Marine Geophysical Research, 18(2), 203-224.

Martinez, F. and Taylor, B. (2002) Mantle wedge control on back-arc crustal accretion. Nature. 416, 417-420.

McDermott, J. M. (2015) Geochemistry of deep-sea hydrothermal vent fluids from the MidCayman Rise, Caribbean Sea. Ph.D. Thesis, MIT/WHOI Joint Program in Oceanography.

McIntire, W. L. (1963) Trace element partition coefficients - a review of theory and applications to geology. Geochim. Cosmochim. Acta, 27(12), 1209-1264. 
Metz, S., and Trefry, J. H. (2000) Chemical and mineralogical influences on concentrations of trace metals in hydrothermal fluids. Geochim. Cosmochim. Acta, 64(13), 2267-2279.

Moore, W. S. and Stakes, D. (1990) Ages of barite-sulfide chimneys from the Mariana Trough. Earth Planet. Sci. Let., 100(1), 265-274.

Mottl, M. J. and Holland, H. D. (1978) Chemical exchange during hydrothermal alteration of basalt by seawater. I. Experimental results for major and minor components of seawater. Geochim. Cosmochim. Acta, 42, 1103-1115.

Mottl, M. J., Seewald, J. S., Wheat, C. G., Tivey, M. K., Michael, P. J., Proskurowski, G., McCollom, M., Reeves, E., Sharkey, S., You, C.-F., Chan, L.-H., and Pichler, T. (2011) Chemistry of hot springs along the Eastern Lau Spreading Center. Geochim Cosmochim. Acta, 75(4), 1013-1038.

Pearce, C. I., Pattrick, R. A. D., Vaughan, D. J., Henderson, C. M. B., and Van der Laan, G. (2006) Copper oxidation state in chalcopyrite: Mixed $\mathrm{Cu}$ d 9 and d 10 characteristics. Geochim. Cosmochim. Acta, 70(18), 4635-4642.

Reed, M. H., and Palandri, J. (2006) Sulfide mineral precipitation from hydrothermal fluids. In Reviews in mineralogy and geochemistry, 61(1) (ed. D.J. Vaughan). Geochemical Society and Mineralogical Society of America. 609-631.

Reeves, E. P., Seewald, J. S., Saccocia, P., Bach, W., Craddock, P. R., Shanks, W. C., Sylva. S., Walsh, E., Pichler, T., and Rosner, M. (2011) Geochemistry of hydrothermal fluids from the PACMANUS, Northeast Pual and Vienna Woods hydrothermal fields, Manus Basin, Papua New Guinea. Geochim. Cosmochim. Acta, 75(4), 1088-1123.

Rouxel, O., Fouquet, Y., and Ludden, J. N. (2004) Copper isotope systematics of the Lucky Strike, Rainbow, and Logatchev sea-floor hydrothermal fields on the Mid-Atlantic Ridge. Econ. Geol., 99(3), 585-600.

Sack, R. O., and Ebel, D. S. (2006) Thermochemistry of sulfide mineral solutions. In Reviews in mineralogy and geochemistry, 61(1) (ed. D.J. Vaughan). Geochemical Society and Mineralogical Society of America. pp. 265-364.

Seewald, J. S. (2017) Chemical composition of hydrothermal fluids collected on RV/Roger Revelle RR1507 in the Eastern Lau Spreading Center and Valu Fa Ridge, April-May 2015 (Functional microbial dynamics of vent deposits project) Biological and Chemical Oceanography Data Management Office (BCO-DMO) Dataset version 2017-01-13 http://lod.bco-dmo.org/id/dataset/674750 (accessed, May 2017). 
Seewald, J. S., Doherty, K. W., Hammar, T. R., and Liberatore, S. P. (2002) A new gas-tight isobaric sampler for hydrothermal fluids. Deep Sea Research Part I: Oceanographic Research Papers, 49(1), 189-196.

Seewald, J. S., Reeves, E. P., Bach, W., Saccocia, P. J., Craddock, P. R., Shanks, W. C., Sylva, S. P., Pichler, T., Rosner, M., and Walsh, E. (2015) Submarine venting of magmatic volatiles in the Eastern Manus Basin, Papua New Guinea. Geochim. Cosmochim. Acta, 163, 178-199.

Seyfried, W. E., Janecky, D. R., and Mottl, M. J. (1984) Alteration of the oceanic crust: implications for geochemical cycles of lithium and boron. Geochim. Cosmochim. Acta, 48(3), 557-569.

Seyfried, W. E., Seewald, J. S., Berndt, M. E., Ding, K., and Foustoukos, D. I. (2003) Chemistry of hydrothermal vent fluids from the Main Endeavour Field, northern Juan de Fuca Ridge: Geochemical controls in the aftermath of June 1999 seismic events. J. Geophys. Res.: Solid Earth, 108(B9).

Shock, E. L., Sassani, D. C., Willis, M., and Sverjensky, D. A. (1997) Inorganic species in geologic fluids: correlations among standard molal thermodynamic properties of aqueous ions and hydroxide complexes. Geochim. Cosmochim. Acta, 61(5), 907-950.

Sinton, J. M., Ford, L. L., Chappell, B., and McCulloch, M. T. (2003) Magma genesis and mantle heterogeneity in the Manus back-arc basin, Papua New Guinea. J. Petrol., 44(1), 159-195.

Sleeper, J. D., and Martinez, F. (2014) Controls on segmentation and morphology along the back- arc Eastern Lau Spreading Center and Valu Fa Ridge. J. Geophys. Res.: Solid Earth, 119(3), 1678-1700.

Sverjensky, D. A., Shock, E. L., and Helgeson, H. C. (1997) Prediction of the thermodynamic properties of aqueous metal complexes to $1000 \mathrm{C}$ and $5 \mathrm{~kb}$. Geochim. Cosmochim. Acta, 61(7), 1359-1412.

Takai, K., Nunoura, T., Ishibashi, J.-I., Lupton, J., Suzuki, R., Hamasaki, H., Ueno, Y., Kawagucci, S., Gamo, T., Suzuki, Y., Hirayama, H., and Horikoshi, K. (2008) Variability in the microbial communities and hydrothermal fluid chemistry at the newly discovered Mariner hydrothermal field, southern Lau Basin. J. Geophys. Res., 113, G02031, doi: $\underline{10.1029 / 2007 \mathrm{JG} 000636 .}$.

Taylor, B. (1979) Bismarck Sea: Evolution of a back-arc basin. Geology, 7(4), 171-174.

Taylor, B. (2006) Swath Bathymetry Compilation. accessed through GeoMapAhttp://www.geomapapp.org 
Tivey, M. K. (1995) The influence of hydrothermal fluid composition and advection rates on black smoker chimney mineralogy: Insights from modeling transport and reaction. Geochim. Cosmochim. Acta, 59(10), 1933-1949.

Tivey, M.K. (2004) Environmental conditions within active seafloor vent structures: sensitivity to vent fluid composition and fluid flow. In Wilcock, W., Cary, C., DeLong, E., Kelley, D., Baross, J. (Eds.) Subseafloor Biosphere at Mid-Ocean Ridges, Geophysical Monograph Series, No. 144. American Geophysical Union, Washington, DC, 137-152.

Trefry, J. H., Butterfield, D. B., Metz, S., Massoth, G. J., Trocine, R. P., and Feely R. A. (1994) Trace metals in hydrothermal solutions from Cleft segment on the southern Juan de Fuca Ridge. J. Geophys. Res.99, 4925-4935.

Tunaboylu, K., Schwarzenbach, G., 1970. Die Löslichkeit von Indiumsulfid. Chimia (Switzerland) 24, 424-427.

Vallier, T. L., Jenner, G. A., Frey, F. A., Gill, J. B., Davis, A. S., Volpe, A. M., Hawkins, J. W., Morris, J.D., Cawood, P.A., Morton, J. L., Scholl, D.W., Rautenschlein, M., White, Williams, W.M., Stevenson, A.J., White, L.D. (1991) Subalkaline andesite from Valu Fa Ridge, a back-arc spreading center in southern Lau Basin: petrogenesis, comparative chemistry, and tectonic implications. Chem. Geol., 91(3), 227-256.

Von Damm, K. L. (1995) Controls on the chemistry and temporal variability of seafloor hydrothermal fluids. In Seafloor Hydrothermal Systems: Physical, Chemical, Biological, and Geological Interactions (eds. S. E. Humphris, R. A. Zierenberg, L. S. Mullineaux, and R. E. Thomson), American Geophysical Union, Washington, D. C., pp. 222-247.

Von Damm, K. L., Edmond, J. M., Grant, B., Measures, C. I., Walden, B., and Weiss, R. F. (1985) Chemistry of submarine hydrothermal solutions at $21^{\circ} \mathrm{N}$, East Pacific Rise. Geochim. Cosmochim. Acta, 49(11), 2197-2220.

Wolery, T. J. (1992) EQ3/6: A software package for geochemical modeling of aqueous systems: package overview and installation guide (version 7.0) Livermore, CA: Lawrence Livermore National Laboratory.

Wood, S. A. and Samson, I. M. (2006) The aqueous geochemistry of gallium, germanium, indium and scandium. Ore Geology Reviews, 28(1), 57-102. 


\section{Appendix A.}

Bivariate plots of fluid $\mathrm{Mg}$ measured by ion chromatography vs. metals and metalloids measured by inductively coupled plasma mass spectrometry (ICP-MS). Concentrations of the dissolved fraction are marked in white. Concentrations of the total fluid samples (total $=$ dregs + dissolved + filter fractions) are marked in black. Samples thought to be contaminated are marked in red. Also shown are sample regression lines to zero-Mg hydrothermal endmember.

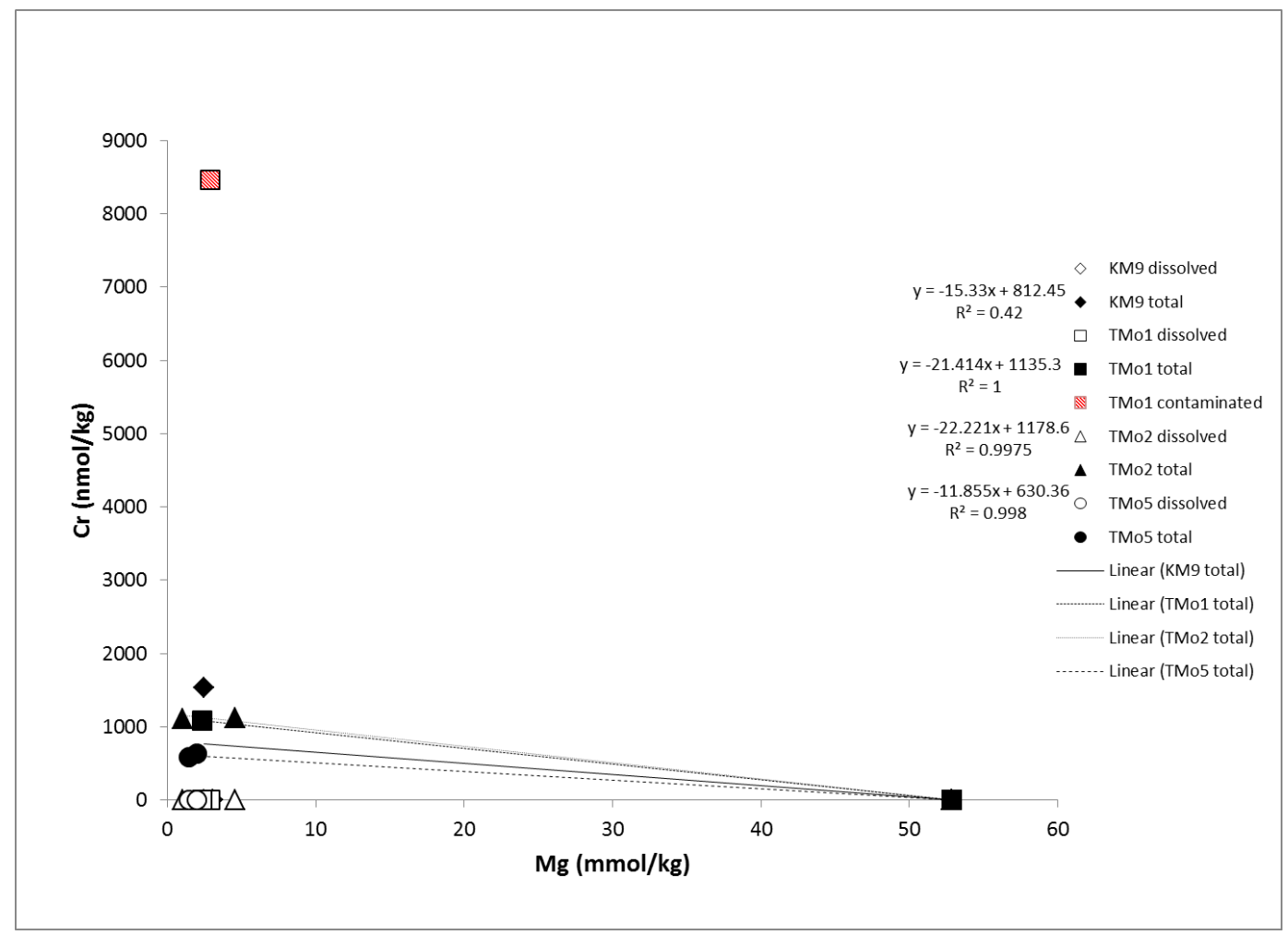




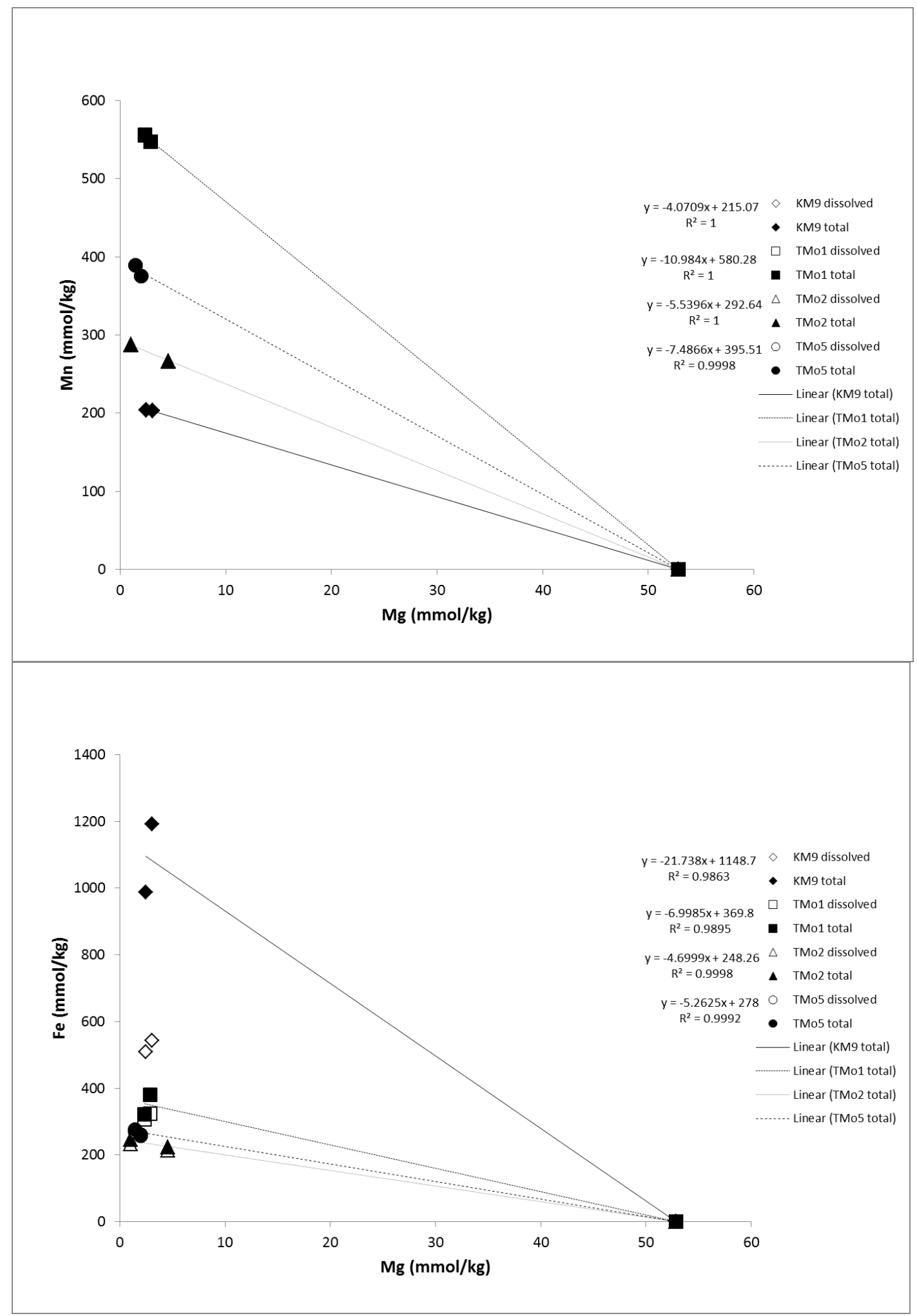




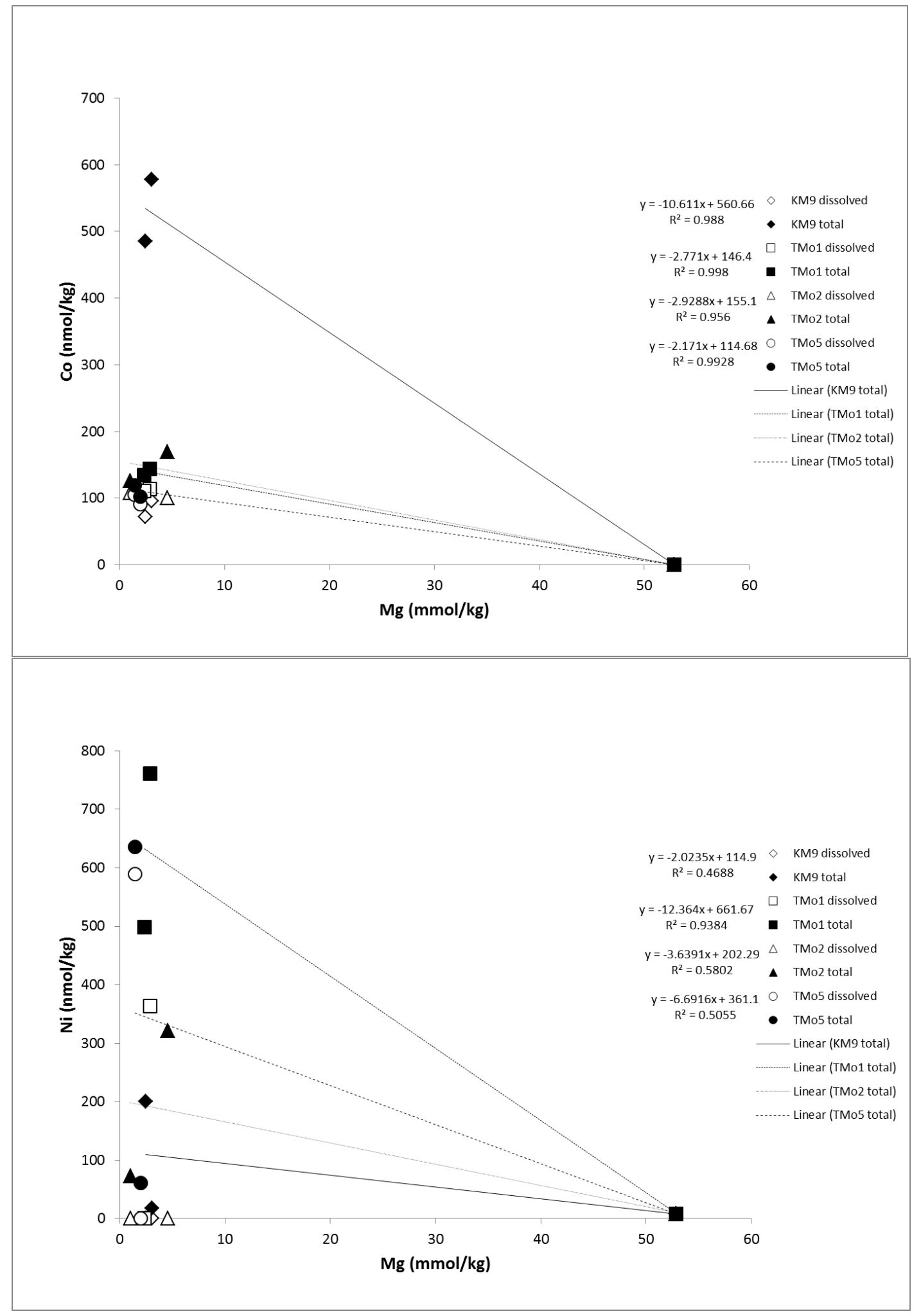




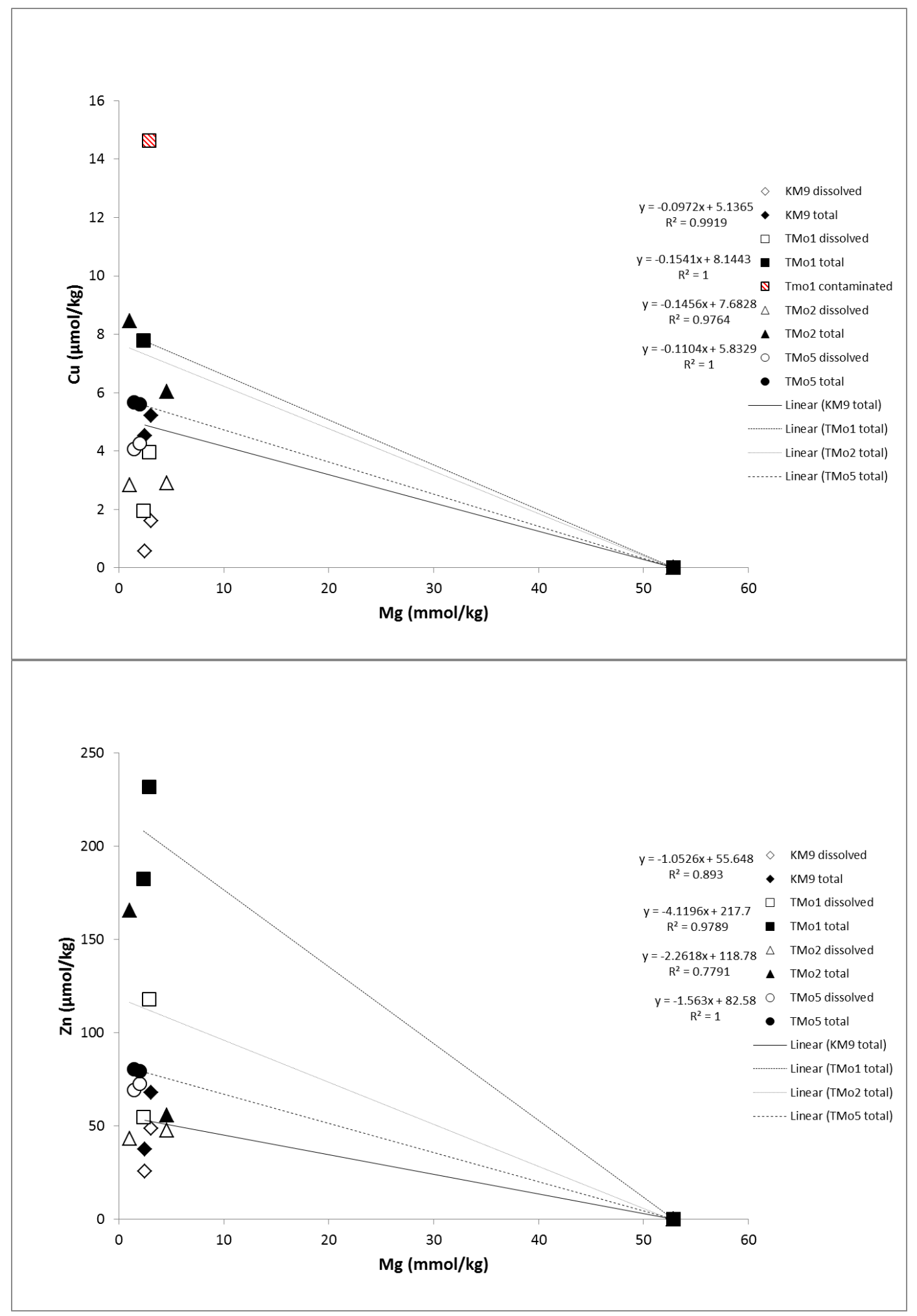




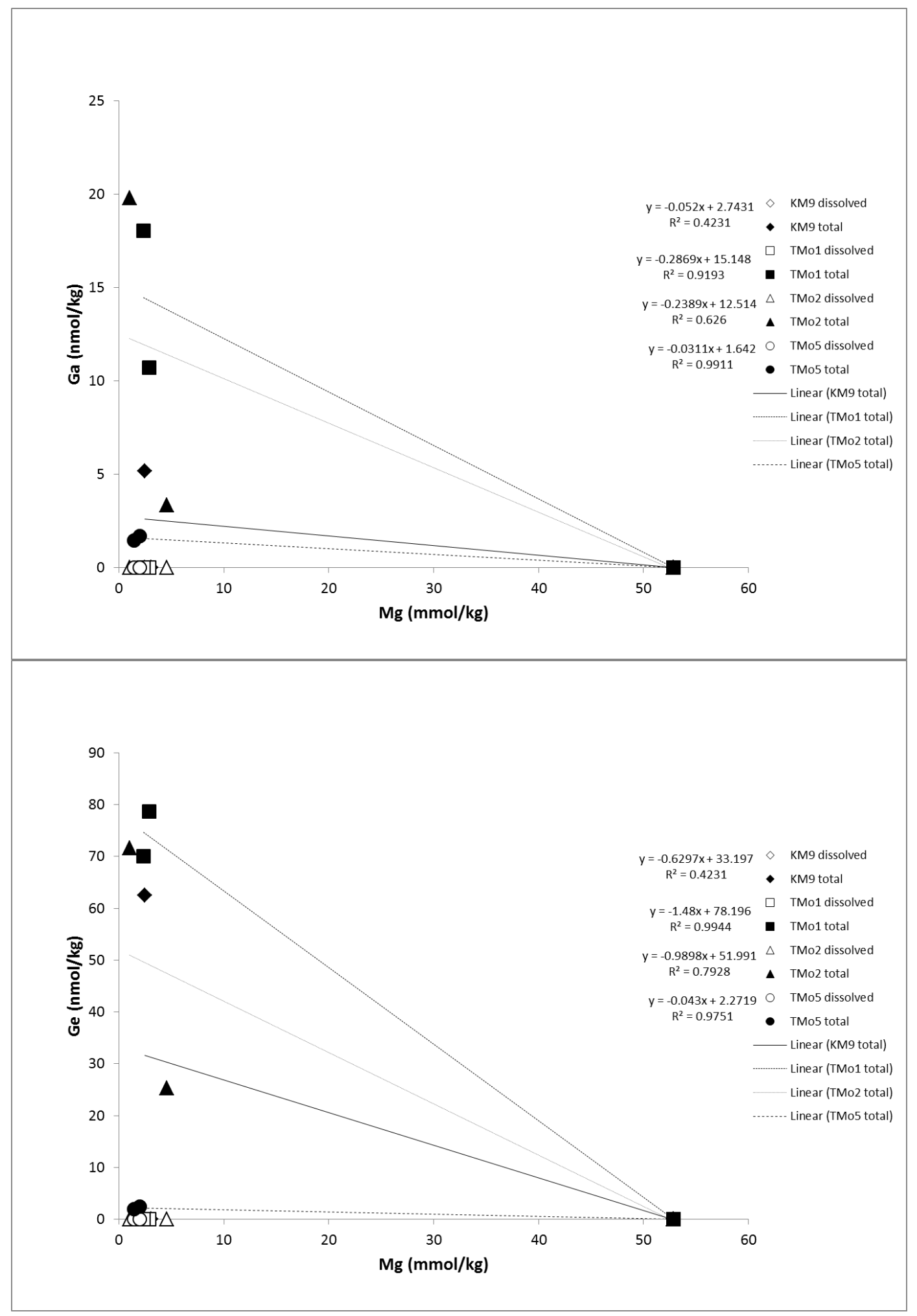




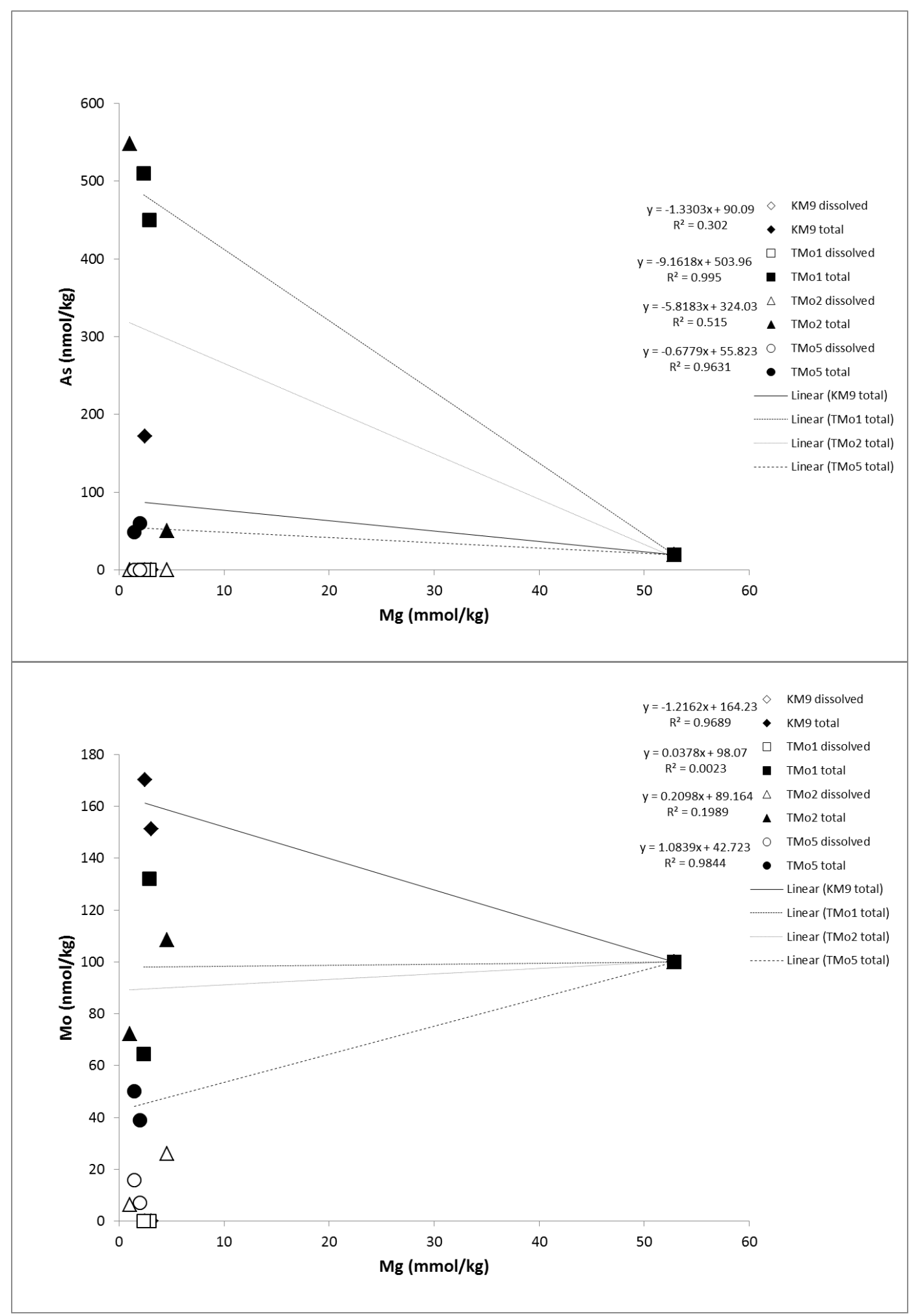




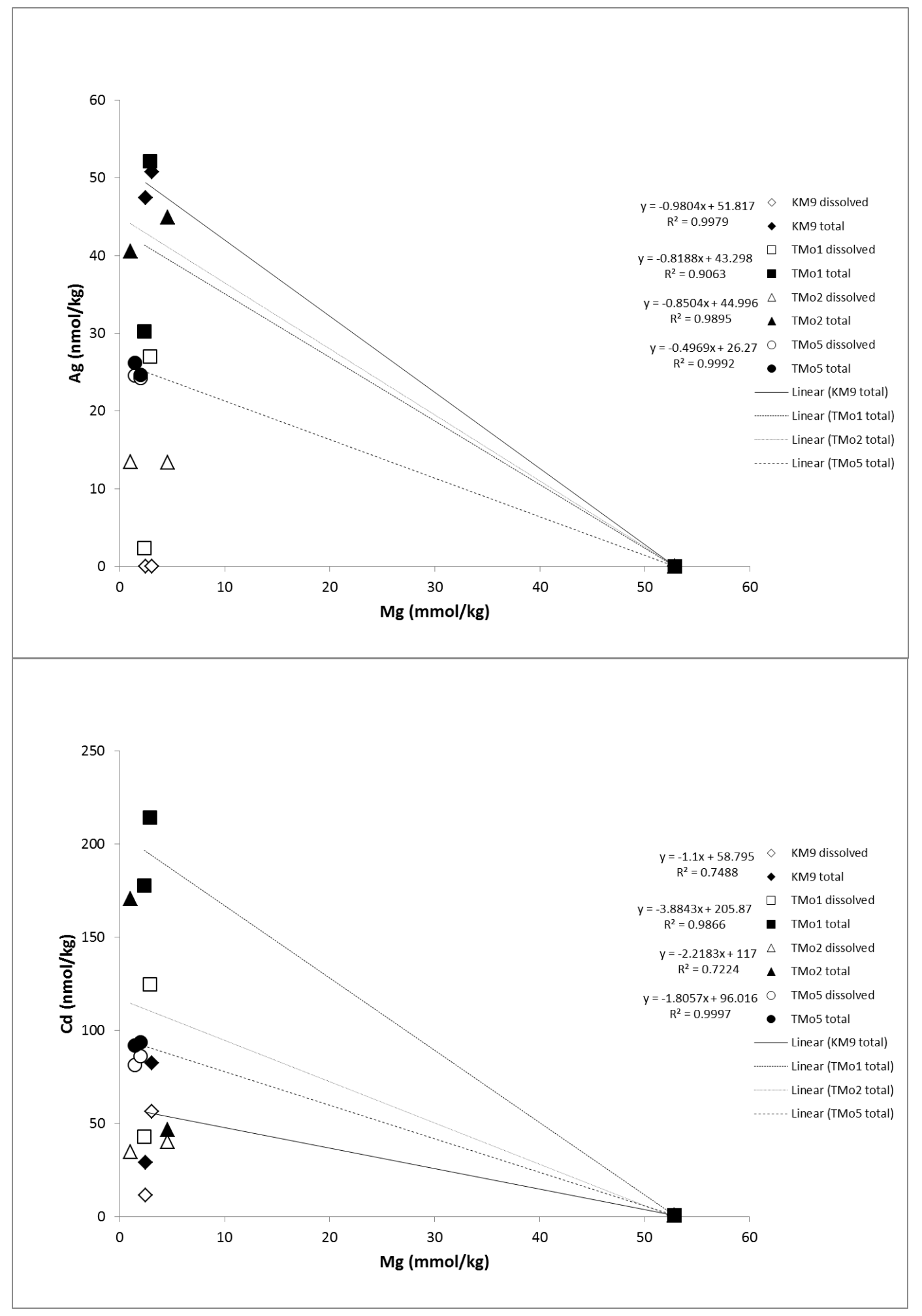




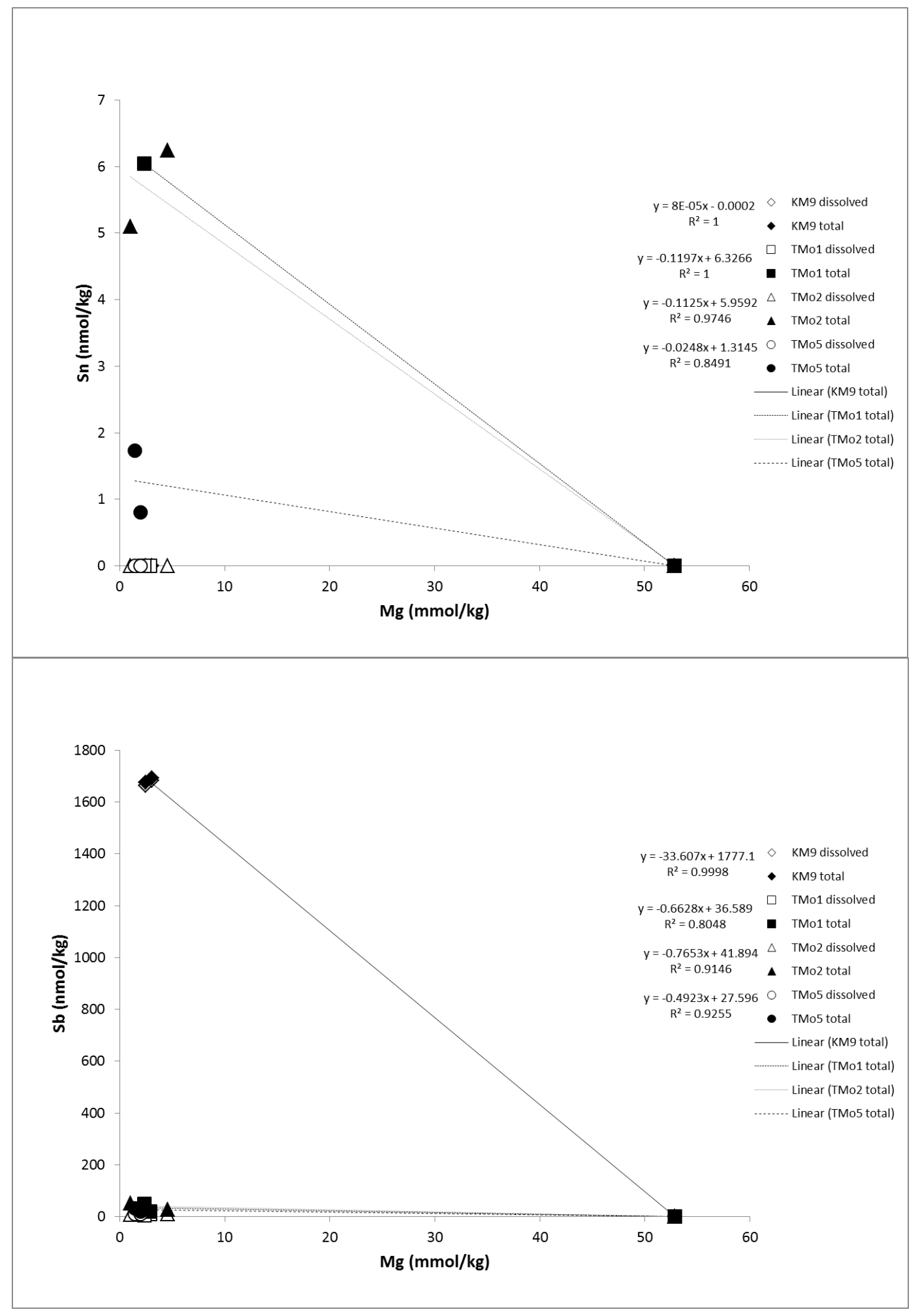




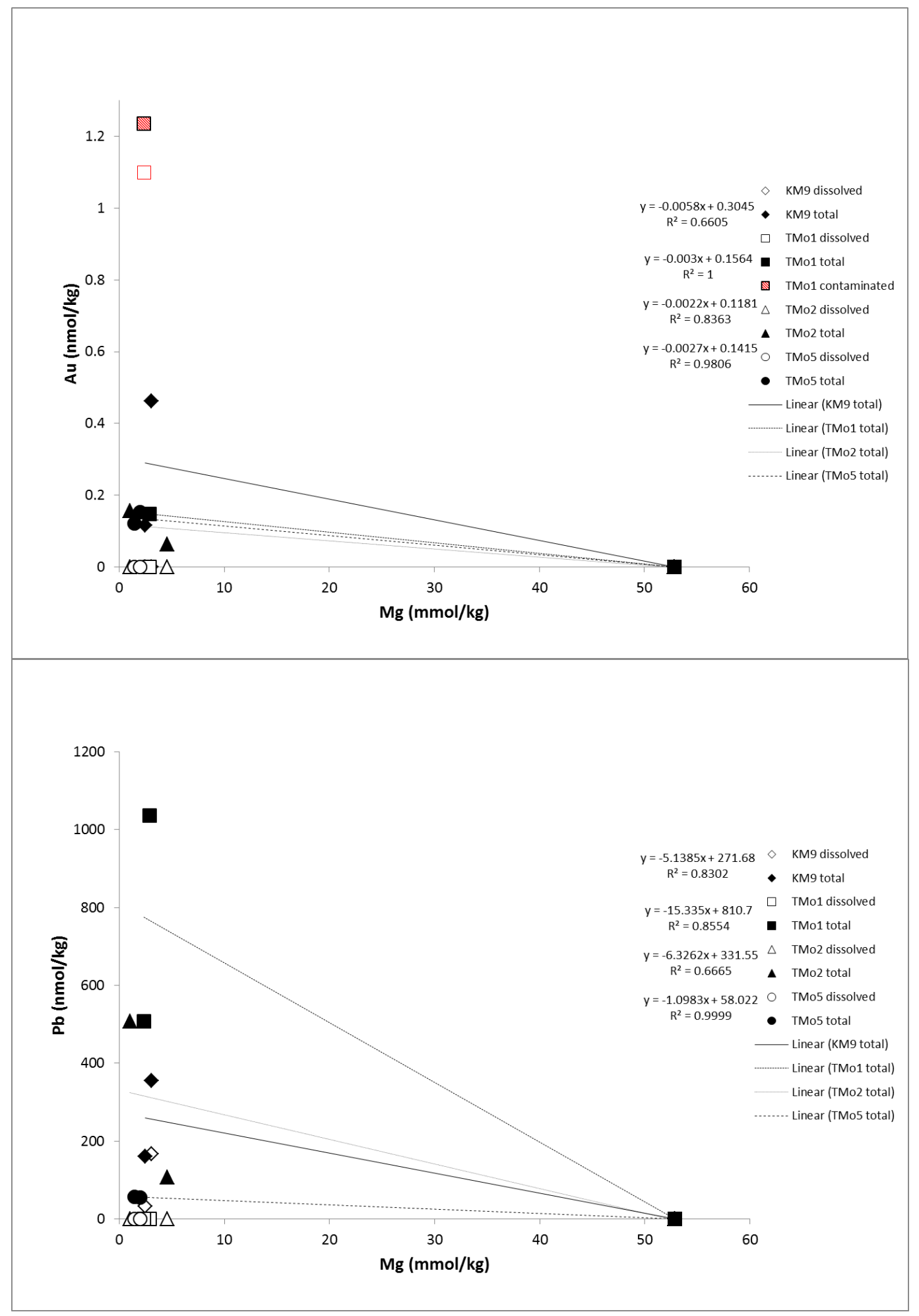




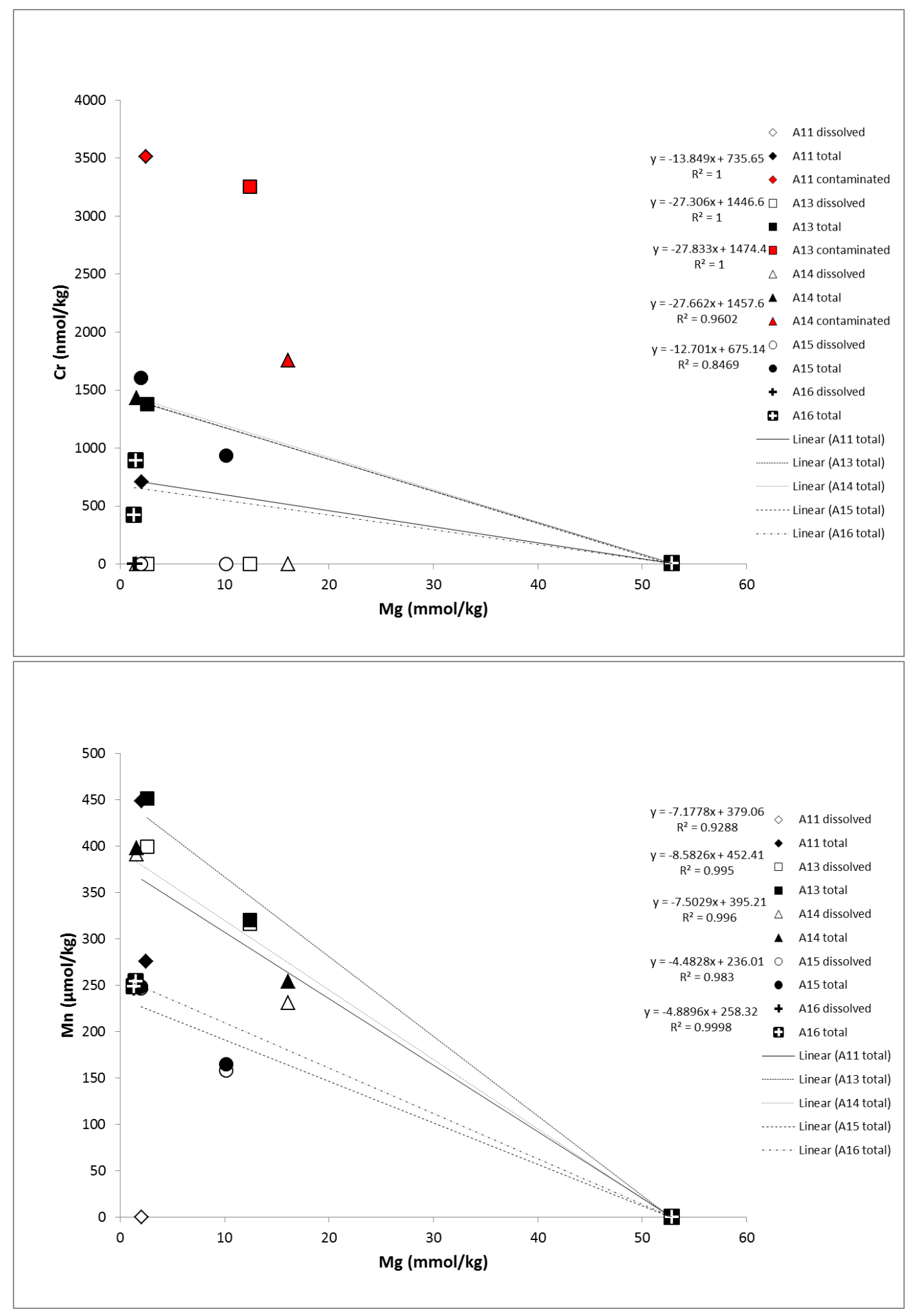




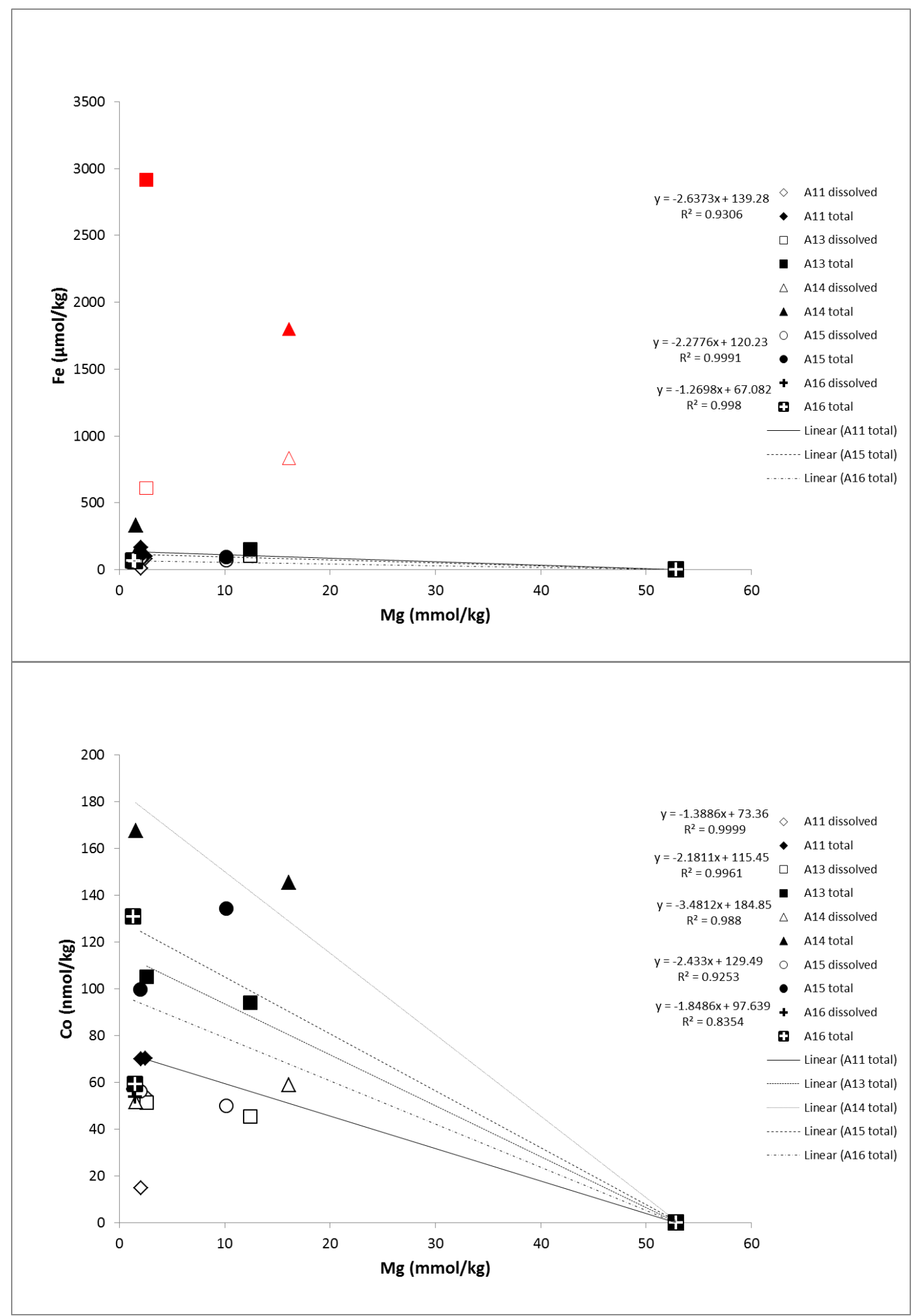




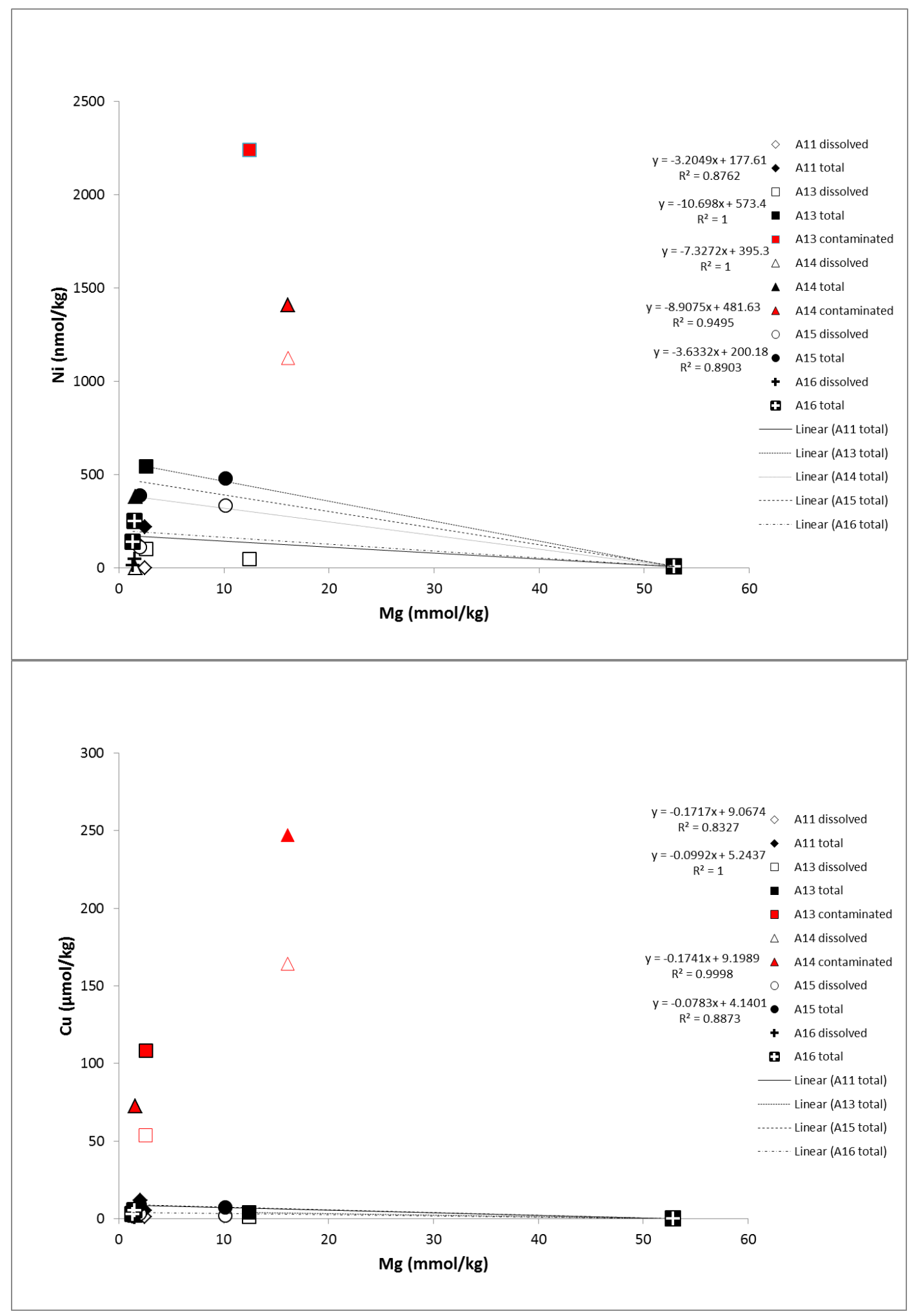




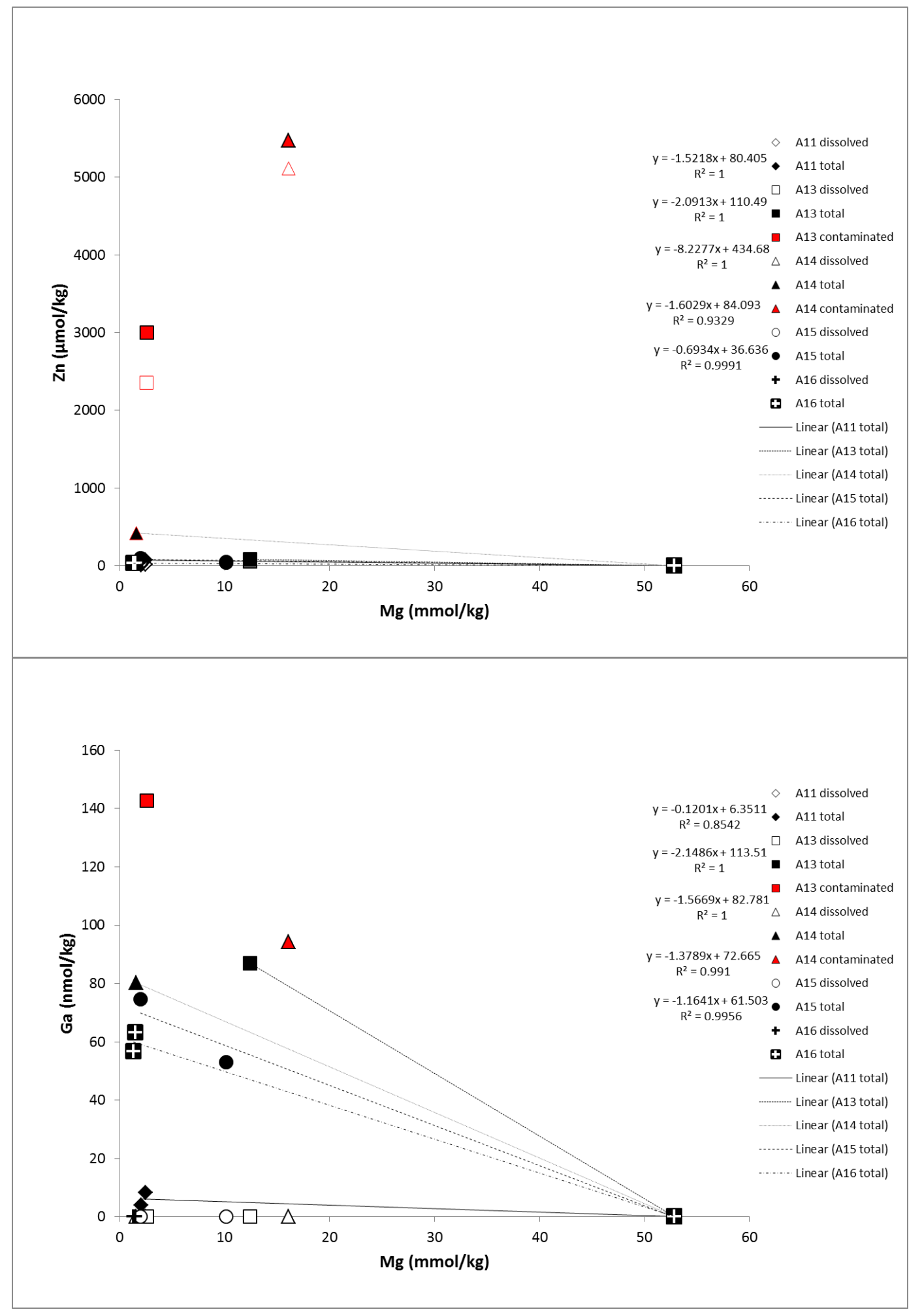




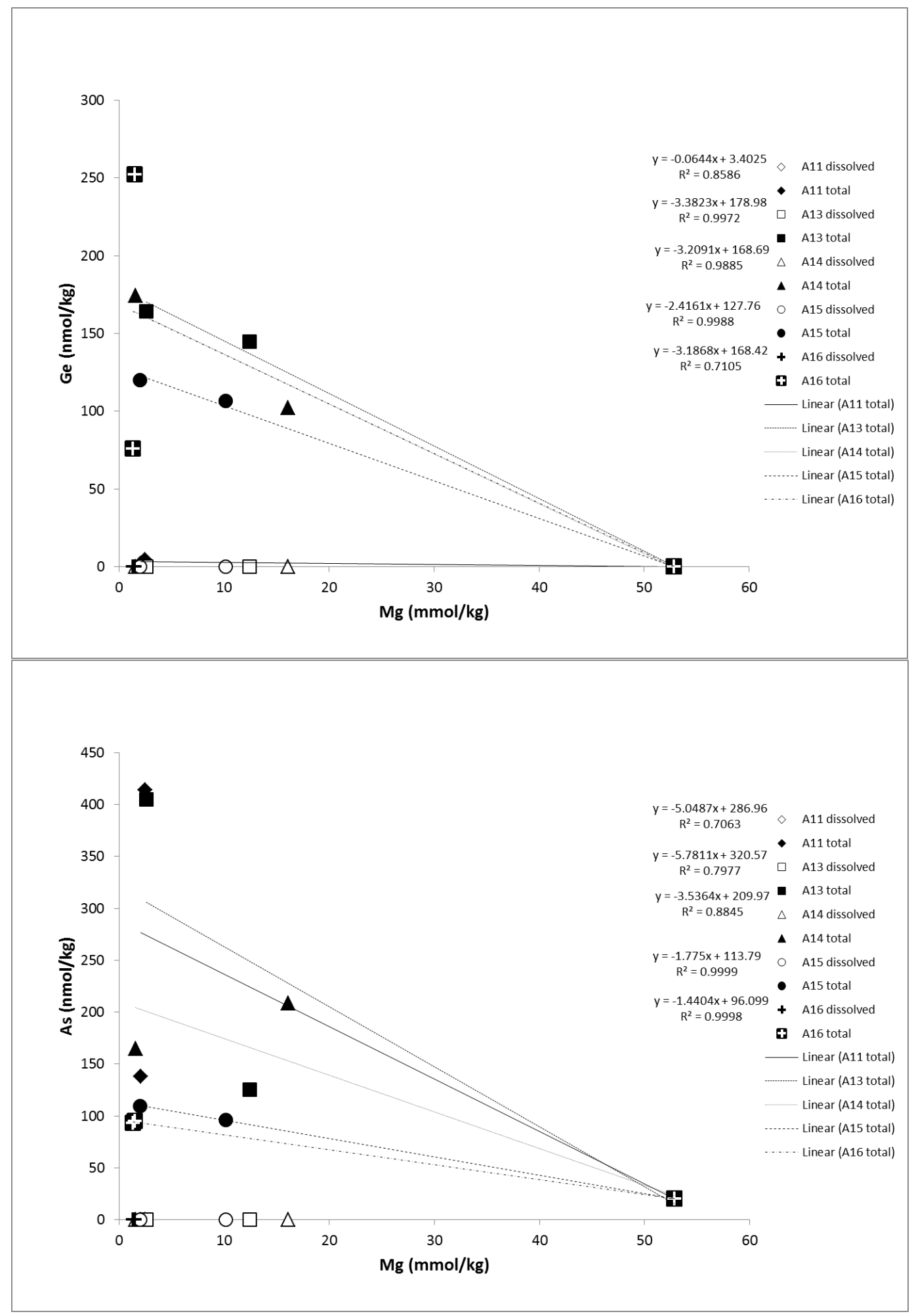




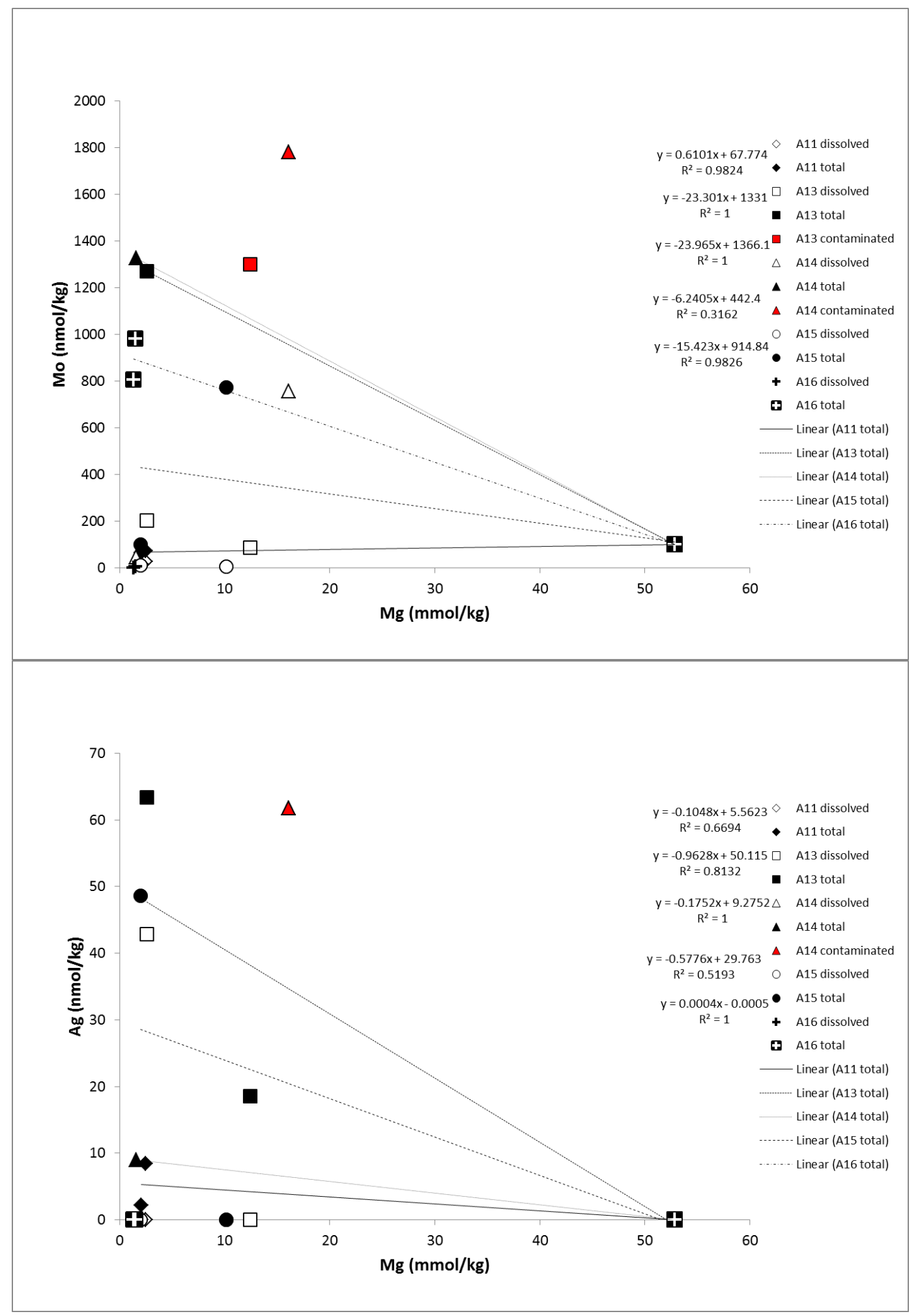




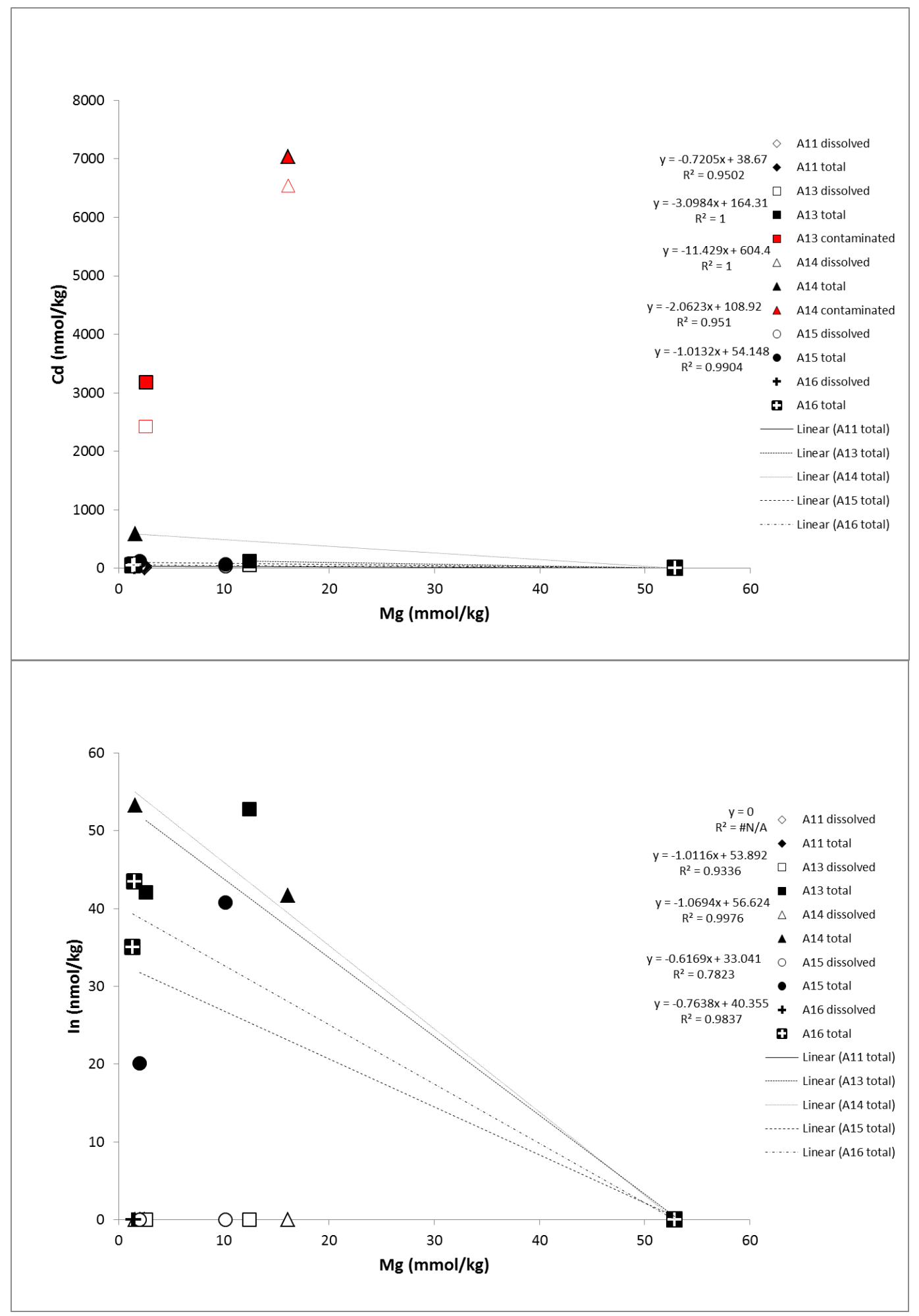




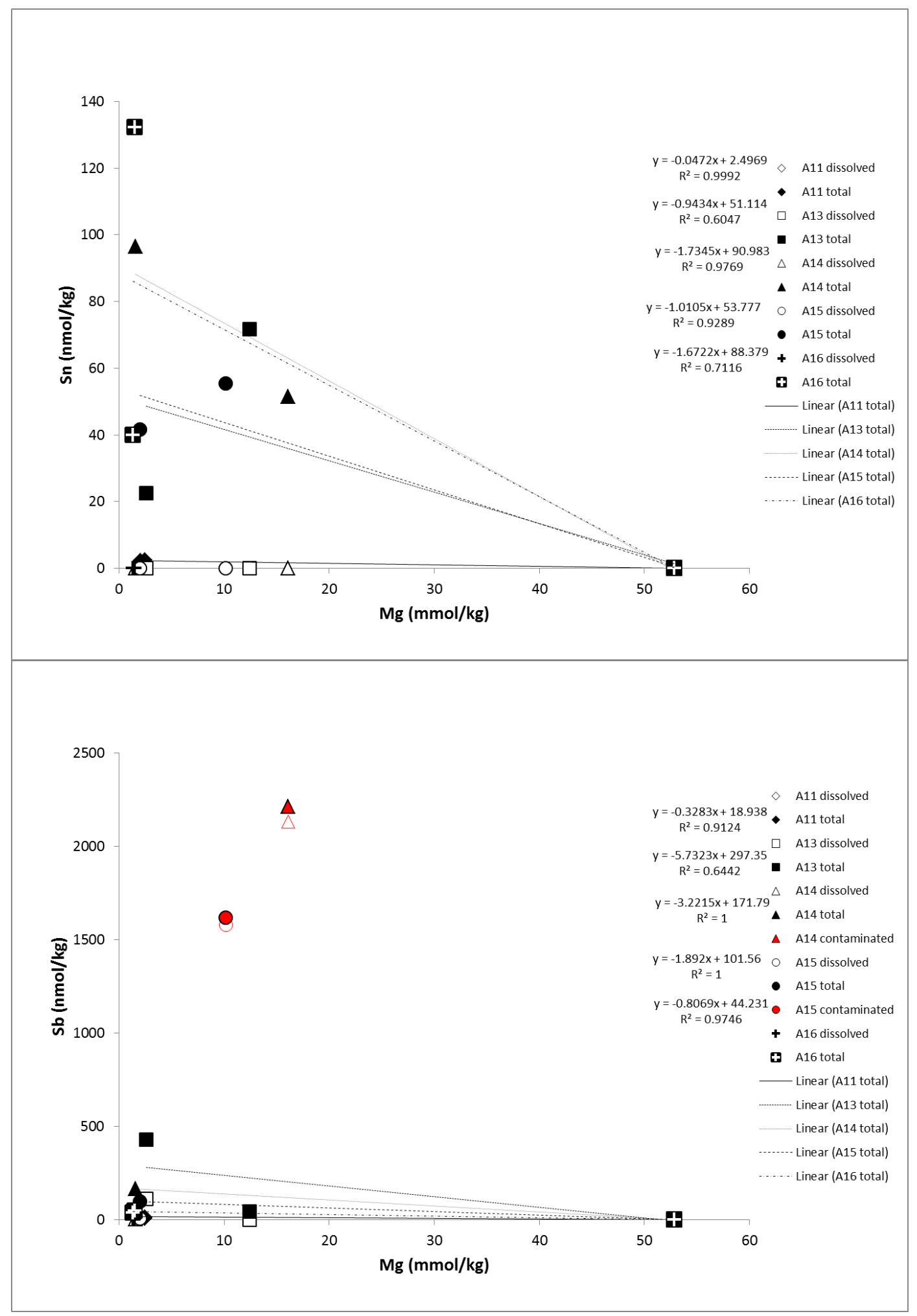




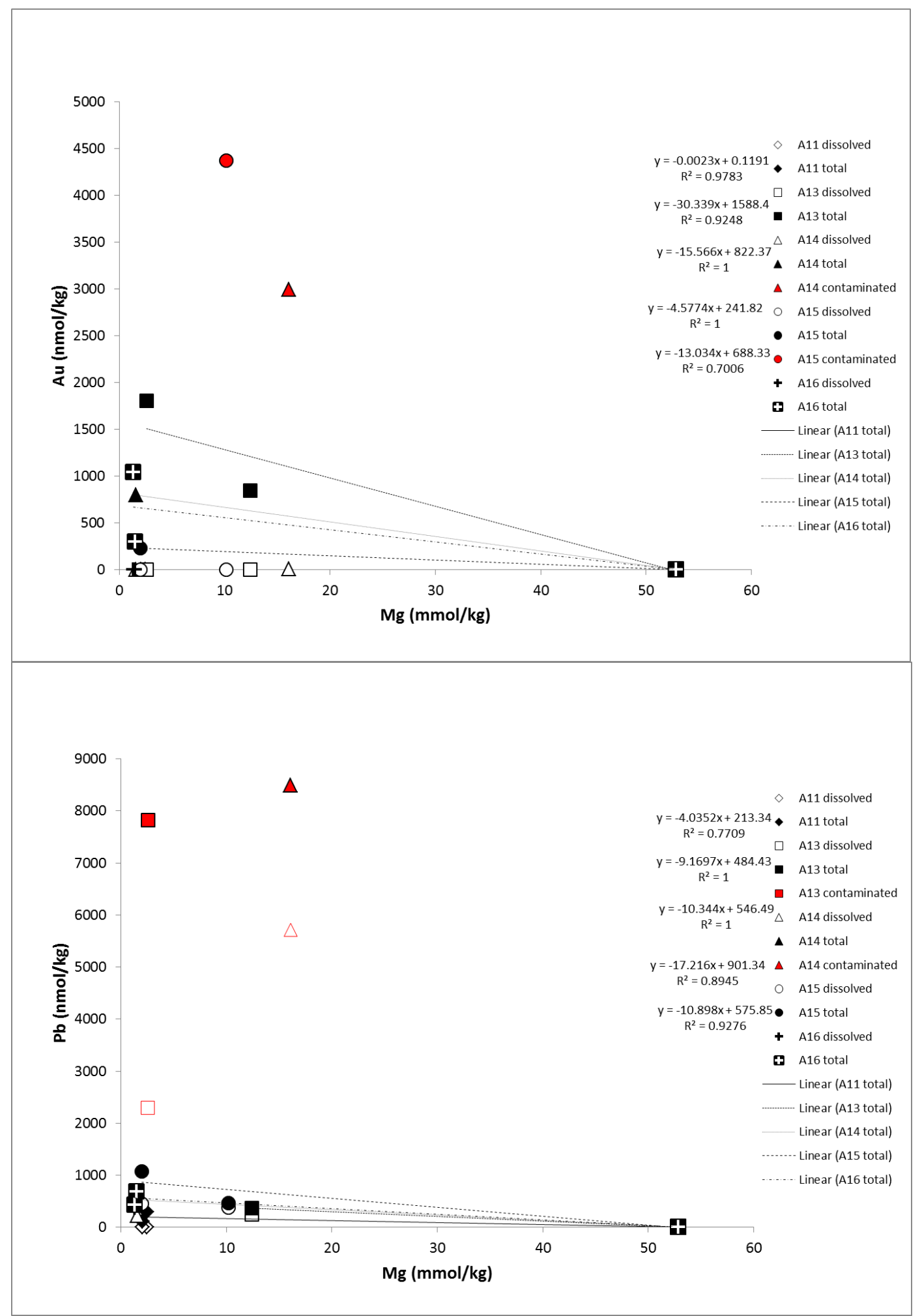




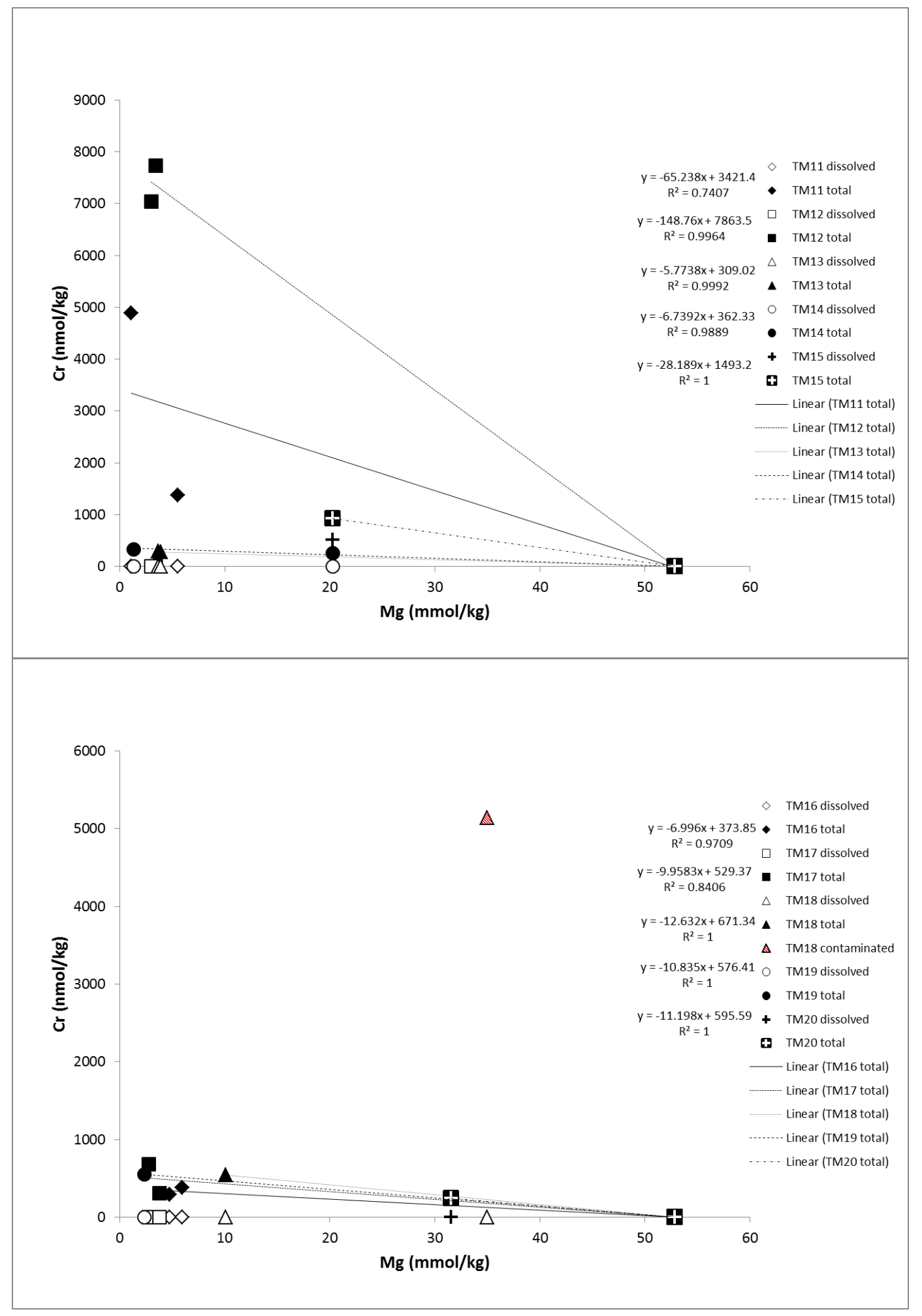




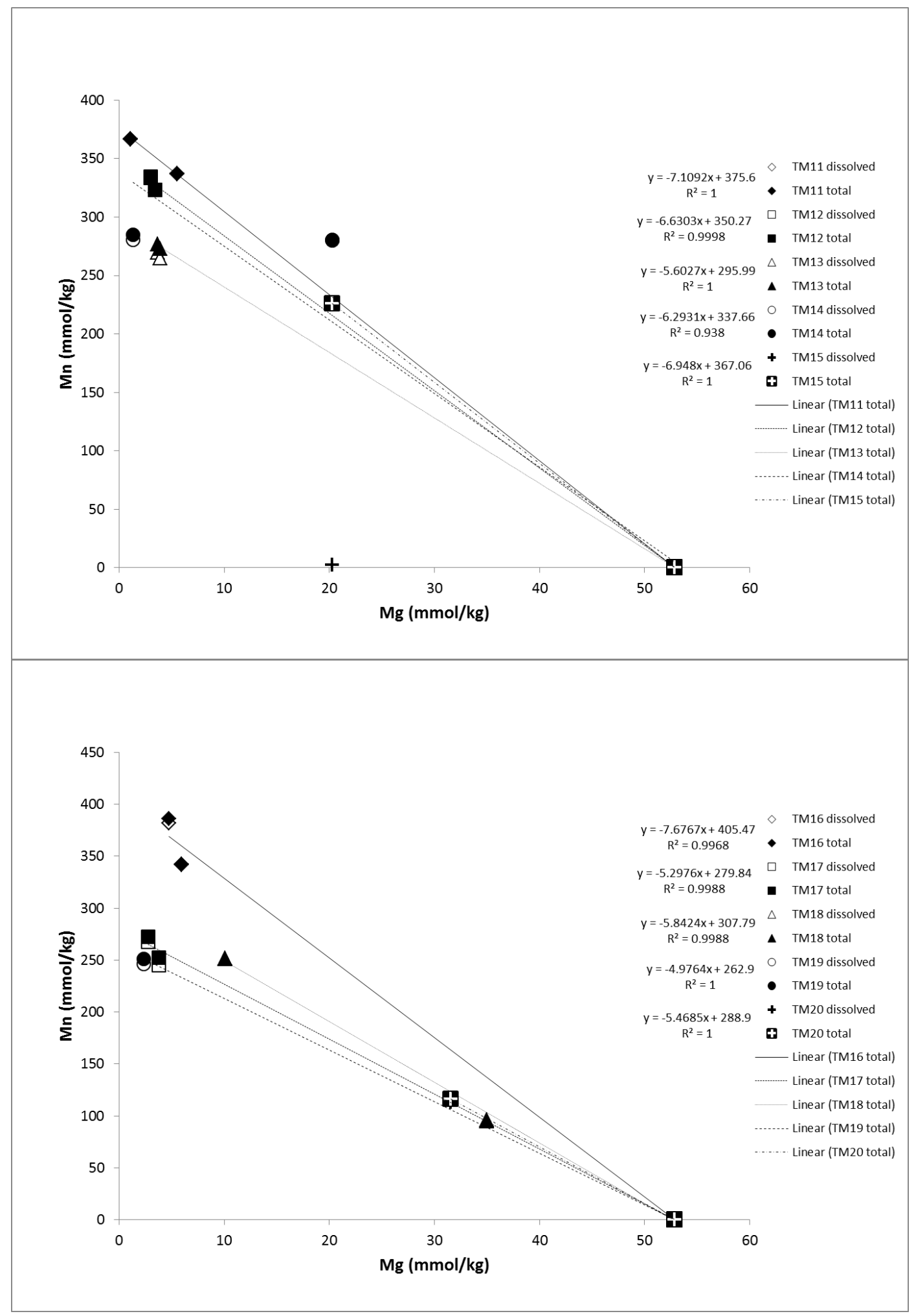




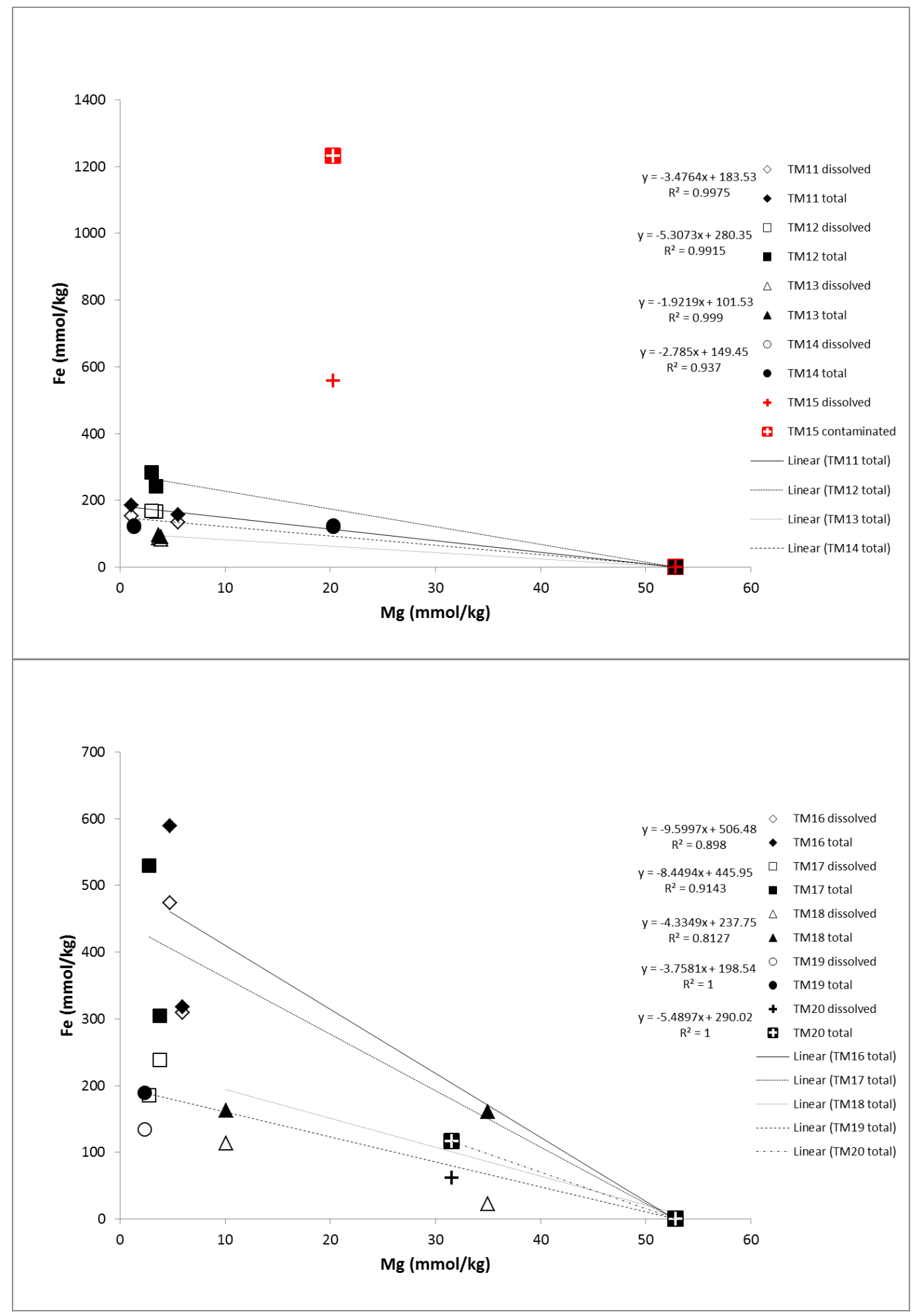




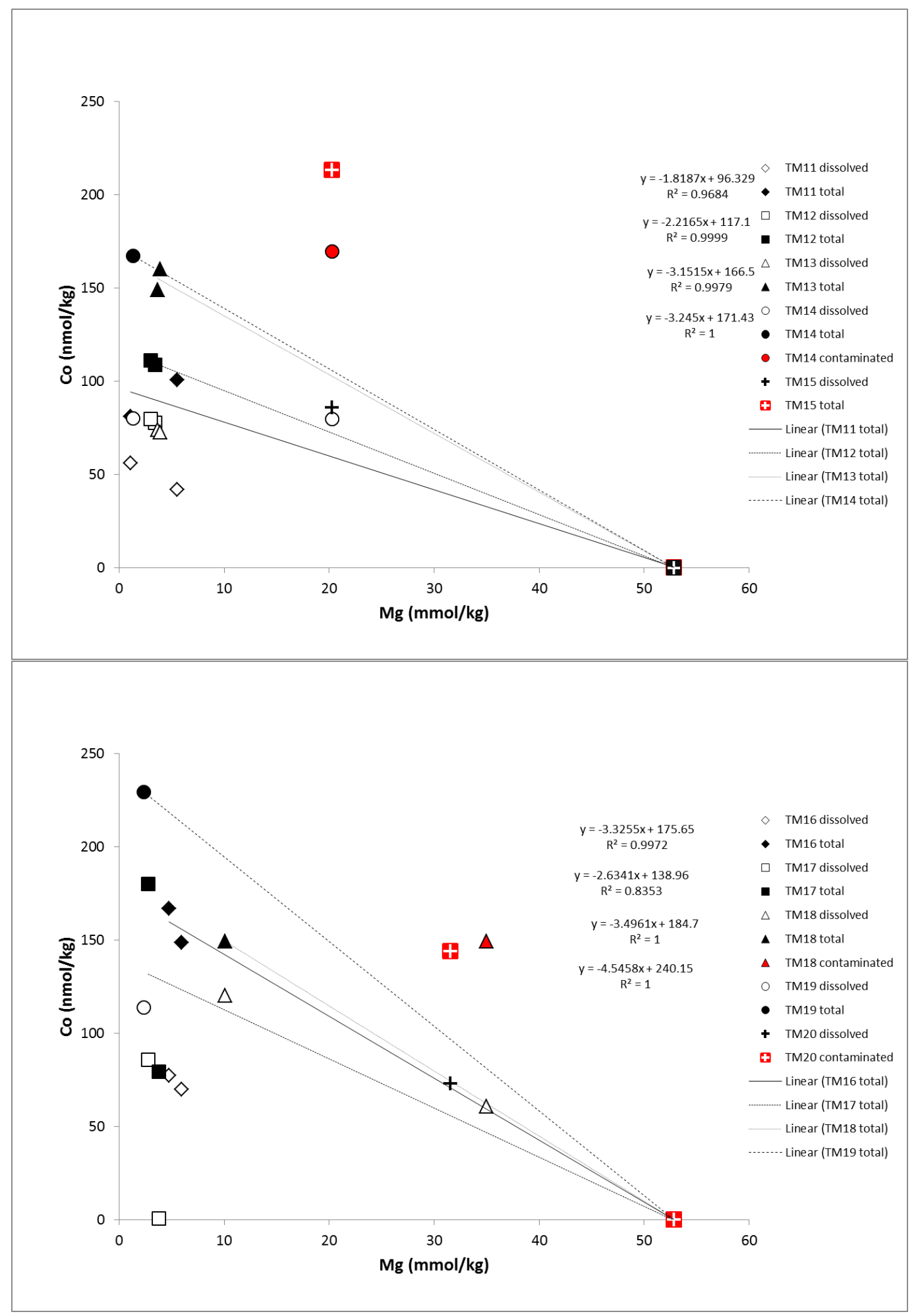




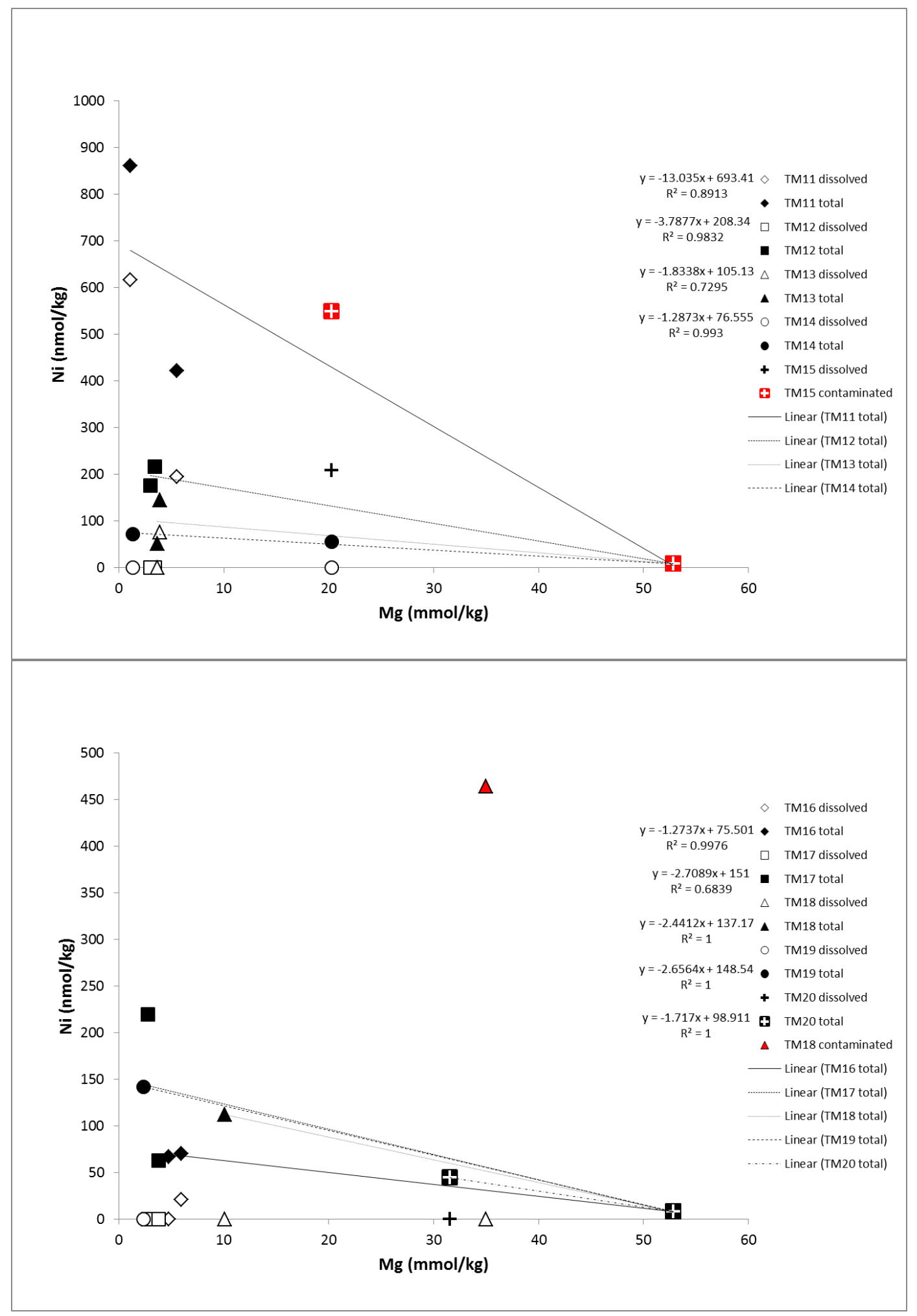




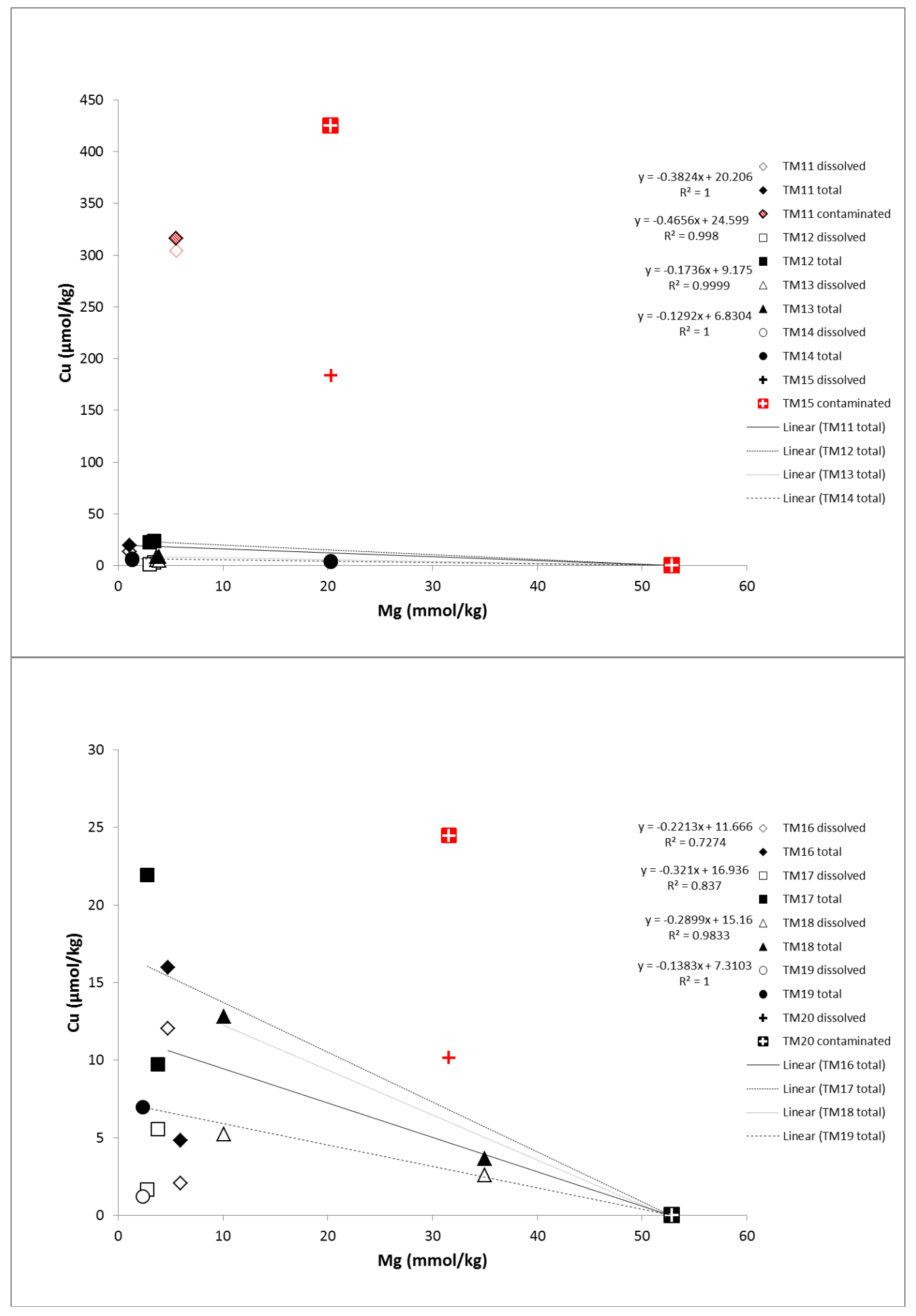




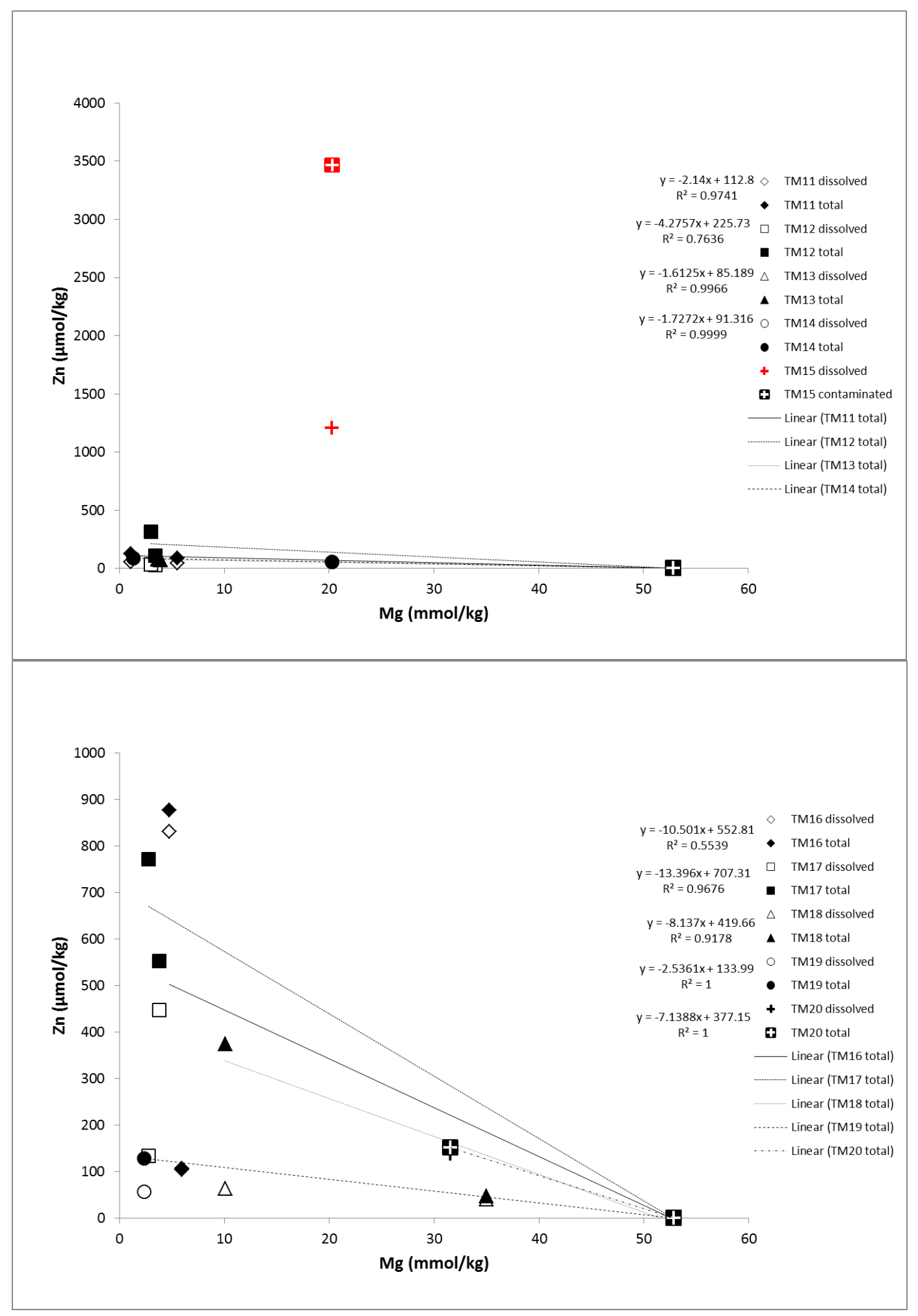




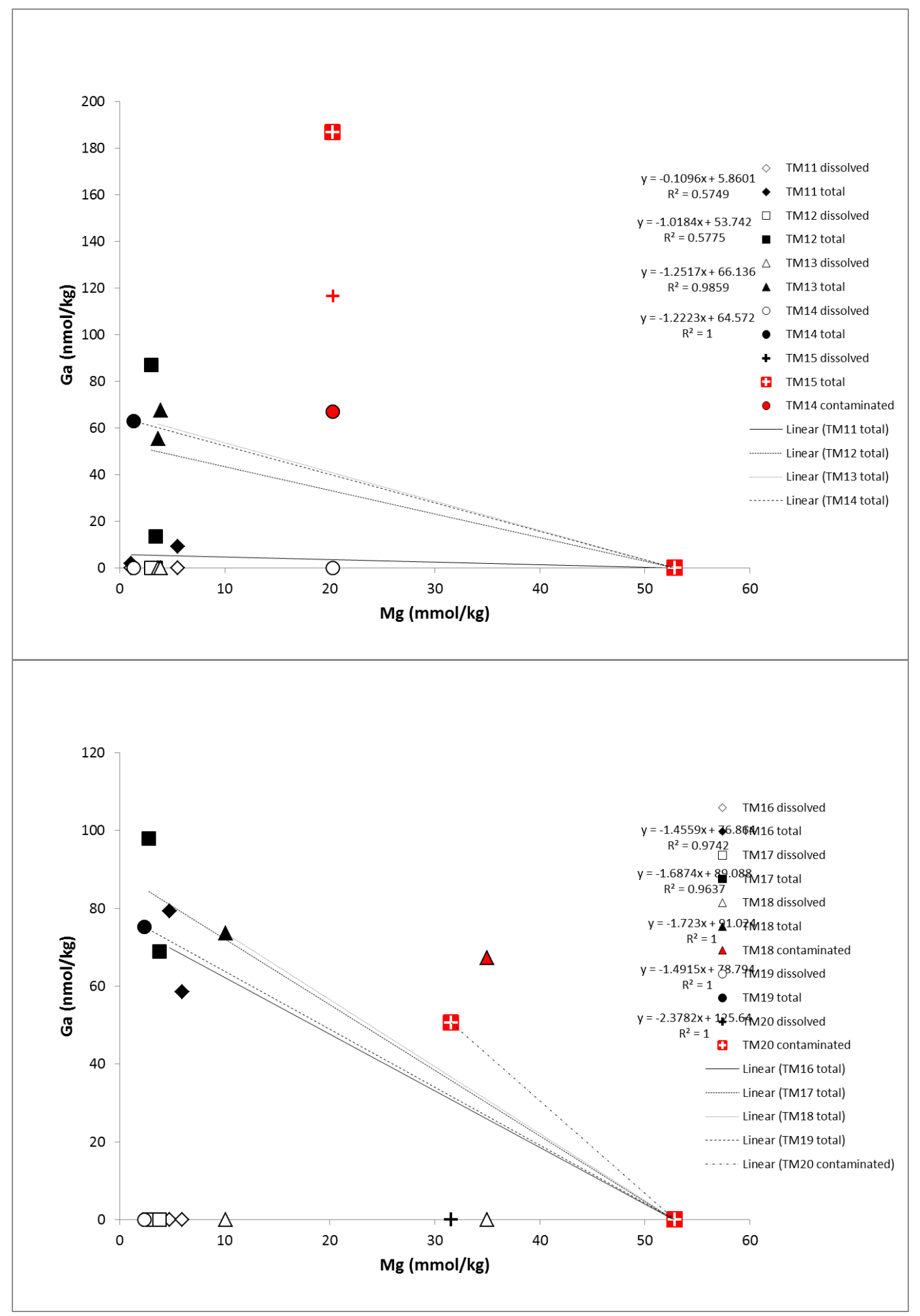




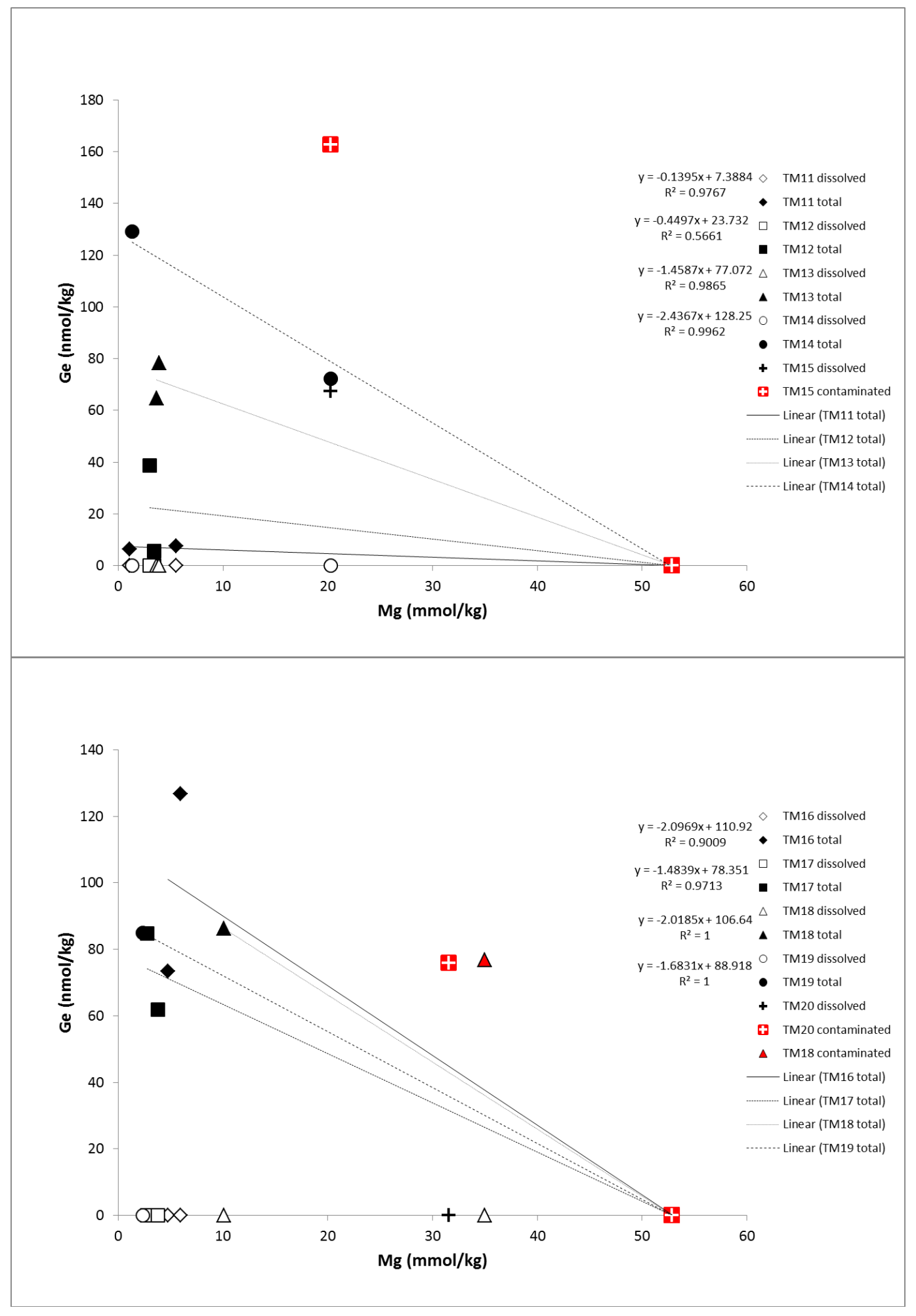




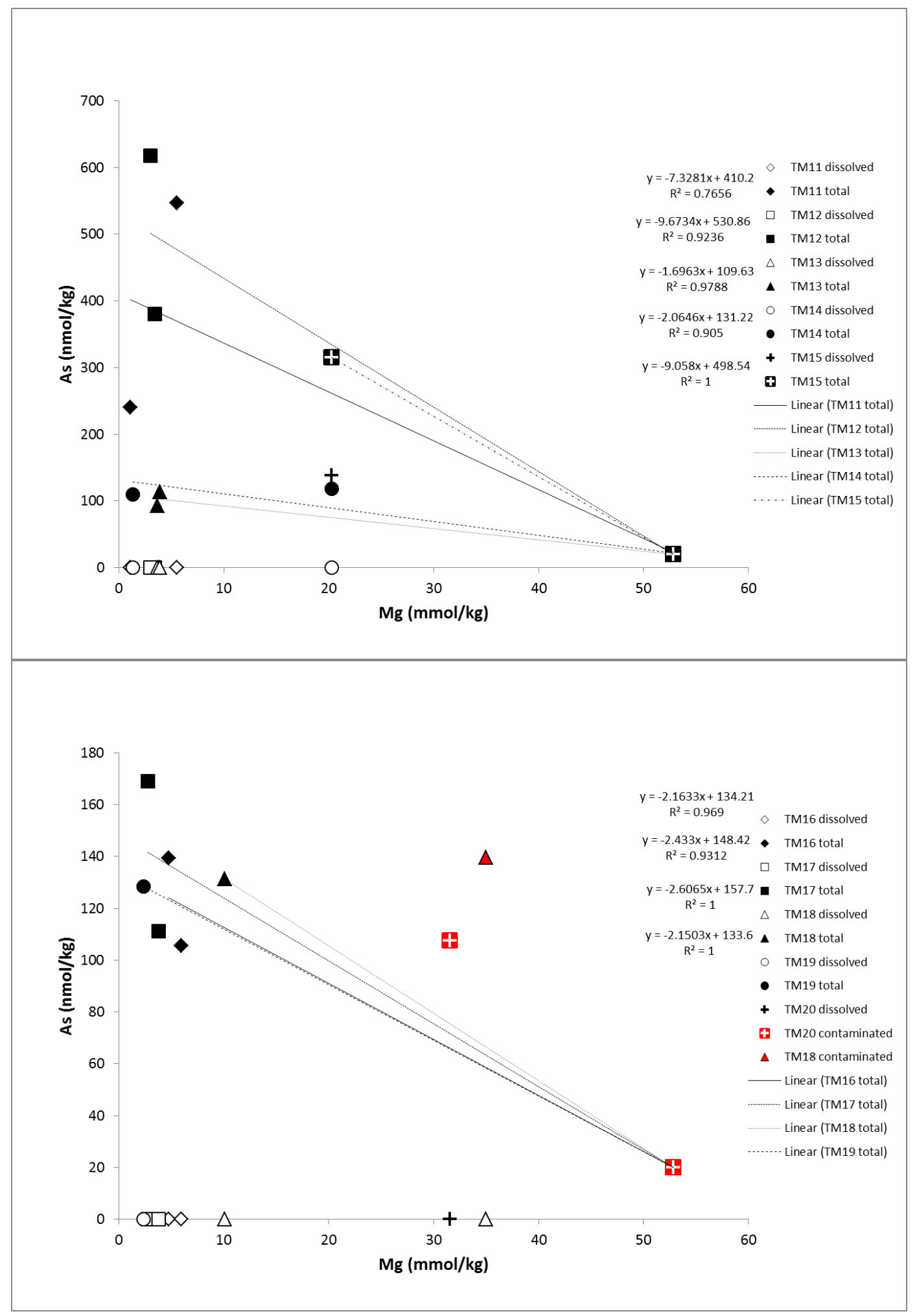




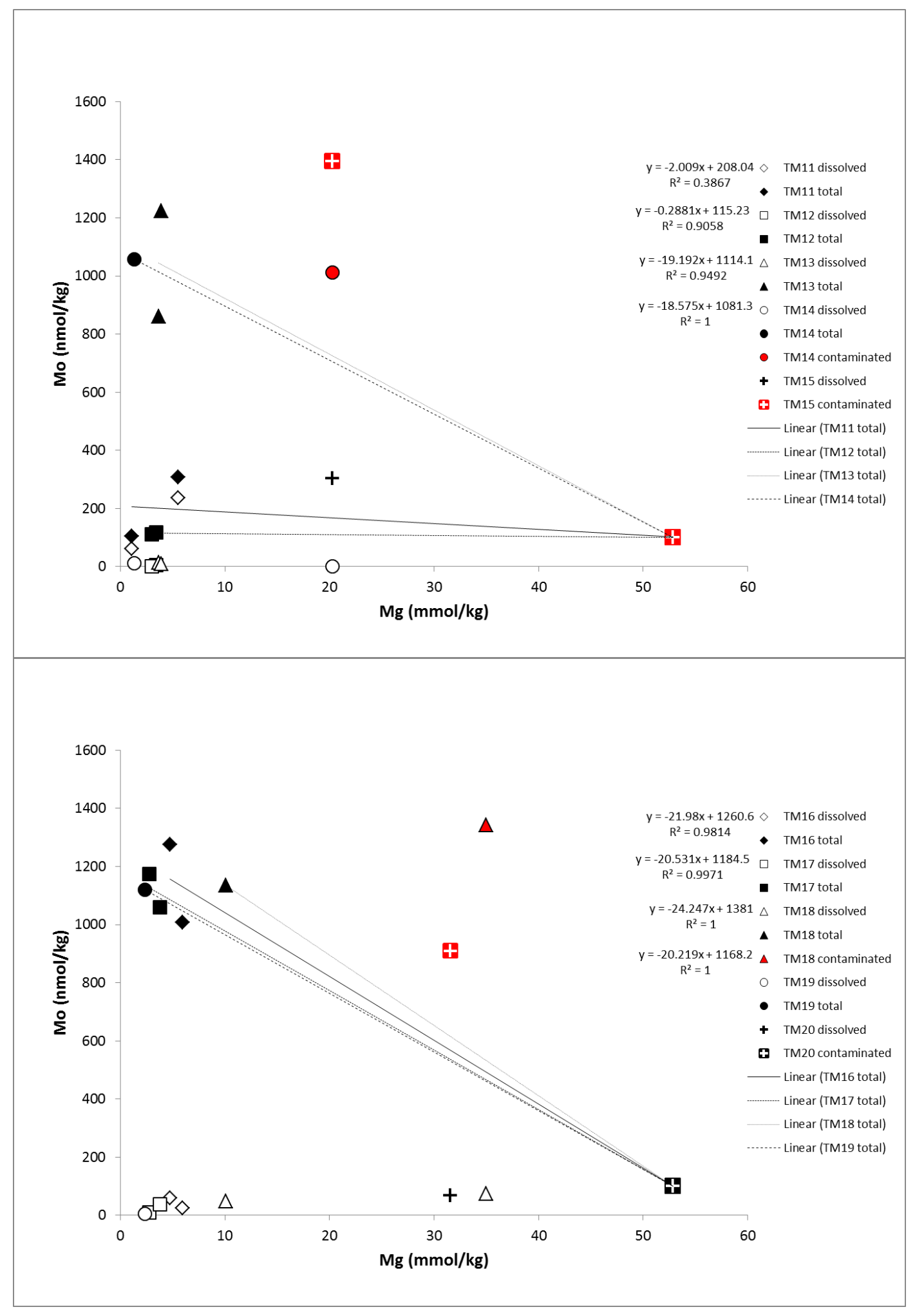




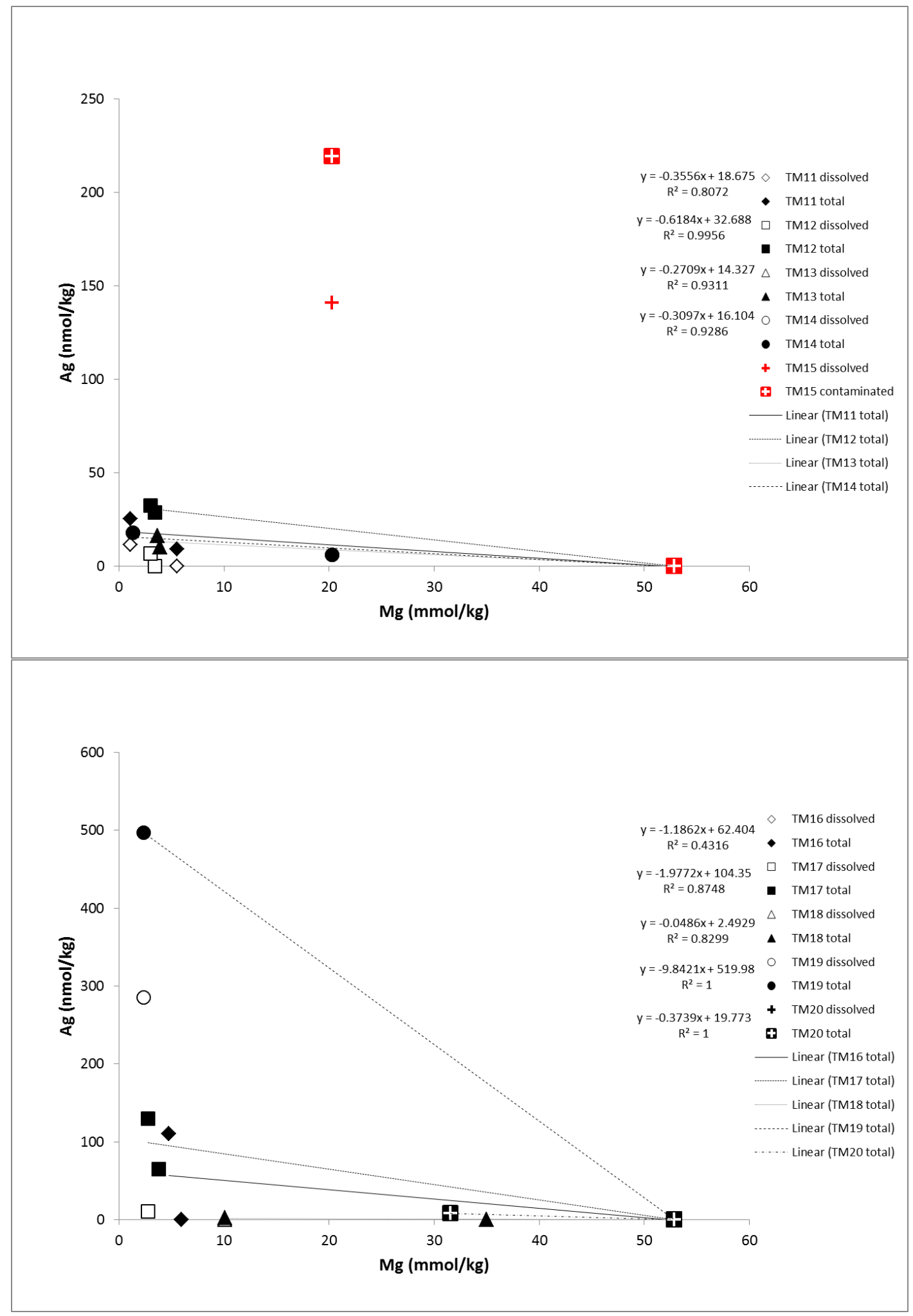




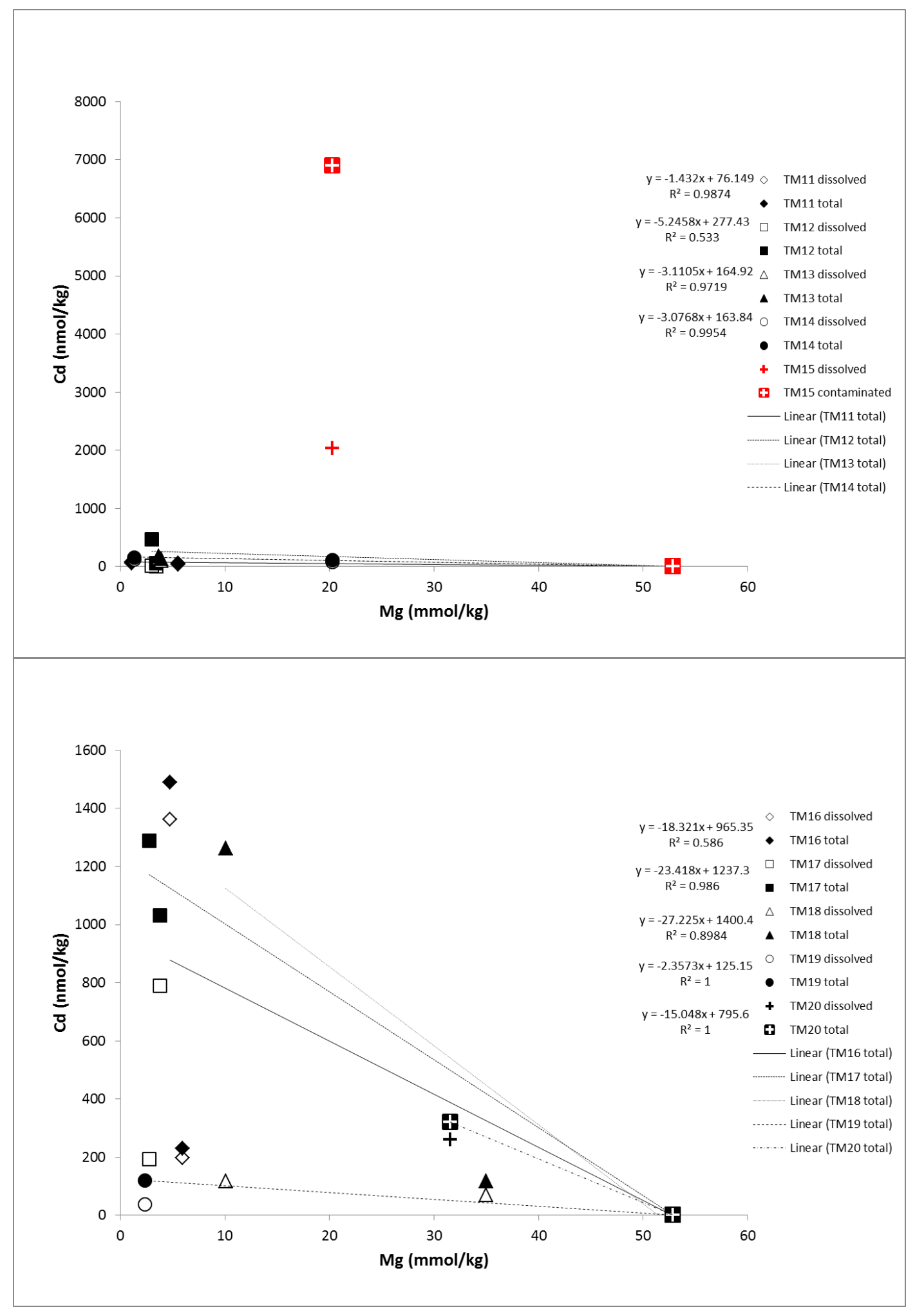




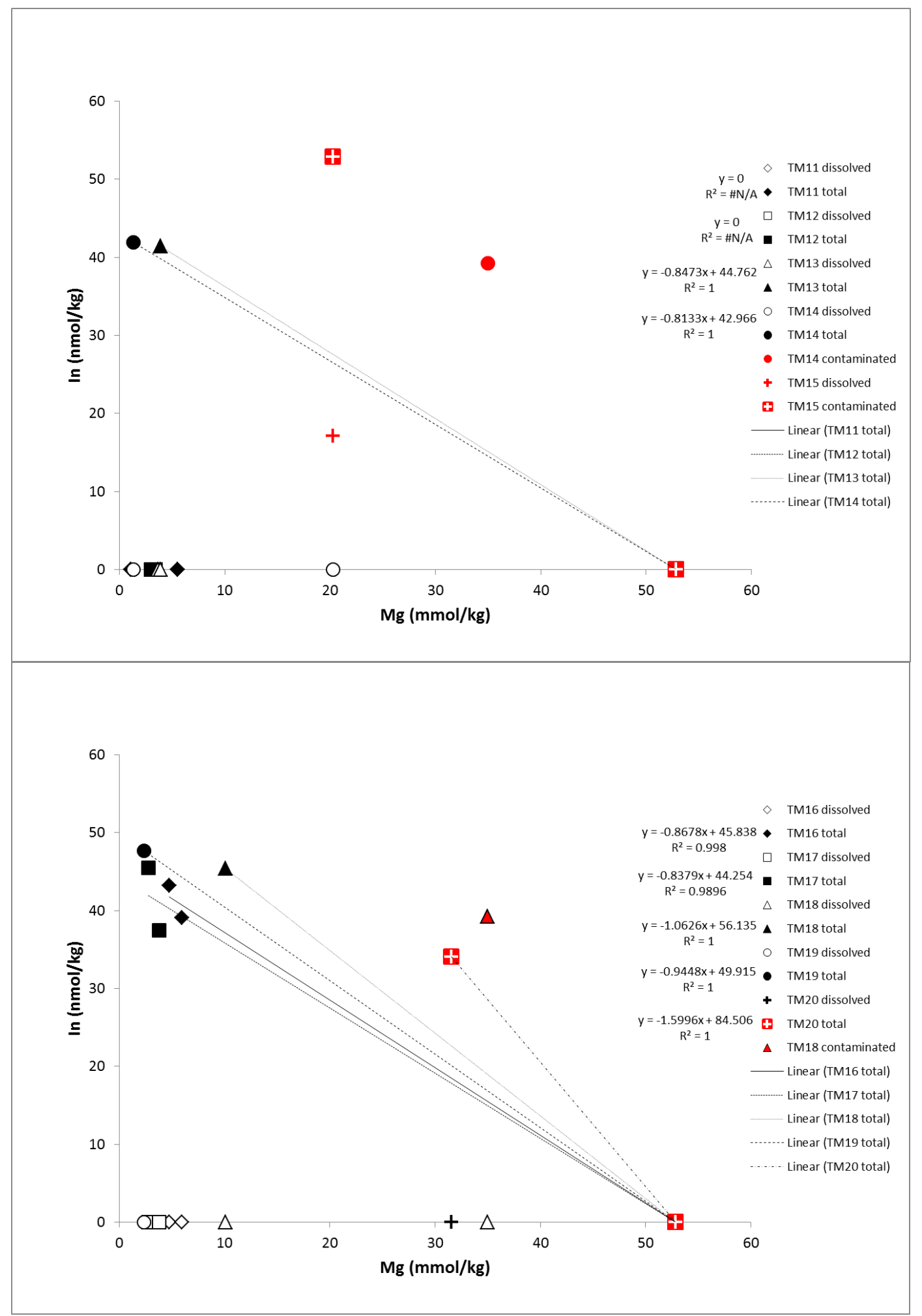




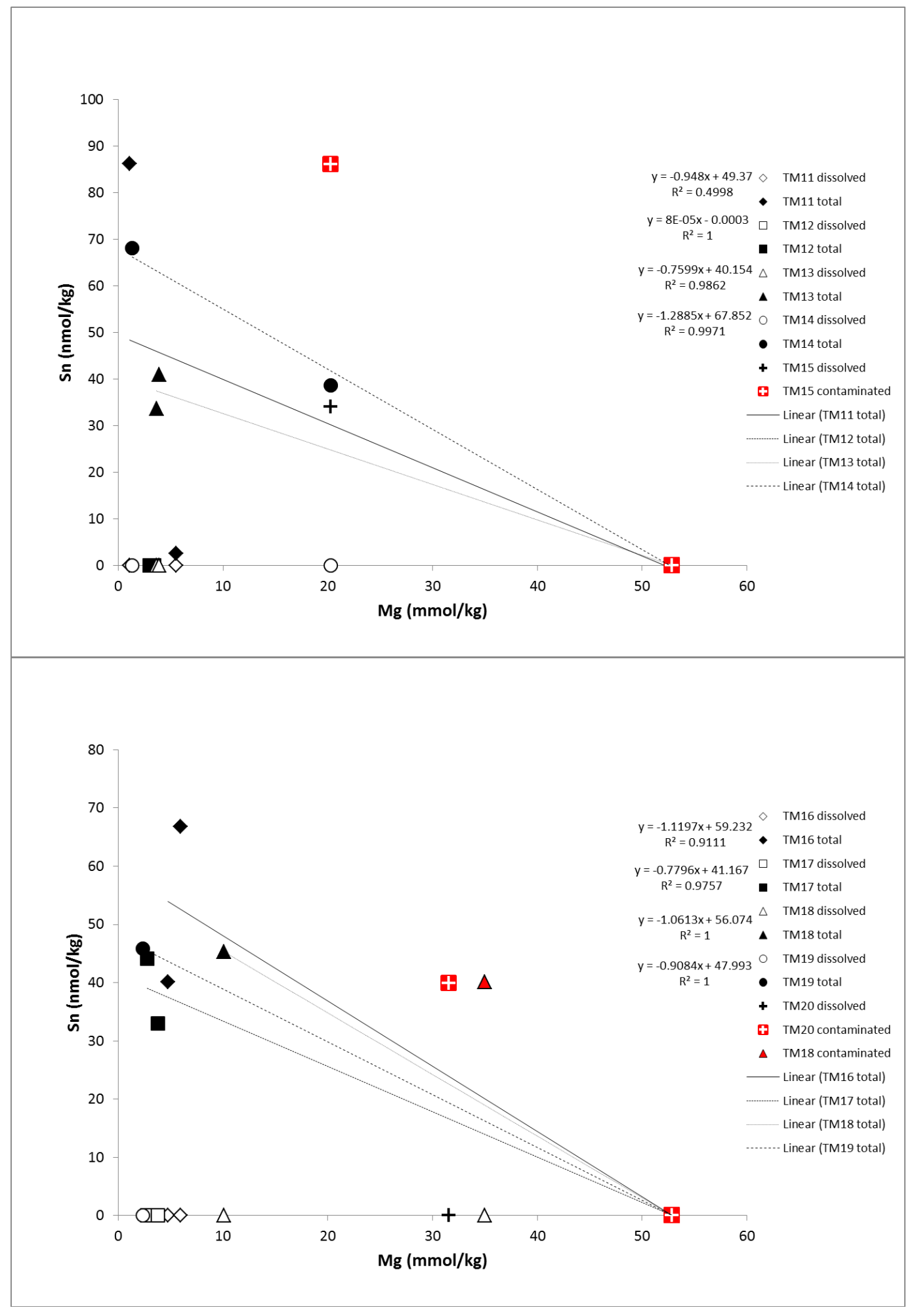




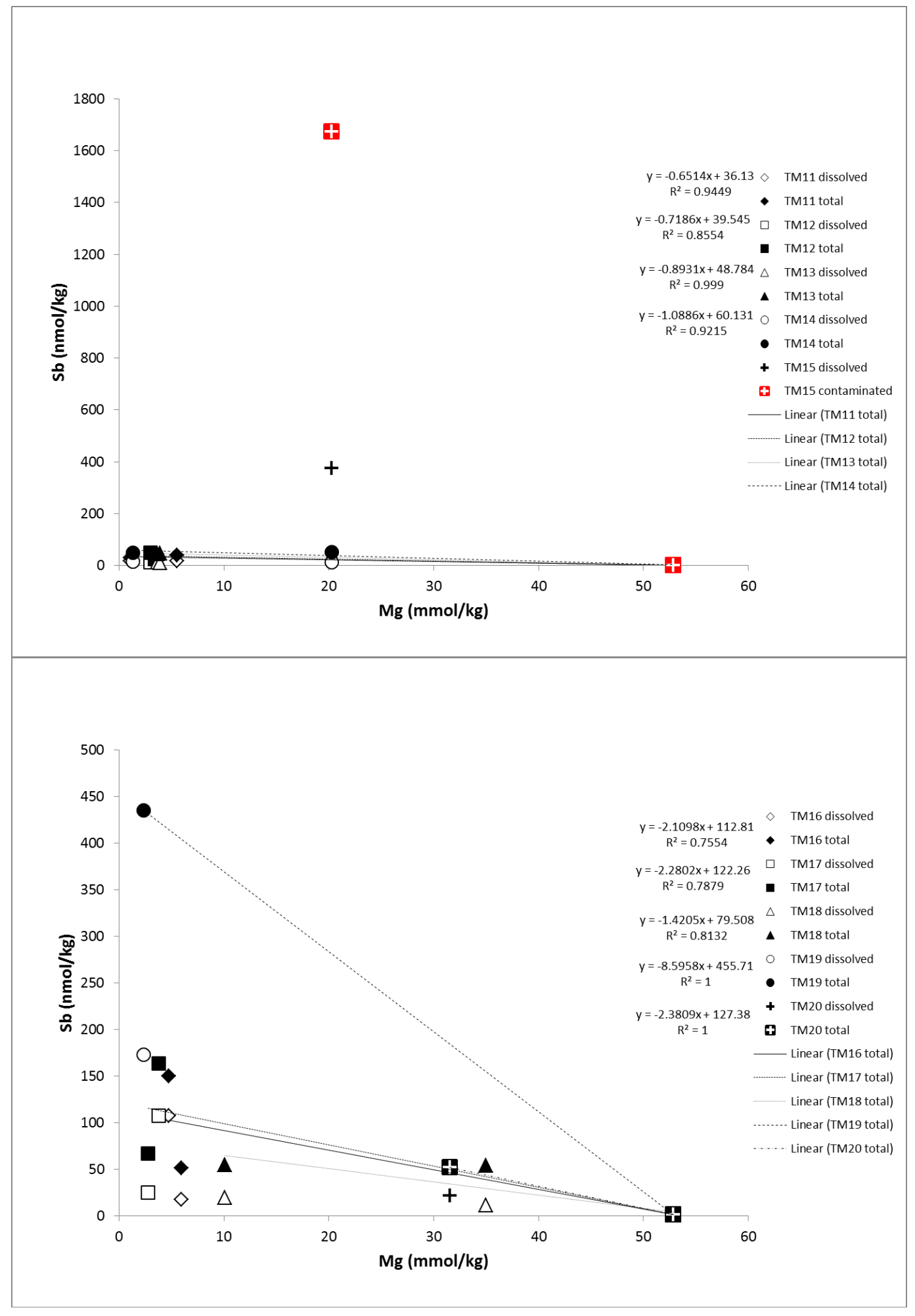




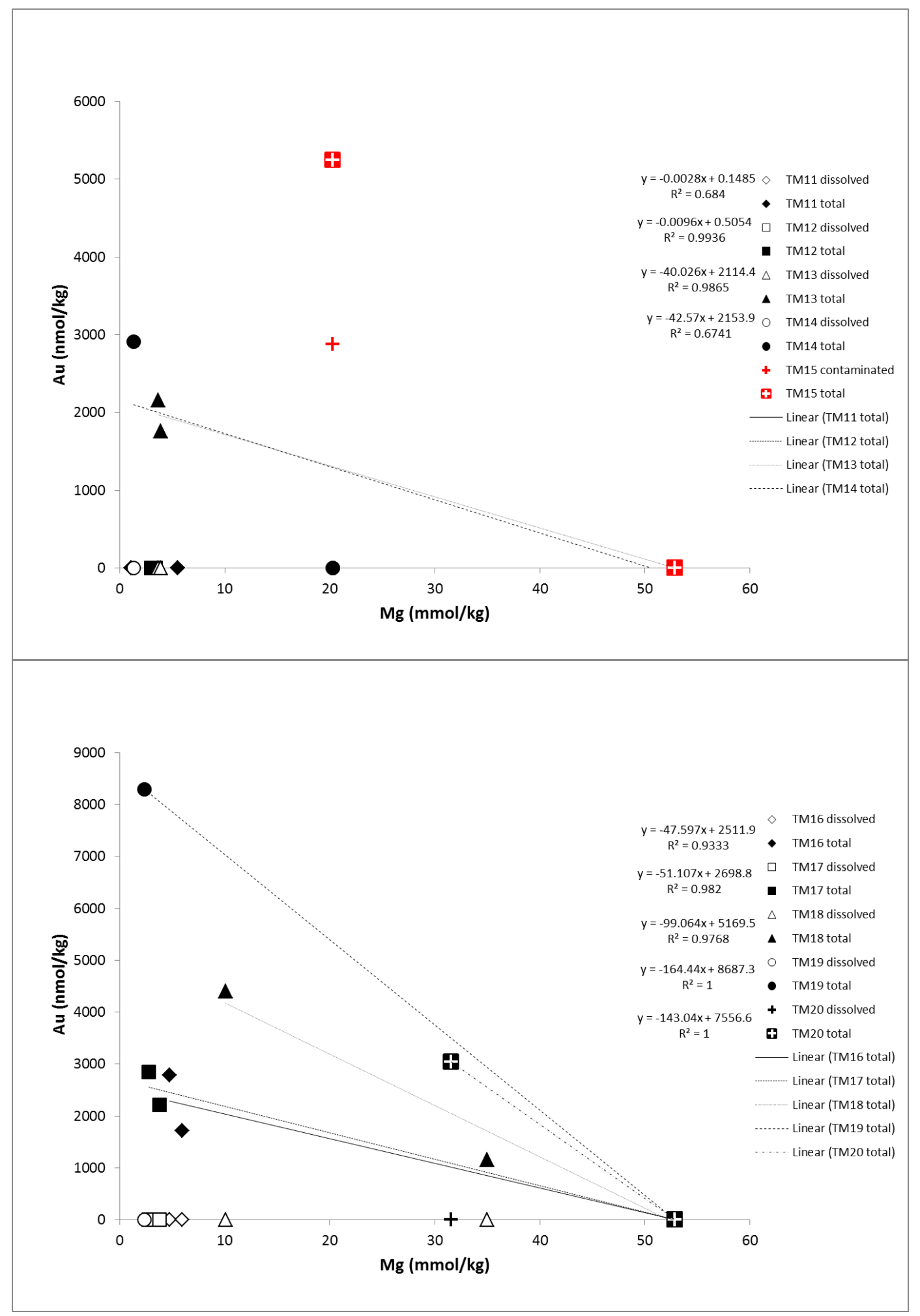




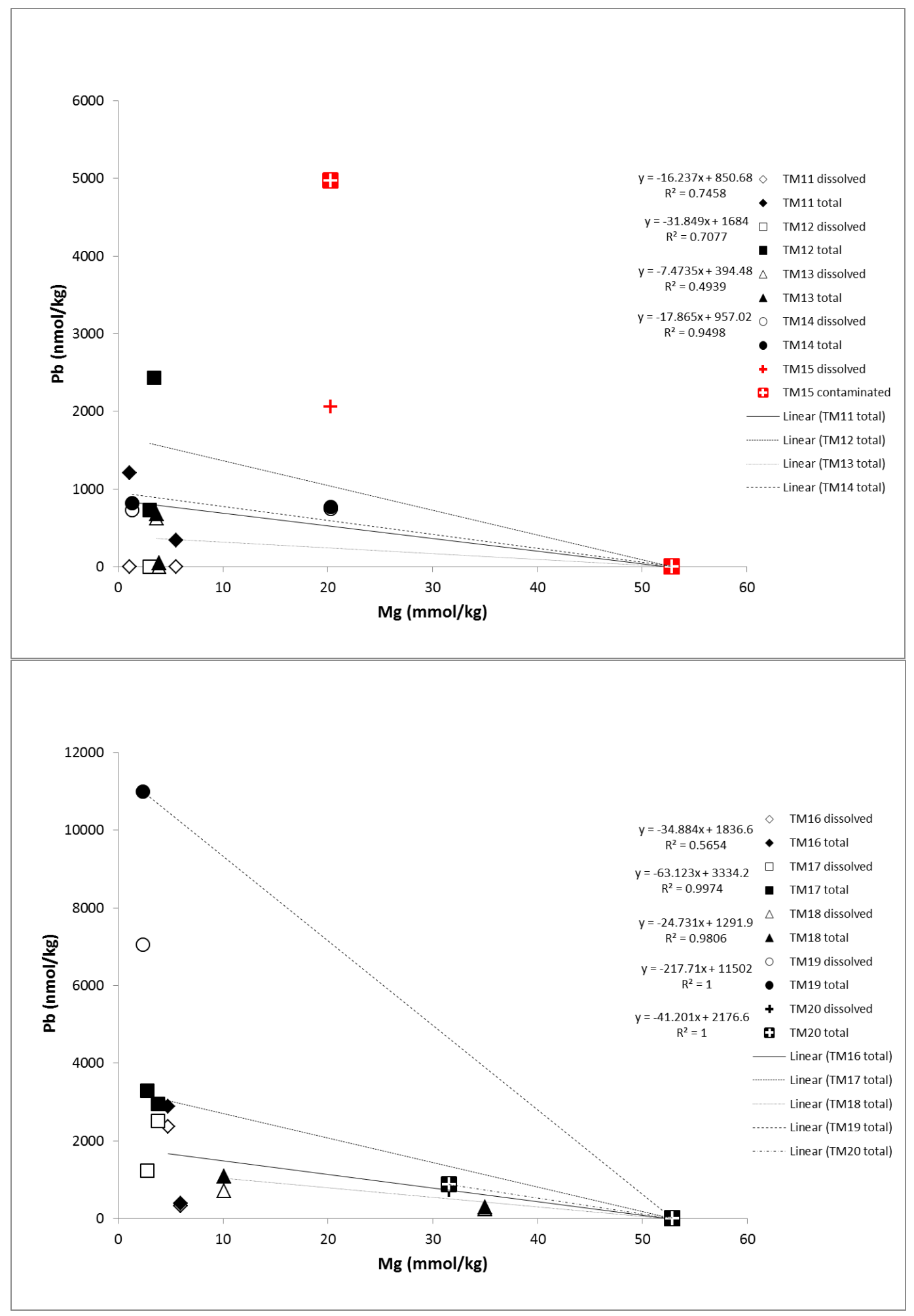




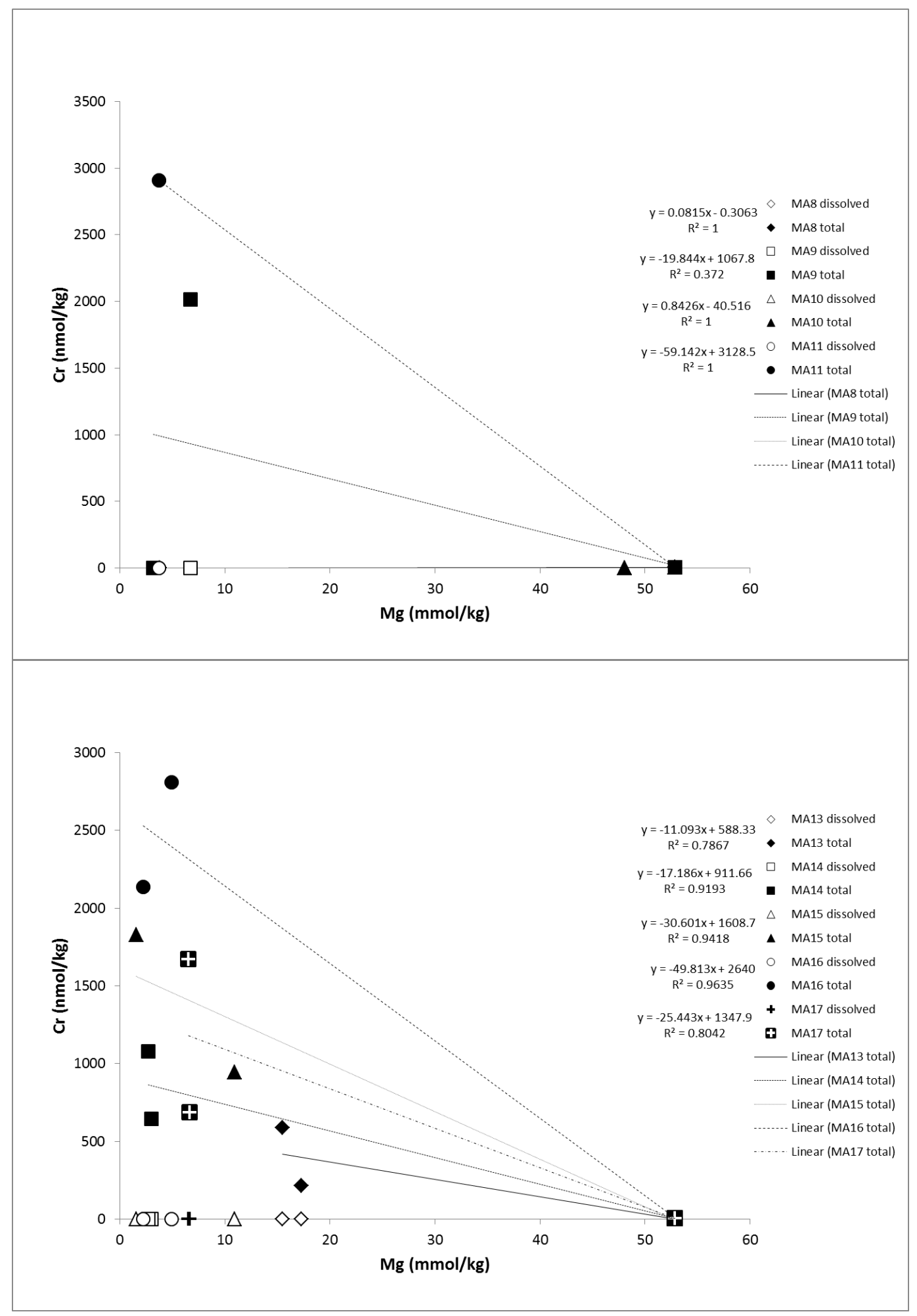




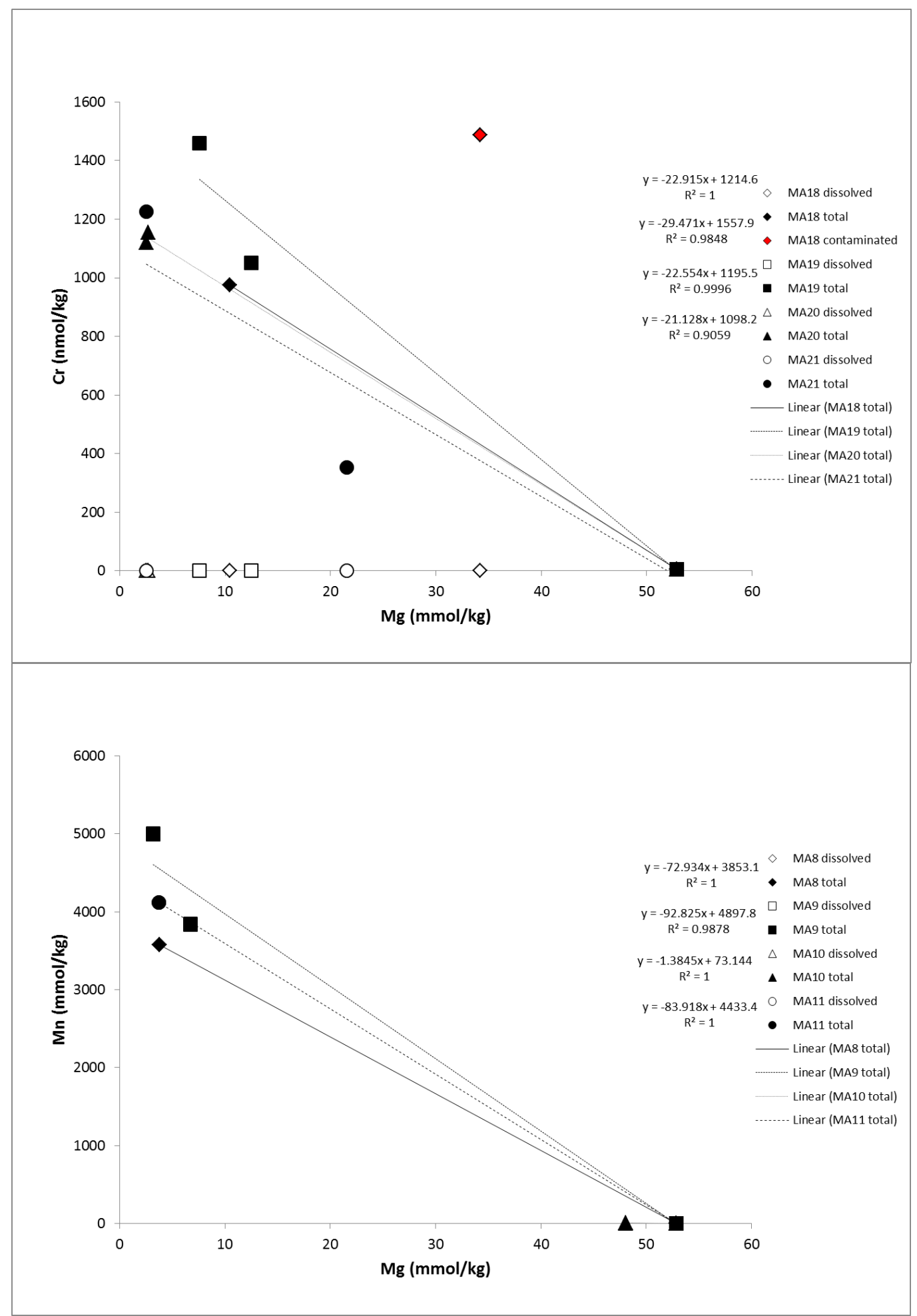




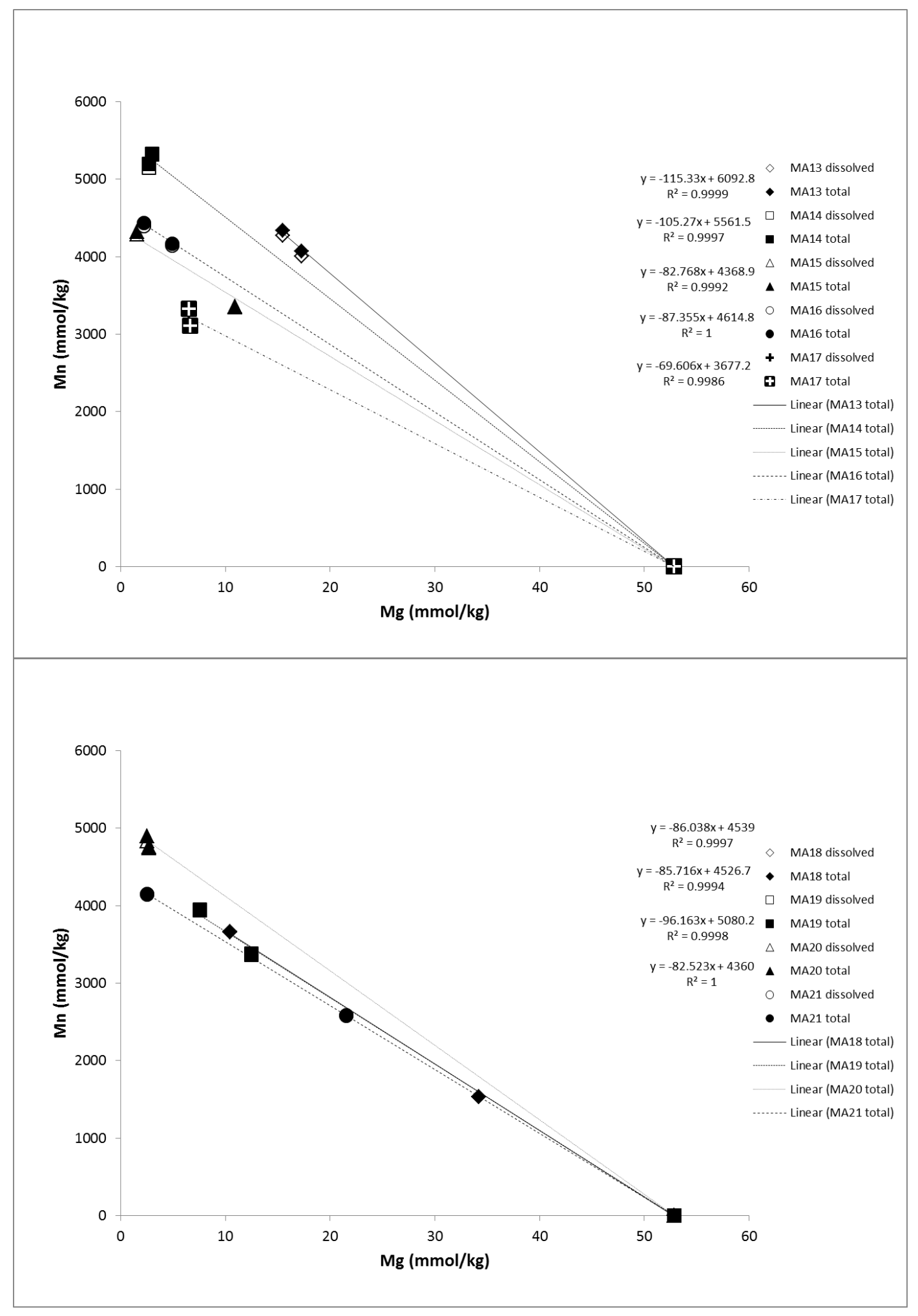




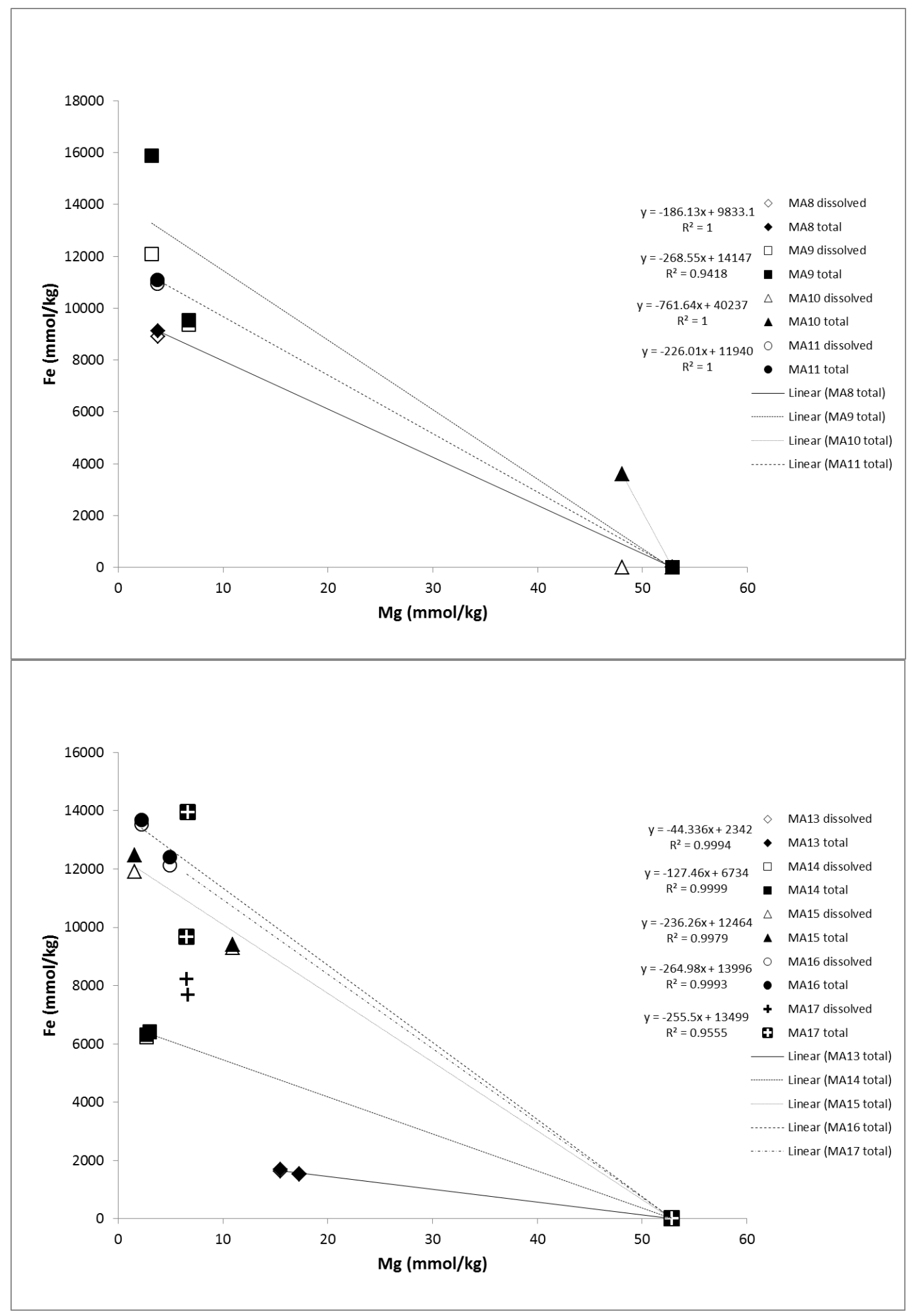




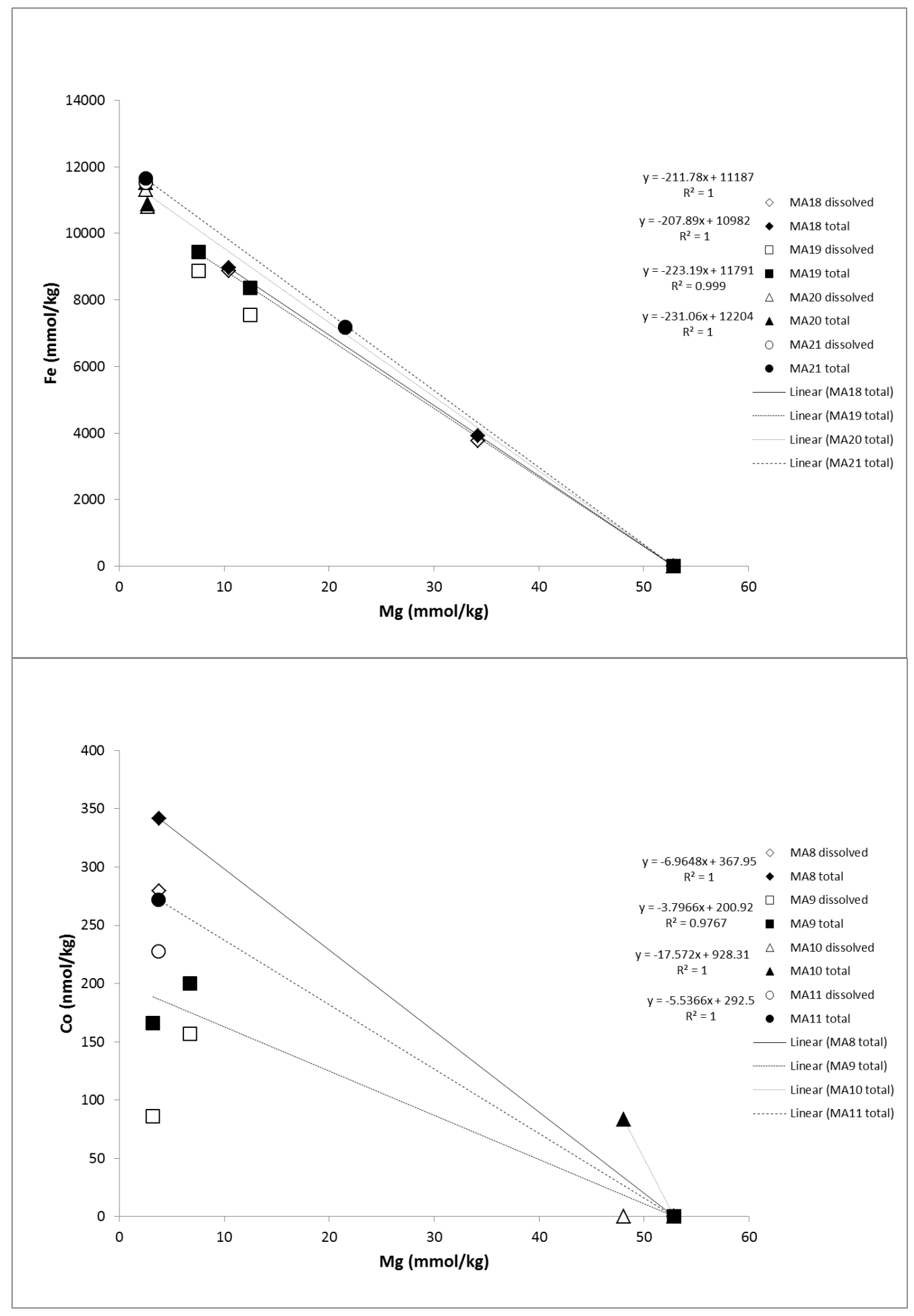




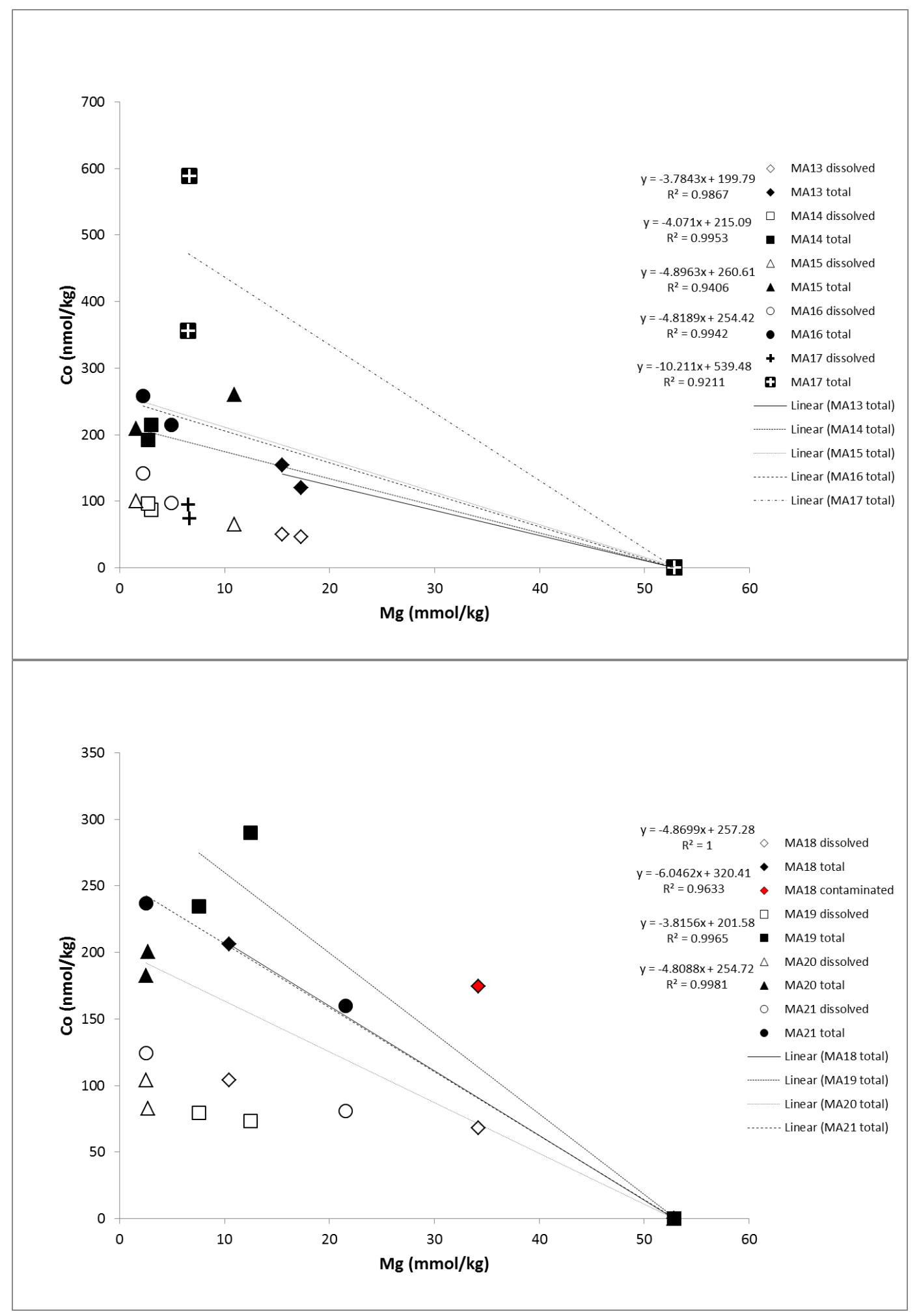




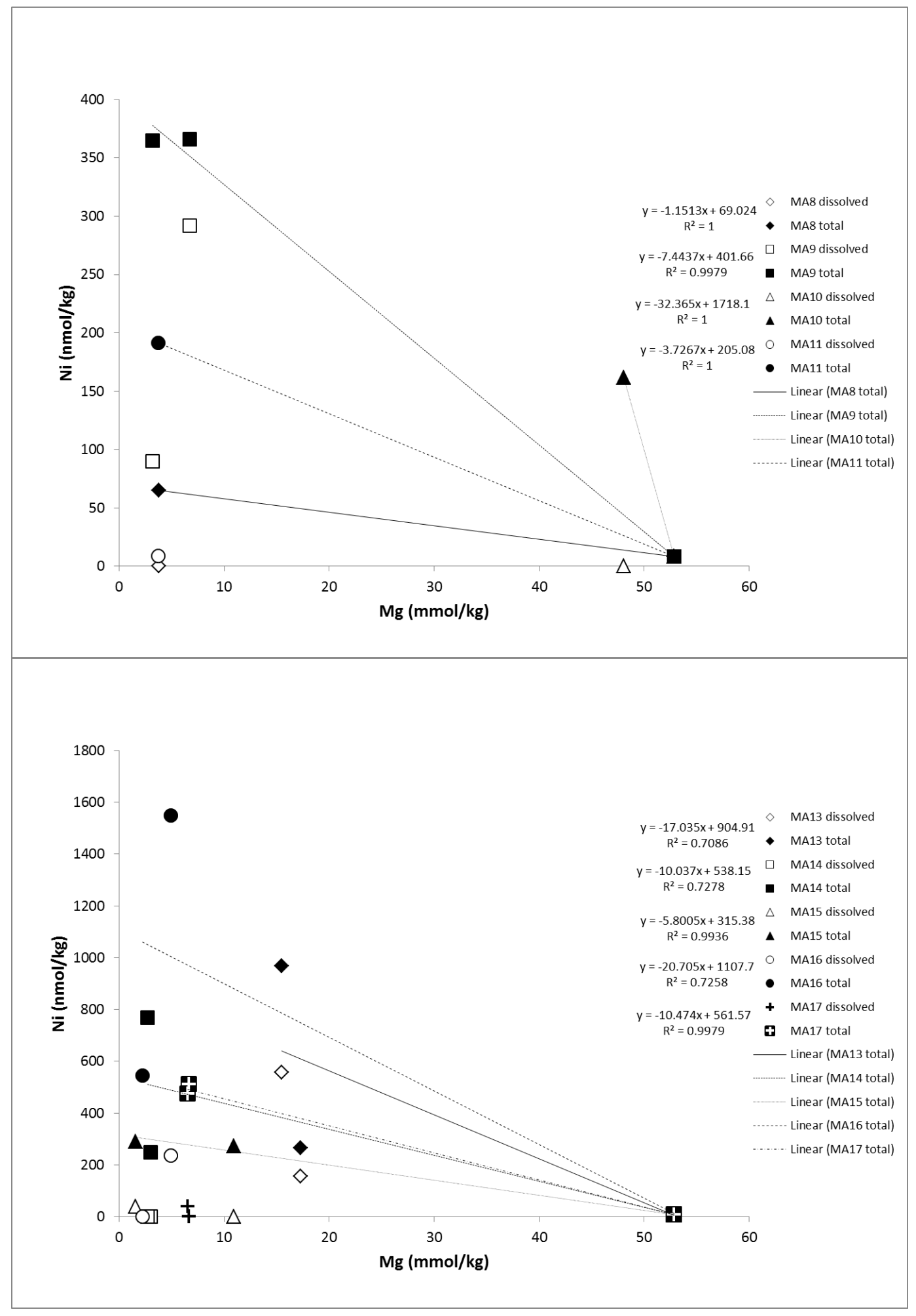




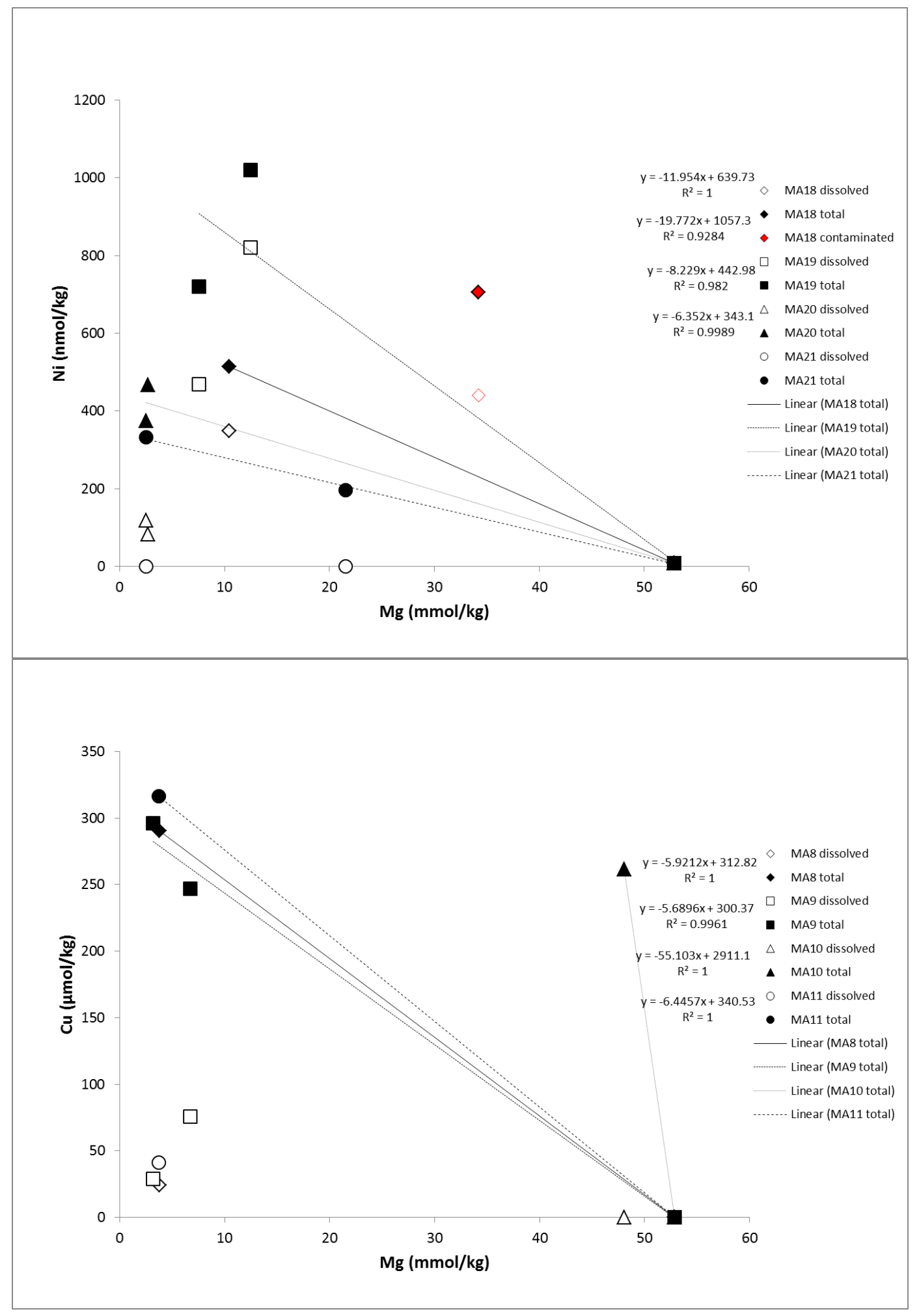




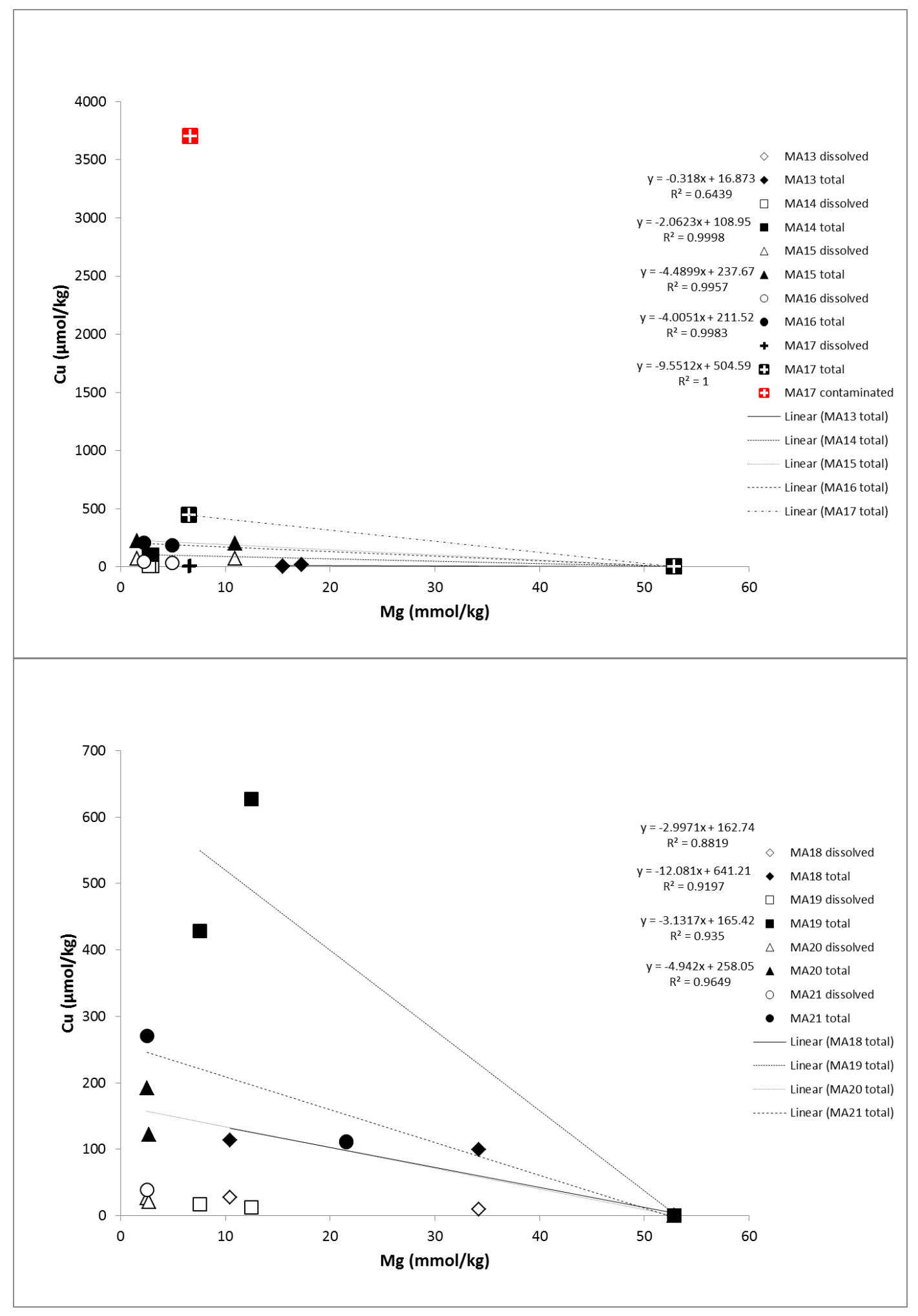




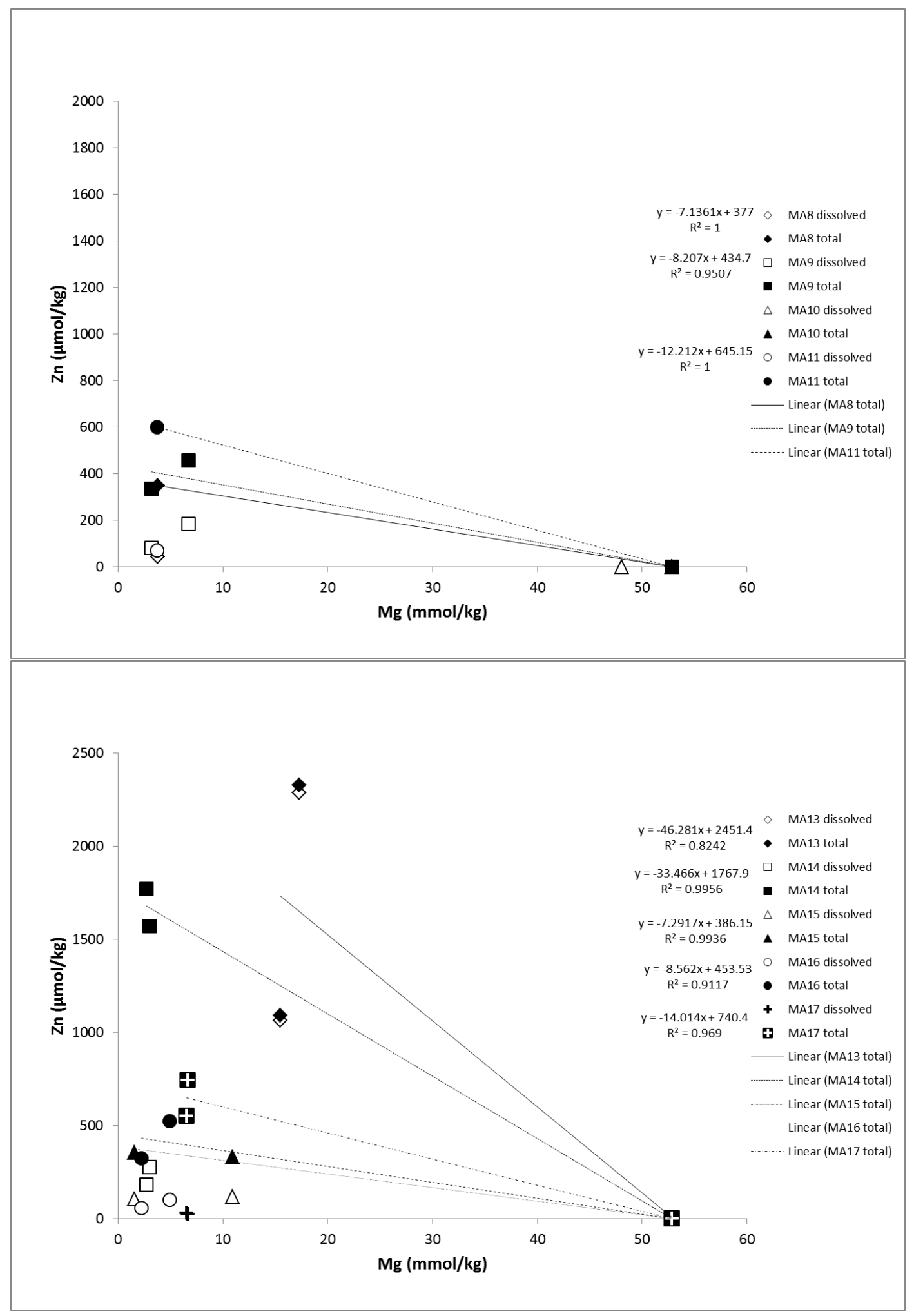




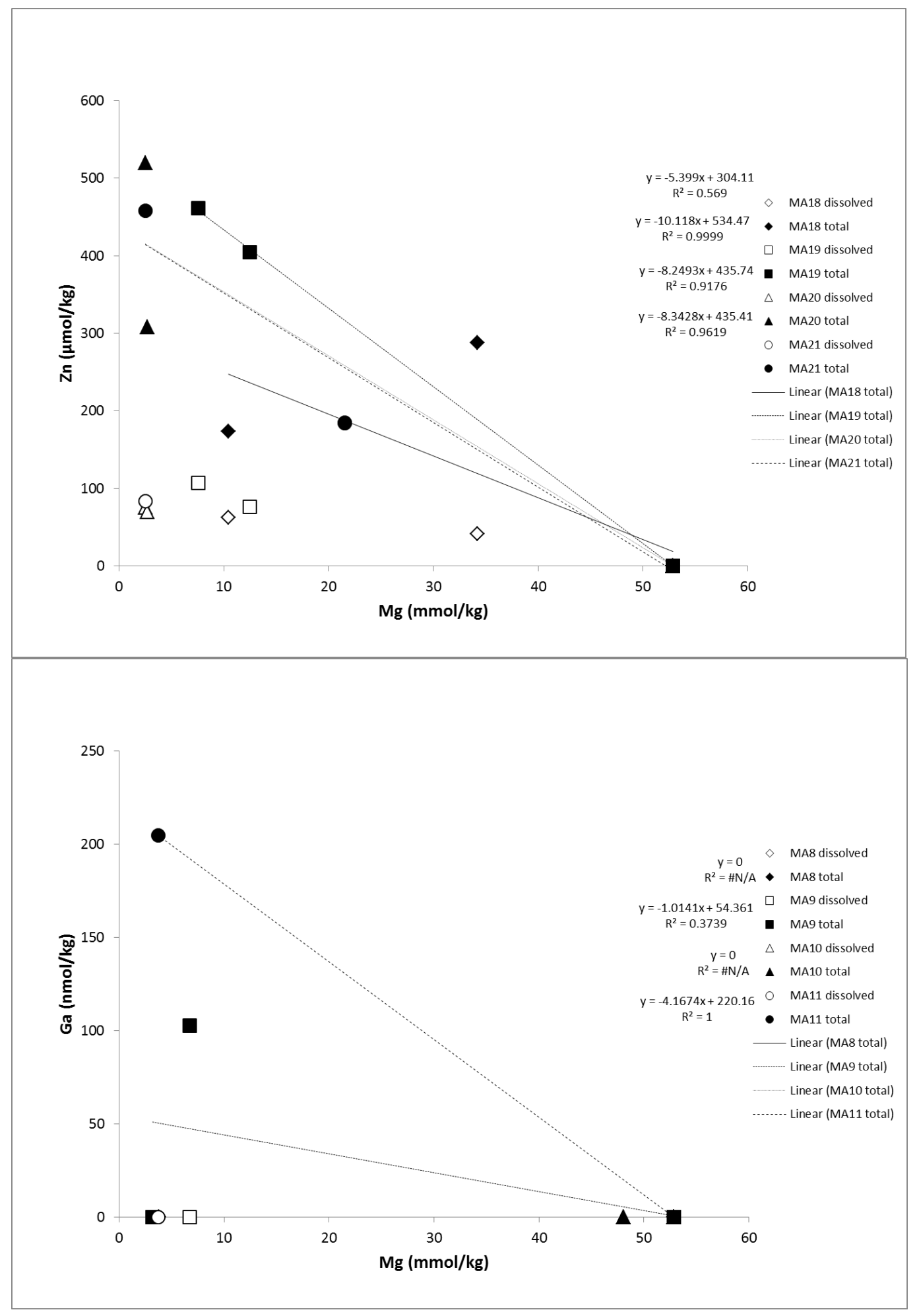




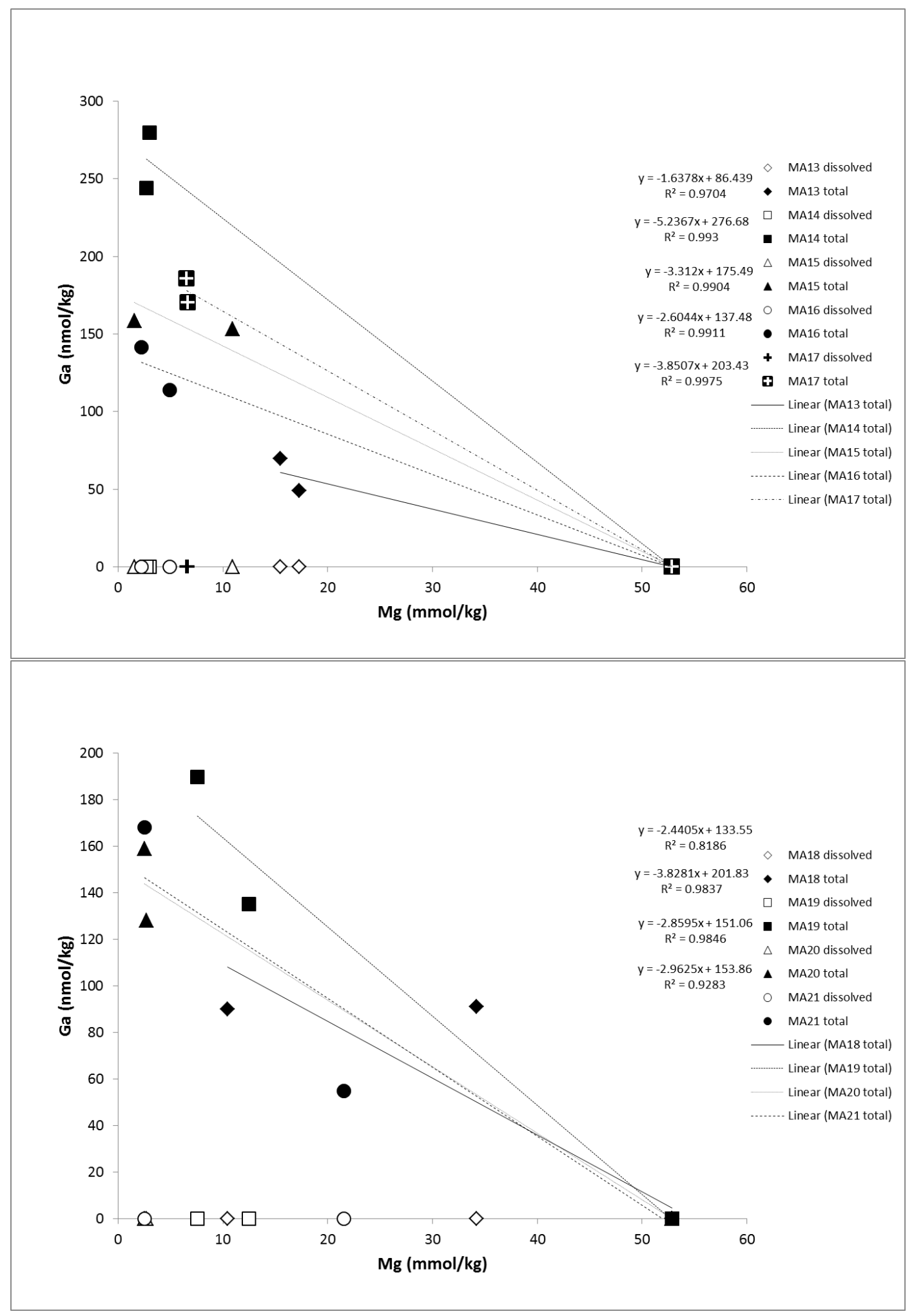




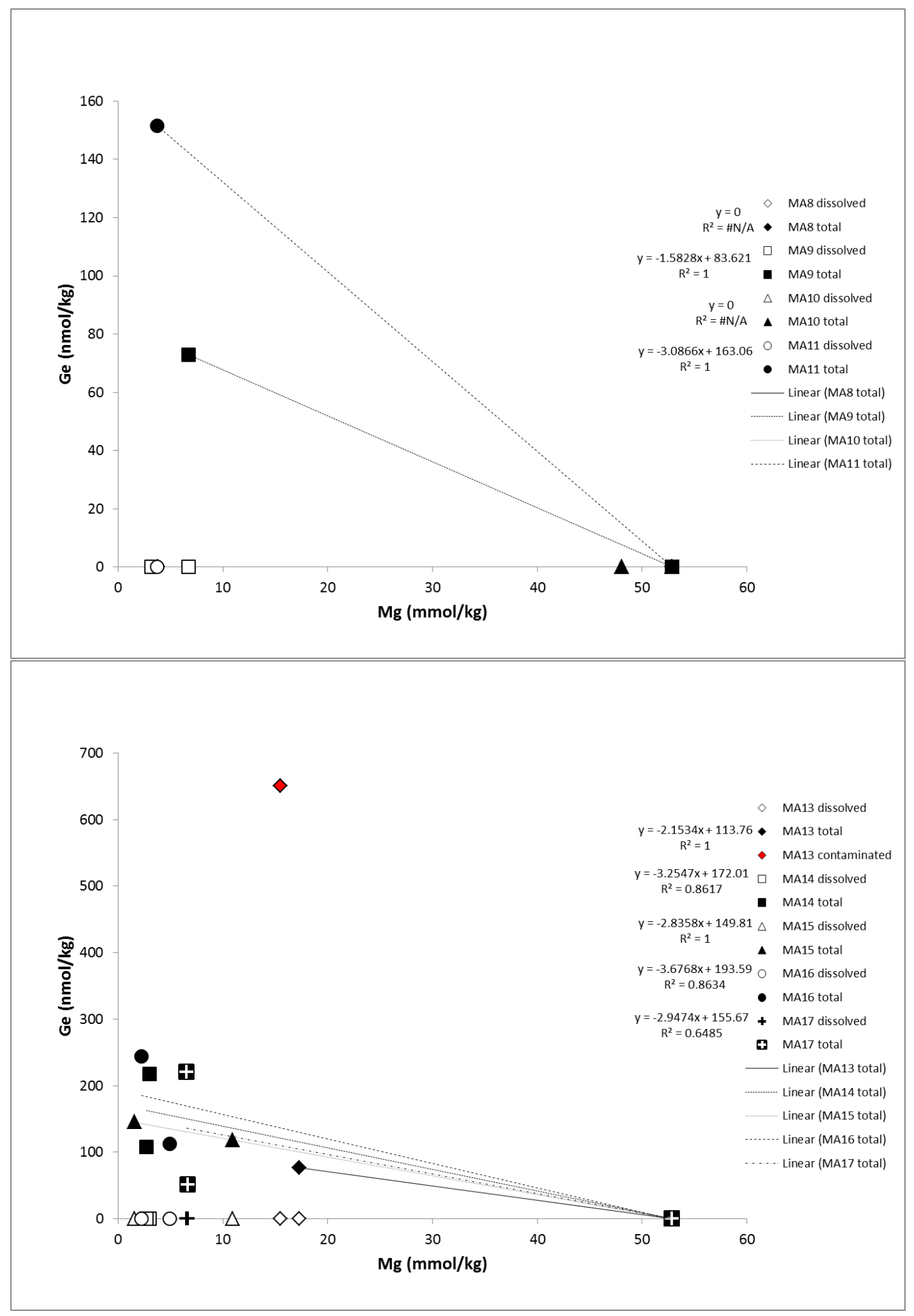




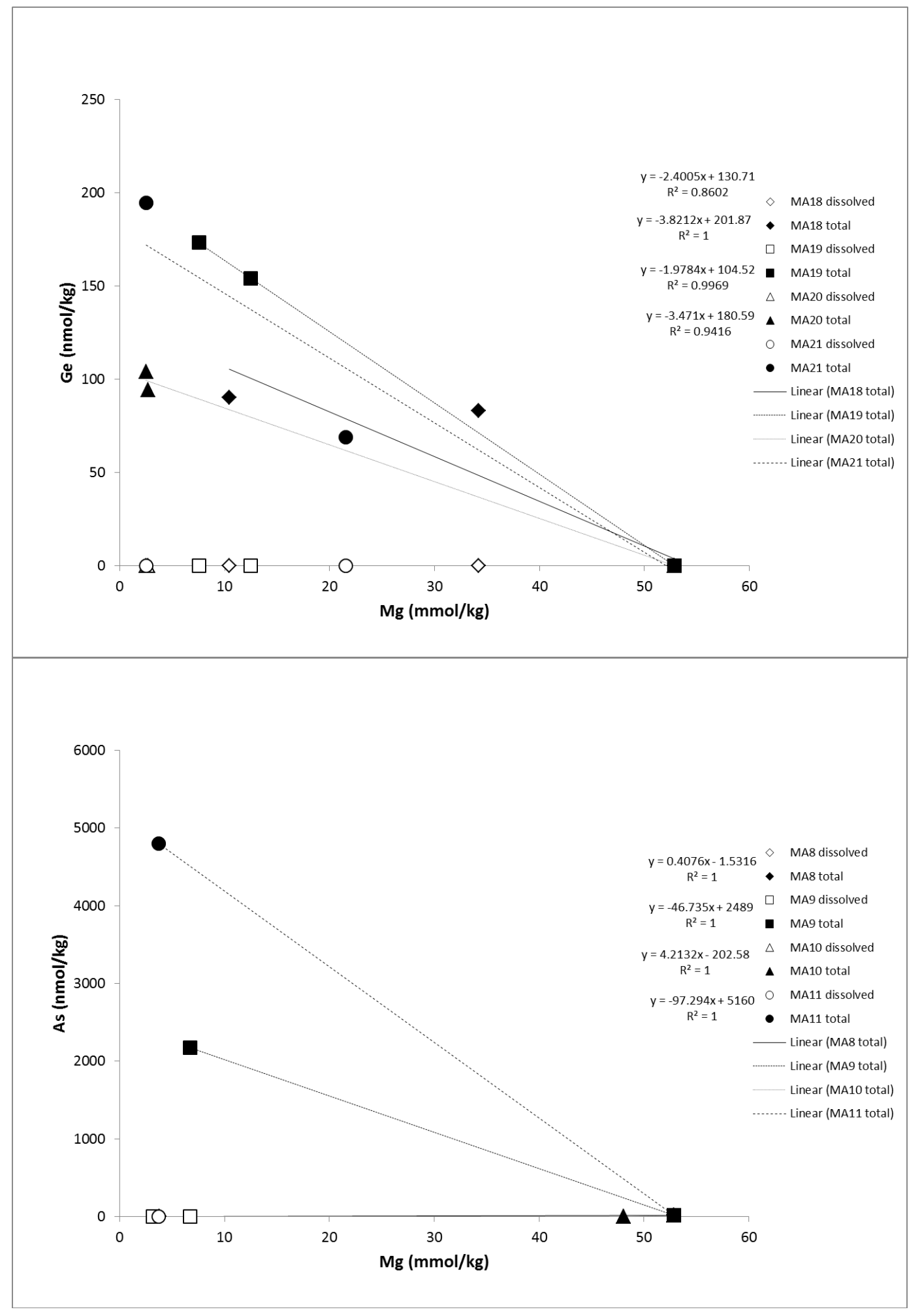




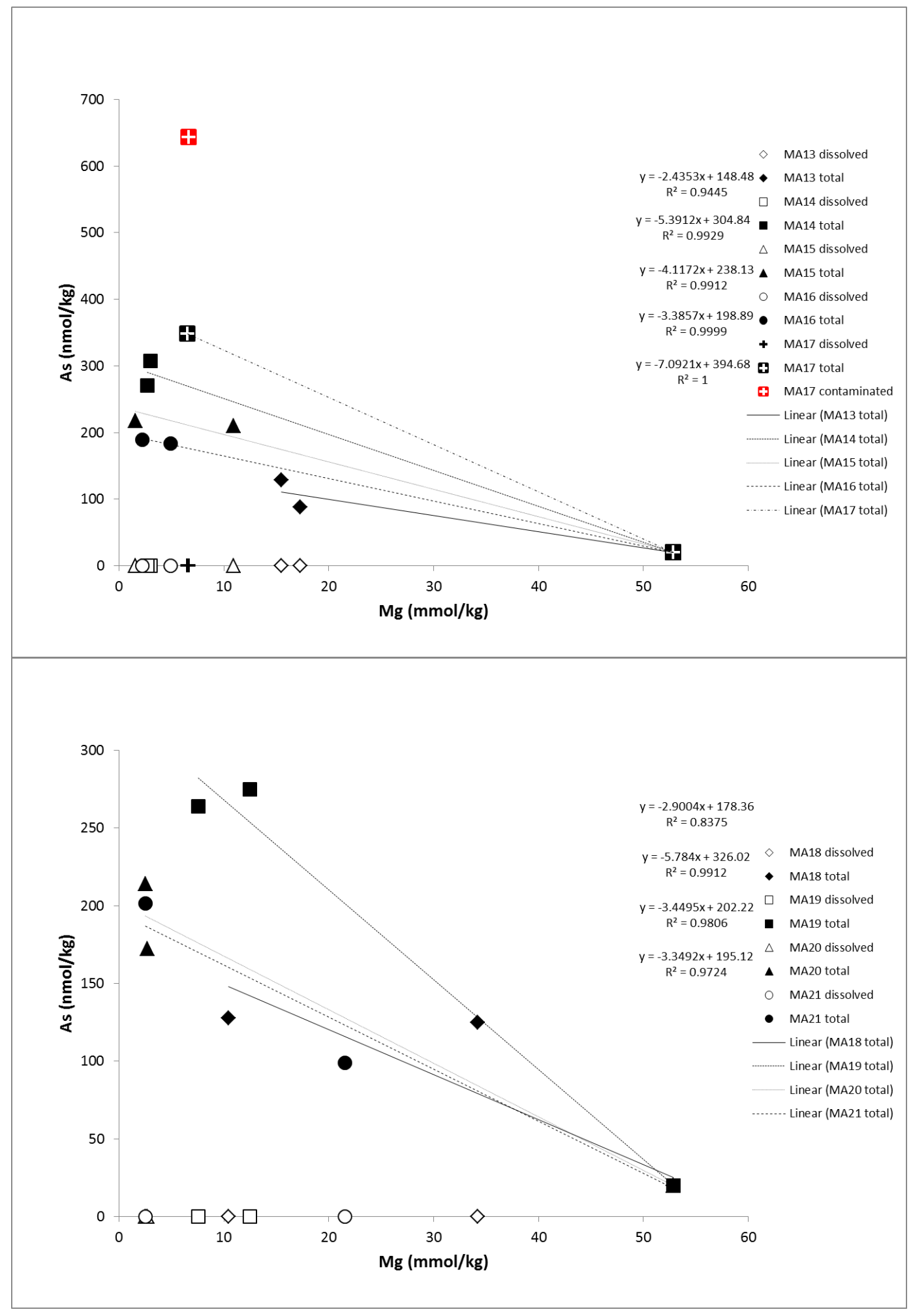




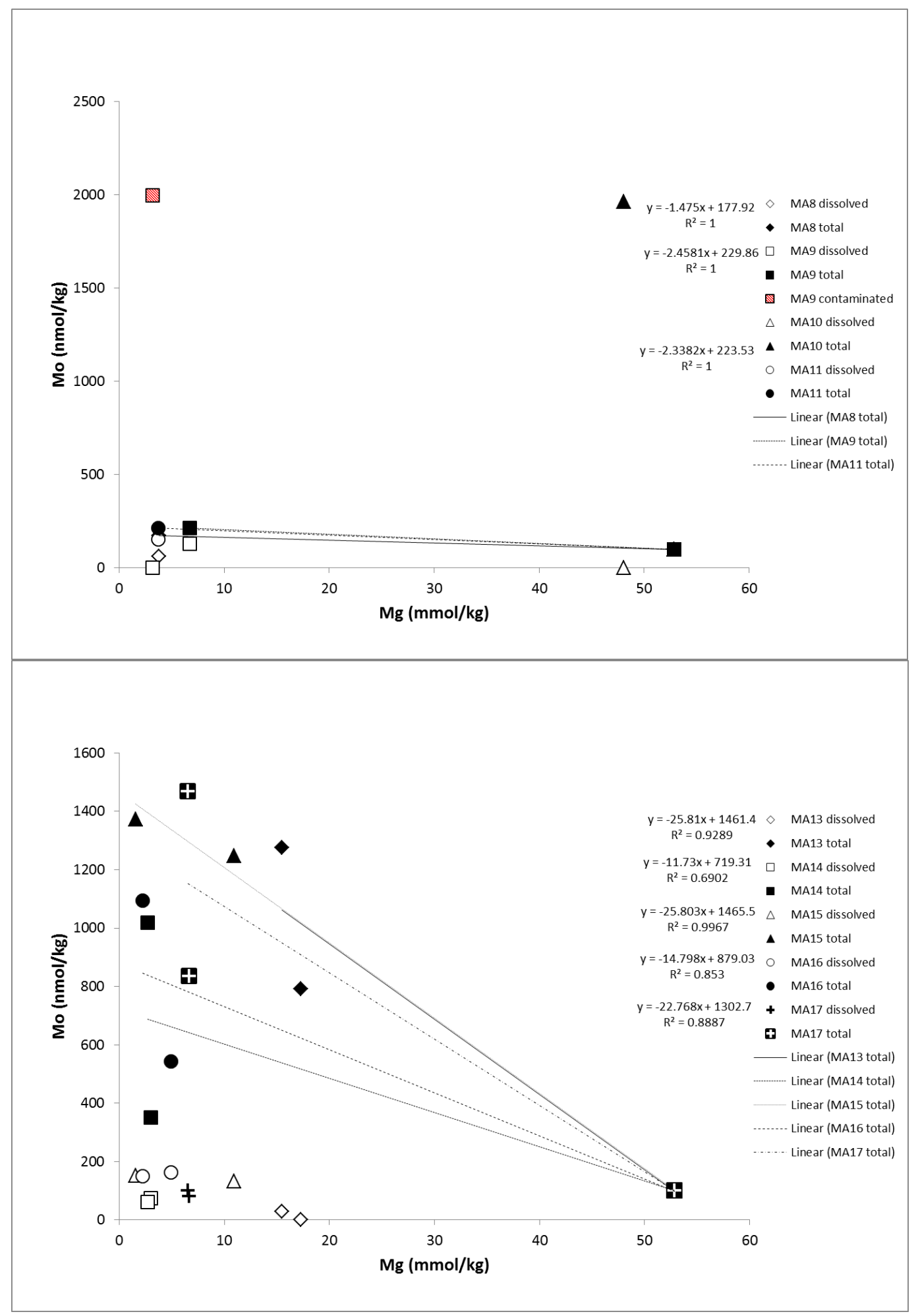




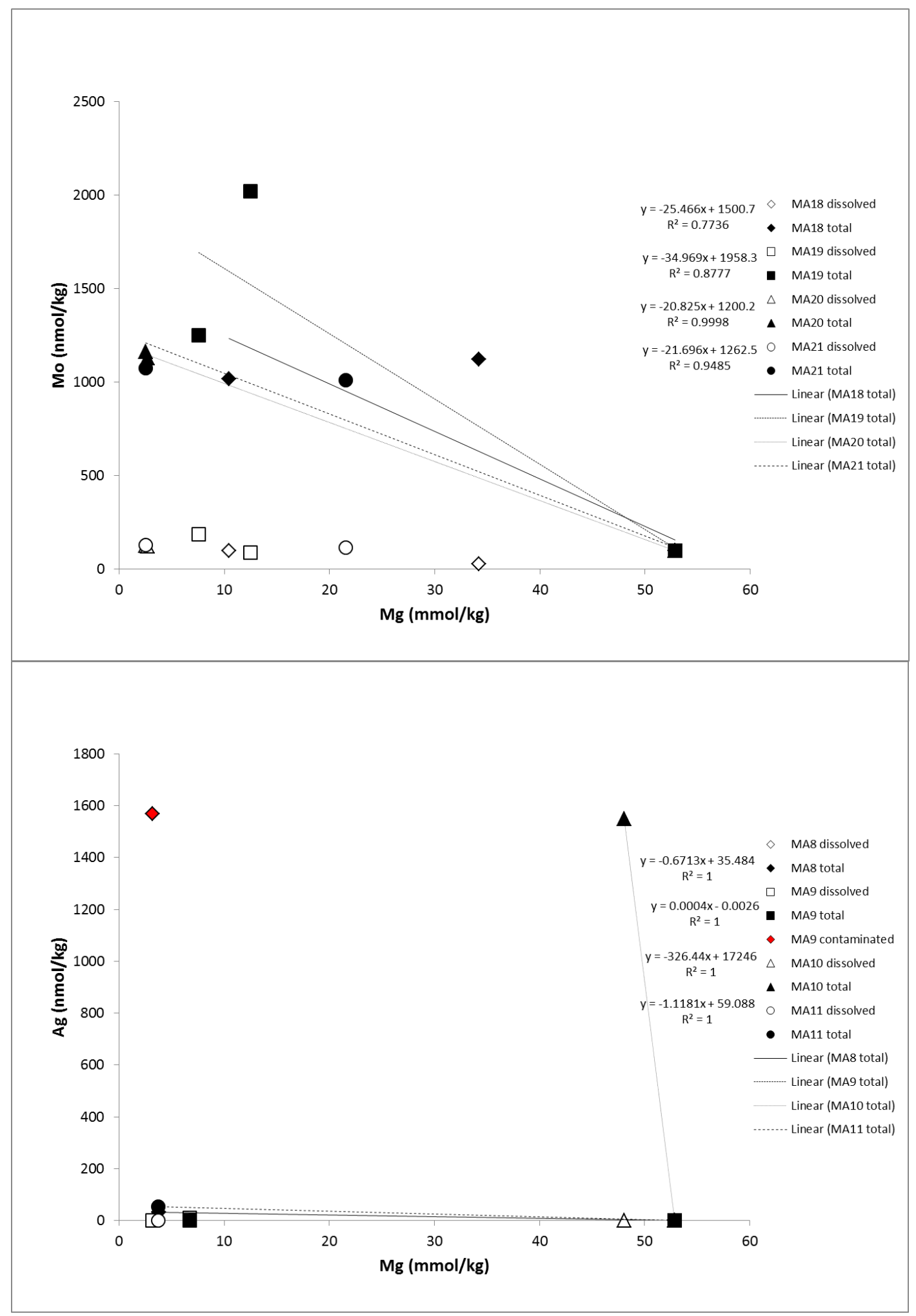




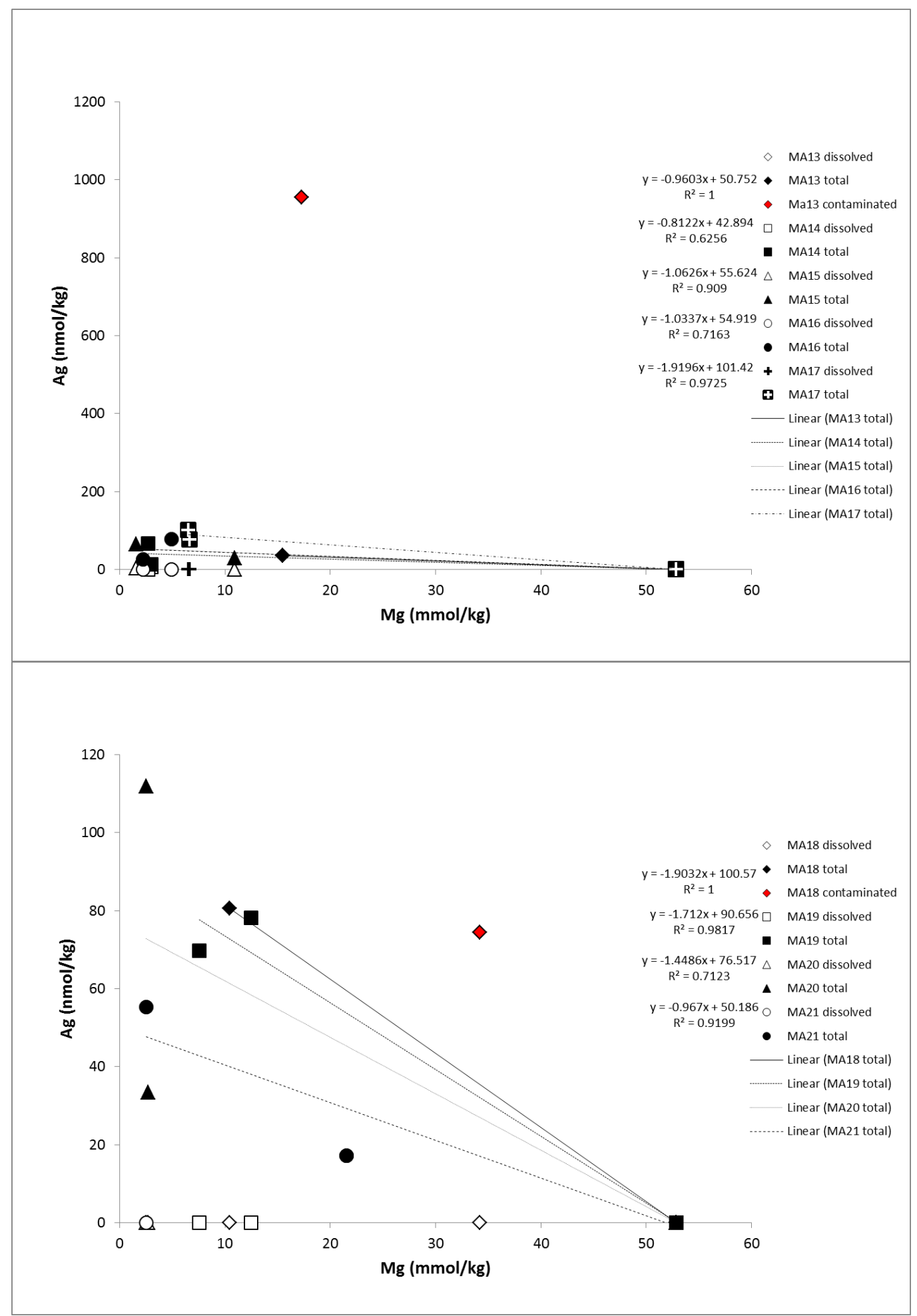




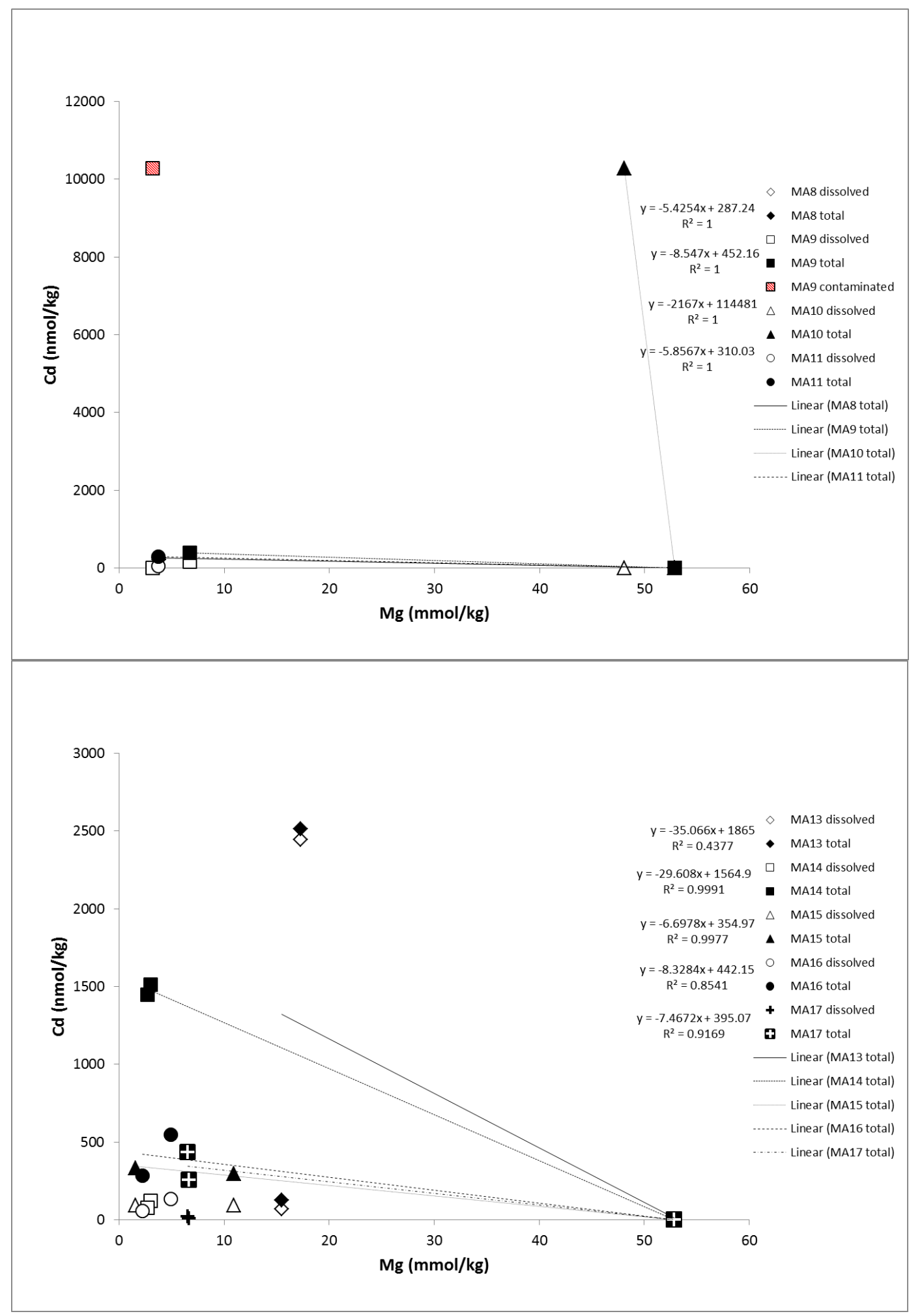




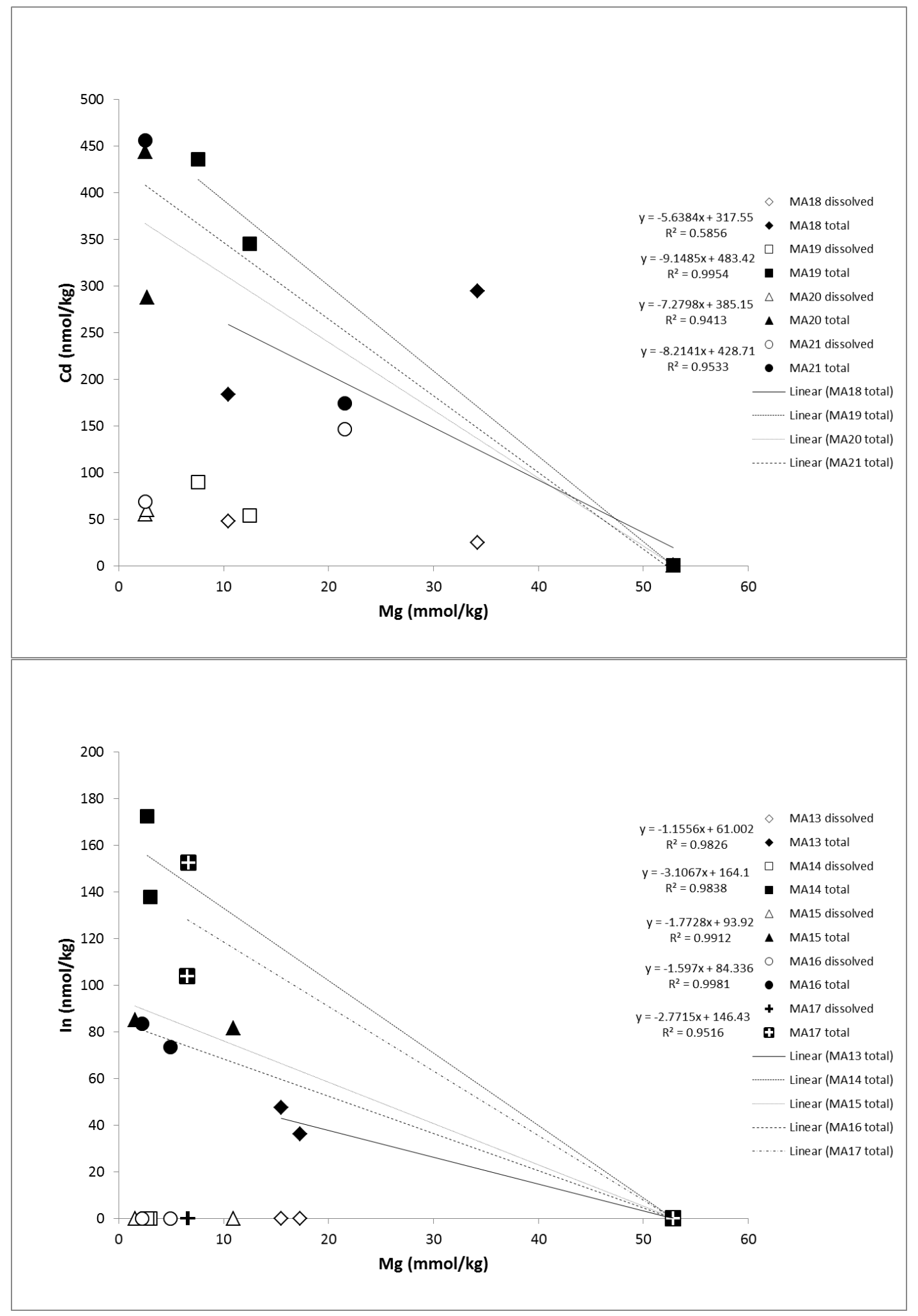




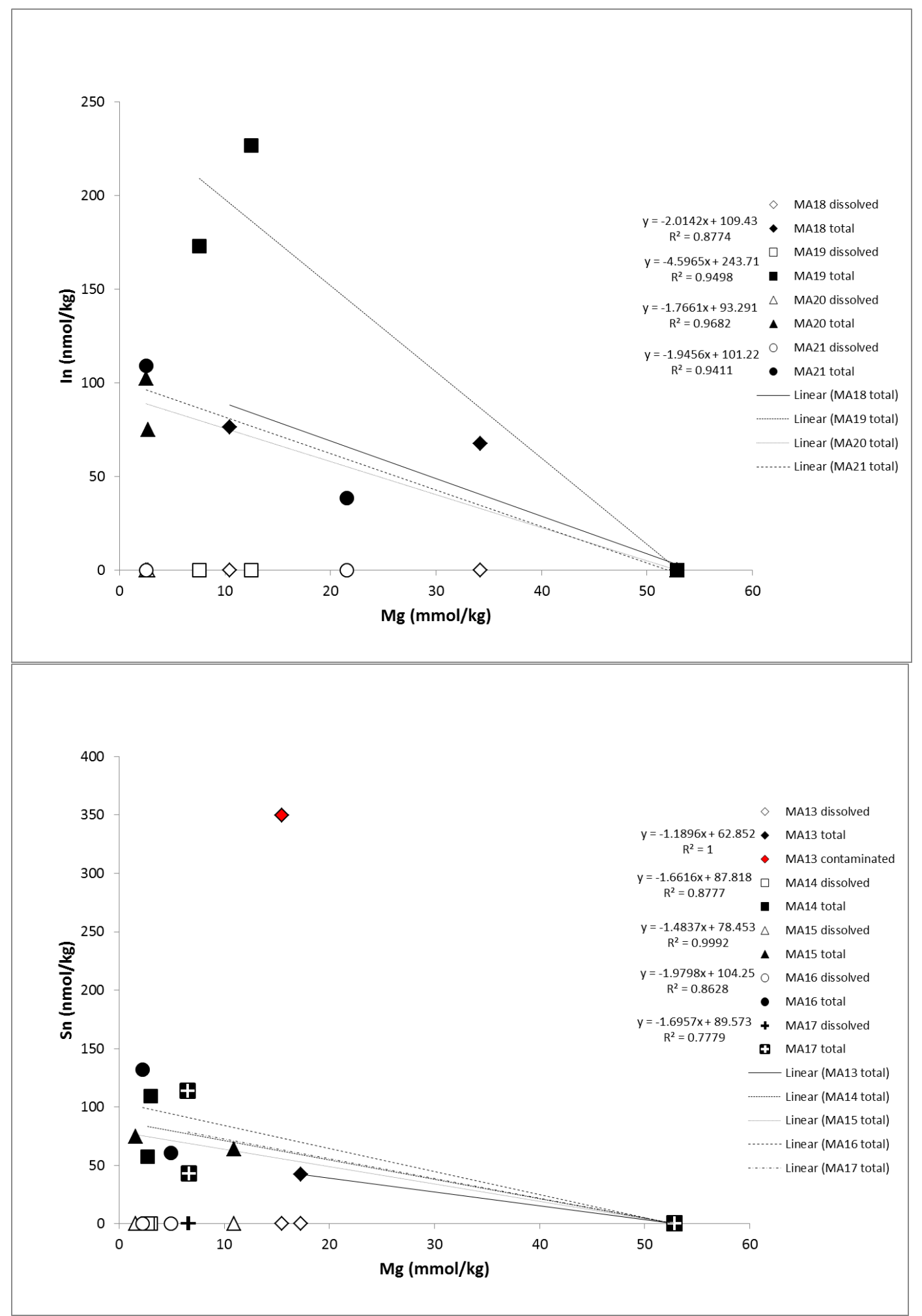




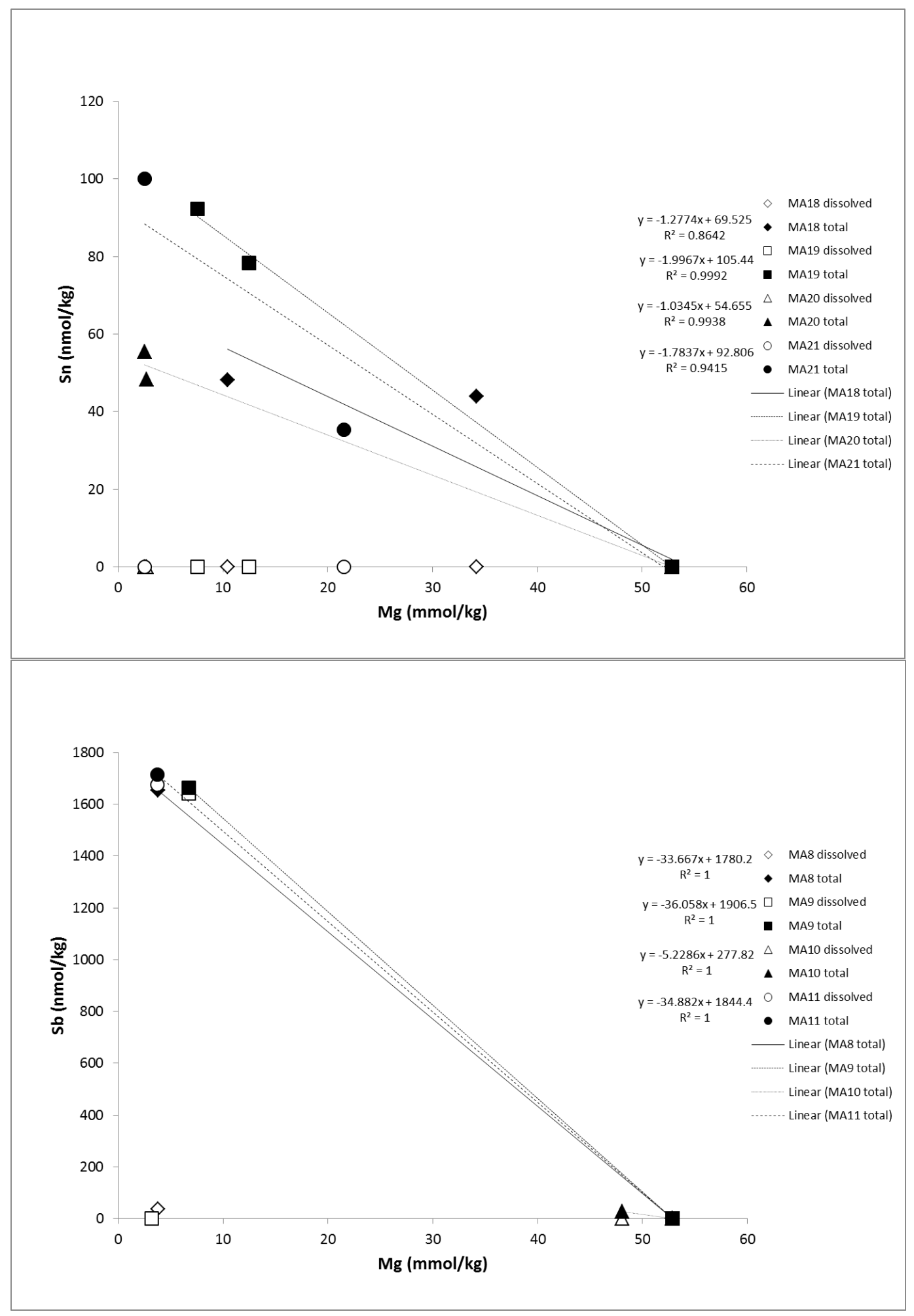




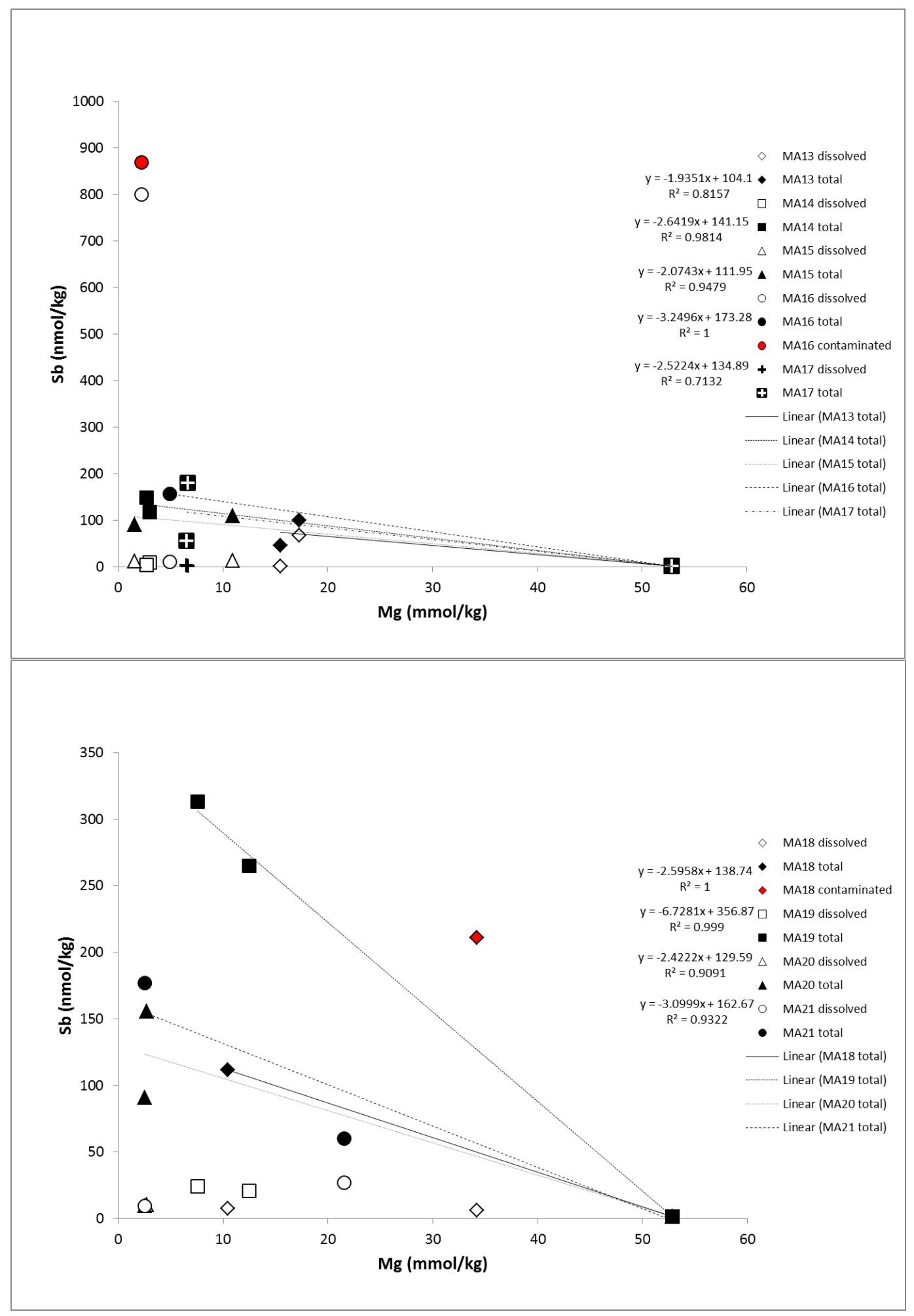




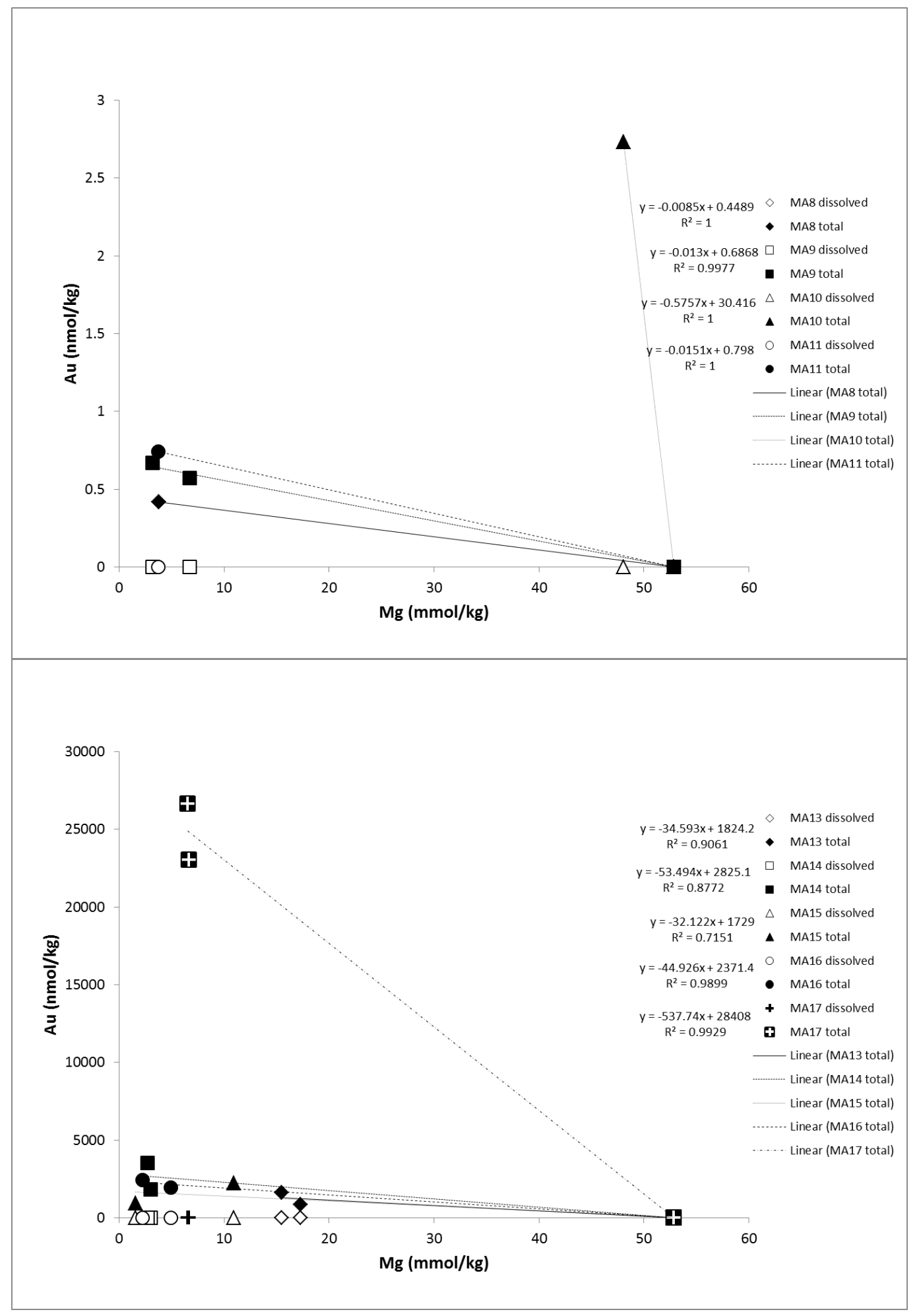




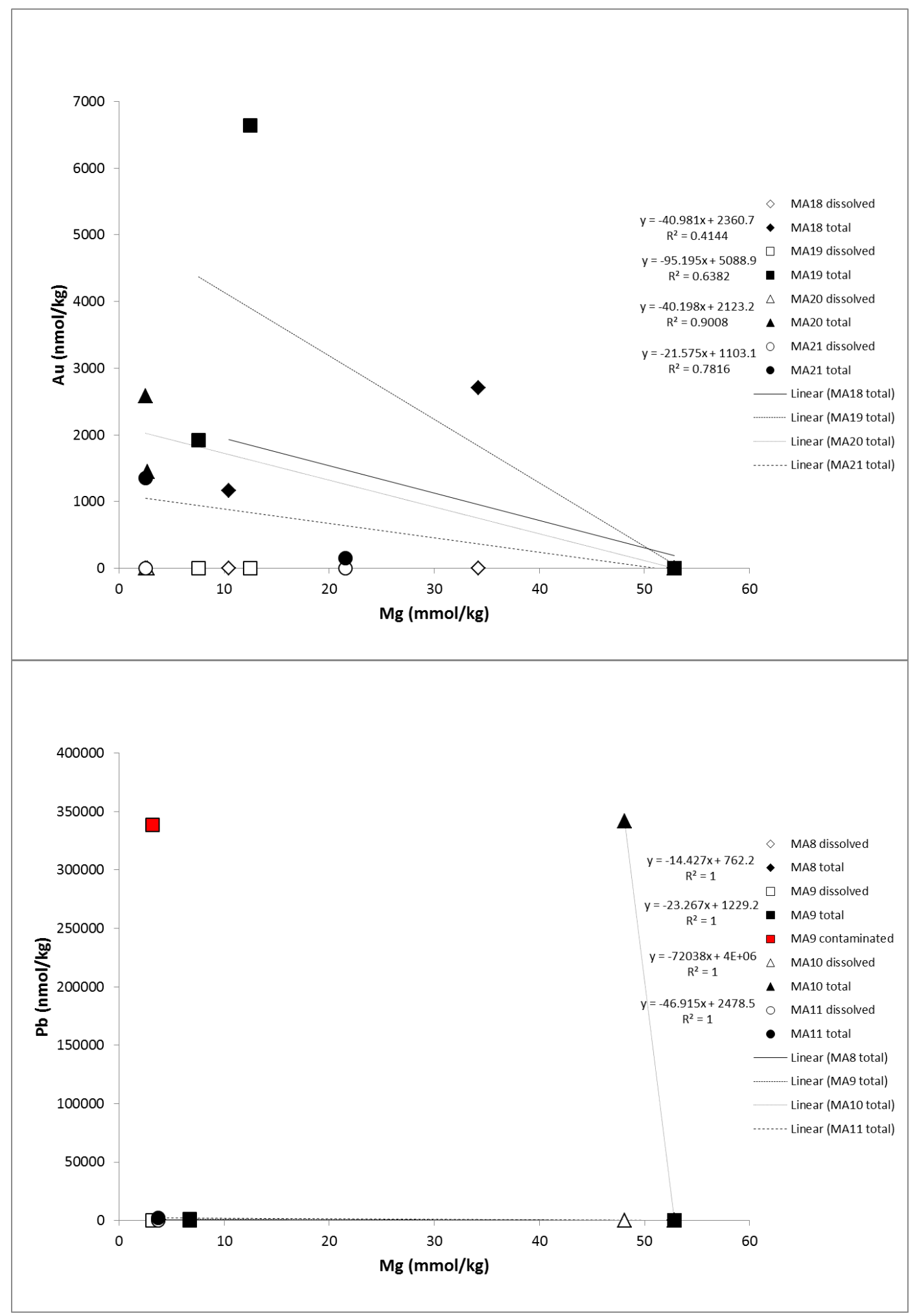




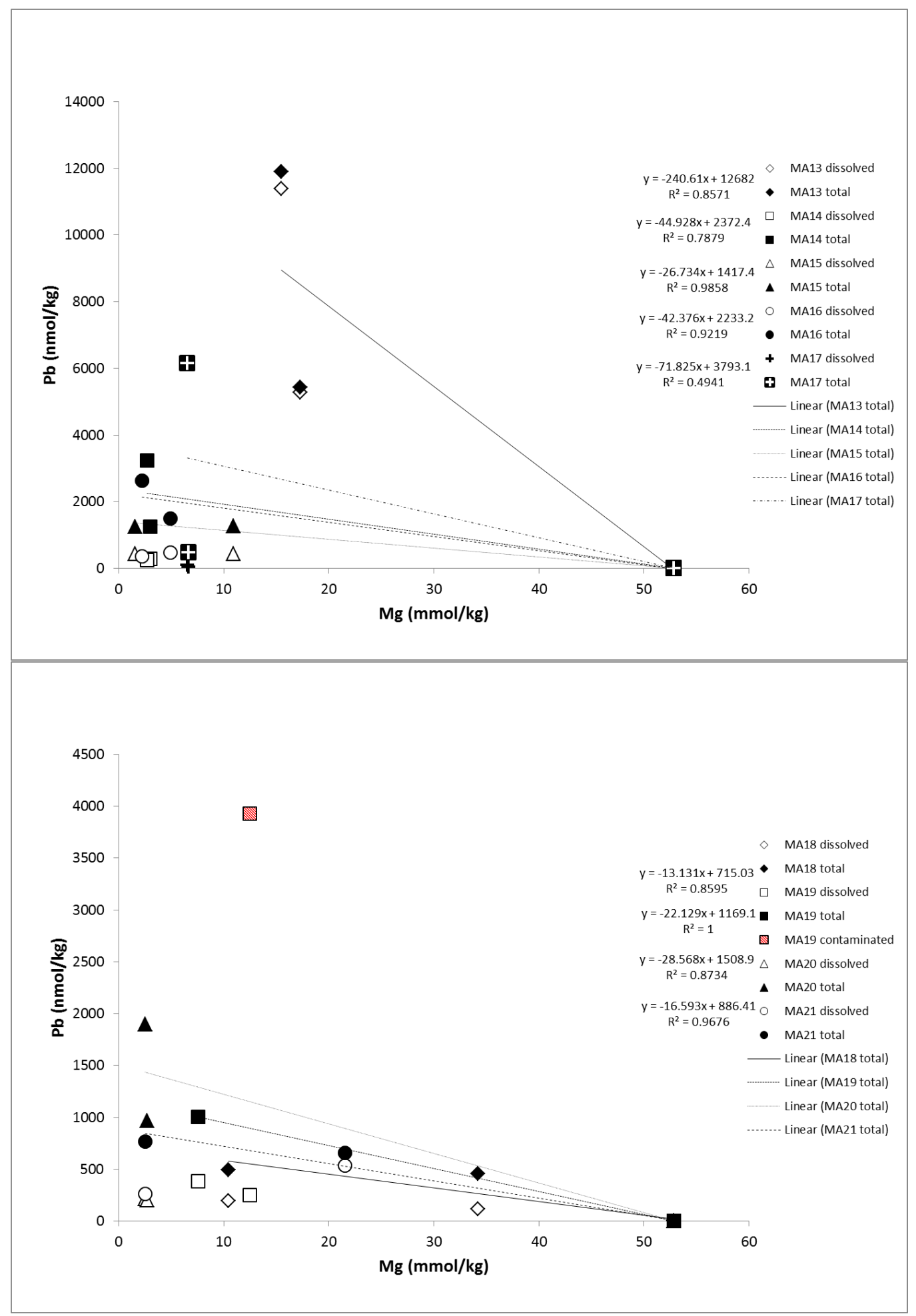


Appendix B. Calculated aqueous speciation of hydrothermal fluids: VW1, A10, SM3, and F3.

Fluid VW1 from the Vienna Woods vent field in the Manus Basin

Temperature $=282^{\circ} \mathrm{C} ; \mathrm{pH}\left(\right.$ at $\left.25^{\circ} \mathrm{C}\right)=4.4 ; \mathrm{pH}\left(\right.$ at $\left.282^{\circ} \mathrm{C}\right)=5.1$

--- Distribution of Aqueous Solute Species ---

Species Molality Log Molality Log Gamma Log Activity

\begin{tabular}{|c|c|c|c|c|}
\hline $\mathrm{Cl}-$ & 4.7634E-01 & -0.3221 & -0.3573 & -0.6794 \\
\hline $\mathrm{Na}+$ & 3.6773E-01 & -0.4345 & -0.3905 & -0.8249 \\
\hline $\mathrm{NaCl}, \mathrm{aq}$ & 1.4086E-01 & -0.8512 & 0.0000 & -0.8512 \\
\hline $\mathrm{Ca}+2$ & 3.0957E-02 & -1.5092 & -1.2014 & -2.7107 \\
\hline $\mathrm{CaCl}+$ & $2.8313 \mathrm{E}-02$ & -1.5480 & -0.3905 & -1.9385 \\
\hline $\mathrm{CaCl} 2, \mathrm{aq}$ & 2.0771E-02 & -1.6825 & 0.0000 & -1.6825 \\
\hline $\mathrm{K}+$ & $1.7981 \mathrm{E}-02 \quad-1$ & $-1.7452 \quad-C$ & $-0.4435 \quad-2$ & -2.1887 \\
\hline SiO2,aq & 1.4944E-02 & -1.8255 & 0.0000 & -1.8255 \\
\hline $\mathrm{CO} 2, \mathrm{aq}$ & 4.2307E-03 & -2.3736 & 0.0963 & -2.2772 \\
\hline $\mathrm{KCl}, \mathrm{aq}$ & 3.2192E-03 & -2.4923 & 0.0000 & -2.4923 \\
\hline $\mathrm{H} 2 \mathrm{~S}$, aq & $1.3457 \mathrm{E}-03$ & -2.8710 & 0.0000 & -2.8710 \\
\hline $\mathrm{MnCl}+$ & 3.4968E-04 & -3.4563 & -0.3905 & -3.8468 \\
\hline $\mathrm{FeCl} 2, \mathrm{aq}$ & $1.4876 \mathrm{E}-04$ & -3.8275 & 0.0000 & -3.8275 \\
\hline $\mathrm{Ca}(\mathrm{HCO} 3)+$ & 5.8991E-05 & $5 \quad-4.2292$ & $2 \quad-0.3905$ & $5 \quad-4.6197$ \\
\hline $\mathrm{H} 2, \mathrm{aq}$ & $4.3000 \mathrm{E}-05$ & -4.3665 & 0.0963 & -4.2702 \\
\hline HS- & $2.2308 \mathrm{E}-05$ & -4.6515 & -0.3573 & -5.0088 \\
\hline $\mathrm{ZnCl}+$ & $1.9368 \mathrm{E}-05$ & -4.7129 & -0.3905 & -5.1034 \\
\hline $\mathrm{H}+$ & $1.5636 \mathrm{E}-05$ & -4.8059 & -0.2509 & -5.0568 \\
\hline HCO3- & 9.8192E-06 & -5.0079 & -0.3043 & -5.3122 \\
\hline $\mathrm{HCl}, \mathrm{aq}$ & $9.5498 \mathrm{E}-06$ & -5.0200 & 0.0000 & -5.0200 \\
\hline $\mathrm{ZnCl} 2, \mathrm{aq}$ & 7.2224E-06 & -5.1413 & 0.0000 & -5.1413 \\
\hline $\mathrm{ZnCl} 4-2$ & 6.1101E-06 & -5.2140 & -1.3216 & -6.5356 \\
\hline $\mathrm{NaHSiO3,aq}$ & 4.3629E-06 & $06-5.3602$ & $2 \quad 0.0000$ & $0 \quad-5.3602$ \\
\hline $\mathrm{CuCl}, \mathrm{aq}$ & $4.0768 \mathrm{E}-06$ & -5.3897 & 0.0000 & -5.3897 \\
\hline $\mathrm{FeCl}+$ & $3.9786 \mathrm{E}-06$ & -5.4003 & -0.3905 & -5.7907 \\
\hline HSiO3- & 2.6357E-06 & -5.5791 & -0.3043 & -5.8834 \\
\hline $\mathrm{OH}-$ & $2.2412 \mathrm{E}-06$ & -5.6495 & -0.3573 & -6.0068 \\
\hline$M n+2$ & 1.3181E-06 & -5.8801 & -1.2014 & -7.0815 \\
\hline $\mathrm{Fe}+2$ & 1.2637E-06 & -5.8984 & -1.2014 & -7.0998 \\
\hline $\mathrm{CuCl} 3-2$ & 4.7623E-07 & -6.3222 & -1.3216 & -7.6438 \\
\hline $\mathrm{CuCl} 2-$ & $4.4622 \mathrm{E}-07$ & -6.3505 & -0.3043 & -6.6547 \\
\hline $\mathrm{ZnCl3-}$ & $2.9898 \mathrm{E}-07$ & -6.5244 & -0.3043 & -6.8287 \\
\hline $\mathrm{Ni}+2$ & $1.9222 \mathrm{E}-07$ & -6.7162 & -1.4074 & -8.1236 \\
\hline $\mathrm{PbCl} 2, \mathrm{aq}$ & 1.3109E-07 & -6.8824 & 0.0000 & -6.8824 \\
\hline $\mathrm{PbCl} 4-2$ & $1.1291 \mathrm{E}-07$ & -6.9473 & -1.3216 & -8.2689 \\
\hline $\mathrm{PbCl} 3-$ & 8.4021E-08 & -7.0756 & -0.3043 & -7.3799 \\
\hline $\mathrm{NiCl}+$ & 5.7779E-08 - & -7.2382 & -0.3905 & -7.6287 \\
\hline $\mathrm{Ca}(\mathrm{CO} 3), \mathrm{aq}$ & 5.5810E-08 & $8 \quad-7.2533$ & $\begin{array}{l}3 \quad 0.0000 \\
\end{array}$ & -7.2533 \\
\hline
\end{tabular}




\begin{tabular}{|c|c|c|c|c|}
\hline $\mathrm{Ga}(\mathrm{OH})+2$ & 4.9988E-08 & -7.3011 & -1.4074 & -8.7085 \\
\hline $\mathrm{InCl}+2$ & 3.8756E-08 & -7.4117 & -1.4074 & -8.8191 \\
\hline $\mathrm{CoCl}+$ & 3.6668E-08 & -7.4357 & -0.3905 & -7.8262 \\
\hline $\mathrm{CdCl} 2, \mathrm{aq}$ & 3.3909E-08 & -7.4697 & 0.0000 & -7.4697 \\
\hline $\mathrm{AgCl} 2-$ & $2.2801 \mathrm{E}-08$ & -7.6420 & -0.3043 & -7.9463 \\
\hline $\mathrm{PbCl}+$ & 2.1672E-08 & -7.6641 & -0.3905 & -8.0545 \\
\hline $\ln (\mathrm{OH})+2$ & 1.1217E-08 & -7.9501 & -1.4074 & -9.3575 \\
\hline $\mathrm{CdCl}+$ & $9.2661 E-09$ & -8.0331 & -0.3905 & -8.4236 \\
\hline $\mathrm{AgCl} 4-3$ & 9.1314E-09 & -8.0395 & -3.0459 & -11.0854 \\
\hline $\mathrm{Co}+2$ & 8.3316E-09 & -8.0793 & -1.4074 & -9.4867 \\
\hline $\mathrm{CdCl} 3-$ & $6.5505 \mathrm{E}-09$ & -8.1837 & -0.3043 & -8.4880 \\
\hline $\mathrm{AgCl} 3-2$ & $5.2505 \mathrm{E}-09$ & -8.2798 & -1.3216 & -9.6014 \\
\hline$Z n+2$ & $1.0282 \mathrm{E}-09$ & -8.9879 & -1.2014 & -10.1893 \\
\hline $\mathrm{AgCl}, \mathrm{aq}$ & $7.4500 \mathrm{E}-10$ & -9.1278 & 0.0000 & -9.1278 \\
\hline $\mathrm{Cu}+$ & 7.2473E-10 & -9.1398 & -0.3905 & -9.5303 \\
\hline $\mathrm{Pb}+2$ & 3.0349E-10 & -9.5179 & -1.3308 & -10.8487 \\
\hline $\mathrm{Cd}+2$ & $1.6453 \mathrm{E}-10$ & -9.7838 & -1.4074 & -11.1912 \\
\hline $\mathrm{CdCl} 4-2$ & 1.1017E-10 & -9.9579 & -1.3216 & -11.2796 \\
\hline AsO2- & $1.0000 \mathrm{E}-10$ & -10.0000 & -0.3043 & -10.3043 \\
\hline HSe- & 1.0000E-10 & -10.0000 & -0.3043 & -10.3043 \\
\hline $\mathrm{Au}(\mathrm{HS}) 2-$ & 9.9761E-11 & -10.0010 & -0.3043 & -10.3053 \\
\hline $\mathrm{BaCl}+$ & $7.7660 \mathrm{E}-11$ & -10.1098 & -0.3905 & -10.5003 \\
\hline $\mathrm{CO} 3-2$ & $7.5825 E-11$ & -10.1202 & -1.1585 & -11.2787 \\
\hline $\mathrm{Ag}(\mathrm{HS}) 2-$ & $6.4403 \mathrm{E}-11$ & -10.1911 & -0.3043 & -10.4954 \\
\hline $\ln +3$ & 2.6379E-11 - & -10.5787 & -2.0487 & -12.6274 \\
\hline $\mathrm{Ba}+2$ & $2.2340 \mathrm{E}-11$ & -10.6509 & -1.3308 & -11.9817 \\
\hline $\mathrm{Ga}+3$ & 1.1944E-11 & -10.9228 & -2.0487 & -12.9715 \\
\hline $\mathrm{Ag}+$ & 7.2612E-12 & -11.1390 & -0.4435 & -11.5825 \\
\hline $\mathrm{AuCl} 2-$ & $1.2882 \mathrm{E}-13$ & -12.8900 & -0.3043 & -13.1943 \\
\hline $\mathrm{AuCl} 3-2$ & $9.0855 \mathrm{E}-14$ & -13.0417 & -1.3216 & -14.3633 \\
\hline $\mathrm{AuCl}, \mathrm{aq}$ & $1.9253 \mathrm{E}-14$ & -13.7155 & 0.0000 & -13.7155 \\
\hline $\mathrm{Cu}+2$ & 7.3523E-17 & -16.1336 & -1.2014 & -17.3350 \\
\hline $\mathrm{Ba}(\mathrm{CO} 3), \mathrm{aq}$ & 7.0185E-18 & $8 \quad-17.1538$ & $\begin{array}{ll}8 & 0.0000\end{array}$ & $\begin{array}{ll}0 & -17.1538\end{array}$ \\
\hline $\mathrm{Au+}$ & $1.0627 \mathrm{E}-18$ & -17.9736 & -0.3905 & -18.3640 \\
\hline $\mathrm{MgCl}+$ & 8.7060E-19 & -18.0602 & -0.3905 & -18.4506 \\
\hline $\mathrm{H} 2 \mathrm{AsO} 3-$ & 2.7475E-19 & -18.5611 & -0.3043 & -18.8654 \\
\hline $\mathrm{Mg}+2$ & 1.2903E-19 & -18.8893 & -1.0092 & -19.8985 \\
\hline $\mathrm{Fe}+3$ & 3.1805E-20 & -19.4975 & -2.0487 & -21.5462 \\
\hline \multicolumn{5}{|c|}{ Species Accounting for $99 \%$ or More of Aqueous Ga+3 } \\
\hline Species & \multicolumn{4}{|c|}{ Factor Molality Per Cent } \\
\hline $\mathrm{Ga}(\mathrm{OH})+2$ & \multicolumn{2}{|c|}{$4.9988 \mathrm{E}-08$} & \multicolumn{2}{|l|}{99.98} \\
\hline \multicolumn{5}{|c|}{ Species Accounting for $99 \%$ or More of Aqueous $\ln +3$} \\
\hline Species & \multicolumn{4}{|c|}{ Factor Molality Per Cent } \\
\hline $\operatorname{lnCl}+2$ & \multicolumn{4}{|c|}{$1.00 \quad 3.8756 \mathrm{E}-08 \quad 77.51$} \\
\hline $\ln (\mathrm{OH})+2$ & \multicolumn{4}{|c|}{$1.00 \quad 1.1217 \mathrm{E}-08 \quad 22.43$} \\
\hline
\end{tabular}


Fluid $\mathrm{A} 10$ from the $\mathrm{ABE}$ vent field in the Lau Basin

Temperature $=317^{\circ} \mathrm{C} ; \mathrm{pH}\left(\right.$ at $\left.25^{\circ} \mathrm{C}\right)=3.9 ; \mathrm{pH}\left(\right.$ at $\left.317^{\circ} \mathrm{C}\right)=4.6$

--- Distribution of Aqueous Solute Species ---

\begin{tabular}{|c|c|c|c|c|}
\hline Species & Molality & Log Molality & \multicolumn{2}{|c|}{ Log Gamma Log Activity } \\
\hline $\mathrm{Cl}-$ & $3.5038 \mathrm{E}-01$ & -0.4555 & -0.3694 & 0.8249 \\
\hline $\mathrm{Na}+$ & 2.9390E-01 & -0.5318 & -0.4074 & -0.9392 \\
\hline $\mathrm{NaCl}, \mathrm{aq}$ & 1.4282E-01 & -0.8452 & 0.0000 & -0.8452 \\
\hline $\mathrm{CO} 2, \mathrm{aq}$ & 6.6837E-02 & -1.1750 & 0.0798 & -1.0952 \\
\hline $\mathrm{K}+$ & 2.0005E-02 -- & $-1.6989 \quad-C$ & $-0.4573 \quad-2$ & -2.1562 \\
\hline $\mathrm{SiO} 2, \mathrm{aq}$ & 1.5593E-02 & -1.8071 & 0.0000 & -1.8071 \\
\hline $\mathrm{CaCl}+$ & 1.4981E-02 & -1.8244 & -0.4074 & -2.2319 \\
\hline $\mathrm{CaCl} 2, \mathrm{aq}$ & 1.4620E-02 & -1.8350 & 0.0000 & -1.8350 \\
\hline $\mathrm{Ca}+2$ & $1.0401 E-02$ & -1.9829 & -1.2558 & -3.2388 \\
\hline $\mathrm{KCl}, \mathrm{aq}$ & $4.5886 \mathrm{E}-03$ & -2.3383 & 0.0000 & -2.3383 \\
\hline $\mathrm{H} 2 \mathrm{~S}, \mathrm{aq}$ & 3.7423E-03 & -2.4269 & 0.0000 & -2.4269 \\
\hline $\mathrm{MnCl}+$ & $4.3515 \mathrm{E}-04$ & -3.3614 & -0.4074 & -3.7688 \\
\hline $\mathrm{Ca}(\mathrm{HCO} 3)+$ & 3.0180E-04 & $04 \quad-3.5203$ & $3 \quad-0.4074$ & $4 \quad-3.9277$ \\
\hline $\mathrm{FeCl} 2, \mathrm{aq}$ & $1.6441 \mathrm{E}-04$ & -3.7841 & 0.0000 & -3.7841 \\
\hline $\mathrm{HCO} 3-$ & $6.6900 \mathrm{E}-05$ & -4.1746 & -0.3195 & -4.4941 \\
\hline $\mathrm{H} 2, \mathrm{aq}$ & $6.1641 \mathrm{E}-05$ & -4.2101 & 0.0798 & -4.1303 \\
\hline $\mathrm{ZnCl+}$ & 5.8232E-05 & -4.2348 & -0.4074 & -4.6423 \\
\hline HS- & $3.4658 \mathrm{E}-05$ & -4.4602 & -0.3694 & -4.8296 \\
\hline $\mathrm{ZnCl} 2, \mathrm{aq}$ & 2.7019E-05 & -4.5683 & 0.0000 & -4.5683 \\
\hline $\mathrm{HCl}, \mathrm{aq}$ & 1.6843E-05 & -4.7736 & 0.0000 & -4.7736 \\
\hline $\mathrm{H}+$ & 1.6046E-05 & $-4.7946 \quad-c$ & -0.2708 & -5.0655 \\
\hline $\mathrm{ZnCl} 4-2$ & 1.5864E-05 & -4.7996 & -1.3624 & -6.1620 \\
\hline $\mathrm{BaCl}+$ & $1.1066 \mathrm{E}-05$ & -4.9560 & -0.4074 & -5.3635 \\
\hline $\mathrm{CuCl}, \mathrm{aq}$ & 8.6181E-06 & -5.0646 & 0.0000 & -5.0646 \\
\hline $\mathrm{NaHSiO} 3, \mathrm{aq}$ & $3.2118 \mathrm{E}-06$ & $.06 \quad-5.4933$ & $33 \quad 0.0000$ & $0 \quad-5.4933$ \\
\hline $\mathrm{FeCl}+$ & 2.9789E-06 & -5.5259 & -0.4074 & -5.9334 \\
\hline $\mathrm{Ba}+2$ & $1.9340 \mathrm{E}-06$ & -5.7135 & -1.3818 & -7.0954 \\
\hline $\mathrm{OH}-$ & $1.9050 \mathrm{E}-06$ & -5.7201 & -0.3694 & -6.0895 \\
\hline HSiO3- & 1.7819E-06 & -5.7491 & -0.3195 & -6.0686 \\
\hline $\mathrm{ZnCl3-}$ & $8.8352 E-07$ & -6.0538 & -0.3195 & -6.3733 \\
\hline$M n+2$ & 8.4721E-07 & -6.0720 & -1.2558 & -7.3278 \\
\hline $\mathrm{CuCl} 2-$ & 7.2718E-07 & -6.1384 & -0.3195 & -6.4579 \\
\hline $\mathrm{CuCl} 3-2$ & $6.5345 \mathrm{E}-07$ & -6.1848 & -1.3624 & -7.5472 \\
\hline $\mathrm{Fe}+2$ & $6.0986 \mathrm{E}-07$ & -6.2148 & -1.2558 & -7.4706 \\
\hline $\mathrm{Ca}(\mathrm{CO} 3), \mathrm{aq}$ & 2.1820E-07 & $07 \quad-6.6612$ & $2 \quad 0.0000$ & -6.6612 \\
\hline $\mathrm{PbCl} 2, \mathrm{aq}$ & $1.4723 \mathrm{E}-07$ & -6.8320 & 0.0000 & -6.8320 \\
\hline $\mathrm{PbCl} 4-2$ & $1.0828 \mathrm{E}-07$ & -6.9654 & -1.3624 & -8.3279 \\
\hline $\mathrm{PbCl} 3-$ & 8.9414E-08 & -7.0486 & -0.3195 & -7.3681 \\
\hline $\mathrm{CoCl}+$ & $6.9400 \mathrm{E}-08$ & -7.1586 & -0.4074 & -7.5661 \\
\hline $\mathrm{Ni}+2$ & 5.5459E-08 & -7.2560 & -1.4556 & -8.7116 \\
\hline $\operatorname{lnCl}+2$ & $3.8838 \mathrm{E}-08$ & -7.4107 & -1.4556 & -8.8663 \\
\hline
\end{tabular}




\begin{tabular}{|c|c|c|c|c|}
\hline $\mathrm{NiCl}+$ & 2.4540E-08 & -7.6101 & -0.4074 & -8.0176 \\
\hline $\mathrm{CdCl} 2, \mathrm{aq}$ & 2.2658E-08 & -7.6448 & 0.0000 & -7.6448 \\
\hline $\mathrm{PbCl}+$ & $1.9895 \mathrm{E}-08$ & -7.7013 & -0.4074 & -8.1087 \\
\hline $\ln (\mathrm{OH})+2$ & 1.1141E-08 & -7.9531 & -1.4556 & -9.4086 \\
\hline $\mathrm{Co}+2$ & 1.0599E-08 & -7.9747 & -1.4556 & -9.4303 \\
\hline $\mathrm{Ga}(\mathrm{OH})+2$ & 9.9982E-09 & -8.0001 & -1.4556 & -9.4557 \\
\hline $\mathrm{AgCl} 2-$ & 8.6249E-09 & -8.0642 & -0.3195 & -8.3838 \\
\hline $\mathrm{CdCl}+$ & 4.4579E-09 & -8.3509 & -0.4074 & -8.7583 \\
\hline $\mathrm{CdCl} 3-$ & $3.7825 \mathrm{E}-09$ & -8.4222 & -0.3195 & -8.7417 \\
\hline $\mathrm{AgCl} 4-3$ & $3.4581 \mathrm{E}-09$ & -8.4612 & -3.1299 & -11.5911 \\
\hline $\mathrm{AgCl} 3-2$ & 1.5466E-09 & -8.8106 & -1.3624 & -10.1731 \\
\hline $\mathrm{Cu}+$ & 1.2815E-09 & -8.8923 & $-0.4074 \quad-$ & -9.2997 \\
\hline$Z n+2$ & 1.2748E-09 & -8.8945 & -1.2558 & -10.1504 \\
\hline $\mathrm{AgCl}, \mathrm{aq}$ & 3.1277E-10 & -9.5048 & 0.0000 & -9.5048 \\
\hline $\mathrm{CO} 3-2$ & $2.8052 \mathrm{E}-10$ & -9.5520 & -1.2060 & -10.7580 \\
\hline $\mathrm{Pb}+2$ & $1.8173 \mathrm{E}-10$ & -9.7406 & -1.3818 & -11.1224 \\
\hline $\mathrm{Ag}(\mathrm{HS}) 2-$ & 5.4692E-11 & -10.2621 & -0.3195 & -10.5816 \\
\hline$C d+2$ & 5.3850E-11 & -10.2688 & -1.4556 & -11.7244 \\
\hline $\mathrm{CdCl} 4-2$ & $4.7753 \mathrm{E}-11$ & -10.3210 & -1.3624 & -11.6834 \\
\hline $\mathrm{Au}(\mathrm{HS}) 2-$ & 3.9942E-11 & -10.3986 & -0.3195 & -10.7181 \\
\hline $\ln +3$ & $2.1037 \mathrm{E}-11$ & -10.6770 & $-2.1644-$ & -12.8414 \\
\hline $\mathrm{Ba}(\mathrm{CO} 3), \mathrm{aq}$ & $6.9781 \mathrm{E}-12$ & $2-11.1563$ & $\begin{array}{l}3 \quad 0.0000 \\
\end{array}$ & $0 \quad-11.1563$ \\
\hline $\mathrm{Ag}+$ & $2.8466 \mathrm{E}-12$ & -11.5457 & $-0.4573-$ & -12.0030 \\
\hline $\mathrm{Ga}+3$ & $1.7360 \mathrm{E}-12$ & -11.7604 & -2.1644 & -13.9248 \\
\hline $\mathrm{AuCl} 2-$ & $3.3650 \mathrm{E}-14$ & -13.4730 & -0.3195 & -13.7925 \\
\hline $\mathrm{AuCl} 3-2$ & $1.8189 \mathrm{E}-14$ & -13.7402 & -1.3624 & -15.1026 \\
\hline $\mathrm{AuCl}, \mathrm{aq}$ & $6.0150 \mathrm{E}-15$ & -14.2208 & 0.0000 & -14.2208 \\
\hline $\mathrm{Cu}+2$ & $1.0324 \mathrm{E}-16$ & -15.9861 & -1.2558 & -17.2420 \\
\hline $\mathrm{MgCl}+$ & $9.1437 \mathrm{E}-19$ & -18.0389 & -0.4074 & -18.4463 \\
\hline $\mathrm{Au}+$ & 4.2470E-19 & -18.3719 & -0.4074 & -18.7794 \\
\hline $\mathrm{Mg}+2$ & 8.2198E-20 & -19.0851 & -1.0655 & -20.1507 \\
\hline $\mathrm{Ag}(\mathrm{CO} 3)-$ & 3.5153E-20 & -19.4540 & -0.3195 & -19.7736 \\
\hline $\mathrm{Fe}+3$ & $1.8430 \mathrm{E}-20$ & -19.7345 & -2.1644 & -21.8988 \\
\hline \multicolumn{5}{|c|}{ Species Accounting for $99 \%$ or More of Aqueous $\mathrm{Ga}+3$} \\
\hline Species & \multicolumn{4}{|c|}{ Factor Molality Per Cent } \\
\hline $\mathrm{Ga}(\mathrm{OH})+2$ & 1.009 .9 & $\begin{array}{l}\text { Dlalıty Per C } \\
9.9982 E-09\end{array}$ & \multicolumn{2}{|c|}{99.98} \\
\hline \multicolumn{5}{|c|}{ Species Accounting for $99 \%$ or More of Aqueous $\ln +3$} \\
\hline Species & \multicolumn{4}{|c|}{ Factor Molality Per Cent } \\
\hline $\operatorname{lnCl}+2$ & $1.00 \quad 3.88$ & \multicolumn{2}{|c|}{$3.8838 \mathrm{E}-08 \quad 77.68$} & \\
\hline $\ln (\mathrm{OH})+2$ & 1.001 .1 & $1.1141 \mathrm{E}-08$ & 22.28 & \\
\hline
\end{tabular}


Fluid SM3 from the Satanic Mills vent field in the Manus Basin Temperature $=288^{\circ} \mathrm{C} ; \mathrm{pH}\left(\right.$ at $\left.25^{\circ} \mathrm{C}\right)=2.5 ; \mathrm{pH}\left(\right.$ at $\left.288^{\circ} \mathrm{C}\right)=3.0$

--- Distribution of Aqueous Solute Species ---

\begin{tabular}{|c|c|c|c|c|}
\hline Species & Molality & og Molality & Log Gamm & na Log Activit \\
\hline $\mathrm{Cl}-$ & 3.6753E-01 & -0.4347 & -0.3398 & 0.7745 \\
\hline $\mathrm{Na}+$ & 2.9031E-01 & -0.5371 & -0.3720 & -0.9092 \\
\hline $\mathrm{CO} 2, \mathrm{aq}$ & 2.6773E-01 & -0.5723 & 0.0771 & -0.4952 \\
\hline $\mathrm{NaCl}, \mathrm{aq}$ & 1.0711E-01 & -0.9702 & 0.0000 & -0.9702 \\
\hline $\mathrm{K}+$ & $5.7850 \mathrm{E}-02$ & -1.2377 & $\begin{array}{ll}-0.4183 & -1\end{array}$ & -1.6560 \\
\hline $\mathrm{SiO} 2, \mathrm{aq}$ & 1.4755E-02 & -1.8311 & 0.0000 & -1.8311 \\
\hline $\mathrm{KCl}, \mathrm{aq}$ & 1.0149E-02 & -1.9936 & 0.0000 & -1.9936 \\
\hline $\mathrm{H} 2 \mathrm{~S}, \mathrm{aq}$ & $9.9658 \mathrm{E}-03$ & -2.0015 & 0.0000 & -2.0015 \\
\hline $\mathrm{Ca}+2$ & $5.1838 \mathrm{E}-03$ & -2.2854 & -1.1565 & -3.4419 \\
\hline $\mathrm{CaCl}+$ & 4.9652E-03 & -2.3041 & -0.3720 & -2.6761 \\
\hline $\mathrm{CaCl} 2, \mathrm{aq}$ & 3.5449E-03 & -2.4504 & 0.0000 & -2.4504 \\
\hline $\mathrm{MnCl}+$ & $2.3071 \mathrm{E}-03$ & -2.6369 & -0.3720 & -3.0089 \\
\hline $\mathrm{H}+$ & 1.6355E-03 - & -2.7863 & -0.2454 & -3.0318 \\
\hline $\mathrm{FeCl} 2, \mathrm{aq}$ & 1.1752E-03 & -2.9299 & 0.0000 & -2.9299 \\
\hline $\mathrm{HCl}, \mathrm{aq}$ & $1.0033 \mathrm{E}-03$ & -2.9986 & 0.0000 & -2.9986 \\
\hline $\mathrm{CuCl}, \mathrm{aq}$ & 1.2152E-04 & -3.9153 & 0.0000 & -3.9153 \\
\hline $\mathrm{ZnCl}+$ & 1.1436E-04 & -3.9417 & -0.3720 & -4.3137 \\
\hline $\mathrm{ZnCl} 2, \mathrm{aq}$ & 4.0871E-05 & -4.3886 & 0.0000 & -4.3886 \\
\hline $\mathrm{FeCl}+$ & 3.0540E-05 & -4.5151 & -0.3720 & -4.8871 \\
\hline $\mathrm{ZnCl} 4-2$ & 2.0419E-05 & -4.6900 & -1.2615 & -5.9514 \\
\hline AsO2- & $1.6100 \mathrm{E}-05$ & -4.7932 & -0.2936 & -5.0868 \\
\hline $\mathrm{CuCl} 2-$ & 1.0339E-05 & -4.9855 & -0.2936 & -5.2791 \\
\hline $\mathrm{Fe}+2$ & 9.2963E-06 & -5.0317 & -1.1565 & -6.1882 \\
\hline $\mathrm{H} 2, \mathrm{aq}$ & 8.4000E-06 & -5.0757 & 0.0771 & -4.9986 \\
\hline $\mathrm{CuCl} 3-2$ & $8.1131 \mathrm{E}-06$ & -5.0908 & -1.2615 & -6.3523 \\
\hline$M n+2$ & 7.8812E-06 & -5.1034 & -1.1565 & -6.2599 \\
\hline $\mathrm{Ca}(\mathrm{HCO} 3)+$ & $6.0772 \mathrm{E}-06$ & $6 \quad-5.2163$ & $3-0.3720$ & $0 \quad-5.5883$ \\
\hline $\mathrm{HCO} 3-$ & 4.4637E-06 & -5.3503 & -0.2936 & -5.6439 \\
\hline $\mathrm{PbCl} 2, \mathrm{aq}$ & 2.0959E-06 & -5.6786 & 0.0000 & -5.6786 \\
\hline $\mathrm{ZnCl3-}$ & $1.3445 \mathrm{E}-06$ & -5.8715 & -0.2936 & -6.1650 \\
\hline HS- & $1.2988 \mathrm{E}-06$ & -5.8865 & -0.3398 & -6.2263 \\
\hline $\mathrm{PbCl} 4-2$ & 1.1221E-06 & -5.9500 & -1.2615 & -7.2115 \\
\hline $\mathrm{PbCl} 3-$ & $1.1146 \mathrm{E}-06$ & -5.9529 & -0.2936 & -6.2465 \\
\hline $\mathrm{PbCl}+$ & 3.6270E-07 & -6.4405 & -0.3720 & -6.8125 \\
\hline $\mathrm{Ni}+2$ & $1.8875 E-07$ & -6.7241 & -1.3417 & -8.0658 \\
\hline $\mathrm{CdCl} 2, \mathrm{aq}$ & 1.5262E-07 & -6.8164 & 0.0000 & -6.8164 \\
\hline $\mathrm{InCl}+2$ & $1.4942 \mathrm{E}-07$ & -6.8256 & -1.3417 & -8.1673 \\
\hline $\mathrm{Ga}(\mathrm{OH})+2$ & 1.4657E-07 & $\begin{array}{ll}7 & -6.8340\end{array}$ & $0 \quad-1.3417$ & -8.1756 \\
\hline $\mathrm{NiCl}+$ & 6.1247E-08 & -7.2129 & -0.3720 & -7.5849 \\
\hline $\mathrm{AgCl} 2-$ & $5.1334 \mathrm{E}-08$ & -7.2896 & -0.2936 & -7.5832 \\
\hline $\mathrm{CdCl}+$ & 4.2395E-08 & -7.3727 & -0.3720 & -7.7447 \\
\hline
\end{tabular}




\begin{tabular}{|c|c|c|c|c|}
\hline $\mathrm{NaHSiO3,aq}$ & $3.2523 \mathrm{E}-08$ & \multicolumn{2}{|l|}{-7.4878} & -7.4878 \\
\hline $\mathrm{CoCl}+$ & 2.6434E-08 & -7.5778 & -0.3720 & -7.9499 \\
\hline $\mathrm{CdCl} 3-$ & 2.3999E-08 & -7.6198 & -0.2936 & -7.9134 \\
\hline $\mathrm{Cu}+$ & 2.2451E-08 & -7.6488 & -0.3720 & -8.0208 \\
\hline HSiO3- & 2.1467E-08 & -7.6682 & -0.2936 & -7.9618 \\
\hline $\mathrm{OH}-$ & 1.9567E-08 & -7.7085 & -0.3398 & -8.0483 \\
\hline $\mathrm{AgCl} 4-3$ & 1.1067E-08 & -7.9560 & -2.9008 & -10.8568 \\
\hline $\mathrm{AgCl} 3-2$ & 8.5317E-09 & -8.0690 & -1.2615 & -9.3304 \\
\hline $\mathrm{Co}+2$ & 5.5660E-09 & -8.2545 & -1.3417 & -9.5961 \\
\hline$Z n+2$ & 5.1960E-09 & -8.2843 & -1.1565 & -9.4408 \\
\hline $\mathrm{Pb}+2$ & $4.7580 \mathrm{E}-09$ & -8.3226 & -1.2733 & -9.5959 \\
\hline $\mathrm{Ga}+3$ & 3.4300E-09 & -8.4647 & -1.9966 & -10.4613 \\
\hline $\mathrm{Au}(\mathrm{HS}) 2-$ & 2.1911E-09 & -8.6593 & -0.2936 & -8.9529 \\
\hline $\mathrm{AgCl}, \mathrm{aq}$ & 2.0455E-09 & -8.6892 & 0.0000 & -8.6892 \\
\hline $\mathrm{Cd}+2$ & 6.9997E-10 & -9.1549 & -1.3417 & -10.4966 \\
\hline $\mathrm{AuCl} 2-$ & $6.5502 \mathrm{E}-10$ & -9.1837 & -0.2936 & -9.4773 \\
\hline $\ln (\mathrm{OH})+2$ & 4.6987E-10 & -9.3280 & -1.3417 & -10.6697 \\
\hline $\mathrm{AuCl} 3-2$ & 3.3217E-10 & -9.4786 & -1.2615 & -10.7401 \\
\hline $\mathrm{CdCl} 4-2$ & $2.8830 \mathrm{E}-10$ & -9.5402 & -1.2615 & -10.8016 \\
\hline $\mathrm{AuCl}, \mathrm{aq}$ & $1.2172 \mathrm{E}-10$ & -9.9146 & 0.0000 & -9.9146 \\
\hline $\ln +3$ & $1.1081 E-10$ & $-9.9554 \quad-$ & $-1.9966 \quad-$ & -11.9520 \\
\hline HSe- & $1.0000 \mathrm{E}-10$ & -10.0000 & -0.2936 & -10.2936 \\
\hline $\mathrm{BaCl}+$ & $7.9086 \mathrm{E}-11$ & -10.1019 & -0.3720 & -10.4739 \\
\hline $\mathrm{Ca}(\mathrm{CO} 3), \mathrm{aq}$ & $5.3184 \mathrm{E}-11$ & $1 \quad-10.2742$ & $2 \quad 0.0000$ & $0 \quad-10.2742$ \\
\hline $\mathrm{Ag}+$ & $2.1318 \mathrm{E}-11$ & -10.6713 & -0.4183 & -11.0895 \\
\hline $\mathrm{Ba}+2$ & 2.0913E-11 & -10.6796 & -1.2733 & -11.9529 \\
\hline $\mathrm{Ag}(\mathrm{HS}) 2-$ & 6.9173E-13 & -12.1601 & -0.2936 & -12.4536 \\
\hline $\mathrm{Cu}+2$ & $5.0841 E-13$ & -12.2938 & -1.1565 & -13.4503 \\
\hline CO3-2 & $2.5761 \mathrm{E}-13$ & -12.5890 & -1.1164 & -13.7055 \\
\hline $\mathrm{Au}+$ & $7.8945 \mathrm{E}-15$ & -14.1027 & -0.3720 & -14.4747 \\
\hline $\mathrm{H} 2 \mathrm{AsO} 3-$ & 1.2249E-15 & -14.9119 & -0.2936 & $6 \quad-15.2055$ \\
\hline $\mathrm{Fe}+3$ & 5.9857E-17 & -16.2229 & -1.9966 & -18.2195 \\
\hline Species Accol & ng for $99 \%$ or $N$ & More of Aque & deous $\mathrm{Ga}+3$ & \\
\hline Species & Factor $\mathrm{Mc}$ & olality Per & r Cent & \\
\hline $\mathrm{Ga}(\mathrm{OH})+2$ & $1.00 \quad 1.4$ & $4657 \mathrm{E}-07$ & 97.71 & \\
\hline $\mathrm{Ga}+3$ & 1.003 .43 & OOOE-09 2. & 29 & \\
\hline Species Acc & ing for $99 \%$ or & More of Aqu & ueous $\ln +3$ & \\
\hline Species & Factor Mo & olality Per & Cent & \\
\hline $\mathrm{InCl}+2$ & 1.001 .49 & $42 \mathrm{E}-07 \quad 99$ & 9.61 & \\
\hline
\end{tabular}


Fluid $\mathrm{F} 3$ from the Fenway vent field in the Manus Basin

Temperature $=358^{\circ} \mathrm{C} ; \mathrm{pH}\left(\right.$ at $\left.25^{\circ} \mathrm{C}\right)=2.7 ; \mathrm{pH}\left(\right.$ at $\left.358^{\circ} \mathrm{C}\right)=3.9$

--- Distribution of Aqueous Solute Species ---

--- Distribution of Aqueous Solute Species ---

\begin{tabular}{|c|c|c|c|c|}
\hline Species & Molality & og Molality & \multicolumn{2}{|c|}{ Log Gamma Log Activity } \\
\hline $\mathrm{NaCl}, \mathrm{aq}$ & 2.5209E-01 & -0.5984 & 0.0000 & -0.5984 \\
\hline $\mathrm{Cl}-$ & $2.0805 \mathrm{E}-01 \quad-\mathrm{C}$ & $\begin{array}{ll}-0.6818 & -0\end{array}$ & $-0.4563-$ & -1.1381 \\
\hline $\mathrm{Na}+$ & $1.5429 \mathrm{E}-01$ & -0.8117 & -0.4683 & -1.2800 \\
\hline $\mathrm{CO} 2, \mathrm{aq}$ & 5.4818E-02 & -1.2611 & 0.0593 & -1.2017 \\
\hline $\mathrm{K}+$ & 4.3792E-02 - & $-1.3586 \quad-0$ & -0.5212 & -1.8798 \\
\hline $\mathrm{KCl}, \mathrm{aq}$ & $3.2308 \mathrm{E}-02$ & -1.4907 & 0.0000 & -1.4907 \\
\hline $\mathrm{H} 2 \mathrm{~S}, \mathrm{aq}$ & 1.8369E-02 & -1.7359 & 0.0000 & -1.7359 \\
\hline $\mathrm{CaCl} 2, \mathrm{aq}$ & $1.7155 \mathrm{E}-02$ & -1.7656 & 0.0000 & -1.7656 \\
\hline $\mathrm{SiO} 2, \mathrm{aq}$ & $1.1921 \mathrm{E}-02$ & -1.9237 & 0.0000 & -1.9237 \\
\hline $\mathrm{FeCl} 2, \mathrm{aq}$ & 1.1587E-02 & -1.9360 & 0.0000 & -1.9360 \\
\hline $\mathrm{CaCl}+$ & 4.4595E-03 & -2.3507 & -0.4683 & -2.8190 \\
\hline $\mathrm{MnCl}+$ & 3.7989E-03 & -2.4203 & -0.4683 & -2.8886 \\
\hline $\mathrm{HCl}$,aq & $2.4602 \mathrm{E}-03$ & -2.6090 & 0.0000 & -2.6090 \\
\hline $\mathrm{Ca}+2$ & $6.8451 \mathrm{E}-04$ & -3.1646 & -1.5036 & -4.6682 \\
\hline $\mathrm{H} 2$,aq & 4.0701E-04 & -3.3904 & 0.0593 & -3.3311 \\
\hline $\mathrm{H}+$ & 2.8089E-04 & -3.5515 & -0.3150 & -3.8665 \\
\hline $\mathrm{FeCl}+$ & 2.0316E-04 & -3.6922 & -0.4683 & -4.1605 \\
\hline $\mathrm{ZnCl} 2$,aq & 1.7613E-04 & -3.7542 & 0.0000 & -3.7542 \\
\hline $\mathrm{ZnCl}+$ & 1.1966E-04 & -3.9220 & -0.4683 & -4.3903 \\
\hline $\mathrm{CuCl}, \mathrm{aq}$ & 1.1108E-04 & -3.9544 & 0.0000 & -3.9544 \\
\hline $\mathrm{ZnCl} 4-2$ & $8.9951 \mathrm{E}-05$ & -4.0460 & -1.6843 & -5.7303 \\
\hline $\mathrm{CuCl} 2-$ & 1.4829E-05 & -4.8289 & -0.4034 & -5.2323 \\
\hline $\mathrm{CuCl} 3-2$ & 1.4077E-05 & -4.8515 & -1.6843 & -6.5358 \\
\hline $\mathrm{H} 2 \mathrm{AsO} 3-$ & 1.3692E-05 & -4.8635 & -0.4034 & -5.2670 \\
\hline $\mathrm{PbCl} 4-2$ & $1.3521 \mathrm{E}-05$ & -4.8690 & -1.6843 & -6.5533 \\
\hline $\mathrm{PbCl} 2, \mathrm{aq}$ & 1.2933E-05 & -4.8883 & 0.0000 & -4.8883 \\
\hline $\mathrm{PbCl} 3-$ & $9.9548 \mathrm{E}-06$ & -5.0020 & -0.4034 & -5.4054 \\
\hline $\mathrm{Fe}+2$ & $9.5098 \mathrm{E}-06$ & -5.0218 & -1.5036 & -6.5254 \\
\hline $\mathrm{ZnCl3-}$ & 4.2568E-06 & -5.3709 & -0.4034 & -5.7744 \\
\hline HS- & $1.5658 \mathrm{E}-06$ & -5.8053 & -0.4563 & -6.2616 \\
\hline$M n+2$ & $1.0628 \mathrm{E}-06$ & -5.9735 & -1.5036 & -7.4771 \\
\hline $\mathrm{Ca}(\mathrm{HCO} 3)+$ & 8.1863E-07 & $7 \quad-6.0869$ & $9 \quad-0.4683$ & $83-6.5552$ \\
\hline $\mathrm{PbCl}+$ & 5.8909E-07 & -6.2298 & -0.4683 & -6.6981 \\
\hline $\mathrm{CoCl}+$ & $4.9948 \mathrm{E}-07$ & -6.3015 & -0.4683 & -6.7698 \\
\hline $\mathrm{CdCl} 2, \mathrm{aq}$ & 4.2163E-07 & -6.3751 & 0.0000 & -6.3751 \\
\hline HCO3- & $3.2491 \mathrm{E}-07$ & -6.4882 & -0.4034 & -6.8917 \\
\hline $\mathrm{AgCl} 4-3$ & $2.9320 \mathrm{E}-07$ & -6.5328 & -3.8408 & -10.3736 \\
\hline $\mathrm{AgCl} 2-$ & $2.5875 E-07$ & -6.5871 & -0.4034 & -6.9906 \\
\hline $\mathrm{NiCl}+$ & $1.6032 \mathrm{E}-07$ & -6.7950 & -0.4683 & -7.2633 \\
\hline $\mathrm{Ga}(\mathrm{OH})+2$ & 1.4977E-07 & $7 \quad-6.8246$ & $5 \quad-1.7245$ & $15 \quad-8.5491$ \\
\hline
\end{tabular}




\begin{tabular}{|c|c|c|c|c|}
\hline $\operatorname{lnCl}+2$ & $1.4875 \mathrm{E}-07$ & -6.8275 & -1.7245 & -8.5521 \\
\hline $\mathrm{Ni}+2$ & 8.9677E-08 & -7.0473 & -1.7245 & -8.7718 \\
\hline $\mathrm{NaHSiO3,aq}$ & 6.2469E-0 & $88 \quad-7.2043$ & $3 \quad 0.0000$ & $0 \quad-7.2043$ \\
\hline $\mathrm{CdCl} 3-$ & $5.8521 \mathrm{E}-08$ & -7.2327 & -0.4034 & -7.6361 \\
\hline $\mathrm{OH}-$ & 4.1202E-08 & -7.3851 & -0.4563 & -7.8414 \\
\hline $\mathrm{AgCl} 3-2$ & 3.9229E-08 & -7.4064 & -1.6843 & -9.0907 \\
\hline $\mathrm{Co}+2$ & $2.0516 \mathrm{E}-08$ & -7.6879 & -1.7245 & -9.4124 \\
\hline $\mathrm{CdCl}+$ & 1.9167E-08 & -7.7175 & -0.4683 & -8.1858 \\
\hline HSiO3- & $1.8260 \mathrm{E}-08$ & -7.7385 & -0.4034 & -8.1420 \\
\hline $\mathrm{Cu}+$ & 1.1805E-08 & -7.9279 & -0.4683 & -8.3962 \\
\hline $\mathrm{AgCl}, \mathrm{aq}$ & 8.7821E-09 & -8.0564 & 0.0000 & -8.0564 \\
\hline H2AsO4- & 7.7371E-09 & -8.1114 & -0.4034 & . -8.5149 \\
\hline $\mathrm{Pb}+2$ & 1.2363E-09 & -8.9079 & -1.6437 & -10.5516 \\
\hline $\ln (\mathrm{OH})+2$ & 1.2184E-09 & -8.9142 & -1.7245 & -10.6387 \\
\hline $\mathrm{CdCl} 4-2$ & $6.1801 \mathrm{E}-10$ & -9.2090 & -1.6843 & -10.8933 \\
\hline $\mathrm{AuCl} 2-$ & $5.8491 \mathrm{E}-10$ & -9.2329 & -0.4034 & -9.6364 \\
\hline $\mathrm{Au}(\mathrm{HS}) 2-$ & $5.4372 \mathrm{E}-10$ & -9.2646 & -0.4034 & -9.6681 \\
\hline AuCl3-2 & $2.6070 \mathrm{E}-10$ & -9.5839 & -1.6843 & -11.2682 \\
\hline$Z n+2$ & 2.3593E-10 & -9.6272 & -1.5036 & -11.1308 \\
\hline $\mathrm{Ga}+3$ & $2.3306 \mathrm{E}-10$ & -9.6325 & -2.6559 & -12.2884 \\
\hline $\mathrm{AuCl}, \mathrm{aq}$ & $1.1066 \mathrm{E}-10$ & -9.9560 & 0.0000 & -9.9560 \\
\hline HSe- & $1.0000 \mathrm{E}-10$ & -10.0000 & -0.4034 & -10.4035 \\
\hline $\mathrm{BaCl}+$ & $9.6510 \mathrm{E}-11$ & -10.0154 & -0.4683 & -10.4837 \\
\hline $\mathrm{Cd}+2$ & 6.2997E-11 & -10.2007 & -1.7245 & -11.9252 \\
\hline $\mathrm{Ag}+$ & $3.4350 \mathrm{E}-11$ & -10.4641 & -0.5212 & -10.9852 \\
\hline $\ln +3$ & $2.6988 \mathrm{E}-11$ & -10.5688 & -2.6559 & -13.2247 \\
\hline $\mathrm{Ca}(\mathrm{CO} 3), \mathrm{aq}$ & $1.9963 \mathrm{E}-11$ & $\begin{array}{ll}1 & -10.6998\end{array}$ & $8 \quad 0.0000$ & $0 \quad-10.699$ \\
\hline $\mathrm{Ba}+2$ & $3.4902 \mathrm{E}-12$ & -11.4572 & -1.6437 & -13.1009 \\
\hline $\mathrm{Ag}(\mathrm{HS}) 2-$ & $2.5315 \mathrm{E}-12$ & -11.5966 & -0.4034 & -12.0001 \\
\hline $\mathrm{HAsO}$ 4-2 & $3.6647 \mathrm{E}-13$ & -12.4360 & -1.6843 & -14.1203 \\
\hline AsO2- & $5.6709 \mathrm{E}-14$ & -13.2463 & -0.4034 & -13.6498 \\
\hline CO3-2 & $1.4623 \mathrm{E}-14$ & -13.8350 & -1.5140 & -15.3490 \\
\hline $\mathrm{Cu}+2$ & 6.4039E-15 & -14.1936 & -1.5036 & -15.6971 \\
\hline $\mathrm{Au}+$ & $6.1448 \mathrm{E}-15$ & -14.2115 & -0.4683 & -14.6798 \\
\hline $\mathrm{Fe}+3$ & 4.6136E-18 & -17.3360 & -2.6559 & -19.9919 \\
\hline $\mathrm{ClO} 4-$ & $1.8151 \mathrm{E}-75$ & -74.7411 & -0.4563 & -75.1974 \\
\hline
\end{tabular}

Species Accounting for $99 \%$ or More of Aqueous Ga+3

Species Factor Molality Per Cent

$\begin{array}{llll}\mathrm{Ga}(\mathrm{OH})+2 & 1.00 & 1.4977 \mathrm{E}-07 & 99.84\end{array}$

Species Accounting for $99 \%$ or More of Aqueous In+3

Species Factor Molality Per Cent

$\begin{array}{llll}\mathrm{InCl}+2 & 1.00 & 1.4875 \mathrm{E}-07 & 99.17\end{array}$ 


\section{SUPPLEMENTARY MATERIAL}

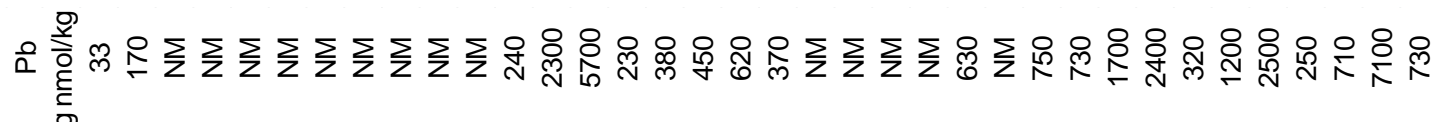

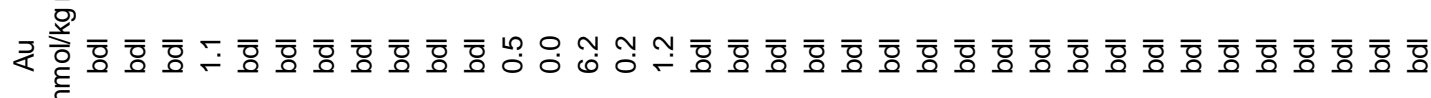

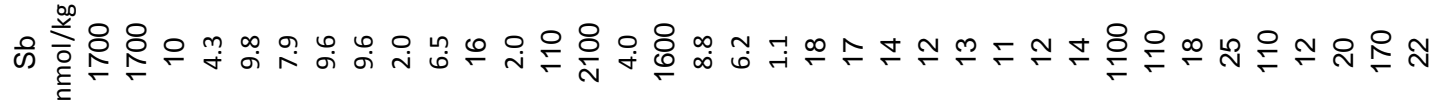

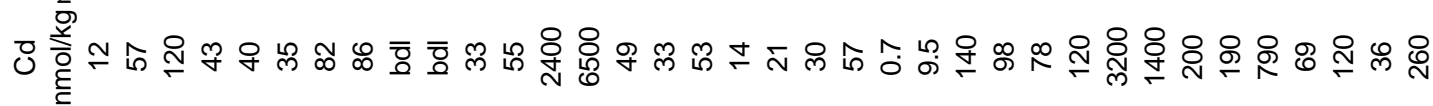

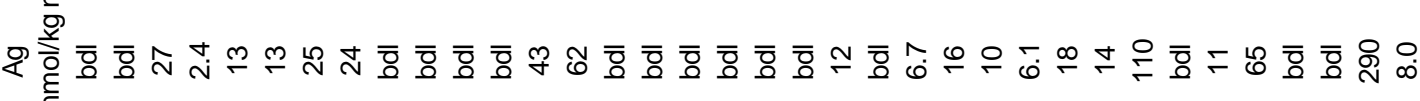

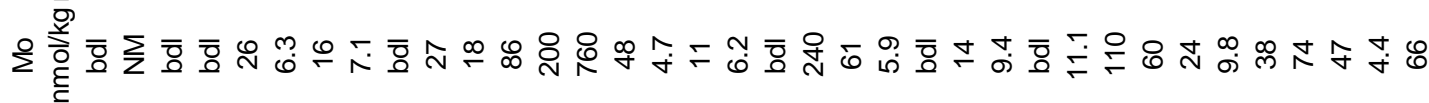

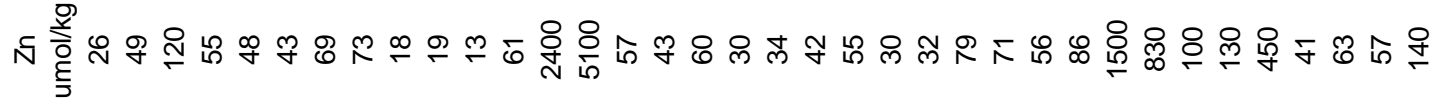
J 旁

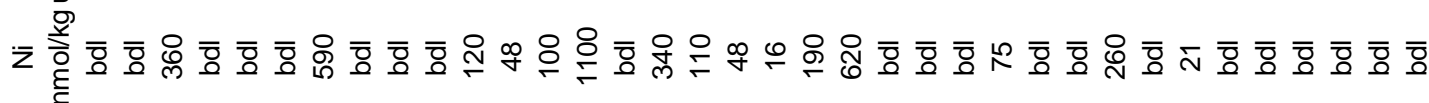

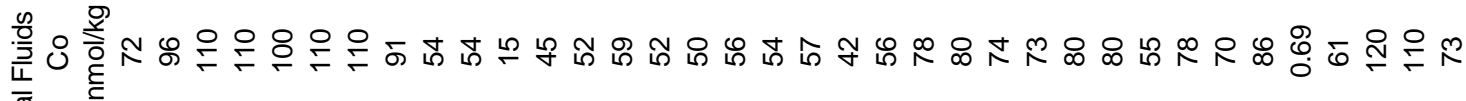
离 产运产 \& \&

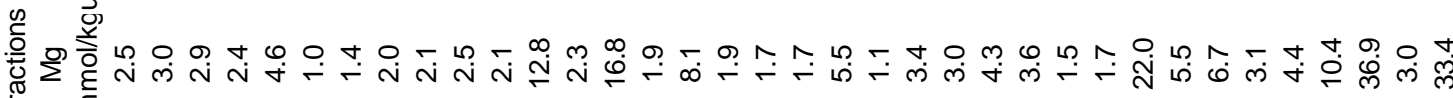

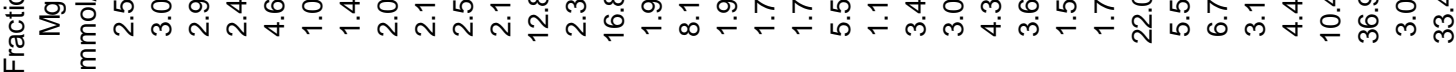

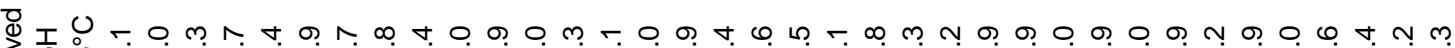

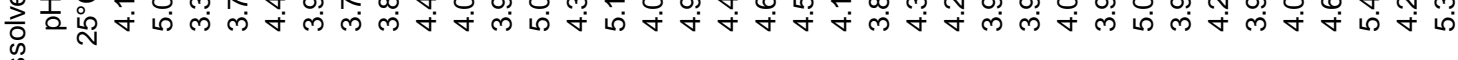
$\stackrel{\square}{\square}$

品 :

-

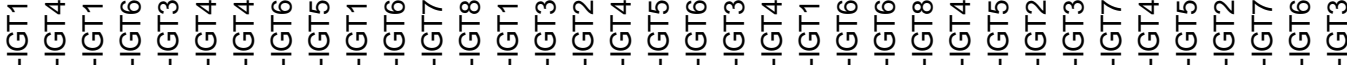

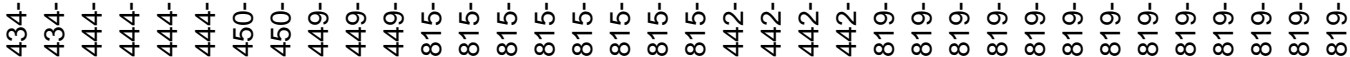

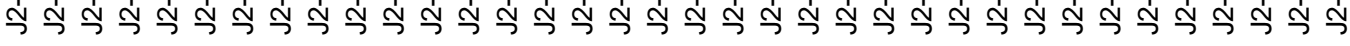

8 영 8

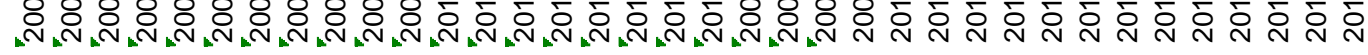

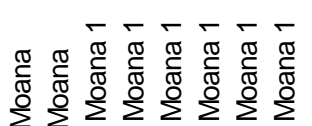




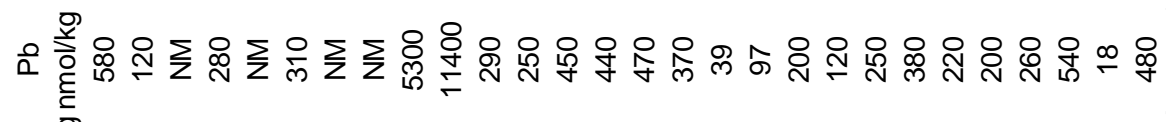

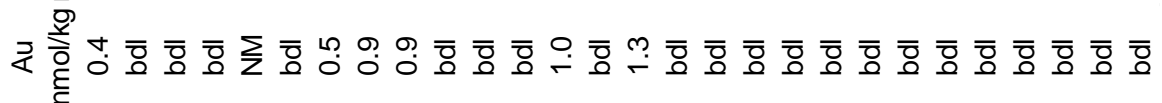

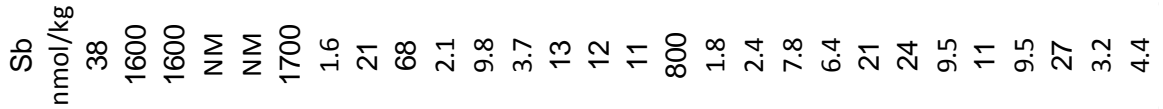

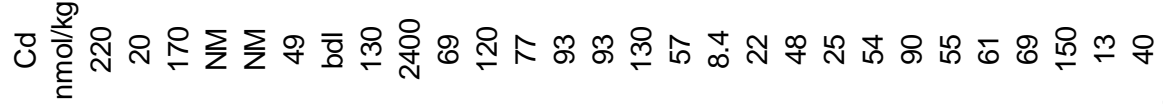

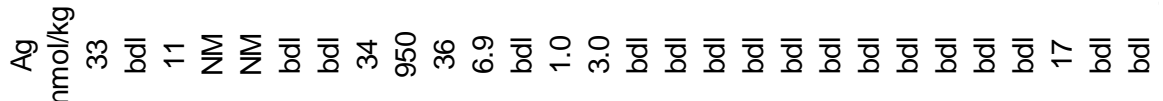

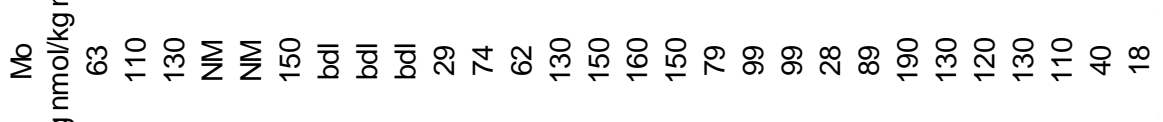

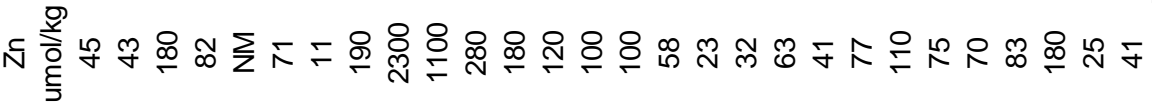

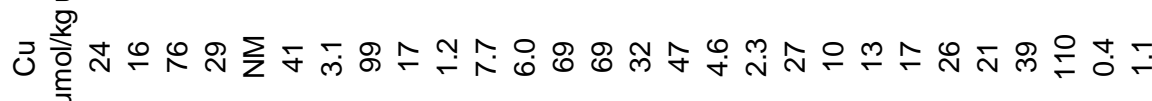

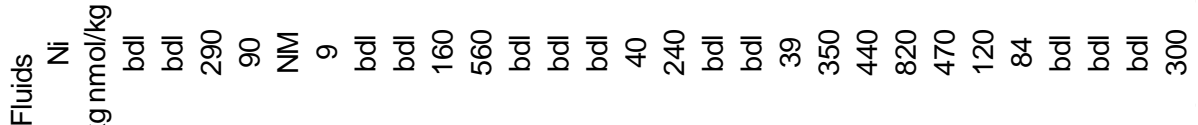

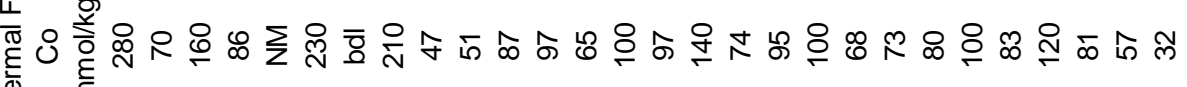
产过 产 \&

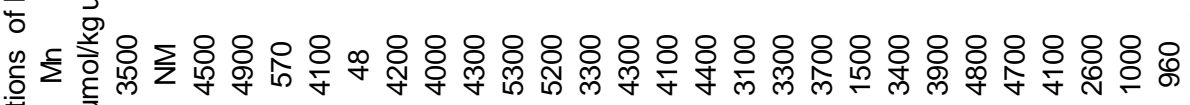

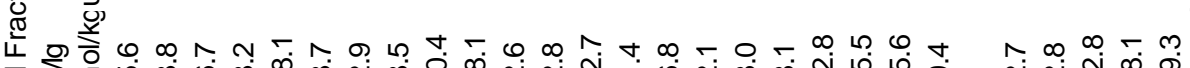

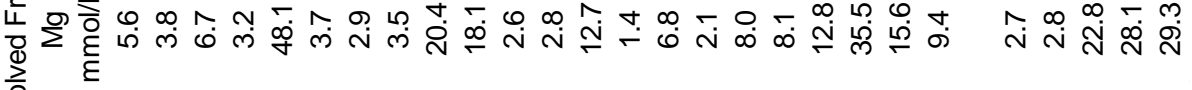

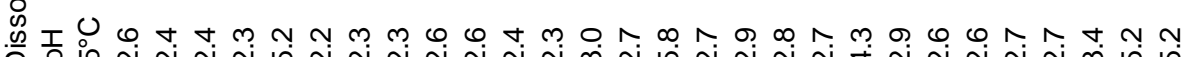
产

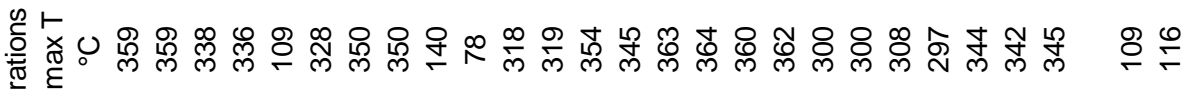
竞

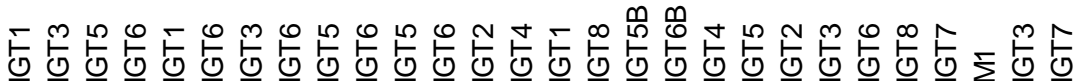

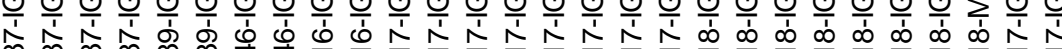

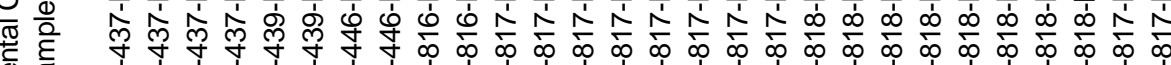
๕ $\frac{\Phi}{\Psi}$

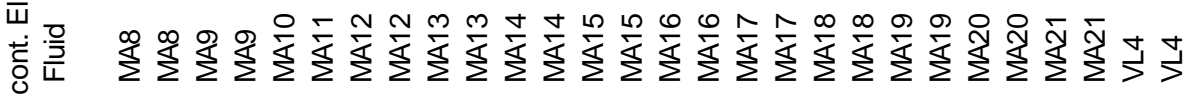
๘

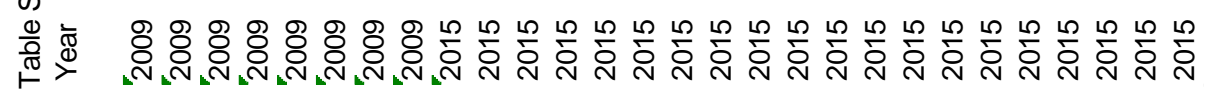

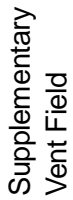

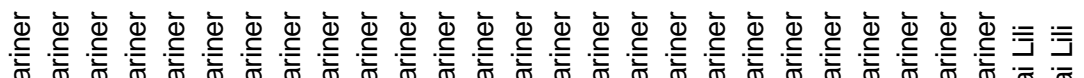

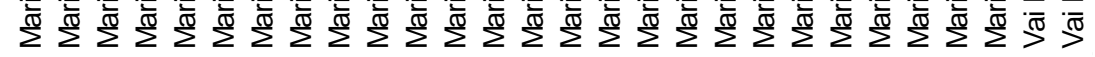


Supplementary Table S2 . Elemental Concentrations in Filters Fractions of Hydrothermal Fluids

\begin{tabular}{|c|c|c|c|c|c|c|c|c|c|c|c|}
\hline Vent Field & Year & Fluid & Sample & $\mathrm{Cr}$ & $\mathrm{Mn}$ & $\mathrm{Fe}$ & Co & $\mathrm{Ni}$ & $\mathrm{Cu}$ & Zn & $\mathrm{Ga}$ \\
\hline & & & & & & & & & & & \\
\hline ABE & 2015 & A13 & J2-815-IGT7 & 1600 & 3.4 & 36 & 41 & 2000 & 0.9 & bdl & 77 \\
\hline ABE & '2015 & A13 & J2-815-IGT8 & 480 & 47 & 2000 & 8.2 & 170 & 20 & 57 & 120 \\
\hline ABE & 2015 & A14 & J2-815-IGT1 & 1800 & 23 & 970 & 87 & 280 & 83 & 360 & 94 \\
\hline ABE & 2015 & A14 & J2-815-IGT3 & 330 & 4.9 & 21 & 81 & 140 & 2.7 & 4.3 & 59 \\
\hline ABE & 2015 & A15 & J2-815-IGT2 & 930 & 6.6 & 24 & 84 & 140 & 5.1 & 6.7 & 53 \\
\hline$A B E$ & '2015 & A15 & J2-815-IGT4 & 450 & 1.1 & 3.5 & bdl & 80 & 2.5 & 3.1 & 63 \\
\hline ABE & 2015 & A16 & J2-815-IGT5 & 520 & 1.2 & 8.1 & bdl & 130 & 3.0 & 2.7 & 54 \\
\hline $\mathrm{ABE}$ & 2015 & A16 & J2-815-IGT6 & 420 & 2.6 & 9.4 & 74 & 120 & 1.5 & 2.2 & 57 \\
\hline Tu'i Malila & 2015 & TM13 & J2-819-IGT6 & 290 & 7.0 & 9.7 & 75 & 52 & 2.8 & 3.9 & 55 \\
\hline Tu'i Malila & 2015 & TM13 & J2-819-IGT8 & 280 & 7.9 & 8.3 & 87 & 69 & 3.2 & 3.6 & 67 \\
\hline Tu'i Malila & 2015 & TM14 & J2-819-IGT4 & 260 & 0.1 & 2.7 & 90 & 55 & 0.7 & 1.0 & 67 \\
\hline Tu'i Malila & 2015 & TM14 & J2-819-IGT5 & 330 & 4.7 & 4.4 & 87 & 72 & 1.2 & 2.3 & 63 \\
\hline Tu'i Malila & 2015 & TM15 & J2-819-IGT2 & 410 & 4.3 & 480 & 73 & 83 & 220 & 780 & 70 \\
\hline Tu'i Malila & 2015 & TM16 & J2-819-IGT3 & 290 & 4.5 & 120 & 89 & 67 & 3.9 & 46 & 79 \\
\hline Tu'i Malila & 2015 & TM16 & J2-819-IGT7 & 380 & 0.3 & 8.3 & 79 & 49 & 2.7 & 2.5 & 59 \\
\hline Tu'i Malila & 2015 & TM17 & J2-819-IGT4B & 220 & 2.8 & 35 & 29 & 34 & 1.8 & 110 & 65 \\
\hline Tu'i Malila & 2015 & TM17 & J2-819-IGT5B & 310 & 7.2 & 66 & 79 & 63 & 4.2 & 110 & 69 \\
\hline Tu'i Malila & 2015 & TM18 & J2-819-IGT2B & 5100 & 1.5 & 140 & 90 & 460 & 1.1 & 6.8 & 67 \\
\hline Tu'i Malila & 2015 & TM18 & J2-819-IGT7B & 340 & 0.4 & 4.6 & 17 & 53 & 1.3 & 19 & 61 \\
\hline Tu'i Malila & 2015 & TM19 & J2-819-IGT6B & 280 & 4.2 & 8.6 & 85 & 50 & 0.8 & 2.3 & 57 \\
\hline Tu'i Malila & 2015 & TM20 & J2-819-IGT3B & 240 & 3.4 & 56 & 71 & 45 & 14.3 & 14 & 51 \\
\hline Mariner & 2015 & MA13 & J2-816-IGT5 & 210 & 64 & 33 & 74 & 110 & 1.4 & 42 & 49 \\
\hline Mariner & 2015 & MA13 & J2-816-IGT6 & 590 & 62 & 68 & 100 & 410 & 3.6 & 25 & 70 \\
\hline Mariner & 2015 & MA14 & J2-817-IGT5 & 230 & 5.7 & 8.6 & 91 & 110 & 0.6 & 0.4 & 82 \\
\hline Mariner & 2015 & MA14 & J2-817-IGT6 & 740 & 49 & 69 & 75 & 93 & 0.7 & 2.1 & 61 \\
\hline Mariner & 2015 & MA15 & J2-817-IGT2 & 200 & 10 & 42 & 88 & 140 & 0.8 & 0.3 & 67 \\
\hline Mariner & 2015 & MA15 & J2-817-IGT4 & 730 & 29 & 92 & 82 & 91 & 1.0 & 2.8 & 60 \\
\hline Mariner & 2015 & MA16 & J2-817-IGT1 & 1200 & 26 & 85 & 52 & 93 & 1.6 & 1.6 & 56 \\
\hline Mariner & 2015 & MA16 & J2-817-IGT8 & 920 & 38 & 69 & 86 & 110 & 1.1 & 3.2 & 66 \\
\hline Mariner & 2015 & MA17 & J2-817-IGT5B & 110 & 3.9 & 11 & 280 & 260 & 0.6 & 0.8 & 0.1 \\
\hline Mariner & 2015 & MA17 & J2-817-IGT6B & 1100 & 29 & 93 & 95 & 200 & 1.3 & 13 & 72 \\
\hline Mariner & 2015 & MA18 & J2-818-IGT4 & 740 & 4.6 & 17 & 81 & 100 & 2.2 & 1.2 & 67 \\
\hline Mariner & 2015 & MA18 & J2-818-IGT5 & 580 & 1.0 & 5.1 & 70 & 59 & 0.6 & 0.3 & 54 \\
\hline Mariner & 2015 & MA19 & J2-818-IGT2 & 370 & 9.8 & 29 & 180 & 98 & 4.1 & 0.6 & 66 \\
\hline Mariner & 2015 & MA19 & J2-818-IGT3 & 880 & 11 & 33 & 120 & 140 & 0.7 & 1.3 & 64 \\
\hline Mariner & 2015 & MA20 & J2-818-IGT6 & 340 & 66 & 140 & 59 & 67 & 1.1 & 1.4 & 67 \\
\hline Mariner & 2015 & MA20 & J2-818-IGT8 & 330 & 12 & 23 & 88 & 280 & 1.2 & 1.0 & 59 \\
\hline Mariner & 2015 & MA21 & J2-818-IGT7 & 410 & 3.3 & 13 & 81 & 60 & 1.9 & 0.4 & 66 \\
\hline Mariner & 2015 & MA21 & J2-818-M1 & 350 & 4.9 & 15 & 79 & 200 & 0.7 & 0.5 & 55 \\
\hline
\end{tabular}


Supplementary Table S2 cont . Elemental Concentrations in Filters Fractions of Hydrothermal Fluids

\begin{tabular}{|c|c|c|c|c|c|c|c|c|c|c|c|}
\hline Vent Field & Year & Fluid & Sample & Mo & $\mathrm{Ag}$ & $\mathrm{Cd}$ & In & Sn & $\mathrm{Sb}$ & $\mathrm{Au}$ & $\mathrm{Pb}$ \\
\hline & & & & $\mathrm{nmol} / \mathrm{kg}$ & & & & & & 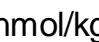 & $\mathrm{mol} / \mathrm{kg}$ \\
\hline $\mathrm{ABE}$ & 2015 & A13 & J2-815-IGT7 & 990 & bdl & 37 & 47 & 64 & 23 & 490 & 55 \\
\hline $\mathrm{ABE}$ & "2015 & A13 & J2-815-IGT8 & 720 & bdl & 75 & 37 & 10 & 44 & 1100 & 4200 \\
\hline$A B E$ & "2015 & A14 & J2-815-IGT1 & 1000 & bdl & 490 & 42 & 52 & 80 & 3000 & 2800 \\
\hline $\mathrm{ABE}$ & 2015 & A14 & J2-815-IGT3 & 980 & bdl & 33 & 41 & 76 & 40 & NM & 52 \\
\hline $\mathrm{ABE}$ & 2015 & A15 & J2-815-IGT2 & 770 & bdl & 35 & 41 & 56 & 38 & 4400 & 87 \\
\hline$A B E$ & 2015 & A15 & J2-815-IGT4 & 37 & 43 & 58 & NM & 21 & 89 & 230 & 250 \\
\hline$A B E$ & 2015 & A16 & J2-815-IGT5 & 740 & bdl & 31 & 38 & 120 & 34 & 300 & 44 \\
\hline ABE & "2015 & A16 & J2-815-IGT6 & 810 & bdl & 27 & 35 & 40 & 36 & 1000 & 59 \\
\hline Tu'i Malila & 2015 & TM13 & J2-819-IGT6 & 850 & bdl & 31 & NM & 34 & 31 & 2200 & 54 \\
\hline Tu'i Malila & 2015 & TM13 & J2-819-IGT8 & 1200 & bdl & 33 & 41 & 41 & 35 & 1800 & 51 \\
\hline Tu'i Malila & 2015 & TM14 & J2-819-IGT4 & 1000 & bdl & 32 & 44 & 39 & 40 & 0.4 & 27 \\
\hline Tu'i Malila & 2015 & TM14 & J2-819-IGT5 & 1000 & bdl & 33 & 42 & 68 & 36 & 2900 & 94 \\
\hline Tu'i Malila & "2015 & TM15 & J2-819-IGT2 & 980 & 64 & 1700 & 36 & 52 & 210 & 2400 & 1200 \\
\hline Tu'i Malila & 2015 & TM16 & J2-819-IGT3 & 1200 & bdl & 130 & 43 & 40 & 43 & 2800 & 520 \\
\hline Tu'i Malila & "2015 & TM16 & J2-819-IGT7 & 980 & bdl & 33 & 39 & 67 & 34 & 1700 & 64 \\
\hline Tu'i Malila & "2015 & TM17 & J2-819-IGT4B & 960 & bdl & 110 & 39 & 36 & 41 & 1600 & 280 \\
\hline Tu'i Malila & "2015 & TM17 & J2-819-IGT5B & 1000 & bdl & 240 & 37 & 33 & 56 & 2200 & 440 \\
\hline Tu'i Malila & "2015 & TM18 & J2-819-IGT2B & 1300 & bdl & 50 & 39 & 40 & 43 & 1200 & 53 \\
\hline Tu'i Malila & 2015 & TM18 & J2-819-IGT7B & 940 & bdl & 61 & 39 & 35 & 35 & 2200 & 110 \\
\hline Tu'i Malila & 2015 & TM19 & J2-819-IGT6B & 980 & bdl & 31 & 41 & 38 & 45 & 3900 & 250 \\
\hline Tu'i Malila & "2015 & TM20 & J2-819-IGT3B & 840 & bdl & 62 & 34 & 40 & 30 & 3000 & 150 \\
\hline Mariner & 2015 & MA13 & J2-816-IGT5 & 790 & bdl & 69 & 36 & 42 & 32 & 880 & 140 \\
\hline Mariner & 2015 & MA13 & J2-816-IGT6 & 1200 & bdl & 58 & 48 & 350 & 44 & 1600 & 520 \\
\hline Mariner & 2015 & MA14 & J2-817-IGT5 & bdl & bdl & 32 & 45 & 94 & 38 & 110 & 25 \\
\hline Mariner & 2015 & MA14 & J2-817-IGT6 & 660 & bdl & 26 & 36 & 42 & 31 & 550 & 22 \\
\hline Mariner & 2015 & MA15 & J2-817-IGT2 & 850 & bdl & 30 & 42 & 46 & 36 & 270 & 56 \\
\hline Mariner & 2015 & MA15 & J2-817-IGT4 & 850 & bdl & 29 & 39 & 52 & 34 & 600 & 37 \\
\hline Mariner & 2015 & MA16 & J2-817-IGT1 & NM & bdl & 26 & 35 & 44 & 33 & 540 & 34 \\
\hline Mariner & 2015 & MA16 & J2-817-IGT8 & 620 & bdl & 31 & 41 & 110 & 36 & 770 & 110 \\
\hline Mariner & 2015 & MA17 & J2-817-IGT5B & 0.9 & 21 & 0.7 & 39 & 24 & 160 & 4.3 & 1.2 \\
\hline Mariner & 2015 & MA17 & J2-817-IGT6B & 990 & bdl & 33 & 42 & 83 & NM & 530 & 38 \\
\hline Mariner & 2015 & MA18 & J2-818-IGT4 & 750 & bdl & 28 & 40 & 40 & 37 & 350 & 27 \\
\hline Mariner & 2015 & MA18 & J2-818-IGT5 & 800 & bdl & 25 & 33 & 32 & 30 & 390 & 24 \\
\hline Mariner & 2015 & MA19 & J2-818-IGT2 & 1300 & bdl & 33 & 46 & 42 & 39 & 340 & 31 \\
\hline Mariner & 2015 & MA19 & J2-818-IGT3 & 770 & bdl & 31 & 43 & 67 & 38 & 170 & 27 \\
\hline Mariner & 2015 & MA20 & J2-818-IGT6 & 730 & bdl & 30 & 41 & 41 & 36 & 1100 & 26 \\
\hline Mariner & 2015 & MA20 & J2-818-IGT8 & 830 & bdl & 27 & 38 & 39 & 39 & 530 & 24 \\
\hline Mariner & 2015 & MA21 & J2-818-IGT7 & 720 & bdl & 28 & 40 & 37 & 33 & 400 & 25 \\
\hline Mariner & 2015 & MA21 & J2-818-M1 & 900 & bdl & 28 & 39 & 35 & 33 & 150 & 120 \\
\hline
\end{tabular}


Supplementary Table S3 . Elemental Concentrations in Dregs Fractions of Hydrothermal Fluids

\begin{tabular}{|c|c|c|c|c|c|c|c|c|c|c|c|}
\hline \multicolumn{12}{|c|}{$\begin{array}{l}\text { Vent Field Year Fluid Sample } \\
\mathrm{NM}=\text { not measured; } N S=\text { no sample }\end{array}$} \\
\hline & & & & $\mathrm{nmol} / \mathrm{kg}$ & $\mathrm{mol} / \mathrm{kg}$ & $\mathrm{mol} / \mathrm{k}$ & $\mathrm{mol} / \mathrm{k}$ & $\mathrm{mol} / \mathrm{k}$ & $\mathrm{mol} / \mathrm{ks}$ & $\mathrm{mol} / \mathrm{kg}$ & $\mathrm{mol} / \mathrm{kg}$ \\
\hline Kilo Moana & "2009 & KM9 & J2-434-IGT1 & 1500 & 0.8 & 480 & 410 & 200 & 4.0 & 12 & 5.2 \\
\hline Kilo Moana & 2009 & KM9 & J2-434-IGT4 & NM & 0.7 & 650 & 480 & 17 & 3.6 & 19 & NM \\
\hline Tahi Moana 1 & 2009 & TMo1 & J2-444-IGT1 & 8500 & 0.3 & 57 & 30 & 400 & 11 & 110 & 11 \\
\hline Tahi Moana 1 & 2009 & TMo1 & J2-444-IGT6 & 1100 & 0.6 & 16 & 24 & 500 & 5.8 & 130 & 18 \\
\hline Tahi Moana 1 & 2009 & TMo2 & J2-444-IGT3 & 1100 & 0.3 & 10 & 69 & 320 & 3.1 & 8.2 & 3.3 \\
\hline Tahi Moana 1 & 2009 & TMo2 & J2-444-IGT4 & 1100 & 0.4 & 13 & 19 & 72 & 5.6 & 120 & 20 \\
\hline Tahi Moana 1 & 2009 & TMo5 & J2-450-IGT4 & 590 & 0.2 & 6.7 & 14 & 46 & 1.6 & 11 & 1.5 \\
\hline Tahi Moana 1 & 2009 & TMo5 & J2-450-IGT6 & 630 & 0.2 & 3.9 & 11 & 60 & 1.3 & 6.5 & 1.7 \\
\hline $\mathrm{ABE}$ & 2009 & A10 & J2-449-IGT5 & 4200 & 0.5 & 25 & 23 & 100 & 7.9 & 80 & 9.7 \\
\hline $\mathrm{ABE}$ & "2009 & A11 & J2-449-IGT1 & 3500 & 0.3 & 22 & 16 & 220 & 4.2 & 58 & 8.2 \\
\hline$A B E$ & 2009 & A11 & J2-449-IGT6 & 710 & 448.6 & 160 & 55 & bdl & 6.5 & 64 & 4.0 \\
\hline$A B E$ & 2015 & A13 & J2-815-IGT7 & 1600 & 0.2 & 14 & 7.6 & 150 & 1.8 & 24 & 9.8 \\
\hline$A B E$ & '2015 & A13 & J2-815-IGT8 & 900 & 4.2 & 280 & 45 & 270 & 34 & 590 & 24 \\
\hline$A B E$ & 2015 & A14 & J2-815-IGT1 & NS & NS & NS & NS & NS & NS & NS & NS \\
\hline$A B E$ & 2015 & A14 & J2-815-IGT3 & 1100 & 1.8 & 190 & 34 & 240 & 68 & 360 & 21 \\
\hline$A B E$ & "2015 & A15 & J2-815-IGT2 & NS & NS & NS & NS & NS & NS & NS & NS \\
\hline$A B E$ & 2015 & A15 & J2-815-IGT4 & 1200 & 0.7 & 22 & 43 & 200 & 3.2 & 33 & 11 \\
\hline$A B E$ & 2015 & A16 & J2-815-IGT5 & 370 & 0.1 & 3.1 & 5.2 & 76 & 1.2 & 1.8 & 9.5 \\
\hline $\mathrm{ABE}$ & "2015 & A16 & J2-815-IGT6 & NS & NS & NS & NS & NS & NS & NS & NS \\
\hline Tu'i Malila & 2009 & TM11 & J2-442-IGT3 & 1400 & 0.3 & 23 & 59 & 230 & 12 & 44 & 9.4 \\
\hline Tu'i Malila & 2009 & TM11 & J2-442-IGT4 & 4900 & 0.4 & 34 & 25 & 250 & 6.0 & 70 & 2.0 \\
\hline Tu'i Malila & 2009 & TM12 & J2-442-IGT1 & 7700 & 0.4 & 75 & 31 & 220 & 21 & 81 & 14 \\
\hline Tu'i Malila & 2009 & TM12 & J2-442-IGT6 & 7000 & 0.7 & 120 & 32 & 180 & 21 & 280 & 87 \\
\hline Tu'i Malila & 2015 & TM13 & J2-819-IGT6 & NS & NS & NS & NS & NS & NS & NS & NS \\
\hline Tu'i Malila & 2015 & TM13 & J2-819-IGT8 & NS & NS & NS & NS & NS & NS & NS & NS \\
\hline Tu'i Malila & 2015 & TM14 & J2-819-IGT4 & NS & NS & NS & NS & NS & NS & NS & NS \\
\hline Tu'i Malila & 2015 & TM14 & J2-819-IGT5 & NS & NS & NS & NS & NS & NS & NS & NS \\
\hline Tu'i Malila & 2015 & TM15 & J2-819-IGT2 & 520 & 2.2 & 560 & 86 & 210 & 180 & 1200 & 120 \\
\hline Tu'i Malila & 2015 & TM16 & J2-819-IGT3 & NS & NS & NS & NS & NS & NS & NS & NS \\
\hline Tu'i Malila & 2015 & TM16 & J2-819-IGT7 & NS & NS & NS & NS & NS & NS & NS & NS \\
\hline Tu'i Malila & 2015 & TM17 & J2-819-IGT4B & 460 & 2.4 & 310 & 65 & 190 & 18 & 520 & 32 \\
\hline Tu'i Malila & 2015 & TM17 & J2-819-IGT5B & NS & NS & NS & NS & NS & NS & NS & NS \\
\hline Tu'i Malila & 2015 & TM18 & J2-819-IGT2B & NS & NS & NS & NS & NS & NS & NS & NS \\
\hline Tu'i Malila & 2015 & TM18 & J2-819-IGT7B & 200 & 0.5 & 44 & 12 & 59 & 6.3 & 290 & 13 \\
\hline Tu'i Malila & 2015 & TM19 & J2-819-IGT6B & 270 & 0.6 & 47 & 30 & 91.9 & 5.0 & 69 & 18 \\
\hline Tu'i Malila & 2015 & TM20 & J2-819-IGT3B & NS & NS & NS & NS & NS & NS & NS & NS \\
\hline
\end{tabular}


Supplementary Table S3 cont. Elemental Concentrations in Dregs Fractions of Hydrothermal Fluids

\begin{tabular}{|c|c|c|c|c|c|c|c|c|c|c|c|}
\hline $\begin{array}{l}\text { Vent Field } \\
N M=\text { not } m\end{array}$ & $\begin{array}{l}\text { Year } \\
\text { Sured. }\end{array}$ & Fluid & Sample & $\mathrm{Cr}$ & $\mathrm{Mn}$ & $\mathrm{Fe}$ & Co & $\mathrm{Ni}$ & $\mathrm{Cu}$ & $Z n$ & G \\
\hline & \multicolumn{11}{|c|}{ NM = not measured; NS = no sample } \\
\hline Mariner & 2009 & MA8 & J2-437-IGT3 & NM & 1.7 & 2100 & 570 & 170 & 1800 & 330 & \\
\hline Mariner & 2009 & MA9 & J2-437-IGT5 & 2000 & 1.0 & 160 & 43 & 74 & 170 & 270 & \\
\hline Mariner & 2009 & MA9 & J2-437-IGT6 & NM & 6.9 & 3800 & 80 & 270 & 270 & 250 & \\
\hline Mariner & 2009 & MA10 & J2-439-IGT1 & NM & 6.6 & 3600 & 83 & 160 & 260 & 17600 & \\
\hline Mariner & 2009 & MA11 & J2-439-IGT6 & 2900 & 0.6 & 160 & 44 & 180 & 280 & 530 & \\
\hline Mariner & 2009 & MA12 & J2-446-IGT3 & 600 & 0.8 & 20 & 14 & 76 & 56 & 130 & \\
\hline Mariner & 2009 & MA12 & J2-446-IGT6 & 2700 & 0.7 & 240 & 87 & 580 & 180 & 420 & \\
\hline Mariner & 2015 & MA13 & J2-816-IGT5 & NS & NS & NS & NS & NS & NS & NS & \\
\hline Mariner & 2015 & MA13 & J2-816-IGT6 & NS & NS & NS & NS & NS & NS & NS & \\
\hline Mariner & 2015 & MA14 & J2-817-IGT5 & 420 & 0.6 & bdl & 36 & 141.2 & 93 & 1300 & \\
\hline Mariner & 2015 & MA14 & J2-817-IGT6 & 340 & 0.9 & 27 & 20 & 676.3 & 98 & 1600 & \\
\hline Mariner & 2015 & MA15 & J2-817-IGT2 & 750 & 0.6 & 58 & 110 & 130.8 & 130 & 210 & \\
\hline Mariner & 2015 & MA15 & J2-817-IGT4 & 1100 & 1.1 & 480 & 27 & 158.4 & 150 & 250 & \\
\hline Mariner & 2015 & MA16 & J2-817-IGT1 & 1600 & 1.7 & 190 & 66 & 1222.2 & 150 & 420 & \\
\hline Mariner & 2015 & MA16 & J2-817-IGT8 & 1200 & 0.5 & 81 & 30 & 430.7 & 160 & 260 & \\
\hline Mariner & 2015 & MA17 & J2-817-IGT5B & 580 & 5.7 & 6300 & 240 & 248.0 & 3700 & 720 & \\
\hline Mariner & 2015 & MA17 & J2-817-IGT6B & 550 & 0.8 & 1400 & 170 & 236.1 & 440 & 510 & \\
\hline Mariner & 2015 & MA18 & J2-818-IGT4 & 240 & 0.3 & 88 & 21 & 63.0 & 85 & 110 & \\
\hline Mariner & 2015 & MA18 & J2-818-IGT5 & 910 & 0.9 & 150 & 36 & 205.8 & 89 & 250 & \\
\hline Mariner & 2015 & MA19 & J2-818-IGT2 & 680 & 2.2 & 780 & 33 & 101.8 & 610 & 330 & \\
\hline Mariner & 2015 & MA19 & J2-818-IGT3 & 580 & 0.9 & 540 & 36 & 113.1 & 410 & 350 & \\
\hline Mariner & 2015 & MA20 & J2-818-IGT6 & 780 & 0.5 & 67 & 19 & 189.3 & 170 & 440 & \\
\hline Mariner & 2015 & MA20 & J2-818-IGT8 & 820 & 0.6 & 59 & 30 & 104.2 & 99 & 240 & \\
\hline Mariner & 2015 & MA21 & J2-818-IGT7 & 810 & 0.9 & 110 & 32 & 273.1 & 230 & 370 & \\
\hline Mariner & 2015 & MA21 & J2-818-M1 & NS & NS & NS & NS & NS & NS & NS & \\
\hline
\end{tabular}


Supplementary Table S3 cont. Elemental Concentrations in Dregs Fractions of Hydrothermal Fluids

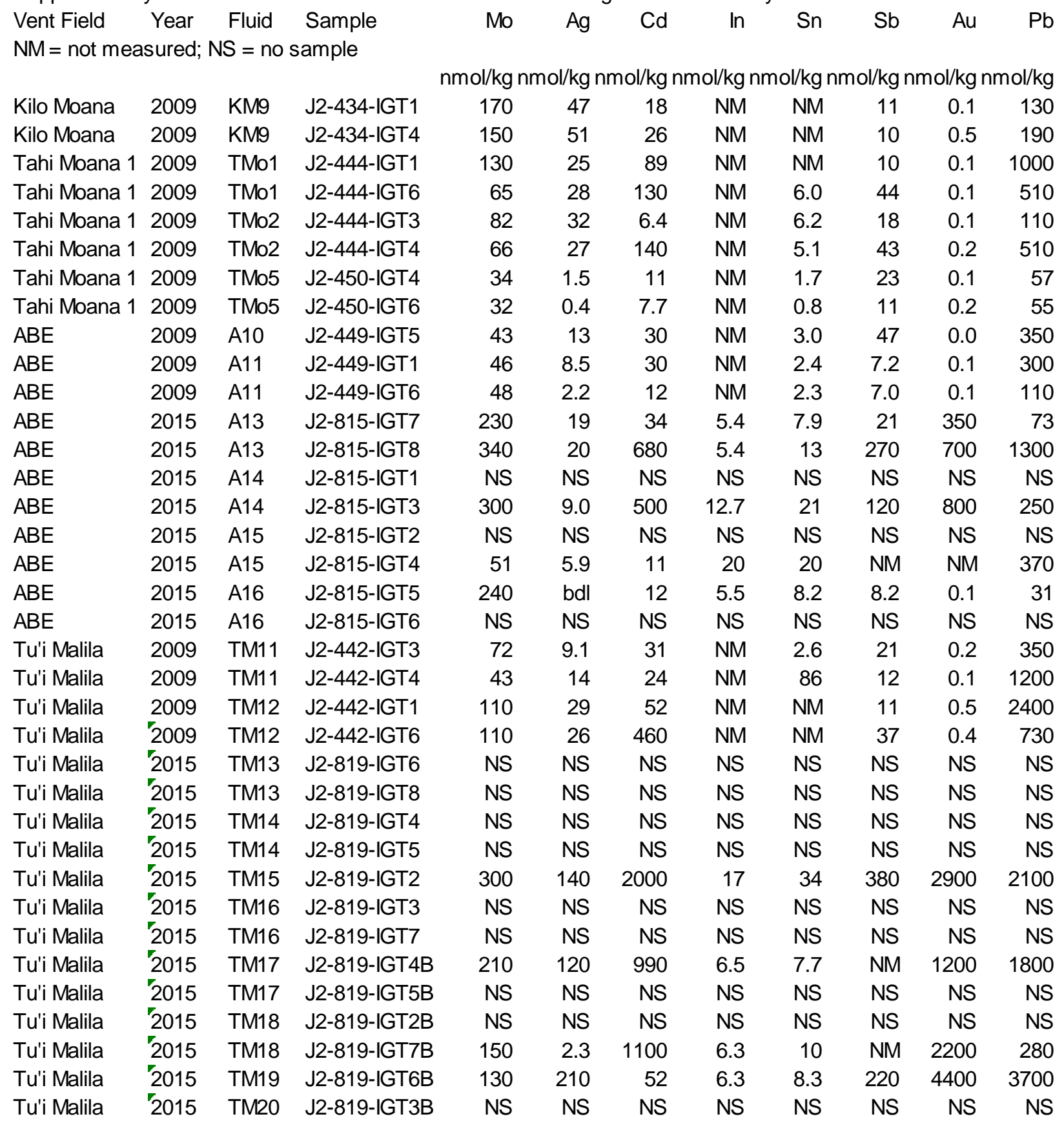


Supplementary Table S3 cont. Elemental Concentrations in Dregs Fractions of Hydrothermal Fluids

\begin{tabular}{|c|c|c|c|c|c|c|c|c|c|c|c|}
\hline Vent Field & Year & Fluid & Sample & Mo & $\mathrm{Ag}$ & $\mathrm{Cd}$ & In & Sn & $\mathrm{Sb}$ & $\mathrm{Au}$ & $\mathrm{Pb}$ \\
\hline \multicolumn{12}{|c|}{ NM = not measured; NS = no sample } \\
\hline Mariner & 2009 & MA8 & J2-437-IGT1 & 110 & bdl & 44 & NM & NM & 1600 & bdl & 130 \\
\hline Mariner & 2009 & MA8 & J2-437-IGT3 & 210 & 67 & 250 & NM & NM & 57 & 1.3 & 1200 \\
\hline Mariner & 2009 & MA9 & J2-437-IGT5 & 84 & 47 & 230 & NM & NM & 23 & 0.6 & 1100 \\
\hline Mariner & 2009 & MA9 & J2-437-IGT6 & 2000 & 1600 & 10300 & NM & NM & 25 & \multicolumn{2}{|c|}{0.7338100} \\
\hline Mariner & "2009 & MA10 & J2-439-IGT1 & 2000 & 1500 & 10300 & NM & NM & 26 & \multicolumn{2}{|c|}{2.7342000} \\
\hline Mariner & 2009 & MA11 & J2-439-IGT6 & 63 & 55 & 240 & NM & NM & 37 & 0.7 & 2000 \\
\hline Mariner & 2009 & MA12 & J2-446-IGT3 & 35 & 10 & 72 & NM & 6.2 & 48 & 0.5 & 710 \\
\hline Mariner & '2009 & MA12 & J2-446-IGT6 & 160 & 56 & 330 & NM & NM & 70 & 0.7 & 5100 \\
\hline Mariner & 2015 & MA13 & J2-816-IGT5 & NS & NS & NS & NS & NS & NS & NS & NS \\
\hline Mariner & 2015 & MA13 & J2-816-IGT6 & NS & NS & NS & NS & NS & NS & NS & NS \\
\hline Mariner & 2015 & MA14 & J2-817-IGT5 & 280 & 7.0 & 1400 & 93 & 15 & 69.7 & 1700 & 930 \\
\hline Mariner & 2015 & MA14 & J2-817-IGT6 & 290 & 67 & 1300 & 140 & 16 & 114.2 & 3000 & 3000 \\
\hline Mariner & 2015 & MA15 & J2-817-IGT2 & 260 & 28 & 170 & 39 & 18 & 60.5 & 2000 & 760 \\
\hline Mariner & 2015 & MA15 & J2-817-IGT4 & 370 & 63 & 210 & 46 & 23 & 45.0 & 370 & 780 \\
\hline Mariner & 2015 & MA16 & J2-817-IGT1 & 380 & 78 & 390 & 38 & 16 & 113.7 & 1400 & 990 \\
\hline Mariner & 2015 & MA16 & J2-817-IGT8 & 330 & 26 & 200 & 43 & 22 & 32.4 & 1700 & 2200 \\
\hline Mariner & 2015 & MA17 & J2-817-IGT5B & 760 & 55 & 250 & 110 & 19 & 14.7 & 23000 & 430 \\
\hline Mariner & 2015 & MA17 & J2-817-IGT6B & 370 & 100 & 380 & 62 & 31 & 53.6 & 26100 & 6000 \\
\hline Mariner & 2015 & MA18 & J2-818-IGT4 & 170 & 81 & 110 & 36 & 8.2 & 66.3 & 820 & 270 \\
\hline Mariner & 2015 & MA18 & J2-818-IGT5 & 290 & 74 & 240 & 34 & 12 & 174.3 & 2300 & 320 \\
\hline Mariner & 2015 & MA19 & J2-818-IGT2 & 660 & 78 & 260 & 180 & 36 & 204.8 & 6300 & 3600 \\
\hline Mariner & "2015 & MA19 & J2-818-IGT3 & 290 & 70 & 310 & 130 & 26 & 251.2 & 1800 & 590 \\
\hline Mariner & 2015 & MA20 & J2-818-IGT6 & 310 & 110 & 360 & 61 & 14 & 45.8 & 1500 & 1700 \\
\hline Mariner & 2015 & MA20 & J2-818-IGT8 & 180 & 33 & 200 & 37 & 8.9 & 106.4 & 920 & 740 \\
\hline Mariner & "2015 & MA21 & J2-818-IGT7 & 230 & 55 & 360 & 69 & 63 & 134.8 & 950 & 480 \\
\hline Mariner & 2015 & MA21 & J2-818-M1 & NS & NS & NS & NS & NS & NS & NS & NS \\
\hline
\end{tabular}


Supplementary Table S4. Selected ELSC Hydrothermal Fluid Data

Selected Hydrothermal Fluid Data from Mottl et al. (2011) and Chapter 2 of this thesis.

\begin{tabular}{|c|c|c|c|c|c|c|c|c|}
\hline Fluid_ID & FieldCode & $\begin{array}{c}\max T \\
{ }^{\circ} \mathrm{C}\end{array}$ & $\begin{array}{c}\mathrm{pH} \\
25^{\circ} \mathrm{C}\end{array}$ & $\begin{array}{r}\mathrm{Mn} \\
\mathrm{umol} / \mathrm{kg}\end{array}$ & $\begin{array}{r}\mathrm{Fe} \\
\mathrm{umol} / \mathrm{kg}\end{array}$ & $\begin{array}{r}\mathrm{Cu} \\
\mathrm{umol} / \mathrm{kg}\end{array}$ & $\begin{array}{r}\mathrm{Zn} \\
\mathrm{umol} / \mathrm{kg}\end{array}$ & $\begin{array}{r}\mathrm{Pb} \\
\mathrm{nmol} / \mathrm{kg}\end{array}$ \\
\hline KM1 & 1 & 333 & 3.6 & 511 & 2485 & 8 & 58 & 272 \\
\hline KM2 & 1 & 332 & 3.6 & 694 & 3202 & $\ldots$ & $\ldots$ & 312 \\
\hline KM3 & 1 & 321 & 2.9 & 733 & 3836 & 9 & 74 & 312 \\
\hline KM4 & 1 & 300 & 3.2 & 524 & 2473 & 11 & $\ldots$ & 226 \\
\hline KM5 & 1 & 329 & 3.5 & 717 & 2898 & 11 & 108 & $\ldots$ \\
\hline KM6 & 1 & 306 & 3.6 & 675 & 3116 & 10 & 60 & 402 \\
\hline KM8 & 1 & 333 & 4.0 & 553 & 2557 & $\ldots$ & 64 & 390 \\
\hline TC1 & 2 & 328 & 4.1 & 388 & 305 & 4 & 19 & 369 \\
\hline TC3 & 2 & 320 & 4.0 & 398 & 267 & 3 & 49 & 430 \\
\hline TC4 & 2 & 316 & 4.1 & 407 & 282 & 5 & 61 & 498 \\
\hline TC5 & 2 & 302 & 3.7 & 329 & 343 & 7 & 53 & $\ldots$ \\
\hline TC6 & 2 & 288 & 3.9 & 389 & 368 & 4 & 50 & 427 \\
\hline TC7 & 2 & 288 & 4.0 & 375 & 313 & 8 & 74 & 515 \\
\hline A1 & 4 & 309 & 4.3 & 461 & 268 & 6 & 36 & 387 \\
\hline A2 & 4 & 309 & 4.1 & 476 & 264 & 5 & 44 & 385 \\
\hline A4 & 4 & 278 & 4.4 & 273 & $\ldots$ & $\ldots$ & $\ldots$ & $\ldots$ \\
\hline A5 & 4 & 290 & 4.5 & 289 & 174 & 4 & 33 & 380 \\
\hline A8 & 4 & 308 & 4.5 & 301 & $\ldots$ & $\ldots$ & $\ldots$ & $\ldots$ \\
\hline A9 & 4 & 295 & 4.6 & 286 & 159 & $\ldots$ & 37 & 573 \\
\hline TM1 & 5 & 279 & 4.5 & 432 & 219 & 16 & 48 & 532 \\
\hline TM2 & 5 & 312 & 4.4 & 406 & 218 & 7 & 28 & 571 \\
\hline TM4 & 5 & 178 & 5.7 & 332 & $\ldots$ & $\ldots$ & $\ldots$ & $\ldots$ \\
\hline TM5 & 5 & 265 & 4.6 & 439 & $\ldots$ & $\ldots$ & $\ldots$ & $\ldots$ \\
\hline TM6 & 5 & 265 & 4.4 & 399 & 227 & 2 & 18 & 564 \\
\hline TM7 & 5 & 198 & 5.0 & 413 & $\ldots$ & & & \\
\hline TM8 & 5 & 229 & 4.4 & 380 & $\ldots$ & 11 & 7 & 786 \\
\hline TM10 & 5 & 274 & 4.1 & 378 & 271 & 4 & 49 & $\ldots$ \\
\hline MA1 & 6 & 334 & 2.5 & 5938 & 11417 & 171 & 467 & 862 \\
\hline MA2 & 6 & 311 & 2.6 & 6275 & 11265 & 105 & 514 & 751 \\
\hline MA3 & 6 & 363 & 2.7 & 5728 & 13122 & 156 & 336 & 1135 \\
\hline MA5 & 6 & 249 & 2.6 & 5440 & 10547 & 96 & 321 & 858 \\
\hline MA6 & 6 & 240 & 2.7 & 4875 & 10684 & 4 & 242 & 1200 \\
\hline
\end{tabular}




\section{Supplementary Table S5. Selected Manus Basin Hydrothermal Fluid Data}

\begin{tabular}{|c|c|c|c|c|c|c|c|c|c|c|c|c|}
\hline Fluid_ID & FieldCode & $\begin{array}{l}\max T \\
{ }^{\circ} \mathrm{C}\end{array}$ & $\begin{array}{l}\mathrm{pH} \\
25^{\circ} \mathrm{C}\end{array}$ & $\begin{array}{r}\mathrm{Mn} \\
\mathrm{umol} / \mathrm{kg}\end{array}$ & $\begin{array}{r}\mathrm{Fe} \\
\mathrm{umol} / \mathrm{kg}\end{array}$ & $\begin{array}{r}\mathrm{Cu} \\
\mathrm{umol} / \mathrm{kg}\end{array}$ & $\begin{array}{r}\mathrm{Zn} \\
\mathrm{umol} / \mathrm{kg}\end{array}$ & $\begin{array}{r}\mathrm{Pb} \\
\mathrm{nmol} / \mathrm{kg}\end{array}$ & $\begin{array}{r}\text { Co } \\
\mathrm{nmol} / \mathrm{kg}\end{array}$ & $\begin{array}{r}\mathrm{Ag} \\
\mathrm{nmol} / \mathrm{kg}\end{array}$ & $\begin{array}{r}\mathrm{Co} \\
\mathrm{nmol} / \mathrm{kg}\end{array}$ & \\
\hline VW1 & 7 & 282 & 4.4 & 349 & 159 & 4 & 33 & 0.35 & 45 & 38 & 50 & 9.50 \\
\hline VW2 & 7 & 273 & 4.2 & 365 & 165 & $(--)$ & 30 & 0.30 & 30 & 28 & 57 & \\
\hline VW3 & 7 & 285 & 4.7 & 209 & 130 & 5 & 23 & 0.25 & 20 & 9 & 36 & 1.80 \\
\hline RMR1 & 8 & 314 & 2.3 & 4155 & 6731 & 165 & 1499 & 22.0 & 234 & 720 & 2600 & 4.38 \\
\hline RMR2 & 8 & 272 & 2.3 & 3345 & 1509 & 62 & 2970 & 137.0 & 71 & 3233 & 4000 & 52.15 \\
\hline RMR3 & 8 & 278 & 2.5 & 5089 & 8079 & 40 & 1095 & 24.0 & 67 & 328 & 1620 & 8.20 \\
\hline RMR4 & 8 & 341 & 2.6 & 3005 & 6829 & 188 & 453 & 8.6 & 272 & 185 & 634 & 0.98 \\
\hline RGR1 & 8 & 320 & 2.7 & 2906 & 4610 & 213 & 490 & 4.0 & 29 & 223 & 720 & 1.05 \\
\hline RGR2 & 8 & 274 & 2.6 & 2822 & 3740 & 475 & 566 & 2.9 & 41 & 580 & 770 & 1.22 \\
\hline SM1 & 9 & 295 & 2.6 & 2745 & 3370 & 141 & 350 & 7.0 & (90) & 124 & 440 & 0.88 \\
\hline SM2 & 9 & 241 & 2.4 & 2520 & 1475 & 800 & 265 & $4.0^{\prime}$ & (35) & 125 & 220 & 0.16 \\
\hline SM3 & 9 & 288 & 2.5 & 2394 & 1298 & 140 & 175 & 5.0 & 10 & 75 & 155 & 0.54 \\
\hline $\mathrm{SC} 1$ & 9 & 152 & 4.6 & 2240 & 70 & 34 & 179 & 31.0 & (58) & 155 & 100 & 4.51 \\
\hline $\mathrm{SC} 2$ & 9 & 180 & 3.4 & 2880 & 241 & 6 & 25 & 2.0 & (50) & 32 & 23 & 5.69 \\
\hline $\mathrm{F} 1$ & 10 & 329 & 2.5 & 2570 & 8500 & 291 & 330 & 6.0 & 39 & 210 & 410 & 0.72 \\
\hline $\mathrm{F} 2$ & 10 & 343 & 2.7 & 4600 & 14400 & 235 & 410 & 5.2 & 508 & 150 & 430 & 0.64 \\
\hline F3 & 10 & 358 & 2.7 & 3962 & 12950 & 138 & 390 & 18.0 & 517 & 290 & 480 & 2.10 \\
\hline F4 & 10 & 284 & 2.4 & 3599 & 8549 & 305 & 367 & 2.6 & 45 & 165 & 353 & 0.54 \\
\hline SZ1 & 11 & 303 & 3.8 & 265 & 720 & 53 & 22 & 1.7 & 230 & 35 & 85 & 0.66 \\
\hline SZ2 & 11 & 274 & 3.6 & 360 & 880 & 27 & 29 & 3.4 & 101 & 60 & 96 & 2.21 \\
\hline SZ3 & 11 & 290 & 3.5 & 329 & 916 & 44 & 32 & 2.4 & 89 & 58 & 125 & 1.33 \\
\hline SZ4 & 11 & 229 & 3.6 & 324 & 495 & 13 & 31 & 2.7 & 122 & 34 & 93 & 2.56 \\
\hline SZ5 & 11 & 249 & 2.3 & 271 & 4571 & 1170 & 340 & 15.5 & 79 & 1400 & 800 & 1.20 \\
\hline SZ6 & 11 & 226 & 3.7 & 382 & 405 & 10 & (35) & 2.0 & 105 & (25) & 124 & \\
\hline NS3 & 11 & 300 & 3.4 & 421 & 2390 & 108 & 38 & 1.4 & 1003 & 52 & 99 & 0.48 \\
\hline NS5 & 11 & 299 & 3.2 & 349 & 4021 & 480 & 15 & 1.8 & 173 & 52 & 82 & 0.11 \\
\hline NS6 & 11 & 325 & 2.8 & 479 & 5858 & 99 & 17 & 2.9 & 2570 & 70 & 79 & 0.71 \\
\hline SS1 & 11 & 271 & 2.6 & 550 & 2194 & 390 & 34 & 1.2 & 28 & 270 & (160) & 0.69 \\
\hline SS2 & 11 & 288 & 2.7 & 485 & 2562 & 136 & 23 & 2.4 & 42 & 60 & 110 & 0.44 \\
\hline
\end{tabular}


Supplementary Table S6

Data for Figure 6

\begin{tabular}{|c|c|c|c|c|c|}
\hline \multirow[t]{3}{*}{ Fluid ID } & \multicolumn{3}{|c|}{$109 \mathrm{Ag} / 63 \mathrm{Cu} 160$} & \multirow{3}{*}{$\begin{array}{l}\mathrm{Ag} / \mathrm{Cu} \\
\text { total element } \\
\text { concentration } \\
\text { ratio }(\times 1000)\end{array}$} & \multirow{3}{*}{$\begin{array}{c}\mathrm{Ag}+/ \mathrm{Cu}+ \\
\text { activity } \\
\text { ratio } \\
(\times 1000)\end{array}$} \\
\hline & & $\begin{array}{c}\text { Counts } \\
\text { Ratio }\end{array}$ & $\begin{array}{c}\text { Counts } \\
\text { Ratio }\end{array}$ & & \\
\hline & $\mathrm{n}$ & Average & Error & & \\
\hline \multicolumn{6}{|c|}{ Eastern Lau Spreading Center } \\
\hline TMo5 & 18 & $6.60 \mathrm{E}-02$ & $1.60 \mathrm{E}-02$ & 4.50 & 6.25 \\
\hline A10 & 22 & $1.21 \mathrm{E}-02$ & 5.35E-03 & 1.40 & 0.92 \\
\hline A11 & 20 & $2.34 \mathrm{E}-02$ & 4.07E-03 & 0.67 & 1.98 \\
\hline A16 & 9 & $1.45 \mathrm{E}-02$ & $1.90 \mathrm{E}-03$ & 1.34 & 1.92 \\
\hline TM11 & 17 & $1.38 \mathrm{E}-02$ & 2.07E-03 & 0.95 & 0.92 \\
\hline MA9 & 12 & 2.95E-03 & 2.00E-03 & 0.77 & 0.31 \\
\hline MA15 & 6 & 2.57E-03 & $4.32 \mathrm{E}-04$ & 0.23 & 0.21 \\
\hline \multicolumn{6}{|c|}{ Manus Basin } \\
\hline VW1 & 88 & $9.56 \mathrm{E}-02$ & $1.65 \mathrm{E}-02$ & 9.50 & 8.87 \\
\hline RGR1 & 28 & 8.71E-02 & 9.91E-02 & 1.05 & 0.89 \\
\hline RMR1 & 24 & $3.25 \mathrm{E}-02$ & $1.61 \mathrm{E}-02$ & 4.38 & 4.83 \\
\hline SM3 & 27 & $1.55 \mathrm{E}-03$ & 7.35E-03 & 0.54 & 0.85 \\
\hline F3 & 13 & 8.10E-03 & $6.32 \mathrm{E}-03$ & 2.10 & 2.58 \\
\hline NS3 & 21 & 7.70E-03 & 2.64E-03 & 0.48 & 0.42 \\
\hline SZ1 & 13 & $6.44 \mathrm{E}-03$ & $1.12 \mathrm{E}-03$ & 0.66 & 0.82 \\
\hline SZ2 & 20 & $1.35 \mathrm{E}-02$ & 5.01E-03 & 2.21 & 2.29 \\
\hline \multicolumn{6}{|l|}{ Others } \\
\hline Sully99 & 27 & $3.08 \mathrm{E}-03$ & $5.55 \mathrm{E}-04$ & 0.33 & 1.34 \\
\hline BB5 & 19 & 3.64E-03 & $2.18 \mathrm{E}-03$ & 0.29 & 0.00 \\
\hline
\end{tabular}


Supplementary Table S7

Data for Figures 7, 8, and 9

\begin{tabular}{|c|c|c|c|c|c|c|c|c|}
\hline Fluid ID & Temp. & $\mathrm{pH}$ & $\mathrm{pH}$ & $\mathrm{Cu}$ & $\mathrm{Ag}$ & $\mathrm{Ag} / \mathrm{Cu}$ & $\mathrm{Ga}$ & $\mathrm{Ga}+3 / \mathrm{Fe}+2$ \\
\hline & $\left({ }^{\circ} \mathrm{C}\right)$ & (at $25^{\circ} \mathrm{C}$ ) & in situ & $\mu \mathrm{mol} / \mathrm{kg}$ & $\mathrm{nmol} / \mathrm{kg}$ & $\mathrm{x} 1000$ & $\mathrm{nmol} / \mathrm{kg}$ & $\times 10^{\wedge} 6$ \\
\hline \multicolumn{9}{|c|}{ Eastern Lau Spreading Center } \\
\hline TMo5 & 310 & 3.7 & 4.6 & 6 & 26 & 4.50 & 2 & 0.10 \\
\hline A10 & 317 & 3.9 & 4.6 & 10 & 14 & 1.40 & 10 & 0.35 \\
\hline A11 & 306 & 4.0 & 5.2 & 9 & 6 & 0.67 & 6 & 0.18 \\
\hline A16 & 300 & 4.0 & 5.2 & 4 & 6 & $1.34 \mathrm{E}+00$ & 62 & 3.93 \\
\hline TM11 & 315 & 3.8 & 4.5 & 20 & 19 & $9.50 \mathrm{E}-01$ & 6 & 0.85 \\
\hline MA9 & 338 & 2.4 & 3.2 & 300 & 230 & 0.77 & 118 & 5.16 \\
\hline MA15 & 354 & 2.7 & 3.8 & 238 & 56 & 0.23 & 175 & 2.39 \\
\hline \multicolumn{9}{|c|}{ Manus Basin } \\
\hline VW1 & 282 & 4.4 & 5.1 & 4 & 38 & 9.50 & 50 & 1.34 \\
\hline RGR1 & 320 & 2.7 & 4.0 & 213 & 223 & 1.05 & 150 & 1.91 \\
\hline RMR1 & 314 & 2.3 & 2.8 & 165 & 720 & 4.38 & 150 & 1.08 \\
\hline SM3 & 288 & 2.5 & 3.0 & 140 & 75 & 0.54 & 150 & 53.32 \\
\hline F3 & 358 & 2.7 & 3.9 & 138 & 290 & 2.10 & 150 & 1.73 \\
\hline NS3 & 300 & 3.4 & 3.9 & 108 & 52 & 0.48 & 50 & 1.93 \\
\hline SZ1 & 303 & 3.8 & 4.1 & 53 & 35 & 0.66 & 50 & 1.03 \\
\hline SZ2 & 274 & 3.6 & 4.0 & 27 & 60 & 2.21 & 50 & 2.81 \\
\hline \multicolumn{9}{|l|}{ Others } \\
\hline Sully99 & 379 & 3.6 & 4.3 & 12 & 4 & 0.33 & 50 & 2.14 \\
\hline BB5 & 395 & 3.0 & 5.0 & 172 & 50 & 0.29 & 50 & 0.06 \\
\hline
\end{tabular}




\section{Chapter 5}

\section{Summary and Conclusions}

\section{Summary of Findings}

The studies presented in this thesis investigate the relationships between active seafloor massive sulfide (SMS) deposits and the hydrothermal fluids from which they form. Particular attention is given to the linings of black smoker chimneys, which are shown to provide mineral and trace element indicators of the temperature, sulfur fugacity, $\mathrm{pH}$, and trace metal content of hydrothermal fluids. Specifically, the Ga and In contents of chalcopyrite chimney linings are identified as proxies for hydrothermal fluid $\mathrm{pH}$ while $\mathrm{Ag}$ contents closely reflect the ratios of free $\mathrm{Ag}^{+}$to free $\mathrm{Cu}^{+}$in paired hydrothermal fluids.

\section{Chapter 2}

Chapter 2 examines the morphology, mineralogy, and geochemistry of SMS deposits along the Eastern Lau Spreading Center (ELSC), and demonstrates how SMS deposits reflect the temperature and composition of hydrothermal fluids influenced by the nearby Tonga Subduction Zone. Closer to the Tonga Subduction Zone, SMS deposits exhibit higher concentrations of Ba, $\mathrm{Pb}, \mathrm{As}$, and $\mathrm{Sb}$ and mineral assemblages contain higher modal abundances of barite $\left(\mathrm{BaSO}_{4}\right)$ and galena $(\mathrm{PbS})$, consistent with elevated concentrations of these elements in more felsic host rocks. The precipitation of barite also influences deposit morphology, contributing to the formation of horizontal flanges and squat terraces. 
The stability of minerals present along open conduit chimneys linings and, where wurtzite is present, the mole\% $\mathrm{FeS}$ in $(\mathrm{Zn}, \mathrm{Fe}) \mathrm{S}$, closely reflect the temperature and sulfur fugacity of hydrothermal fluids. Additionally, the presence of co-precipitated wurtzite and chalcopyrite is associated with higher $\mathrm{pH}\left(\mathrm{pH}\left(\right.\right.$ at $\left.\left.25^{\circ} \mathrm{C}\right) \sim 4\right)$ vent fluids. Bulk geochemical data also provide an indicator of $\mathrm{pH}$, with $\mathrm{Zn}$ and $\mathrm{Ag}$ positively correlated in deposits associated with hydrothermal systems that vent fluids of minimum $\mathrm{pH}\left(\right.$ at $\left.25^{\circ} \mathrm{C}\right)<3.3$, but not in deposits associated with hydrothermal systems that vent fluids of minimum $\mathrm{pH}$ (at $\left.25^{\circ} \mathrm{C}\right)>3.3$.

\section{Chapter 3}

Chapter 3 focuses on the development of secondary ion mass spectrometry (SIMS) as a method for measuring trace element concentrations in the chalcopyrite linings of black smoker chimneys. Advantages of this technique include small ( $40 \mu \mathrm{m}$ diameter) spot sizes and low $(\sim 0.1 \mathrm{ppb})$ detection limits. A key aspect of this study is the construction of SIMS calibration

curves for $\mathrm{Co}, \mathrm{Ni}, \mathrm{Ga}, \mathrm{Ag}$, and In. This was done by comparing SIMS measurements of selected black smoker chimney linings with analyses of digested chalcopyrite grains picked from the linings of the same samples. Picked grains are analyzed by inductively coupled plasma mass spectrometry (ICP-MS) calibrated against serial dilutions of standard reference solutions. Another key aspect of this study is the use of SIMS to measure concentrations of Co, Ni, Ga, $\mathrm{Ag}$, and In in black smoker chimney samples representing a variety of geologic settings (e.g., fast-, intermediate-, slow-, and ultraslow-spreading mid-ocean ridges, and back-arc spreading centers) and hydrothermal fluid conditions (e.g., $\mathrm{pH}\left(\right.$ at $\left.25^{\circ} \mathrm{C}\right)=2.3$ to 4.4 and temperature $=274^{\circ} \mathrm{C}$ to $\left.395^{\circ} \mathrm{C}\right)$. 
Chapter 3 advances the use of SIMS as a technique for measuring $\mathrm{Co}, \mathrm{Ni}, \mathrm{Ga}, \mathrm{Ag}$, and In concentrations in chalcopyrite and identifies patterns between the concentrations of these elements and hydrothermal fluid parameters. Specific patterns for trace metal concentrations in the mineral chalcopyrite include:

1) covariation of $\mathrm{Co}$ and $\mathrm{Ni}$ concentrations

2) association of high $\mathrm{Co}$ and $\mathrm{Ni}$ concentrations with high-temperature vent fluids from basalt-hosted mid-ocean ridges

3) a negative correlation between $\mathrm{Ga}$ and In concentrations and the $\mathrm{pH}$ of hydrothermal fluids

This third pattern is particularly intriguing as it provides a potential trace element proxy for hydrothermal fluid $\mathrm{pH}$. Complexing of $\mathrm{Ga}$ and $\mathrm{In}$ by $\mathrm{OH}^{-}$and the inverse relationship between $\mathrm{OH}^{-}$and $\mathrm{H}^{+}$activity (i.e., $\mathrm{pH}$ ) is proposed as a possible explanatory mechanism. Overall, this study demonstrates the potential of SIMS to quantitatively measure $\mathrm{Co}, \mathrm{Ni}, \mathrm{Ga}, \mathrm{Ag}$, and In in chalcopyrite and identifies several natural chalcopyrite samples that are homogeneous with respect to these and possibly other trace elements, making them potentially useful as calibration standards in geochemical analyses.

\section{Chapter 4}

Chapter 4 builds on the findings of Chapter 3 and compares the $\mathrm{Co}, \mathrm{Ni}, \mathrm{Ga}, \mathrm{Ag}$, and In concentrations of black smoker chimney linings with those of the hydrothermal fluids that were flowing through them at the time of collection. This comparison is aided by thermodynamic modelling of fluid speciation at in situ conditions. A significant result of Chapter 4 is the observation of a strong linear correlation between the $\mathrm{Ag}$ content of black smoker chimney 
linings with the free ion activity ratio of $\mathrm{Ag}: \mathrm{Cu}$ in the corresponding hydrothermal fluids. This correlation supports partitioning of Ag into chalcopyrite as a lattice substitution for $\mathrm{Cu}$, once aqueous complexing is considered. When combined with the correlation identified in Chapter 3 between the $\mathrm{Ga}$ and In concentrations of black smoker chimneys and hydrothermal fluid $\mathrm{pH}$, the Ag concentrations of black smoker chimney linings provide the following proxies of hydrothermal fluid chemistry:

1) low $\mathrm{Ag}$ concentration and high $\mathrm{Ga}$ and In concentrations indicate formation from low-pH fluids.

2) high Ag concentration and low Ga and In concentrations indicate formation from higher-pH, Cu-poor fluids.

3) high Ag concentration and high Ga and In concentrations indicate formation from low-pH fluids in which Ag is highly enriched, likely as a result of subsurface remobilization

The correlation between the Ga and In concentrations of black smoker chimney linings and hydrothermal $\mathrm{pH}$ is investigated further with measurements of the Ga and In concentrations of some hydrothermal fluids and thermodynamic modelling of fluid speciation, including $\mathrm{pH}$ and the activities of Ga and In free ions and complexes at in situ conditions (temperatures, pressures, fluid composition). These calculations generally support $\mathrm{OH}^{-}$complexing as an explanatory mechanism for the observed correlation between $\mathrm{Ga}$ and In and hydrothermal fluid $\mathrm{pH}$. Additionally, results of species distributions at in situ conditions support regular partitioning of Ga for Fe. However, there is a need for additional analyses of Ga and In in hydrothermal fluids as well as a need to refine thermodynamic data concerning Ga and In complexes at hydrothermal conditions to better quantify these relationships. 


\section{Significance of Findings}

This thesis investigates trace element proxies and mineral indicators of hydrothermal fluid $\mathrm{pH}$ and metal content based on careful study of actively forming SMS deposits. Because studies focus on actively forming SMS deposits, and especially black smoker chimney linings, the correspondence between mineral samples and collected hydrothermal fluid samples is straightforward and well constrained.

Chapters 3 and 4 propose new proxies of hydrothermal fluid chemistry ( $\mathrm{Ga}$ and In as a proxy for $\mathrm{pH}, \mathrm{Ag}$ as a proxy for free ion activity ratio of $\mathrm{Ag}: \mathrm{Cu}$ and indicator of subsurface remobilization). These elements are thought to occur as stoichiometric lattice substitutions in chalcopyrite $\left(\mathrm{Ag}^{+}\right.$for $\mathrm{Cu}^{+}, \mathrm{Ga}^{3+}$ and $\mathrm{In}^{3+}$ for $\left.\mathrm{Fe}^{3+}\right)$. Elements that occur as lattice substitutions are less likely to be remobilized by hydrothermal recrystallization than elements that occur as inclusions or nonstoichiometric lattice inclusions (Huston et al., 1995). Thus, proxies based on these elements are more likely to be geologically preserved and thereby useful for the study of inactive or fossil deposits. Moreover, the proxies and indicators of hydrothermal fluid temperature and chemistry presented in this thesis are based on the mineralogy and trace element contents of ore minerals (e.g., chalcopyrite, wurtzite, sphalerite) rather than the associated gangue minerals. This means that it is not necessary to assume that both ore and gangue minerals were co-precipitated under the same temperature and chemical conditions and from the same source fluid. Future studies should investigate the applicability of $\mathrm{pH}$ proxies based on the $\mathrm{Ga}$ and In concentrations in chalcopyrite and proxies of $\mathrm{Ag}$ and $\mathrm{Cu}$ concentrations based on combined knowledge from Ga, In, and Ag concentrations in chalcopyrite to fossilized SMS deposits. 
A second contribution of this thesis is the identification of black smoker chimney linings that are homogeneous with respect to $\mathrm{Co}, \mathrm{Ni}, \mathrm{Ga}, \mathrm{Ag}, \mathrm{In}$, and likely other trace elements. Such samples may be useful as analytical standards from which to derive calibration curves for other elements or microanalytical techniques or as matrix-matched materials (for chalcopyrite) by which to validate the performance of proposed non-matrix matched standards. Previous work by McDermott et al. (2015) demonstrated that the innermost chalcopyrite linings of black smoker chimneys are in equilibrium with hydrothermal fluids with respect to sulfur isotopes. Together with the work presented in this thesis, these results suggest that black smoker chimney linings very closely reflect the hydrothermal fluids from which they form provided that careful picking or microanalysis allows for analysis of only the innermost linings. Future work should seek to combine trace element and isotopic studies particularly with the aim of better understanding remobilization and zone refinement processes. It should also be noted that several of the black smoker chimney samples investigated in this study contain intergrown chalcopyrite and wurtzite or chalcopyrite and pyrite. Such samples provide an excellent basis from which to quantify trace element partitioning between different metal sulfide minerals under well constrained, but difficult to engineer, geochemical conditions.

Third, the trace element proxies presented in Chapters 3 and 4 highlight the importance of aqueous complexing in determining the trace element contents of chalcopyrite and present a strategy by which to search for additional trace element proxies based on isovalent lattice substitutions. In cases such as $\mathrm{Ag}$ and $\mathrm{Cu}$, where elements are predominantly complexed by the same ion in the hydrothermal fluid (i.e. $\mathrm{Cl}^{-}$), trace element concentrations primarily reflect the ratio of the concentration of the trace element to that of the major element it replaces. More precisely, trace element concentrations are controlled by the activity ratio of the free ions, which 
can be calculated through thermodynamic modelling provided that major fluid parameters are known or can be accurately estimated. Alternatively, in cases where there are major differences in the complexing behavior of the trace element and the major element it replaces, mineral trace element concentrations reflect the activities of the relevant ligands. For example, complexing of $\mathrm{Ga}$ and $\mathrm{In}$ by $\mathrm{OH}^{-}$contrasts with the predominance of $\mathrm{Cl}^{-}$complexing for Fe. This contrast in aqueous complexing behavior provides an explanatory mechanism for the observed correlation between hydrothermal fluid $\mathrm{pH}$ and concentrations of $\mathrm{Ga}$ and $\mathrm{In}$ in the associated black smoker chimney linings. Future studies should identify pairs of trace element and carrier elements that exhibit contrasting complexing behavior as a strategy for identifying additional proxies of hydrothermal fluid $\mathrm{pH}$. Additionally, a better understanding is needed of possible crystal chemical controls on trace element partitioning. This is particularly true of divalent ions (e.g., $\mathrm{Co}^{2+}, \mathrm{Ni}^{2+}$ ), which may partition more readily into more $\mathrm{Fe}$-rich copper iron sulfide minerals containing divalent Fe than into chalcopyrite, where Fe is trivalent.

\section{Future Directions}

This thesis has identified several trace element proxies and mineral indicators of hydrothermal fluid $\mathrm{pH}$ and metal content (i.e. $\mathrm{Ag}: \mathrm{Cu}$ ratio) and developed SIMS as a technique

for measuring $\mathrm{Co}, \mathrm{Ni}, \mathrm{Ga}, \mathrm{Ag}$, and In in chalcopyrite. Future directions for this research can be divided into short term, medium term, and long term goals.

\section{Short Term}

In the immediate short term, efforts can be made to refine the techniques used in this thesis and to expand their use to include additional samples and scientific applications. In 
particular, SIMS analyses of trace elements $(\mathrm{Co}, \mathrm{Ni}, \mathrm{Ga}, \mathrm{Ag}, \mathrm{In})$ in chalcopyrite can be improved by refining the SIMS calibration curves constructed in Chapter 3. Specific improvements include validation of the $\mathrm{Ag}$ calibration curve and reduction of the uncertainties surrounding measurements of $\mathrm{Ni}$ at low concentrations. Validation of the Ag calibration curve can be achieved through electron microprobe analyses of black smoker chimney samples containing high concentrations of $\mathrm{Ag}(>1000 \mu \mathrm{g} / \mathrm{g}$ ). In order to obtain better ICP-MS measurements of $\mathrm{Ni}$ in digested picked grains of chalcopyrite, analyses should be repeated using $\mathrm{Pt}$ rather than $\mathrm{Ni}$ cones. In order to identify possible effects of major element ratios on trace element concentrations, electron microprobe analyses of black smoker chimney linings should be conducted. Additionally, elements that were not considered in this thesis, but which offer potential for expanded use of SIMS measurements in the near term, include Sn, Se, and Te. Measurements of Se and Te can be obtained by switching from a $\mathrm{O}_{2}{ }^{-}$to a $\mathrm{Cs}^{+}$ion beam and by modifying the digestion of picked grains to avoid volatilization of Se.

The sample suite examined in this thesis is heavily biased toward samples from back-arc basins. One possibility for expanding the current sample suite would be to focus on samples from mid-ocean ridges (of various spreading rate) to more closely reflect the full population of actively forming SMS deposits. A second possibility would be to focus on samples from volcanic arcs or marginal basins which are more likely to be geologically preserved as volcanogenic massive sulfide (VMS) deposits. Yet a third possibility would be to focus on vent sites such as those along the Endeavour segment of the Juan de Fuca Ridge, where analyses of black smoker chimney linings can be integrated with detailed monitoring of hydrothermal fluid chemistry and changes in hydrothermal venting related to volcanic and tectonic activity. Alternatively, data presented here concerning the bulk geochemistry of SMS deposits and the 
trace element contents of hydrothermal fluids at the ABE, Tu'i Malila and Mariner vent fields can be integrated using the known locations of SMS deposit and hydrothermal fluid samples to directly track and estimate the efficiency of trace element incorporation into SMS deposits from hydrothermal fluids.

\section{Medium Term}

Coincident with the desire to conduct trace element analyses of additional black smoker chimney samples is the desire to obtain additional data for these elements in paired hydrothermal fluids, particularly for $\mathrm{Ga}, \mathrm{Ag}$, and In. While relatively straightforward given the techniques used in this thesis, detailed sampling and analysis of paired black smoker chimneys and hydrothermal fluid samples likely requires sampling cruises where this is a priority. As such, this is a medium term rather than short term goal

An additional direction in which to apply SIMS measurements of trace elements would be to investigate grains along a transect from the interior to the exterior of a black smoker chimney wall. Several models have been proposed regarding the temperature and chemical conditions within black smoker chimney walls (e.g., Janecky and Seyfried, 1984; Tivey, 1995; La Rowe at al., 2014), but results vary widely in predictions of $\mathrm{H}_{2}$ and $\mathrm{H}_{2} \mathrm{~S}$ concentrations (collectively sulfur fugacity) and fluid $\mathrm{pH}$. Because estimates of temperature alone are better constrained and easier to calculate than estimates of fluid chemistry, geochemical proxies of sulfur fugacity and $\mathrm{pH}$ such as those presented in this thesis could be useful in helping to discriminate between the various model predictions. Because models need to be implemented and studies would likely benefit from the integration of thermodynamic data for Ga and In complexes into these models, this is also a medium term rather than short term goal. 


\section{Long term}

Long term, there is a desire to obtain a better understanding of the incorporation of trace elements into sulfide minerals. Specific deficits in understanding concern the spatial distributions of trace elements within sulfide mineral grains precipitated under various chemical conditions, the valence states of the incorporated trace elements, trace element partitioning between mineral pairs, and trace element behavior during solid-phase solution and dissolution processes (e.g., the formation of dissolution lamellae). Answering these questions will likely involve the use of additional analytical techniques including line scans and/or spot analyses using microsecond or femtosecond laser ablation inductively coupled plasma mass spectrometry and, in the case of investigating valence states, synchrotron techniques such as $\mathrm{x}$-ray absorption near edge structure (XANES).

Additionally, there is a desire to integrate these studies with studies of ocean chemistry and mined ore deposits. With respect to ocean chemistry, better understandings of the trace element contents of hydrothermal vent fluids will lead to better estimates of hydrothermal fluxes of these elements into the ocean and the efficiency with which various elements are precipitated and removed from the ocean as sedimentary particles. With respect to mined ore deposits, many questions remain regarding the $\mathrm{pH}$ and metal contents of ore-formation fluids as well as the processes responsible for observed differences between various deposits. While modern SMS deposits are imperfect analogues for mined VMS deposits, insights into the partitioning of trace elements into metal sulfide minerals derived from SMS deposits studies can nevertheless be useful in helping to interpret the observed mineralogy and geochemistry of VMS deposits. Expansion of investigated samples to include additional types of hydrothermal (e.g., porphyry 
copper, iron oxide copper gold, Mississippi Valley Type) and magmatic sulfide occurrences is also desired.

\section{References}

Huston, D. L., Sie, S. H., Suter, G. F., Cooke, D. R., and Both, R. A. (1995). Trace elements in sulfide minerals from eastern Australian volcanic-hosted massive sulfide deposits; Part I, Proton microprobe analyses of pyrite, chalcopyrite, and sphalerite, and Part II, Selenium levels in pyrite; comparison with delta $34 \mathrm{~S}$ values and implications for the source of sulfur in volcanogenic hydrothermal systems. Econ. Geol., 90(5), 1167-1196.

Janecky, D. R. and Seyfried, W. E. (1984). Formation of massive sulfide deposits on oceanic ridge crests: Incremental reaction models for mixing between hydrothermal solutions and seawater. Geochim. Cosmochim. Acta, 48(12), 2723-2738.

La Rowe, D. E., Dale, A. W., Aguilera, D. R., L'Heureux, I., Amend, J. P., and Regnier, P. (2014). Modeling microbial reaction rates in a submarine hydrothermal vent chimney wall. Geochim. Cosmochim. Acta, 124, 72-97.

McDermott, J. M., Ono, S., Tivey, M. K., Seewald, J. S., Shanks, W. C., and Solow, A. R. (2015). Identification of sulfur sources and isotopic equilibria in submarine hot-springs using multiple sulfur isotopes. Geochim. Cosmochim. Acta, 160, 169-187.

Tivey, M. K. (1995) The influence of hydrothermal fluid composition and advection rates on black smoker chimney mineralogy: Insights from modeling transport and reaction.

Geochim. Cosmochim. Acta, 59(10), 1933-1949. 